A Practical Guide to Introductory Geology 


\title{
A Practical Guide to Introductory Geology
}

\author{
SIOBHAN MCGOLDRICK
}

MOUNT ROYAL UNIVERSITY

CALGARY, ALBERTA 


\section{() (1)}

A Practical Guide to Introductory Geology by Siobhan McGoldrick is licensed under a Creative Commons Attribution 4.0 International License, except where otherwise noted.

\section{(C) 2020 Siobhan McGoldrick}

The CC licence permits you to retain, reuse, copy, redistribute, and revise this book-in whole or in part-for free providing the author is attributed as follows:

A Practical Guide to Introductory Geology by Siobhan McGoldrick is used under a Creative Commons Attribution 4.0 International Licence.

If you redistribute all or part of this book, it is recommended the following statement be added to the copyright page so readers can access the original book at no cost:

Download for free at: https://openeducationalberta.ca/practicalgeology.

\section{Sample APA-style citation:}

This textbook can be referenced. In APA citation style, it would appear as follows:

McGoldrick, S. (2020). A practical guide to introductory geology. Mount Royal University Library. https://openeducationalberta.ca/practicalgeology.

\section{Cover image attribution:}

This book was produced with Pressbooks (https://pressbooks.com) and rendered with Prince.

Cover design by Matt Laidlow. Cover image: "Mt. Tyrwhitt (2020)" by Candace Toner is under a Creative Commons Attribution 4.0 International Licence.

Mt. Tyrwhitt-peak to the right-displays some of the classic folds and faults in the Front Ranges of the Rocky Mountains just east of the Alberta - B.C. border. The Lewis Thrust, exposed immediately to the west of this photo, is a fault over $450 \mathrm{~km}$ long 
that transported Paleozoic strata over $80 \mathrm{~km}$ to the east during the formation of the Rocky Mountains. In this photo, a smaller thrust fault cuts the spectacularly folded beds of mudstone, sandstone, and conglomerate of the Jurassic Kootenay Formation and Lower Cretaceous Cadomin Formation. 


\section{Contents}

Exceptions to the CC BY Licence

Acknowledgments

Introduction to Geology

What is Geology?

2

Why Study Earth?

4

What Do Geologists Do?

5

Minerals and Rocks

7

Fundamentals of Plate Tectonics

Geological Time

Summary

Google Earth Tutorial

Getting Started in Google Earth Pro

Grid Systems and Coordinates

Lab I: Plate Tectonics

1.1 Discovering Plate Tectonics

1.2 Plates, Plate Motions, and Plate Boundaries

Lab 2: Mineral Properties and Non-Silicate Minerals

2.1 Bonding and Lattices

2.2 Mineral Groups

2.3 Mineral Properties

2.4 Economic Minerals

Lab 2 Exercises 
Lab 3: Silicate Minerals

3.1 Silicate Mineral Groups

Lab 3 Exercises 85

Summary

Lab 4: Igneous Rocks

4.1 Magma and Magma Formation 92

4.2 Crystallization of Magma 96

4.3 Classification of Igneous Rocks 101

Lab 4 Exercises 105

Summary 111

Lab 5: Sediments and Sedimentary Rocks

5.1 Weathering 115

5.2 The Products of Weathering and Erosion 121

5.3 Clastic Sedimentary Rocks 124

5.4 Chemical Sedimentary Rocks 135

5.5 Depositional Environments and Sedimentary Basins 142

Lab 5 Exercises $\quad 145$

$\begin{array}{ll}\text { Summary } & 151\end{array}$

Lab 6: Metamorphic Rocks and the Rock Cycle

6.1 Metamorphism and Plate Tectonics 153

$\begin{array}{ll}\text { 6.2 Classification of Metamorphic Rocks } & 160\end{array}$

$\begin{array}{lr}\text { 6.3 The Rock Cycle } & 168\end{array}$

$\begin{array}{lr}\text { Lab } 6 \text { Exercises } & 170\end{array}$

$\begin{array}{ll}\text { Summary } & 177\end{array}$

$\begin{array}{ll}\text { Review of Minerals and Rocks } & 178\end{array}$

Lab 7: Relative Dating and Geological Time

7.1 The Geological Time Scale 182 
7.2 Relative Dating Methods

Lab 8: Mapping Fluvial Landscapes

8.1 Stream Erosion and Deposition

8.2 Stream Types

206

8.3 What Makes a Map?

209

Lab 8 Exercises

Lab 9: Structural Geology Part I

9.1 Introduction to Structural Geology

$\begin{array}{ll}9.3 \text { Estimating Dip Direction from a Geological Map } & 227\end{array}$

Lab 9 Exercises $\quad 229$

Summary

Take-Home Mapping Assignment

Lab Io: Structural Geology Part II

10.1 Stress and Strain

238

10.2 Folding

10.3 Faulting 245

Lab 10 Exercises 253

Summary 258

Mineral Identification Tables 259

Rock Classification Tables 261

Glossary 267

Appendix 1: List of Geologically Important Elements and the Periodic Table 295

Appendix 2: Answers to Practice Exercises 298

Appendix 3: Answers to Lab Exercises 309

Appendix 4: Economic Minerals 
Appendix 5: Block Models

Links for Print Edition 


\section{Exceptions to the CC BY Licence}

The content of A Practical Guide to Introductory Geology by Siobhan McGoldrick is under a Creative Commons Attribution 4.0 International (CC BY 4.0) licence, except where otherwise noted. The following materials have been included in this text but are under licences with additional restrictions.

\section{All rights reserved}

The following All Rights Reserved pieces are used for non-commercial purposes in this open textbook according to their terms of use or with permission of the copyright holders. If you plan to adapt any content including these pieces, please reconfirm permission with the copyright holders or remove them from your version.

- Figure I2: East Village Calgary Flood 2013 C Ryan L. C. Quan.

- Geoscience for the Future poster (C) Geological Society of London. (What Do Geologists Do?).

- Maps of plate boundaries, topography/bathymetry, seismology, volcanology, seafloor age @ Dale S. Sawyer. (Lab 1 Exercises).

- Derivative of Discovering Plate Boundaries activity (C) Dale S. Sawyer. (Lab 1 Exercises). Used with permission.

- 082J-16 NTS Priddis topographic map: (C) Natural Resources Canada. The Government of Canada retains the copyright of this image but allows for reproduction for non-commercial use. (Lab 8 Exercises).

- Figure 9.2.1: (C) Siobhan McGoldrick. CC BY. Includes copyrighted still images produced using Visible Geology.

- Sheep Canyon Geological Map by Robert E. Ladd (C) Wyoming State Geological Survey. (Lab 9 Exercises).

- Figures T1, T2, T3, T4, T5, T6, T7, T8, T9, T10, and T11 (Google Earth Tutorial Activity), Elbow River Map Area satellite image (Lab 8 Exercises), Glenmore Reservoir and area satellite image (Lab 8 Exercises).

\section{BY-SA}

- Figure 2.1.2 (left): Halite. (C) Rob Lavinsky, iRocks.com.

- Figure 2.3.4c: Almandine garnet (C) Eurico Zimbres (FGEL/UERJ) and Tom Epaminondas (mineral collector).

- Figure 2.3.5: (C) Lyndsay Hauber and Joyce M. McBeth. CC BY. Adapted from Randa Harris and M.C. Rygel. CC BY-SA 3.0.

- Figure 2.4.1: "Ipad Air" (C) Zach Vega. Adapted by Steven Earle.

- Figure 2.4.2: "Ballpoint pen parts" by unknown.

- Practice Exercise 5.3, first image: Aplite Red (C) Rudolf Pohl.

- Figure 5.5.1: Schematic diagram showing types of depositional environment (C) Mike Norton. Adapted by Steven Earle. 
- Figure 6.2.4c: Schist detail (C) Michael C. Rygel.

- Figure 10.3.10 (Bottom left): "Moab fault with vehicles for scale" (c) Andrew Wilson.

\section{BY-NC}

- Cover photograph of Mt. Tyrwhitt: (c) Candace Toner.

- Figures 2.3.4a, 2.3.4b, 2.3.9: C Candace Toner.

- Figure A: (C) Candace Toner. (Lab 4 Exercises).

\section{BY-NC-SA}

- Google Earth kmz file (C) Susan Schwartz and Erin Todd (Lab 1 Exercises).

- Arrow figure (C) Susan Schwartz and Erin Todd (Lab 1 Exercises).

- 1101 Lab 9.kmz file by Siobhan McGoldrick. Derivative of Kmz file of placemarks for other structural mapping examples (C) Barbara Tewksbury, Locations in Google Earth for teaching geologic mapping and map interpretation (Lab 9 Exercises). 


\section{Acknowledgments}

This laboratory manual would not have been possible were it not for the work of Steven Earle, whose open textbook "Physical Geology - 2nd Edition" was the basis for this adaptation. Steven is thanked tremendously for his contribution to open educational resources in the geosciences in Western Canada. I thank Geological Technician Candace Toner for her assistance in organizing samples and materials from the Mount Royal University collection, and for her support. Thanks also to the Mount Royal University Library staff, particularly Cari Merkley for her excellent guidance and devotion to this project, and also to Subject Librarian Brian Jackson. Matt Laidlow is thanked for designing the cover of this manual. I also thank Michelle Brailey at Open Education Alberta for her support.

\section{About the Author}

Siobhan McGoldrick earned a MSc in geology from the University of Victoria following the completion of a BSc with First Class Honours in geology from Dalhousie University. She has worked with territorial and federal government geological surveys, as well as in the mining industry. Siobhan taught a wide range of geology courses at Yukon University and Mount Royal University before accepting her current position as a Senior Laboratory Instructor in the School of Earth and Ocean Sciences at the University of Victoria.

This book project was supported by Mount Royal University Library in partnership with the University of Alberta through the Open Education Alberta project.

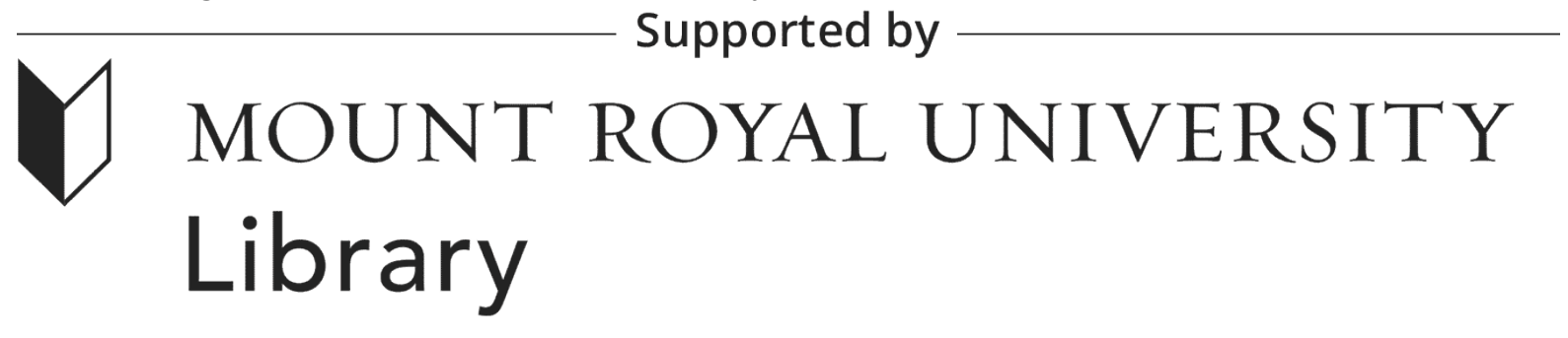

In partnership with

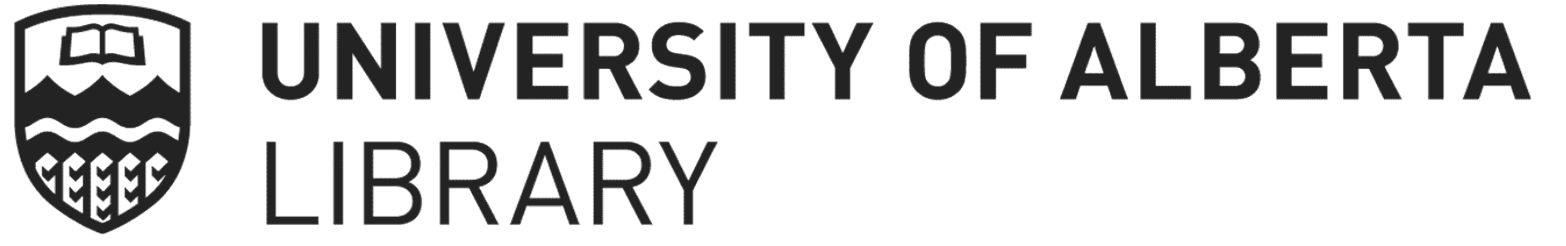




\section{INTRODUCTION TO GEOLOGY}

\section{Learning Objectives}

After carefully reading this chapter, completing the exercises within it, and answering the questions at the end, you should be able to:

- Explain what geology is, how it incorporates the other sciences, and how it is different from the other sciences.

- $\quad$ Discuss why we study the Earth and what type of work geologists do.

- $\quad$ Define some of the properties of a mineral and explain the differences between minerals and rocks.

- $\quad$ Describe the nature of Earth's interior and some of the processes that take place deep beneath our feet.

- Explain how those processes are related to plate tectonics and describe a few of the features that are characteristic of plate boundaries.

- Use the notation for geological time, gain an appreciation for the vastness of geological time, and describe how very slow geological processes can have enormous impacts over time. 


\section{What is Geology?}

In its broadest sense, geology is the study of Earth-its interior and its exterior surface, the minerals, rocks and other materials that are around us, the processes that have resulted in the formation of those materials, the water that flows over the surface and through the ground, the changes that have taken place over the vastness of geological time, and the changes that we can anticipate will take place in the near future. Geology is a science, meaning that we use deductive reasoning and scientific methods to understand geological problems. It is, arguably, the most integrated of all of the sciences because it involves the understanding and application of all of the other sciences: physics, chemistry, biology, mathematics, astronomy, and others. But unlike most of the other sciences, geology has an extra dimension, that of time-deep time-billions of years of it. Geologists study the evidence that they see around them, but in most cases, they are observing the results of processes that happened thousands, millions, and even billions of years in the past. Those were processes that took place at incredibly slow rates-millimetres per year to centimetres per year-but because of the amount of time available, they produced massive results.

Geology is displayed on a grand scale in mountainous regions, perhaps nowhere better than the Rocky Mountains in Canada (Figure I1). The peak on the right is Rearguard Mountain, which is a few kilometres northeast of Mount Robson, the tallest peak in the Canadian Rockies (3,954 metres). The large glacier in the middle of the photo is the Robson Glacier. The river flowing from Robson Glacier drains into Berg Lake in the bottom right. There are many geological features portrayed here. The sedimentary rock that these mountains are made of formed in ocean water over 500 million years ago. A few hundred million years later, these beds were pushed east for tens to hundreds of kilometres by tectonic plate convergence and also pushed up to thousands of metres above sea level. Over the past two million years this area-like most of the rest of Canada-has been repeatedly glaciated, and the erosional effects of those glaciations are obvious.

The Robson Glacier is now only a small remnant of its size during the Little Ice Age of the 15th to 18th centuries, and even a lot smaller that it was just over a century ago in 1908. The distinctive line on the slope on the left side of both photos shows the elevation of the edge of the glacier a few hundred years ago. Like almost all other glaciers in the world, it receded after the 18th century because of natural climate change, is now receding even more rapidly because of human-caused climate change.
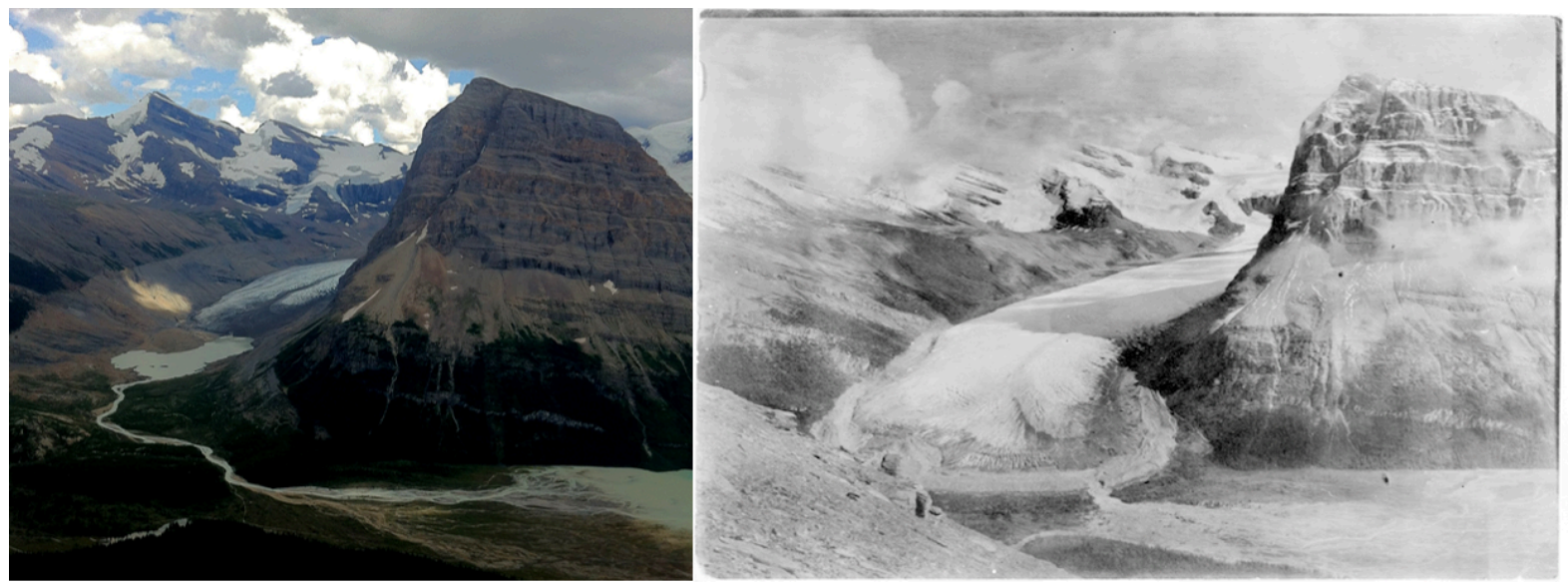

Figure I1: Rearguard Mountain and Robson Glacier in the Rocky Mountains of British Columbia.

Geology is also about understanding the evolution of life on Earth; about discovering resources such as water, metals and energy; about recognizing and minimizing the environmental implications of our use of those resources; and about learning how to mitigate the hazards related to earthquakes, volcanic eruptions, 
and slope failures. Many of these aspects of geology are covered in this textbook and will be discussed in the lab.

What are scientific methods?

There is no single method of inquiry that is specifically the "scientific method"; furthermore, scientific inquiry is not necessarily different from serious research in other disciplines. The most important thing that those involved in any type of inquiry must do is to be skeptical. As the physicist Richard Feynman once said: the first principle of science is that "you must not fool yourself-and you are the easiest person to fool." A key feature of serious inquiry is the creation of a hypothesis (a tentative explanation) that could explain the observations that have been made, and then the formulation and testing (by experimentation) of one or more predictions that follow from that hypothesis.

For example, we might observe that most of the cobbles in a stream bed are well rounded, and then derive the hypothesis that the rocks are rounded by transportation along the stream bed. A prediction that follows from this hypothesis is that cobbles present in a stream will become increasingly rounded as they are transported downstream. An experiment to test this prediction would be to place some angular cobbles in a stream, label them so that we can be sure to find them again later, and then return at various time intervals (over a period of years) to carefully measure their locations and roundness.

A critical feature of a good hypothesis and any resulting predictions is that they must be testable. For example, an alternative hypothesis to the one above is that an extraterrestrial organization creates rounded cobbles and places them in streams when nobody is looking. This may indeed be the case, but there is no practical way to test this hypothesis. Most importantly, there is no way to prove that it is false, because if we aren't able to catch the aliens at work, we still won't know if they did it!

\section{Media Attributions}

- Figure I1 (left): (C) Steven Earle. CC BY.

- Figure I1 (right): A.P. Coleman. Public domain. Source: Arthur P. Coleman Collection at Victoria University Library. 


\section{Why Study Earth?}

The simple answer to this question is that Earth is our home-our only home for the foreseeable future-and in order to ensure that it continues to be a great place to live, we need to understand how it works. Another answer is that some of us can't help but study it because it's fascinating. But there is more to it than that:

- We rely on Earth for valuable resources such as soil, water, metals, industrial minerals, and energy, and we need to know how to find these resources and exploit them sustainably.

- We can study rocks and the fossils they contain to understand the evolution of our environment and the life within it.

- We can learn to minimize our risks from earthquakes, volcanoes, slope failures, and damaging storms.

- We can learn how and why Earth's climate has changed naturally in the past, and use that knowledge to understand both natural and human-caused climate change.

- We can recognize how our activities have altered the environment in many ways and the climate in increasingly serious ways, and how to avoid more severe changes in the future.

- We can use our knowledge of Earth to understand other planets in our solar system, as well as those around distant stars.

An example of the importance of geological studies for minimizing risks to the public is illustrated in Figure I2. This is the Downtown East Village neighbourhood in Calgary, Alberta in the aftermath of the June 2013 floods that impacted several communities in southern Alberta, caused over \$ 5 billion in damages, and left five people dead. Understanding the behaviour of streams, the long term evolution of flood plains, and how both impact infrastructure and public safety is one contribution geologists can make to mitigate this type of destructive natural event.

Another example is the slope failure that took place in January 2005 in the Riverside Drive area of North Vancouver. The steep bank beneath a house gave way, and a slurry of mud and sand flowed down, destroying another house below and killing one person. This event took place following a heavy rainfall, which is a common occurrence in southwestern B.C. in the winter. The irony of the 2005 slope failure is that the District of North Vancouver had been warned in a geological report written in 1980 that this area was prone to slope failure and that steps should be taken to minimize the risk to residents. Very little was done in the intervening 25 years, and the consequences of that were deadly.

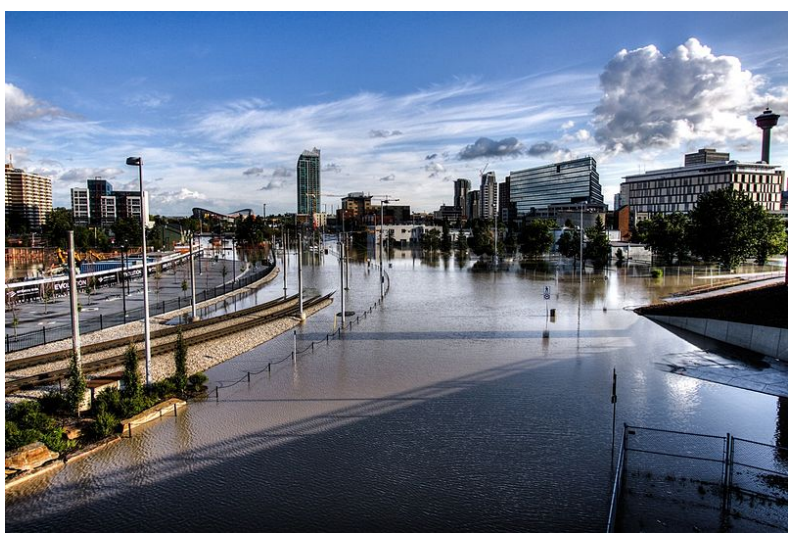

Figure I2: Flooding in the Downtown East Village neighbourhood of Calgary, Alberta during the 2013 flood.

\section{Media Attributions}

- Figure I2: East Village Calgary Flood 2013 (c) Ryan L. C. Quan. All rights reserved. Used with permission. 


\section{What Do Geologists Do?}

Geologists are involved in a range of widely varying occupations with one thing in common: the privilege and responsibility of studying this fascinating planet. In Canada, many geologists work in the resource industries, including mineral exploration and mining and energy exploration and extraction. Other major areas where geologists work include hazard assessment and mitigation (e.g., assessment of risks from slope failures, earthquakes, and volcanic eruptions); water supply planning, development, and management; waste management; and assessment of geological issues in the forest industry, and on construction projects such as highways, tunnels, and bridges. Most geologists are employed in the private sector, but many work for government-funded geological organizations, such as the Geological Survey of Canada or one of the provincial geological surveys. And of course, many geologists are involved in education at the secondary and the post-secondary levels.

The future of geoscience, in Canada and around the world, is bright. Geoscientists will play a key role in meeting society's future needs by contributing to everything from resource extraction to power electric car batteries, to identifying geothermal energy sources, to understanding the geology of other planets!

Some people are attracted to geology and geoscience because they like to be outdoors, and it is true that many geological opportunities involve fieldwork in places that are as amazing to see as they are interesting to study. But a lot of geological work is also done in offices or laboratories. Geological work tends to be varied and challenging, and for these reasons and many others, geologists are among those who are the most satisfied with their employment.

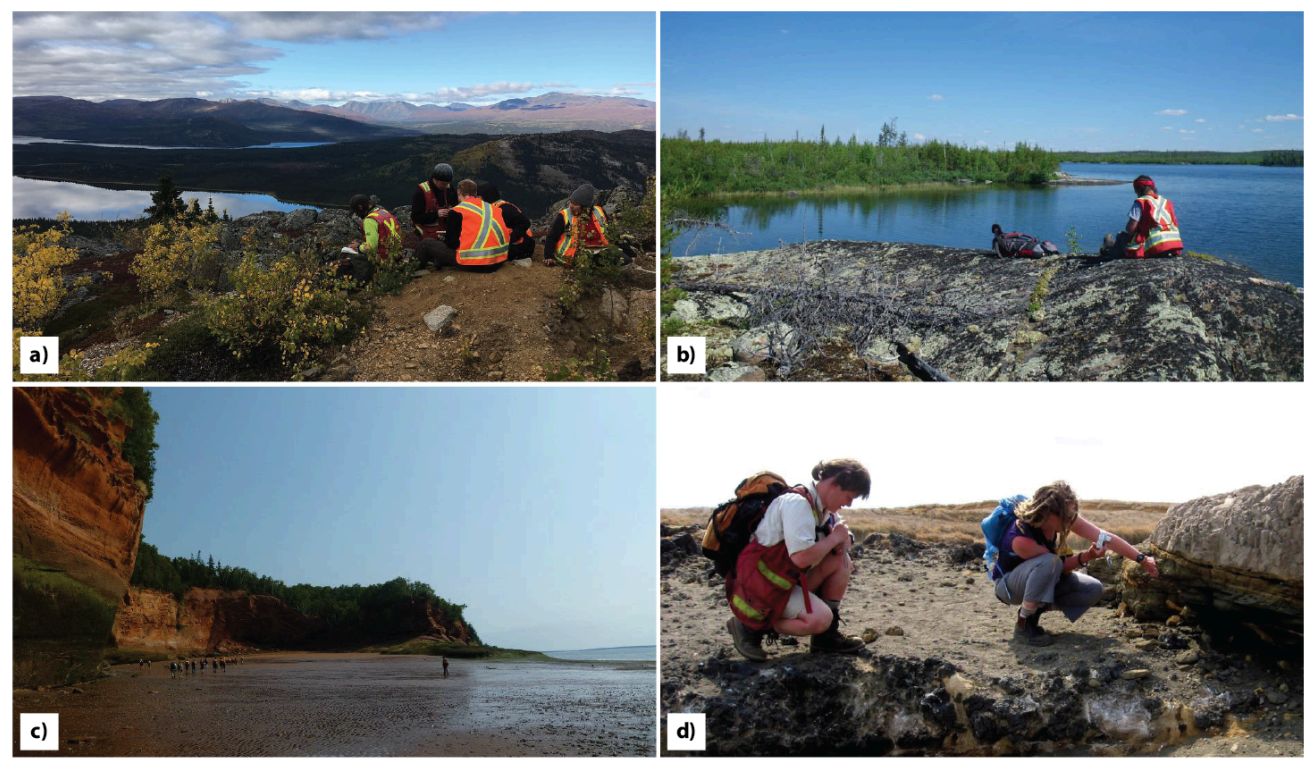

Figure I3: Examples of spectacular geological field sites. a) Students collect samples of copper-bearing rocks from an exploration property in southwestern Yukon. b) A government geologist studies 2.5 billion year old volcanic rocks in the Northwest Territories. c) Students examine ancient desert sand dunes in the cliffs along the Bay of Fundy at Five Islands Provincial Park, Nova Scotia. d) Geologists examining ash-layer deposits at Kilauea Volcano, Hawaii.

In Canada, most working geologists are required to be registered with an association of professional geoscientists. This typically involves meeting specific post-secondary educational standards and gaining several 
years of relevant professional experience under the supervision of a registered geoscientist. More information can be found by visiting the Association of Professional Engineers and Geoscientists of Alberta.

\section{Media Attributions}

- Figure I3 (a, b, c): (C) Siobhan McGoldrick. CC BY.

- Figure I3 (d): (C) Steven Earle. CC BY.

- Geoscience for the Future poster (C) Geological Society of London. All rights reserved. Used with permission. 


\section{Minerals and Rocks}

The rest of this chapter is devoted to a brief overview of a few of the important aspects of physical geology, starting with minerals and rocks. This is followed by a review of Earth's internal structure and the processes of plate tectonics, and an explanation of geological time.

The Earth is made up of varying proportions of the 90 naturally occurring elements-hydrogen, carbon, oxygen, magnesium, silicon, iron, and so on. In most geological materials, these combine in various ways to make minerals. Minerals will be covered in some detail in Labs 2 and 3, but here we will briefly touch on what minerals are, and how they are related to rocks.

A mineral is a naturally occurring combination of specific elements that are arranged in a particular repeating three-dimensional structure or lattice. ${ }^{1}$ The mineral halite is shown as an example in Figure I4.

In this case, atoms of sodium (Na: purple) alternate with atoms of chlorine (Cl: green) in all three dimensions, and the angles between the bonds are all $90^{\circ}$. Even in a tiny crystal, like the ones in your salt shaker, the lattices extend in all three directions for thousands of repetitions. Halite always has this composition and this structure.

There are thousands of minerals, although only a few dozen are mentioned in this book. In nature, minerals are found in rocks, and the vast majority of rocks are composed of at least a few different minerals. A close-up view of granite, a common rock, is shown in Figure I5. Although a hand-sized piece of granite may have thousands of individual mineral crystals in it, there are typically only a few different minerals, as shown here.

Rocks can form in a variety of ways. Igneous rocks form

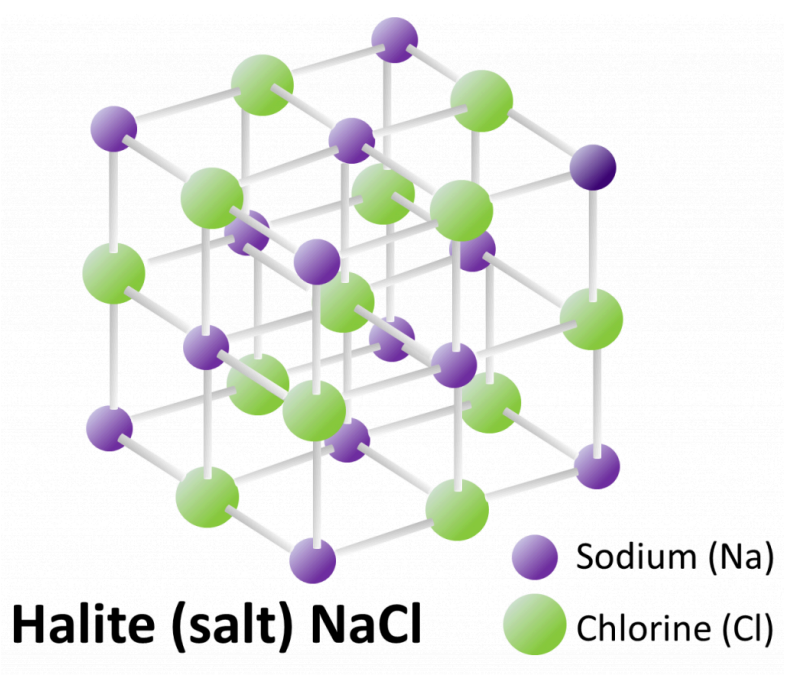

Figure I4: The lattice structure and composition of the mineral halite (common table salt). from magma (molten rock) that has either cooled slowly underground (e.g., to produce granite) or cooled quickly at the surface after a volcanic eruption (e.g., basalt). Sedimentary rocks, such as sandstone, form when the weathered products of other rocks accumulate at the surface and are then buried by other sediments. Metamorphic rocks form when either igneous or sedimentary rocks are heated and squeezed to the point where some of their minerals are unstable and new minerals form to create a different type of rock. An example is schist.

Note: Element symbols (e.g., $\mathrm{Na}$ and $\mathrm{Cl}$ ) are used extensively in this book. In Appendix 1, you will find a list of the symbols and names of the elements common in minerals and a copy of the periodic table. Please use those resources if you are not familiar with the element symbols. 


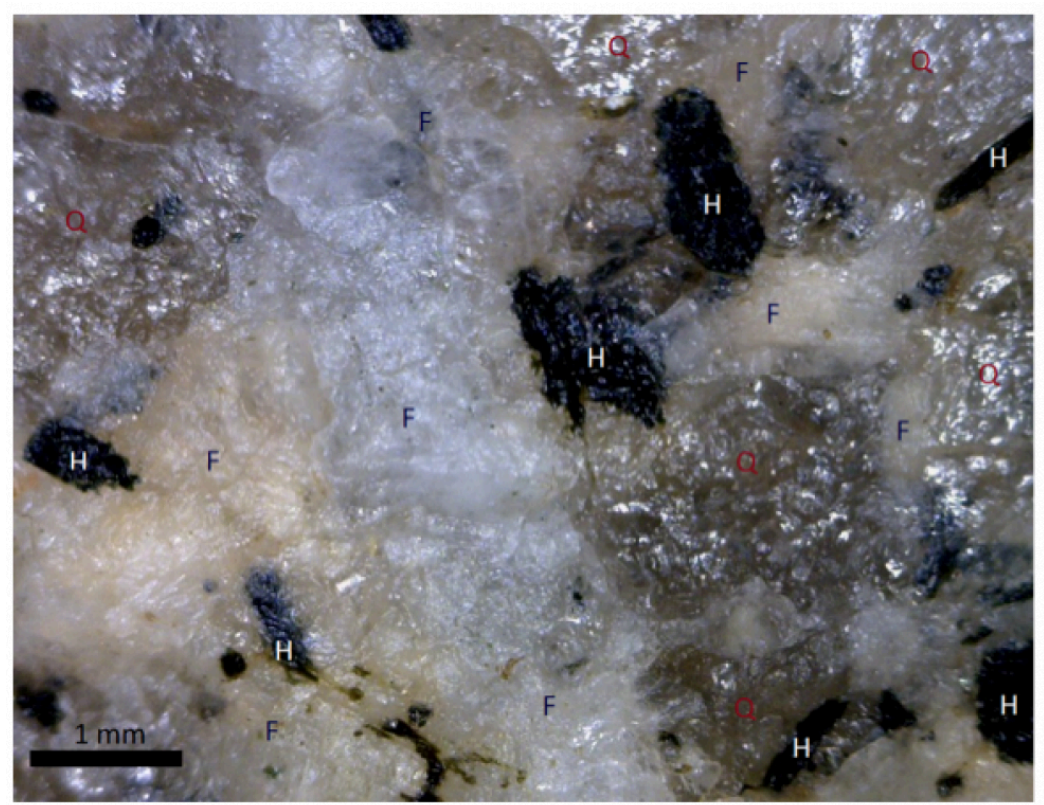

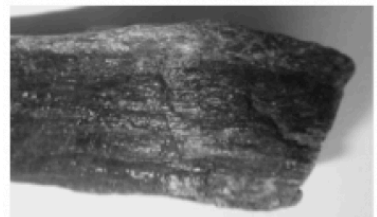

Hornblende (amphibole)

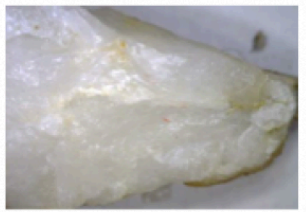

Quartz

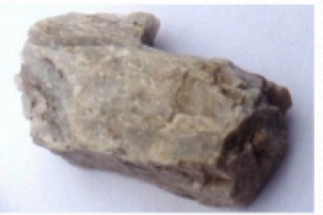

Plagioclase feldspar

Figure I5: A close-up view of the rock granite and some of the minerals that it typically contains $(\mathrm{H}=$ hornblende (amphibole), $\mathrm{Q}=$ quartz and $\mathrm{F}=$ feldspar). The crystals range from about 0.1 to 3 millimetres $(\mathrm{mm})$ in diameter. Most are irregular in outline, but some are rectangular.

A critical point to remember is the difference between a mineral and a rock. A mineral is a pure substance with a specific composition and structure, while a rock is typically a mixture of several different minerals (although a few types of rock may include only one type of mineral). Examples of minerals are feldspar, quartz, mica, halite, calcite, and amphibole. Examples of rocks are granite, basalt, sandstone, limestone, and schist.

Key Takeaway: Know the difference between minerals and rocks!

If you are currently taking a geology course, you'll likely be asked more than once to name a mineral or a rock that has specific characteristics or composition, or was formed in a specific environment. Please make sure that if you're asked for a rock name that you don't respond with a mineral name, and vice versa. Confusing minerals and rocks is one of the most common mistakes that geology students make.

\section{Media Attributions}

- Figure I4, I5: (C) Steven Earle. CC BY. 
Notes

1. Terms in bold are defined in the glossary at the end of the book. 


\section{Fundamentals of Plate Tectonics}

Plate tectonics is the model or theory that has been used for the past 60 years to understand and explain how the Earth works-more specifically the origins of continents and oceans, of folded rocks and mountain ranges, of earthquakes and volcanoes, and of continental drift. We will explore the concept of plate tectonics further in Lab 1, but is introduced here because it includes concepts that are important to many of the topics we will cover in the lab this semester.

Key to understanding plate tectonics is an understanding of Earth's internal structure, which is illustrated in Figure I6 Earth's core consists mostly of iron. The outer core is hot enough for the iron to be liquid. The inner core-although even hotter-is under so much pressure that it is solid. The mantle is made up of iron and magnesium silicate minerals. The bulk of the mantle surrounding the outer core is solid rock, but is plastic enough to be able to flow slowly. The outermost part of the mantle is rigid. The crust-composed mostly of granite on the continents and mostly of basalt beneath the oceans-is also rigid. The crust and outermost rigid mantle together make up the lithosphere. The lithosphere is divided into about 20 tectonic plates that move in different directions on Earth's surface.

An important property of Earth (and other planets) is that the temperature increases with depth, from close to $0^{\circ} \mathrm{C}$ at the surface to about $7000^{\circ} \mathrm{C}$ at the centre of the core. In the crust, the rate of temperature increase is about $30^{\circ} \mathrm{C}$ every kilometre. This is known as the geothermal gradient.

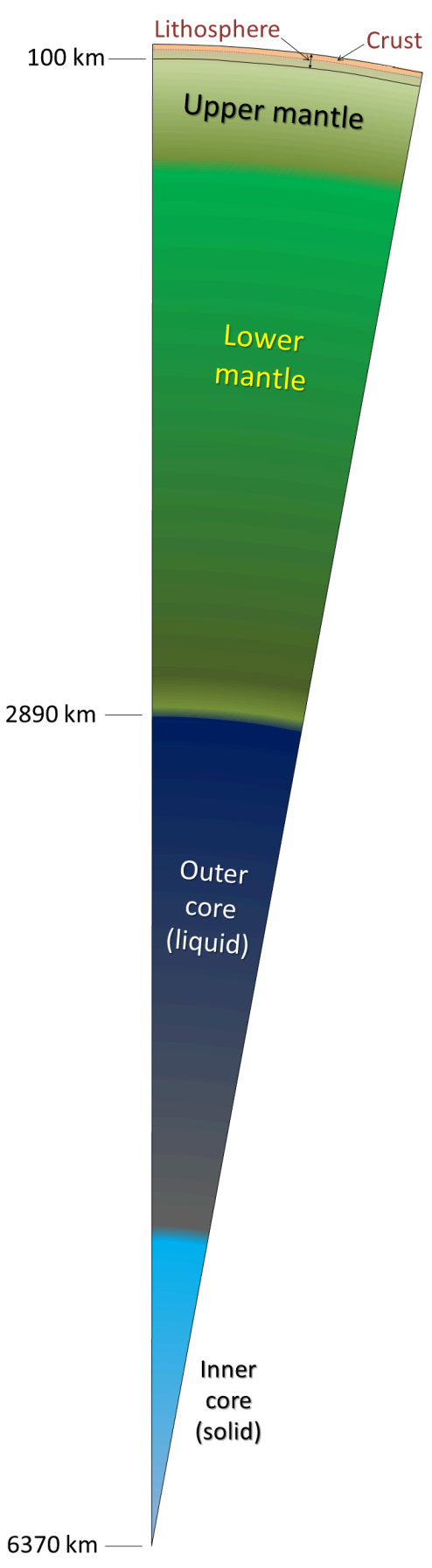

Figure I6: The components of the interior of the Earth (click on the image to see a full-size version). 


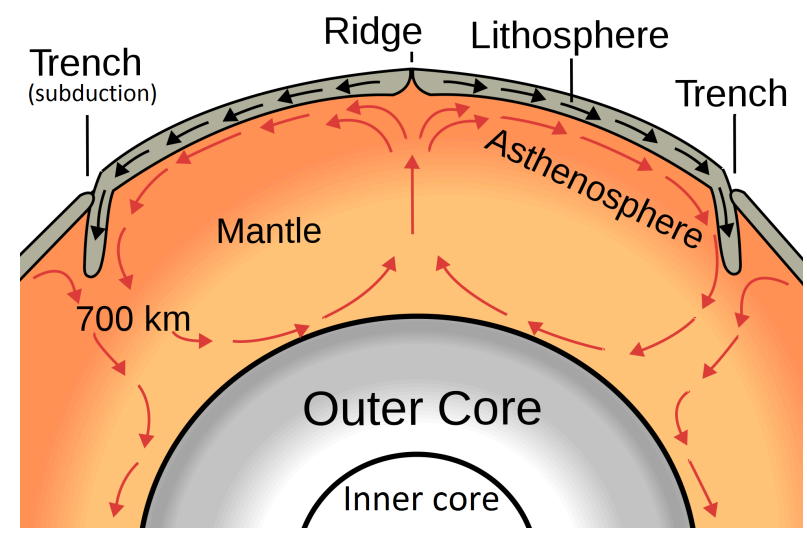

Figure I7: Depiction of the convection in the mantle and it's relationship to plate motion. The movement of currents in the Earth's mantle puts pressure on the Lithosphere are causes plates to move.

Heat is continuously flowing outward from Earth's interior, and the transfer of heat from the core to the mantle causes convection in the mantle (Figure 17). This convection is the primary driving force for the movement of tectonic plates. At places where convection currents in the mantle are moving upward, new lithosphere forms (at ocean ridges), and the plates move apart (diverge). Where two plates are converging (and the convective flow is downward), one plate will be subducted (pushed down) into the mantle beneath the other. Many of Earth's major earthquakes and volcanoes are associated with convergent boundaries.

\section{Media Attributions}

- Figure I6: (C) Steven Earle. CC BY.

- Figure I7: Oceanic Spreading by Surachit. Public domain. 


\section{Geological Time}

In 1788, after many years of geological study, James Hutton, one of the great pioneers of geology, wrote the following about the age of Earth: The result, therefore, of our present enquiry is, that we find no vestige of a beginning - no prospect of an end. ${ }^{1}$ Of course he wasn't exactly correct, there was a beginning and there will be an end to Earth, but what he was trying to express is that geological time is so vast that we humans, who typically live for less than a century, have no means of appreciating how much geological time there is. Hutton didn't even try to assign an age to Earth, but we now know that it is approximately 4,570 million years old. Using the scientific notation for geological time, that is 4,570 Ma (for mega annum or "millions of years") or $4.57 \mathrm{Ga}$ (for giga annum or billions of years). More recent dates can be expressed in ka (kilo annum); for example, the last cycle of glaciation ended at approximately 11.7 ka or 11,700 years ago. This notation will be used for geological dates throughout this book.

Practice Exercise: Using geological time notation

To help you understand the scientific notation for geological time-which is used extensively in this book-write the following out in numbers (for example, $3.23 \mathrm{Ma}=3,230,000$ years).

1. $2.75 \mathrm{ka}$

2. $\quad 0.93 \mathrm{Ga}$

3. $\quad 14.2 \mathrm{Ma}$

We use this notation to describe geological events in the same way that we might say "they arrived at 2 pm." For example, we can say "this rock formed at 45 Ma." But this notation is not used to express elapsed time. We don't say: "I studied for 4 pm for that test." And we don't say: “The dinosaurs lived for 160 Ma." Instead, we could say: "The dinosaurs lived from 225 Ma to 65 Ma, which is 160 million years."

See Appendix 2 for Practice Exercise answers.

Unfortunately, knowing how to express geological time doesn't really help us understand or appreciate its extent. A version of the geological time scale is included as Figure I8. Unlike time scales you'll see in other places, or even later in this book, this time scale is linear throughout its length, meaning that 50 Ma during the Cenozoic is drawn as the same thickness on the diagram as 50 Ma during the Hadean-in each case about the height of the " $\mathrm{M}$ " in Ma. The Pleistocene glacial epoch began at about 2.6 Ma, which is equivalent to half the thickness of the thin grey line at the top of the yellow bar marked "Cenozoic." Most other time scales have earlier parts of Earth's history compressed so that more detail can be shown for the more recent parts. That makes it difficult to appreciate the extent of geological time. 
To create some context, the Phanerozoic Eon (the last 542 million years) is named for the time during which visible (phaneros) life (zoi) is present in the geological record. In fact, large organisms-those that leave fossils visible to the naked eye-have existed for a little longer than that, first appearing around $600 \mathrm{Ma}$, or a span of just over 13\% of geological time. Animals have been on land for 360 million years, or $8 \%$ of geological time. Mammals have dominated since the demise of the dinosaurs around $65 \mathrm{Ma}$, or $1.5 \%$ of geological time, and the genus Homo has existed since approximately $2.8 \mathrm{Ma}$, or $0.06 \%(1 / 1,600$ th) of geological time.

Geologists (and geology students) need to understand geological time. That doesn't mean memorizing the geological time scale; instead, it means getting your mind around the concept that although most geological processes are extremely slow, very large and important things can happen if such processes continue for enough time.

For example, the Atlantic Ocean between Nova Scotia and northwestern Africa has been getting wider at a rate of about 2.5 centimetres $(\mathrm{cm})$ per year. Imagine yourself taking a journey at that rate-it would be impossibly and ridiculously slow. And yet, since it started to form at around $200 \mathrm{Ma}$ (just $4 \%$ of geological time), the Atlantic Ocean has grown to a width of over 5,000 kilometres $(\mathrm{km})$ !

A useful mechanism for understanding geological time is to scale it all down into one year. The origin of the solar system and Earth at $4.57 \mathrm{Ga}$ would be represented by January 1 , and the present year would be represented by the last tiny fraction of a second on New Year's Eve. At this scale, each day of the year represents 12.5 million years; each hour represents about 500,000 years; each minute represents 8,694 years; and each second represents 145 years. Some significant events in Earth's history, as expressed on this time scale, are summarized on Table I1.

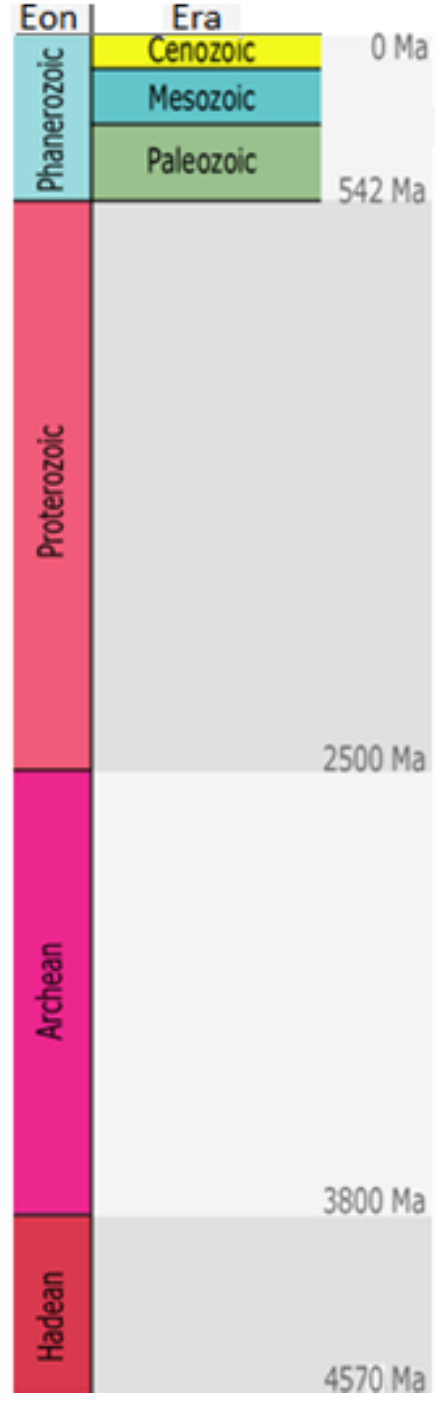

Figure I8: The geological time scale. [Image description] 


\begin{tabular}{|c|c|c|}
\hline Event & $\begin{array}{l}\text { Approximate } \\
\text { Date }\end{array}$ & Calendar Equivalent \\
\hline Formation of oceans and continents & 4.5 to $4.4 \mathrm{Ga}$ & January \\
\hline Evolution of the first primitive life forms & $3.8 \mathrm{Ga}$ & early March \\
\hline Formation of Alberta's oldest sedimentary rocks & $1.4 \mathrm{Ga}$ & mid September \\
\hline Evolution of the first multi-celled animals & $\begin{array}{l}0.6 \mathrm{Ga} \text { or } 600 \\
\mathrm{Ma}\end{array}$ & November 15 \\
\hline Animals first crawled onto land & $360 \mathrm{Ma}$ & December 1 \\
\hline Rocky Mountains were formed & $90 \mathrm{Ma}$ & December 25 \\
\hline Extinction of the non-avian dinosaurs & $65 \mathrm{Ma}$ & December 26 \\
\hline Beginning of the Pleistocene ice age & $\begin{array}{l}2 \text { Ma or } 2000 \\
\text { ka }\end{array}$ & 8 p.m., December 31 \\
\hline Retreat of the most recent glacial ice from southern Canada & $14 \mathrm{ka}$ & 11:58 p.m., December 31 \\
\hline Evidence of First Nations living in the Bow Valley, Alberta & $10 \mathrm{ka}$ & 11:59 p.m., December 31 \\
\hline $\begin{array}{l}\text { Arrival of the first Europeans on the west coast of what is now } \\
\text { Canada }\end{array}$ & 250 years ago & $\begin{array}{l}2 \text { seconds before midnight, } \\
\text { December } 31\end{array}$ \\
\hline
\end{tabular}

\section{Practice Exercise: Take a trip through geological time}

We're going on a road trip! Pack some snacks and grab some of your favourite music. We'll start in Tofino on Vancouver Island and head for the Royal Tyrrell Museum just outside of Drumheller, Alberta, 1,500 km away. Along the way, we'll talk about some important geological sites that we pass by, and we'll use the distance as a way of visualizing the extent of geological time. Of course it's just a "virtual" road trip, but it will be fun anyway. To join in, go to: Virtual Road Trip.

Once you've had a chance to do the road trip, answer these questions:

1. We need oxygen to survive, and yet the first presence of free oxygen $\left(\mathrm{O}_{2}\right.$ gas) in the atmosphere and the oceans was a "catastrophe" for some organisms. When did this happen and why was it a catastrophe?

2. Approximately how much time elapsed between the colonization of land by plants and animals?

3. Explain why the evolution of land plants was such a critical step in the evolution of life on Earth.

See Appendix 2 for Practice Exercise answers.

\section{Image descriptions}

Figure 18 image description: The geological time scale drawn such that the thickness that represents $50 \mathrm{Ma}$ is the same anywhere on the diagram. By drawing the time scale in this linear way, it is easier to appreciate the vast amount of time represented by the Hadean, Archean, and Proterozoic eons, and the comparatively short amount of time represented by all of the Phanerozoic. The Hadean eon (3800 Ma to $4570 \mathrm{Ma}$ ), Archean 
eon (2500 Ma to $3800 \mathrm{Ma}$ ), and Proterozoic eon (542 Ma to $2500 \mathrm{Ma}$ ) make up 88\% of geological time. The Phanerozoic eon makes up the last $12 \%$ of geological time. The Phanerozoic eon (0 Ma to $542 \mathrm{Ma}$ ) contains the Paleozoic, Mesozoic, and Cenozoic eras. [Return to Figure I8]

\section{Media Attributions}

- Figure I8: (C) Steven Earle. CC BY.

\section{Notes}

1. Hutton, J, 1788. Theory of the Earth; or an investigation of the laws observable in the composition, dissolution, and restoration of land upon the Globe. Transactions of the Royal Society of Edinburgh. 


\section{Summary}

The topics covered in this chapter can be summarized as follows:

\begin{tabular}{|c|c|}
\hline Section & Summary \\
\hline $\begin{array}{l}\text { What is } \\
\text { Geology? }\end{array}$ & $\begin{array}{l}\text { Geology is the study of Earth. It is an integrated science that involves the application of many of the } \\
\text { other sciences, but geologists also have to consider geological time because most of the geological } \\
\text { features that we see today formed thousands, millions, or even billions of years ago. }\end{array}$ \\
\hline $\begin{array}{l}\text { Why Study } \\
\text { Earth? }\end{array}$ & $\begin{array}{l}\text { Geologists study Earth out of curiosity and for other more practical reasons, including } \\
\text { understanding the evolution of life on Earth, searching for resources, understanding risks from } \\
\text { geological events such as earthquakes, volcanoes, and slope failures, and documenting past } \\
\text { environmental and climate changes so that we can understand how human activities are affecting } \\
\text { Earth. }\end{array}$ \\
\hline $\begin{array}{l}\text { What Do } \\
\text { Geologists } \\
\text { Do? }\end{array}$ & $\begin{array}{l}\text { Geologists work in the resource industries and in efforts to protect our natural resources and the } \\
\text { environment in general. They are involved in ensuring that risks from geological events (e.g., } \\
\text { earthquakes) are minimized and that the public understands what the risks are. Geologists are also } \\
\text { engaged in fundamental research about Earth and in teaching. }\end{array}$ \\
\hline $\begin{array}{l}\text { Minerals and } \\
\text { Rocks }\end{array}$ & $\begin{array}{l}\text { Minerals are naturally occurring, specific combinations of elements that have particular } \\
\text { three-dimensional structures. Rocks are made up of mixtures of minerals and can form though } \\
\text { igneous, sedimentary, or metamorphic processes. }\end{array}$ \\
\hline $\begin{array}{l}\text { Fundamentals } \\
\text { of Plate } \\
\text { Tectonics }\end{array}$ & $\begin{array}{l}\text { The Earth's mantle is convecting because it is being heated from below by the hot core. Those } \\
\text { convection currents contribute to the movement of tectonic plates (which are composed of the crust } \\
\text { and the uppermost rigid mantle). Plates are formed at divergent boundaries and consumed } \\
\text { (subducted) at convergent boundaries. Many important geological processes take place at plate } \\
\text { boundaries. }\end{array}$ \\
\hline $\begin{array}{l}\text { Geological } \\
\text { Time }\end{array}$ & $\begin{array}{l}\text { Earth is approximately } 4,570,000,000 \text { years old; that is, } 4.57 \text { billion years or } 4.57 \mathrm{Ga} \text { or } 4,570 \mathrm{Ma} \text {. It's } \\
\text { such a huge amount of time that even extremely slow geological processes can have an enormous } \\
\text { impact. }\end{array}$ \\
\hline
\end{tabular}




\section{GOOGLE EARTH TUTORIAL}

This is a pre-lab tutorial activity to be completed independently before Lab I.

Learning Objectives

After completing the exercises in this tutorial assignment, you should understand how to use Google Earth Pro to:

- $\quad$ Examine the Earth's surface in plan view and in three-dimensions.

- $\quad$ Use the compass to understand direction when navigating in Google Earth Pro.

- $\quad$ Use the scale bar and measure tools to determine on-the-ground distances.

- $\quad$ Specify locations using geographic and Universal Transverse Mercator (UTM) grid systems.

- $\quad$ Modify the options in Google Earth Pro to use metric or imperial units, and geographic or UTM coordinates.

- $\quad$ Search for specific locations by place name or using geographic coordinates.

- View historical satellite imagery to examine changes to an area over time.

Google Earth Pro is an excellent tool for visualizing landscapes using satellite imagery. We will be using Google Earth Pro in several lab exercises in this course to examine volcanoes, rivers, and geologic structures. You will need to be familiar with how to navigate and use various features in Google Earth Pro to complete these exercises. To prepare for your first lab, complete the tutorial assignment in the next section before you meet for Lab 1.

If you are familiar with Google Earth Pro and the use of geographic and UTM coordinate systems to describe locations on Earth, this tutorial should take you about 25 minutes to complete. If you are not familiar with Google Earth Pro or the use of geographic and UTM coordinate systems, this tutorial could take up to 1 hour to complete. Contact your lab instructor if you have questions as you complete this tutorial.

To get started, download Google Earth Pro (free) for desktop: https://www.google.com/earth/versions/. Although there are also web and mobile versions of Google Earth Pro available, these do not have all the features you will be required to use in this course. It is recommended that you use the desktop version on a computer. 


\section{Getting Started in Google Earth Pro}

Once you have downloaded and installed Google Earth Pro for desktop, open the program on your computer.

In the search bar in the upper left part of your screen, type in "Mount Royal University". Click Search.

You are now looking at a bird's eye view, or map view of the Mount Royal University (MRU) campus. This is definitely a bird's eye view: in the bottom right-hand* corner of the image it will tell you the altitude from which you are looking down. In Figure T1, we are looking down at MRU from an altitude of $2.12 \mathrm{~km}$ !

*Note that these instructions have been written for Google Earth Pro on a PC running Windows 10. If you are using a

Mac computer, the description of where certain features are found may differ. Contact your lab instructor for more information.

Text boxes like this one contain questions you need to answer, or specific actions you need to practice, in order to complete this tutorial assignment.

From what altitude are you looking down on MRU?

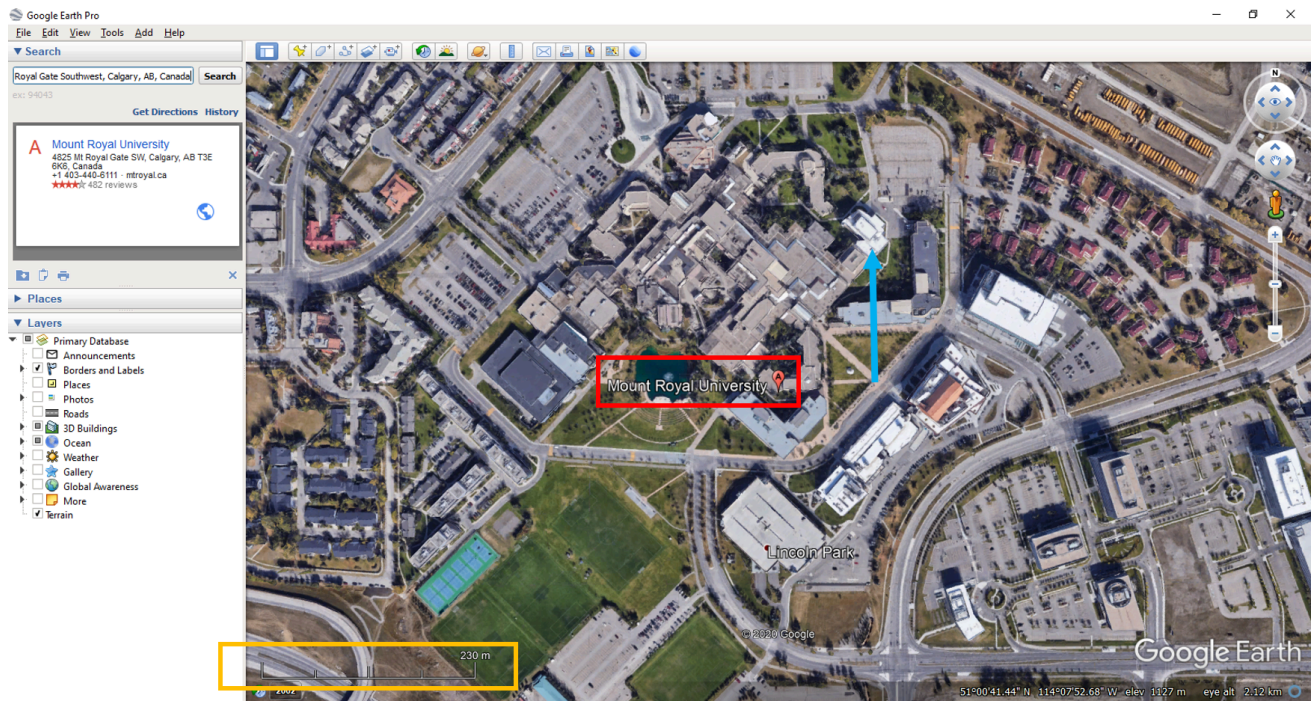

Figure T1: Annotated Google Earth map view of Mount Royal University (MRU), highlighting where to find the location marker for MRU (red box), the scale bar (yellow box), and north (blue arrow and compass in upper right corner).

Let's point out a few things you should know about Google Earth.

1. The red place marker shows the name and the exact location of the place you typed into the search bar. (See the red box in Figure T1 below)

2. In the top right corner, the compass shows which direction is north in the current view. In Figure T1, north is toward the top of the image (in the direction of the blue arrow).

3. The bar in the bottom left corner of the image shows the scale bar (inside the orange box in Figure T1). A scale bar helps you determine the actual, on the ground, distance between points or along lines. In 
Figure T1 below, the entire length of the scale bar represents a real distance of $230 \mathrm{~m}$, and each division along the scale bar represents a real distance of $57.5 \mathrm{~m}$.

Try spinning the view around by clicking on the ' $\mathrm{N}$ ' on the compass, holding down your mouse, and spinning the ' $N$ ' around. You can also hold down the shift key and use the right and left arrow keys on your keyboard to rotate the view.

To return to the original view press the letter ' $r$ ' on your keyboard, or click View, Reset, Compass.

Let's check out a few more features in Google Earth. Look at the numbers in the bottom right corner of the image (See red box in Figure T2).

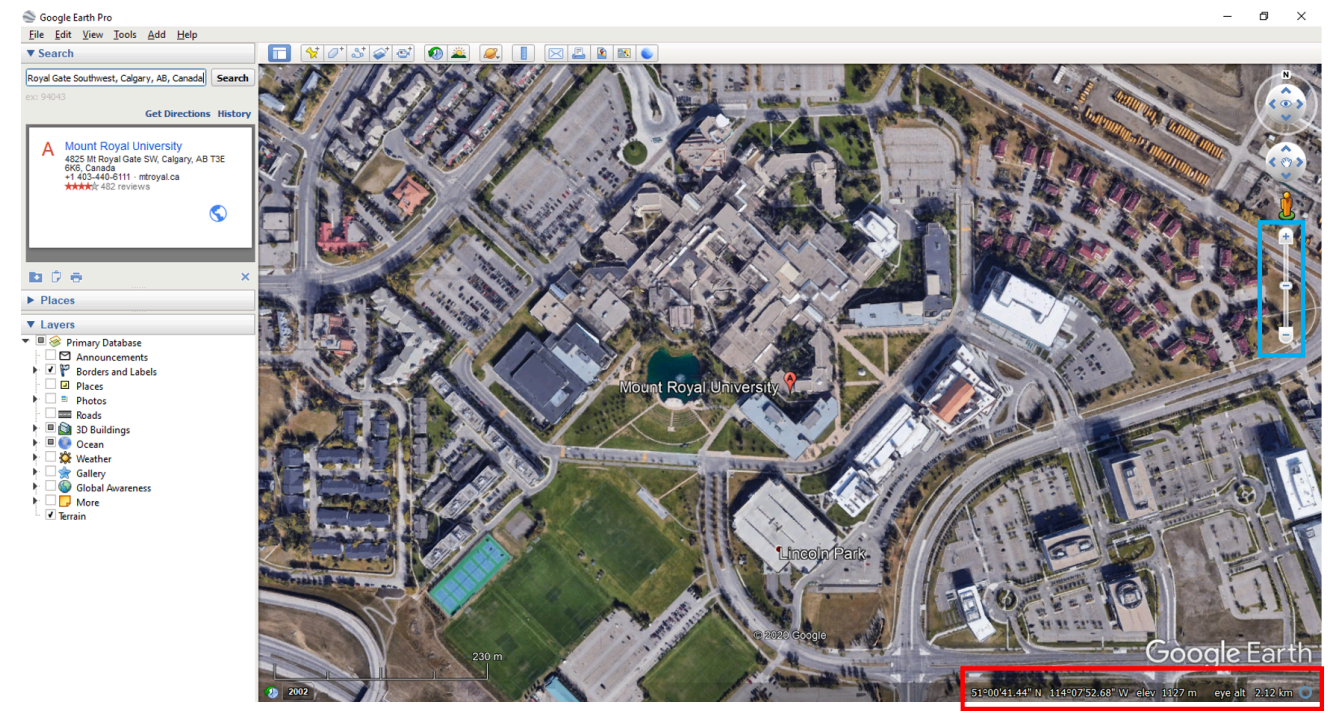

Figure T2: Annotated Google Earth map view of MRU highlighting the location information shown in the red box. In this example, the location of the cursor is given in latitude and longitude coordinates. The information in this area of the screen also shows the elevation of the land at the location specified by the cursor, which is $1127 \mathrm{~m}$ above sea level in this example.

What happens to these numbers as you move your cursor around?

These numbers are the coordinates for the cursor location and they change as you change the position of the cursor. Coordinates are used to specify an exact location using a series of numbers in a grid system. Grid systems are used to divide the Earth's surface into imaginary squares formed by two sets of perpendicular lines. Two common grid systems used in Google Earth that we will use throughout this term are geographic (latitude and longitude), andUniversal Transverse Mercator(UTM). We will come back to the concept of grid systems in the next part of this tutorial.

The sliding bar in the blue box in Figure T2 can be used to zoom in and out. You can also zoom in and out using the scroll wheel on your mouse or the keyboard shortcuts defined in the table below. Notice how when you do this, the number value on the scale bar changes. Zooming in and out changes the scale of the image.

What happens when you zoom in dramatically? You probably jump into "Street View" (See Figure T3). To return to 
map view, click on "Exit Street View" in the top right corner.

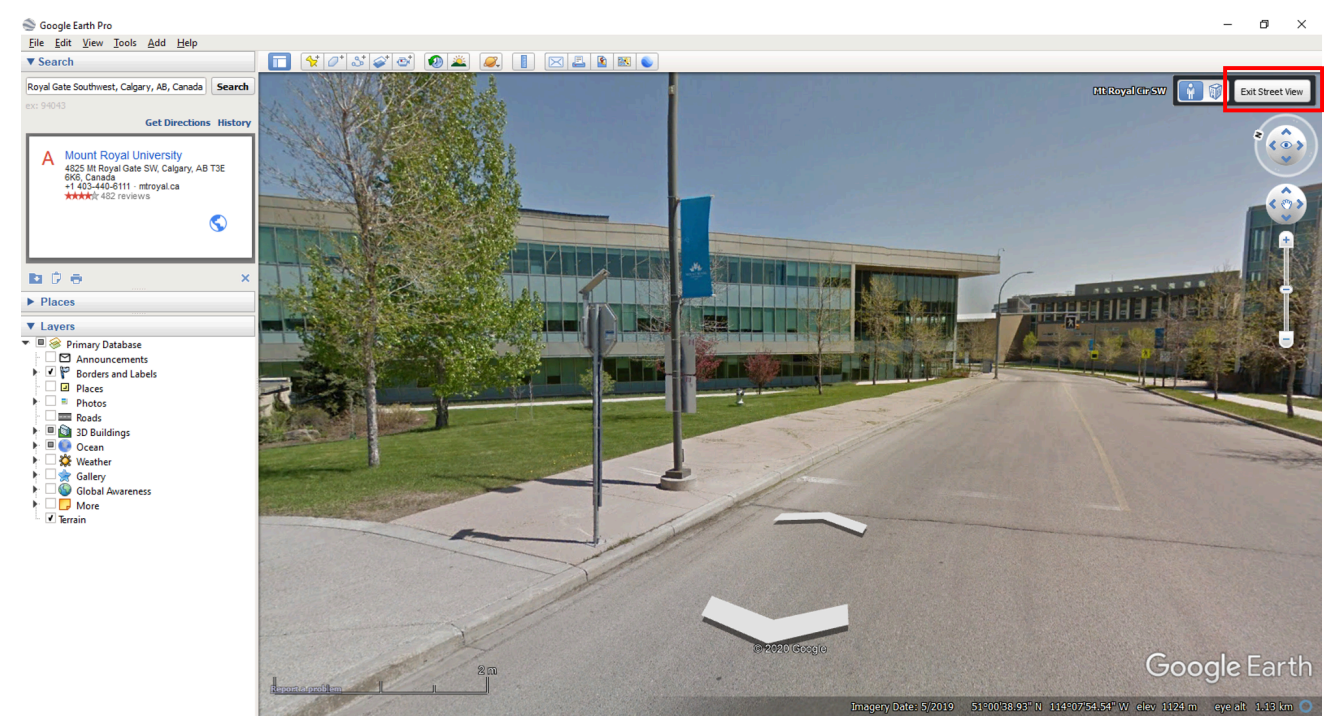

Figure T3: An example of street view in Google Earth. To exit Street View, click on "Exit Street View" in the top right-hand corner of the image.

Now let's explore how we can measure distances in Google Earth. First, make sure you are back in map view. To do this, on your keyboard press 'r', or click View, Reset, Tilt and Compass.

Click on the ruler icon in the toolbar located at the top of the screen. A dialogue box should pop up (see Figure T4). Let's use a line to measure the length of the two soccer fields at MRU. Click once to start measuring and click again to stop. What distance did you measure? In Figure T4, the length of the line measured represents a real distance of $151.47 \mathrm{~m}$.

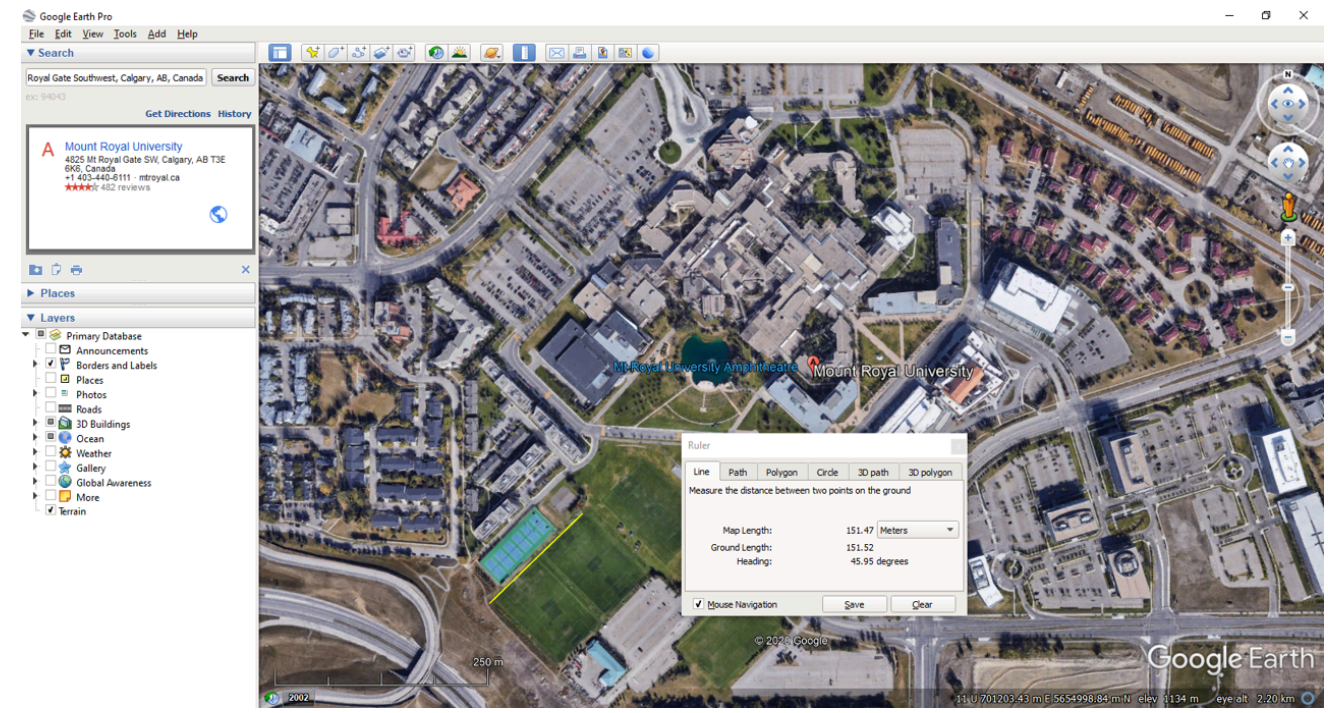

Figure T4: Using the ruler tool to measure distances in Google Earth. The dialogue box will tell you the length of the line you are measuring. This example shows that the length of two soccer fields at MRU is $151.47 \mathrm{~m}$ (see yellow line on map). 
You can also measure the length of a path, rather than just a straight line. Figure $\mathrm{T} 5$ shows a measured path along the ring road around MRU. The total length of the path is $1.55 \mathrm{~km}$. Notice that you can change the unit of measurement by using the drop down menu. Click clear to erase the line or path you measured.

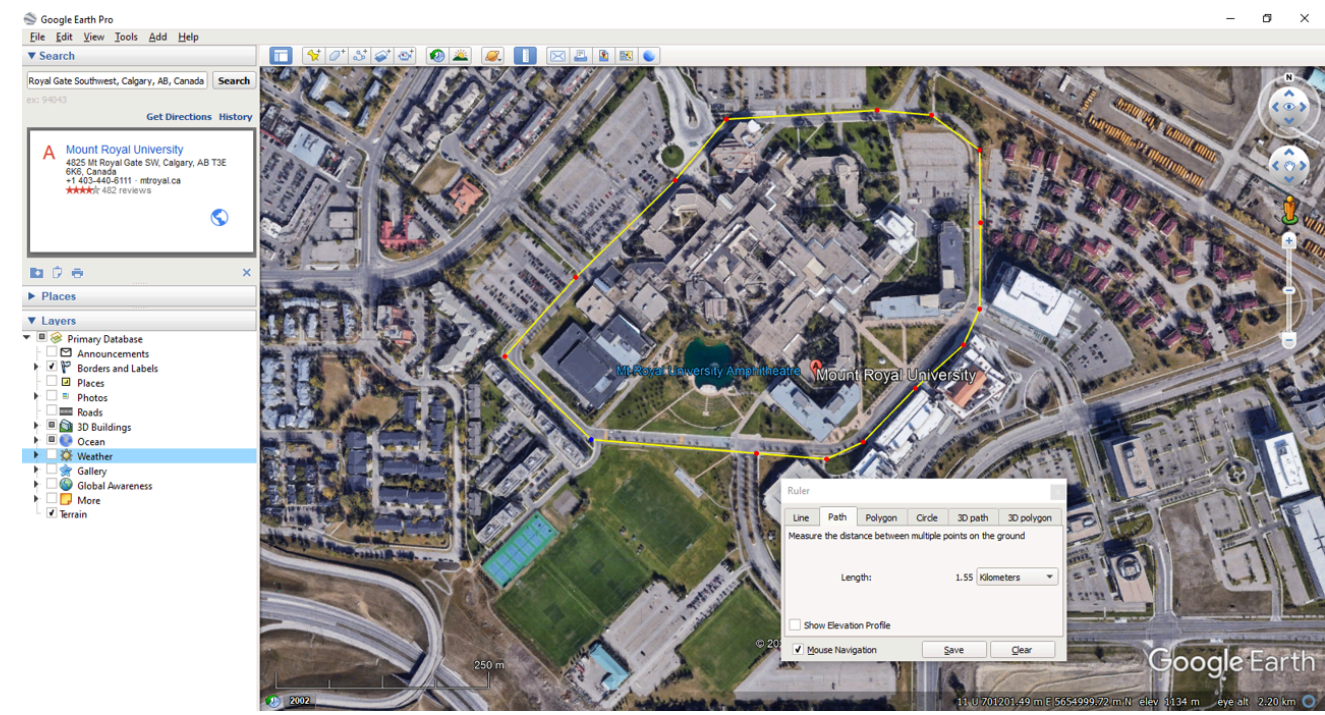

Figure T5: Using the ruler tool to measure the length of a path, rather than a simple straight line. The length of a path drawn around the ring road of MRU is $1.55 \mathrm{~km}$ (see yellow path on image).

Let's try changing some options in Google Earth Pro. Click on Tools, Options. The dialogue box shown in Figure T6 should appear. Examine the 3D View tab, where you can choose between using UTM coordinates or Lat/Long coordinates (Figure T6, red box). Choose to display lat/long coordinates in one of three ways: decimal degrees, degrees-minutes-seconds, or degrees-decimal minutes. You can also change the default units of measurement (Figure T6, blue box) from imperial (feet, miles) to metric (metres, kilometres). When you are happy with your selections, click Apply.

Finally, let's examine some historical satellite imagery. Google Earth is a great tool for examining changes to Earth's surface over the past few decades. By clicking on the clock icon in the top toolbar (Figure T7, red arrow), you can see historical imagery for the area on your screen. Use the scroll bar to look through the historical imagery of the city of Calgary from an altitude of $\sim 70-80 \mathrm{~km}$.

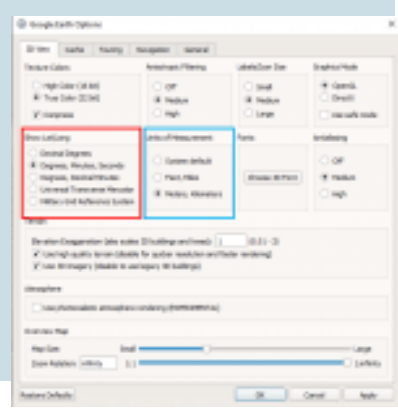

Figure T6: Annotated options menu in Google Earth highlighting where grid coordinates (red box) and units of measurement (blue box) can be changed. 


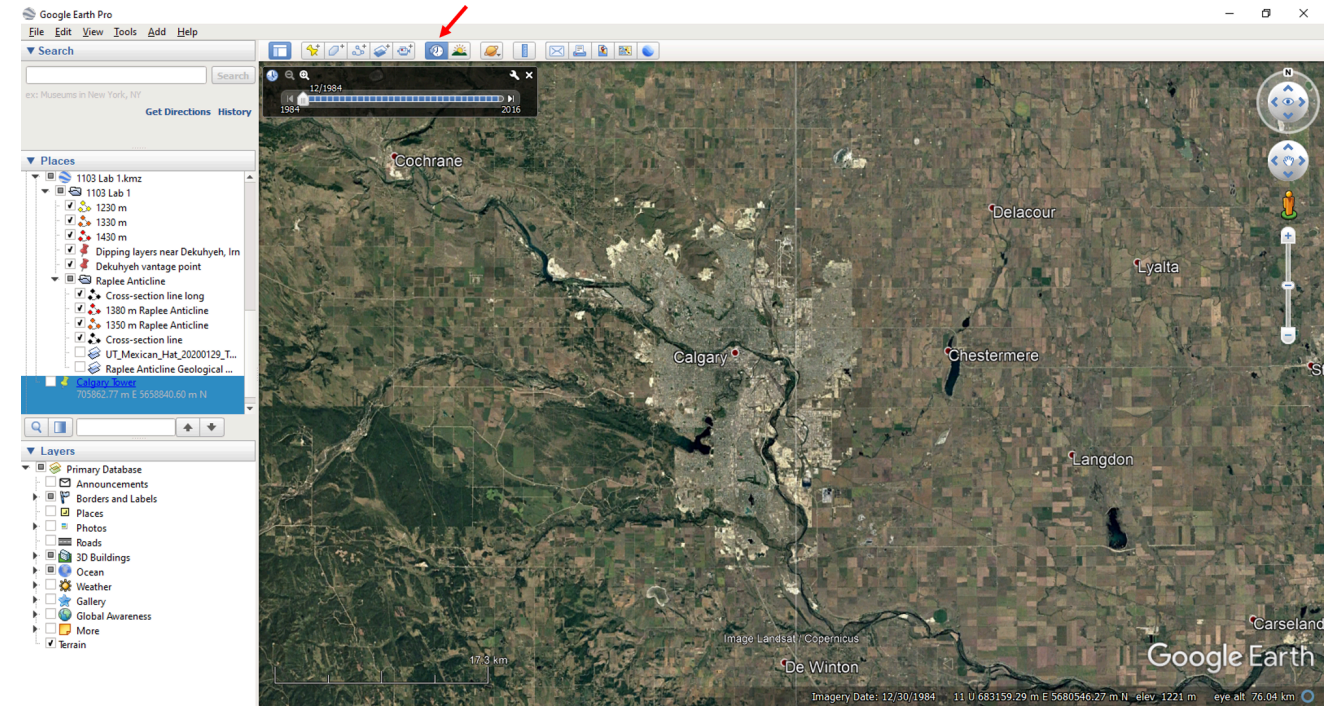

Figure T7: Annotated historical Google Earth imagery of Calgary and surrounding areas from 1984.

What distance is represented by the entire length of the scale bar?

In what year was the oldest image of this area at this scale captured?

In what year was the most recent image of this area at this scale captured? 


\section{Keyboard Shortcuts for Google Earth Pro}

\begin{tabular}{|l|l|l|}
\hline Action & Shortcut (Windows \& Linux) & Shortcut (Mac) \\
\hline Move left & Left arrow & Left arrow \\
\hline Move right & Right arrow & Right arrow \\
\hline Move up & Up arrow & Up arrow \\
\hline Move down & Down arrow & Down arrow \\
\hline Rotate clockwise & Shift + Left arrow & Shift + Left arrow \\
\hline Rotate counter-clockwise & Shift + Right arrow & Shift + Right arrow \\
\hline Tilt up & Shift then click and drag down & Shift + Down arrow \\
\hline Tilt down & Shift + Up arrow & Shift + Up arrow \\
\hline Reset to north-up view & Shift then click and drag up & n \\
\hline Reset to top-down tilt & n & u \\
\hline Return to plan and north-up view & r & r \\
\hline Zoom in & + & + \\
\hline Zoom out & - & - \\
\hline Stop current motion & Spacebar & Spacebar \\
\hline
\end{tabular}

\section{Media Attributions}

- Figures T1, T2, T3, T4, T5, T6, T7 used under the following Google Maps and Google Earth guidelines. 


\section{Grid Systems and Coordinates}

\section{What is a grid system?}

A grid is a regular pattern made of squares formed by two sets of lines that intersect at right angles. Grid systems are used to precisely identify locations on a map. The two types of grid systems we will cover in this course are:

- Geographic, where locations are specified using degrees and minutes of latitude and longitude.

- Universal Transverse Mercator (UTM), where locations are specified in metres using an easting and northing.

Depending on your settings in Google Earth Pro, you might be using the geographic grid system (latitude and longitude) OR the Universal Transverse Mercator grid system (UTM). If you are not sure which grid system you are using, return to the Options menu to check.

\section{Latitude and longitude}

The geographic grid system is made up of meridians of longitude and parallels of latitude. Figures T8 and T9 illustrate the geographic grid system in Canada.

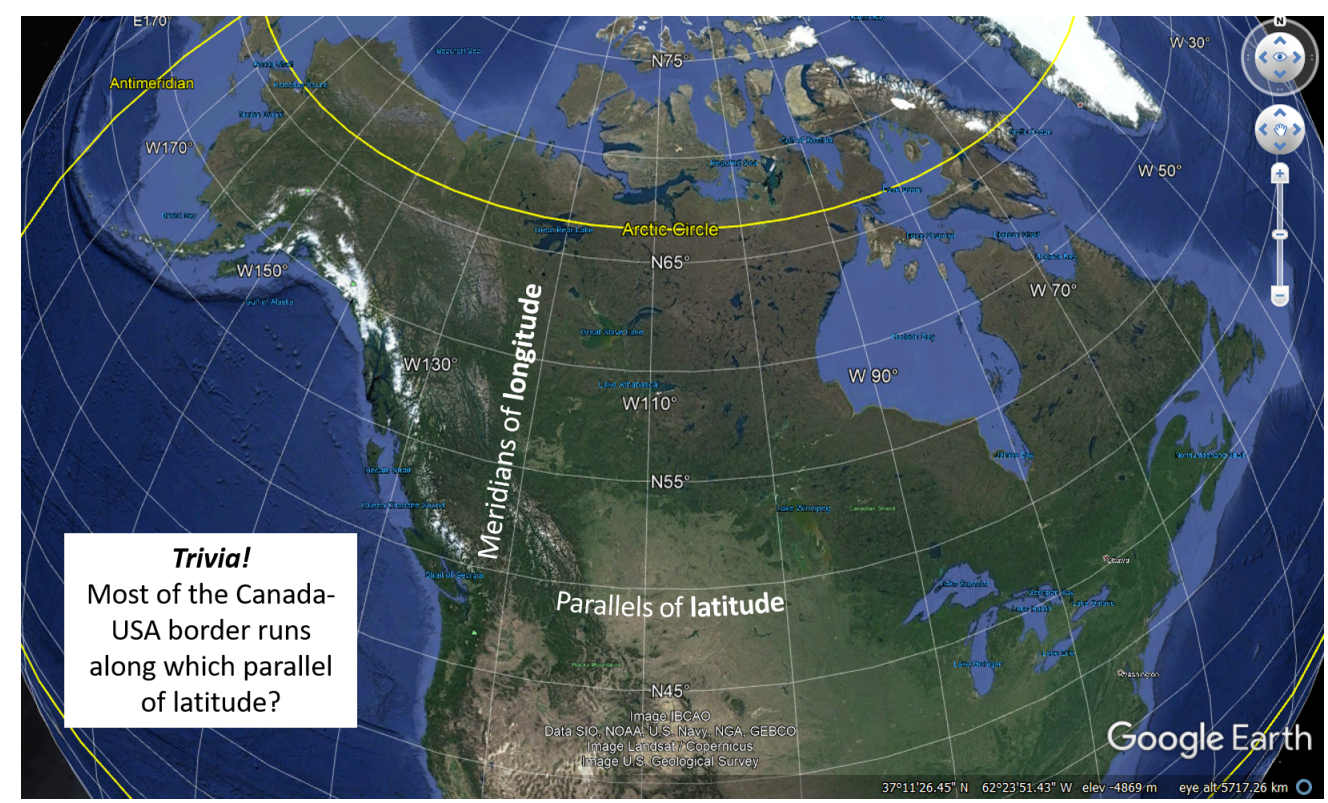

Figure T8: The geographic grid system is comprised of meridians of longitude and parallels of latitude. Meridians of longitude run north-south whereas parallels of latitude run east-west. 


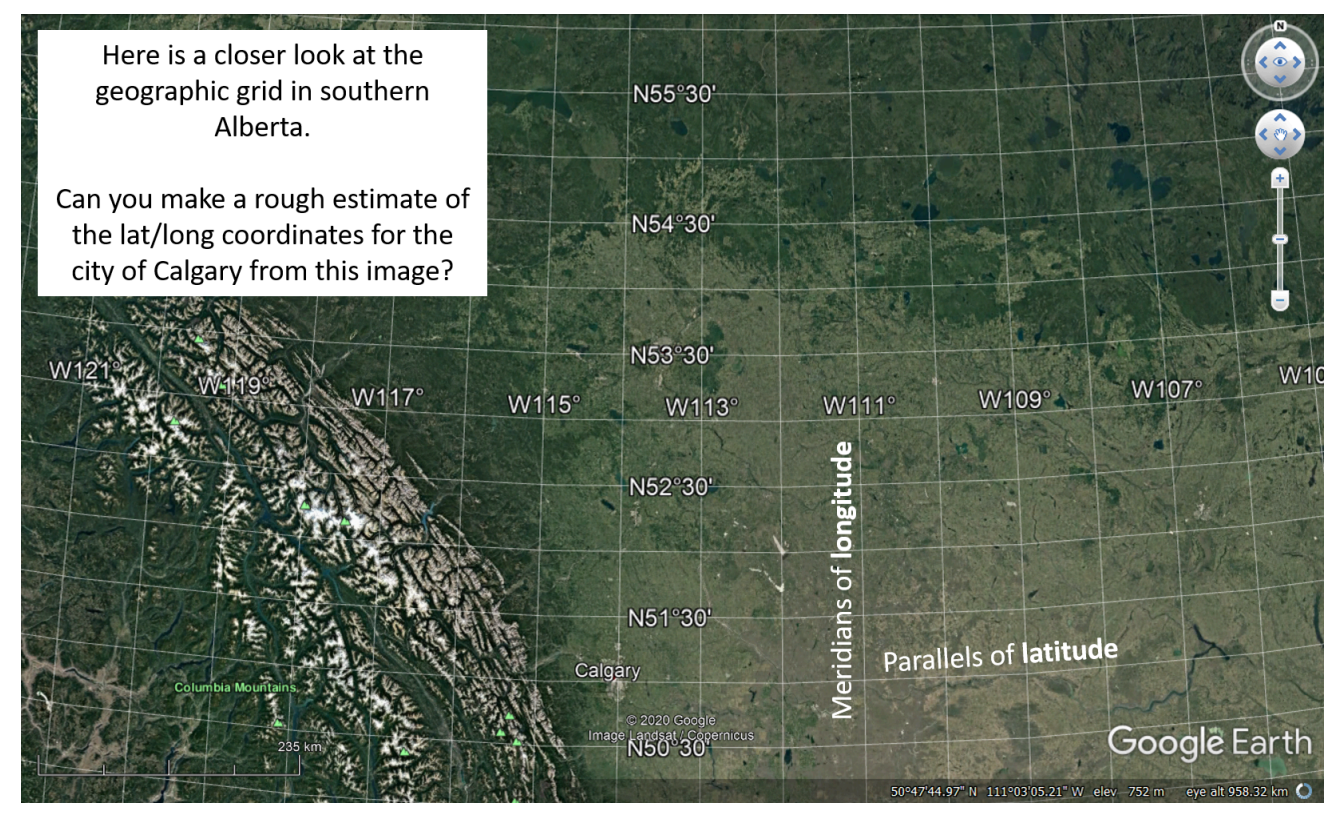

Figure T9: Geographic grid system displayed over southern Alberta.

Coordinates that describe an exact location on the surface of Earth are represented in degrees, minutes and seconds of latitude and longitude. Depending on the accuracy required in locating a point on a map, degrees $\left(^{\circ}\right)$ may be subdivided into 60 subdivisions known as minutes (') and minutes may be subdivided into 60 subdivisions known as seconds ("). The line of $0^{\circ}$ longitude is the prime meridian located in Greenwich, England, and longitude increases from $0^{\circ}$ to $180^{\circ}$ as you move east or west away from the prime meridian. The line of $0^{\circ}$ latitude is the equator, and latitude increases from $0^{\circ}$ to $90^{\circ}$ as you move north or south towards the poles.

When using the geographic grid system, one must specify whether coordinates are north $(\mathrm{N})$ or south $(\mathrm{S})$ of the equator, and east (E) or west (W) of the prime meridian. For anywhere in Canada, latitude will always be north of the equator and longitude will always be west of the prime meridian, e.g., 51 $02^{\prime} 39^{\prime \prime} \underline{\mathbf{N}} 114^{\circ} 03^{\prime} 47^{\prime \prime}$ $\underline{\mathbf{W}}$. Notice that latitude is listed first, followed by longitude. Together, these coordinates describe an exact location.

Try typing these coordinates into the search bar in Google Earth. What geographic feature is located at $51^{\circ} 02^{\prime} 39^{\prime \prime}$ N 11403'47" W? See Appendix 2 for Google Earth Tutorial answers.

\section{Universal Transverse Mercator (UTM)}

In this grid system designed by the military, Earth's surface is divided into 60 north-south zones designated by a number and letter, each covering $6^{\circ}$ of longitude in width (Figure T10). Inside each zone, coordinates are measured in metres north and east. The city of Calgary is actually divided into two UTM zones: zone 11 $\mathrm{U}$ and zone $12 \mathrm{U}$ (Figure T11). 


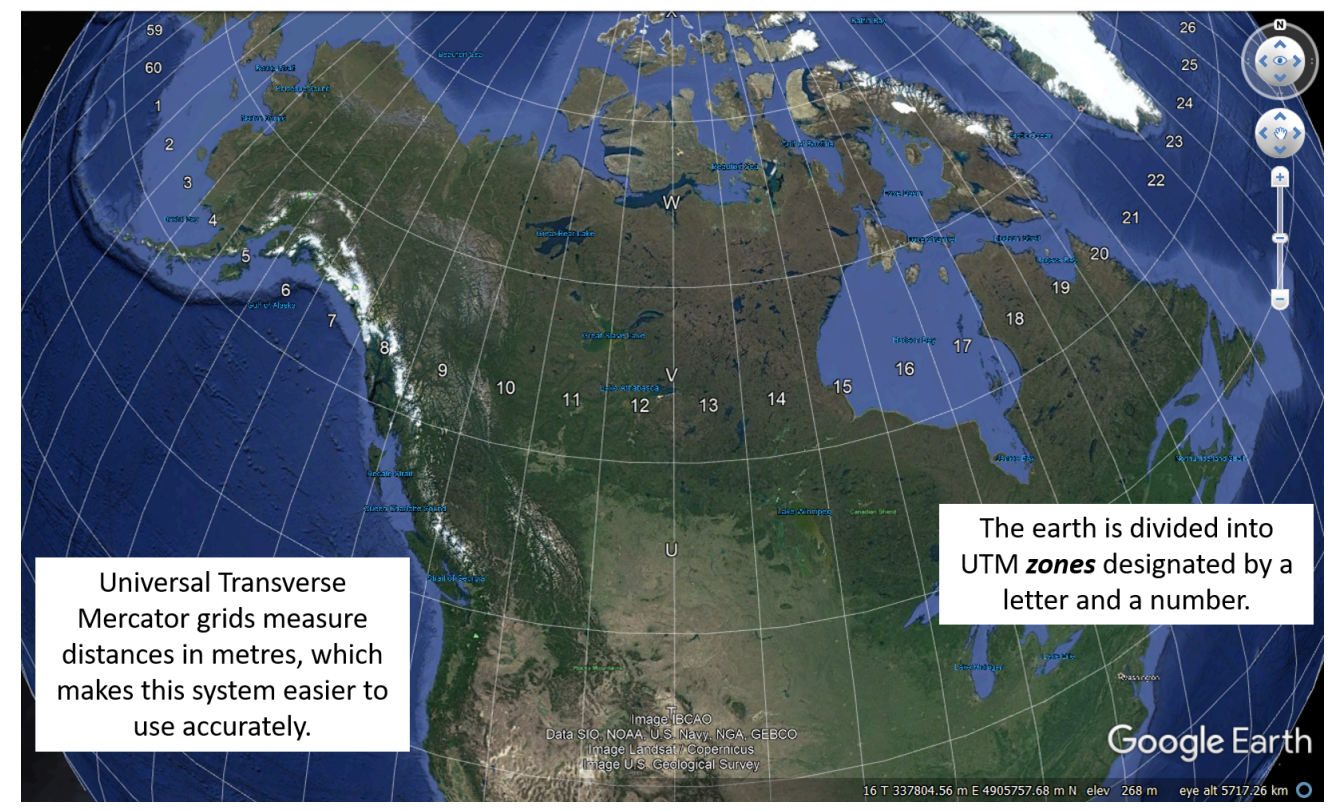

Figure T10: Universal Transverse Mercator (UTM) zones in Canada. Zones are designated by a number and a letter, e.g., the city of Vancouver, BC is in UTM zone $10 \mathrm{U}$.

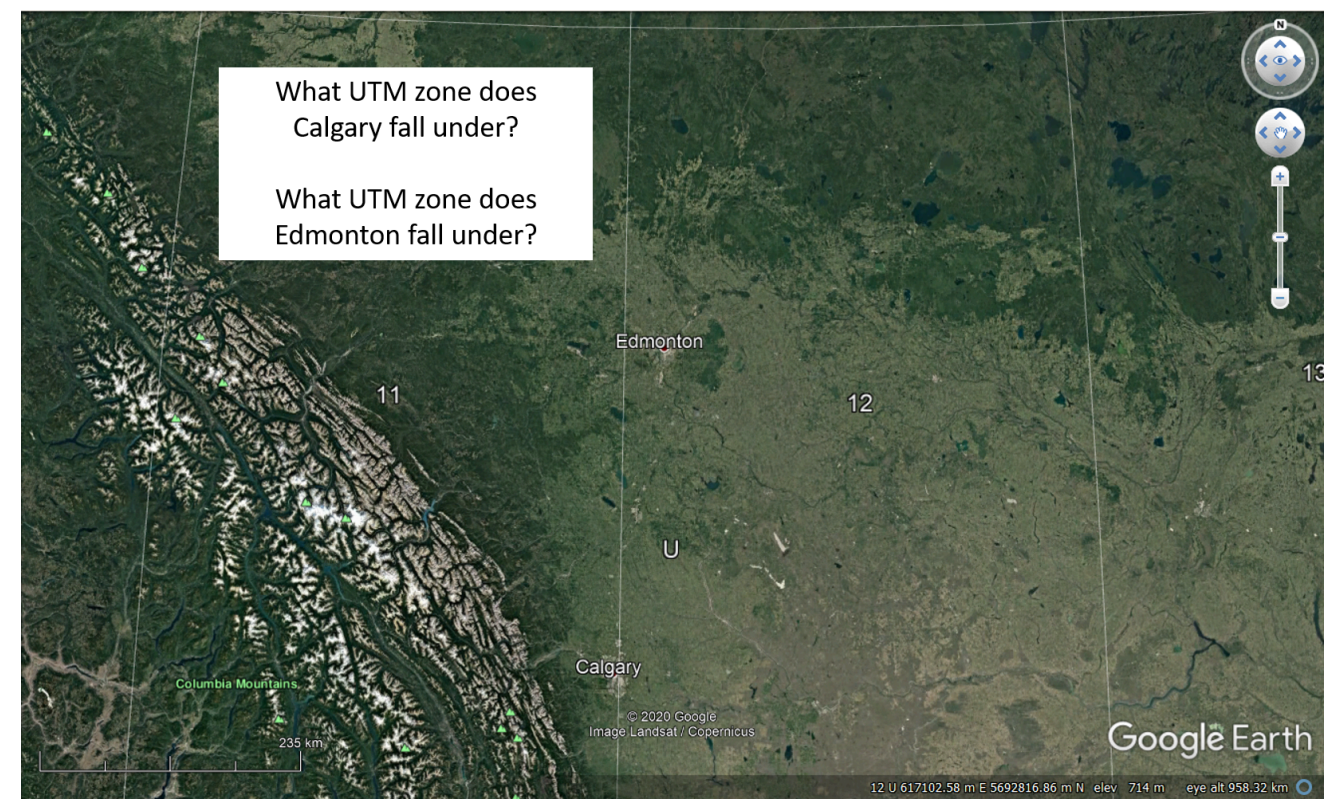

Figure T11: Universal Transverse Mercator (UTM) zones $11 \mathrm{U}$ and $12 \mathrm{U}$ in Alberta.

A UTM coordinate always begins with the zone, which in the case for most of Calgary is $11 \mathrm{U}$. The easting is always given first, followed by the northing. For example, $11 \mathrm{U} 705863 \mathrm{~m} \mathrm{E} 5658841 \mathrm{~m} \mathrm{~N}$ are the approximate coordinates for the Calgary Tower.

In Figure T12, a point is located using UTM coordinates $11 \mathrm{U} 708400 \mathrm{~m}$ E $5659200 \mathrm{~m} \mathrm{~N}$, meaning that the location is known to within a $100 \mathrm{~m}$ by $100 \mathrm{~m}$ square. If you were using GPS to pin-point your location, you might be able to record UTM coordinates to within a $1 \mathrm{~m}$ by $1 \mathrm{~m}$ square, and your coordinates might look something like: 11 U $708411 \mathrm{~m}$ E $5659284 \mathrm{~m} \mathrm{~N}$. Note that the UTM system is a true metric measuring system, and that it is the easiest to use accurately. 

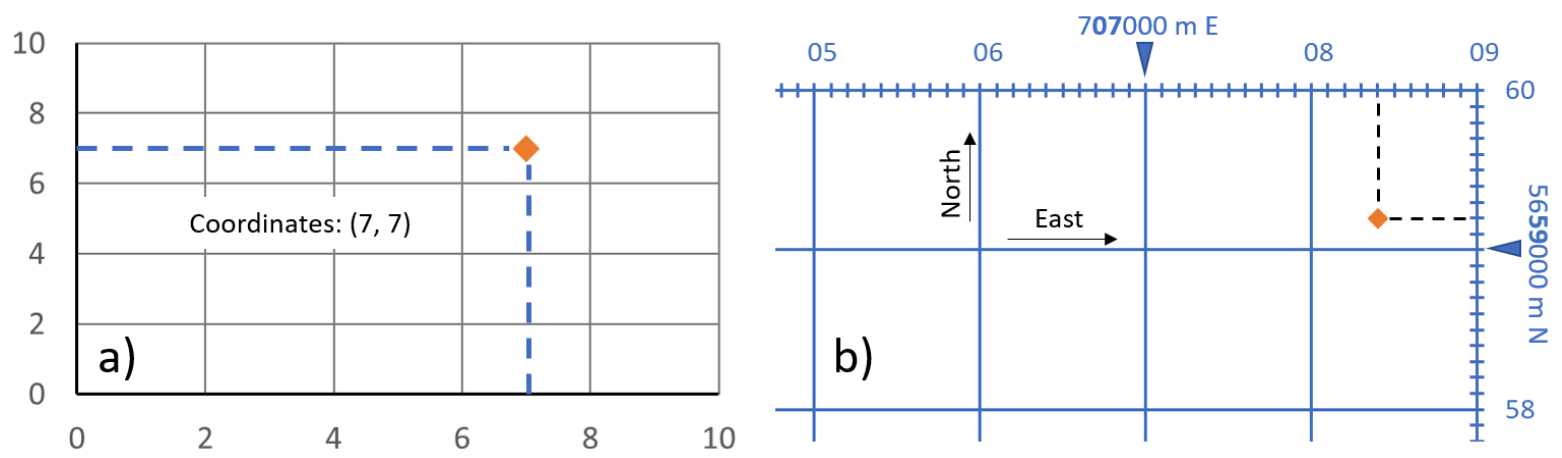

Figure T12: An example of coordinates $(7,7)$ plotted on a simple X-Y graph (a, left) and the same principle used to plot a point using UTM coordinates for zone $11 \mathrm{U}$ in Calgary (b, right). Notice how not all the numbers labeled along the edge are written in full. Some values are abbreviated to save space on the map, e.g., the number 06 represents the grid line for easting $706000 \mathrm{~m}$, and the number 58 represents the grid line for northing $5658000 \mathrm{~m} \mathrm{~N}$.

\section{Universal Transverse Mercator (UTM) grid references}

Instead of reporting the full UTM coordinates, an abbreviated 6-digit grid reference can be reported to give a location to nearest $100 \mathrm{~m}$. To report an abbreviated grid reference, look at the nearest grid line and estimate tenths of a square eastward or northward from this line to the location of interest. Record the UTM zone followed by the three digits in the 10000, 1000 and 100 position for both the easting and the northing.

For example, the full UTM coordinates $\underline{11 \mathrm{U}} 7 \underline{\mathbf{0 8 4}} 11 \mathrm{~m}$ E $56 \underline{592} 84 \mathrm{~m} \mathrm{~N}$ can be abbreviated using only the bolded and underlined portions of the full coordinates, $\underline{\mathbf{1 1} \mathrm{U} \mathbf{0 8 4 5 9 2}}$.

\section{Using grid coordinates to find a location}

Using coordinates to specify a position in a grid is just like locating a point on a simple X-Y graph. On an $\mathrm{X}$-Y graph, the first number in the coordinate refers to the position along the $\mathrm{X}$-axis and the second number refers to the position along the Y-axis (Figure T12 a). To use coordinates in a geographic grid system, simply use the labeled grid lines or graticules around the outer border of a map and plot the longitude first, followed by the latitude. To use coordinates in a UTM grid system, simply use the labeled grid lines or graticules around the outer border of a map and plot the easting first, followed by the northing (Figure T12 b).

1. What are the UTM coordinates (easting and northing) of the point in Figure T12 b?

2. Try plotting the coordinate $11 \mathrm{U} 707500 \mathrm{~m}$ E $5658200 \mathrm{~m}$ N on Figure T12 b.

3. In the UTM grid shown in Figure T12 b, what is the length in metres of each side of each square on the grid?

4. To see the grid lines for each system in Google Earth, click on View, Grid. Try zooming in and out to see how each grid type looks. Try this using the geographic grid (lat/long) and the UTM grid.

5. Type "Mount Royal University" into the search bar and click Search. Hover your cursor right on the place 
marker. What are the coordinates for MRU in lat/long? Remember, you must specify that MRU is north of the equator and west of the prime meridian!

6. What are the coordinates for MRU in UTM coordinates? Remember, you must specify the zone number!

7. What are the coordinates for MRU in UTM as a grid reference? Remember, you must specify the zone number!

See Appendix 2 for Google Earth Tutorial answers.

\section{Media Attributions}

- Figures T8, T9, T10, T11 used under the following Google Maps and Google Earth guidelines.

- Figure T12: (C) Siobhan McGoldrick. CC BY. 


\section{LAB I: PLATE TECTONICS}

\section{Lab Structure}

Recommended additional work

Required materials
Yes - complete Google Earth Tutorial before Lab 1

Pencil, pencil crayons, ruler, printed Plate Boundaries Map

After carefully reading this section, completing the exercises within it, and answering the questions at the end, you should be able to:

- $\quad$ Explain the difference between oceanic and continental crust.

- Describe the motion of plates at divergent, convergent, and transform boundaries.

- Characterize divergent, convergent, and transform plate boundaries by their associated geological features and processes.

- Describe how mantle plumes and resulting hot spot volcanoes can be used to determine the direction of plate motion.

- Understand the historical contributions of geoscientists who proposed the theory of plate tectonics.

Key Terms

- Lithosphere

- Continental crust

- Oceanic crust

- Mantle

- Asthenosphere
- Tectonic plate

- Divergent

- Convergent

- Transform

- Seismology
- Volcanology

- Bathymetry

- Topography

- Geochronology

- Mantle plume

- Hot spot 


\section{I.I Discovering Plate Tectonics}

As we discovered in the introduction to this lab manual, plate tectonics is the model or theory that we use to understand how our planet works. More specifically it is a model that explains the origins of continents and oceans, folded rocks and mountain ranges, igneous and metamorphic rocks, earthquakes, volcanoes, and continental drift. Plate tectonics was first proposed just over 100 years ago, but did not become an accepted part of geology until about 50 years ago. It took 50 years for this theory to be accepted for a few reasons. First, it was a true revolution in thinking about Earth, and that was difficult for many established geologists to accept. Second, there was a political gulf between the main proponent of the theory Alfred Wegener (from Germany) and the geological establishment of the day, which was mostly centred in Britain and the United States. Third, the evidence and understanding of Earth that would have supported plate tectonic theory simply didn't exist until the middle of the 20th century. Before we delve into the details of plate tectonics, we need to examine some historical context to understand how this theory developed over the course of the 20th century.

Most of the key evidence for plate tectonics came from studying the ocean floor. Before 1900, we knew virtually nothing about the bathymetry and geology of the oceans. By the end of the 1960s, we had detailed maps of the topography of the ocean floors, a clear picture of the geology of ocean floor sediments and the solid rocks underneath them, and almost as much information about the geophysical nature of ocean rocks as of continental rocks. Some of the most influential discoveries by geoscientists in the 20th century that have shaped modern plate tectonic theory are briefly summarized below.

\section{The ig20s to 1950 s}

Development of acoustic depth sounders to map the ocean floor (Figure 1.1.1) leads to discovery of major mountain chains in all of the world's oceans. During and after World War II, there was a wellorganized campaign to study the oceans, and by 1959, sufficient bathymetric data had been collected to produce detailed maps of all the oceans (Figure 1.1.2).

The important physical features of the ocean floor are:

- Extensive linear ridges (commonly in the cen-

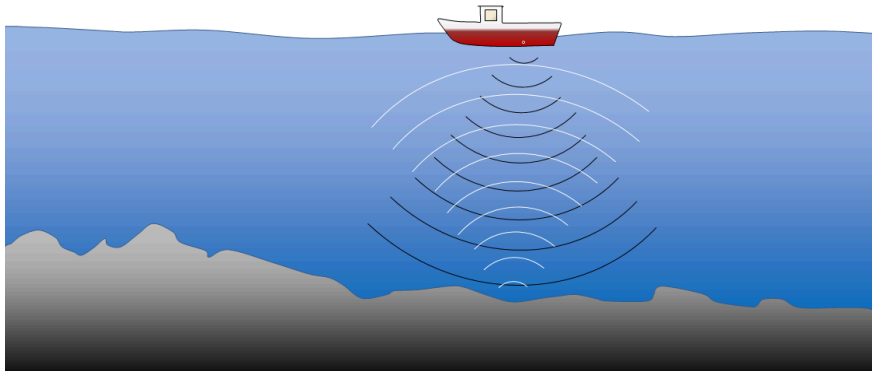

Figure 1.1.1: Depiction of a ship-borne acoustic depth sounder. The instrument emits a sound (black arcs) that bounces off the seafloor and returns to the surface (white arcs). The travel time is proportional to the water depth. tral parts of the oceans) with water depths in the order of 2,000 to 3,000 m (Figure 1.1.2, inset a)

- Fracture zones perpendicular to the ridges (inset a)

- Deep-ocean plains at depths of 5,000 to 6,000 m (insets a and d)

- Relatively flat and shallow continental shelves with depths under $500 \mathrm{~m}$ (inset b)

- Deep trenches (up to 11,000 m deep), most near the continents (inset c)

- Seamounts and chains of seamounts (inset d) 


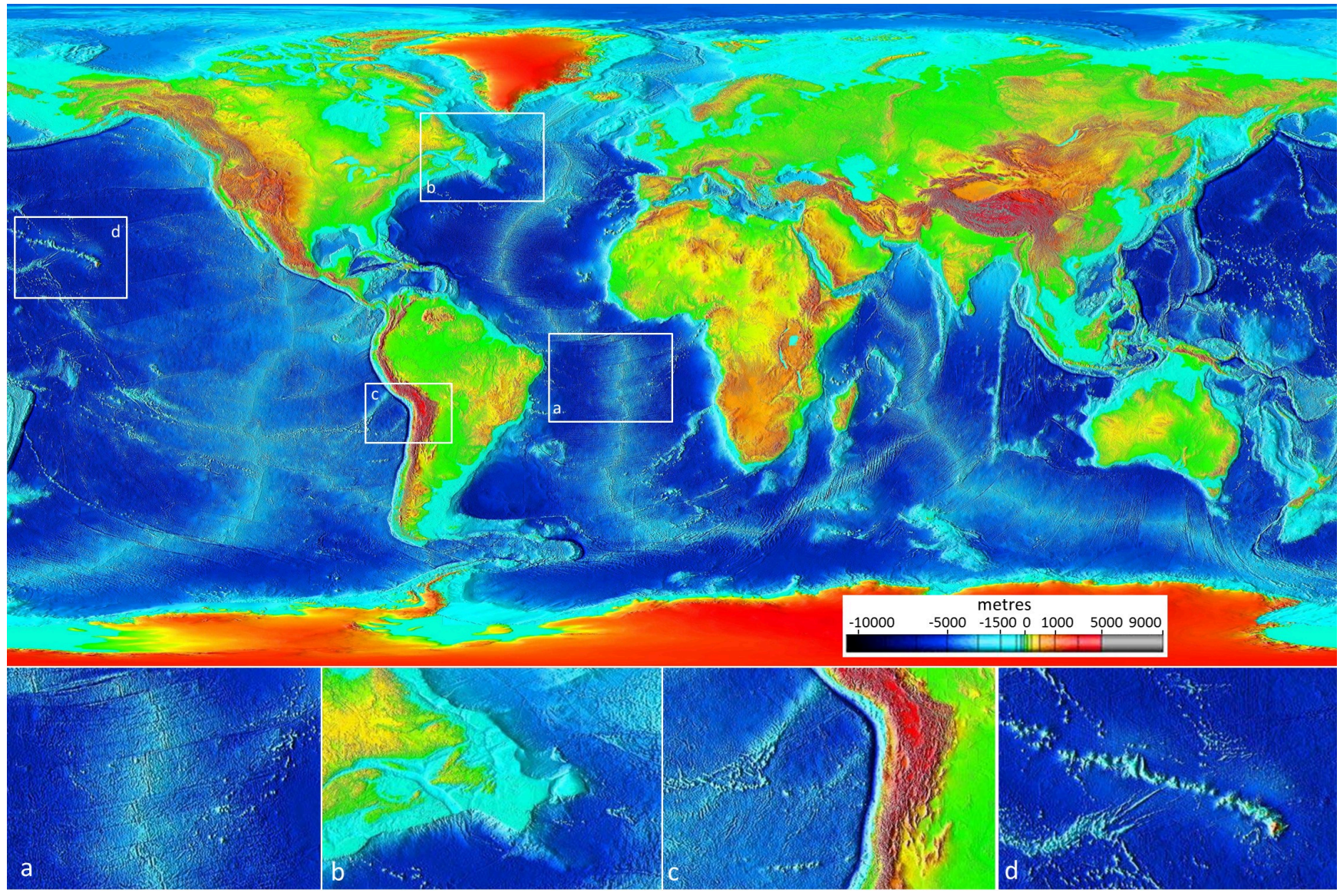

Figure 1.1.2: Ocean floor bathymetry (and continental topography). Inset (a): the mid-Atlantic ridge, (b): the Newfoundland continental shelf, (c): the Nazca trench adjacent to South America, and (d): the Hawaiian Island chain.

With developments of networks of seismograph stations in the 1950s, it became possible to plot the locations and depths of both major and minor earthquakes with great accuracy. It was found that there is a remarkable correspondence between earthquakes and both the mid-ocean ridges and the deep ocean trenches. In 1954 Gutenberg and Richter showed that the ocean-ridge earthquakes were all relatively shallow, and confirmed what had first been shown by Benioff in the 1930s - that earthquakes in the vicinity of ocean trenches were both shallow and deep, but that the deeper ones were situated progressively farther inland from the trenches (Figure 1.1.3).
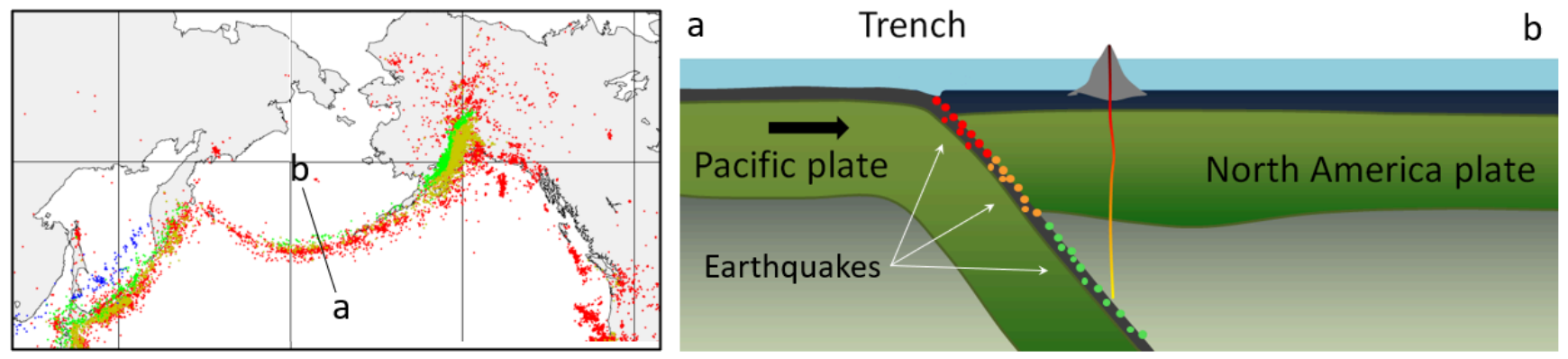

Figure 1.1.3: Cross-section through the Aleutian subduction zone with a depiction of the increasing depth of earthquakes "inshore" from the trench. [Image Description]

Another key component in the case for plate tectonics came from studies of remnant magnetism in the rocks that make up the ocean crust. Usually, remnant magnetism is caused by the presence of ferrous (unox- 
idized) iron on the seafloor, often from a volcanic rock containing grains of magnetite $\left(\mathrm{Fe}_{3} \mathrm{O}_{4}\right)$, a highly magnetic mineral. As the mineral magnetite crystallizes from magma, it becomes magnetized with an orientation parallel to that of Earth's magnetic field at that time. Rocks like basalt, which cool from a high temperature and commonly have relatively high levels of magnetite (up to 1 or $2 \%$ ), are particularly susceptible to being magnetized in this way, but even sediments and sedimentary rocks, as long as they have small amounts of magnetite, will take on remnant magnetism because the magnetite grains gradually become reoriented following deposition.

In the 1950s, scientists from the Scripps Oceanographic Institute in California persuaded the U.S. Coast Guard to include magnetometer readings on one of their expeditions to study ocean floor topography. The first comprehensive seafloor paleomagnetic data set was compiled in 1958 for an area off the coast of B.C. and Washington State. This survey revealed a bewildering pattern of low and high magnetic intensity in seafloor rocks (Figure 1.1.4). When the data were first plotted on a map in 1961, nobody understood them - not even the scientists who collected them. But these paleomagnetic data became a key piece of evidence for seafloor spreading.

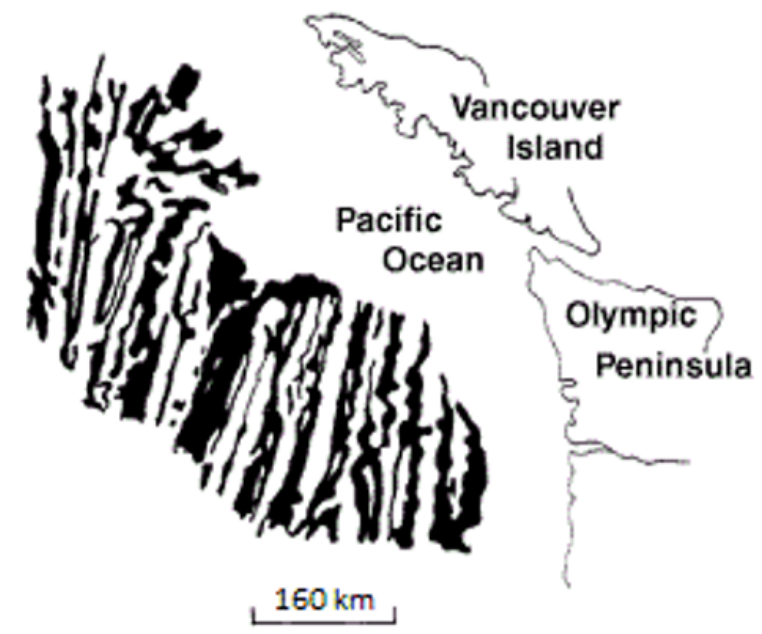

Figure 1.1.4: Pattern of seafloor magnetism off of the west coast of British Columbia and Washington.

The 1960 s

In 1960, Harold Hess, a widely respected geologist from Princeton University, advanced a theory with many of the elements that we now accept as plate tectonics. Hess proposed that:

- new sea floor was generated from mantle material at the ocean ridges,

- old sea floor was dragged down at the ocean trenches and re-incorporated into the mantle,

- plate tectonics are driven by mantle convection currents, rising at the ridges and descending at the trenches (Figure 1.1.5),

- the less-dense continental crust did not descend with oceanic crust into trenches, but that colliding land masses were thrust up to form mountains.

Hess's theory formed the basis for our ideas on seafloor spreading and continental drift, but it did not deal with the concept that the crust is made up of specific plates. Although the Hess model was not roundly criticized, it was not widely accepted (especially in the U.S.), partly because it was not well supported by hard evidence.

In 1963, J. Tuzo Wilson of the University of Toronto proposed the idea of a mantle plume or

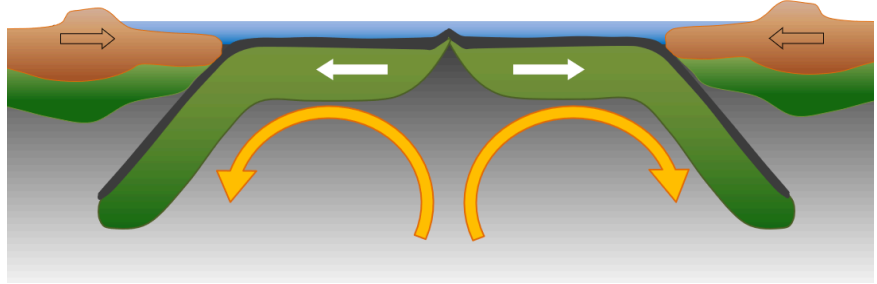

Figure 1.1.5: A representation of Harold Hess's model for seafloor spreading and subduction.

hot spot-a place where hot mantle material rises in a stationary and semi-permanent plume, and affects the overlying crust. He based this hypothesis partly on the distribution of the Hawaiian and Emperor Seamount island chains in the Pacific Ocean (Figure 1.1.6). The volcanic rock making up these islands gets 
progressively younger toward the southeast, culminating with the island of Hawaii itself, which consists of rock that is almost all younger than $1 \mathrm{Ma}$. Wilson suggested that a stationary plume of hot upwelling mantle material is the source of the Hawaiian volcanism, and that the ocean crust of the Pacific Plate is moving toward the northwest over this hot spot. Near the Midway Islands, the chain takes a pronounced change in direction, from northwest-southeast for the Hawaiian Islands and to nearly north-south for the Emperor Seamounts. This change is widely ascribed to a change in direction of the Pacific Plate moving over the stationary mantle plume, but a more plausible explanation is that the Hawaiian mantle plume has not actually been stationary throughout its history, and in fact moved at least 2,000 km south over the period between 81 and $45 \mathrm{Ma}^{1}$

In addition to his contributions on mantle plumes and plate motion, Wilson also introduced the idea that the crust can be divided into a series of rigid plates in a 1965 paper, and thus he is responsible for the term plate tectonics.

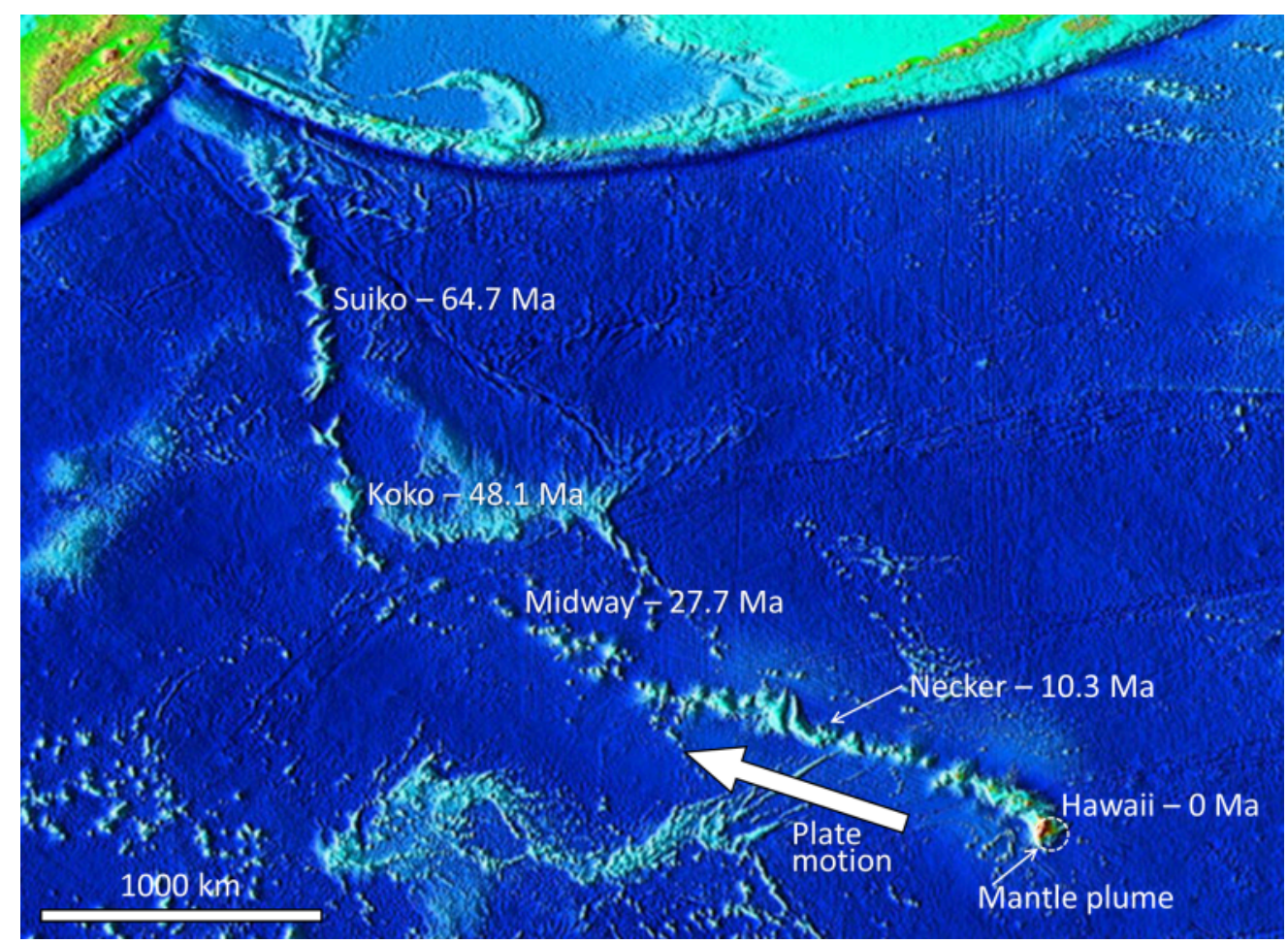

Figure 1.1.6: The ages of the Hawaiian Islands and the Emperor Seamounts in relation to the location of the Hawaiian mantle plume.

The Hawaiian and Emperor volcanoes shown in Figure 1.1.6 are listed in the table below along with their ages and their distances from the centre of the mantle plume under Hawaii (the Big Island). 
Ages of Hawaiian and Emperor volcanoes and their distances from the centre of the mantle plume. Calculate their rate of movement in centimetres per year.

\begin{tabular}{llll}
\hline Island & Age & Distance & Rate \\
Hawaii & $0 \mathrm{Ma}$ & $0 \mathrm{~km}$ & - \\
Necker & $10.3 \mathrm{Ma}$ & $1,058 \mathrm{~km}$ & $10.2 \mathrm{~cm} / \mathrm{y}$ \\
Midway & $27.7 \mathrm{Ma}$ & $2,432 \mathrm{~km}$ & \\
Koko & $48.1 \mathrm{Ma}$ & $3,758 \mathrm{~km}$ \\
Suiko & $64.7 \mathrm{Ma}$ & $4,860 \mathrm{~km}$ & \\
\hline
\end{tabular}

Plot the data on Figure 1.1.7, and use the numbers in the table to estimate the rates of plate motion for the Pacific Plate in $\mathrm{cm} /$ year. (The first two are plotted for you.)

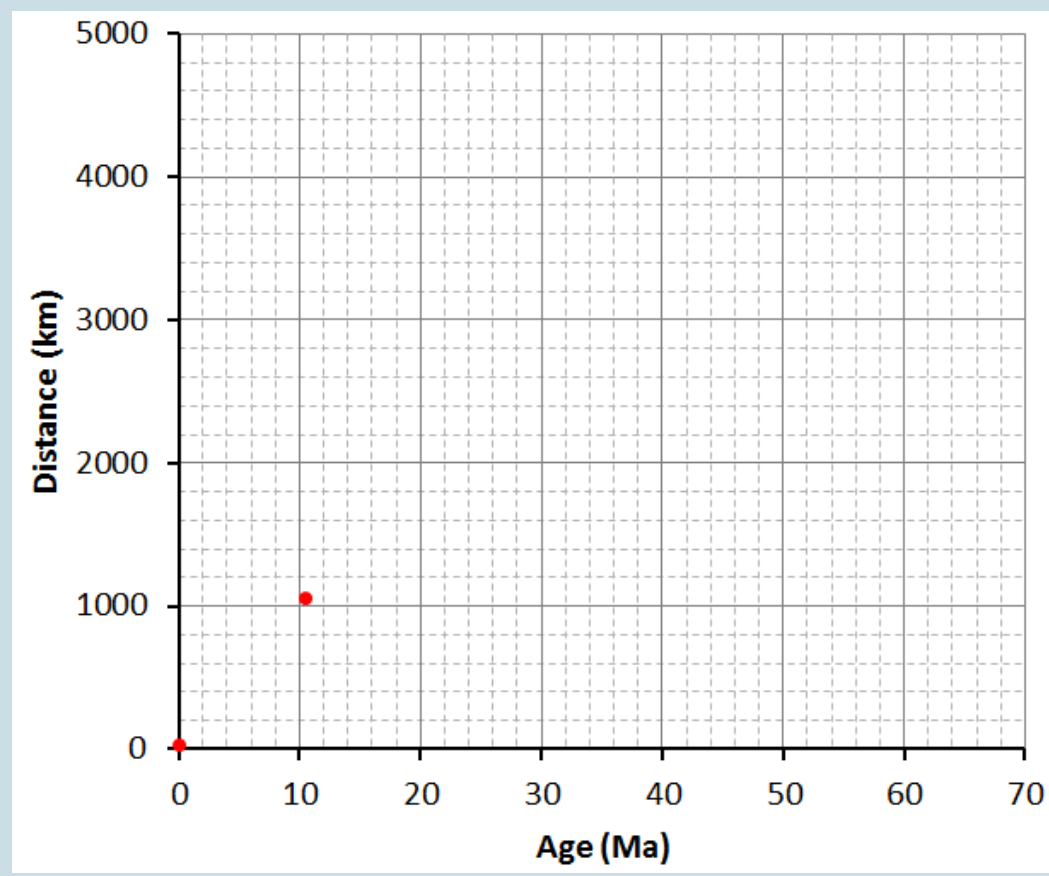

Figure 1.1.7: Graph of hot spot volcano age (millions of years, Ma) against distance $(\mathrm{km})$.

See Appendix 2 for Practice Exercise 1.1 answers.

There is evidence of many such mantle plumes around the world (Figure 1.1.8). Most are within the ocean basins-including places like Hawaii, Iceland, and the Galapagos Islands-but some are under continents. One example is the Yellowstone hot spot in the west-central United States, and another is the one responsible for the Anahim Volcanic Belt in central British Columbia. It is evident that mantle plumes are very longlived phenomena, lasting for at least tens of millions of years, possibly for hundreds of millions of years in some cases. 


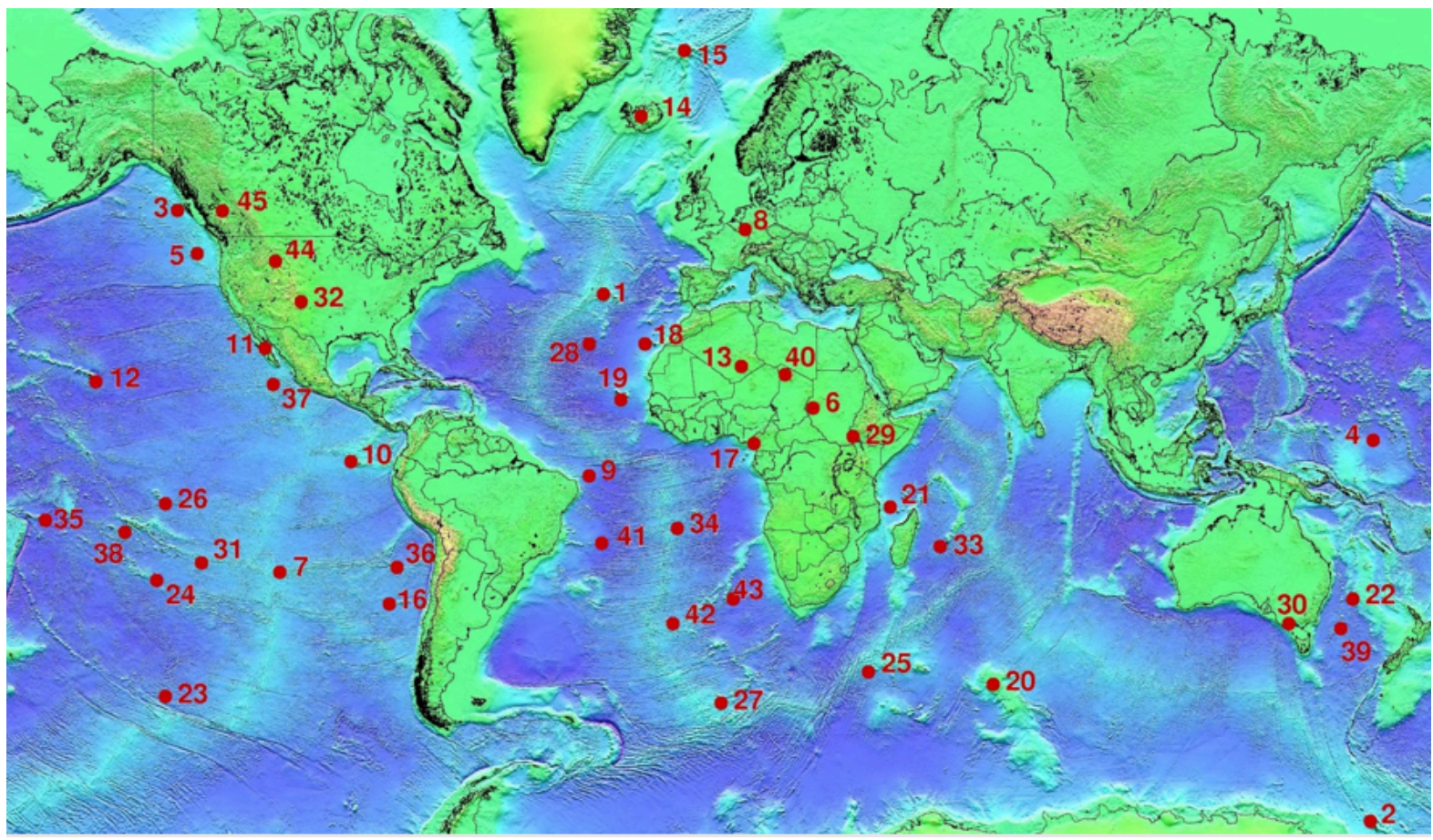

Figure 1.1.8: Mantle plume locations. Selected Mantle plumes: 1: Azores, 3: Bowie, 5: Cobb, 8: Eifel, 10: Galapagos, 12: Hawaii, 14: Iceland, 17: Cameroon, 18: Canary, 19: Cape Verde, 35: Samoa, 38: Tahiti, 42: Tristan, 44: Yellowstone, 45: Anahim

\section{Image Descriptions}

Figure 1.1.3 image description: A cross section of the trench formed at the Aleutian subduction zone as the Pacific plate subducts under the North American plate in the middle of the Pacific Ocean. The farther away an earthquake is from this trench (on the North America plate side), the deeper it is. [Return to Figure 1.1.3]

\section{Media Attributions}

- Figures 1.1.1, 1.1.3, 1.1.5, 1.1.7: (C) Steven Earle. CC BY.

- Figure 1.1.2: "Elevation" by NOAA. Adapted by Steven Earle. Public domain.

- Figure 1.1.4: "Juan de Fuca Ridge" by USGS. Adapted by Steven Earle. Public domain. Based on Raff, A. and Mason, R., 1961, Magnetic survey off the west coast of North America, $40^{\circ} \mathrm{N}$ to $52^{\circ} \mathrm{N}$ latitude, Geol. Soc. America Bulletin, V. 72, p. 267-270.

- Figure 1.1.6: "Hawaii Hotspot" by National Geophysical Data Center. Adapted by Steven Earle. Public domain.

- Figure 1.1.8: "Hotspots" by Ingo Wölbern. Public domain.

\section{Notes}

1. J. A. Tarduno et al., 2003, The Emperor Seamounts: Southward Motion of the Hawaiian Hotspot Plume in Earth's Man- 
tle, Science 301 (5636): 1064-1069.

1.1 Discovering Plate Tectonics | 36 


\section{I.2 Plates, Plate Motions, and Plate Boundaries}

By the end of 1967 the Earth's surface had been mapped into a series of plates. The major plates are Eurasia, Pacific, India, Australia, North America, South America, Africa, and Antarctic. There are also numerous small plates (e.g., Juan de Fuca, Cocos, Nazca, Scotia, Philippine, Caribbean), and many very small plates or sub-plates. For example the Juan de Fuca Plate is actually three separate plates (Gorda, Juan de Fuca, and Explorer) that all move in the same general direction but at slightly different rates.

Rates of motions of the major plates range from less than $1 \mathrm{~cm} / \mathrm{y}$ to over $10 \mathrm{~cm} / \mathrm{y}$. The Pacific Plate is the fastest, followed by the Australian and Nazca Plates. The North American Plate is one of the slowest, averaging around $1 \mathrm{~cm} / \mathrm{y}$ in the south up to almost $4 \mathrm{~cm} / \mathrm{y}$ in the north. Plates move as rigid bodies, so it may seem surprising that the North American Plate can be moving at different rates in different places. The explanation is that plates move in a rotational manner. The North American Plate, for example, rotates counter-clockwise; the Eurasian Plate rotates clockwise.

Boundaries between the plates are of three types:

- divergent (i.e., moving apart),

- convergent (i.e., moving together), and

- transform (moving side by side).

Before we talk about processes at plate boundaries, it's important to point out that there are never gaps between plates. The plates are made up of the lithosphere. The lithosphere consists of the crust, which can be thin, relatively dense oceanic crust or thick, relatively buoyant continental crust, and the rigid uppermost part of the mantle (Figure 1.2.1). Even though tectonic plates are moving all the time, and in different directions, there is never a significant amount of space between them. Plates are thought to move along the lithosphere-asthenosphere boundary, as the asthenosphere is the zone of partial melting. It is assumed that the relative lack of strength of the partial melting zone facilitates the sliding of the lithospheric plates. The fact that the plates include both crustal material and lithospheric mantle material makes it possible for a single plate to be made up of both oceanic and continental crust. For example, the North American Plate includes most of North America (continental crust), plus half of the northern Atlantic Ocean (oceanic crust). The Pacific Plate is almost entirely oceanic, but it does include the part of California west of the San Andreas Fault.

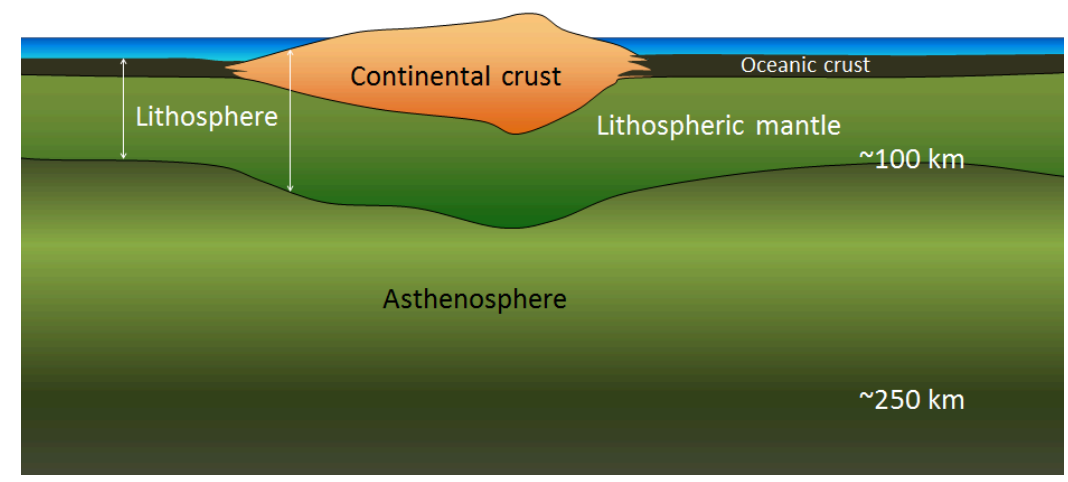

Figure 1.2.1: The crust and upper mantle. Tectonic plates consist of lithosphere, which includes the crust and the uppermost (rigid) part of the mantle. 


\section{Divergent Boundaries}

Divergent boundaries are spreading boundaries, where new oceanic crust is created from magma derived from partial melting of the mantle caused by decompression as hot mantle rock from depth is moved toward the surface (Figure 1.2.2). The triangular zone of partial melting near the ridge crest produces oceanic crust that is about $6 \mathrm{~km}$ thick. Most divergent boundaries are located at the oceanic ridges, although some are on land.

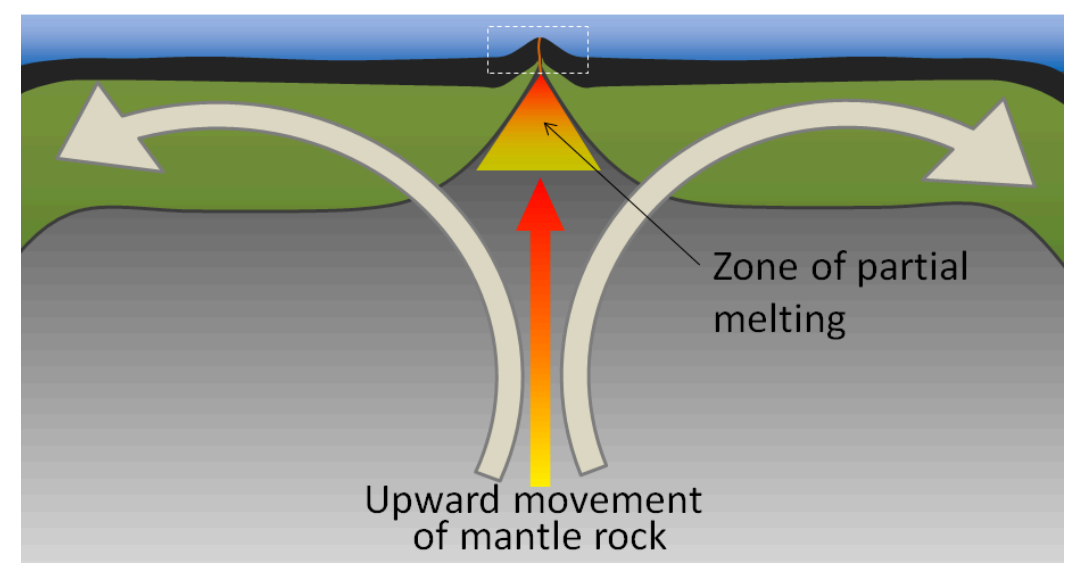

Figure 1.2.2: The general processes that take place at a divergent boundary.

\section{Convergent Boundaries}

Convergent boundaries, where two plates are moving toward each other, are of three types, depending on whether oceanic or continental crust is present on either side of the boundary. The types are: ocean-ocean, ocean-continent, and continent-continent.

At an ocean-ocean convergent boundary, one of the plates (oceanic crust and lithospheric mantle) is pushed, or subducted, under the other. Often it is the older and colder plate that is denser and subducts beneath the younger and hotter plate. There is commonly an ocean trench along the boundary. The significant volume of water within the subducting material is released as the subducting crust is heated. The water that is released rises and mixes with the overlying mantle. The addition of water to the hot mantle lowers the rocks's melting point and leads to the formation of magma (flux melting) (Figure 1.2.3). The magma, which is lighter than the surrounding mantle material, rises through the mantle and the overlying oceanic crust to the ocean floor where it creates a chain of volcanic islands known as an island arc.

As described above in the context of Benioff zones (Figure 1.1.3), earthquakes take place close to the boundary between the subducting crust and the overriding crust. The largest earthquakes occur near the surface where the subducting plate is still cold and strong. 


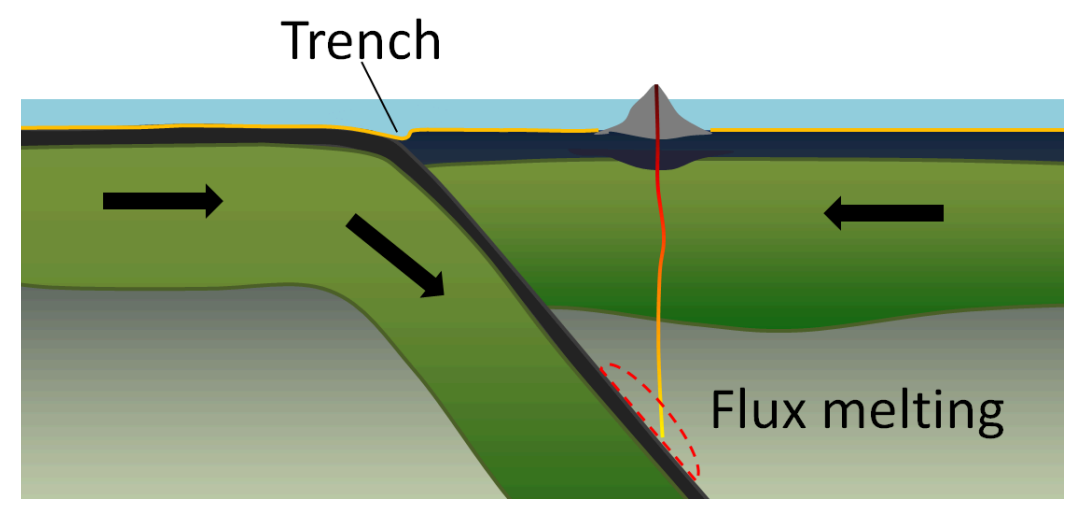

Figure 1.2.3: Configuration and processes of an ocean-ocean convergent boundary.

At an ocean-continent convergent boundary, the oceanic plate is pushed under the continental plate in the same manner as at an ocean-ocean boundary. Sediment that has accumulated on the continental slope is thrust up into an accretionary wedge, and compression leads to deformation within the continental plate (thrust faults shown in Figure 1.2.4). The mafic magma produced adjacent to the subduction zone rises to the base of the continental crust and leads to partial melting of the crustal rock. The resulting magma ascends through the crust, producing a chain of volcanoes that form a continental arc.

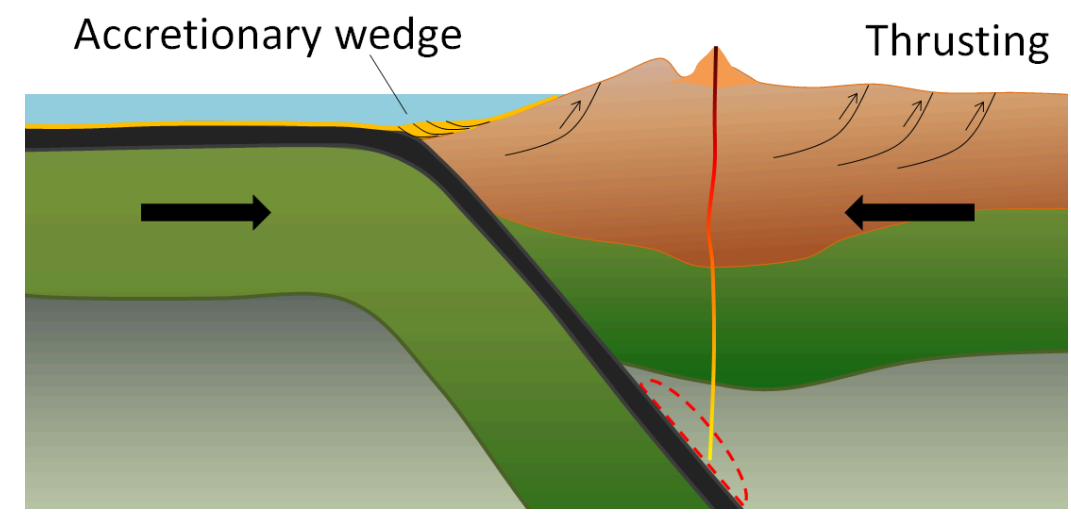

Figure 1.2.4: Configuration and processes of an ocean-continent convergent boundary.

A continent-continent collision occurs when a continent or large island that has been moved along with subducting oceanic crust collides with another continent (Figure 1.2.5). The colliding continental material will not be subducted because it is too light and buoyant, but the root of the oceanic plate will eventually break off and sink into the mantle. There is tremendous deformation of the pre-existing continental rocks, and creation of mountains from that rock, from any sediments that had accumulated along the shores of both continental masses, and commonly also from some ocean crust and upper mantle material. 


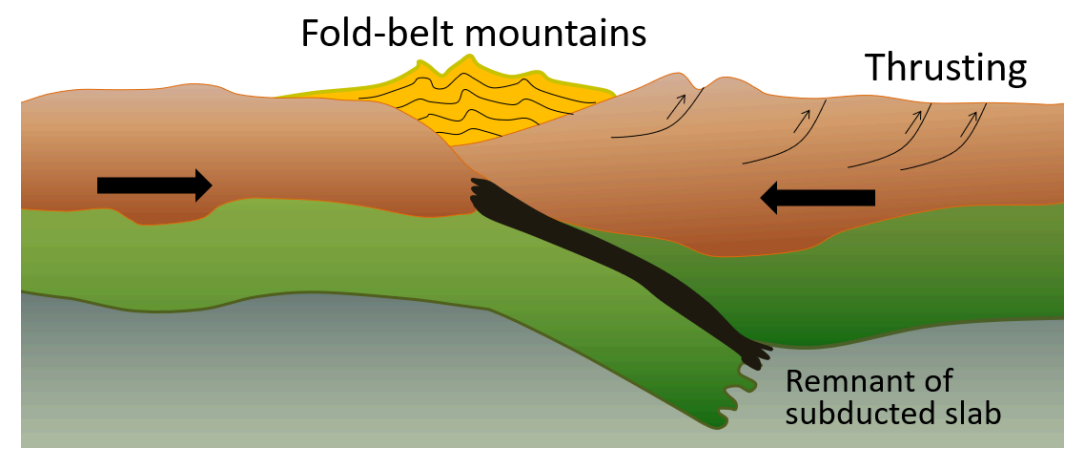

Figure 1.2.5: Configuration and processes of a continent-continent convergent boundary.

\section{Transform Boundaries}

Transform boundaries exist where one plate slides past another without production or destruction of crustal material. Although oceanic spreading ridges appear to be curved features on Earth's surface, in fact the ridges are composed of a series of straight-line segments, offset at intervals by faults perpendicular to the ridge (Figure 1.2.6). In a paper published in 1965, Tuzo Wilson termed these features transform faults.

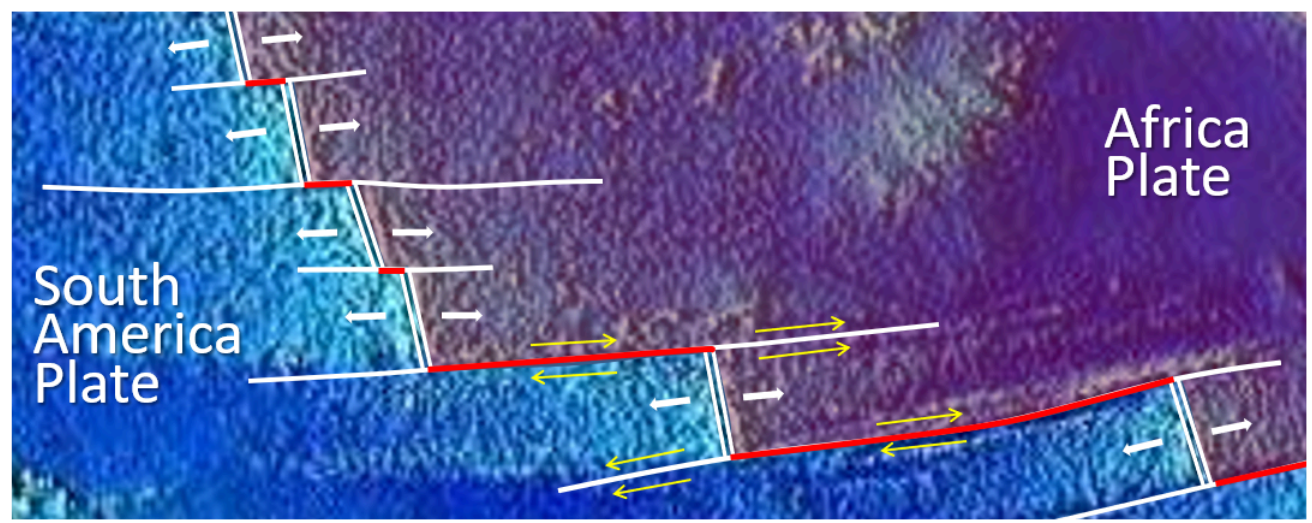

Figure 1.2.6: A part of the mid-Atlantic ridge near the equator. The double white lines are spreading ridges. The solid white lines are fracture zones. As shown by the yellow arrows, the relative motion of the plates on either side of the fracture zones can be similar (arrows pointing the same direction) or opposite (arrows pointing opposite directions). Transform faults (red lines) are in between the ridge segments, where the yellow arrows point in opposite directions. 
While most transform faults connect segments of mid-ocean ridges and are thus ocean-ocean plate boundaries, some transform faults connect continental parts of plates. An example is the San Andreas Fault, which extends from the southern end of the Juan de Fuca Ridge to the northern end of the East Pacific Rise (ridge) in the Gulf of California (Figure 1.2.7). The part of California west of the San Andreas Fault and all of Baja California are on the Pacific Plate. Transform faults do not just connect divergent boundaries. For example, the Queen Charlotte Fault connects the north end of the Juan de Fuca Ridge, starting at the north end of Vancouver Island, to the Aleutian subduction zone.

\section{Media Attributions}

- Figures 1.2.1, 1.2.2, 1.2.3, 1.2.4, 1.2.5, 1.2.6, 1.2.7: (C) Steven Earle. CC BY.

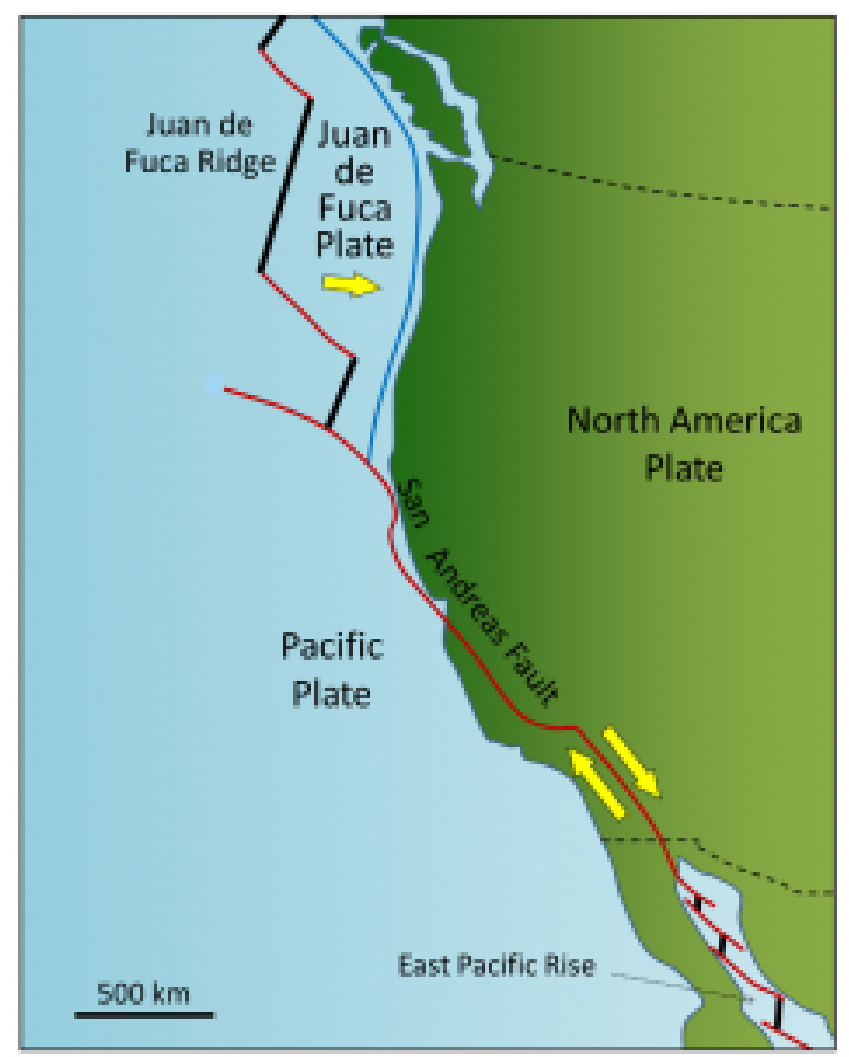

Figure 1.2.7: The San Andreas Fault extends from the north end of the East Pacific Rise in the Gulf of California to the southern end of the Juan de Fuca Ridge. All of the red lines on this map are transform faults. 


\section{Lab i Exercises}

\section{Activity I: Plate Boundary Characteristics}

In this activity you will learn to identify types of plate boundaries based on the characteristics they exhibit. This activity is based on the "Discovering Plate Boundaries" activity by Dale S. Sawyer at Rice University and modified based on teaching experiences at the SEOS department of the University of Victoria, Canada.

In groups, we will examine five types of plate boundaries today:

- Ocean-Ocean Divergent (the boundary between two plates where oceanic crust is being pullled apart)

- Ocean-Ocean Convergent (where two plates of oceanic crust are moving toward one another leading to the subduction of one plate)

- Ocean-Continent Convergent (where oceanic and continental crust are moving toward one another leading to the subduction of the oceanic crust)

- Continent-Continent Convergent (where two plates of continental crust are moving toward one another)

- Ocean-Ocean Transform (where oceanic crust is moving horizontally in opposite directions across a transform fault)

To start, download or view the plate boundaries map. Seven plate boundaries are highlighted and numbered on your map. You will also be assigned a map displaying one of four data sets: volcanoes, earthquakes, topography/bathymetry, and seafloor age.

You will each, individually, study your data set and attempt to draw conclusions about what geological features and processes characterize each of the numbered plate boundaries.

Later in lab today, you will be joining a live video conference in small groups to share your observations with your group mates. You will be asked to summarize your observations so write down your conclusions and be prepared to teach your peers!

Step I

Examine your assigned map. Start by locating all the numbered plate boundaries on your assigned map. Are they easy or difficult to find? Looking closely at your data type, start making notes about the spatial distribution of the data points. Exactly what you look for will vary with data type. For the point data (volcanoes and earthquakes) you are looking for distribution patterns. For surface data (topography and seafloor age) you are looking for where the surface is high and where it is low, where it is old and where it is young. In this activity you are focusing on observations, not interpretations, meaning that you do not need to worry about why there is or is not a pattern, you just need to observe and record what you see. You are analyzing the data, not interpreting them! 
Step 2

Now focus your attention on the numbered plate boundaries on the plate boundaries map. Identify the nature of your data near each of the numbered plate boundaries. Is it high or low, symmetric or asymmetric, missing or not missing, varying along the boundary or constant along the boundary, etc. Complete Table 1.1 below to classify the plate boundaries based on your observations of your assigned data, using the tips below for guidance. Right now, you will only fill in the column for your assigned data set. Remember: do not try to explain the data; just observe!

Below are some suggestions for the kinds of observations that are useful for each data set. Compare your boundary to the types of boundaries on the map as you do this. Remember, the goal is to find unique characteristics for each boundary type.

Volcanoes: Observe and make notes on the distribution patterns. Are the volcanoes near a given boundary randomly distributed, tightly clustered, or do they define a linear trend?

Earthquakes: Observe and make notes on the distribution patterns and depth of the earthquakes. Note both the range of depths (extremes) and the more typical or average. For example, a given boundary might have all shallow earthquakes $(0-33 \mathrm{~km})$ with rare deeper earthquakes between $33-70 \mathrm{~km}$ depth. Earthquakes might be randomly distributed, tightly clustered, or may define a linear trend.

Topography/bathymetry: Look for any topographic features that seem to be related to the boundary, such as nearby mountain chains, deep sea trenches, broad gradual highs or lows, offset (broken and shifted) features, etc. Briefly describe how extreme they are (e.g., a very high or wide mountain chain). Make sure that you understand how the colour scale on the map represents elevations above sea level. For example, your should recognize that bright fuchsia colours correspond to large negative values and represent the deepest parts of ocean where the seafloor is far beneath sea level.

Seafloor age: This data set can be tricky; be careful not to see patterns where there are none! For example, you might observe that in some places, the seafloor age changes from place to place along the boundary. In this case there is no clear pattern and this indicates no relationship between seafloor age and the boundary, but this is still a good observation! Alternately, the seafloor age may be the same everywhere along the boundary, or it may change in a consistent pattern. Do your best to describe what you see, and whether or not your observations fit a clear, consistent pattern. 


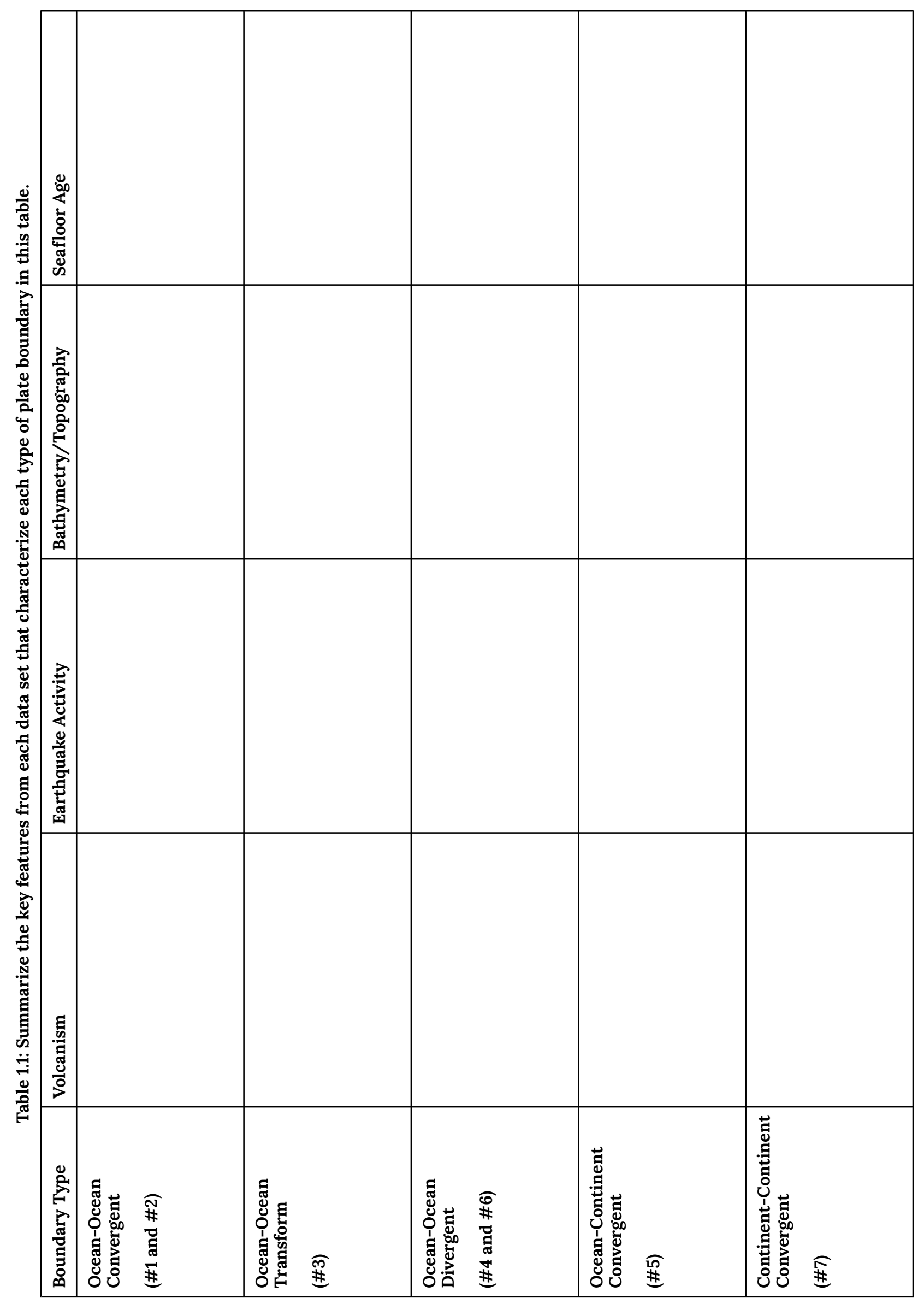


Everyone has been randomly assigned to a group and provided with a link to a video meeting to discuss your observations in real time in groups of four. Each group has at least one representative of each data set. Consider yourselves a group of experts gathering to compare observations. In your group, introduce yourself and what type of data you have been analyzing. Taking turns, each group member will share their observations about their assigned data set from Step 2. It is helpful to share your screen while you teach, so that your group members can see your data. If you are not sure how to share your screen, ask your instructor. Your instructor will periodically join each group video meeting group to check in while you complete this part of the activity.

Work together in your group to complete Table 1.1 by summarizing your observations on the characteristics of each type of plate boundary. By the end of this activity, each member of your group should have a completed Table 1.1. Each group member should be able to describe the characteristics of each type of plate boundary using all four data types.

\section{Activity II: Hot Spot Volcanoes and Plate Motion}

In this activity you will use data from chains of hot spot volcanoes in Google Earth Pro to make a rough estimate of the rate of motion of the Pacific Plate, and to determine the direction of plate motion for several different tectonic plates. This activity and the Google Earth data provided are based on the "Determining Plate Rates From Hot Spot Tracks Using Google Earth" activity developed by Susan Schwartz and Erin Todd at the University of California-Santa Cruz.

Step I

Download the Hawaii-Emperor.kmz file provided by your instructor to examine hot spot volcanoes in Google Earth Pro. Load the file into Google Earth Pro by double-clicking on the file, or in Google Earth Pro by clicking on File, Open and navigating to where you saved the .kmz file.

Step 2

Once the Hawaii-Emperor.kmz is loaded, click and drag to move it from "Temporary Places" to "My Places." Then save "My Places" by clicking File, Save, Save My Places. This .kmz file will now be available every time you open Google Earth Pro on this computer. **NOTE: When you close the program, Google Earth Pro should save everything in "My Places", but to be safe you should manually save "My Places" to your computer whenever you make significant changes to it. 
Examine the data in the Hawaii-Emperor.kmz file to answer the questions below. Each place marker indicates a location where a volcanic rock was sampled and dated. This type of dating uses radioactive elements in the rock to give geologists a precise age of when the lava cooled and solidified to form a volcanic rock. The number next to each place marker is the age of the rock in millions of years (Ma). The current location of the hot spot at Kilauea Volcano in southeast Hawai'i is shown by the marker labeled 0 Ma.

\section{Hot Spot Volcanoes and Plate Motion Exercise Questions}

1. Using what you learned in the Google Earth Tutorial, list the lat/long coordinates of Kilauea Volcano, Diakakuji Seamount (located at the bend in the Hawaii-Emperor chain), and Midway Island.

2. Using what you learned in the Google Earth Tutorial, list the UTM coordinates of Mauna Kea (located near the centre of the island of Hawaii), the 75.82 Ma volcano near Detroit Seamount (located near the northern end of the Hawaii-Emperor chain), and the 5.77 Ma volcano on Kaua'i. Remember to include the zone at the beginning of the coordinate!

3. Using the ruler tool in Google Earth Pro, found in the top toolbar, measure the distance between the present location of the hot spot at Kilauea Volcano and Midway Island in kilometers $(\mathrm{km})$. Measure the distance as a line from the point of each pin and round to the nearest whole $\mathrm{km}$.

4. Make a rough estimate of the average rate of motion for the Pacific Plate in kilometres per million years. To do this, divide the distance between two volcanoes along the chain by their difference in ages (shown in millions of years, Ma). The rate is calculated as the distance over time. Round to the nearest tenth.

5. Most plate rates reported in scientific literature are measured in $\mathrm{cm} / \mathrm{yr}$. Convert your estimated rate to $\mathrm{cm} / \mathrm{yr}$. Again, round your result to the nearest tenth. Remember this calculation is a rough estimate! 
6. Examine the entire length of the Hawaii-Emperor chain. What do you think might have caused this chain to form such a distinctive "elbow-like" shape?

Download the HotspotVolcanism.kmz file provided by your instructor and load it into Google Earth Pro. Remember to save it in "My Places" once it is loaded into Google Earth Pro! Notice that this file includes the locations of boundaries between tectonic plates as well as place markers and ages for volcanoes along several hot spot chains (or tracks) around the world.

7. Based on the hot spot tracks shown in the HotspotVolcanism.kmz file and the ages of the volcanoes, determine the direction of plate motion for the African, Australian, Nazca, North American, and Pacific plates. Match the plate name to the arrow that most closely illustrates the vector (direction) of motion.

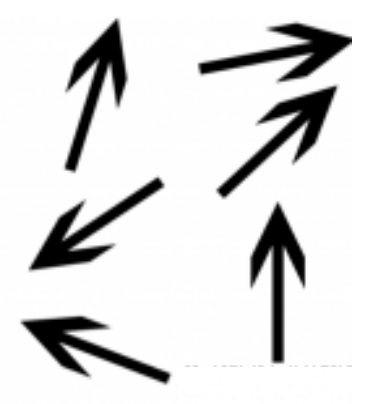

8. Predict whether the plate boundary between the following pairs of plates is convergent or divergent based on the plate motion determined from the hot spot tracks:

a) Pacific \& Nazca Plates

b) South American \& African Plates

See Appendix 3 for answers to lab exercises.

\section{Media Attributions}

- Maps of plate boundaries, topography/bathymetry, seismology, volcanology, seafloor age by Dale S. Sawyer, Discovering Plate Boundaries activity. All rights reserved. Used with permission.

- Google Earth kmz file by Susan Schwartz and Erin Todd, CC-BY-NC-SA 3.0

- Determining Plate Rates From Hot Spot Tracks Using Google Earth activity Title, by Siobhan McGoldrick, CC-BY-NC-SA 4.0. Derivative of Student Handout for Plate Rate Assignment by Susan Schwartz and Erin Todd, Determining Plate Rates From Hot Spot Tracks Using Google Earth activity, CC-BY-NC-SA 3.0

- Arrow figure, adapted by Siobhan McGoldrick, CC-BY-NC-SA 4.0. Derivative of figure by Susan Schwartz and Erin Todd, Determining Plate Rates From Hot Spot Tracks Using Google Earth activity, CC-BY-NC-SA 3.0 


\section{Summary}

The topics covered in this chapter can be summarized as follows:

\begin{tabular}{|c|c|}
\hline Section & Summary \\
\hline $\begin{array}{l}1.1 \\
\text { Discovering } \\
\text { Plate } \\
\text { Tectonics }\end{array}$ & $\begin{array}{l}\text { Giant strides were made in understanding Earth during the middle decades of the 20th century, } \\
\text { including discovering magnetic evidence of continental drift, mapping the topography of the ocean } \\
\text { floor, describing the depth relationships of earthquakes along ocean trenches, measuring heat flow } \\
\text { differences in various parts of the ocean floor, and mapping magnetic reversals on the sea floor. By the } \\
\text { mid-1960s, the fundamentals of the theory of plate tectonics were in place. }\end{array}$ \\
\hline $\begin{array}{l}\text { 1.2 Plates, } \\
\text { Plate } \\
\text { Motions, } \\
\text { and Plate } \\
\text { Boundaries }\end{array}$ & $\begin{array}{l}\text { Earth's lithosphere is made up of over } 20 \text { plates that are moving in different directions at rates of } \\
\text { between } 1 \mathrm{~cm} / \mathrm{y} \text { and } 10 \mathrm{~cm} / \mathrm{y} \text {. The three types of plate boundaries are divergent (plates moving apart } \\
\text { and new crust forming), convergent (plates moving together and one being subducted), and transform } \\
\text { (plates moving side by side). Divergent boundaries form where existing plates are rifted apart, and it is } \\
\text { hypothesized that this is caused by a series of mantle plumes. Subduction zones are assumed to form } \\
\text { where accumulation of sediment at a passive margin leads to separation of oceanic and continental } \\
\text { lithosphere. Supercontinents form and break up through these processes. }\end{array}$ \\
\hline $\begin{array}{l}\text { Lab } 1 \\
\text { Exercises }\end{array}$ & $\begin{array}{l}\text { Characteristic features of divergent, convergent, and transform plate boundaries can be explored by } \\
\text { examining global datasets of volcanology, seismology (earthquakes), topography/bathymetry, and } \\
\text { seafloor age displayed on a world map. Since tectonic plates move over a mantle plume that we assume } \\
\text { to be stationary, we can use chains or tracks of hot spot volcanoes to interpret the direction of plate } \\
\text { motion. By using the age of these hot spot volcanoes, and the distance between volcanoes in the same } \\
\text { chain, we can estimate the rate of plate motion. }\end{array}$ \\
\hline
\end{tabular}




\section{LAB 2: MINERAL PROPERTIES AND NON-SILICATE MINERALS}

\section{Lab Structure}

Recommended additional work

Required materials
Yes - review concepts from Labs 1 and 2 in preparation for Test 1

Mineral ID kit, Mineral Kits 1 and 2, pencil

\section{Learning Objectives}

After reading this chapter, completing the exercises within it, and answering the questions at the end, you should be able to:

- Describe mineral lattices and explain how they influence mineral properties.

- Categorize minerals into groups based on their compositions.

- Describe some of the important techniques for identifying minerals.

- Identify and describe the physical properties of a range of non-silicate minerals in hand sample.

- Discuss the economic uses of non-silicate minerals.

Key Terms

- Cation

- Anion

- Silicate

- Non-silicate

- Native element

- Sulphide

- Oxide

- Hydroxide

- Sulphate

- Carbonate

- Halide
- Phosphate

- Colour

- Streak

- Lustre

- Hardness

- Crystal habit

- Cleavage

- Fracture

- Conchoidal fracture

- Specific gravity

Minerals are all around us: the graphite in your pencil, the salt on your table, the plaster on your walls, and the trace amounts of gold in your computer. Minerals can be found in a wide variety of consumer products including paper, medicine, processed foods, cosmetics, electronic devices, and many more. And of course, everything made of metal is also derived from minerals. 
As defined in the introductory chapter, a mineral is a naturally occurring combination of specific elements arranged in a particular repeating three-dimensional structure (Figure I4).

"Naturally occurring" implies that minerals are not artificially made. Many minerals (e.g., diamond) can be made in laboratories, but if they can also occur naturally, they still qualify as minerals. "Specific elements" means that most minerals have a specific chemical formula or composition. The mineral pyrite, for example, is $\mathrm{FeS}_{2}$ (two atoms of sulfur for each atom of iron), and any significant departure from that would make it a different mineral. But many minerals can have variable compositions within a specific range. The mineral olivine, for example, can range all the way from $\mathrm{Fe}_{2} \mathrm{SiO}_{4}$ to $\mathrm{FeMgSiO}_{4}$ to $\mathrm{Mg}_{2} \mathrm{SiO}_{4}$. Intervening compositions are written as $(\mathrm{Fe}, \mathrm{Mg})_{2} \mathrm{SiO}_{4}$ meaning that $\mathrm{Fe}$ and $\mathrm{Mg}$ can be present in any proportion, and that there are two of them for each Si present. This type of substitution is known as solid solution.

Most important of all, a mineral has a specific "repeating three-dimensional structure" or "lattice," which is the way in which the atoms are arranged. We've already seen in Figure I4 of the introductory chapter how sodium and chlorine atoms in halite alternate in a regular pattern. Halite happens to have the simplest mineral lattice, most other minerals have more complex lattices. Some substances that we think must be minerals are not because they lack that repeating 3-dimensional structure of atoms. Volcanic glass is an example, as is pearl or opal. 


\section{I Bonding and Lattices}

In the introductory chapter Minerals and Rocks, you learned that geologists define a mineral as being a naturally occurring, solid material made of an orderly crystalline structure that is represented by a defined chemical formula, and is generally inorganic.

\section{Practice Exercise 2.1}

Using the criteria established above, which of the following materials are minerals?

- Amethyst

- Sugar

- Cubic zirconia

- Halite

- Ice

- Obsidian

See Appendix 2 for Practice Exercise 2.1 answers.

As described in the introductory chapter, all minerals are characterized by a specific three-dimensional pattern known as a lattice or crystal structure. These structures range from the simple cubic pattern of halite $(\mathrm{NaCl})$ (Figure I4), to the very complex patterns of some silicate minerals. Two minerals may have the same composition, but very different crystal structures and properties. Graphite and diamond, for example, are both composed only of carbon, but while diamond is the hardest substance known, graphite is softer than paper. Their lattice structures are compared in Figure 2.1.1.

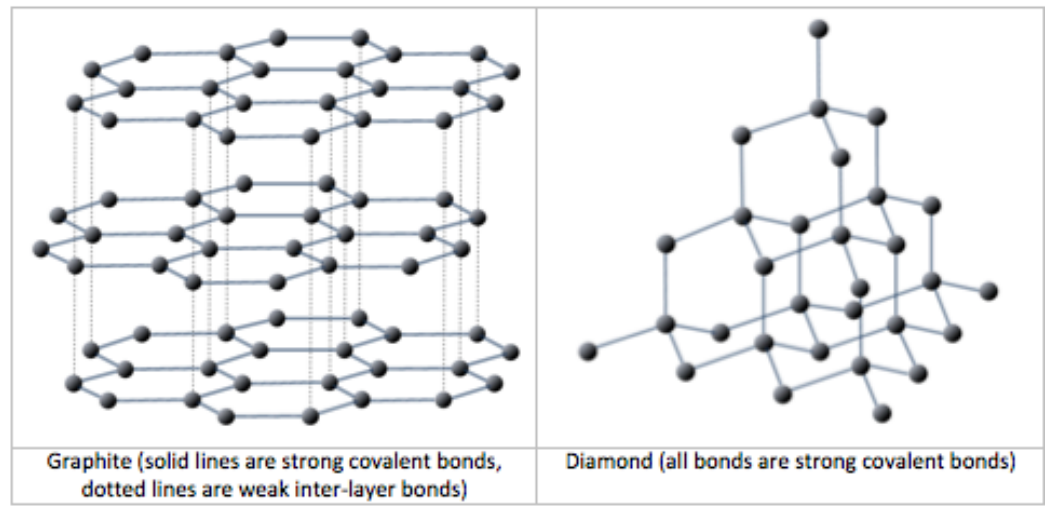

Figure 2.1.1: A depiction of the crystal lattices of graphite and diamond.

Depending on the mineral and its defined chemical formula, the bonds between the atoms the form the lattice may be ionic or covalent. On a molecular level, slight differences in the type of chemical bonds can have a significant impact on physical properties of the mineral. For example, the minerals diamond and graphite both have the same composition: both are composed exclusively of carbon atoms. In both cases, the crystal lattice is made of carbon atoms sharing electrons to form covalent bonds. In the mineral diamond, the car- 
bon atoms are linked together in a three-dimensional framework, where each carbon atom is bonded to four other carbon atoms and every bond is a very strong covalent bond. In the mineral graphite, the carbon atoms are linked together in sheets or layers (Figure 2.1.1), and each carbon atom is covalently bonded to three others. Graphite-based compounds, which are strong because of the strong intra-layer covalent bonding, are used in high-end sports equipment such as ultralight racing bicycles. Graphite itself is soft because the bonding between these layers is relatively weak, and it is used in a variety of applications, including lubricants and pencils.

Mineral lattices have important implications for mineral properties, as exemplified by the hardness of diamond and the softness of graphite. Lattices also determine the shape that mineral crystals grow in and how they break. For example, the right angles in the lattice of the mineral halite influence both the shape of its crystals (cubic), and the way those crystals break (Figure 2.1.2).
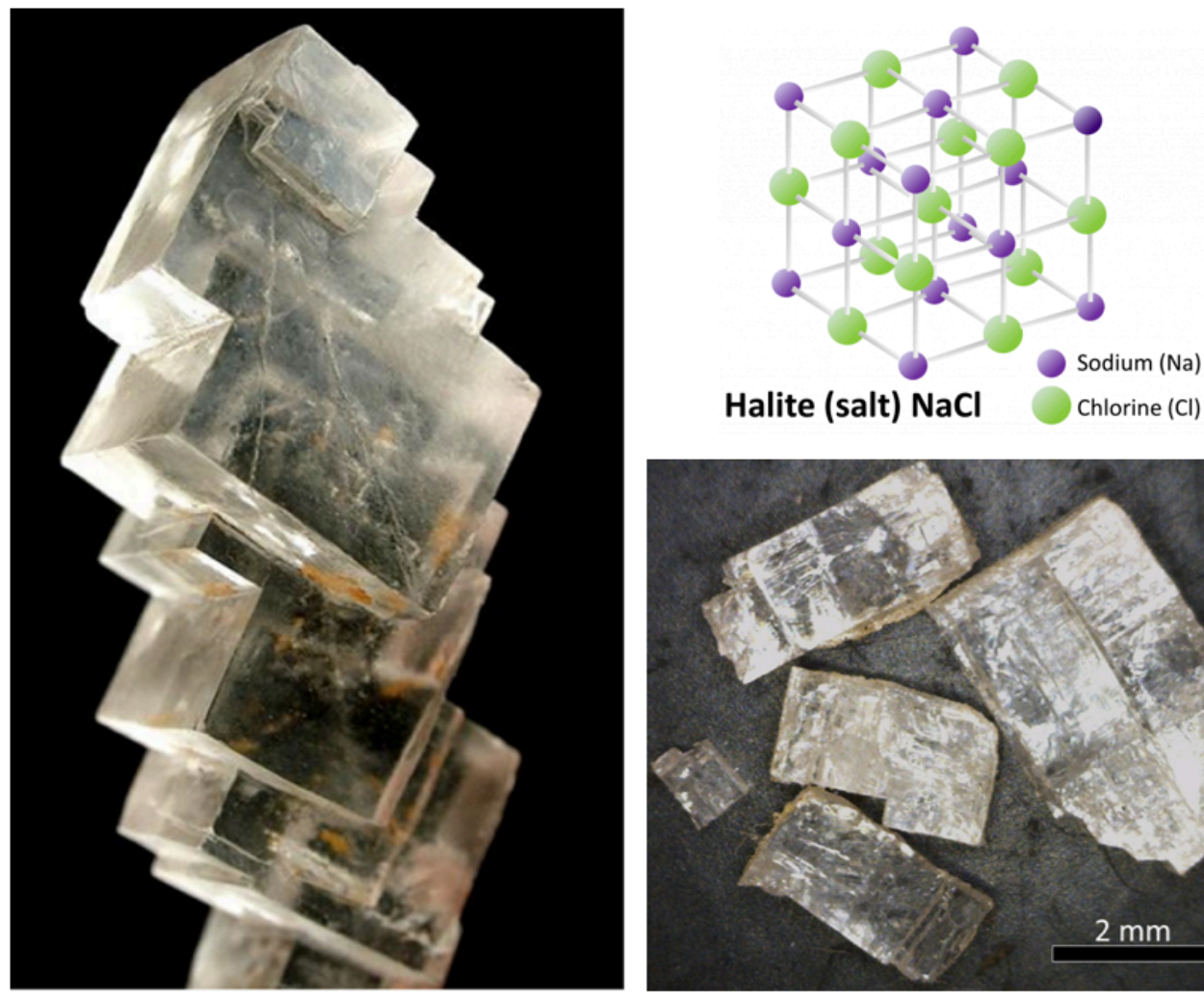

Figure 2.1.2: Cubic crystals (left), lattice structure and composition (top right), and right-angle cleavage planes (bottom right) of the mineral halite. If you look closely at the cleavage fragment on the right, you can see where it would break again (cleave) along a plane parallel to an existing surface. In most minerals, cleavage planes do not align with crystal surfaces.

\section{Media Attributions}

- Figures 2.1.1, 2.1.2 (top and bottom right): (C) Steven Earle. CC BY.

- Figure 2.1.2 (left): Halite. (C) Rob Lavinsky, iRocks.com. CC BY-SA. 


\subsection{Mineral Groups}

Most minerals are made up of a cation (a positively charged ion) or several cations, plus an anion (a negatively charged ion (e.g., $\left.\mathrm{S}^{2-}\right)$ ) or an anion complex (e.g., $\mathrm{SO}_{4}{ }^{2-}$ ). For example, in the mineral hematite $\left(\mathrm{Fe}_{2} \mathrm{O}_{3}\right)$, the cation is $\mathrm{Fe}^{3+}$ (iron) and the anion is $\mathrm{O}^{2-}$ (oxygen). The two $\mathrm{Fe}^{3+}$ ions have an overall charge of +6 and that balances the overall charge of -6 from the three $\mathrm{O}^{2-}$ ions.

We group minerals into classes on the basis of their predominant anion or anion complex. These include oxides, sulphides, carbonates, silicates, and others. Silicates are by far the predominant group in terms of their abundance within the crust and mantle, and will be discussed in more detail in Lab 3. Some examples of minerals from the different mineral groups are given in Table 2.2.

Table 2.2 The main mineral groups and some examples of minerals in each group.

\begin{tabular}{|c|c|}
\hline Group & Examples \\
\hline Oxides & Hematite (iron oxide $\mathrm{Fe}_{2} \mathrm{O}_{3}$ ), corundum (aluminum oxide $\mathrm{Al}_{2} \mathrm{O}_{3}$ ), water ice $\left(\mathrm{H}_{2} \mathrm{O}\right.$ ) \\
\hline Sulphides & Galena (lead sulphide PbS), pyrite (iron sulphide $\mathrm{FeS}_{2}$ ), chalcopyrite (copper-iron sulphide $\mathrm{CuFeS}_{2}$ ) \\
\hline Sulphates & $\begin{array}{l}\left.\text { Gypsum (calcium sulphate } \mathrm{CaSO}_{4} \cdot \mathrm{H}_{2} \mathrm{O}\right) \text {, barite }\left(\text { barium sulphate } \mathrm{BaSO}_{4}\right) \text { (Note that sulphates are } \\
\text { different from sulphides. Sulphates have the } \mathrm{SO}_{4}^{-2} \text { ion while sulphides have the } \mathrm{S}^{-2} \text { ion) }\end{array}$ \\
\hline Halides & $\begin{array}{l}\left.\left.\text { Fluorite (calcium flouride } \mathrm{CaF}_{2}\right) \text {, halite (sodium chloride } \mathrm{NaCl}\right)(\text { Halide minerals have halogen elements } \\
\text { as their anion - the minerals in the second last column on the right side of the periodic table, including } \mathrm{F} \text {, } \\
\mathrm{Cl}, \mathrm{Br} \text {, etc. - see the periodic table in Appendix } 1 \text { : List of Geologically Important Elements and the Periodic } \\
\text { Table.) }\end{array}$ \\
\hline Carbonates & Calcite (calcium carbonate $\left.\mathrm{CaCO}_{3}\right)$, dolomite (calcium-magnesium carbonate $\left.(\mathrm{Ca}, \mathrm{Mg}) \mathrm{CO}_{3}\right)$ \\
\hline Phosphates & Apatite $\left(\mathrm{Ca}_{5}\left(\mathrm{PO}_{4}\right) 3(\mathrm{OH})\right)$, Turquoise $\left(\mathrm{CuAl}_{6}\left(\mathrm{PO}_{4}\right) 4(\mathrm{OH})_{8} \cdot 5 \mathrm{H}_{2} \mathrm{O}\right)$ \\
\hline Silicates & $\begin{array}{l}\text { Quartz }\left(\mathrm{SiO}_{2}\right) \text {, feldspar (sodium-aluminum silicate } \mathrm{NaAlSi}_{3} \mathrm{O}_{8} \text { ), olivine (iron or magnesium silicate } \\
\left.(\mathrm{Mg}, \mathrm{Fe})_{2} \mathrm{SiO}_{4}\right) \text { (Note that in quartz the anion is oxygen, and while it could be argued, therefore, that } \\
\text { quartz is an oxide, it is always classed with the silicates.) }\end{array}$ \\
\hline $\begin{array}{l}\text { Native } \\
\text { minerals }\end{array}$ & Gold $(\mathrm{Au})$, diamond $(\mathrm{C})$, graphite $(\mathrm{C})$, sulphur $(\mathrm{S})$, copper $(\mathrm{Cu})$ \\
\hline
\end{tabular}

Oxide minerals have oxygen $\left(\mathrm{O}^{2-}\right)$ as their anion, but they exclude those with oxygen complexes such as carbonate $\left(\mathrm{CO}_{3}{ }^{2-}\right)$, sulphate $\left(\mathrm{SO}_{4}{ }^{2-}\right)$, and silicate $\left(\mathrm{SiO}_{4}{ }^{4-}\right)$. The most important oxides are the iron oxides hematite and magnetite $\left(\mathrm{Fe}_{2} \mathrm{O}_{3}\right.$ and $\mathrm{Fe}_{3} \mathrm{O}_{4}$, respectively). Both of these are common ores of iron. Corundum $\left(\mathrm{Al}_{2} \mathrm{O}_{3}\right)$ is used as an abrasive, but can also be a gemstone in its ruby and sapphire varieties. If the oxygen is also combined with hydrogen to form the hydroxyl anion $\left(\mathrm{OH}^{-}\right)$the mineral is known as a hydroxide. Some important hydroxides are limonite and bauxite, which are ores of iron and aluminium respectively. Frozen water $\left(\mathrm{H}_{2} \mathrm{O}\right)$ is a mineral (an oxide), but liquid water is not because it doesn't have a regular lattice.

Sulphides are minerals with the $\mathrm{S}^{-2}$ anion, and they include galena $(\mathrm{PbS})$, sphalerite $(\mathrm{ZnS})$, chalcopyrite $\left(\mathrm{CuFeS}_{2}\right)$, and molybdenite $\left(\mathrm{MoS}_{2}\right)$, which are the most important ores of lead, zinc, copper, and molybdenum respectively. Some other sulphide minerals are pyrite $\left(\mathrm{FeS}_{2}\right)$, bornite $\left(\mathrm{Cu}_{5} \mathrm{FeS}_{4}\right)$, stibnite $\left(\mathrm{Sb}_{2} \mathrm{~S}_{3}\right)$, and arsenopyrite (FeAsS).

Sulphates are minerals with the $\mathrm{SO}_{4}{ }^{-2}$ anion, and these include anhydrite $\left(\mathrm{CaSO}_{4}\right)$ and its cousin gypsum $\left(\mathrm{CaSO}_{4} .2 \mathrm{H}_{2} \mathrm{O}\right)$ and the sulphates of barium and strontium: barite $\left(\mathrm{BaSO}_{4}\right)$ and celestite $\left(\mathrm{SrSO}_{4}\right)$. In all of these minerals, the cation has a +2 charge, which balances the -2 charge on the sulphate ion. 
The halides are so named because the anions include the halogen elements chlorine, fluorine, bromine, etc. Examples are halite $(\mathrm{NaCl})$, cryolite $\left(\mathrm{Na}_{3} \mathrm{AlF}_{6}\right)$, and fluorite $\left(\mathrm{CaF}_{2}\right)$.

The carbonates include minerals in which the anion is the $\mathrm{CO}_{3}{ }^{-2}$ complex. The carbonate combines with +2 cations to form minerals such as calcite $\left(\mathrm{CaCO}_{3}\right)$, magnesite $\left(\mathrm{MgCO}_{3}\right)$, dolomite $\left((\mathrm{Ca}, \mathrm{Mg}) \mathrm{CO}_{3}\right)^{1}$, and siderite $\left(\mathrm{FeCO}_{3}\right)$. The copper minerals malachite and azurite are also carbonates.

In phosphate minerals, the anion is the $\mathrm{PO}_{4}{ }^{-3}$ complex. An important phosphate mineral is apatite $\left(\mathrm{Ca}_{5}\left(\mathrm{PO}_{4}\right)_{3}(\mathrm{OH})\right)$, which is what your teeth are made of. Note that it is called a phosphate, not a hydroxide, even though it has a hydroxyl ion.

The silicate minerals include the elements silicon and oxygen in varying proportions ranging from $\mathrm{Si}$ : $\mathrm{O}_{2}$ to $\mathrm{Si}: \mathrm{O}_{4}$. These are discussed at length in Section 2.4.

Native minerals are single-element minerals, such as gold, copper, sulphur, and graphite.

\section{Practice Exercise 2.2}

We classify minerals according to the anion part of the mineral formula, and mineral formulas are always written with the anion part on the right. For example, for pyrite $\left(\mathrm{FeS}_{2}\right), \mathrm{Fe}^{2+}$ is the cation and $\mathrm{S}^{-}$is the anion. This helps us to know that it's a sulphide, but it is not always that obvious. Hematite $\left(\mathrm{Fe}_{2} \mathrm{O}_{3}\right)$ is an oxide; that's easy, but anhydrite $\left(\mathrm{CaSO}_{4}\right)$ is a sulphate because $\mathrm{SO}_{4}{ }^{2-}$ is the anion, not $\mathrm{O}$. Along the same lines, calcite $\left(\mathrm{CaCO}_{3}\right)$ is a carbonate, and olivine $\left(\mathrm{Mg}_{2} \mathrm{SiO}_{4}\right)$ is a silicate. Minerals with only one element (such as $\mathrm{S}$ ) are native minerals, while those with an anion from the halogen column of the periodic table ( $\mathrm{Cl}, \mathrm{F}, \mathrm{Br}$, etc.) are halides. Provide group names for the following minerals:

Table 2.5 Provide group names for the following minerals

\begin{tabular}{|l|l|l|}
\hline Name & Formula & Group \\
\hline sphalerite & $\mathrm{ZnS}$ & \\
\hline magnetite & $\mathrm{Fe}_{3} \mathrm{O}_{4}$ & \\
\hline pyroxene & $\mathrm{MgSiO}_{3}$ & \\
\hline anglesite & $\mathrm{PbSO}_{4}$ & \\
\hline sylvite & $\mathrm{KCl}$ & \\
\hline silver & $\mathrm{Ag}$ & \\
\hline fluorite & $\mathrm{CaF}_{2}$ & \\
\hline ilmenite & $\mathrm{FeTiO}_{3}$ & \\
\hline siderite & $\mathrm{FeCO}_{3}$ & \\
\hline potassium feldspar & $\mathrm{KAlSi}_{3} \mathrm{O}_{8}$ & \\
\hline sulphur & $\mathrm{S}$ & \\
\hline xenotime & $\mathrm{YPO}_{4}$ & \\
\hline
\end{tabular}

See Appendix 2 for Practice Exercise 2.2 answers. 
Notes

1. The notations of two (or more) elements enclosed in parentheses with a comma between them: (Ca, Mg), indicates that both can be present, in varying proportions, but that there is still only one of them for each anion present. 


\subsection{Mineral Properties}

Minerals are universal. A crystal of hematite on Mars will have the same properties as one on Earth, and the same as one on a planet orbiting another star. That's good news for geology students who are planning interplanetary travel since we can use those properties to help us identify minerals anywhere. That doesn't mean that it's easy, however; identification of minerals takes a lot of practice. Some of the mineral properties that are useful for identification are as follows: colour, streak, lustre, hardness, crystal habit, cleavage/ fracture, specific gravity (density), and a few others.

\section{Colour}

For most of us, colour is one of our key ways of identifying objects. While some minerals have particularly distinctive colours that make good diagnostic properties, many do not, and for many, colour is simply unreliable. The mineral sulphur (2.3.1 left) is always a distinctive and unique yellow. Hematite, on the other hand, is an example of a mineral for which colour is not diagnostic. In some forms hematite is deep dull red, but in others it is black and shiny metallic (Figure 2.3.2). Many other

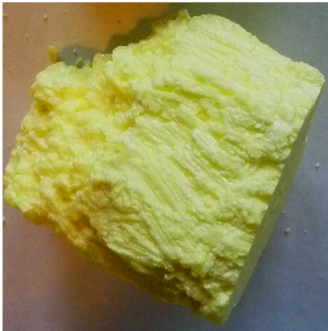

Sulphur

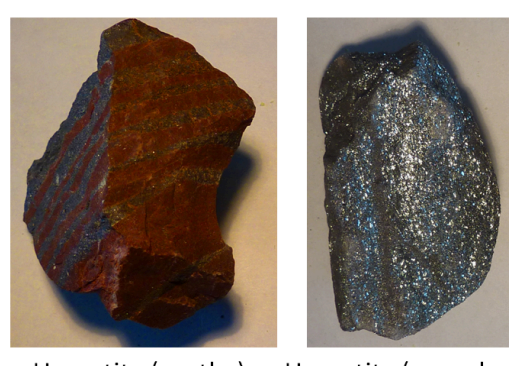

Hematite (earthy) Hematite (specular)

Figure 2.3.1 Examples of the colours of the minerals sulphur and hematite. minerals can have a wide range of colours (e.g., quartz, feldspar, amphibole, fluorite, and calcite). In most cases, the variations in colours are a result of varying proportions of trace elements within the mineral. In the case of quartz, for example, yellow quartz (citrine) has trace amounts of ferric iron $\left(\mathrm{Fe}^{3+}\right)$, rose quartz has trace amounts of manganese, purple quartz (amethyst) has trace amounts of iron, and milky quartz, which is very common, has millions of fluid inclusions (tiny cavities, each filled with water).

\section{Streak}

In the context of minerals, "colour" is what you see when light reflects off the surface of the sample. One reason that colour can be so variable is that the type of surface is variable. It may be a crystal face or a fracture surface or a cleavage plane, and the crystals may be large or small depending on the nature of the rock. If we grind a small amount of the sample to a powder we get a much better indication of its actual colour. This can easily be done by scraping a corner of the sample across a streak plate (a piece of unglazed porcelain) to make a

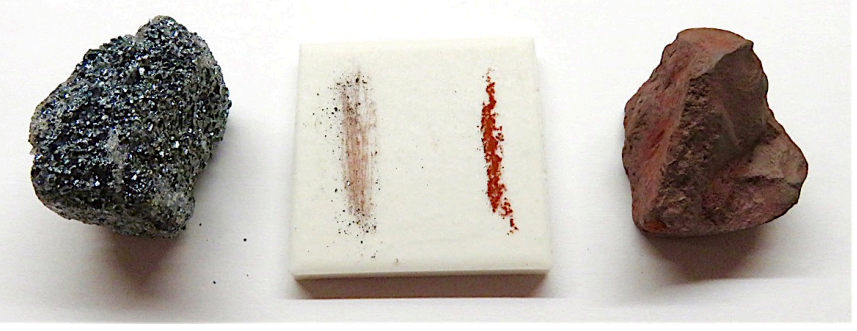

Figure 2.3.2 The streak colours of specular (metallic) hematite (left) and earthy hematite (right). Hematite leaves a distinctive reddish-brown streak whether the sample is metallic or earthy. 
streak. The result is that some of the mineral gets ground to a powder and we can get a better impression of its "true" colour (Figure 2.3.2).

\section{Lustre}

Lustre is the way light reflects off the surface of a mineral, and the degree to which it penetrates into the interior. The key distinction is between metallic and non-metallic lustre. Light does not pass through metals, and that is the main reason they look "metallic" (e.g., specular hematite in Figure 2.3.1 and pyrite in Figure 2.3.4b). Even a thin sheet of metal-such as aluminum foil-will not allow light to pass through it. Many non-metallic minerals may look as if light will not pass through them, but if you take a closer look at a thin edge of the mineral you can see that it does. If a non-metallic mineral has a shiny, reflective surface, then it is called "glassy" (Figure 2.3.4a). If it is dull and non-reflective, it is "earthy" (see earthy hematite in Figure 2.3.2). Other types of non-metallic lustres are "silky," "pearly," and "resinous." Lustre is a good diagnostic property since most minerals will always appear either metallic or non-metallic. There are a few exceptions to this (e.g., hematite in Figure 2.3.2).

\section{Hardness}

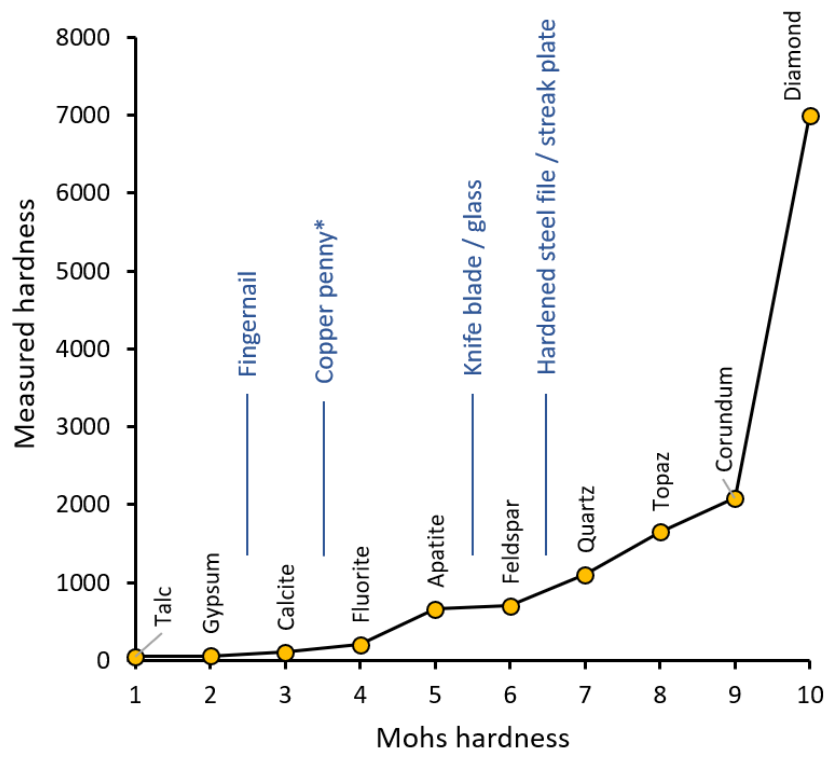

Figure 2.3.3: Minerals and reference materials in the Mohs scale of hardness. The "measured hardness" values are Vickers Hardness numbers. *Note that many modern copper coins are actually copper-plated steel, and are therefore harder.
One of the most important diagnostic properties of a mineral is its hardness. In 1812 German mineralogist Friedrich Mohs came up with a list of 10 reasonably common minerals that had a wide range of hardnesses. These minerals are shown in Figure 2.3.3, with the Mohs scale of hardness along the bottom axis. In fact, while each mineral on the list is harder than the one before it, the relative measured hardnesses (vertical axis) are not linear. For example apatite is about three times harder than fluorite and diamond is three times harder than corundum. Some commonly available reference materials are also shown on this diagram, including a typical fingernail (2.5), a piece of copper wire (3.5), a knife blade or a piece of window glass (5.5), a hardened steel file (6.5), and a porcelain streak plate (6.5 to 7). These are tools that a geologist can use to measure the hardness of unknown minerals. For example, if you have a mineral that you can't scratch with your fingernail, but you can scratch with a copper wire, then its hardness is between 2.5 and 3.5. And of course the minerals themselves can be used to test other minerals. 


\section{Crystal Habit}

When minerals form within rocks, there is a possibility that they will form in distinctive crystal shapes if they formed slowly and if they are not crowded out by other pre-existing minerals. Every mineral has one or more distinctive crystal habits, but it is not that common, in ordinary rocks, for the shapes to be obvious. Quartz, for example, will form six-sided prisms with pointed ends (Figure 2.3.4a), but this typically happens only when it crystallizes from a hot water solution within a cavity in an existing rock. Pyrite can form cubic crystals (Figure 2.3.4b), but can also form crystals with 12 faces, known as dodecahedra ("dodeca" means 12). The mineral garnet also forms dodecahedral crystals (Figure 2.3.4c).

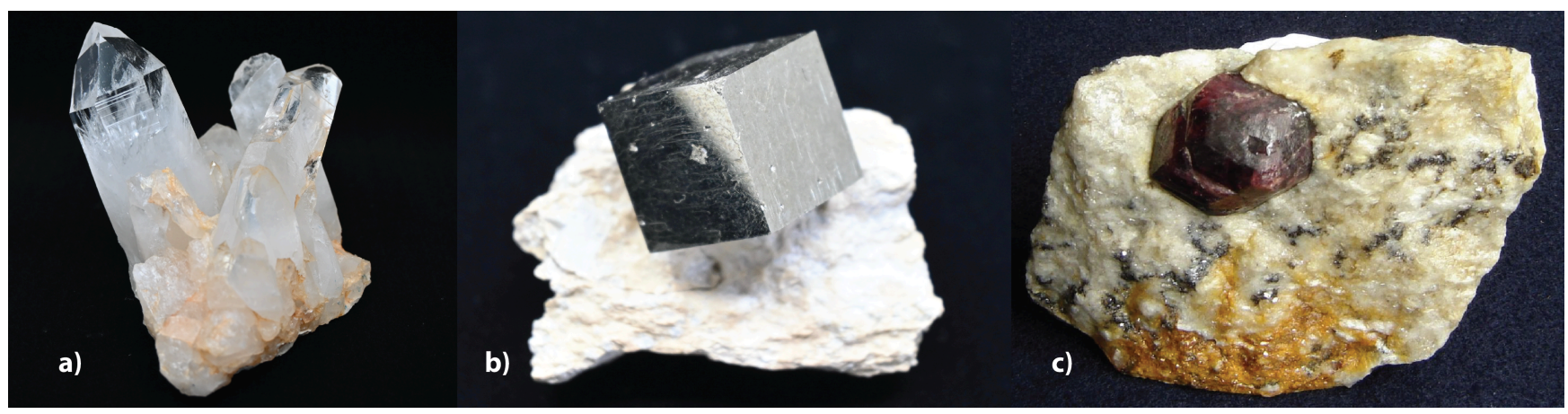

Figure 2.3.4: Hexagonal prisms of quartz with striations visible on crystal faces (a), a cubic crystal of pyrite (b), and a dodecahedral crystal of garnet (c).

Because well-formed crystals are rare in ordinary rocks, habit isn't as useful a diagnostic feature as one might think. However, there are several minerals for which it is important. One is garnet, which is common in some metamorphic rocks and typically displays the dodecahedral shape. Another is amphibole, which forms long thin crystals, and is common in igneous rocks like granite (Figure I5).

Mineral habit is often related to the regular arrangement of the molecules that make up the mineral. Some of the terms that are used to describe habit include bladed, botryoidal (grape-like), dendritic (branched), drusy (an encrustation of minerals), equant (similar in all dimensions), fibrous, platy, prismatic (long and thin), and stubby.

\section{Cleavage and Fracture}

Crystal habit is a reflection of how a mineral grows, while cleavage and fracture describe how it breaks. Cleavage and fracture are the most important diagnostic features of many minerals, and often the most difficult to understand and identify. Cleavage is what we see when a mineral breaks along a specific plane or planes, while fracture is an irregular break. One particularly distinct type of fracture, common in quartz, is called conchoidal fracture (top left photograph in Figure 2.3.5). Some minerals tend to cleave along planes at various fixed orientations (Figure 2.3.5), some do not cleave at all (they only fracture). Minerals that have cleavage can also fracture along surfaces that are not parallel to their cleavage planes (Figure 2.3.6). 
No cleavage; mineral fractures

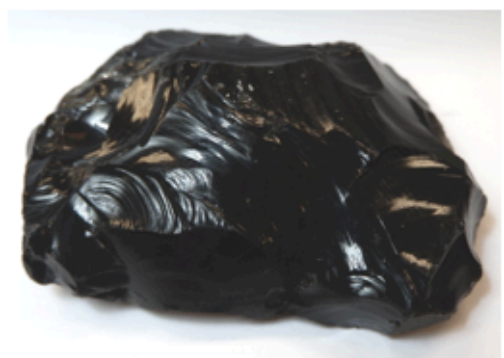

No cleavage planes
One cleavage plane

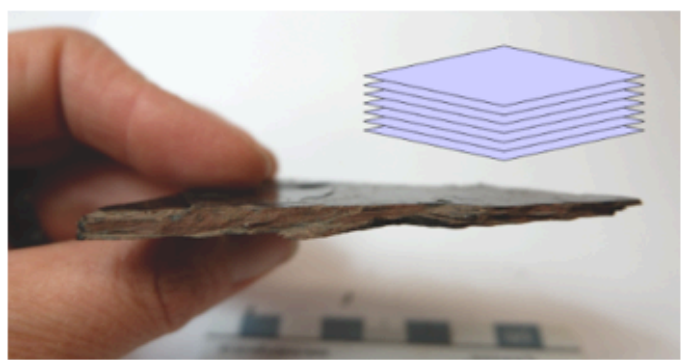

Basal cleavage - flat sheets
Two cleavage planes, at or near $90^{\circ}$

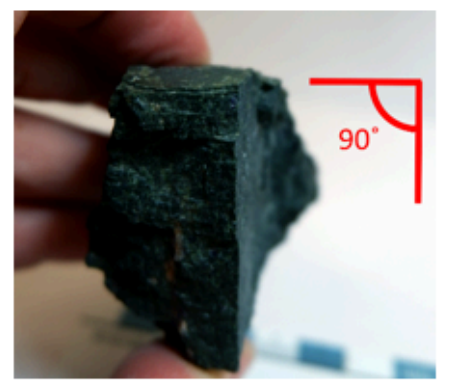

Three cleavage planes not at $90^{\circ}$

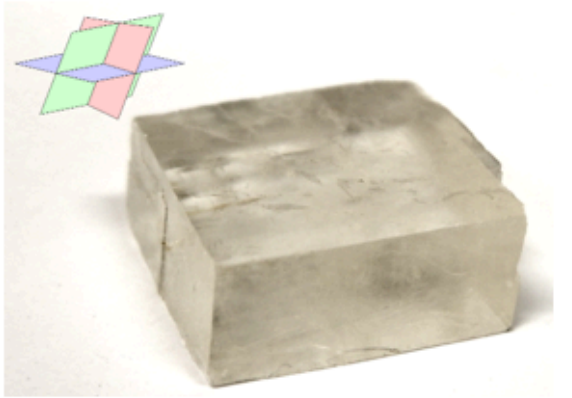

Three cleavage planes at $90^{\circ}$

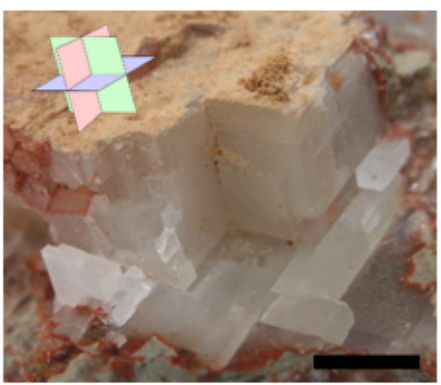

Cubic cleavage - cubes
Two cleavage planes not at $90^{\circ}$

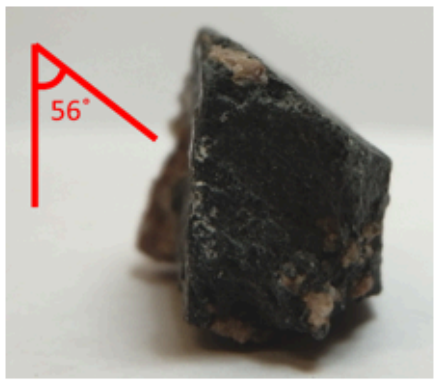

Four cleavage planes

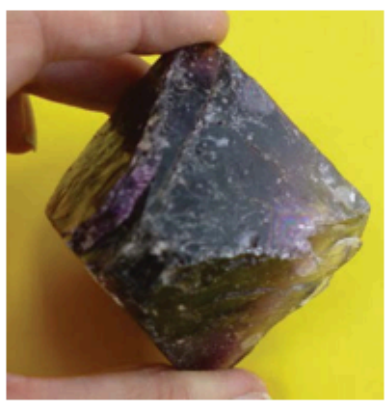

Figure 2.3.5: Common types of cleavage, and conchoidal fracture (top left), with illustrations to indicate cleavage directions and angles between cleavage planes. 


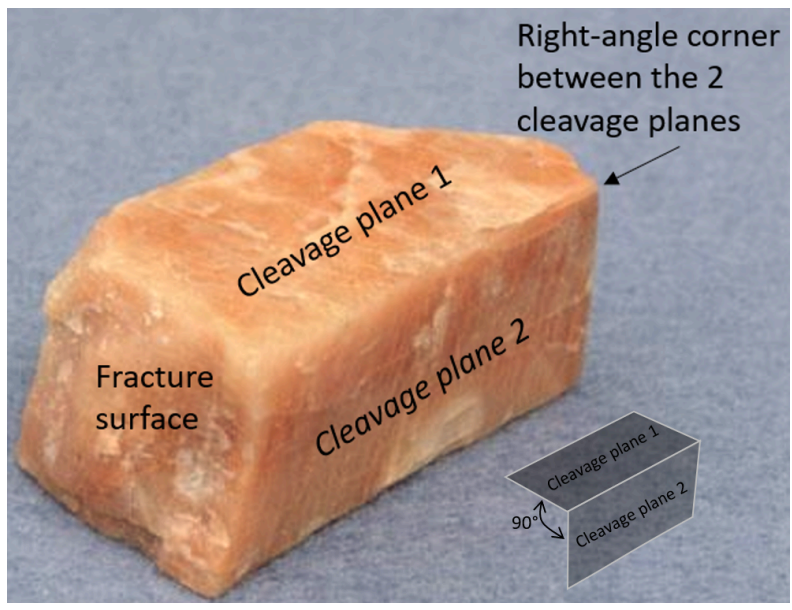

Figure 2.3.6: Cleavage and fracture in potassium feldspar. Feldspar minerals, including plagioclase and potassium feldspar, have two cleavage planes at right-angles to one another. Some feldspar samples may display other flat surfaces, but if you look closely these are fracture surfaces, not cleavage planes.

As we've already discussed, the way that minerals break is determined by their atomic arrangement and specifically by the orientation of weaknesses within the lattice. Graphite and the micas, for example, have cleavage planes parallel to their sheets (Figure 2.1.1), and halite has three cleavage planes parallel to the lattice directions (Figure 2.1.2). Quartz has no cleavage because it has equally strong $\mathrm{Si}-\mathrm{O}$ bonds in all directions, and feldspar minerals have two cleavages at $90^{\circ}$ to each other (Figure 2.3.6). When a mineral has more than one cleavage plane or cleavage direction, it is important to specify the number of cleavage planes and the approximate angle between them.

Tips for recognizing cleavage in mineral samples

There are a few common difficulties that students encounter when learning to recognize and describe cleavage. One of the main difficulties is that cleavage is visible only in individual crystals. Most rocks have small crystals and it's very difficult to see the cleavage within those crystals. Use your hand lens to magnify your field of view, and make sure you have an adequate light source nearby. If crystals are very small, it may not be possible to see cleavage at all.

Some minerals have perfect cleavage, meaning that the cleavage planes are perfectly flat, they glint light back at you as you rotate the mineral around, and are generally easy to recognize. Mica and feldspar minerals commonly have perfect cleavage. Some minerals, on the other hand, have poor cleavage, meaning that the planes are not perfectly flat and may be harder to recognize. Talc is an example of the latter. Talc has one cleavage plane, but with a Mohs hardness of just 1 , any recognizable plane is often scratched and uneven, making it more difficult to recognize that talc has cleavage at all!

It can also be easy to misidentify flat crystal faces, or even smooth flat fractures, as cleavage planes. As already noted, crystal faces are related to how a mineral grows while cleavage planes are related to how it breaks. In most minerals cleavage planes and crystal faces do not align with one-another. An exception is halite, which grows in cubic crystals and has cleavage along those same planes (Figure 2.1.2). But this doesn't hold for most minerals. For 
example, fluorite forms cubic crystals like those of halite, but it cleaves along planes that differ in orientation from the crystal surfaces. This is illustrated in Figure 2.3.7.
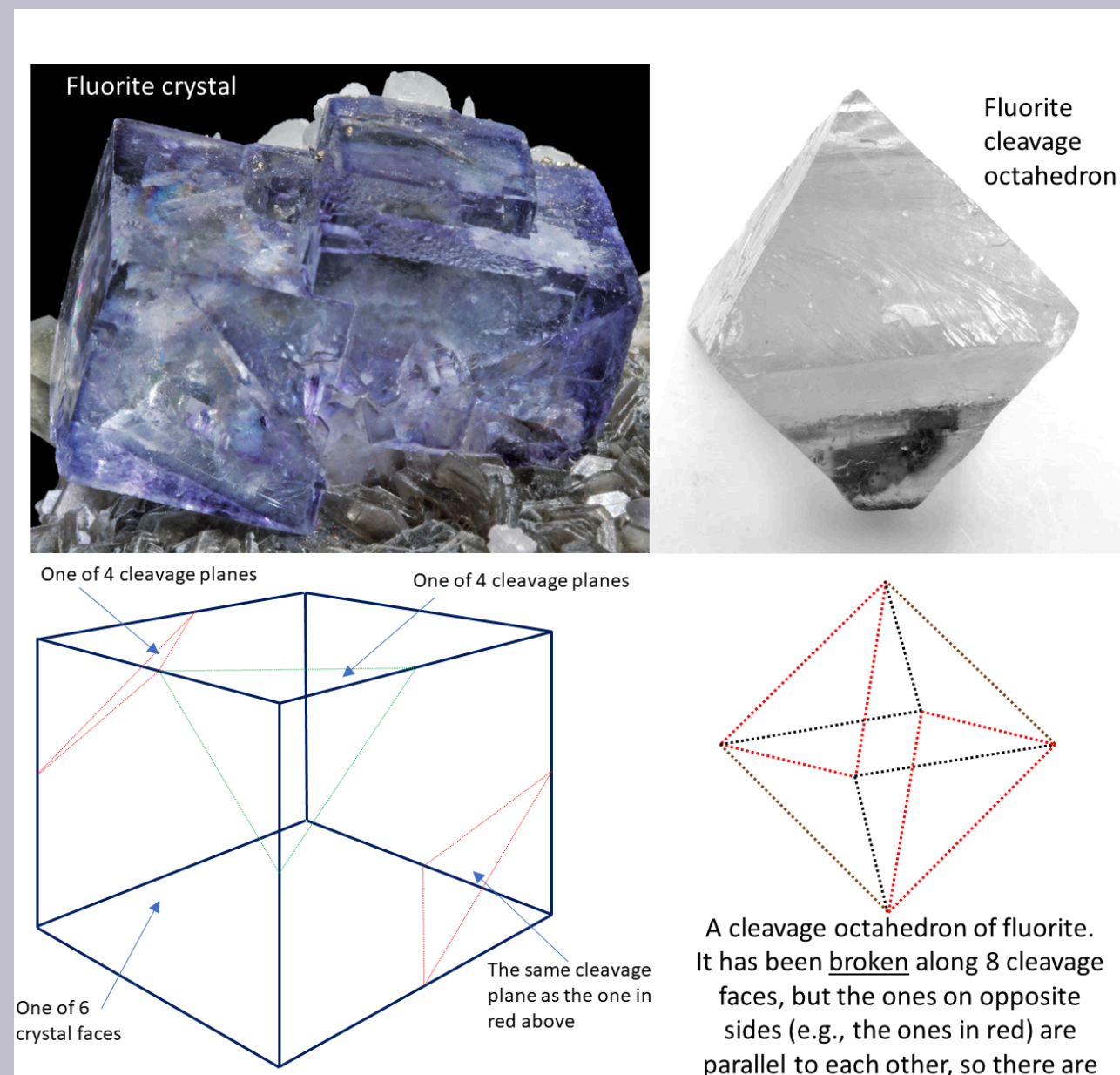

A cleavage octahedron of fluorite. It has been broken along 8 cleavage faces, but the ones on opposite sides (e.g., the ones in red) are parallel to each other, so there are actually only 4 cleavage planes.

A crystal of fluorite. It has grown with 6 crystal faces in the form of a cube.

Figure 2.3.7: Crystal faces and cleavage planes in the mineral fluorite. The top-left photo shows a natural crystal of fluorite. It has crystal surfaces but you can see some future cleavage planes inside the crystal. The top-right photo shows what you can create if you take a crystal like the one on the left and carefully break it along its cleavage planes.

Remember that cleavage planes are controlled at the molecular level by the crystal lattice, and so they tend to repeat themselves at different depths throughout the mineral. Planes that are parallel are considered the same direction of cleavage and should only count as one. If are unsure whether the flat surface you are examining is a cleavage plane, try rotating the mineral under bright light, like a desk lamp. If the mineral has cleavage, you will generally find that all of the cleavage
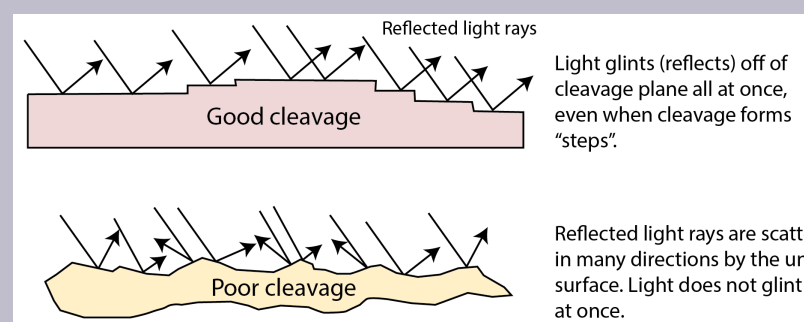

Reflected light rays are scattered in many directions by the uneven surface. Light does not glint all at once.

Figure 2.3.8: Examples of a mineral with good (top) and poor (bottom) cleavage planes. [Image description] surfaces of a given cleavage direction will glint in the light simultaneously (Figure 2.3.8). Crystal faces will also glint under the light, but do not repeat themselves at depth throughout the mineral. In some minerals, crystal faces have striations, as shown by the faint parallel lines on the faces of the quartz crystal in Figure 2.3.4a. Finally, if you have identified more than one cleavage plane or direction 
within a mineral, it can take practice to describe the angle between those cleavage directions. To help visualize the angle between two cleavage planes try extending the planes using both hands. Place one finger from each hand flat on each cleavage plane, and examine the angle between your fingers. Is the angle between your fingers close to $90^{\circ}$, or definitely not $90^{\circ}$ ? Remember, for the purposes of this course you do not need to describe cleavage with an exact angle. Geology students have to work hard to understand and recognize cleavage, but it's worth the effort since it is a reliable diagnostic property for most minerals.

\section{Density and Specific Gravity}

Density, reported in units of grams per cubic centimetre $\left(\mathrm{g} / \mathrm{cm}^{3}\right)$, is a useful diagnostic tool in some cases. Specific gravity (SG) is a related measure that geologist's use to describe the density of a mineral. For the purposes of this course, the specific gravity of a mineral can be described as "low", "moderate", or "high". Most minerals you will encounter in this course like quartz (2.65), feldspar, calcite, amphibole, and mica have "moderate" SG between 2.6 and 3.4, and it would be difficult to tell them apart on the basis of their SG alone. In comparison to these minerals, galena, for example, has distinctly high SG (7.5), while graphite has distinctly low SG (1.75). To determine this qualitatively in the lab, try comparing samples of quartz and galena of roughly the same size by hefting them in your hands. The sample of galena should feel much heavier than the similarly-sized sample of quartz. A limitation of using density (or SG) as a diagnostic tool is that one cannot assess it in minerals that are a small part of a rock that is mostly made up of other minerals.

\section{Other Properties}

Several other properties are also useful for identification of some minerals, including:

- Calcite reacts (fizzes vigorously) with dilute acid and will give off bubbles of carbon dioxide.

- Magnetite is strongly magnetic, and some other minerals, like pyrrhotite, are weakly magnetic.

- Halite tastes salty - please do not lick the lab samples; there are other diagnostic properties you should use to identify halite!

- Sphalerite has a pale yellow streak that gives off a sulphurous (rotten egg-like) smell.

- Talc feels soapy to the touch.

- Plagioclase feldspar commonly has striations (Figure 2.3.9).

- Some potassium feldspars have exsolution lamellae. 


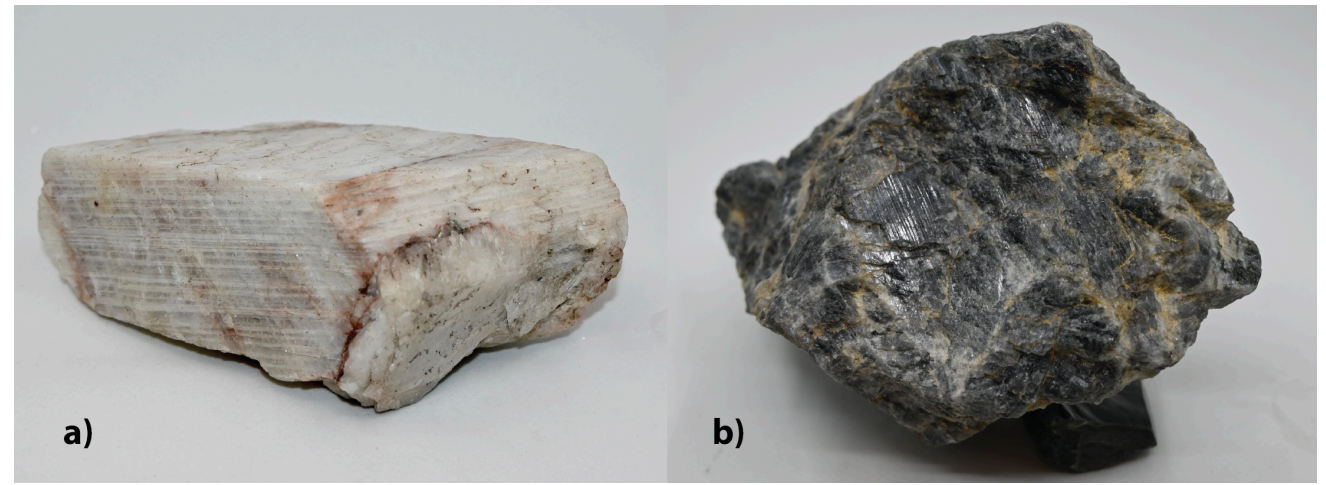

Figure 2.3.9: Striations on light-coloured plagioclase feldspar (albite, a), and dark-coloured plagioclase feldspar (labradorite, $b$ ).

\section{Image Descriptions}

Figure 2.3.8 image description: As you rotate a mineral with good cleavage (top) under a light source, you will see the light glint back at you all at once, as the rays of light are reflected by the mirror-smooth cleavage plane. Even if the cleavage plane causes the mineral to break along "steps", you will still see a single glint off of these steps all at once. Minerals with poor cleavage (bottom) do not glint all at once, as their cleavage planes are rough and uneven, causing light rays to scatter. [Return to Figure 2.3.8]

\section{Media Attributions}

- Figures 2.3.1, 2.3.7: (C) Steven Earle. CC BY.

- Figure 2.3.2: (C) Karla Panchuk. CC BY.

- Figures 2.3.3 and 2.3.6: (C) Siobhan McGoldrick. CC BY. Derivatives of Figures 2.6.3 and 2.6.5 (C) Steven Earle. CC BY.

- Figure 2.3.4a, 2.3.4b, 2.3.9: (C) Candace Toner. CC BY-NC.

- Figure 2.3.4c: Almandine garnet (C) Eurico Zimbres (FGEL/UERJ) and Tom Epaminondas (mineral collector). CC BY-SA.

- Figure 2.3.5: (C) Lyndsay Hauber and Joyce M. McBeth. CC BY. Adapted from Randa Harris and M.C. Rygel. CC BY-SA 3.0.

- Figure 2.3.8: (C) Siobhan McGoldrick. CC BY. 


\title{
2.4 Economic Minerals
}

\author{
If you can't grow it, you have to mine it
}

Anything we can't grow we have to extract from Earth in one way or another. This includes water, of course, our most important resource, but it also includes all the other materials that we need to construct things like roads, dams, and bridges, or manufacture things like plates, toasters, and telephones.

Virtually everything we use every day is made from resources from Earth. For example, let's look at a tablet computer (Figure 2.4.1). Most of the case is made of a plastic known as ABS, which is made from either gas or petroleum. Some tablets have a case made from aluminum. The glass of a touch screen is made mostly from quartz combined with smaller amounts of sodium oxide $\left(\mathrm{Na}_{2} \mathrm{O}\right)$, sodium carbonate $\left(\mathrm{Na}_{2} \mathrm{CO}_{3}\right)$, and calcium oxide $(\mathrm{CaO})$. To make it work as a touch screen, the upper surface is coated with indium tin oxide. When you touch the screen you're actually pushing a thin layer of polycarbonate plastic (made from petroleum) against the coated glass-completing an electrical circuit.
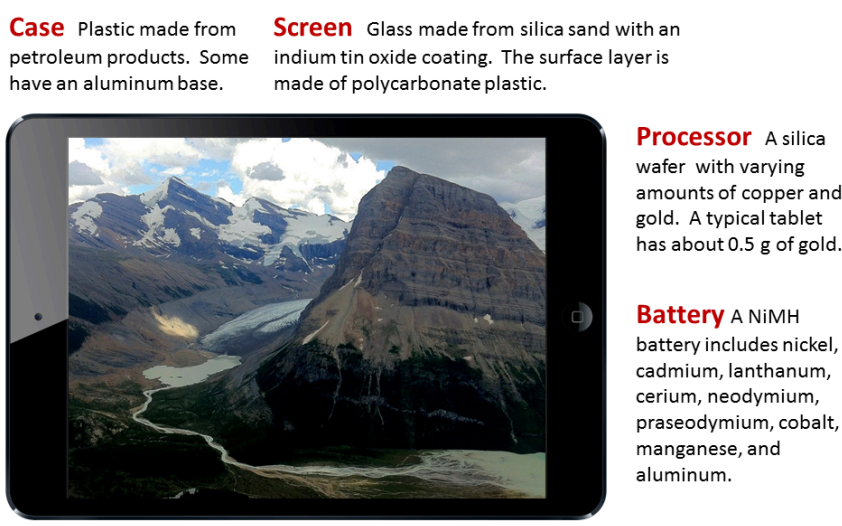

Printed circuit board The electronic components are attached to a printed circuit board made from fibreglass (more silica) plus copper and small amounts of lead and tin.

Figure 2.4.1 The main components of a tablet computer.

The computer is then able to figure out exactly where you touched the screen. Computer processors are made from silica wafers (more quartz) and also include a significant amount of copper and gold. Gold is used because it is a better conductor than copper and doesn't tarnish the way silver or copper does. Most computers have nickel-metal-hydride (NiMH) batteries, which contain nickel, of course, along with cadmium, cobalt, manganese, aluminum, and the rare-earth elements lanthanum, cerium, neodymium, and praseodymium. The processor and other electronic components are secured to a circuit board, which is a thin layer of fibreglass sandwiched between copper sheets coated with small amounts of tin and lead. Various parts are put together with steel screws that are made of iron and molybdenum.

That's not everything that goes into a tablet computer, but to make just those components we need a pure-silica sand deposit, a salt mine for sodium, a rock quarry for calcium, an oil well, a gas well, an aluminum mine, an iron mine, a manganese mine, a copper-molybdenum-gold mine, a cobalt-nickel mine, a rare-earth element and indium mine, and a source of energy to transport all of the materials, process them, put them together, and finally transport the computer to your house or the store where you bought it.

Practice Exercise 2.3 Where does it come from?

Look around you and find at least five objects (other than a computer or a phone) that have been made from materials that had to be mined, quarried, or extracted from an oil or gas well. Try to identify the materials involved, and think about where they might have come from. This pen (Figure 2.4.2) is just an example.

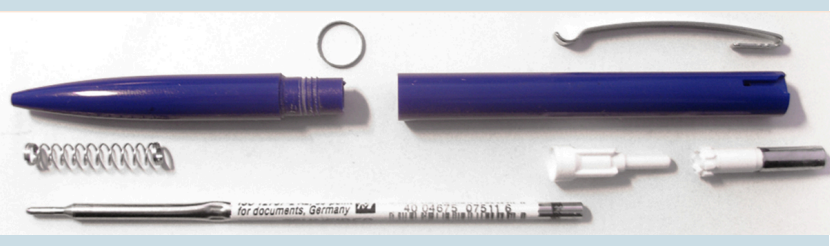

Figure 2.4.2 Pieces of a ballpoint pen 
You may find it helpful to consult the overview of ore and industrial minerals, their uses, and notable Canadian sources provided in Appendix 4 to complete this exercise.

See Appendix 2 for Practice Exercise 2.3 answers.

Mining has always been a major part of Canada's economy. Canada has some of the largest mining districts and deposits in the world, and for the past 150 years, we have been one of the world's most important suppliers of metals. Extraction of Earth's resources goes back a long way in Canada. For example, the First Nations of British Columbia extracted obsidian from volcanic regions for tools and traded it up and down the coast. In the 1850s, gold was discovered in central British Columbia, and in the 1890s, even more gold was discovered in the Klondike area of Yukon. These two events were critical to the early development of British Columbia, Yukon, and Alaska.

Canada's mining sector had revenues in the order of \$44 billion in 2017 (Figure 2.4.3). The 4 most valuable commodities were gold, coal, copper and potash, with important amounts from iron, nickel, diamonds, sand and gravel aggregates, stone and zinc. Revenues from the petroleum sector are significantly higher, at over $\$ 100$ billion per year.

An ore deposit is a body of rock in which one or more metals have been concentrated to the point of being economically viable for recovery. Some background levels of important metals in average rocks are shown on Table 2.4, along with the typical grades necessary to make a viable deposit, and the corresponding concentration factors. Looking at copper, for example, we can see that while average rock has around $40 \mathrm{ppm}$ (parts per million) of cop-

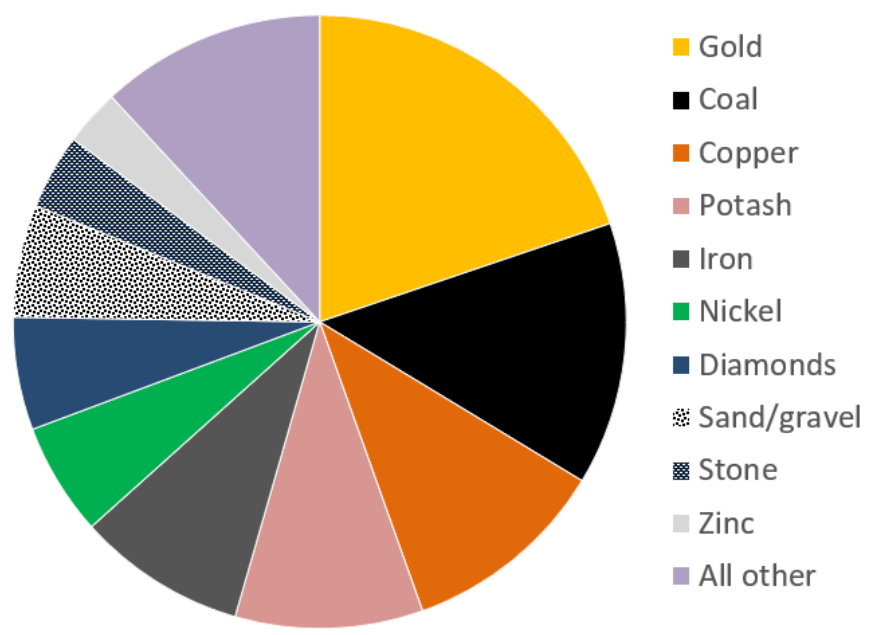

Figure 2.4.3: The value of various Canadian mining sectors in 2017. The total value of these products was about $\$ 44$ billion in 2017. per, a grade of around 10,000 ppm or $1 \%$ is necessary to make a viable copper deposit. In other words, copper ore has about 250 times as much copper as typical rock. For the other elements in the list, the concentration factors are much higher. For gold, it's 2,000 times and for silver it's around 10,000 times. 
Table 2.4 Typical background and ore levels of some important metals.

\begin{tabular}{|l|l|l|l|}
\hline Metal & Typical Background Level & Typical Economic Grade* & Concentration Factor \\
\hline Copper & $40 \mathrm{ppm}$ & $10,000 \mathrm{ppm}(1 \%)$ & 250 times \\
\hline Gold & $0.003 \mathrm{ppm}$ & $6 \mathrm{ppm}(0.006 \%)$ & 2,000 times \\
\hline Lead & $10 \mathrm{ppm}$ & $50,000 \mathrm{ppm}(5 \%)$ & 5,000 times \\
\hline Molybdenum & $1 \mathrm{ppm}$ & $1,000 \mathrm{ppm}(0.1 \%)$ & 1,000 times \\
\hline Nickel & $25 \mathrm{ppm}$ & $20,000 \mathrm{ppm}(2 \%)$ & 800 times \\
\hline Silver & $0.1 \mathrm{ppm}$ & $1,000 \mathrm{ppm}(0.1 \%)$ & 10,000 times \\
\hline Uranium & $2 \mathrm{ppm}$ & 10,000 ppm $(1 \%)$ & 5,000 times \\
\hline $\begin{array}{l}\text { Zinc } \\
\text { *It's important to note that the economic viability of any deposit depends on a wide range of factors including its } \\
\text { grade, size, shape, depth below the surface, and proximity to infrastructure, the current price of the metal, the } \\
\text { labour and environmental regulations in the area, and many other factors. }\end{array}$ & 1,000 times \\
\hline
\end{tabular}

It is clear that some very significant concentration must take place to form a mineable deposit. This concentration may occur during the formation of the host rock, or after the rock forms, through a number of different types of processes. There is a very wide variety of ore-forming processes, and there are hundreds of types of mineral deposits.

\section{Mining and mineral processing}


Metal deposits are mined in a variety of different ways depending on their depth, shape, size, and grade. Relatively large deposits that are quite close to the surface and somewhat regular in shape are mined using open-pit mine methods (Figure 2.4.4). Creating a giant hole in the ground is generally cheaper than making an underground mine, but it is also less precise, so it is necessary to mine a lot of waste rock along with the ore. Relatively deep deposits or those with elongated or irregular shapes are typically mined from underground with deep vertical shafts, declines (sloped tunnels), and levels (horizontal tunnels) (Figure 2.4.4). In this way, it is possible to focus the mining on the ore body itself. However, with relatively large ore bodies, it may be necessary to leave some pillars to hold up the roof.

In many cases, the near-surface part of an ore body is mined with an open pit, while the deeper parts are mined underground (Figure 2.4.4).

A typical metal deposit might contain a few percent of ore minerals (e.g., chalcopyrite or sphalerite), mixed with the minerals of the original rock (e.g., quartz or feldspar). Other sulphide minerals are commonly present within the ore, especially

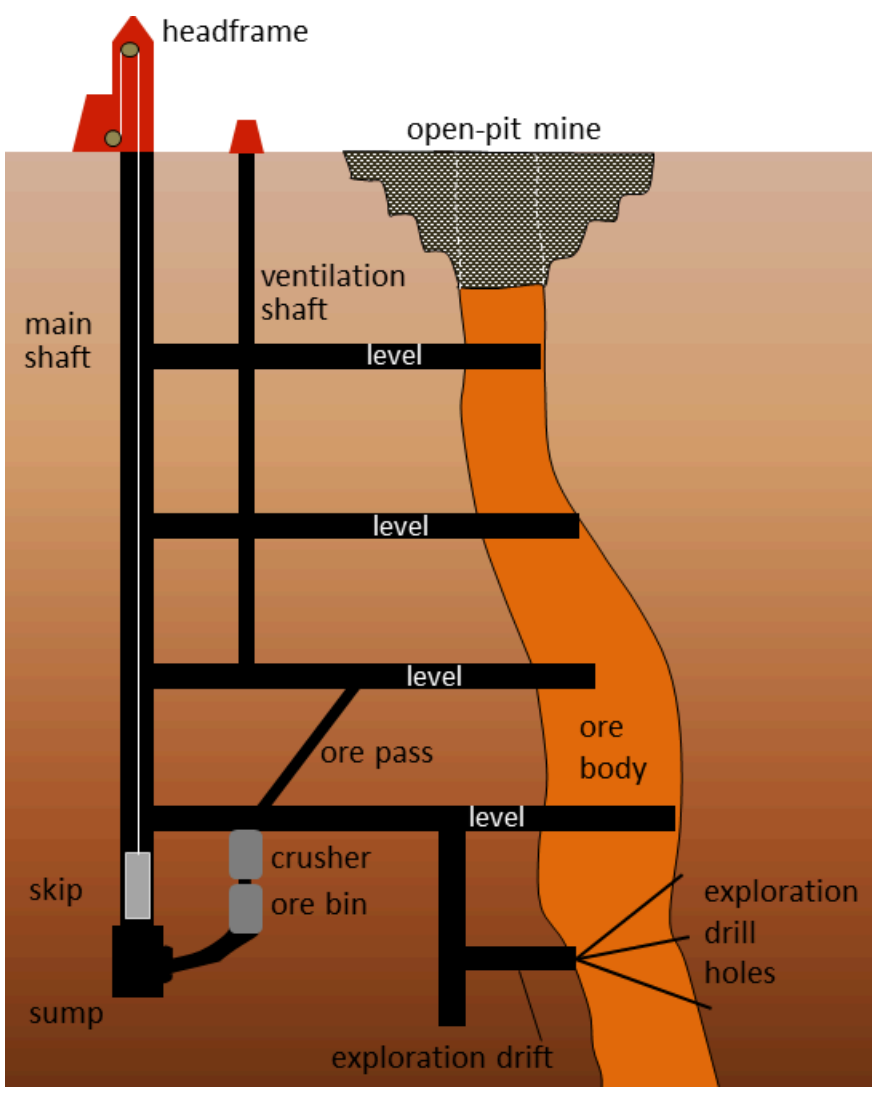

Figure 2.4.4: Schematic cross-section of a typical underground mine. [Image Description] pyrite.

When ore is processed (typically very close to the mine), it is ground to a fine powder and the ore minerals are physically separated from the rest of the rock to make a concentrate. The rest of the rock is known as tailings. It comes out of the concentrator as a wet slurry and must be stored near the mine, in most cases, in a tailings pond.

The tailings pond at the Myra Falls Mine on Vancouver Island and the settling ponds for waste water from the concentrator are shown in Figure 2.4.5. The tailings are contained by an embankment. Also visible in the foreground is a pile of waste rock, which is non-ore rock that was mined in order to access the ore. Although this waste rock contains little or no ore minerals, at many mines it contains up to a few percent pyrite. The tailings and the waste rock at most mines are an environmental liability because they contain pyrite plus small amounts of ore minerals. When pyrite is exposed to oxygen and water, it generates sulphuric acid-also known as acid rock drainage (ARD). Acidity itself is a problem to the environment, but because the ore elements, such as copper or lead, are more soluble in acidic water than neutral water, ARD is also typically quite rich in metals, many of which are toxic. 


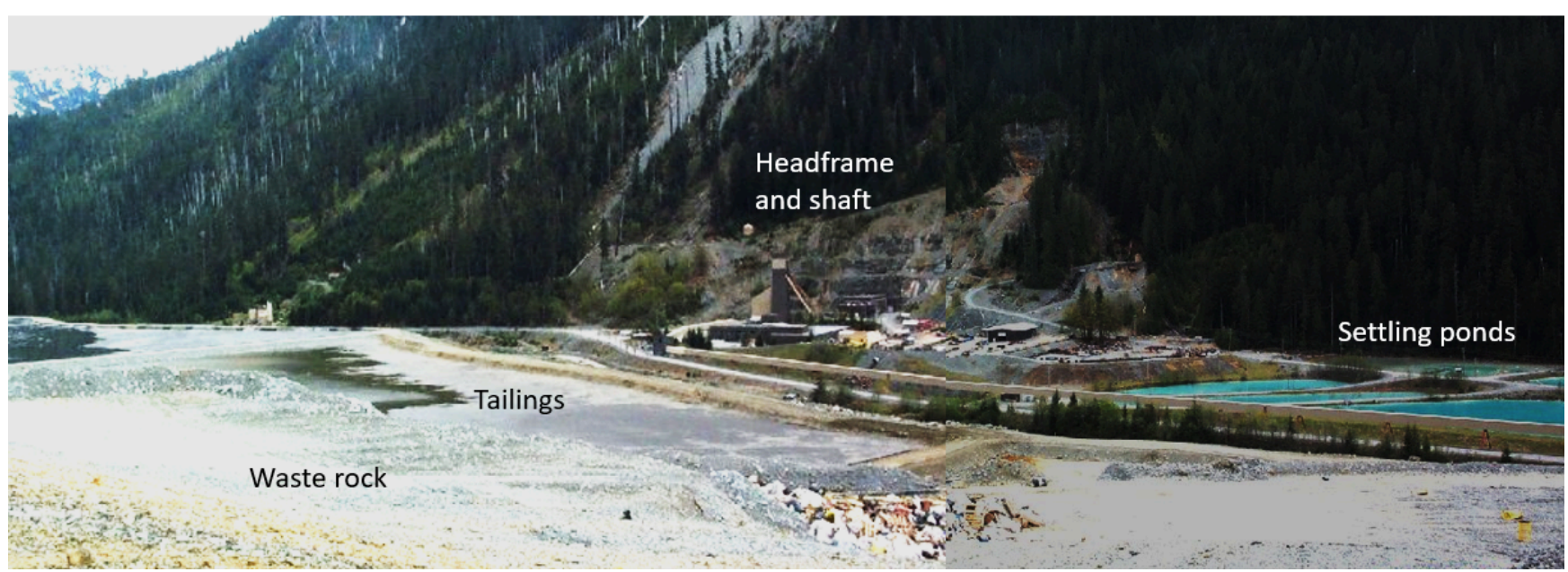

Figure 2.4.5: The tailings pond at the Myra Falls Mine on Vancouver Island. The dry rock in the middle of the image is waste rock. Myra Creek flows between the tailings pond and the headframe. The settling ponds (right) are used for processing water from the concentrator.

Most mines have concentrators on site because it is relatively simple to separate ore minerals from non-ore minerals and this significantly reduces the costs and other implications of transportation. But separation of ore minerals is only the preliminary stage of metal refinement, for most metals the second stage involves separating the actual elements within the ore minerals. For example, the most common ore of copper is chalcopyrite $\left(\mathrm{CuFeS}_{2}\right)$. The copper needs to be separated from the iron and sulphur to make copper metal and that involves complicated and very energy-intensive processes that are done at smelters or other types of refineries. Because of their cost and the economies of scale, there are far fewer refineries than there are mines.

There are several metal refineries (including smelters) in Canada; some examples are the aluminum refinery in Kitimat, B.C. (which uses ore from overseas); the lead-zinc smelter in Trail, B.C.; the nickel smelter at Thompson, Manitoba; numerous steel smelters in Ontario, along with several other refining operations for nickel, copper, zinc, and uranium; aluminum refineries in Quebec; and a lead smelter in New Brunswick.

Practice Exercise 2.4 Sources of important lighter metals

When we think of the manufacture of consumer products, plastics and the heavy metals (copper, iron, lead, zinc) easily come to mind, but we often forget about some of the lighter metals and non-metals that are important. Consider the following elements and determine their sources. Answers for all of these except magnesium are given above. See if you can figure out a likely mineral source of magnesium.

What are the sources of the following elements?

\begin{tabular}{|l|l|}
\hline Element & Source(s) \\
\hline Silicon & \\
\hline Calcium & \\
\hline Sodium & \\
\hline Potassium & \\
\hline Magnesium & \\
\hline
\end{tabular}




\section{Image Descriptions}

Figure 2.4.4 image description: An open-pit mine is dug to access the ore that is near the surface. For ore farther down, an underground mine will be constructed to access the ore. This diagram shows the main shaft (a large vertical tunnel) with four levels (horizontal tunnels) connected to it. The levels run from the main shaft into the ore body. A ventilation shaft runs up through the four levels in between the main shaft and the ore for air circulation.

[Return to Figure 2.4.4]

\section{Media Attributions}

- Figure 2.4.1: "Ipad Air" (C) Zach Vega. Adapted by Steven Earle. CC BY-SA.

- Figure 2.4.2: "Ballpoint pen parts" by unknown. CC BY-SA.

- Figure 2.4.3: (C) Steven Earle. CC BY. Based on data from Natural Resources Canada.

- Figures 2.4.4, 2.4.5: (C) Steven Earle. CC BY. 


\section{Lab 2 Exercises}

The exercises below will guide you through the mineral samples in Mineral Kits 1 and 2. Review the physical properties of minerals presented in Chapter 2.3 before you begin these exercises. You may wish to consult the mineral identification tables at the back of this manual as you complete the exercises below.

\section{Part I: Cleavage and Fracture}

The minerals in this part include a mix of silicate and non-silicate minerals found in Mineral Kits 1 and 2.

1. Do the following samples exhibit cleavage or fracture? If the sample exhibits cleavage, specify the number of cleavage planes and approximate angle between them.

\begin{tabular}{|l|l|l|l|l|l|l|l|}
\hline Sample & M226S & M225S & M1S & M251S & M111S & M223S & M131S \\
\hline $\begin{array}{l}\text { Cleavage or } \\
\text { fracture }\end{array}$ & & & & & & & \\
\hline
\end{tabular}

2. What is the difference between a crystal face and a cleavage plane?

3. Look at sample M202(S). This is a good example of a mineral with 2 cleavages at almost right angles to each other. Select two other samples that also demonstrate this type of cleavage.

4. Now select a sample which also appears to have a least two cleavages but with the cleavage surfaces oblique (at some angle other than $90^{\circ}$ ) to each other.

5. Which sample has one (perfect) cleavage only?

6. Look at the fractured surface of sample M225. Try to describe this surface (rough? curved? splintery? etc.). This is an example of conchoidal fracture. Does this sample exhibit any cleavage? 
7. What other sample also exhibits conchoidal fracture?

\section{Part II: Non-silicate Minerals}

Certain physical properties are diagnostic for a particular mineral. These diagnostic properties will help you distinguish a particular mineral. The questions below will help you identify these diagnostic properties. Remember: you must be able to identify all the physical properties of each mineral, not just the diagnostic properties. You should also know the group to which each mineral belongs (e.g., sulphides, oxides).

Mineral Group: Native Elements

Sample M21

Mineral name:

1. Does this mineral exhibit cleavage? If yes, describe the cleavage:

2. What is the approximate hardness of the sample on the Mohs scale of hardness?

3. What is the specific gravity of the sample (high, medium or low)?

4. Describe the lustre of this mineral:

5. Describe the streak:

6. What is a diagnostic property of graphite?

Mineral Group: Oxides

Sample M11/M12

Sample M51/M52

Sample M53

\section{Mineral name: \\ Mineral name: \\ Mineral name:}

1. Do any of these samples exhibit cleavage?

2. If yes, which one? Describe the cleavage:

3. Looking at samples M51/52 and M53, what is the lustre of each sample?

Sample M51/M52

Sample M53
Lustre:

Lustre: 
4. Compare the streak of each sample. Describe what you see:

5. Do any of the samples attract a magnet? Which one?

6 . What is the diagnostic property of magnetite?

7. What is the diagnostic property of hematite?

Mineral Group: Carbonates

Sample M251

Mineral name:

1. Does this mineral exhibit cleavage?

If so, describe the cleavage:

2. What is the approximate hardness of the sample on the Mohs scale of hardness?

3. Describe the lustre of this mineral.

4. Does the sample react to a drop of $\mathrm{HCl}$ ?

5 . What is a diagnostic property of calcite?

Mineral Group: Sulphides

\begin{tabular}{ll}
\hline Sample M41/M42 & Mineral name: \\
Sample M31 & Mineral name: \\
Sample M1 & Mineral name: \\
Sample M141 & Mineral name:
\end{tabular}

1. What do all these minerals have in common?

2. Test all four minerals for hardness. Do any of these minerals scratch the glass plate? 
3. Which is harder pyrite or chalcopyrite?

4. Describe the streak of sphalerite:

5. What is the lustre of pyrite, chalcopyrite and galena?

6. What is the lustre of sphalerite?

7. Which mineral has the highest specific gravity?

8. Do you see cleavage faces on any of these minerals?

9. How can you tell pyrite from chalcopyrite?

10. What is a diagnostic property of galena?

11. What is a diagnostic property of sphalerite?

12. Many sulphide minerals contain valuable ore metals that are used to manufacture the objects and technology you use every day. Using Appendix 4 as a guide, complete the table below.

\begin{tabular}{|l|l|l|l|}
\hline Sample \# & Mineral Name & Mineral Formula & Ore Metal \\
\hline M1 & & & \\
\hline M31 & & & \\
\hline M141 & & & \\
\hline
\end{tabular}

13. Name two economic uses for the mineral galena.

14. Explain the steps involved in extracting galena from an ore deposit and eventually producing pure lead metal.

Mineral Group: Sulphates 
1. What is the approximate hardness of this mineral?

2. Describe the lustre of this mineral:

3. What is the diagnostic property of gypsum?

4. What is the main economic use for gypsum and where is the world's most productive gypsum mining area?

Mineral Group: Halides

Sample M231

Sample M261

Sample M262
Mineral name:

Mineral name:

Mineral name:

1. Describe the cleavage of each sample.

Sample M231

Sample M261

Sample M262
Cleavage:

Cleavage:

Cleavage:

2. What is the approximate hardness of the two minerals on the Mohs scale of hardness?

Halite:

Fluorite:

3. Compare the specific gravity of the two minerals. Which is higher?

4. What is a diagnostic property of halite?

5. What is a diagnostic property of fluorite?

6. How can you distinguish fluorite from quartz? Quartz is a silicate mineral that will be studied in Lab 3. 


\section{Summary}

The topics covered in this chapter can be summarized as follows:

\begin{tabular}{|c|c|}
\hline Section & Summary \\
\hline $\begin{array}{l}2.1 \\
\text { Bonding } \\
\text { and } \\
\text { Lattices }\end{array}$ & $\begin{array}{l}\text { The main types of bonding in minerals are ionic bonding (electrons transferred) and covalent bonding } \\
\text { (electrons shared). Some minerals have metallic bonding or other forms of weak bonding. Minerals form } \\
\text { in specific three-dimensional lattices, and the nature of the lattices and the type of bonding within them } \\
\text { have important implications for mineral properties. }\end{array}$ \\
\hline $\begin{array}{l}2.2 \\
\text { Mineral } \\
\text { Groups }\end{array}$ & $\begin{array}{l}\text { Minerals are grouped according to the anion part of their formula, with some common types being } \\
\text { oxides, sulphides, sulphates, halides, carbonates, phosphates, silicates, and native minerals. }\end{array}$ \\
\hline $\begin{array}{l}2.3 \\
\text { Mineral } \\
\text { Properties }\end{array}$ & $\begin{array}{l}\text { Some of the important properties for mineral identification include hardness, cleavage/fracture, density, } \\
\text { lustre, colour, and streak colour. It's critical to be able to recognize these properties in order to be able } \\
\text { to identify minerals. }\end{array}$ \\
\hline $\begin{array}{l}2.4 \\
\text { Economic } \\
\text { Minerals }\end{array}$ & $\begin{array}{l}\text { Geological resources are critical to our way of life and important to the Canadian economy. Gold, coal, } \\
\text { iron, copper, nickel, and potash are Canada's most valuable mined commodities. The concentrations of } \\
\text { metals in mineral deposits are typically several thousand times higher than those in average rocks, and } \\
\text { such concentrations only form through specific geological processes. Mining involves both surface and } \\
\text { underground methods, but in either case, rock is brought to surface that can react with water and } \\
\text { oxygen to produce acid rock drainage and metal contamination. }\end{array}$ \\
\hline $\begin{array}{l}\text { Lab } 2 \\
\text { Exercises }\end{array}$ & $\begin{array}{l}\text { The best way to learn mineral identification is to practice by examining the mineral samples in your } \\
\text { Mineral Kit } 1 \text { and } 2 \text {. It is important to know all the properties of each mineral in your kits, but especially } \\
\text { the diagnostic properties that are most helpful for identifying each mineral. Remember, different } \\
\text { samples of the same mineral may not always look exactly the same, but their other physical properties } \\
\text { (e.g., hardness, cleavage, lustre) will be consistent. }\end{array}$ \\
\hline
\end{tabular}




\section{LAB 3: SILICATE MINERALS}

\section{Lab Structure}

\begin{tabular}{ll}
\hline Recommended additional work & $\begin{array}{l}\text { Yes - review concepts from Labs 1, } 2 \text { and } 3 \text { in preparation } \\
\text { for Test 1 }\end{array}$ \\
Required materials & Mineral ID kit, Mineral Kits 1 and 2, pencil \\
\hline
\end{tabular}

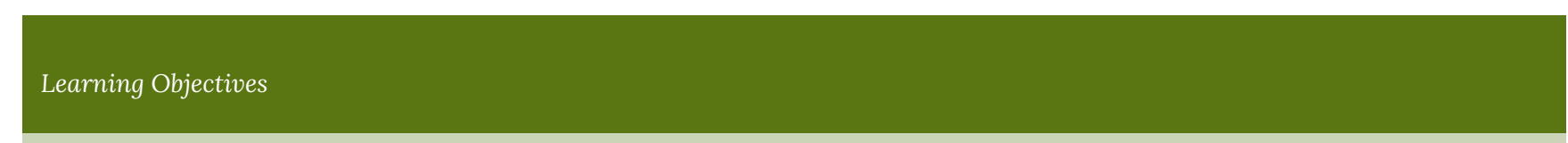

After carefully reading this section, completing the exercises within it, and answering the questions at the end, you should be able to:

- $\quad$ Describe a silica tetrahedron and the ways in which tetrahedra combine to make silicate minerals.

- $\quad$ Differentiate between ferromagnesian and other silicate minerals.

- Identify and describe the physical properties of a range of silicate minerals in hand sample, and how these properties are used to identify minerals.

Key Terms

- Isolated silicate

- Single chain silicate

- Double chain silicate

- Phyllosilicate (sheet silicate)

- Framework silicate

- Colour

- Streak
- Lustre

- Hardness

- Crystal habit

- Cleavage

- Fracture

- Conchoidal fracture

- Specific gravity 


\section{I Silicate Mineral Groups}

The vast majority of the minerals that make up the rocks of Earth's crust are silicate minerals. These include minerals such as quartz, feldspar, mica, amphibole, pyroxene, olivine, and a variety of clay minerals. The building block of all of these minerals is the silica tetrahedron, a combination of four oxygen atoms and one silicon atom that form a four-sided pyramid shape with $\mathrm{O}$ at each corner and $\mathrm{Si}$ in the middle (Figure 3.1.1). The bonds in a silica tetrahedron have some of the properties of covalent bonds and some of the properties of ionic bonds. As a result of the ionic character, silicon
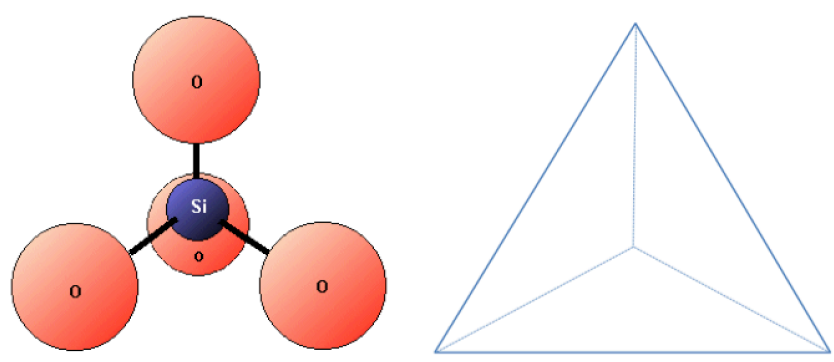

Figure 3.1.1: The silica tetrahedron, the building block of all silicate minerals. (Because the silicon ion has a charge of +4 and the four oxygen ions each have a charge of -2 , the silica tetrahedron has a net charge of -4.) becomes a cation (with a charge of +4 ) and oxygen becomes an anion (with a charge of -2 ). The net charge of a silica tetrahedron $\left(\mathrm{SiO}_{4}\right)$ is: $4+4(-2)=4-8=-4$. As we will see later, silica tetrahedra (plural of tetrahedron) link together in a variety of ways to form most of the common minerals of the crust.

What's with all of these "sili" names?

The element silicon (Si) is one of the most important geological elements and is the second-most abundant element in Earth's crust (after oxygen). Silicon bonds readily with oxygen to form a silica tetrahedron (Figure 3.1.1). Pure silicon crystals (created in a lab) are used to make semi-conductive media for electronic devices. A silicate mineral is one in which silicon and oxygen are present as silica tetrahedra. Silica also refers to a chemical component of a rock and is expressed as $\% \mathrm{SiO}_{2}$. The mineral quartz is made up entirely of silica tetrahedra, and some forms of quartz are also known as "silica". Silicone is a synthetic product (e.g., silicone rubber, resin, or caulking) made from silicon-oxygen chains and various organic molecules. To help you keep the "sili" names straight, here is a summary table:

Table 3.1 Summary of "Sili" names

\begin{tabular}{|l|l|}
\hline "Sili" name & Definition \\
\hline Silicon & The $14^{\text {th }}$ element on the periodic table ( $\left.\mathrm{Si}\right)$ \\
\hline Silicon wafer & A crystal of pure silicon sliced very thinly and used for electronics \\
\hline $\begin{array}{c}\text { Silica } \\
\text { tetrahedron }\end{array}$ & A combination of one silicon atom and four oxygen atoms that form a tetrahedron \\
\hline \% silica & The proportion of a rock that is composed of the component $\mathrm{SiO}_{2}$ \\
\hline Silica & A solid made out of $\mathrm{SiO}_{2}$ (but not necessarily a mineral - e.g., opal) \\
\hline Silicate & A mineral that contains silica tetrahedra (e.g., quartz, feldspar, mica, olivine) \\
\hline Silicone & A flexible synthetic material made up of Si-O chains with attached organic molecules \\
\hline
\end{tabular}

In silicate minerals, these tetrahedra are arranged and linked together in a variety of ways, from single units 
to complex frameworks (Table 3.2). The simplest silicate structure, that of the mineral olivine, is composed of isolated tetrahedra bonded to iron and/or magnesium ions. In olivine, the -4 charge of each silica tetrahedron is balanced by two divalent (i.e., +2) iron or magnesium cations. Olivine can be either $\mathrm{Mg}_{2} \mathrm{SiO}_{4} \mathrm{Or}$ $\mathrm{Fe}_{2} \mathrm{SiO}_{4}$, or some combination of the two $(\mathrm{Mg}, \mathrm{Fe})_{2} \mathrm{SiO}_{4}$. The divalent cations of magnesium and iron are quite close in radius $\left(0.73\right.$ versus 0.62 angstroms $\left.{ }^{1}\right)$. Because of this size similarity, and because they are both divalent cations (both can have a charge of +2 ), iron and magnesium can readily substitute for each other in olivine and in many other minerals.

Recall that for non-silicate minerals, we classified minerals into groups according to their anion or anionic group. For silicate minerals, we group minerals based on their silicate structure into groups called: isolated, pair, ring, single chain, double chain, sheet, and framework silicates. In this course, we will focus on just the isolated, single chain, double chain, sheet, and framework silicates. 
Table 3.2 Silicate mineral configurations. The triangles represent silica tetrahedra.

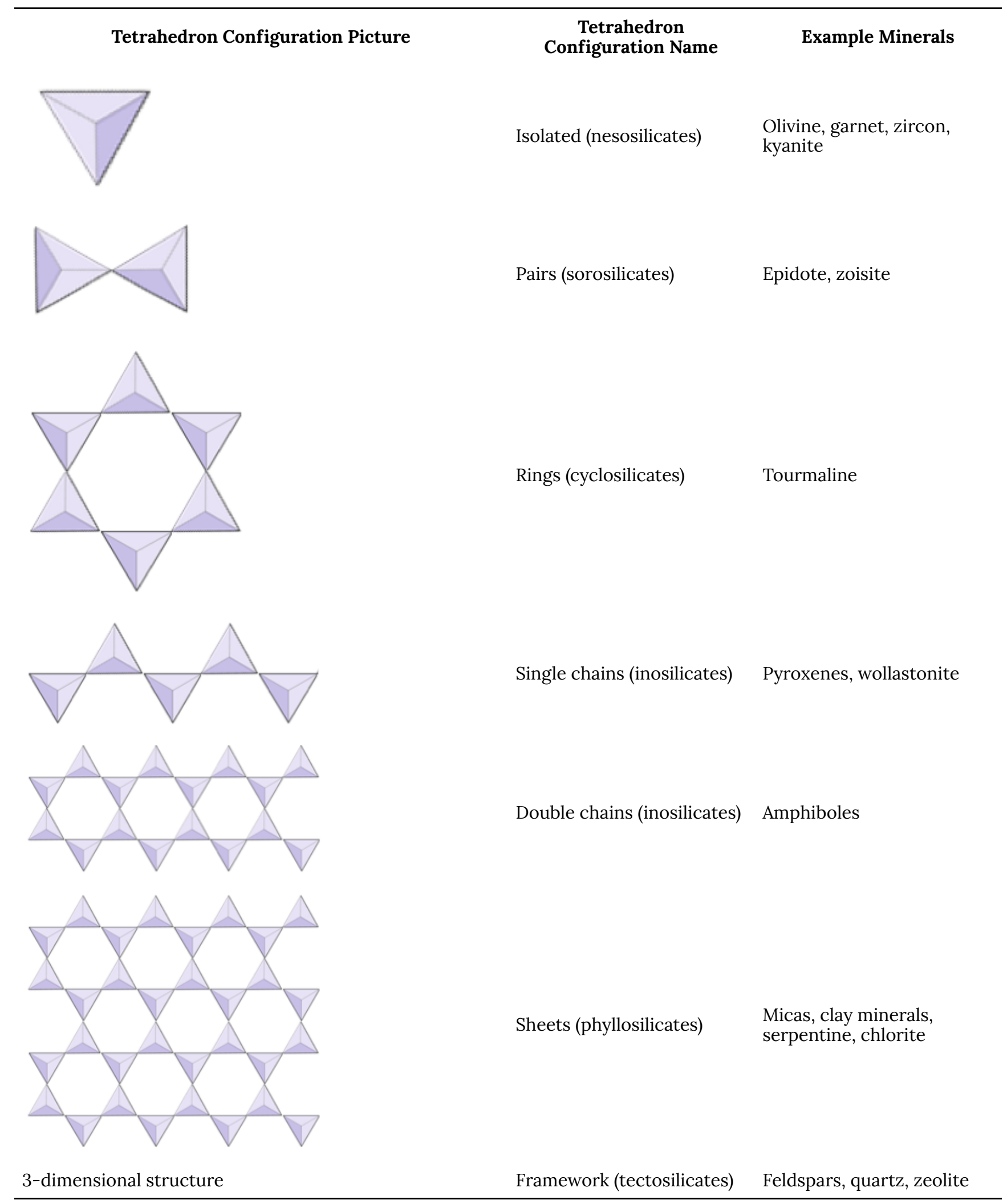

In olivine, unlike most other silicate minerals, the silica tetrahedra are not bonded to each other. Instead they are bonded to the iron and/or magnesium ions, in the configuration shown on Figure 3.1.2. 


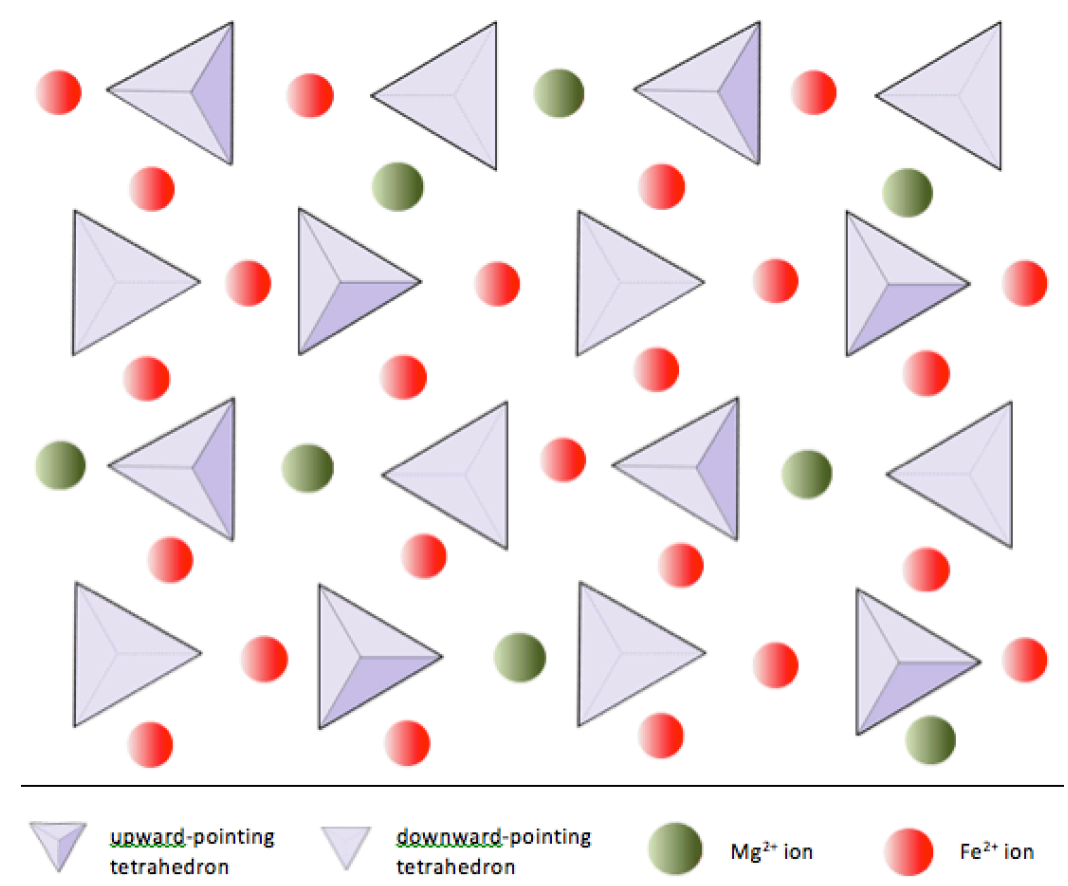

Figure 3.1.2: A depiction of the structure of olivine as seen from above. The formula for this particular olivine, which has three Fe ions for each $\mathrm{Mg}$ ion, could be written: $\mathrm{Mg}_{0.5} \mathrm{Fe}_{1.5} \mathrm{SiO}_{4}$.

As already noted, the 2 ions of iron and magnesium are similar in size (although not quite the same). This allows them to substitute for each other in some silicate minerals. In fact, the ions that are common in silicate minerals have a wide range of sizes, as depicted in Figure 3.1.3. All of the ions shown are cations, except for oxygen. Note that iron can exist as both $\mathrm{a}+2$ ion (if it loses two electrons during ionization) or a +3 ion (if it loses three). $\mathrm{Fe}^{2+}$ is known as ferrous iron. $\mathrm{Fe}^{3+}$ is known as ferric iron. Ionic radii are critical to the composition of silicate minerals, so we'll be referring to this diagram again.

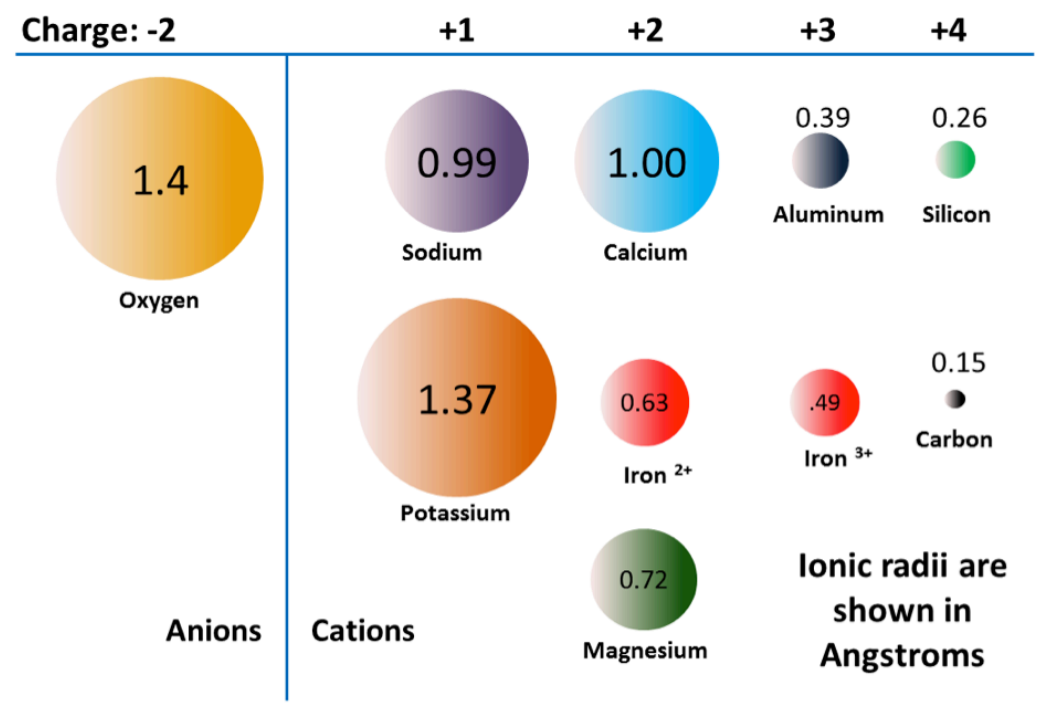

Figure 3.1.3: The ionic radii (effective sizes) in angstroms, of some of the common ions in silicate minerals. 
The structure of the single-chain silicate pyroxene is shown on Figures 3.1.4 and 3.1.5. In pyroxene, silica tetrahedra are linked together in a single chain, where one oxygen ion from each tetrahedron is shared with the adjacent tetrahedron, hence there are fewer oxygens in the structure. The result is that the oxygen-tosilicon ratio is lower than in olivine (3:1 instead of 4:1), and the net charge per silicon atom is less (-2 instead of -4). Therefore, fewer cations are necessary to balance that charge. The structure of pyroxene is more "permissive" than that of olivine-meaning that cations with a wider range of ionic radii can fit into it. That's why pyroxenes can have iron (radius $0.63 \AA$ ) or magnesium (radius $0.72 \AA$ ) or calcium (radius $1.00 \AA$ ) cations (see Figure 3.1.3 above). Pyroxene compositions are of the type $\mathrm{MgSiO}_{3}, \mathrm{FeSiO}_{3}$, and $\mathrm{CaSiO}_{3}$, or some combination of these, written as $(\mathrm{Mg}, \mathrm{Fe}, \mathrm{Ca}) \mathrm{SiO}_{3}$, where the elements in the brackets can be present in any proportion.

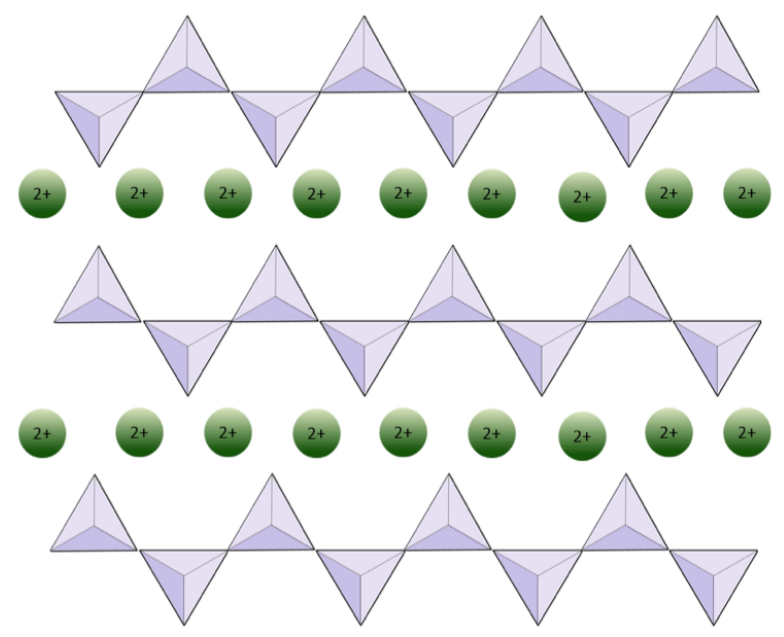

Figure 3.1.4: A depiction of the structure of pyroxene. The tetrahedral chains continue to left and right and each is interspersed with a series of divalent cations. If these are $\mathrm{Mg}$ ions, then the formula is $\mathrm{MgSiO}_{3}$.
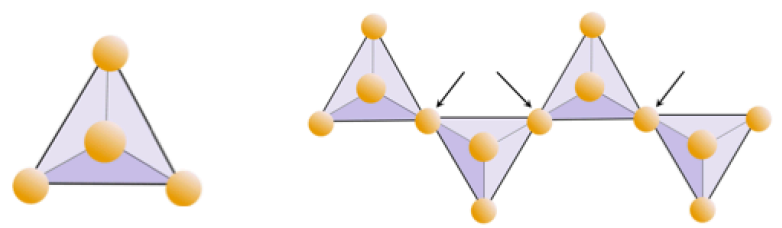

Figure 3.1.5: A single silica tetrahedron (left) with four oxygen ions per silicon ion $\left(\mathrm{SiO}_{4}\right)$. Part of a single chain of tetrahedra (right), where the oxygen atoms at the adjoining corners are shared between two tetrahedra (arrows). For a very long chain the resulting ratio of silicon to oxygen is 1 to $3\left(\mathrm{SiO}_{3}\right)$.

In amphibole structures, the silica tetrahedra are linked in a double chain that has an oxygen-to-silicon ratio lower than that of pyroxene, and hence still fewer cations are necessary to balance the charge. Amphibole is even more permissive than pyroxene and its compositions can be very complex. Hornblende, for example, can include sodium, potassium, calcium, magnesium, iron, aluminum, silicon, oxygen, fluorine, and the hydroxyl ion $\left(\mathrm{OH}^{-}\right)$.

In mica minerals, the silica tetrahedra are arranged in continuous sheets. There is even more sharing of oxygens between adjacent tetrahedra and hence fewer cations are needed to balance the charge of the silica-tetrahedra structure in sheet silicate minerals. Bonding between sheets is relatively weak, and this 
accounts for the well-developed one-directional cleavage in micas. Biotite mica can have iron and/or magnesium in it and that makes it a ferromagnesian silicate mineral (like olivine, pyroxene, and amphibole). Chlorite is another similar mineral that commonly includes magnesium. In muscovite mica, the only cations present are aluminum and potassium; hence it is a non-ferromagnesian silicate mineral.

Apart from muscovite, biotite, and chlorite, there are many other sheet silicates (a.k.a. phyllosilicates), many of which exist as clay-sized fragments (i.e., less than 0.004 millimetres). These include the clay minerals kaolinite, illite, and smectite, and although they are difficult to study because of their very small size, they are extremely important components of rocks and especially of soils.

Silica tetrahedra are bonded in three-dimensional frameworks in both the feldspars and quartz. These are non-ferromagnesian minerals - they don't contain any iron or magnesium. In addition to silica tetrahedra, feldspars include the cations aluminum, potassium, sodium, and calcium in various combinations. Quartz contains only silica tetrahedra.

The three main feldspar minerals are potassium feldspar, (a.k.a. K-feldspar or K-spar) and two types of plagioclase feldspar: albite (sodium only) and anorthite (calcium only). As is the case for iron and magnesium in olivine, there is a continuous range of compositions (solid solution series) between albite and anorthite in plagioclase. Because the calcium and sodium ions are almost identical in size (1.00 ̊ versus $0.99 \AA)$ any intermediate compositions between $\mathrm{CaAl}_{2} \mathrm{Si}_{3} \mathrm{O}_{8}$ and $\mathrm{NaAlSi}_{3} \mathrm{O}_{8}$ can exist (Figure 3.1.6).

The intermediate-composition plagioclase feldspars are oligoclase $(10 \%$ to $30 \% \mathrm{Ca})$, andesine $(30 \%$ to $50 \% \mathrm{Ca}$ ), labradorite (50\% to $70 \% \mathrm{Ca}$ ), and bytownite (70\% to $90 \% \mathrm{Ca})$. Potassium feldspar $\left(\mathrm{KAlSi}_{3} \mathrm{O}_{8}\right)$ has a slightly different structure than that of plagioclase, owing to the larger size of the potassium ion (1.37 $\AA$ ) and because of this large size, potassium and sodium do not readily substitute for each other, except at high temperatures. These high-temperature feldspars are likely to be found only in volcanic rocks because intrusive igneous rocks cool slowly enough to low temperatures for the feldspars to change into one of the lower-temperature forms.

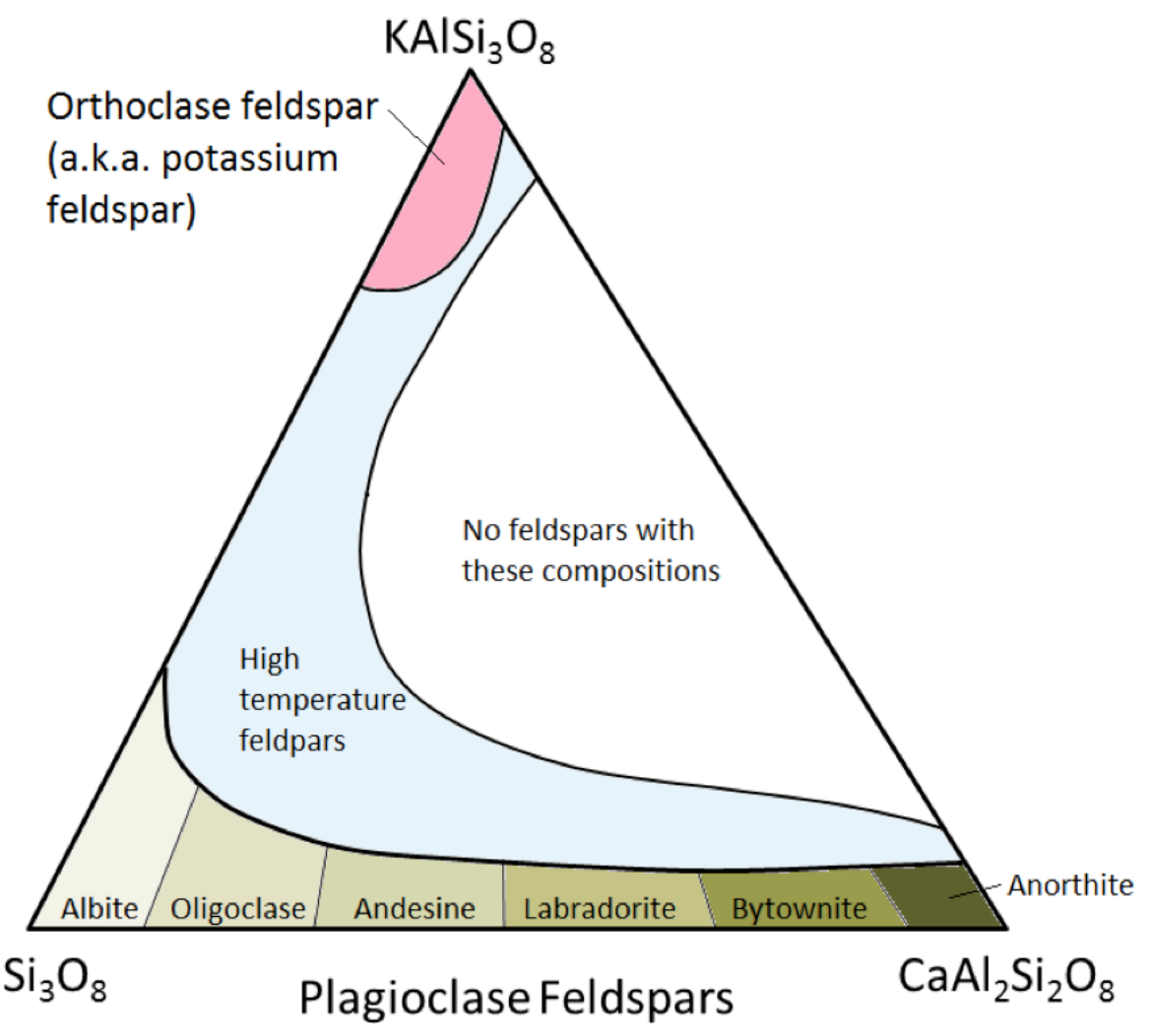

Figure 3.1.6: Compositions of the feldspar minerals. 
The names "pyroxene", "amphibole", "mica", and "feldspar" can be confusing at first, as these are technically names of mineral "families" and not names of a specific mineral. Minerals within the same family tend to share common structures, but each individual mineral is distinguished by its chemical formula. In the examples below the mineral names are bolded.

- $\quad$ One type of pyroxene mineral that you will see in this course is called augite $\left((\mathrm{Ca}, \mathrm{Na})(\mathrm{Mg}, \mathrm{Fe}, \mathrm{Al}, \mathrm{Ti})(\mathrm{Si}, \mathrm{Al})_{2} \mathrm{O} 6\right)$. Augite is one of many minerals within the pyroxene family.

- $\quad$ One of the most common amphibole minerals is called hornblende $\left((\mathrm{Ca}, \mathrm{Na})_{2}(\mathrm{Mg}, \mathrm{Fe}, \mathrm{Al})_{5}(\mathrm{Al}, \mathrm{Si})_{8} \mathrm{O}_{22}(\mathrm{OH})_{2}\right)_{\text {, }}$ which is just one of many minerals within the amphibole family.

- Two common minerals from the mica family that you will see in this course are biotite $\left(\mathrm{K}(\mathrm{Mg}, \mathrm{Fe})_{3} \mathrm{AlSi}_{3} \mathrm{O}_{10}(\mathrm{OH})_{2}\right)$ and muscovite $\left(\mathrm{KAl}_{2}\left(\mathrm{AlSi}_{3} \mathrm{O}_{10}(\mathrm{~F}, \mathrm{OH})_{2}\right)\right.$.

- $\quad$ Three feldspar minerals you will encounter in this course are potassium feldspar $\left(\mathrm{KAlSi}_{3} \mathrm{O}_{8}\right)$, albite $\left(\mathrm{NaAlSi}_{3} \mathrm{O}_{8}\right)$, and labradorite $\left((\mathrm{Ca}, \mathrm{Na})(\mathrm{Al}, \mathrm{Si})_{4} \mathrm{O}_{8}\right)$.

In quartz $\left(\mathrm{SiO}_{2}\right)$, the silica tetrahedra are bonded in a "perfect" three-dimensional framework. Since in every silica tetrahedron one silicon cation has a +4 charge and the two oxygen anions each have a -2 charge, the charge is balanced. There is no need for aluminum or any of the other cations such as sodium or potassium. The hardness and lack of cleavage in quartz result from the strong bonds characteristic of the silica tetrahedron.

Practice Exercise 3.1 Ferromagnesian silicates?

Silicate minerals are classified as being either ferromagnesian or non-ferromagnesian depending on whether or not they have iron (Fe) and/or magnesium (Mg) in their formula. A number of minerals and their formulas are listed below. For each one, indicate whether or not it is a ferromagnesian silicate.

\begin{tabular}{|l|l|l|}
\hline Mineral & Formula & Ferromagnesian silicate? \\
\hline olivine & $(\mathrm{Mg}, \mathrm{Fe})_{2} \mathrm{SiO}_{4}$ &. \\
\hline pyrite & $\mathrm{FeS}_{2}$ &. \\
\hline plagioclase feldspar & $\mathrm{CaAl}_{2} \mathrm{Si}_{2} \mathrm{O}_{8}$ &. \\
\hline pyroxene & $\mathrm{MgSiO}_{3}$ &. \\
\hline hematite & $\mathrm{Fe}_{2} \mathrm{O}_{3}$ &. \\
\hline orthoclase feldspar & $\mathrm{KAlSiO}_{3}$ &. \\
\hline quartz & $\mathrm{SiO}_{2}$ &. \\
\hline
\end{tabular}

See Appendix 2 for Practice Exercise 3.1 answers.*Some of the formulas, especially the more complicated ones, have been simplified. 


\section{Media Attributions}

- Figures 3.1.1, 3.1.2, 3.1.3, 3.1.4, 3.1.5, 3.1.6: @ Steven Earle. CC BY.

\section{Notes}

1. An angstrom is the unit commonly used for the expression of atomic-scale dimensions. One angstrom is $10^{-10} \mathrm{metres}$ or 0.0000000001 metres. The symbol for an angstrom is $\AA$. 


\section{Lab 3 Exercises}

The exercises below will guide you through the silicate mineral samples in Mineral Kits 1 and 2. Review the physical properties of minerals presented in Chapter 2.3 before you begin these exercises. You may wish to consult the mineral identification tables at the back of this manual as you complete the exercises below. Note that all silicate minerals have non-metallic lustre. As you are observing the following samples keep in mind you have to classify the lustre using more descriptive terms such as vitreous, earthy or dull, pearly, satiny, etc. Remember: you must be able to identify all the physical properties of each mineral, not just the diagnostic properties.

\section{Silicate Mineral Group: Framework Silicates}

1. Examine samples M221, M223, and M225. All of these samples are varieties of the same mineral. Name the mineral:

2. Describe the cleavage or fracture exhibited in these samples:

3. How can you distinguish between a cleavage plane and a crystal face?

4. Test all four minerals for hardness. What is the hardness of quartz?

5. Describe the lustre of the samples.

6. What is a diagnostic property of quartz?

7. Sample M225 is flint, an example of microcrystalline quartz that is always grey to black in colour. Do the diagnostic properties for quartz apply to flint as well?

\section{Feldspars}

\section{Sample M201}

Sample M202

Sample M211
Mineral name:

Mineral name:

Mineral name:

You have a pink/salmon coloured sample and a white sample of potassium feldspar (K-feldspar). A pink feldspar will always be K-feldspar, and may show exsolution lamellae. A white feldspar may be K-feldspar or plagioclase feldspar (albite). If you have a white K-feldspar and a white plagioclase feldspar look for stria- 
tions on the plagioclase feldspar and that will differentiate them. The dark plagioclase feldspar (labradorite) will exhibit striations and has diagnostic iridescence.

1. Examine all your K-feldspar and plagioclase feldspars. These minerals are all feldspars however, we will refer to them by their mineral names and classify them as framework silicates. Test each sample for hardness:

Sample M201

Sample M202

Sample M211

\section{Hardness:}

Hardness:

Hardness:

2. Describe the cleavage exhibited by these samples:

3. Looking at M201 and M211, do either of these samples exhibit striations? Do either of the samples exhibit iridescence?

4. How can you distinguish between K-feldspar and plagioclase feldspar?

\section{Silicate Mineral Group: Sheet Silicates (phyllosilicates)}

\section{Sample M121}

Sample M271
Mineral name:

Mineral name:

1. Describe the cleavage of these two minerals:

2. What is the hardness of these two minerals?

3. What is a diagnostic property of mica minerals?

4. How can you distinguish between muscovite and biotite?

\section{Sample M281}

Mineral name:

5. What is the hardness of the sample?

6. Describe the lustre of this mineral:

7. What is a diagnostic property of talc? 
8. Describe the lustre of this mineral:

9. What is a diagnostic property of kaolinite?

\section{Silicate Mineral Group: Single Chain Silicates}

Single chain silicates include the pyroxene family of minerals. There is one pyroxene (augite) in the mineral kit and the samples vary in colour.

1. Describe the cleavage of the pyroxene:

2. What is the colour of this mineral?

3. What is a diagnostic property of pyroxene?

\section{Silicate Mineral Group: Double Chain Silicates}

Double chain silicates include the amphibole family of minerals. There is one amphibole (hornblende) in the mineral kit and the samples vary in colour.

\section{Sample M111}

Mineral name:

1. Describe the cleavage of hornblende:

2. What is the colour of this mineral?

3. What is a diagnostic property of hornblende?

\section{Silicate Mineral Group: Isolated Silicates}

\section{Sample M131}

Mineral name:

The garnet family also contains various kinds of garnet. The most common is almandine, a dark ruby red coloured garnet.

1. Do you see any crystal faces on your sample?

2. What is the hardness of the sample?

3. What is the lustre of garnet?

4. What is a diagnostic property of garnet? 
Olivine is an igneous mineral that is green, one of the few minerals that can be identified by colour. The samples of olivine in your kit are actually samples of an ultramafic igneous rock composed of many small crystals of olivine.

5 . What is the hardness of olivine?

6. Describe the feel of the sample:

7. What is a diagnostic property of olivine? 


\section{Summary}

The topics covered in this chapter can be summarized as follows:

\section{Section Summary}

3.1 Silicate minerals are, by far, the most important minerals in Earth's crust. They all include silica

Silicate tetrahedra (four oxygens surrounding a single silicon atom) arranged in different structures (chains,

Minerals sheets, etc.). Some silicate minerals include iron or magnesium and are called ferromagnesian silicates.

The best way to learn mineral identification is to practice by examining the mineral samples in your

Lab 3 Mineral Kit 1 and 2. It is important to know all the properties of each mineral in your kits, but especially

Exercises the diagnostic properties that are most helpful for identifying each mineral. Remember, different samples of the same mineral may not always look exactly the same, but their other physical properties (e.g, hardness, cleavage, lustre) will be consistent. 


\section{LAB 4: IGNEOUS ROCKS}

\section{Lab Structure}

Recommended additional work

Required materials
None

Mineral ID kit, Rock Kits 1 and 2, pencil

Learning Objectives

After carefully reading this chapter, completing the exercises within it, and answering the questions at the end, you should be able to:

- Describe, in general terms, the range of chemical compositions of magmas.

- Discuss the processes that take place during the cooling and crystallization of magma, and the typical order of mineral crystallization according to the Bowen reaction series.

- Describe the origins of phaneritic, porphyritic, and vesicular rock textures.

- Apply the criteria for igneous rock classification based on mineral proportions.

- Use observations of mineralogy and texture to correctly identify and name an igneous rock.

Key Terms

- Magma

- Lava

- Partial melting

- Crystallization

- Intrusive

- Extrusive

- Felsic

- Intermediate

- Mafic
- Ultramafic

- Phaneritic

- Aphanitic

- Porphyritic

- Vesicular

- Glassy

- Phenocrysts

- Groundmass

A rock is a consolidated mixture of minerals. By consolidated, we mean hard and strong; real rocks don't fall apart in your hands! A mixture of minerals implies the presence of more than one mineral grain, but not necessarily more than one type of mineral. A rock can be composed of only one type of mineral (e.g., limestone is commonly made up of only calcite), but most rocks are composed of several different minerals. A rock can also include non-minerals, such as fossils or the organic matter within a coal bed or in some types of mudstone.

Rocks are grouped into three main categories based on how they form: 
1. Igneous: formed from the cooling and crystallization of magma (molten rock)

2. Sedimentary: formed when weathered fragments of other rocks are buried, compressed, and cemented together, or when minerals precipitate directly from solution

3. Metamorphic: formed by alteration (due to heat, pressure, and/or chemical action) of a pre-existing igneous or sedimentary rock

For the next few weeks you will learn about each of these categories of rock in the lab, beginning with igneous rocks in Lab 4. You will practice identifying minerals and textures, and you will use your observations to classify samples of rocks. Finally, by Lab 6, you will use the processes of the rock cycle to link all three categories of rocks together. 


\section{I Magma and Magma Formation}

Magmas can vary widely in composition, but in general they are made up of only eight elements; in order of importance: oxygen, silicon, aluminum, iron, calcium, sodium, magnesium, and potassium (Figure 4.1.1). Oxygen, the most abundant element in magma, comprises a little less than half the total, followed by silicon at just over one-quarter. The remaining elements make up the other one-quarter. Magmas derived from crustal material are dominated by oxygen, silicon, aluminum, sodium, and potassium.

The composition of magma depends on the rock it was formed from (by melting), and the conditions of that melting. Magmas derived from the mantle have higher levels of iron, magnesium, and calcium, but they are still likely to be dominated by oxygen and silicon. All magmas have varying proportions of elements such as hydrogen, carbon, and sulphur, which are converted into gases like water vapour, carbon dioxide, and hydrogen sulphide as the magma cools.

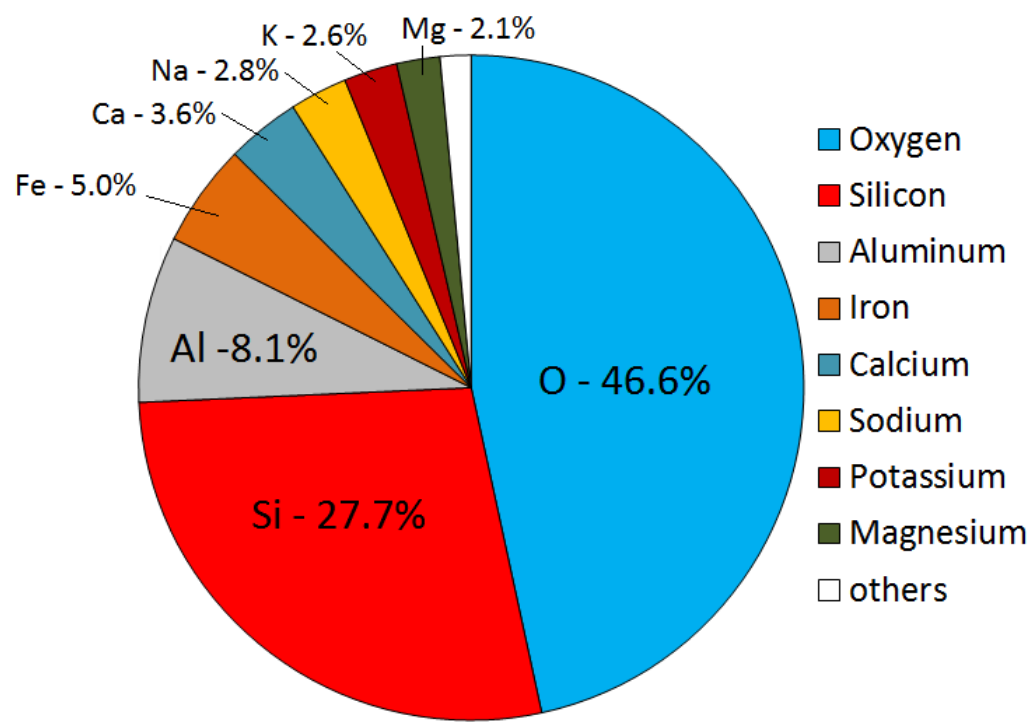

Figure 4.1.1: Average elemental proportions in Earth's crust, which is close to the average composition of magmas within the crust. [Image Description]

Virtually all of the igneous rocks that we see on Earth are derived from magmas that formed from partial melting of existing rock, either in the upper mantle or the crust. Partial melting is what happens when only some parts of a rock melt; it takes place because rocks are not pure materials. Most rocks are made up of several minerals, each of which has a different melting temperature. The wax in a candle is a pure material. If you put some wax into a warm oven $\left(50^{\circ} \mathrm{C}\right.$ will do as the melting temperature of most wax is about $40^{\circ} \mathrm{C}$ ) and leave it there for a while, it will soon start to melt. That's complete melting, not partial melting. If instead you took a mixture of wax, plastic, aluminum, and glass and put it into the same warm oven, the wax would soon start to melt, but the plastic, aluminum, and glass would not melt (Figure 4.1.2a). That's partial melting and the result would be solid plastic, aluminum, and glass surrounded by liquid wax (Figure 4.1.2b). If we heat the oven up to around $120^{\circ} \mathrm{C}$, the plastic would melt too and mix with the liquid wax, but the aluminum and glass would remain solid (Figure 4.1.2c). Again this is partial melting. If we separated the wax/ plastic "magma" from the other components and let it cool, it would eventually harden. As you can see from Figure 4.1.2d, the liquid wax and plastic have mixed, and on cooling, have formed what looks like a single 
solid substance. It is most likely that this is a very fine-grained mixture of solid wax and solid plastic, but it could also be some other substance that has formed from the combination of the two.
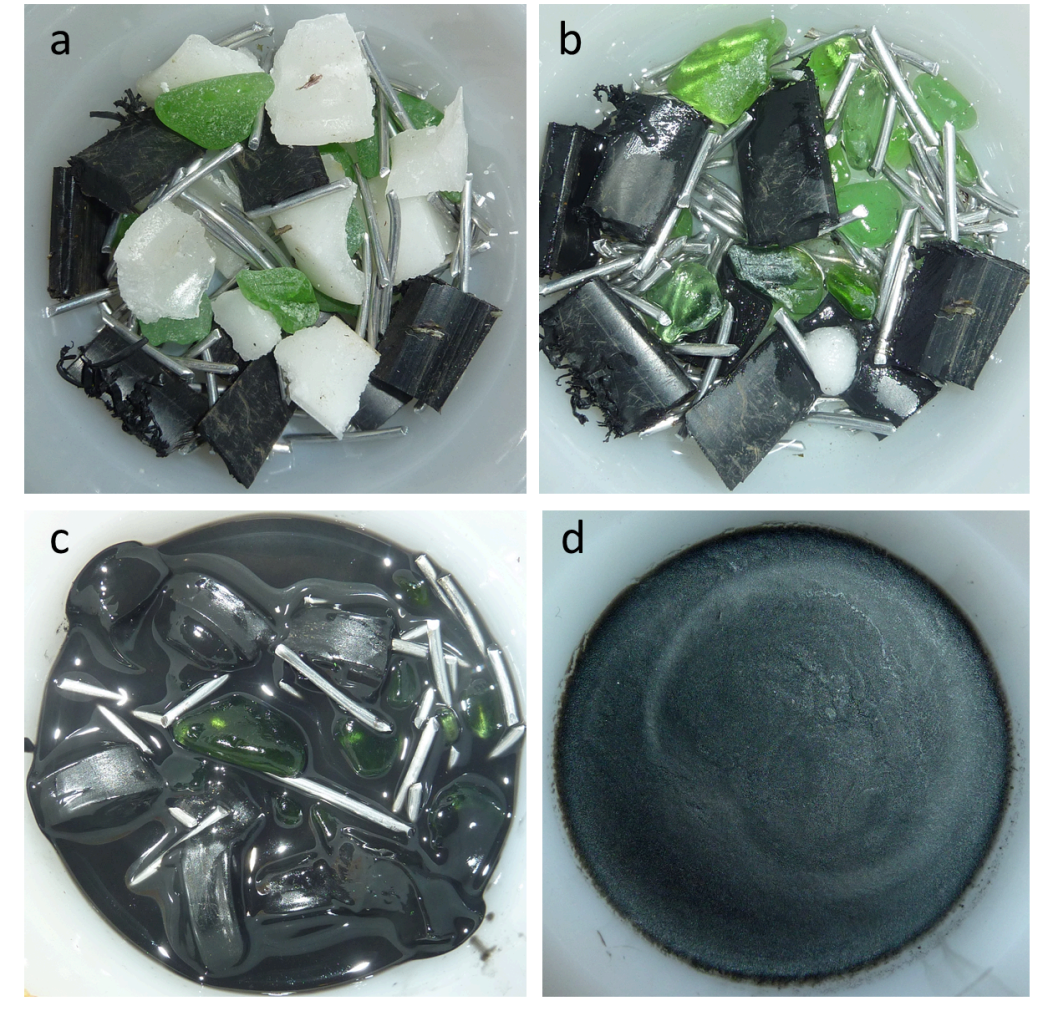

Figure 4.1.2: Partial melting of "pretend rock": (a) the original components of white candle wax, black plastic pipe, green beach glass, and aluminum wire, (b) after heating to $50^{\circ} \mathrm{C}$ for 30 minutes only the wax has melted, (c) after heating to $120^{\circ} \mathrm{C}$ for 60 minutes much of the plastic has melted and the two liquids have mixed, (d) the liquid has been separated from the solids and allowed to cool to make a "pretend rock" with a different overall composition.

In this example, we partially melted some pretend rock to create some pretend magma. We then separated the magma from the source and allowed it to cool to make a new pretend rock with a composition quite different from the original material (it lacks glass and aluminum).

Of course partial melting in the real world isn't exactly the same as in our pretend-rock example. The main differences are that rocks are much more complex than the four-component system we used, and the mineral components of most rocks have more similar melting temperatures, so two or more minerals are likely to melt at the same time to varying degrees. Another important difference is that when rocks melt, the process takes thousands to millions of years, not the 90 minutes it took in the pretend-rock example.

Contrary to what one might expect, and contrary to what we did to make our pretend rock, most partial melting of real rock does not involve heating the rock up. The two main mechanisms through which rocks melt are decompression melting and flux melting. Decompression melting takes place within Earth when a body of rock is held at approximately the same temperature but the pressure is reduced. Flux melting is facilitated by the addition of a flux (typically water and other volatiles) that lowers the melting point of the rock.

The partial melting of rock happens in a wide range of situations, most of which are related to plate tectonics. The more important of these are shown in Figure 4.1.3. Decompression melting occurs when rock is being moved toward the surface, either at a mantle plume, or in the upwelling part of a mantle convection 
cell (e.g., at a spreading centre formed at a divergent plate boundary, like a mid-ocean ridge). At subduction zones, water from the wet, subducting oceanic crust is transferred into the overlying hot mantle. This provides the flux needed to lower the melting temperature. In both of these cases, only partial melting takes place-typically only about $10 \%$ of the rock melts-and it is always the most silica-rich components of the rock that melt, creating a magma that is more silica-rich than the rock from which it is derived. (By analogy, the melt from our pretend rock is richer in wax and plastic than the "rock" from which it was derived.) The magma produced, being less dense than the surrounding rock, moves up through the mantle, and eventually into the crust.

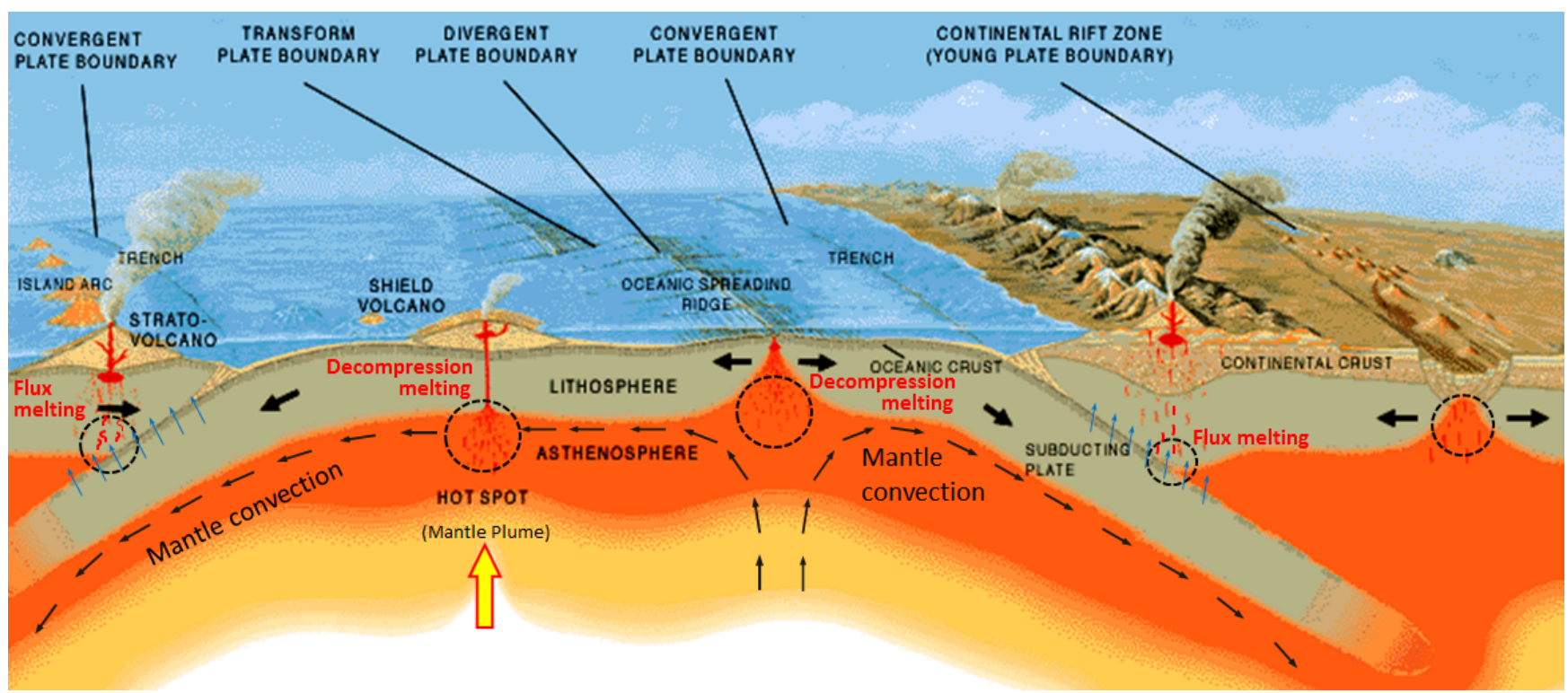

Figure 4.1.3: Common sites of magma formation in the upper mantle. The black circles are regions of partial melting. The blue arrows represent water being transferred from the subducting plates into the overlying mantle.

As it moves toward the surface, and especially when it moves from the mantle into the lower crust, the hot magma interacts with the surrounding rock. This typically leads to partial melting of the surrounding rock because most such magmas are hotter than the melting temperature of crustal rock. (In this case, melting is caused by an increase in temperature.) Again, the more silica-rich parts of the surrounding rock are preferentially melted, and this contributes to an increase in the silica content of the magma.

At very high temperatures (over $1300^{\circ} \mathrm{C}$ ), most magma is entirely liquid because there is too much energy for the atoms to bond together. As the temperature drops, usually because the magma is slowly moving upward, things start to change. Silicon and oxygen combine to form silica tetrahedra, and then, as cooling continues, the tetrahedra start to link together to make chains (polymerize). These silica chains have the important effect of making the magma more viscous (less runny), which has significant implications for volcanic eruptions. As the magma continues to cool, crystals start to form.

\section{Image Descriptions}

Figure 4.1.1 image description: The average elemental proportions in the Earth's crust from the largest amount to the smallest amount. Oxygen (46.6\%), Silicon (27.7\%), Aluminum (8.1\%), Iron (5.0\%), Calcium (3.6\%), Sodium (2.8\%), Potassium (2.6\%), Magnesium (2.1\%), Others (1.5\%). [Return to Figure 4.1.1] 


\section{Media Attributions}

- Figure 4.1.1, 4.1.2: (C) Steven Earle. CC BY.

- Figure 4.1.3: "Cross section" by José F. Vigil from This Dynamic Planet - a wall map produced jointly by the U.S. Geological Survey, the Smithsonian Institution, and the U.S. Naval Research Laboratory.

Adapted by Steven Earle. Public domain. 


\subsection{Crystallization of Magma}

The minerals that make up igneous rocks crystallize at a range of different temperatures. This explains why a cooling magma can have some crystals within it and yet remain predominantly liquid. The sequence in which minerals crystallize from a magma is known as the Bowen Reaction Series (Figures 4.2 .1 and 4.2.2).

Of the common silicate minerals, olivine normally crystallizes first, at between $1200^{\circ}$ and $1300^{\circ} \mathrm{C}$. As the temperature drops, and assuming that some silica remains in the magma, the olivine crystals will react (combine) with some of the silica in the magma to form pyroxene. As long as there is silica remaining and the rate of cooling is slow, this process continues down the discontinuous branch: olivine to pyroxene, pyroxene to amphibole, and (under the right conditions) amphibole to biotite.

At about the point where pyroxene begins to crystallize, plagioclase feldspar also begins to crystallize. At that temperature, the plagioclase is calcium-rich (anorthite) (see Figure 3.1.6). As the temperature drops, and providing that there is sodium left in the magma, the plagioclase that forms is a more sodium-rich variety (e.g., albite).

Finally, if the magma is quite silica-rich to begin with, there will still be some left at around $750^{\circ}$ to $800^{\circ} \mathrm{C}$, and from this last magma, potassium feldspar, quartz, and maybe muscovite will form.

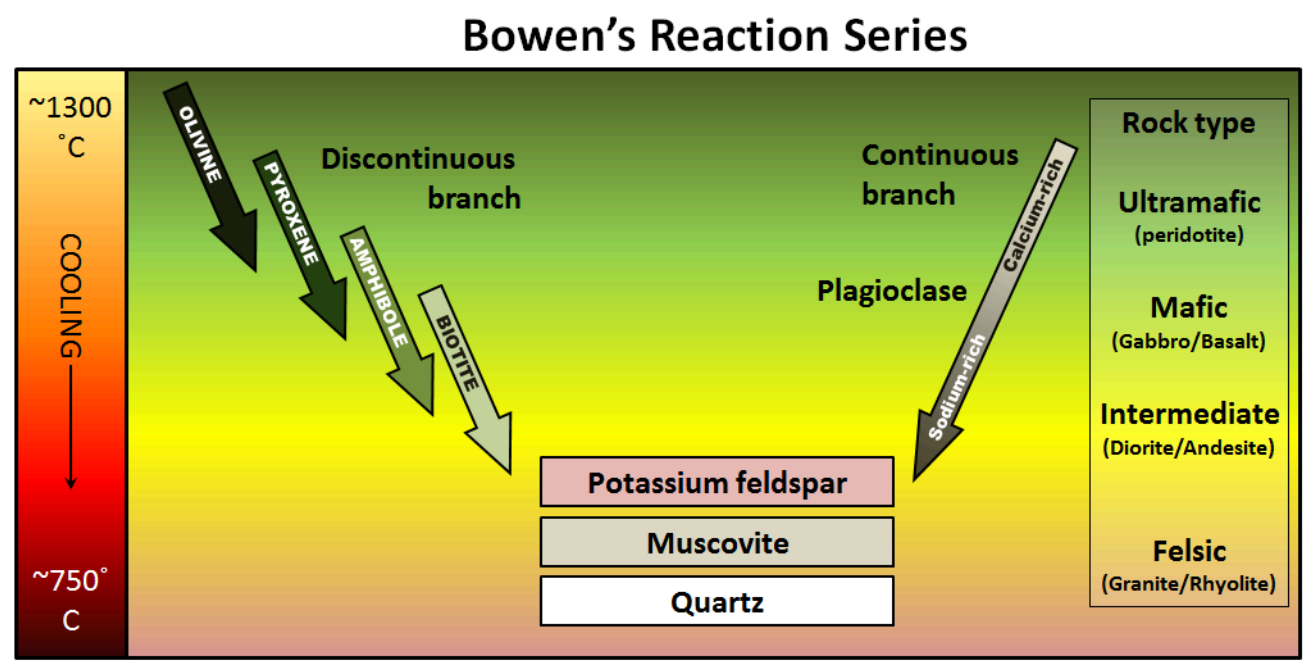

Figure 4.2.1: The Bowen reaction series describes the process of magma crystallization.

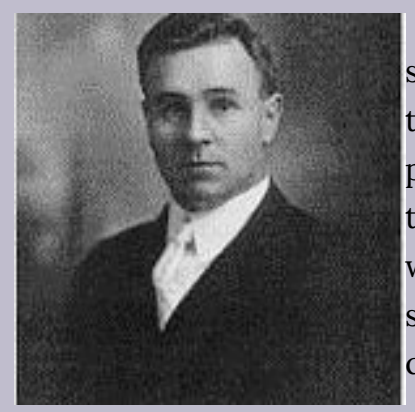

Norman Levi Bowen, born in Kingston, Ontario, studied geology at Queen's University and then at MIT in Boston. In 1912, he joined the Carnegie Institution in Washington, D.C., where he carried out groundbreaking experimental research into the processes of cooling magmas. Working mostly with basaltic magmas, he determined the order of crystallization of minerals as the temperature drops. The method, in brief, was to melt the rock to a magma in a specially-made kiln, allow it to cool slowly to a specific temperature (allowing some minerals to form), and then quench it (cool it quickly) so that no new minerals form (only glass). The results were studied under the

Figure 4.2 .2 
microscope and by chemical analysis. This was done over and over, each time allowing the magma to cool to a lower temperature before quenching.

The Bowen reaction series is one of the results of his work, and even a century later, it is an important basis for our understanding of igneous rocks. The word reaction is critical. In the discontinuous branch, olivine is typically the first mineral to form (at just below $1300^{\circ} \mathrm{C}$ ). As the temperature continues to drop, olivine becomes unstable while pyroxene becomes stable. The early-forming olivine crystals react with silica in the remaining liquid magma and are converted into pyroxene, something like this:

$\mathrm{Mg}_{2} \mathrm{SiO}_{4}$ (olivine) $+\mathrm{SiO}_{2}$ becomes $2 \mathrm{MgSiO}_{3}$ (pyroxene)

This continues down the chain, as long as there is still silica left in the liquid.

The composition of the original magma is critical to magma crystallization because it determines how far the reaction process can continue before all of the silica is used up. The compositions of typical mafic, intermediate, and felsic magmas are shown in Figure 4.2.3. Note that, unlike Figure 4.1.1, these compositions are expressed in terms of "oxides" (e.g., $\mathrm{Al}_{2} \mathrm{O}_{3}$ rather than just $\mathrm{Al}$ ). There are two reasons for this: one is that in the early analytical procedures, the results were always expressed that way, and the other is that all of these elements combine readily with oxygen to form oxides.

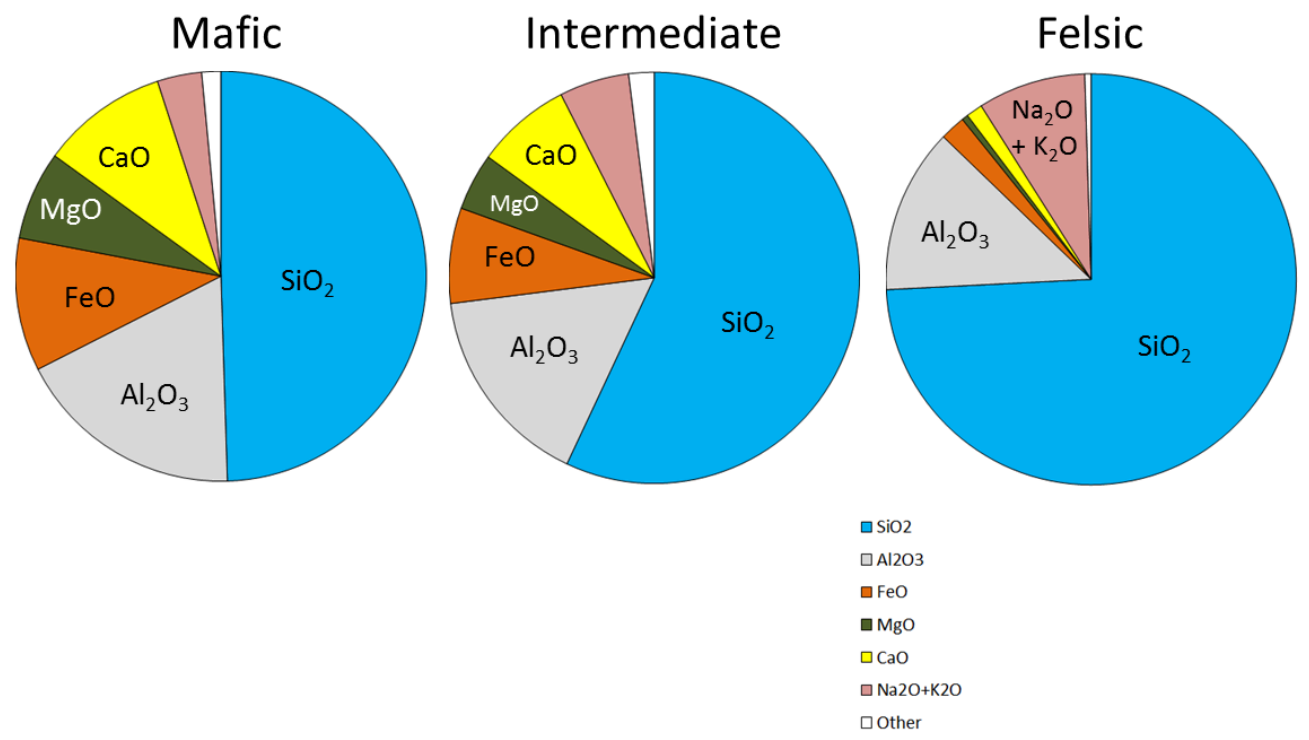

Figure 4.2.3: The chemical compositions of typical mafic, intermediate, and felsic magmas and the types of rocks that form from them.

Mafic magmas have $45 \%$ to $55 \% \mathrm{SiO}_{2}$, about $25 \%$ total of $\mathrm{FeO}$ and $\mathrm{MgO}$ plus $\mathrm{CaO}$, and about $5 \% \mathrm{Na}_{2} \mathrm{O}+\mathrm{K}_{2} \mathrm{O}$. Felsic magmas, on the other hand, have much more $\mathrm{SiO}_{2}\left(65 \%\right.$ to $75 \%$ ) and $\mathrm{Na}_{2} \mathrm{O}+\mathrm{K}_{2} \mathrm{O}$ (around $10 \%$ ) and much less $\mathrm{FeO}$ and $\mathrm{MgO}$ plus $\mathrm{CaO}$ (about 5\%).

Practice Exercise 4.1 Determining rock types based on magma composition

The proportions of the main chemical components of felsic, intermediate, and mafic magmas are listed in the table below. (The values are similar to those shown in Figure 4.2.3) 
Table 4.1 Proportions of the main chemical components in felsic, intermediate, and mafic magma

\begin{tabular}{|l|l|l|l|}
\hline Oxide & Felsic Magma & Intermediate Magma & Mafic Magma \\
\hline $\mathrm{SiO}_{2}$ & $65 \%$ to $75 \%$ & $55 \%$ to $65 \%$ & $45 \%$ to $55 \%$ \\
\hline $\mathrm{Al}_{2} \mathrm{O}_{3}$ & $12 \%$ to $16 \%$ & $14 \%$ to $18 \%$ & $14 \%$ to $18 \%$ \\
\hline $\mathrm{FeO}$ & $2 \%$ to $4 \%$ & $4 \%$ to $8 \%$ & $8 \%$ to $12 \%$ \\
\hline $\mathrm{CaO}$ & $1 \%$ to $4 \%$ & $4 \%$ to $7 \%$ & $7 \%$ to $11 \%$ \\
\hline $\mathrm{MgO}$ & $0 \%$ to $3 \%$ & $2 \%$ to $6 \%$ & $5 \%$ to $9 \%$ \\
\hline $\mathrm{Na}_{2} \mathrm{O}$ & $2 \%$ to $6 \%$ & $3 \%$ to $7 \%$ & $1 \%$ to $3 \%$ \\
\hline $\mathrm{K}_{2} \mathrm{O}$ & $3 \%$ to $5 \%$ & $2 \%$ to $4 \%$ & $0.5 \%$ to $3 \%$ \\
\hline
\end{tabular}

Chemical data for four rock samples are shown in the following table. Compare these with those in the table above to determine whether each of these samples is felsic, intermediate, or mafic.

Table 4.2 Chemical Data for Four Unidentified Rock Samples

\begin{tabular}{|l|c|c|c|c|c|c|c|c|}
\hline Rock Sample & $\mathrm{SiO}_{2}$ & $\mathrm{Al}_{2} \mathrm{O}_{3}$ & $\mathbf{F e O}$ & $\mathbf{C a O}$ & $\mathrm{MgO}$ & $\mathrm{Na}_{2} \mathrm{O}$ & $\mathbf{K}_{2} \mathrm{O}$ & What type of magma is it? \\
\hline Rock $\mathbf{1}$ & $55 \%$ & $17 \%$ & $5 \%$ & $6 \%$ & $3 \%$ & $4 \%$ & $3 \%$ & \\
\hline Rock 2 & $74 \%$ & $14 \%$ & $3 \%$ & $3 \%$ & $0.5 \%$ & $5 \%$ & $4 \%$ & \\
\hline Rock 3 & $47 \%$ & $14 \%$ & $8 \%$ & $10 \%$ & $8 \%$ & $1 \%$ & $2 \%$ & \\
\hline Rock 4 & $65 \%$ & $14 \%$ & $4 \%$ & $5 \%$ & $4 \%$ & $3 \%$ & $3 \%$ & \\
\hline
\end{tabular}

See Appendix 2 for Practice Exercise 4.1 answers.

As a mafic magma starts to cool, some of the silica combines with iron and magnesium to make olivine. As it cools further, much of the remaining silica goes into calcium-rich plagioclase, and any silica left may be used to convert some of the olivine to pyroxene. Soon after that, all of the magma is used up and no further changes takes place. The minerals present will be olivine, pyroxene, and calcium-rich plagioclase. If the magma cools slowly underground, the product will be gabbro; if it cools quickly at the surface, the product will be basalt (Figure 4.2.4).

Felsic magmas tend to be cooler than mafic magmas when crystallization begins (because they don't have to be as hot to remain liquid), and so they may start out crystallizing pyroxene (not olivine) and plagioclase. As cooling continues, the various reactions on the discontinuous branch will proceed because silica is abundant, the plagioclase will become increasingly sodium-rich, and eventually potassium feldspar and quartz will form. Commonly even very felsic rocks will not have biotite or muscovite because they may not have enough aluminum or enough hydrogen to make the $\mathrm{OH}$ complexes that are necessary for mica minerals. Typical felsic rocks are granite and rhyolite (Figure 4.2.4). 


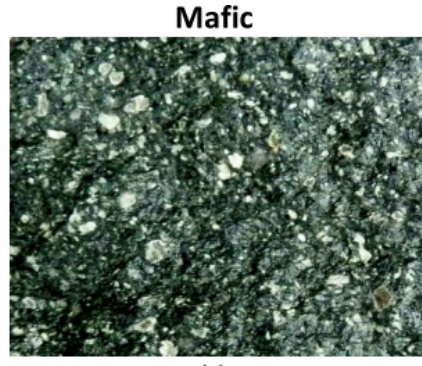

Gabbro

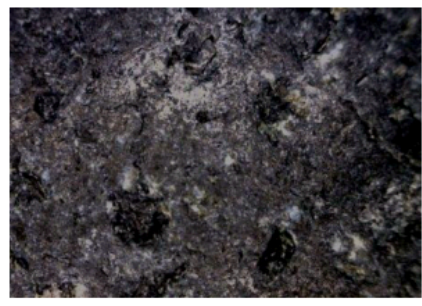

Basalt

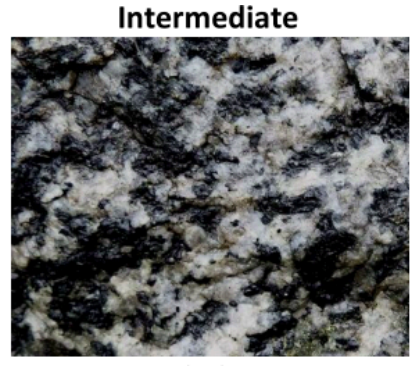

Diorite

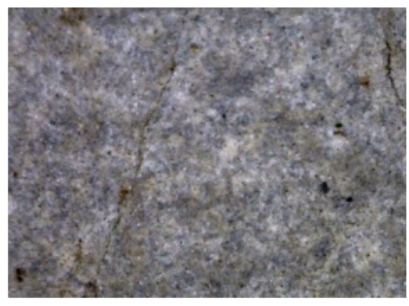

Andesite

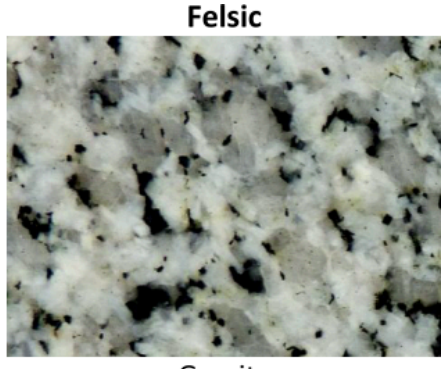

Granite

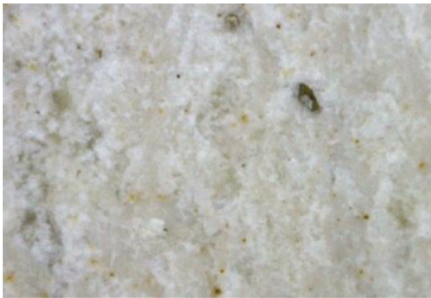

Rhyolite

Figure 4.2.4: Examples of the igneous rocks that form from mafic, intermediate, and felsic magmas.

The cooling behaviour of intermediate magmas lie somewhere between those of mafic and felsic magmas. Typical mafic rocks are gabbro (intrusive) and basalt (extrusive). Typical intermediate rocks are diorite and andesite. Typical felsic rocks are granite and rhyolite (Figure 4.2.4).

An igneous rock with large crystals, called phenocrysts, embedded in a groundmass of much finer crystals is indicative of a two-stage cooling process, and the texture is porphyritic (Figure 4.2.5). For the rock to be called "porphyritic" there has to be a significant difference in crystal size, where the larger crystals are at least 10 times larger than the average size of the smaller crystals.

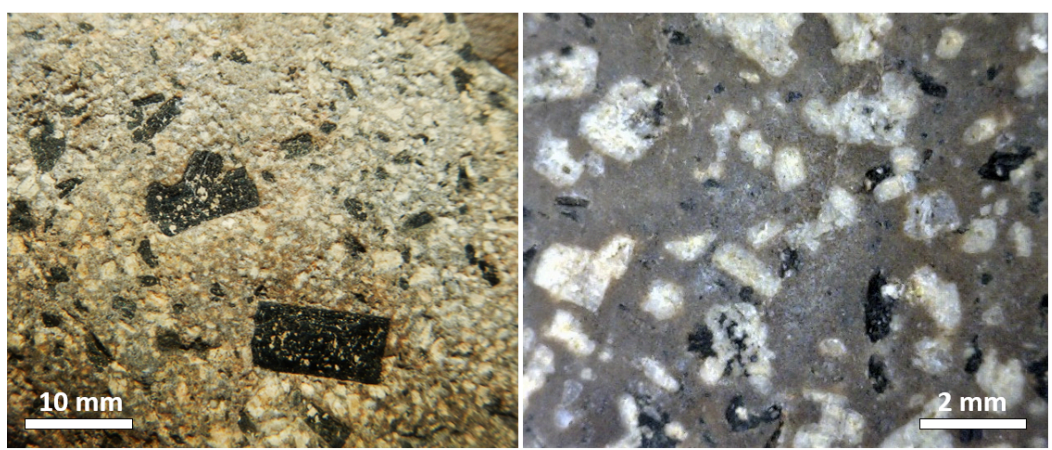

Figure 4.2.5: Porphyritic textures, left: $1.3 \mathrm{~cm}$ long amphibole crystals in an intrusive igneous rock in which most of the crystals are less than $1 \mathrm{~mm}$, right: 1 to $2 \mathrm{~mm}$ long feldspar crystals and $1 \mathrm{~mm}$ long amphibole crystals in a volcanic rock where most of the crystals are less than $0.1 \mathrm{~mm}$.

Practice Exercise 4.2 Porphyritic minerals

As a magma cools below $1300^{\circ} \mathrm{C}$, minerals start to crystallize within it. If that magma is then involved in a volcanic eruption, the rest of the liquid will cool quickly to form a porphyritic texture. The rock will have some relatively large crystals (phenocrysts) of the minerals that crystallized early, and the rest will be very fine grained or even 
glassy. Using Figure 4.2.6, predict what phenocrysts might be present where the magma cooled as far as line a in one case, and line $\mathbf{b}$ in another.

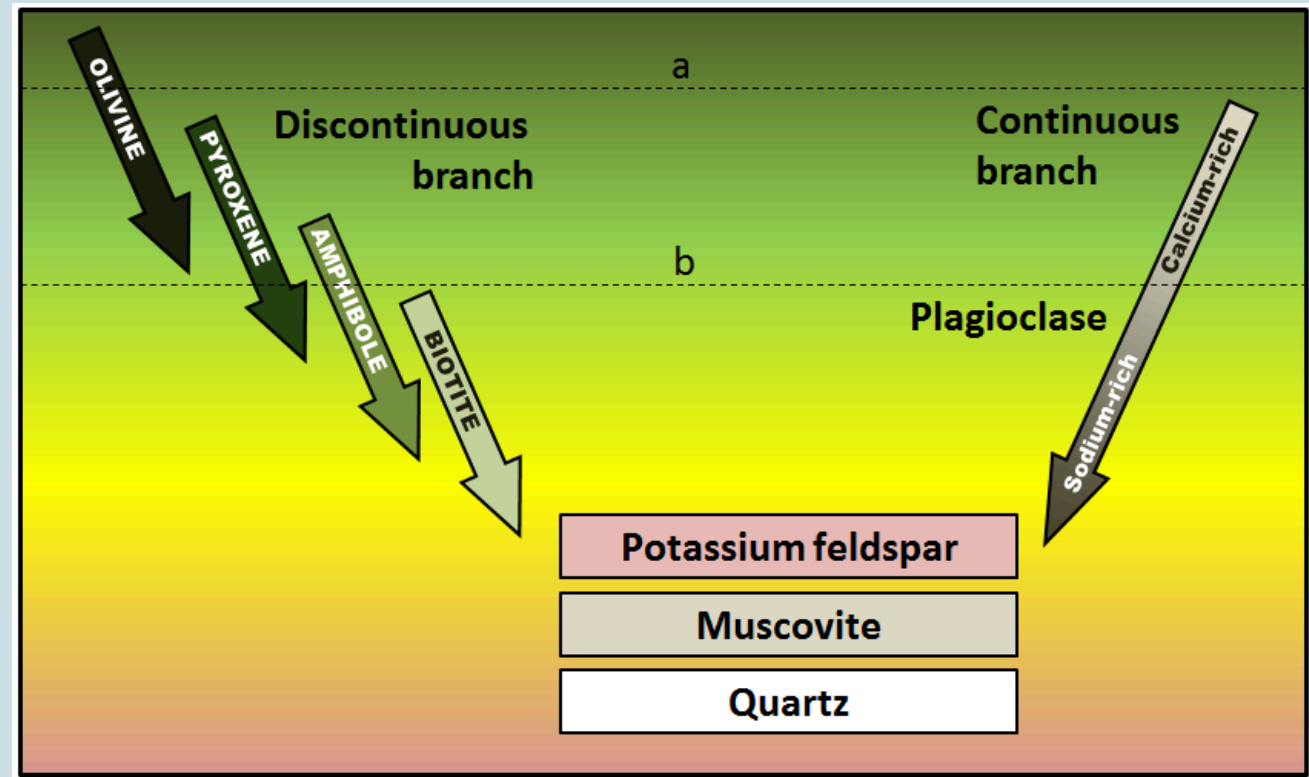

Figure 4.2.6: Bowen reaction series. Line $a$ - at high temperature - intersects olivine, Line b - at a lower temperature - intersects pyroxene and amphibole on the left, and plagioclase feldspar on the right

See Appendix 2 for Practice Exercise 4.2 answers.

\section{Media Attributions}

- Figure 4.2.1, 4.2.3, 4.2.4, 4.2.5, 4.2.6: (C) Steven Earle. CC BY.

- Figure 4.2.2: "Norman L. Bowen." Public domain. 


\subsection{Classification of Igneous Rocks}

Igneous rocks are classified into four categories: felsic, intermediate, mafic, and ultramafic, based on either their chemistry or their mineral composition. The diagram in Figure 4.3.1 can be used to help classify igneous rocks by their mineral composition. An important feature to note on this diagram is the red line separating the non-ferromagnesian silicates in the lower left (K-feldspar, quartz, and plagioclase feldspar) from the ferromagnesian silicates in the upper right (biotite, amphibole, pyroxene, and olivine). In classifying intrusive igneous rocks, the first thing to consider is the percentage of ferromagnesian silicates. In most igneous rocks the ferromagnesian silicate minerals are clearly darker than the others, but it is still quite difficult to estimate the proportions of minerals in a rock.

Based on the position of the red line in Figure 4.3.1, it is evident that felsic rocks can have between $1 \%$ and $20 \%$ ferromagnesian silicates (the red line intersects the left side of the felsic zone $1 \%$ of the distance from the top of the diagram, and it intersects the right side of the felsic zone $20 \%$ of the distance from the top). Intermediate rocks have between $20 \%$ and 50\% ferromagnesian silicates, and mafic rocks have 50\% to $100 \%$ ferromagnesian silicates. To be more specific, felsic rocks typically have biotite and/or amphibole; intermediate rocks have amphibole and, in some cases, pyroxene; and mafic rocks have pyroxene and, in some cases, olivine.

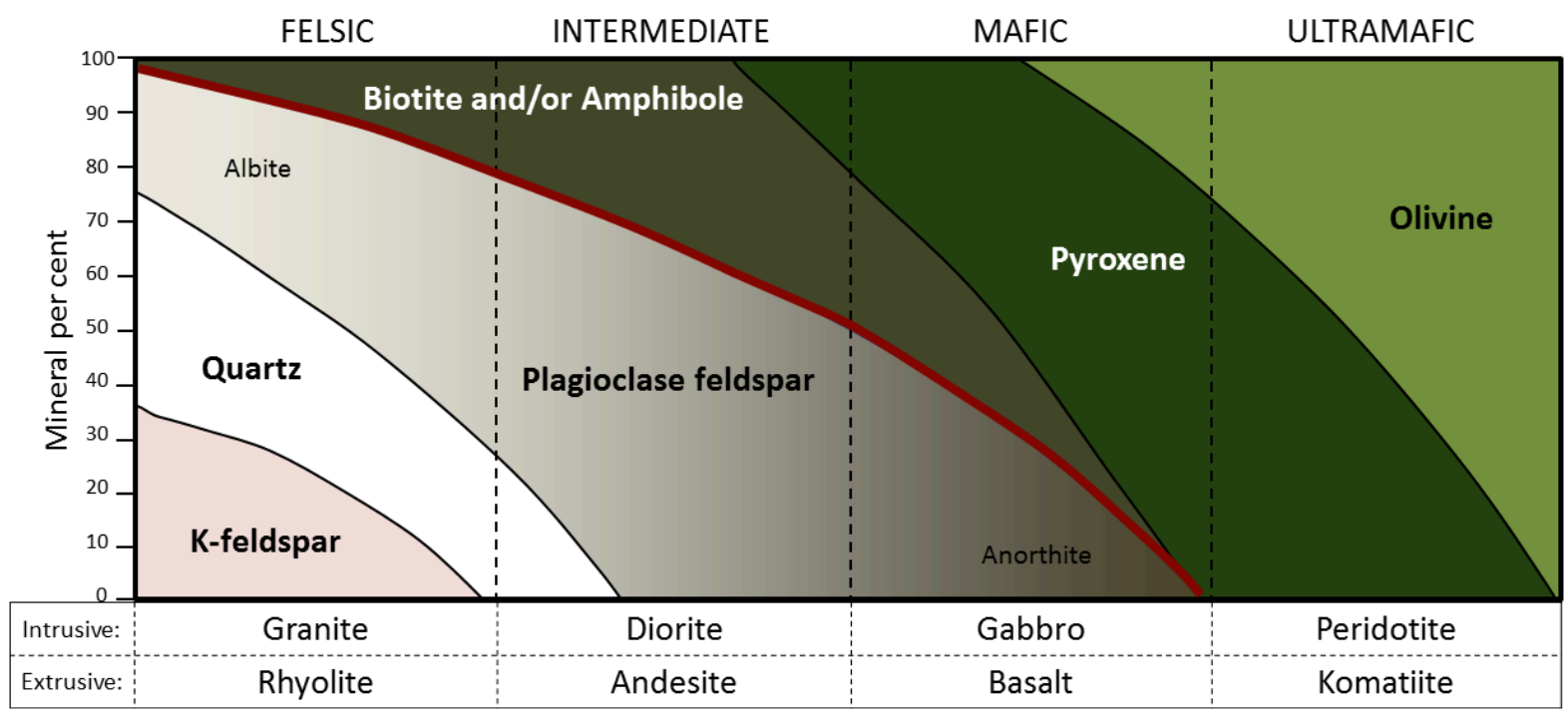

Figure 4.3.1: A simplified classification diagram for igneous rocks based on their mineral compositions. [Image Description]

If we focus on the non-ferromagnesian silicates, it is evident that felsic rocks can have from $0 \%$ to $35 \% \mathrm{~K}-$ feldspar, from $25 \%$ to $35 \%$ quartz (the vertical thickness of the quartz field varies from $25 \%$ to $35 \%$ ), and from $25 \%$ to $50 \%$ plagioclase (and that plagioclase will be sodium-rich, or albitic). Intermediate rocks can have up to $25 \%$ quartz and $50 \%$ to $75 \%$ plagioclase. Mafic rocks only have plagioclase (up to 50\%), and that plagioclase will be calcium-rich, or anorthitic. 


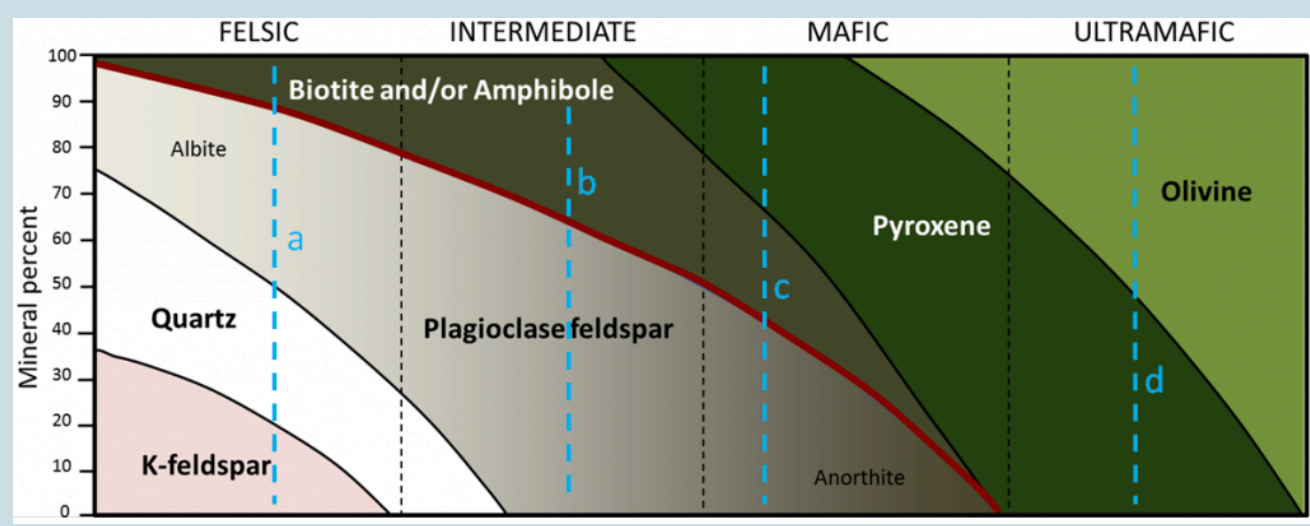

Figure 4.3.2

The dashed blue lines (labelled a, b, c, d) in Figure 4.3.2 represent four igneous rocks. Complete the table by estimating the mineral proportions (percent) of the four rocks (to the nearest 10\%).

Hint: Rocks $\mathbf{b}$ and $\mathbf{d}$ are the easiest; start with those.

\begin{tabular}{|c|c|c|c|c|c|c|}
\hline Rock & Biotite/amphibole & Pyroxene & Olivine & Plagioclase & Quartz & K-feldspar \\
\hline a & & & & & & \\
\hline b & & & & & & \\
\hline c & & & & & & \\
\hline d & & & & & & \\
\hline
\end{tabular}

See Appendix 2 for Practice Exercise 4.3 answers.

Figure 4.3.3 provides a diagrammatic representation of the proportions of dark minerals in light-coloured rocks. You can use that when trying to estimate the ferromagnesian mineral content of actual rocks, and you can get some practice doing that by completing Practice Exercise 4.4. Be warned! Geology students almost universally over-estimate the proportion of dark minerals.

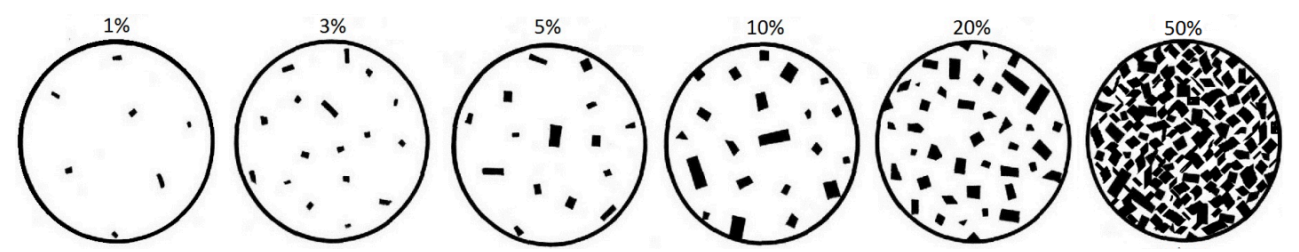

Figure 4.3.3: A guide to estimating the proportions of dark minerals in light-coloured rocks.

The four igneous rocks shown below have differing proportions of ferromagnesian silicates. Estimate those proportions using the diagrams in Figure 4.3.3, and then use Figure 4.3.1 to determine the likely rock name for each one. 


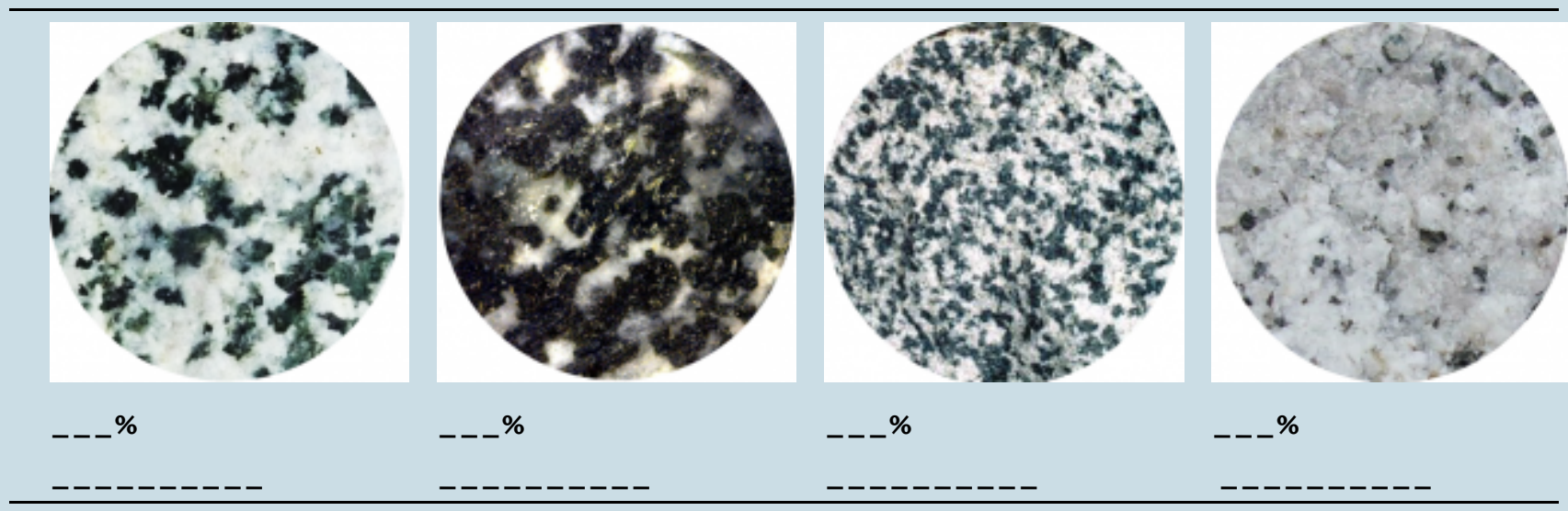

See Appendix 2 for Practice Exercise 4.4 answers.

Igneous rocks are also classified according to their textures. Almost all intrusive igneous rocks are phaneritic (from the Greek word phaneros meaning visible), meaning that they have crystals that are large enough to see with the naked eye. Typically that means they are larger than about 0.5 millitmeres $(\mathrm{mm})$ - the thickness of a strong line made with a ballpoint pen. The intrusive rocks shown in Figure 4.2.4 are all phaneritic, as are those shown in Practice Exercise 4.4. If the crystals are too small to distinguish, which is typical of most extrusive (volcanic) rocks, we use the term aphanitic (from the Greek word aphanos - unseen). Although the individual crystals in an aphantic rock cannot be observed with the naked eye, they still influence the physical properties of the rock, specifically its colour. In an aphanitic rock, the colour of the groundmass, as seen on a fresh non-weathered surface, can provide clues about its mineral composition. Mafic rocks (basalt) tend to be dark black to grey in colour, intermediate rocks (andesite) tend to be a lighter grey, and felsic rocks (rhyolite) tend to be pale grey, white, cream or pale pink in colour.

In general, the size of crystals is proportional to the rate of cooling. The longer it takes for a body of magma to cool, the larger the crystals can grow. As already described, if an igneous rock goes through a two-stage cooling process, its texture will be porphyritic (Figure 4.2.5).

Igneous rocks that form when lava cools so rapidly that few, if any, crystals form, are often glassy. Two common glassy rocks formed rapid cooling (or quenching) of lava are pumice and obsidian. Pumice is typically light in colour owing to its felsic composition, and is distinguished by its frothy glassy texture and low density. Obsidian is distinguished by its vitreous lustre and pronounced conchoidal fracture. Although obsidian is typically black to dark brown in colour, it is actually felsic in composition.

One final textural term for igneous rocks is vesicular. The vesicles in vesicular rocks form when gasses exsolve from the magma as it rises toward the surface of the Earth. When magma is deep beneath the surface and under high pressure from the surrounding rocks, the gases remain dissolved in the magma, much like the dissolved $\mathrm{CO}_{2}$ gas in an unopened bottle of pop. As magma approaches the surface, the pressure exerted on it decreases, and gas bubbles start to form, much like once a bottle of pop has been opened. The more gas there is in the magma, the more bubbles form. If the magma is runny enough, the gases will rise up through it and escape to surface. In some cases, however, the bubbles of gas are "frozen" in the lava as it cools and form vesicles as it crystallizes into solid rock at the surface.

Names of igneous rocks, based on both composition and texture as described above, can be enhanced by adding using terms like vesicular or porphyritic as modifiers. For example, an andesite that contains hornblende and plagioclase phenocrysts would be described as a hornblende plagioclase porphyritic andesite. A basalt that contains olivine phenocrysts and vesicles would be called an olivine porphyritic vesicular basalt. 


\section{Image Descriptions}

Figure 4.3.1 image description: Mineral composition of igneous rocks

\begin{tabular}{|l|l|l|l|l|}
\hline Igneous Rocks & Felsic & Intermediate & Mafic & Ultramafic \\
\hline K-feldspar & 0 to $35 \%$ & $0 \%$ & $0 \%$ & $0 \%$ \\
\hline Quartz & 25 to $35 \%$ & 0 to $25 \%$ & $0 \%$ & $0 \%$ \\
\hline Plagioclase feldspar & 25 to $50 \%$ & 50 to $70 \%$ & 0 to $50 \%$ & $0 \%$ \\
\hline Biotite and/or Amphibole & 0 to $20 \%$ & 20 to $40 \%$ & 0 to $30 \%$ & $0 \%$ \\
\hline Pyroxene & $0 \%$ & 0 to $20 \%$ & 20 to $75 \%$ & $0 \%$ to $75 \%$ \\
\hline Olivine & $0 \%$ & $0 \%$ & 0 to $25 \%$ & $25 \%$ to $100 \%$ \\
\hline Intrusive & Granite & Diorite & Gabbro & Peridotite \\
\hline Extrusive & Rhyolite & Andesite & Basalt & Komatiite \\
\hline
\end{tabular}

[Return to Figure 4.3.1]

\section{Media Attributions}

- Figure 4.3.1, 4.3.2, 4.3.3: @ Steven Earle. CC BY. 


\title{
$\mathrm{Lab}_{4}$ Exercises
}

\author{
Classifying Rocks
}

All rocks are classified by just two characteristics: texture and mineralogy. The 20 or so minerals which form most rocks are already very familiar to you, the remaining 6000 are not very common and not significant in rock classification, and you can manage in this course without being able to identify them.

The two main textural terms you will use as you examine rocks in labs 4, 5 and 6 are:

Crystalline: consisting of a network of interlocking crystals. Igneous, sedimentary and metamorphic rocks may have a crystalline texture.

Clastic: consisting of grains eroded from pre-existing rocks. These grains have been transported at least some distance from their place of origin. Only some sedimentary rocks have a clastic texture.

It is essential that you are able to recognize these textures (Fig-

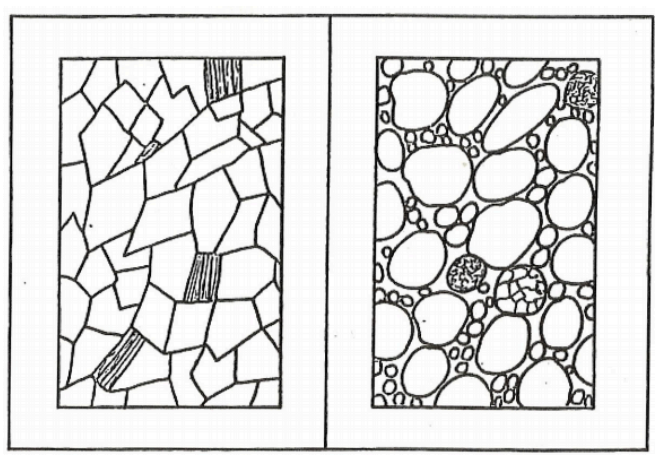

Figure A: (left) crystalline texture produced by a mosaic of interlocking crystals, and (right) clastic texture composed of individual grains bonded by a chemical cement. Grains may consist of a single mineral, or fragments from pre-existing rocks.

ure A). They form the major division between many rocks. Failure to differentiate between a crystalline versus a clastic texture could result in you being responsible for drilling through granite instead of sandstone!

1. Examine samples R2, R151, and R281 and identify the texture of each sample to complete the table below.

\section{Sample R2}

Sample R151

Sample R281
Texture:

Texture:

Texture:

The exercises below will guide you through the igneous rock samples in Rock Kits 1 and 2. Review the background information presented in Chapters 4.1 to 4.3 before you begin these exercises. You may wish to consult the Rock Classification Tables at the back of this manual as you complete the exercises below.

Tips for Identifying Igneous Rocks

- Your first step when examining any igneous rock is to look closely at the size of the crystals and to determine if its texture is aphanitic (individual crystals are too fine to be visible with the naked eye), phaneritic (individual crystals are visible with the naked eye), or porphyritic (crystals of two or more distinctly different sizes present). If the sample contains no crystals at all and has a vitreous lustre, its texture can be described as glassy. If the sample contains gas bubbles called vesicles, its texture is vesicular.

- If the sample is phaneritic, or contains phenocrysts, try to identify the minerals within the sample. 
This will be tricky, as the crystals are much smaller than the samples you examined in Labs 2 and 3 . Make sure you examine the sample carefully with your hand lens. You will see much more than with your naked eye alone!

- Start by asking yourself, "how many different minerals can I see in this sample?" and make a short list of the physical properties you observe (e.g., colour, lustre, cleavage).

- Use your observations and the mineral identification tables to identify the minerals present, and make an estimate of their proportions using Figure A in the Rock Classification Tables appendix as a guide. Some mineral-specific hints are outlined here:

- Quartz crystals come in many colours, but quartz always has vitreous lustre and is often translucent.

- Potassium feldspar (K-feldspar) is commonly white or pink in colour, and is often opaque (milky) to semi-translucent.

- Plagioclase feldspar is commonly white to dark bluish grey in colour (depending on the composition), is often opaque (milky) to semi-translucent, and has striations.

- Examining a weathered surface can help to differentiate quartz from feldspar minerals: feldspars chemically weather tend to look chalky and dull (see Figure 5.1.4), whereas quartz always looks glassy. If you look for freshly broken surfaces or edges of the sample you may even see that the feldspar crystals break along cleavage planes while the quartz crystals have conchoidal fracture.

- Muscovite (colourless, translucent) and biotite (dark brown to black) both appear as thin sheets or flakes.

- To tell biotite from other ferromagnesian minerals, test its hardness with a steel file or thin knife: biotite has a Mohs hardness of $~ 2.5-3$ whereas amphibole and pyroxene are much harder $(\mathrm{H}=$ 5-6).

- It can be difficult to tell amphibole from pyroxene in rocks, as they have similar hardnesses, form blocky crystals, and can be found in similar colours (shades of green to black). Look closely for cleavage: amphibole has 2 planes not at $90^{\circ}$, whereas pyroxene has 2 planes at $90^{\circ}$. If you are unsure whether a ferromagnesian mineral is amphibole or pyroxene and have already identified the other minerals present, it may help to use Figure 4.3.1 as a guide. For example, if you have identified K-feldspar, quartz, and white plagioclase in a sample, chances are the dark coloured blocky mineral you see is amphibole and not pyroxene. Why? Because a felsic magma that is crystallizing K-feldspar and quartz will not normally also crystallize pyroxene.

- Olivine can be distinguished by its vitreous lustre and olive green to yellow-green colour. Caution: weathered olivine may appear dull or rusty (from iron oxide staining).

- If the sample is aphanitic, use the colour of a fresh surface to estimate the composition: felsic rocks are light-coloured (beige, buff, tan, pink, white, pale grey) whereas mafic rocks are dark-coloured (dark grey to black).

- Finally, combine your observations of texture and composition, and use Figure B in the Rock Classification Tables appendix to name the rock.

- If the sample is porphyritic with an aphanitic groundmass, identify the phenocryst mineral(s), interpret the overall composition based on the colour of the groundmass, and name the rock as [phenocryst mineral name] porphyritic [rock name]. For example, a porphyritic volcanic rock with pyroxene phenocrysts in a dark grey aphanitic groundmass is a pyroxene porphyritic basalt.

- Rock names can likewise be modified by other textural terms (e.g., vesicular basalt).

2. Remove samples R1, R2, R11, R21, R31, R41, R42, R51, R61, and R71 from Rock Kit 1 and place the samples on the table in front of you. Arrange these samples according to colour, in a line or into groups. What does the colour of an igneous rock tell you? 
3. Keeping the same colour groups you just arranged, within each group arrange the same set of samples according to their grain size (the size of the crystals that make up these rocks). As you examine each sample decide whether:

- all or most of the crystals are large enough for you to see with your naked eye,

- all or most of the crystals are too fine to see clearly with your naked eye, or

- there are no crystals at all (sample is glassy).

4. What does grain size tell you about the cooling history of an igneous rock?

The groups of igneous rocks you just arranged should reflect the classification presented in Figure B in the Rock Classification Tables. Now that you have had a chance to compare all the samples, let's examine each sample in more detail.

Sample R1

Sample R2
Rock name:

Rock name:

5. It can be useful to look at both weathered and fresh (unweathered) surfaces of a rock sample, as both can be useful when identifying minerals. However, it is important to make note of what type of surface you are describing in your notes. Are you looking at a fresh or a weathered surface?

6. Are these rocks comprised of grains or crystals?

7. These samples are both crystalline rocks (in contrast to clastic rocks which you will be examining in lab 5). Notice the prominent cleavage faces which can be seen on some of the crystals. Which mineral(s) is (are) showing cleavage?

8. Are these rocks aphanitic or phaneritic?

9. Are the crystals all of relatively similar size or obviously different sizes?

10. Describe the colour of the rock:

11. What do you estimate is the percentage of light (non-ferromagnesian) and dark-coloured (ferromagnesian) minerals?

Non-ferromagnesian:

$\%$

Ferromagnesian:

$\%$

12. List below the minerals which you recognize in order of abundance (remember to use your hand lens).

13. Which mineral is responsible for unique colour of sample R2? 
14. Are you looking at a fresh or a weathered surface?

15. Choose a term which best describes the texture of this rock:

16. Describe the colour of this rock (light/intermediate/dark):

17. What do you think is the basic difference between specimens R1 and R11?

18. Did sample R11 cool slowly (intrusive) or rapidly (extrusive) compared to R1?

\section{Sample R21}

Rock name:

19. Are you looking at a fresh or a weathered surface?

20. Which textural term best describes this rock?

21. The larger crystals in the aphanitic groundmass are called

22. Do you see cleavage planes on any of the larger crystals?

23. What size (in $\mathrm{mm}$ ) are the larger crystals?

24 . Are these crystals all the same mineral?

25. Describe the overall colour of the rock (light/intermediate/dark):

Sample R31

Rock name:

26. Are you looking at a fresh or a weathered surface?

27. Is the rock aphanitic or phaneritic?

28. Does the textural term, 'porphyritic' apply to this rock?

29 . Did the rock cool slowly or rapidly?

30. List the minerals in this rock in order of abundance:

31. What do you estimate is the percentage of light and dark-coloured minerals?

\begin{tabular}{llll}
\hline Non-ferromagnesian: & $\%$ & Ferromagnesian: & $\%$ \\
\hline
\end{tabular}

32. Do you see cleavage planes on any of the minerals?

If so, which ones?

33. Describe the colour of this rock (compare the colour to that of R1 and R51):

Rock name:

34. Are you looking at a fresh or a weathered surface?

35 . Which textural term best describes this rock? 
37. What do you estimate is the percentage of light and dark-coloured minerals?

Non-ferromagnesian:

$\%$

Ferromagnesian:

$\%$

38. Would you say that texture (grain size) or mineralogy (mineral composition) is the basic difference between R1, R31, and R51?

Sample R41

Rock name:

39. Which textural term best describes this rock?

40. Do you see any phenocrysts in this rock?

41. Describe the colour of the rock on a fresh surface

42. Is this rock intrusive or extrusive? What evidence supports your answer?

43. What is the basic difference between this rock and R51?

Sample R42

Rock name:

44. Which textural term applies to this sample?

45. What are the small spherical cavities occurring throughout the rock called, and how did they form?

46. What is the difference between this rock and R41?

Sample R61

Rock name:

47. Describe the texture of this rock (Hint: what substance does it resemble):

48. Can you see the individual crystals in this rock?

49. What term best describes the type of fracture of this rock?

This is a sample of obsidian and its texture is due to the super cooling of magma, resulting in a non-crystalline, glassy texture. 
50. Compare this specimen to R71 (pumice) which is also a type of glass. How do they differ?

\section{Media Attributions}

- Figure A: (C) Candace Toner. CC-BY-NC. 


\section{Summary}

The topics covered in this chapter can be summarized as follows:

\begin{tabular}{|c|c|}
\hline Section & Summary \\
\hline $\begin{array}{l}\text { 4.1 Magma } \\
\text { and Magma } \\
\text { Formation }\end{array}$ & $\begin{array}{l}\text { Magma is molten rock, and in most cases, it forms from partial melting of existing rock. The two } \\
\text { main processes of magma formation are decompression melting and flux melting. Magmas range in } \\
\text { composition from ultramafic to felsic. Mafic rocks are rich in iron, magnesium, and calcium, and } \\
\text { have around } 50 \% \text { silica. Felsic rocks are rich in silica }(\sim 75 \%) \text { and have lower levels of iron, } \\
\text { magnesium, and calcium and higher levels of sodium and potassium than mafic rocks. Intermediate } \\
\text { rocks have compositions between felsic and mafic. }\end{array}$ \\
\hline $\begin{array}{l}4.2 \\
\text { Crystallization } \\
\text { of Magma }\end{array}$ & $\begin{array}{l}\text { As a body of magma starts to cool, the first process to take place is the polymerization of silica } \\
\text { tetrahedra into chains. This increases the magma's viscosity (makes it thicker) and because felsic } \\
\text { magmas have more silica than mafic magmas, they tend to be more viscous. The Bowen reaction } \\
\text { series allows us to predict the order of crystallization of magma as it cools. }\end{array}$ \\
\hline $\begin{array}{l}4.3 \\
\text { Classification } \\
\text { of Igneous } \\
\text { Rock }\end{array}$ & $\begin{array}{l}\text { Igneous rocks are classified based on their mineral composition and texture. Felsic igneous rocks } \\
\text { have less than } 20 \% \text { ferromagnesian silicates (amphibole and/or biotite) plus varying amounts of } \\
\text { quartz and both potassium and plagioclase feldspars. Mafic igneous rocks have more than } 50 \% \\
\text { ferromagnesian silicates (primarily pyroxene) plus plagioclase feldspar. Most intrusive igneous rocks } \\
\text { are phaneritic (crystals are visible to the naked eye), whereas most extrusive (volcanic) rocks are } \\
\text { aphanitic (crystals are too small to be seen with the naked eye). If there were two stages of cooling } \\
\text { (slow then fast), the texture may be porphyritic (large crystals in a matrix of smaller crystals). Gas } \\
\text { bubbles "frozen" in an igneous rock are called vesicles, and the textural term for a rock with vesicles } \\
\text { is vesicular. }\end{array}$ \\
\hline $\begin{array}{l}\text { Lab } 4 \\
\text { Exercises }\end{array}$ & $\begin{array}{l}\text { The best way to learn rock identification is to practice by examining the samples in your Rock Kit } 1 \\
\text { and } 2 \text {. Igneous rocks are classified according to their mineral composition (or colour, in the case of } \\
\text { aphanitic rocks), and texture (size of the crystals). Knowing the diagnostic properties of the minerals } \\
\text { within an igneous rock help you identify its composition as mafic, intermediate, or felsic. Just as } \\
\text { with mineral samples, different samples of the same rock may not always look exactly the same (e.g., } \\
\text { pink versus white granite), but they can always be identified by closely examining the mineral } \\
\text { composition and texture. }\end{array}$ \\
\hline
\end{tabular}




\title{
LAB 5: SEDIMENTS AND SEDIMENTARY ROCKS
}

\author{
Lab Structure
}

\begin{tabular}{ll}
\hline Recommended additional work & None \\
Required materials & $\begin{array}{l}\text { Mineral ID kit, Rock Kits 1 and 2, Mineral Kits 1 and 2, } \\
\text { pencil }\end{array}$ \\
\hline
\end{tabular}

Learning Objectives

After carefully reading this chapter, completing the exercises within it, and answering the questions at the end, you should be able to:

- $\quad$ Describe the main processes of mechanical weathering, and the types of materials that are produced when mechanical weathering predominates.

- $\quad$ Describe the main processes of chemical weathering, and the products of chemical weathering of minerals such as feldspar, ferromagnesian silicates, and calcite.

- $\quad$ Explain the type of weathering processes that are likely to have taken place to produce a particular sediment deposit.

- $\quad$ Describe the differences between cobbles, pebbles, sand, silt, and clay and explain the relationship between clast size and the extent to which clasts can be transported by moving water or by wind.

- Identify and describe the characteristics of the various types of clastic and chemical sedimentary rock based on their texture and mineralogy.

Key Terms

- Sediment

- Sedimentary rock

- Mechanical weathering

- Chemical weathering

- Erosion

- Deposition

- Lithification
- Clast

- Boulder

- Cobble

- Pebble

- Granule

- Sand

- Silt

- Clay
- Cement

- Crystalline

- Clastic

- Oolitic

- Amorphous

- Bioclastic

- Fossiliferous 


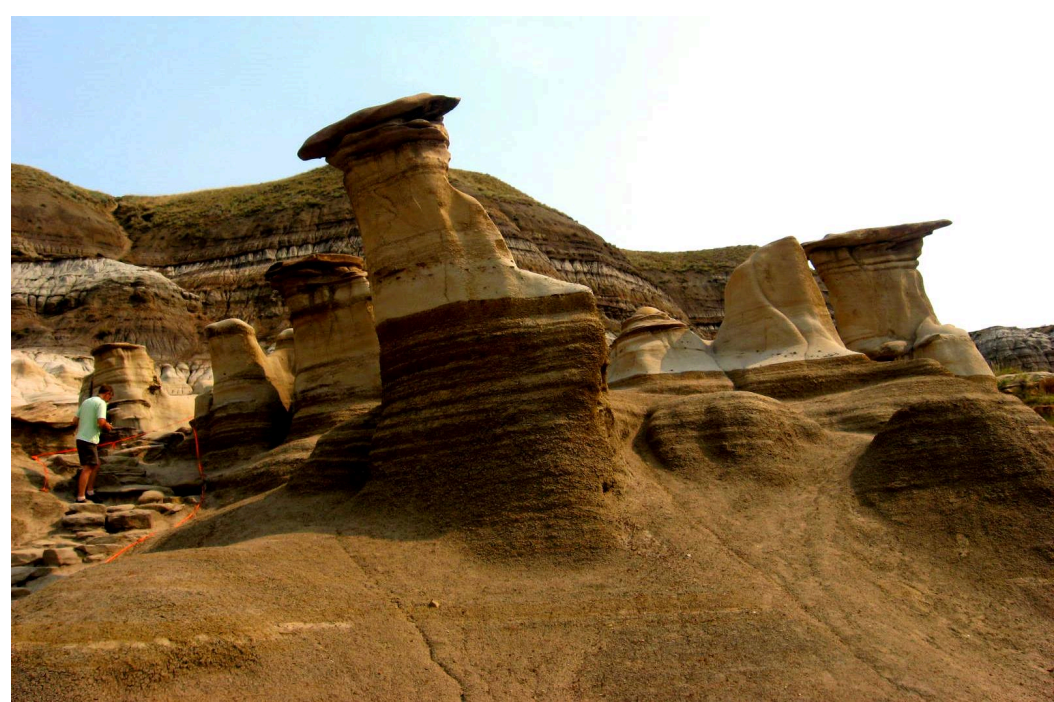

Figure 5.0.1: The Hoodoos, near Drumheller, Alberta, have formed from the differential weathering of sedimentary rock that was buried beneath other rock for close to $100 \mathrm{Ma}$.

Weathering is what takes place when a body of rock is exposed to the "weather"-in other words, to the forces and conditions that exist at Earth's surface. With the exception of volcanic rocks and some sedimentary rocks, most rocks are formed at some depth within the crust. There they experience relatively constant temperature, high pressure, no contact with the atmosphere, and little or no moving water. Once a rock is exposed at the surface, which is what happens when the overlying rock is eroded away, conditions change dramatically. Temperatures vary widely, there is much less pressure, oxygen and other gases are plentiful, and in most climates, water is abundant (Figure 5.0.1). The various processes related to uplift and weathering are summarized in the rock cycle in Figure 5.0.2.

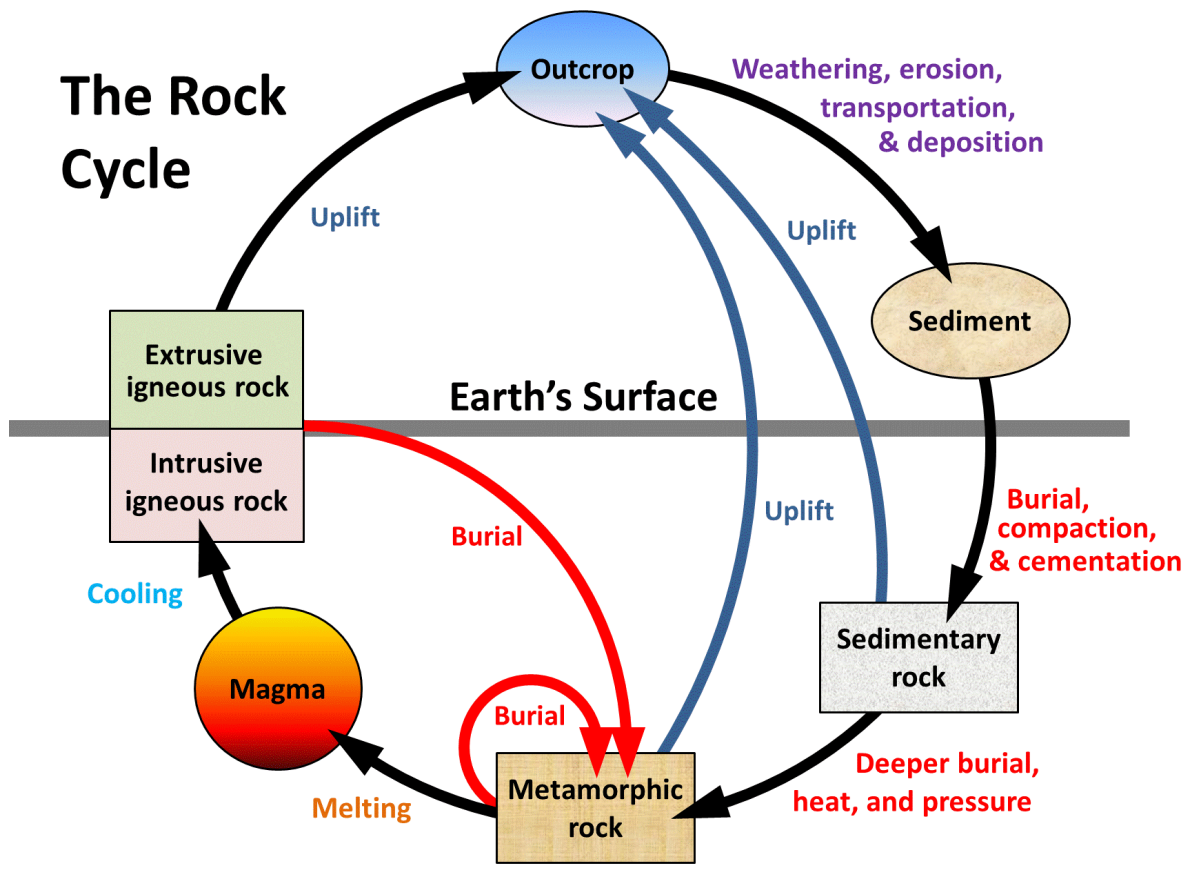

Figure 5.0.2: The rock cycle, showing the processes related to sedimentary rocks on the right-hand side.[Image description] 
In this chapter, we will cover three core concepts: the formation of sediment through the weathering of rocks at the Earth's surface, the formation of sedimentary rocks from accumulated sediments, and the classification of various types of sedimentary rocks. The weathering and erosion of existing rocks at the Earth's surface are the first two steps in the transformation of existing rocks into sedimentary rocks. The remaining steps in the formation of sedimentary rocks-transportation, deposition, burial, and lithification (Figure 5.0.2) - will be discussed in more detail in chapter 5.3.

In this course, we divide sedimentary rocks into two main types: clastic and chemical. Clastic sedimentary rocks are mainly composed of material that has been transported as solid fragments (clasts). Chemical sedimentary rocks are mainly composed of material that has been transported as ions in solution. It's important not to assume that mechanical weathering leads only to clastic sedimentary rocks, while chemical weathering leads only to chemical sedimentary rocks. In most cases, millions of years separate the weathering and depositional processes, and both types of sedimentary rocks tend to include at least some material derived from both types of weathering.

\section{Image Descriptions}

Figure 5.0.2 image description: "The Rock Cycle." The rock cycle takes place both above and below the Earth's surface. The rock deepest beneath the Earth's surface and under extreme heat and pressure is metamorphic rock. This metamorphic rock can melt and become magma. When magma cools, if below the Earth's surface it becomes "intrusive igneous rock." If magma cools above the earth's surface it is "extrusive igneous rock" and becomes part of the outcrop. The outcrop is subject to weathering and erosion, and can be moved and redeposited around the earth by forces such as water and wind. As the outcrop is eroded, it becomes sediment which can be buried, compacted, and cemented beneath the Earth's surface to become sedimentary rock. As sedimentary rock gets buried deeper and comes under increased heat and pressure, it changes into a metamorphic rock. Rocks in the rock cycle do not always make a complete loop. It is possible for sed-

imentary rock to be uplifted back above the Earth's surface and for intrusive and extrusive igneous rock to be reburied and became metamorphic rock. [Return to Figure 5.0.2]

\section{Media Attributions}

- Figures 5.0.1, 5.0.2: (C) Steven Earle. CC BY. 


\section{I Weathering}

\section{Mechanical Weathering}

Intrusive igneous rocks form at depths of several hundreds of metres to several tens of kilometres. Sediments are turned into sedimentary rocks only when they are buried by other sediments to depths in excess of several hundreds of metres. Most metamorphic rocks are formed at depths of kilometres to tens of kilometres. Weathering cannot even begin until these rocks are uplifted through various processes of mountain building-most of which are related to plate tectonics-and the overlying material has been eroded away and the rock is exposed as an outcrop.

The most important agents of mechanical weathering are:

- The decrease in pressure that results from removal of overlying rock

- Freezing and thawing of water in cracks in the rock

- Cracking from plant roots and removal of material by burrowing animals

- Formation of salt crystals within the rock

When a mass of rock is exposed by weathering and removal of the overlying rock, there is a decrease in the confining pressure on the rock, and the rock expands. This unloading promotes cracking of the rock, known as exfoliation.

Frost wedging is the process by which water seeps into cracks in a rock, expands on freezing, and thus enlarges the cracks (Figure 5.1.1). The effectiveness of frost wedging is related to the frequency of freezing and thawing. Frost wedging is most effective in a climate like Canada's. In warm areas where freezing is infrequent, in very cold areas where thawing is infrequent, or in very dry areas, where there is little water to seep into cracks, the role of frost wedging is limited. If you are ever hiking in the mountains you might hear the effects of frost wedging when the Sun warms a steep rocky slope and the fragments of rock that were pried away from the surface by freezing the night before are released as that ice melts.

In many parts of Canada, the transition between freezing nighttime temperatures and thawing daytime temperatures is frequent - tens to hundreds of times a year. A common feature in areas of effective frost wedging is a talus slope-a fan-shaped deposit of fragments removed by frost wedging from the steep rocky slopes above (Figure 5.1.2).

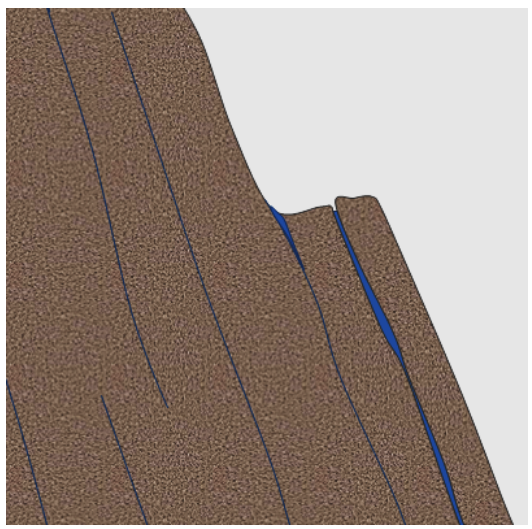

Figure 5.1.1: The process of frost wedging on a steep slope. Water gets into fractures and then freezes, expanding the fracture a little. When the water thaws it seeps a little farther into the expanded crack. The process is repeated many times, and eventually a piece of rock will be wedged away. 


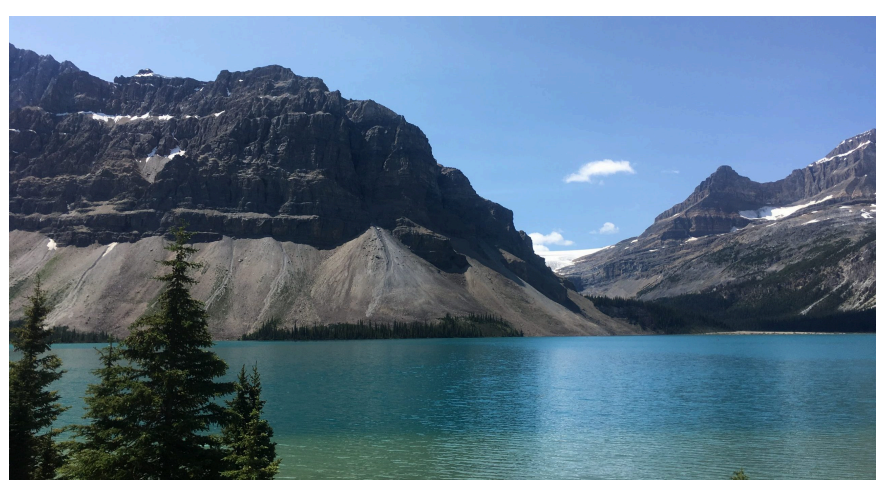

Figure 5.1.2: An area with very effective frost-wedging along glacial-fed Bow Lake in Banff National Park. The fragments that have been wedged away from the cliffs above have accumulated in a talus deposit at the base of the slope.
A related process, frost heaving, takes place within unconsolidated materials on gentle slopes. In this case, water in the soil freezes and expands, pushing the overlying material up. Frost heaving is responsible for winter damage to roads all over North America.

Mechanical weathering is greatly facilitated by erosion, which is the removal of weathering products, allowing for the exposure of more rock for weathering. A good example of this is shown in Figure 5.1.2. On the steep rock faces at the top of the cliff, rock fragments have been broken off by ice wedging, and then removed by gravity. This is a form of mass wasting. Other important agents of erosion that also have the effect of removing the products of weathering include water in streams (Lab 8), glacial ice, and waves on the coasts.

\section{Chemical Weathering}

Chemical weathering results from chemical changes to minerals that become unstable when they are exposed to surface conditions. The kinds of changes that take place are highly specific to the mineral and the environmental conditions. Some minerals, like quartz, are virtually unaffected by chemical weathering, while others, like feldspar, are easily altered. In general, the degree of chemical weathering is greatest in warm and wet climates, and least in cold and dry climates. The important characteristics of surface conditions that lead to chemical weathering are the presence of water (in the air and on the ground surface), the abundance of oxygen, and the presence of carbon dioxide, which produces weak carbonic acid $\left(\mathrm{H}_{2} \mathrm{CO}_{3}\right)$ when combined with water. That process, which is fundamental to most chemical weathering, can be shown as follows:

$\mathrm{H}_{2} \mathrm{O}+\mathrm{CO}_{2} \leftrightarrow \mathrm{H}_{2} \mathrm{CO}_{3}$ then $\mathrm{H}_{2} \mathrm{CO}_{3} \leftrightarrow \mathrm{H}^{+}+\mathrm{HCO}_{3}^{-}$

water + carbon dioxide $\leftrightarrow$ carbonic acid then carbonic acid $\leftrightarrow$ dissolved hydrogen ions + dissolved bicarbonate ions

Yikes! Chemical formulas

Lots of people seize up when they are asked to read chemical or mathematical formulas. It's OK, you don't necessarily have to! If you don't like the formulas just read the text underneath them. In time you may get used to reading the formulas.

The double-ended arrow " $\leftrightarrow$ " indicates that the reaction can go either way, but for our purposes these reactions are going towards the right.

Here we have water (e.g., as rain) plus carbon dioxide in the atmosphere, combining to create carbonic acid. 
Then carbonic acid dissociates (comes apart) to form hydrogen and bicarbonate ions. The amount of $\mathrm{CO}_{2}$ in the air is enough to make weak carbonic acid. There is typically much more $\mathrm{CO}_{2}$ in the soil, so water that percolates through the soil can become more acidic. In either case, this acidic water is a critical to chemical weathering.

In some types of chemical weathering the original mineral becomes altered to a different mineral. For example, feldspar is altered-by hydrolysis-to form clay minerals plus some ions in solution. In other cases the minerals dissolve completely, and their components go into solution. For example, calcite $\left(\mathrm{CaCO}_{3}\right)$ is soluble in acidic solutions.

The hydrolysis of feldspar can be written like this:

\author{
$\mathrm{CaAl}_{2} \mathrm{Si}_{2} \mathrm{O}_{8}+\mathrm{H}_{2} \mathrm{CO}_{3}+1 / 2 \mathrm{O}_{2} \leftrightarrow \mathrm{Al}_{2} \mathrm{Si}_{2} \mathrm{O}_{5}(\mathrm{OH})_{4}+\mathrm{Ca}^{2+}+\mathrm{CO}_{3}{ }^{2-}$ \\ plagioclase feldspar + carbonic acid $\leftrightarrow$ kaolinite + dissolved calcium ions + dissolved carbonate ions
}

This reaction shows calcium-bearing plagioclase feldspar, but similar reactions could also be written for sodium or potassium feldspars. In this case, we end up with the mineral kaolinite, along with calcium and carbonate ions in solution. Those ions can eventually combine (probably in the ocean) to form the mineral calcite. The hydrolysis of feldspar to clay is illustrated in Figure 5.1.3, which shows two images of the same granitic rock, a recently broken fresh surface on the left and a clay-altered weathered surface on the right. Other silicate minerals can also go through hydrolysis, although the end results will be a little different. For example, pyroxene can be converted to the minerals chlorite or smectite, and olivine can be converted to the mineral serpentine.
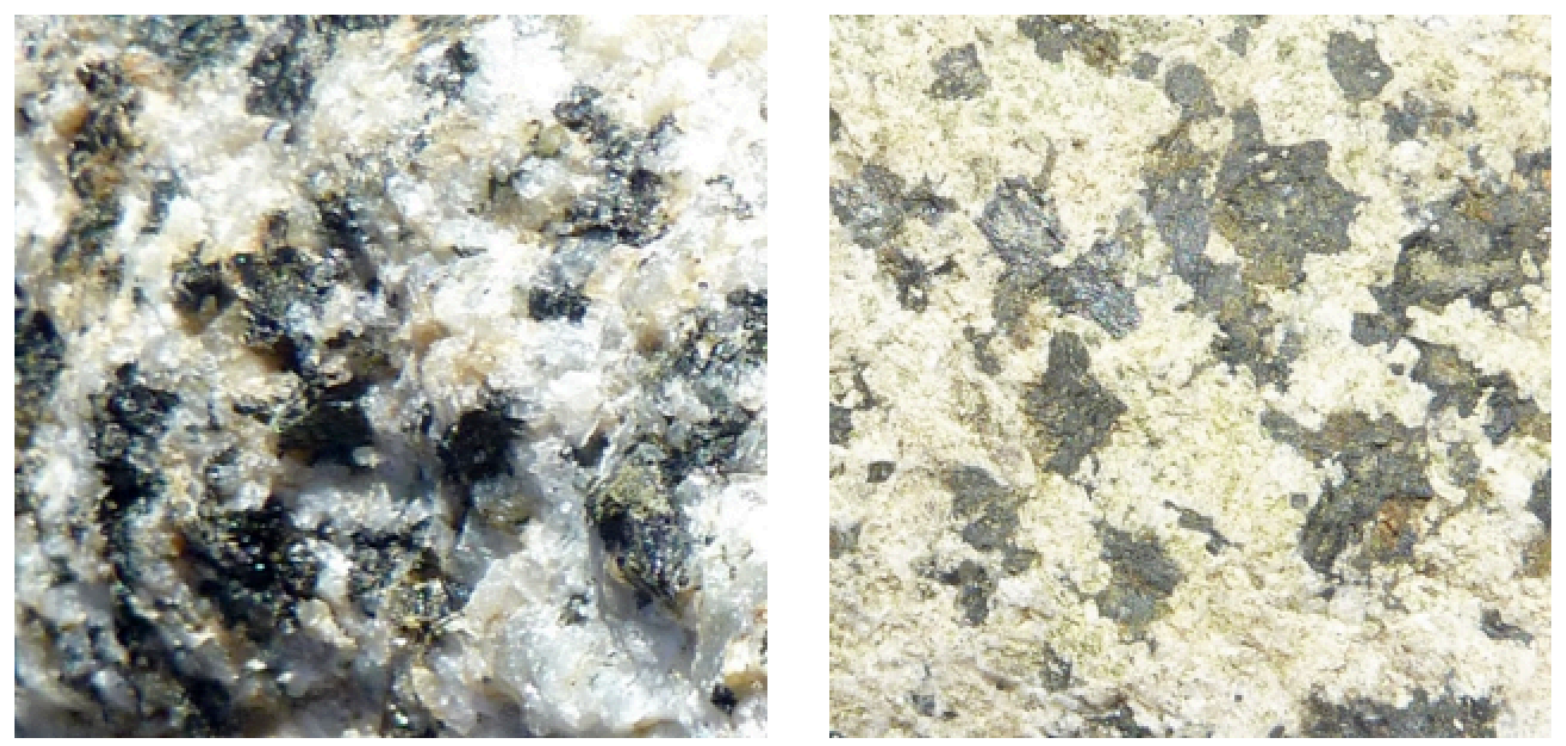

Figure 5.1.3: Unweathered (left) and weathered (right) surfaces of the same piece of granitic rock. On the unweathered surfaces the feldspars are still fresh and glassy-looking. On the weathered surface much of the feldspar has been altered to the chalky-looking clay mineral kaolinite.

Oxidation is another very important chemical weathering process. The oxidation of the iron in a ferromagnesian silicate starts with the dissolution of the iron. For olivine, the process looks like this, where olivine in the presence of carbonic acid is converted to dissolved iron, carbonate, and silicic acid: 
$\mathrm{Fe}_{2} \mathrm{SiO}_{4}+4 \mathrm{H}_{2} \mathrm{CO}_{3} \leftrightarrow 2 \mathrm{Fe}^{2^{+}}+4 \mathrm{HCO}_{3}^{-}+\mathrm{H}_{4} \mathrm{SiO}_{4}$

olivine + (carbonic acid) $\leftrightarrow$ dissolved iron ions + dissolved carbonate ions + dissolved silicic acid

But in the presence of oxygen and carbonic acid, the dissolved iron is then quickly converted to the mineral hematite:

$2 \mathrm{Fe}^{2^{+}}+4 \mathrm{HCO}_{3}{ }^{-}+1 / 2 \mathrm{O}_{2}+2 \mathrm{H}_{2} \mathrm{O} \leftrightarrow \mathrm{Fe}_{2} \mathrm{O}_{3}+4 \mathrm{H}_{2} \mathrm{CO}_{3}$

dissolved iron ions + dissolved bicarbonate ions + oxygen + water $\leftrightarrow$ hematite + carbonic acid

The equation shown here is for olivine, but it could apply to almost any other ferromagnesian silicate, including pyroxene, amphibole, or biotite. Iron in the sulphide minerals (e.g., pyrite) can also be oxidized in this way. And the mineral hematite is not the only possible end result, as there is a wide range of iron oxide minerals that can form in this way. The results of this process are illustrated in Figure 5.1.4, which shows a granitic rock in which some of the biotite and amphibole have been altered to form the iron oxide mineral limonite.

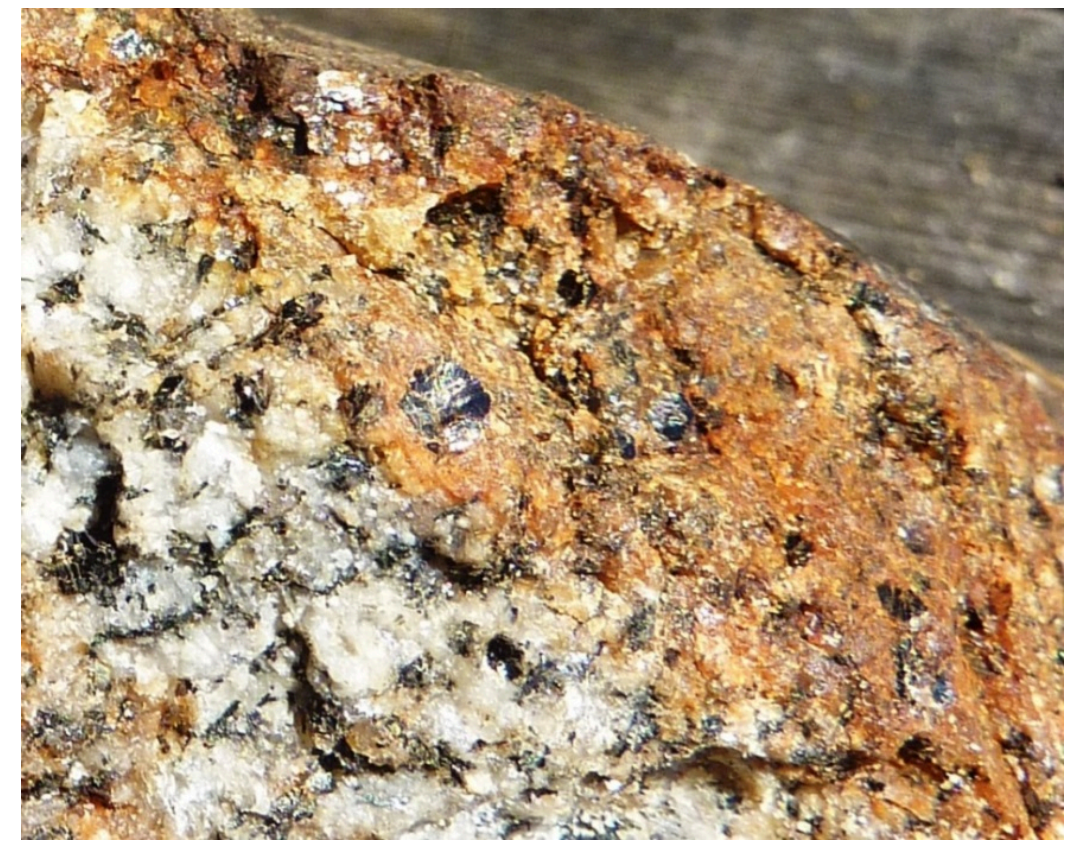

Figure 5.1.4: A granitic rock containing biotite and amphibole which have been altered near to the rock's surface to limonite, which is a mixture of iron oxide minerals.

A special type of oxidation takes place in areas where the rocks have elevated levels of sulphide minerals, especially pyrite $\left(\mathrm{FeS}_{2}\right)$. Pyrite reacts with water and oxygen to form sulphuric acid, as follows:

$2 \mathrm{FeS}_{2}+7 \mathrm{O}_{2}+2 \mathrm{H}_{2} \mathrm{O} \leftrightarrow 2 \mathrm{Fe}^{2+} \mathrm{H}_{2} \mathrm{SO}_{4}+2 \mathrm{H}^{+}$

pyrite + oxygen + water $\leftrightarrow$ dissloved iron ions + sulphuric acid + dissolved hydrogen ions

The runoff from areas where this process is taking place is known as acid rock drainage (ARD), and even a rock with $1 \%$ or $2 \%$ pyrite can produce significant ARD. While ARD does occur naturally when rocks con- 
taining pyrite are exposed at the Earth's surface, some of the worst examples of ARD are at mine sites. These sites can have significant problems with ARD, especially where pyrite-bearing rock and waste material have been mined from deep underground and then piled up and left exposed to water and oxygen. One example of that is the Mt. Washington Mine on Vancouver Island in B.C. (Figure 5.1.5), but there are many similar sites across Canada and around the world.
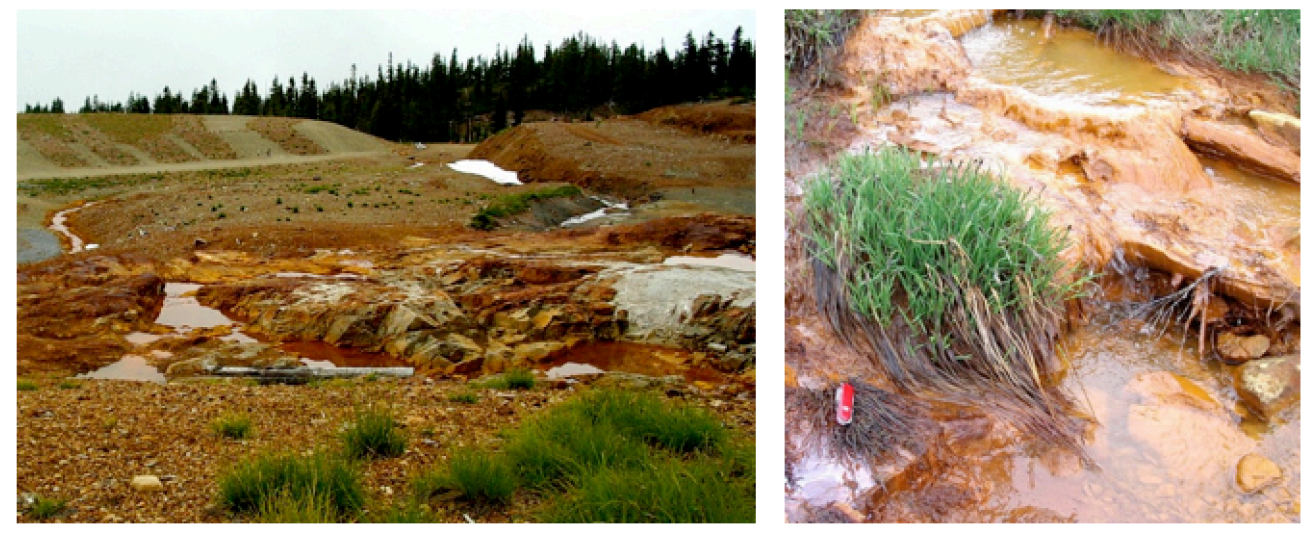

Figure 5.1.5: Exposed oxidizing and acid generating rocks and mine waste at the abandoned Mt. Washington Mine, B.C. (left), and an example of acid drainage downstream from the mine site (right).

The hydrolysis of feldspar and other silicate minerals and the oxidation of iron in ferromagnesian silicates all serve to create rocks that are softer and weaker than they were to begin with, and thus more susceptible to mechanical weathering.

The weathering reactions that we've discussed so far involved the transformation of one mineral to another mineral (e.g., feldspar to clay), and the release of some ions in solution (e.g., $\mathrm{Ca}^{2+}$ or $\mathrm{Fe}^{2+}$ ). Some weathering processes involve the complete dissolution of a mineral. Calcite, for example, will dissolve in weak acid, to produce calcium and bicarbonate ions. The equation is as follows:

$\mathrm{CaCO}_{3}+\mathrm{H}^{+}+\mathrm{HCO}_{3}^{-} \leftrightarrow \mathrm{Ca}^{2+}+2 \mathrm{HCO}_{3}^{-}$

calcite + dissolved hydrogen ions + dissolved bicarbonate ions $\leftrightarrow$ dissolved calcium ions + dissolved bicarbonate ions

Calcite is the major component of limestone (typically more than 95\%), and under surface conditions, limestone can dissolve completely. Limestone also dissolves at relatively shallow depths underground, forming limestone caves.

Practice Exercise 5.1 Chemical Weathering

The main processes of chemical weathering are hydrolysis, oxidation, and dissolution. Indicate which process is primarily involved during each of the following chemical weathering changes:

1. Pyrite to hematite

2. Calcite to calcium and bicarbonate ions

See Appendix 2 for Practice Exercise 5.1 answers. 


\section{Media Attributions}

- Figures 5.1.1, 5.1.3, 5.1.4, 5.1.5: (C) Steven Earle. CC BY.

- Figure 5.1.2: (C) Siobhan McGoldrick. CC BY. 


\subsection{The Products of Weathering and Erosion}

The products of weathering and erosion are the unconsolidated materials that we find around us on slopes, beneath, beside and on top of glaciers, in stream valleys, on beaches, and in deserts. The nature of these materials - their composition, size, degree of sorting, and degree of rounding-is determined by the type of rock that is being weathered, the nature of the weathering, the erosion and transportation processes, and the climate.

In addition to these solid sediments, the other important products of weathering are several different types of ions in solution.

A summary of the weathering products of some of the common minerals present in rocks is provided in Table 5.1. In addition to the weathering products listed in the table, most of the larger fragments-larger than sand grains - that make up sediments will be pieces of rock as opposed to individual minerals.

Table 5.1 A list of the typical weathering products of some of the minerals in common rocks

\begin{tabular}{|l|l|}
\hline Common Mineral & Typical Weathering Products \\
\hline Quartz & Quartz as sand grains \\
\hline Feldspar & Clay minerals plus potassium, sodium, and calcium in solution \\
\hline $\begin{array}{l}\text { Biotite and } \\
\text { amphibole }\end{array}$ & Chlorite plus iron and magnesium in solution \\
\hline Pyroxene and olivine & Serpentine plus iron and magnesium in solution \\
\hline Calcite & Calcium and carbonate in solution \\
\hline Pyrite & Iron oxide minerals plus iron in solution and sulphuric acid \\
\hline
\end{tabular}

Some examples of the products of weathering are shown in Figure 5.2.1. They range widely in size and shape depending on the processes involved in their transportation. If and when deposits like these are turned into sedimentary rocks, the textures of those rocks will vary significantly. Importantly, when we describe sedimentary rocks that formed millions of years in the past, we can use those properties to make inferences about the conditions that existed during their formation. 


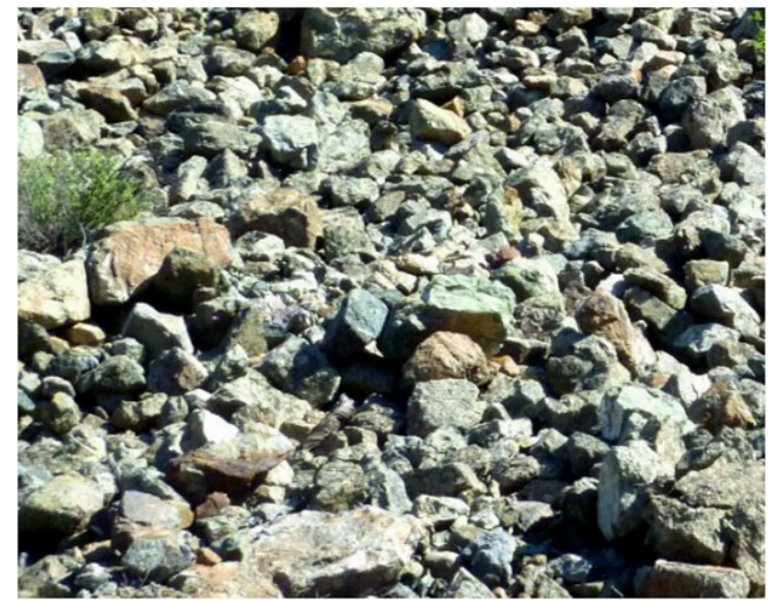

Boulders in a talus deposit at Keremeos. All are angular fragments from the same rock source.

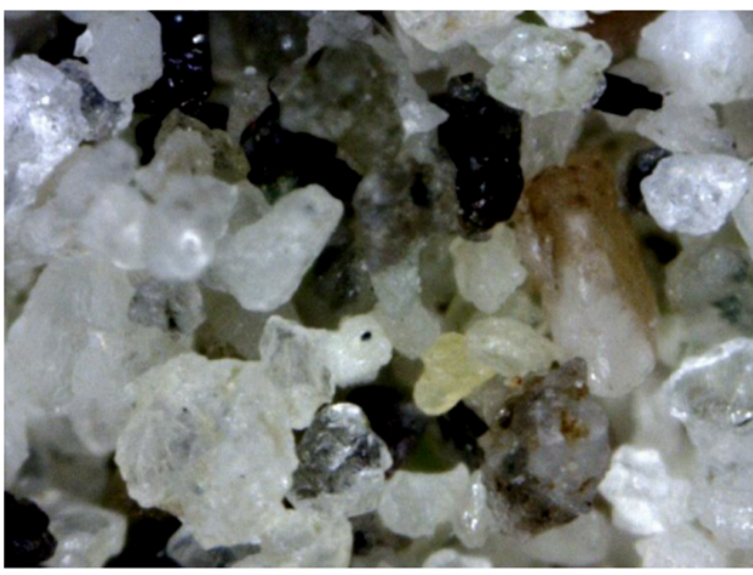

Sand from a beach at Gabriola. Most are angular quartz grains, some are fragments of rock.

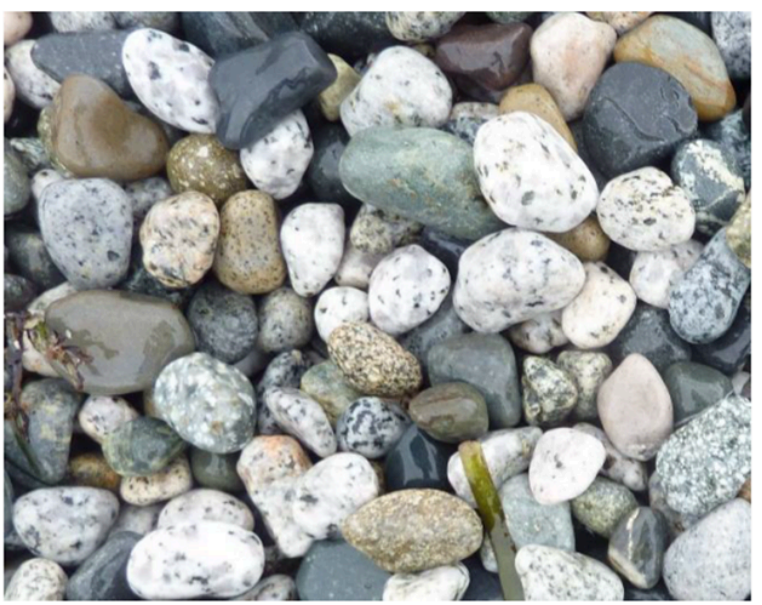

Pebbles on a beach in Victoria. All are rounded fragments of rock from different sources.

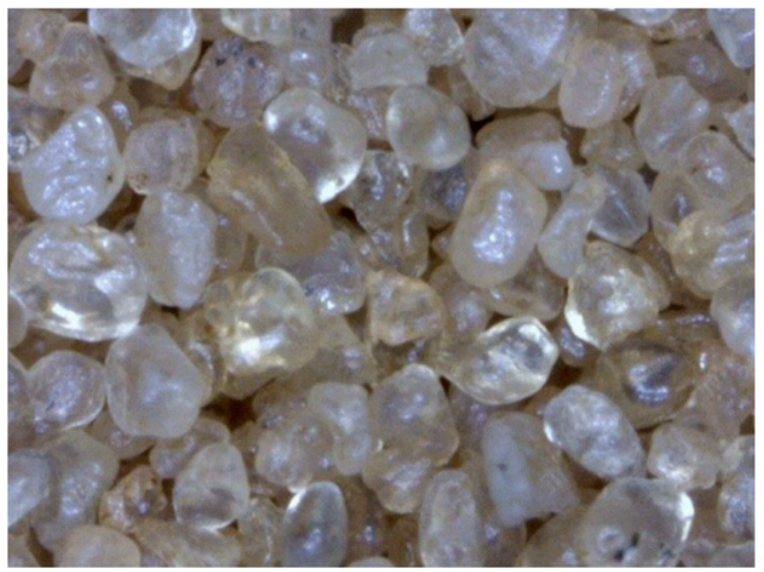

Sand from a dune in Utah. All are rounded quartz grains.

Figure 5.2.1: Products of weathering and erosion formed under different conditions.

We'll talk more about the nature and interpretation of sediments and sedimentary rocks in the next section, but it's worth considering here why the sand-sized sediments shown in Figure 5.2.1 are so strongly dominated by the mineral quartz, even though quartz makes up less than $20 \%$ of Earth's crust. The explanation is that quartz is highly resistant to the types of weathering that occur at Earth's surface. It is not affected by weak acids or the presence of oxygen. This makes it unique among the minerals that are common in igneous rocks. Quartz is also very hard, and doesn't have cleavage, so it is resistant to mechanical weathering.

So when a rock like granite is subject to chemical weathering the feldspar and the ferromagnesian silicates get converted to clays and dissolved ions such as: $\mathrm{Ca}^{2+}, \mathrm{Na}^{+}, \mathrm{K}^{+}, \mathrm{Fe}^{2+}, \mathrm{Mg}^{2+}$, and $\mathrm{H}_{4} \mathrm{SiO}_{4}$, but the quartz is resistant to those processes and remains intact. The clay gradually gets eroded away, then the rock breaks apart leaving lots of grains of quartz. In other words, quartz, clay minerals, and dissolved ions are the most common products of weathering. Quartz and some of the clay minerals tend to form sedimentary deposits on and at the edges of continents, while the rest of the clay minerals and the dissolved ions tend to be washed out into the oceans to form sediments on the sea floor. 
In the left side of the following table, a number of different sands are pictured and described. Describe some of the important weathering processes that might have led to the development of these sands.

See Appendix 2 for Practice Exercise 5.2 answers.

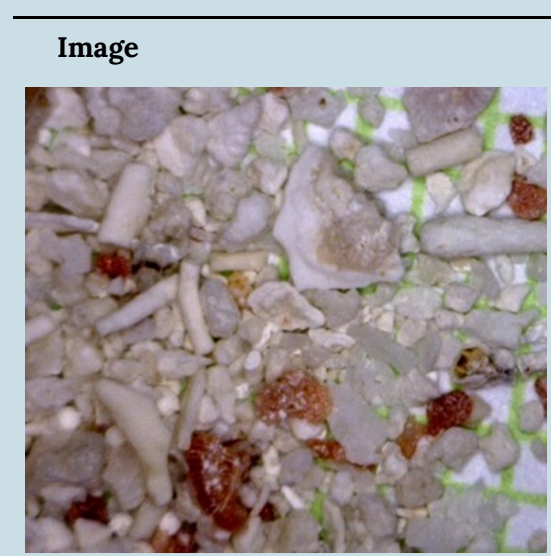

\section{Description and Location}

Fragments of coral, algae, and urchin from a shallow water area (roughly 2 metres deep) near a reef in Belize. The grain diameters are between 0.1 and 1 millimetres.

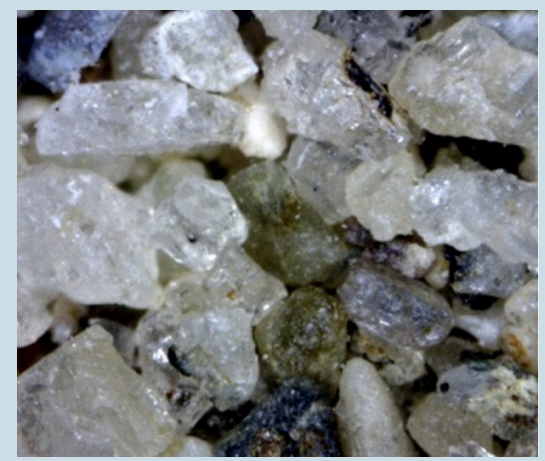

Angular quartz and rock fragments from a glacial stream deposit near Osoyoos, B.C. The grain diameters are between 0.25 and 0.5 milimetres.

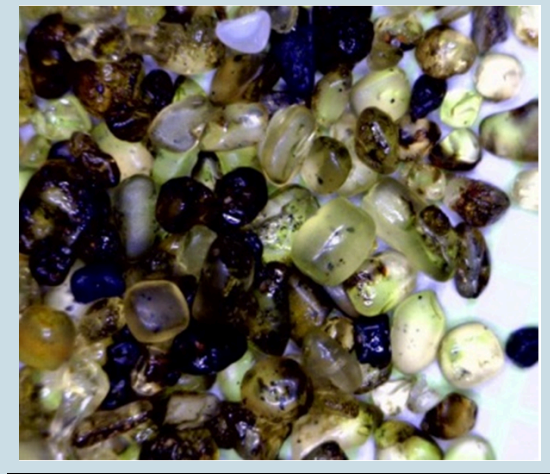

Rounded grains of olivine (green) and volcanic glass (black) from a beach on the big island of Hawaii. The grains are approximately 1 millimetre across.

\section{Media Attributions}

- Figure 5.2.1 and Practice Exercise 5.2 images: (C) Steven Earle. CC BY. 


\subsection{Clastic Sedimentary Rocks}

A clast is a fragment of rock or mineral, ranging in size from less than a micron ${ }^{1}$ (too small to see) to as big as an apartment block. Various types of clasts are shown in Figure 5.2.1 and in Practice Exercise 5.2. The smaller ones tend to be composed of a single mineral crystal, and the larger ones are typically composed of pieces of rock. As we've seen, most sand-sized clasts are made of quartz because quartz is more resistant to weathering than any other common mineral. Many of the clasts that are smaller than sand size (less than $1 / 16$ or $0.063 \mathrm{~mm}$ ) are made of clay minerals. Most clasts larger than sand size (greater than $2 \mathrm{~mm}$ ) are actual fragments of rock, and commonly these might be fine-grained rock like basalt or andesite, or if they are bigger, coarse-grained rock like granite or gneiss. Sedimentary rocks that are made up of clasts are called clastic sedimentary rocks. A comparable term is "detrital sedimentary rocks".

\section{Grain-Size Classification}

Geologists that study sediments and sedimentary rocks use the Udden-Wentworth grain-size scale for describing the sizes of the grains in these materials (Table 5.2). There are six main grain-size categories; five are broken down into subcategories, with clay being the exception. The diameter limits for each successive subcategory are twice as large as the one beneath it. In general, a boulder is bigger than a toaster and difficult to lift. There is no upper limit to the size of boulder. ${ }^{2}$ Sand ranges from 2 millimetres down to 0.063 millimetres, and its key characteristic is that it feels "sandy" or gritty between your fingers-even the finest sand grains feel that way. Silt is essentially too small for individual grains to be visible, and while sand feels sandy to your fingers, silt feels smooth to your fingers but gritty in your mouth. Clay is so fine that it feels smooth even in your mouth. 
Table 5.2 The Udden-Wentworth grain-size scale for classifying sediments and the grains that make up clastic sedimentary rocks

\begin{tabular}{|c|c|c|c|}
\hline Type & Description & Size range (millimetres, $\mathrm{mm}$ ) & Size range (microns, $\mu \mathrm{m})$ \\
\hline \multirow{3}{*}{ Boulder } & large & 1024 and up & \\
\hline & medium & 512 to 1024 & \\
\hline & small & 256 to 512 & \\
\hline \multirow{2}{*}{ Cobble } & large & 128 to 256 & \\
\hline & small & 64 to 128 & \\
\hline \multirow{5}{*}{ Pebble (Granule) } & very coarse & 32 to 64 & \\
\hline & coarse & 16 to 32 & \\
\hline & medium & 8 to 16 & \\
\hline & fine & 4 to 8 & \\
\hline & very fine & 2 to 4 & \\
\hline \multirow{5}{*}{ Sand } & very coarse & 1 to 2 & 1000 to 2000 \\
\hline & coarse & 0.5 to 1 & 500 to 1000 \\
\hline & medium & 0.25 to $0.5(1 / 4$ to $1 / 2 \mathrm{~mm})$ & 250 to 500 \\
\hline & fine & 0.125 to $0.25(1 / 8$ to $1 / 4 \mathrm{~mm})$ & 125 to 250 \\
\hline & very fine & 0.063 to $0.125(1 / 16$ to $1 / 8 \mathrm{~mm})$ & 63 to 125 \\
\hline \multirow{5}{*}{ Silt } & very coarse & & 32 to 63 \\
\hline & course & & 16 to 32 \\
\hline & medium & & 8 to 16 \\
\hline & fine & & 4 to 8 \\
\hline & very fine & & 2 to 4 \\
\hline Clay & clay & & 0 to 2 \\
\hline
\end{tabular}

If you drop a granule into a glass of water, it will sink quickly to the bottom (less than half a second). If you drop a grain of sand into the same glass, it will sink more slowly (a second or two depending on the size). A grain of silt will take several seconds to get to the bottom, and a particle of fine clay may never get there. The rate of settling is determined by the balance between gravity and friction, as shown in Figure 5.3.1. Large particles settle quickly because the gravitational force (which is proportional to the mass, and therefore to the volume of the particle) is much greater than the frictional resistance (which is proportional to the surface area of the particle). For smaller particles the difference between gravitational push and frictional resistance is less, so they settle slowly. 
Small particles that settle slowly spend longer suspended in the water, and therefore tend to get moved farther than large particles if the water is moving.

\section{Transportation}

One of the key principles of sedimentary geology is that the ability of a moving medium (air, ice, or water) to move sedimentary particles-and keep them moving-is dependent on the velocity of flow. The faster the medium flows, and therefore the higher the energy of the flow, the larger the particles it can move. This is illustrated in Figure 5.3.2. Parts of the river are moving faster than other parts, especially where the slope is greatest and the channel is narrow. Not only does the velocity of a river change from place to place, but it changes from season to season. During peak discharge ${ }^{3}$ at the location of Figure 5.3.2, the water is high enough to flow over the embankment on the right, and it flows fast enough to move the boulders that cannot be moved during low flows.
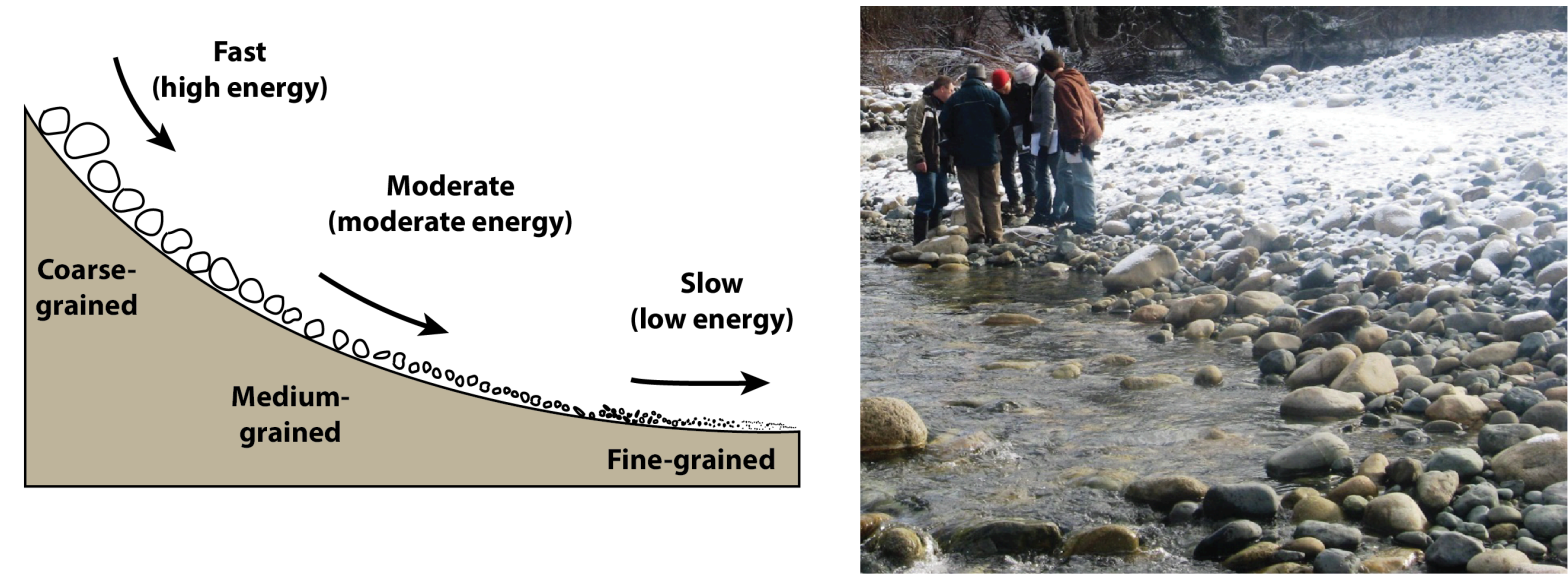

Figure 5.3.2: (left) Schematic relationship between flow velocity (fast, moderate, slow), energy, and clast size. (right) Variations in flow velocity on the Englishman River near Parksville, B.C. When the photo was taken the river was not flowing fast enough anywhere to move the boulders and cobbles visible here. During flood events the water flows right over the snow-covered bank on the right, and is fast enough to move boulders.

Clasts within streams are moved in several different ways, as illustrated in Figure 5.3.3. Large bed load clasts are pushed (by traction) or bounced along the bottom (by saltation), while smaller clasts are suspended in the water and kept there by the turbulence of the flow. As the flow velocity changes, different-sized clasts may be either incorporated into the flow or deposited on the bottom. At various places along a river, there are always some clasts being deposited, some staying where they are, and some being eroded and transported. This changes over time as the discharge of the river changes in response to changing weather conditions. 


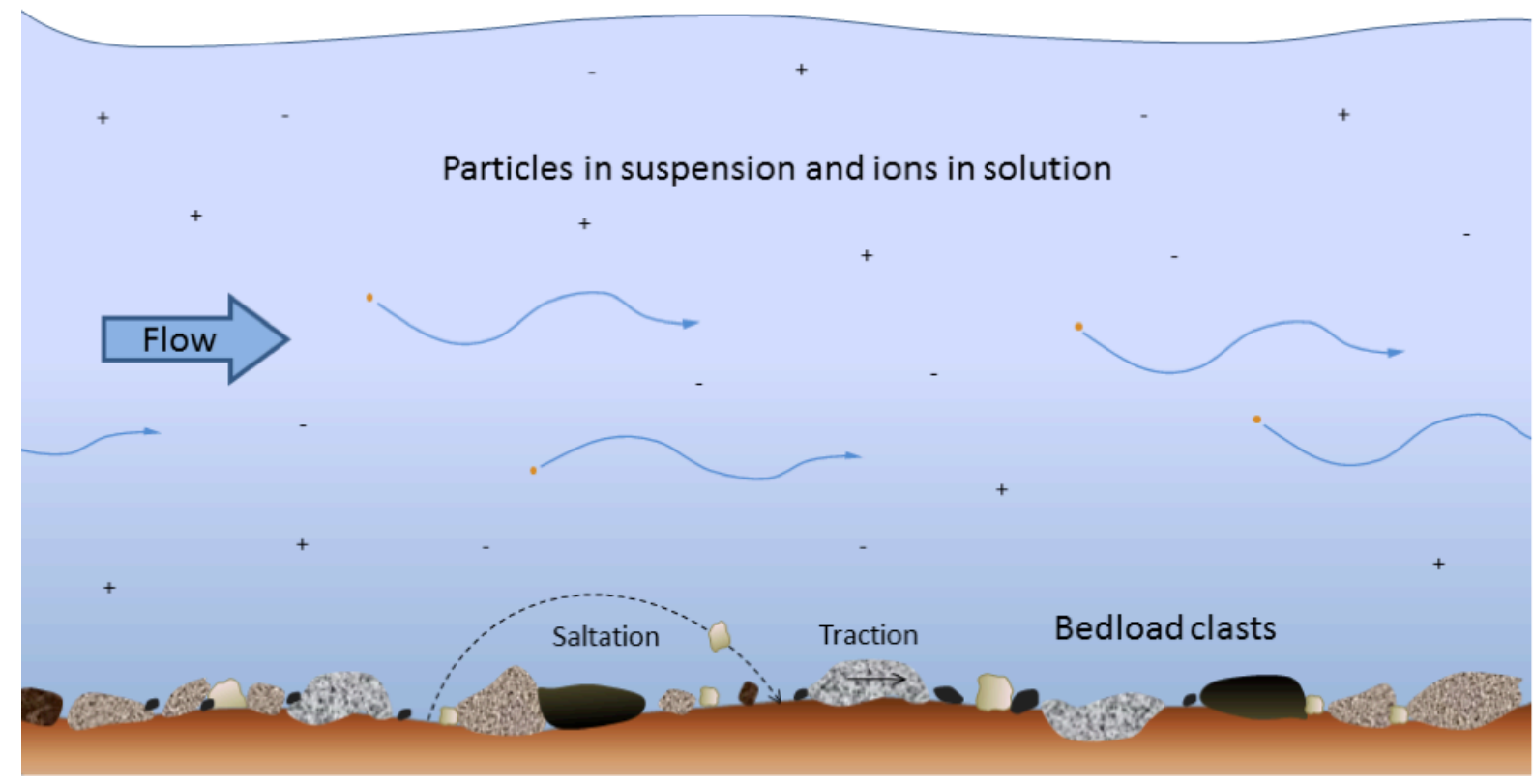

Figure 5.3.3: Transportation of sediment clasts by stream flow. The larger clasts, resting on the bottom (bedload), are moved by traction (sliding) or by saltation (bouncing). Smaller clasts are kept in suspension by turbulence in the flow. Ions (depicted as + and - in the image, but invisible in real life) are dissolved in the water.

Other sediment transportation media, such as waves, ocean currents, and wind, operate under similar principles, with flow velocity as the key underlying factor that controls transportation and deposition.

\section{Deposition}

When the velocity, and the energy level, of the transporting medium (e.g., flowing water in a river, ice in a glacier, wind) decreases and it no longer has sufficient energy to continue transporting sediment, the sediment is deposited. For example, where a river flows into the sea, the velocity of the water decreases abruptly, and the sediment that can no longer be carried is deposited to form a delta. Clastic sediments are deposited in a wide range of environments, including glacial environments, talus slopes, alluvial fans, rivers-both fast and slow-lakes, deltas, and ocean environments-both shallow and deep. If the sedimentary deposits last long enough to be covered with other sediments they may eventually form into rocks ranging from fine shale to coarse conglomerate.

\section{Burial and Lithification}

Lithification is the term used to describe a number of different processes that take place within a deposit of sediment to turn it into solid rock (Figure 5.3.4). One of these processes is burial by other sediments, which leads to compaction of the material and removal of some of the intervening water and air. After this stage, the individual clasts are touching one another. Cementation is the process of crystallization of minerals within the pores (void space) between the small clasts, and especially at the points of contact between clasts. Depending on the pressure, temperature, and chemical conditions, this cement might be formed by 
a range of minerals, the common ones being calcite, hematite, and quartz. You can determine whether a clastic sedimentary rock, like a sandstone, is cemented with calcite by adding a drop of dilute acid to a fresh surface on the sample. If the sample reacts readily with the acid, it is likely cemented by calcite.

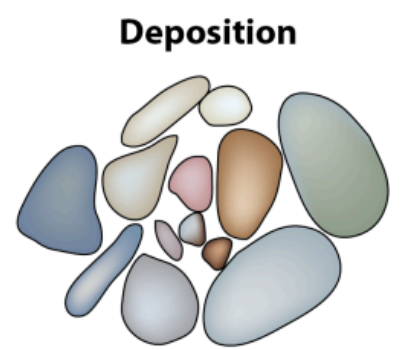

Clasts are dropped or settle out.

\section{Lithification turns} sediment into rock

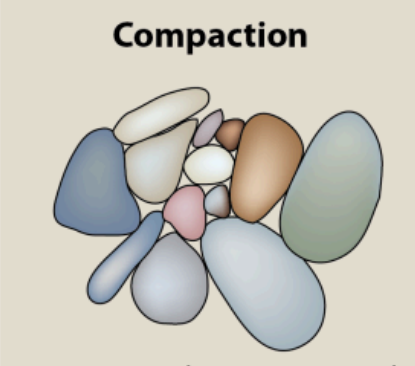

As more sediments accumulate above, clasts are forced closer together.

\section{Cementation}

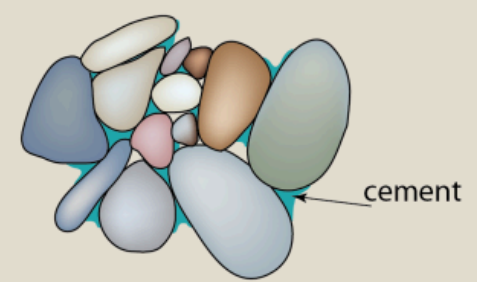

Groundwater moves between the grains and leaves behind mineral deposits, bonding the grains to each other.

\section{LITHIFICATION}

Figure 5.3.4: Lithification turns sediments into solid rock. Lithification involves the compaction of sediments and then the cementation of grains by minerals that precipitate from groundwater in the spaces between these grains.

\section{Roundness and Sorting}

For any geologist describing sediments and clastic sedimentary rocks, it is not only the size of the clasts that is important for classification, but also the range of sizes and shapes. To describe the shape of clasts in a sedimentary rock, or grains in a unconsolidated sediment, geologists use the term roundness. This scale of roundness from angular to well-rounded is illustrated in Figure 5.3.5. The roundness of a clast tends to reflect the extent to which it has been transported, but keep in mind that the composition of the clast also plays an important role! Grains of phyllosilicate minerals such as biotite or muscovite, for example, will never form rounded grains due to their sheet-like shape. Typically, the longer a clast is in transport, the more it is abraded by other clasts and the more rounded it becomes. Angular clasts, like those common to talus slopes beneath steep mountains, tend to indicate deposition very close to their source, meaning that they have not experienced significant transport. 

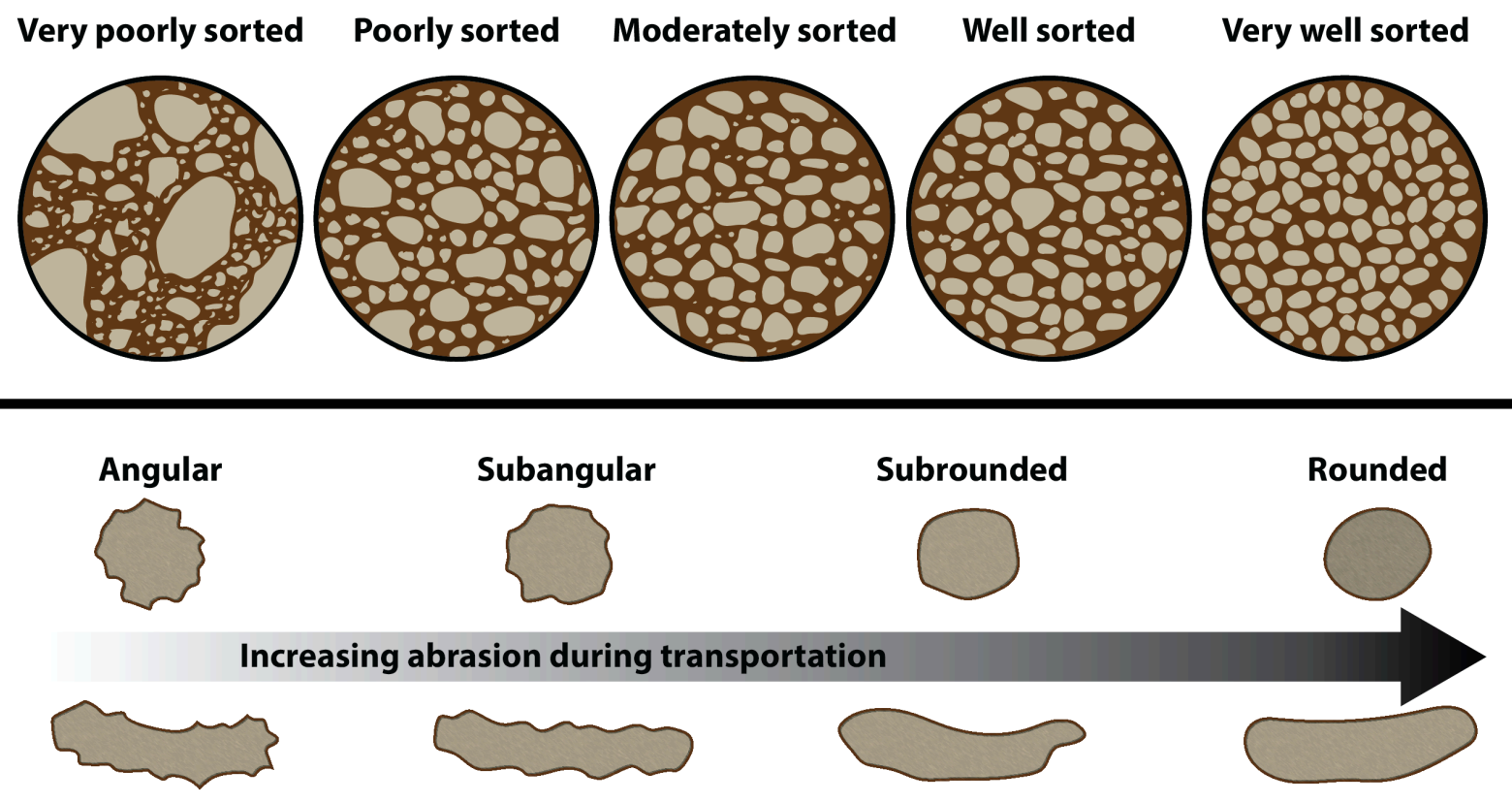

Figure 5.3.5: A visual reference for descriptions of sorting (top) and roundness (bottom) of sediments and grains in clastic sedimentary rocks. Note that rounded grains are not necessarily spherical in shape! Grain shapes are controlled by both the extent of transportation (and abrasion) and by the physical properties of the grain.

Increased transport also tends to result in well-sorted sediment deposits. Sorting refers to the range of grain sizes in a sediment deposit or in a clastic sedimentary rock (Figure 5.3.5). Poorly sorted sediments contain a wide range of grain sizes. Deposits of glacial till, for example, tend to be very poorly sorted as they contain grain sizes ranging from house-sized boulders to very fine grains of clay. A deposit of fine sand on a beautiful sandy beach, on the other hand, is an example of a well-sorted sediment, as all the grains are sand-sized.

\section{Classification of Clastic Sedimentary Rocks}

Clastic sedimentary rocks are classified and named based on both composition and texture. The composition of the grains is particularly important for sandstones, as described below and in Figure 5.3.6. Texture in this case refers to grain size (using the Udden-Wentworth grain-size scale in Table 5.2), roundness, and sorting. The characteristics and distinguishing features of clastic sedimentary rocks are summarized in Table 5.3. 
Table 5.3 The main types of clastic sedimentary rocks and their characteristics. You are expected to be able to identify the bolded rock names in this course.

\begin{tabular}{|c|c|c|}
\hline Group & Examples & Characteristics \\
\hline Conglomerate & & $\begin{array}{l}\text { Dominated by rounded clasts, granule size and larger }(>2 \mathrm{~mm}) \text {, poorly to very } \\
\text { poorly sorted }\end{array}$ \\
\hline Breccia & & $\begin{array}{l}\text { Dominated by angular clasts, granule size and larger }(>2 \mathrm{~mm}) \text {, poorly to very } \\
\text { poorly sorted }\end{array}$ \\
\hline \multirow{3}{*}{ Sandstone } & $\begin{array}{l}\text { quartz } \\
\text { sandstone }\end{array}$ & $\begin{array}{l}\text { Dominated by sand ( } 1 / 16 \text { to } 2 \mathrm{~mm}) \text {, greater than } 90 \% \text { quartz, range of roundness } \\
\text { and sorting possible }\end{array}$ \\
\hline & $\begin{array}{l}\text { arkose } \\
\text { (feldspathic } \\
\text { sandstone) }\end{array}$ & $\begin{array}{l}\text { Dominated by sand ( } 1 / 16 \text { to } 2 \mathrm{~mm}) \text {, greater than } 10 \% \text { feldspar, range of roundness } \\
\text { and sorting possible }\end{array}$ \\
\hline & lithic wacke & $\begin{array}{l}\text { Dominated by sand ( } 1 / 16 \text { to } 2 \mathrm{~mm}) \text {, greater than } 10 \% \text { rock fragments, greater than } \\
15 \% \text { silt and clay, range of roundness and sorting possible }\end{array}$ \\
\hline \multirow{2}{*}{ Mudrock } & mudstone & $\begin{array}{l}\text { Greater than } 75 \% \text { silt }(1 / 256 \text { to } 1 / 16 \mathrm{~mm}) \text { and clay }(<1 / 256 \mathrm{~mm}) \text {, not bedded, } \\
\text { well-sorted, grains too fine to judge roundness using hand lens }\end{array}$ \\
\hline & shale & $\begin{array}{l}\text { Greater than } 75 \% \text { silt }(1 / 256 \text { to } 1 / 16 \mathrm{~mm}) \text { and clay }(<1 / 256 \mathrm{~mm}) \text {, thinly bedded, } \\
\text { well-sorted, grains too fine to judge roundness using hand lens }\end{array}$ \\
\hline
\end{tabular}

Mudrock is composed of at least $75 \%$ silt- and clay-sized fragments. If it shows evidence of bedding or fine laminations, it is shale; otherwise, it is mudstone. Mudrocks form in very low energy environments, such as lakes, river backwaters, and the deep ocean.

It's worth taking a closer look at the different types of sandstone because sandstone is a common and important sedimentary rock. Typical sandstone compositions are shown in Figure 5.3.6. Sandstones are mostly made up of sand-sized grains of course, but they also include some finer material-both silt and clay. The term arenite applies to a so-called "clean" sandstone, meaning one with less than $15 \%$ silt and clay. Considering the sand-sized grains only (the grains larger than $1 / 16$ or $0.063 \mathrm{~mm}$ ), arenites with greater than $90 \%$ quartz are called quartz arenites. If they have more than $10 \%$ feldspar and more feldspar than rock fragments, they are called feldspathic arenites or arkosic arenites (or just arkose). If they have more than $10 \%$ rock fragments, and more rock fragments than feldspar, they are lithic arenites. ${ }^{4}$ A sandstone with more than $15 \%$ silt or clay is called a wacke (pronounced wackie). The terms quartz wacke, lithic wacke, and felds-

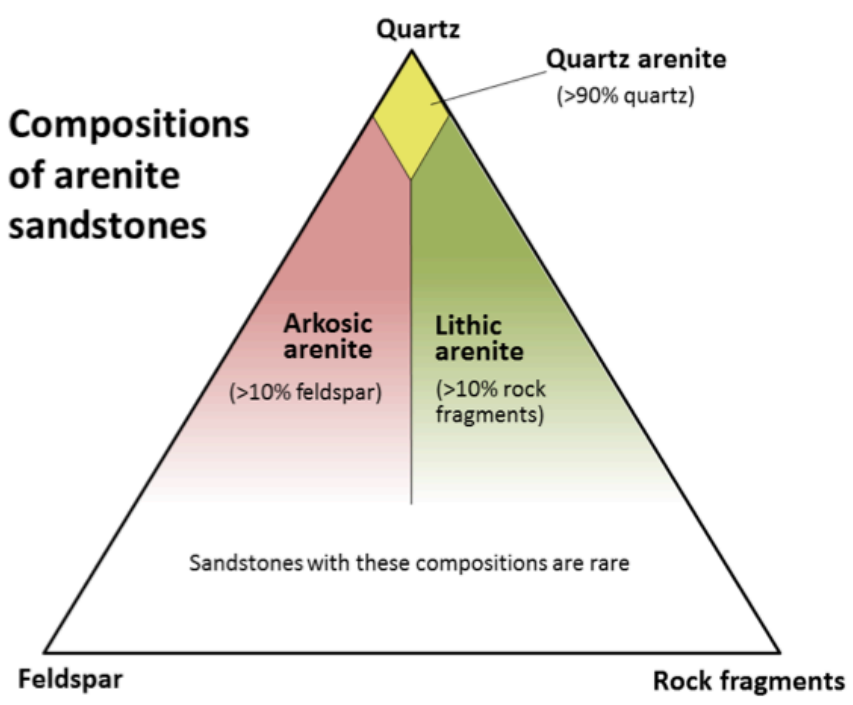

Figure 5.3.6: A compositional triangle for arenite sandstones, with the three most common components of sand-sized grains: quartz, feldspar, and rock fragments. Arenites have less than $15 \%$ silt or clay. Sandstones with more than 15\% silt and clay are called wackes (e.g., quartz wacke, lithic wacke).

pathic wacke are used with limits similar to those on the arenite diagram. Another name for a lithic wacke is greywacke. Sandstones form in a wide range of environments, including rivers, lakes, beaches, deserts, and shallow oceans.

Some examples of sandstones, magnified in thin section are shown in Figure 5.3.7. (A thin section is rock sliced thin enough so that light can shine through.) 


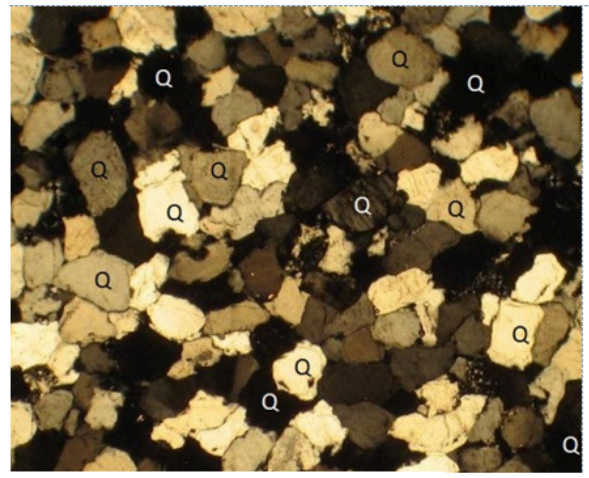

Quartz arenite

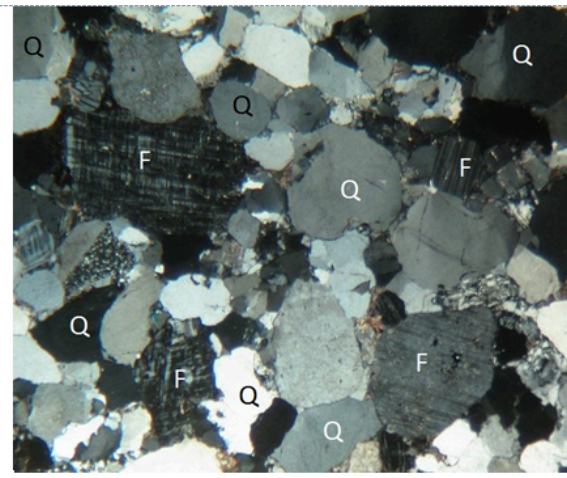

Arkose

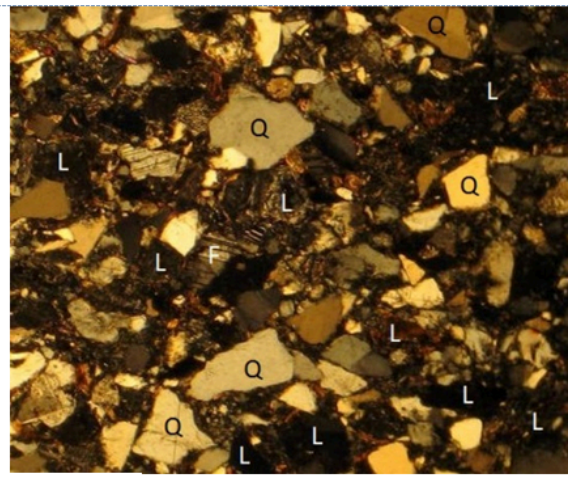

Lithic wacke

Figure 5.3.7: Microscope photos of three types of sandstone in thin-section. Some of the minerals are labelled: $\mathrm{Q}=q u a r t z$, $\mathrm{F}=$ feldspar and $\mathrm{L}=$ lithic (rock fragments). The quartz arenite and arkose have relatively little silt-clay matrix between the larger sand-sized grains, while the lithic wacke has abundant matrix.

Clastic sedimentary rocks in which a significant proportion of the clasts are larger than $2 \mathrm{~mm}$ are known as conglomerate if the clasts are well rounded, and breccia if they are angular. Conglomerates form in high-energy environments such as fast-flowing rivers, where the particles can become rounded. Breccias, characterized by their granule and larger-sized angular clasts, typically form where the particles are not transported a significant distance in water, such as alluvial fans and talus slopes. Some examples of clastic sedimentary rocks are shown on Figure 5.3.8. 


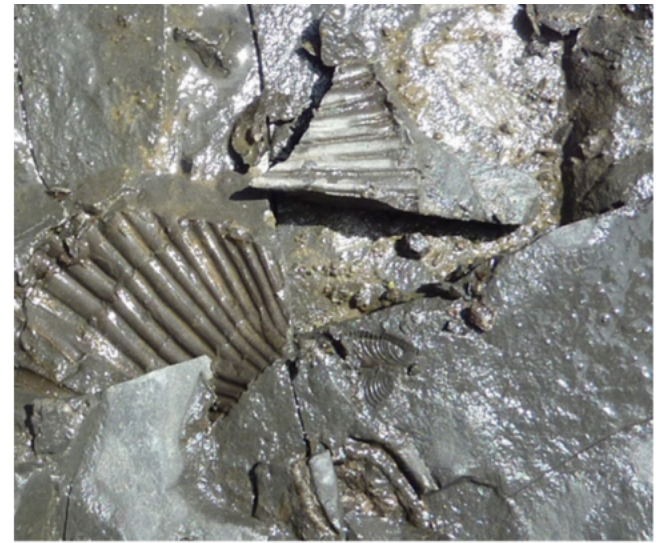

(a) Mudrock with bivalve impressions, Cretaceous Nanaimo Group, Browns River, Vancouver Island

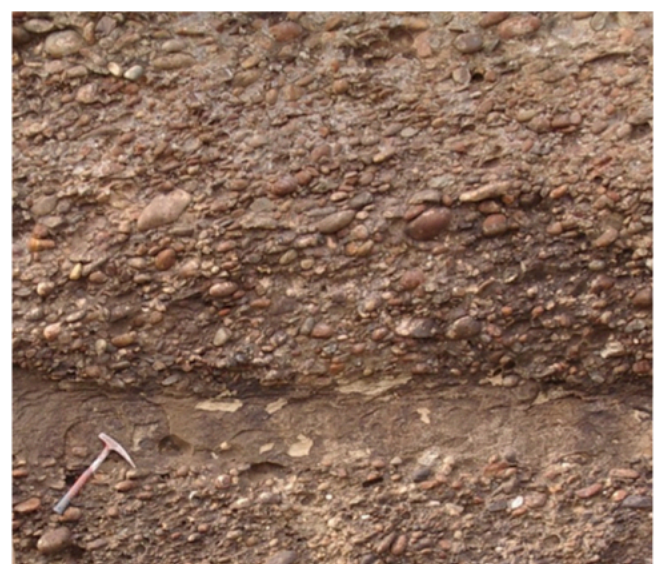

(c) Conglomerate with imbricate (aligned, tilted down to the left) cobbles, Cretaceous Geoffrey Formation, Hornby Island, BC

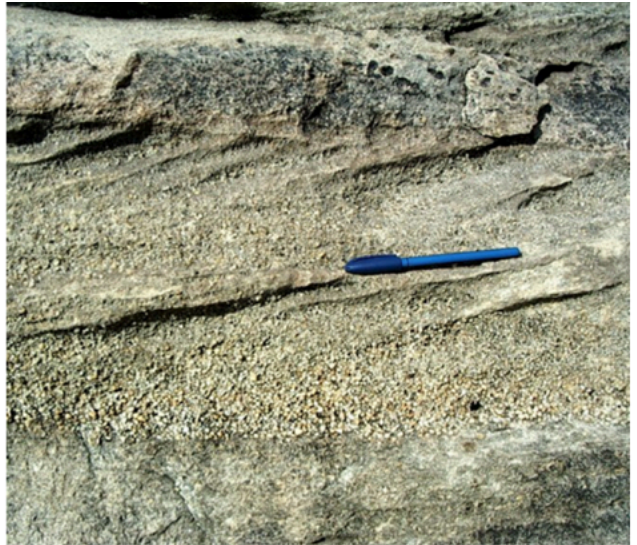

(b) Coarse sandstone with cross-bedding,

Cambrian Tapeats Formation Chino Valley, Arizona

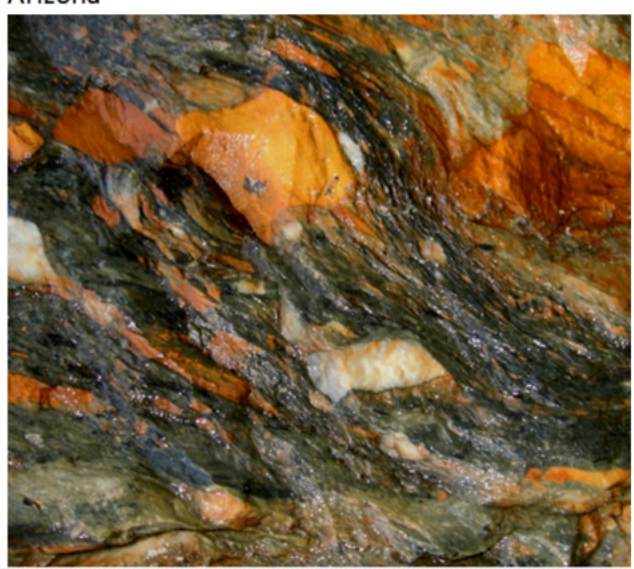

(d) Sedimentary breccia, the Pre-Cambrian Toby Formation, east of Castlegar, BC (image is approx. $1 \mathrm{~m}$ across)

Figure 5.3.8: Examples of various clastic sedimentary rocks.

Table 5.4 below shows magnified thin sections of three sandstones, along with descriptions of their compositions. Using Table 5.3 and Figure 5.3.6, find an appropriate name for each of these rocks. Using Figure 5.3.5, describe the roundness and sorting in each of the sandstones. 
Table 5.4 Classifying sandstones

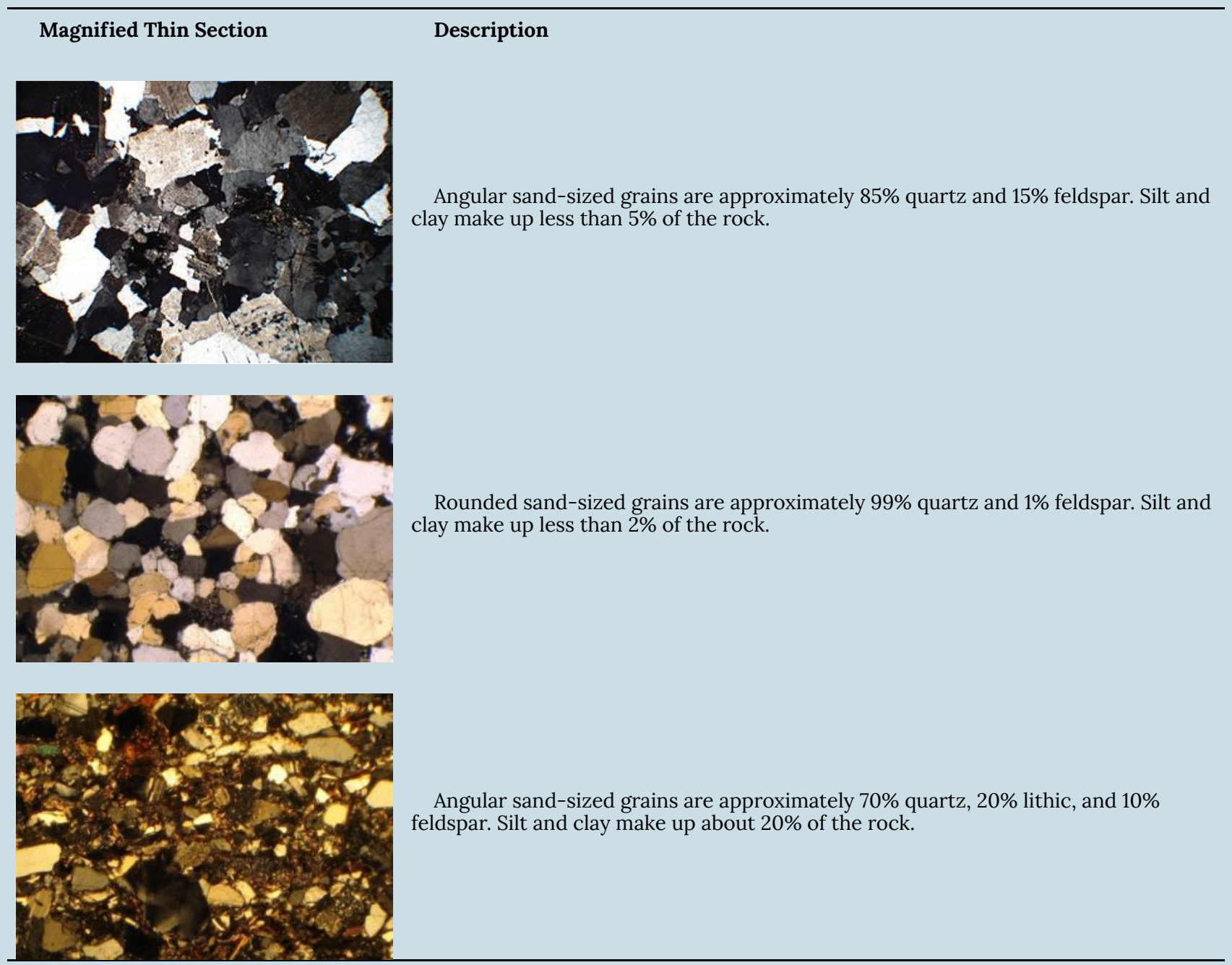

See Appendix 2 for Practice Exercise 5.3 answers.

\section{Media Attributions}

- Figures 5.3.1, 5.3.2 (right), 5.3.3, 5.3.6, 5.3.7, 5.3.8, Practice Exercise 5.3 bottom two images: (C) Steven Earle. CC BY.

- Figure 5.3.2 (left): (C) Siobhan McGoldrick. CC BY.

- Figure 5.3.4: CKarla Panchuk. CC BY.

- Figure 5.3.5: (C) Siobhan McGoldrick. CC BY.

- Practice Exercise 5.3, first image: Aplite Red (C) Rudolf Pohl. CC BY-SA. 


\section{Notes}

1. A micron is a millionth of a metre. There are 1,000 microns in a millimetre.

2. The largest known free-standing rock (i.e., not part of bedrock) is Giant Rock in the Mojave Desert, California. It's about as big as an apartment building-seven stories high!

3. Discharge of a stream is the volume of flow passing a point per unit time. It's normally measured in cubic metres per second $\left(\mathrm{m}^{3} / \mathrm{s}\right)$.

4. "Lithic" means "rock." Lithic clasts are rock fragments, as opposed to mineral fragments. 


\subsection{Chemical Sedimentary Rocks}

Whereas clastic sedimentary rocks are dominated by components that have been transported as solid clasts (clay, silt, sand, etc.), chemical sedimentary rocks are dominated by components that have been transported as ions in solution $\left(\mathrm{Na}^{+}, \mathrm{Ca}^{2+}, \mathrm{HCO}_{3}{ }^{-}\right.$, etc.). There is some overlap between the two because almost all clastic sedimentary rocks contain cement formed from dissolved ions, and many chemical sedimentary rocks include some clasts. Since ions can stay in solution for tens of thousands of years (some much longer), and can travel for tens of thousands of kilometres, it is virtually impossible to relate chemical sediments back to their source rocks.

Chemical weathering and chemical sedimentary rocks

Many students confuse chemical weathering with chemical sedimentary rocks, or mistakenly assume that when and where chemical weathering is taking place, chemical sedimentary rocks will accumulate. Most ions in solution in rivers, lakes and the ocean are produced during chemical weathering, but those ions can remain in solution for millions of years, and during that time they can travel hundreds of thousands of km (yes, literally around the world, several times). They might eventually come out of solution as a result of a biological process or a change in the chemical conditions and will then become a mineral crystal that can settle to form a chemical sediment.

So the calcium ions that are part of a calcite mud on the sea floor near Australia's Great Barrier Reef could literally have come from anywhere on Earth (and almost certainly came from many different places), and might have been in solution for as little as a few days or for as long as tens of millions of years.

The most common chemical sedimentary rock, by far, is limestone. Others include chert, chalk, evaporites like rock gypsum and rock salt, and coal. Biological processes are important in the formation of some chemical sedimentary rocks, especially limestone, chert, and coal. For example, limestone is made up almost entirely of fragments of marine ${ }^{1}$ organisms that manufacture calcite for their shells and other hard parts, and most chert includes at least some of the silica tests (shells) of tiny marine organisms (such as diatoms and radiolarians). Coal forms in fluvial or delta environments from decaying plant matter that accumulates in long-lasting swamps with low oxygen levels.

Chemical sedimentary rocks are classified based on their composition. As these rocks are often monomineralic, you will find that some of the same physical properties you learned in Lab 2 can be utilized to identify chemical sedimentary rocks. For instance, rock gypsum is comprised predominantly of the mineral gypsum and can be easily identified by its hardness $(\mathrm{H}=2$, can be scratched with a fingernail).

The name of a chemical sedimentary rock can be modified by a textural term, to create a more descriptive and meaningful name. Some important textures for chemical sedimentary rocks include crystalline, oolitic, bioclastic, fossiliferous ${ }^{2}$, and amorphous. A simplified classification chart for chemical sedimentary rocks is presented in Table 5.5 . 
Table 5.5: Classification chart for chemical sedimentary rocks

\begin{tabular}{|c|c|c|c|}
\hline Composition & Texture & Distinctive Properties & Rock Name \\
\hline \multirow{5}{*}{$\begin{array}{l}\text { Calcite }\left(\mathrm{CaCO}_{3}\right) \\
\text { *Note that all lime- } \\
\text { stones will react with } \\
\text { dilute } \mathrm{HCl} \text {. }\end{array}$} & Crystalline & Crystalline; fine to coarse grained & Crystalline limestone \\
\hline & Fossiliferous & $\begin{array}{l}\text { Various fossil fragments well } \\
\text { cemented together }\end{array}$ & Fossiliferous limestone \\
\hline & Oolitic & $\begin{array}{l}\text { Comprised of ooids (spheroidal } \\
\text { particles typically }<2 \mathrm{~mm} \text { in } \\
\text { diameter) }\end{array}$ & Oolitic limestone \\
\hline & Bioclastic & $\begin{array}{l}\text { Visible shell fragments weakly } \\
\text { cemented together }\end{array}$ & Coquina \\
\hline & Bioclastic & Soft rock made of microscopic shells & Chalk \\
\hline Quartz $\left(\mathrm{SiO}_{2}\right)$ & Microcrystalline & $\begin{array}{l}\text { Microcrystalline; hardness of } \sim 7 \text { (can } \\
\text { scratch glass); may exhibit } \\
\text { conchoidal fracture }\end{array}$ & $\begin{array}{l}\text { Chert (note that dark coloured } \\
\text { varieties may be called flint and red } \\
\text { coloured varieties may be called } \\
\text { jasper) }\end{array}$ \\
\hline Halite (NaCl) & Crystalline & $\begin{array}{l}\text { Crystalline; fine to coarse grained; } \\
\text { commonly forms cubic crystals; } \\
\text { tastes salty }\end{array}$ & Rock salt \\
\hline Gypsum $\left(\mathrm{CaSO}_{4} \cdot \mathrm{H}_{2} \mathrm{O}\right)$ & Crystalline & $\begin{array}{l}\text { Crystalline; fine to coarse grained; } \\
\text { hardness } \sim 2 \text { (can scratch with } \\
\text { fingernail) }\end{array}$ & Rock gypsum \\
\hline $\begin{array}{l}\text { Organic material } \\
\text { (plant fragments) }\end{array}$ & Amorphous & $\begin{array}{l}\text { Black brittle rock with amorphous } \\
\text { texture; low density }\end{array}$ & Coal \\
\hline
\end{tabular}

\section{Limestone}

Almost all limestone forms in the oceans, and most of that forms on the shallow continental shelves, especially in tropical regions with coral reefs. Reefs are highly productive ecosystems populated by a wide range of organisms, many of which use calcium and bicarbonate ions in seawater to make carbonate minerals (especially calcite) for their shells and other structures. These include corals, of course, but also green and red algae, urchins, sponges, molluscs, and crustaceans. The hard parts of these organisms are eroded by waves and currents to produce carbonate fragments that accumulate in the surrounding region.

Figure 5.4.1 shows a cross-section through a typical reef in a tropical environment (normally between $40^{\circ} \mathrm{N}$ and $40^{\circ} \mathrm{S}$ ). Reefs tend to form in areas with clear water (e.g., not close to the mouths of large rivers), and near the edges of steep drop-offs because the reef organisms thrive on nutrient-rich upwelling currents. As the reef builds up, it is eroded by waves and currents to produce carbonate sediments that are transported into the steep offshore fore reef area and the shallower inshore back reef area. These sediments are dominated by reef-type carbonate fragments of all sizes, including mud. In many such areas, carbonate-rich sediments also accumulate in quiet lagoons, where mud and mollusc-shell fragments predominate (Figure 5.4.2a) or in offshore areas with strong currents, where either foraminifera tests accumulate (Figure 5.4.2b) or calcite crystallizes inorganically to form ooids-spheres of calcite that form in shallow tropical ocean water with strong currents (Figure 5.4.2c). Coquina, another type of limestone, forms from shells and shell fragments mechanically broken by waves and once deposited, loosely cemented together. 


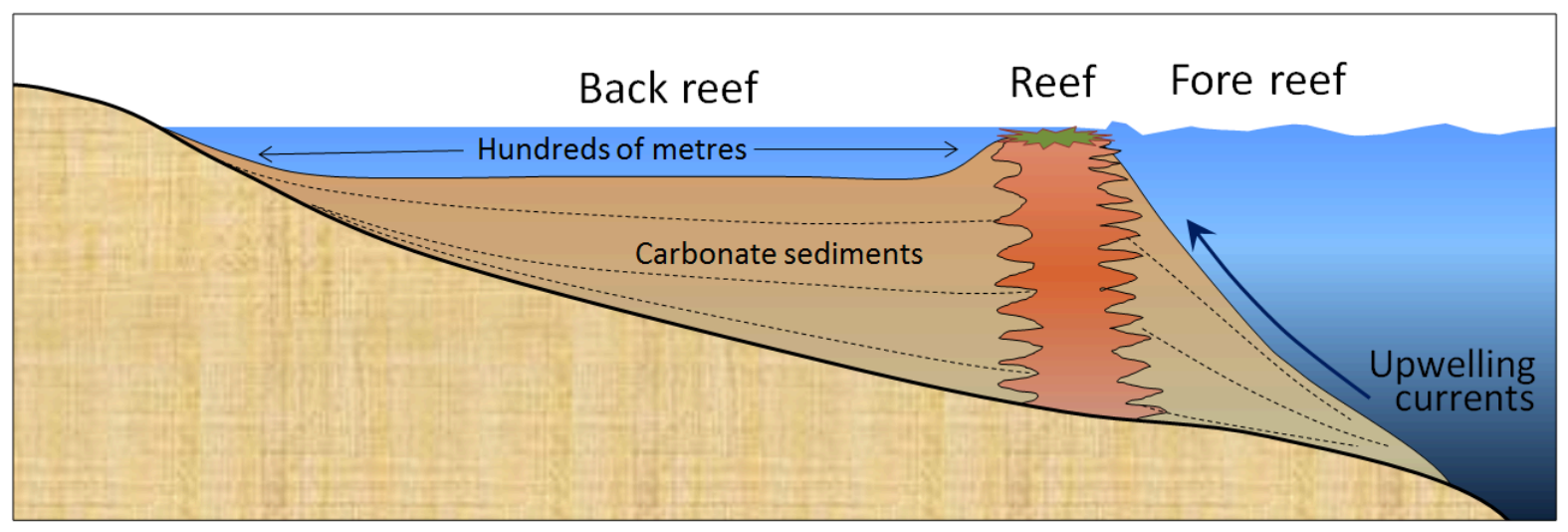

Figure 5.4.1: Schematic cross-section through a typical tropical reef.
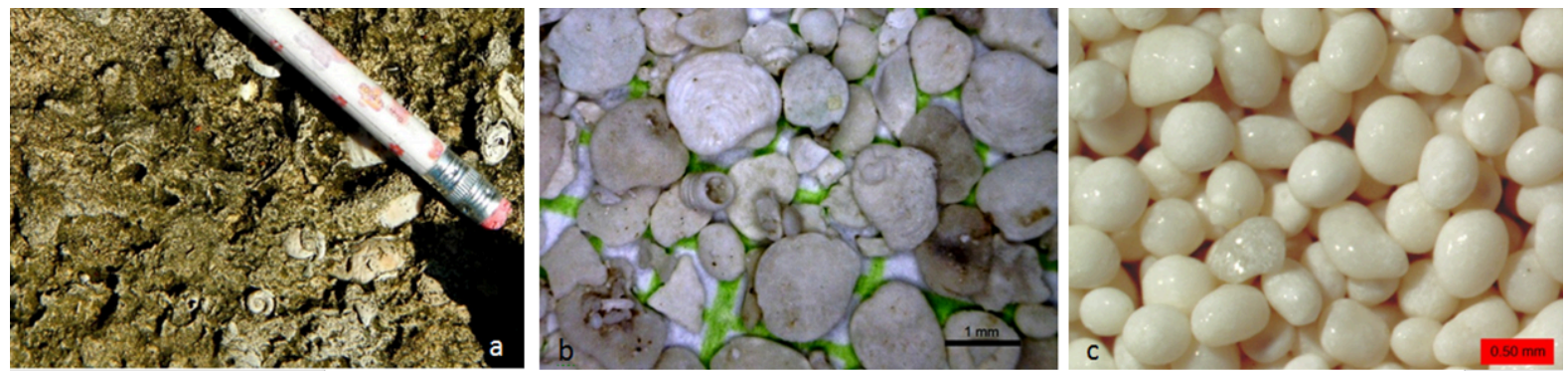

Figure 5.4.2: Carbonate rocks and sediments: (a) mollusc-rich limestone formed in a lagoon area at Ambergris, Belize, (b) foraminifera-rich sediment from a submerged carbonate sandbar in Belize (c) ooids from a beach at Joulters Cay, Bahamas.

Limestone also accumulates in deeper water, from the steady rain of the carbonate shells of tiny organisms that lived near the ocean surface. For example, chalk forms from the accumulation of the calcite shells of microscopic organisms like foraminifera and coccoliths. The lower limit for limestone accumulation is around 4,000 metres. Beneath that depth, calcite is soluble so limestone does not accumulate.

Calcite can also form on land in a number of environments. Tufa forms at springs (Figure 5.4.3) and travertine forms at hot springs. Similar material precipitates within limestone caves to form stalactites, stalagmites, and a wide range of other speleothems. Tufa, travertine and speleothems make up only a tiny proportion of all limestone. 


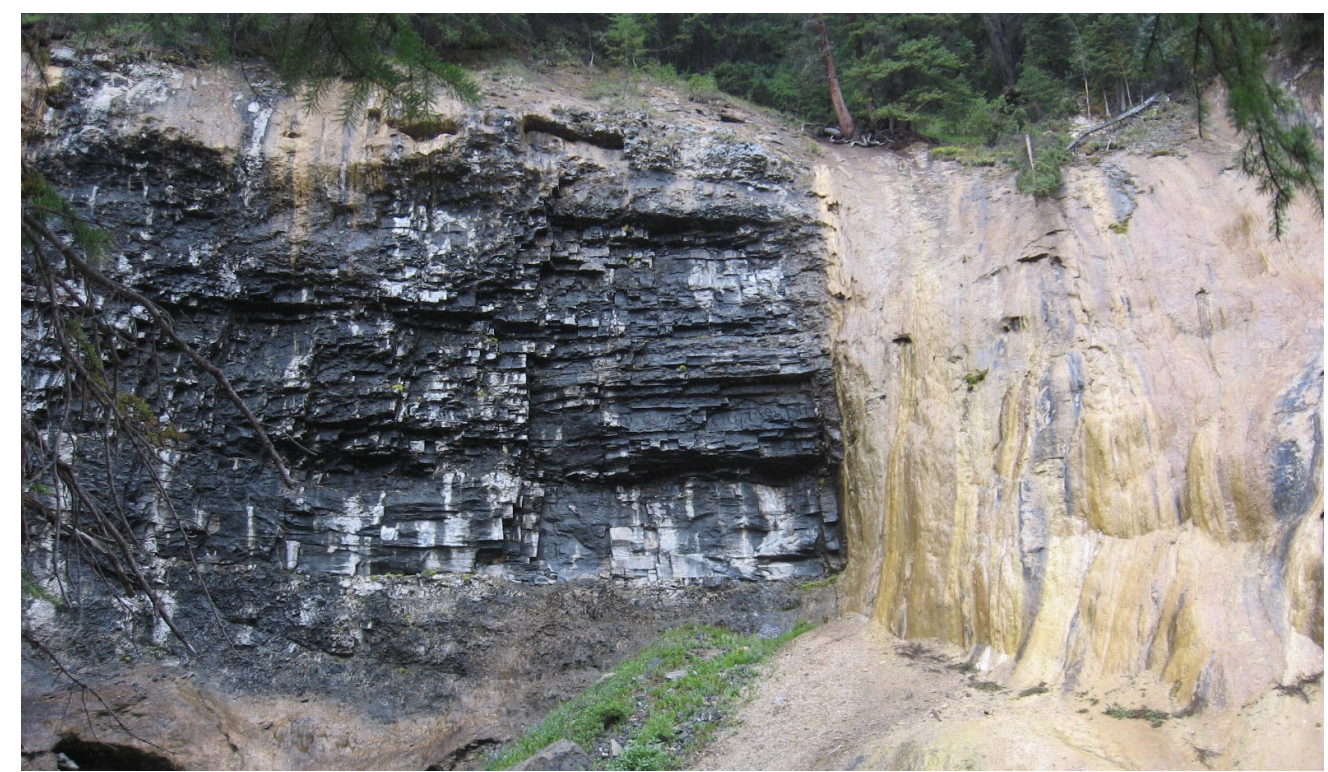

Figure 5.4.3: Tufa (yellow-brown colour to the right) formed at a spring at Johnston Creek, Alberta. The bedded grey rock to the left is limestone.

As all limestones are composed predominately of the carbonate mineral calcite, the fresh surface of a limestone will produce a strong reaction with dilute acid (i.e., will fizz vigorously). The carbonate mineral dolomite $\left(\mathrm{CaMg}\left(\mathrm{CO}_{3}\right)_{2}\right)$, on the other hand, only produces a weak reaction with dilute acid if powdered. This is one way to distinguish the mineral dolomite from calcite, and the rock dolomite from limestone. ${ }^{3}$ Dolomite rock is quite common (there's a whole Italian mountain range named after it), which is surprising since marine organisms don't make dolomite. All of the dolomite found in ancient rocks has been formed through the chemical process of magnesium replacing some of the calcium in the calcite in carbonate muds and sands. This process is known as dolomitization, and it is thought to take place where magnesium-rich water percolates through the sediments in carbonate tidal flat environments. 


\section{Chert}

Not all marine organisms make their hard parts out of calcite; some, like radiolarians and diatoms, use silica $\left(\mathrm{SiO}_{2}\right)$, and when they die their tiny shells (or tests) settle slowly to the bottom where they accumulate as chert. In some cases, chert is deposited along with limestone in the moderately deep ocean, but the two tend to remain separate, so chert beds within limestone are quite common (Figure 5.4.4), as are nodules, like the flint nodules within the Cretaceous chalk of southeastern England. In other situations, and especially in very deep water, chert accumulates on its own, commonly in thin beds.

\section{Evaporites}

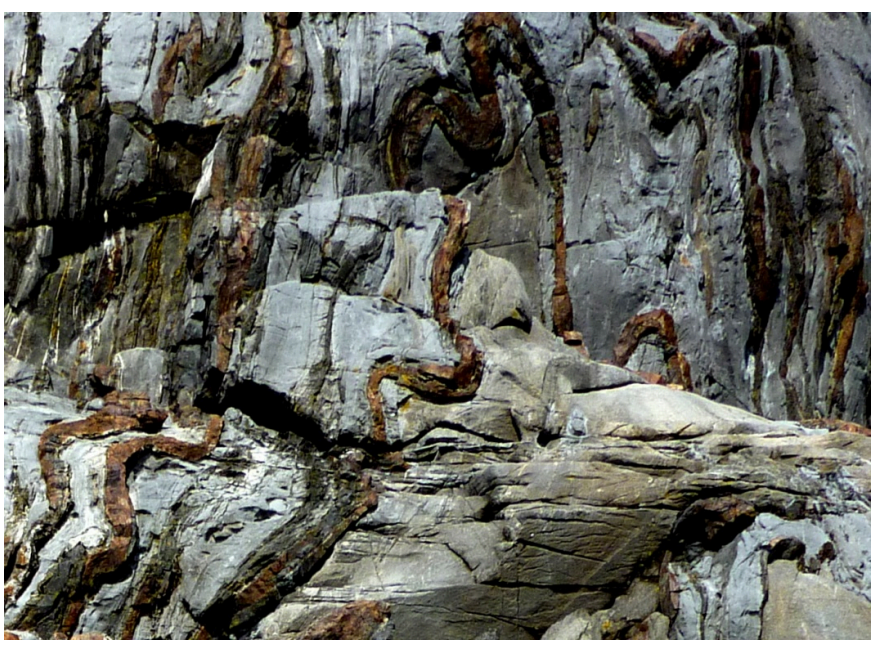

Figure 5.4.4: Chert (brown layers) interbedded with Triassic Quatsino Formation limestone on Quadra Island, B.C. All of the layers have been folded, and the chert, being insoluble and harder than limestone, stands out.

In arid regions many lakes and inland seas have no stream outlet and the water that flows into them is removed only by evaporation. Under these conditions, the water becomes increasingly concentrated with dissolved salts, and eventually some of these salts reach saturation levels and start to crystallize (Figure 5.4.5). Although all evaporite deposits are unique because of differences in the chemistry of the water, in most cases minor amounts of carbonates start to precipitate when the solution is reduced to about $50 \%$ of its original volume. Gypsum $\left(\mathrm{CaSO}_{4} \cdot \mathrm{H}_{2} \mathrm{O}\right)$ precipitates at about $20 \%$ of the original volume and halite $(\mathrm{NaCl})$ precipitates at $10 \%$. Other important evaporite minerals include sylvite $(\mathrm{KCl})$ and borax $\left(\mathrm{Na}_{2} \mathrm{~B}_{4} \mathrm{O}_{7} \cdot 10 \mathrm{H}_{2} \mathrm{O}\right)$. Sylvite is mined at numerous locations across Saskatchewan from evaporites that were deposited during the Devonian ( 385 Ma) when an inland sea occupied much of the region.

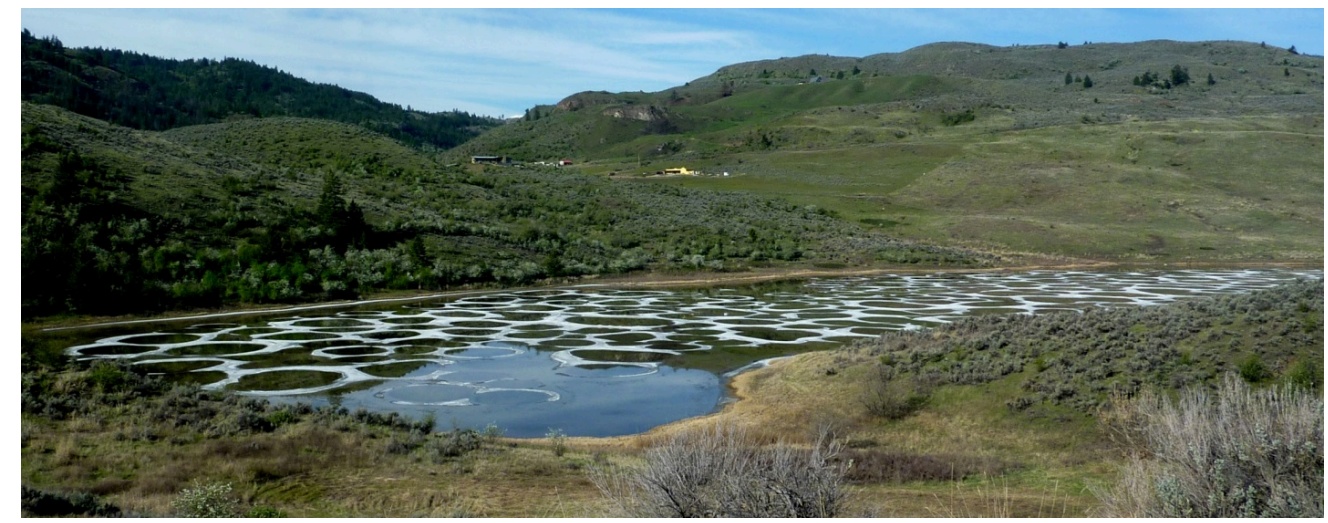

Figure 5.4.5: Spotted Lake, near Osoyoos, B.C. The patterns on the surface are salt. This photo was taken in May when the water was relatively fresh because of winter rains. By the end of the summer the surface of this lake is typically fully encrusted with salt deposits. 
Coal, the first fossil fuel to be widely used, forms mostly on land in swampy areas adjacent to rivers and deltas in areas with humid tropical to temperate climates. The vigorous growth of vegetation leads to an abundance of organic matter that accumulates within stagnant water, and thus does not decay and oxidize. This situation, where the dead organic matter is submerged in oxygen-poor water, must be maintained for centuries to millennia in order for enough material to accumulate to form a thick layer (Figure 5.4.6a). At some point, the swamp deposit is covered with more sediment - typically because a river changes its course or sea level rises (Figure 5.4.6b). As more sediments are added, the organic matter starts to become compressed and heated. Low-grade lignite coal forms at depths between a few $100 \mathrm{~m}$ and 1,500 $\mathrm{m}$ and temperatures up to about $50^{\circ} \mathrm{C}$ (Figure $5.4 .6 \mathrm{c}$ ). At between $1,000 \mathrm{~m}$ to $5,000 \mathrm{~m}$ depth and temperatures up to $150^{\circ} \mathrm{C} \mathrm{m}$, bituminous coal forms (Figure 5.4.6d). At depths beyond $5,000 \mathrm{~m}$ and temperatures over $150^{\circ} \mathrm{C}$, anthracite coal forms.
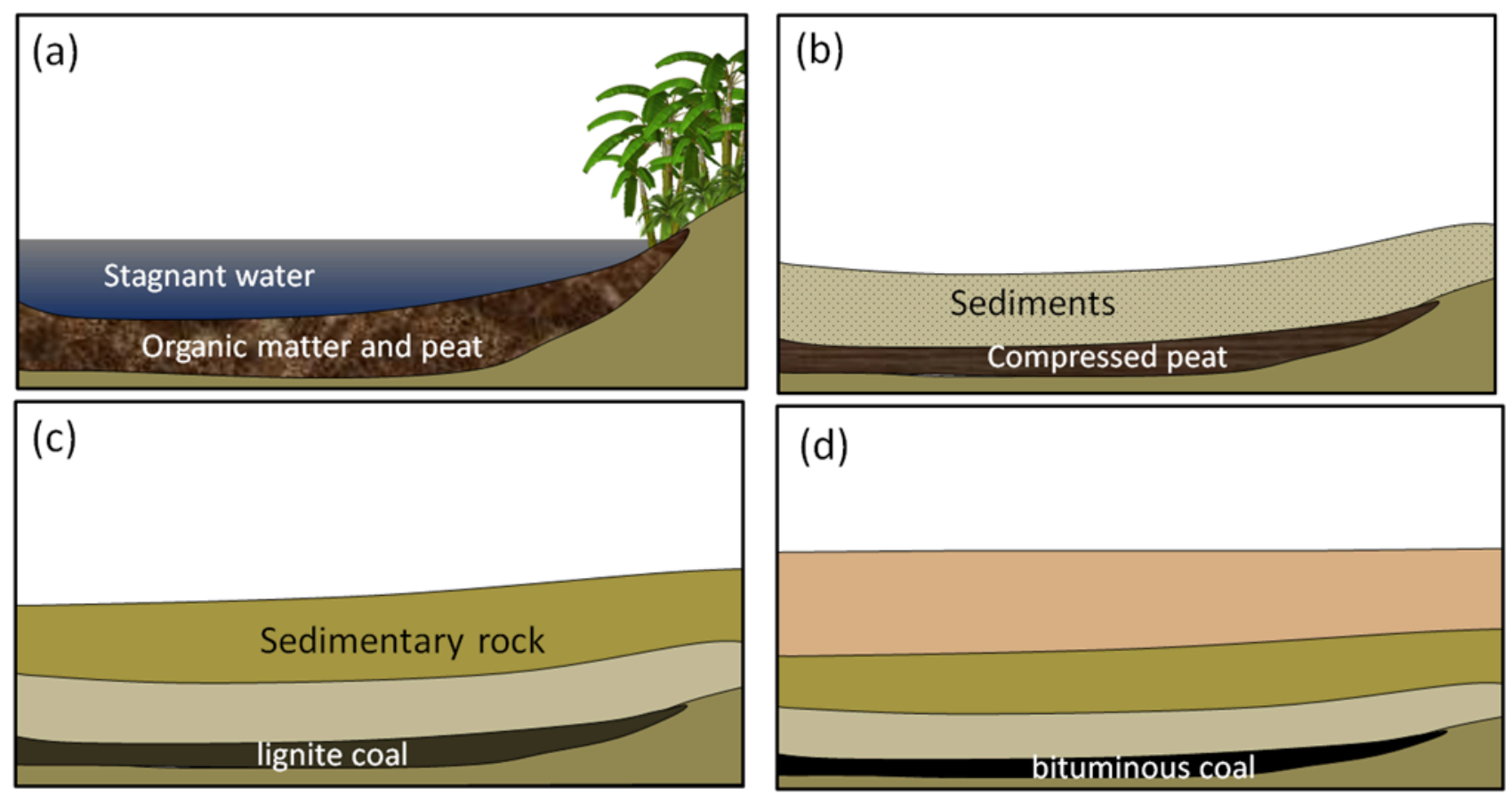

Figure 5.4.6: Formation of coal: (a) accumulation of organic matter within a swampy area; (b) the organic matter is covered and compressed by deposition of a new layer of clastic sediments; (c) with greater burial, lignite coal forms; and (d) at even greater depths, bituminous and eventually anthracite coal form.

There are significant coal deposits in many parts of Canada, including the Maritimes, Ontario, Saskatchewan, Alberta, and British Columbia. In Alberta and Saskatchewan, much of the coal is used for electricity generation. Coal from the Highvale Mine, Canada's largest, is used to feed the Sundance and Keephills power stations west of Edmonton. Almost all of the coal mined in British Columbia is exported for use in manufacturing steel.

\section{Media Attributions}

- Figures 5.4.1, 5.4.2, 5.4.3, 5.4.4, 5.4.5, 5.4.6: (C) Steven Earle. CC BY. 
- Figure 5.4.2c: JoultersCayOoids by Wilson44691. Public domain.

\section{Notes}

1. We use the word marine when referring to salt water (i.e., oceanic) environments, and the word aquatic when referring to freshwater environments.

2. Note that the term "fossiliferous" can also be used to modify the name of a clastic sedimentary rock (e.g., shale, mudstone, sandstone) that contains recognizable evidence of past life.

3. Dolomite is both a name for a mineral and for a rock composed of the mineral dolomite (although some geologists use the term dolostone to avoid confusion). 


\subsection{Depositional Environments and Sedimentary Basins}

Sediments accumulate in a wide variety of environments, both on the continents and in the oceans. Some of the more important of these environments are illustrated in Figure 5.5.1.

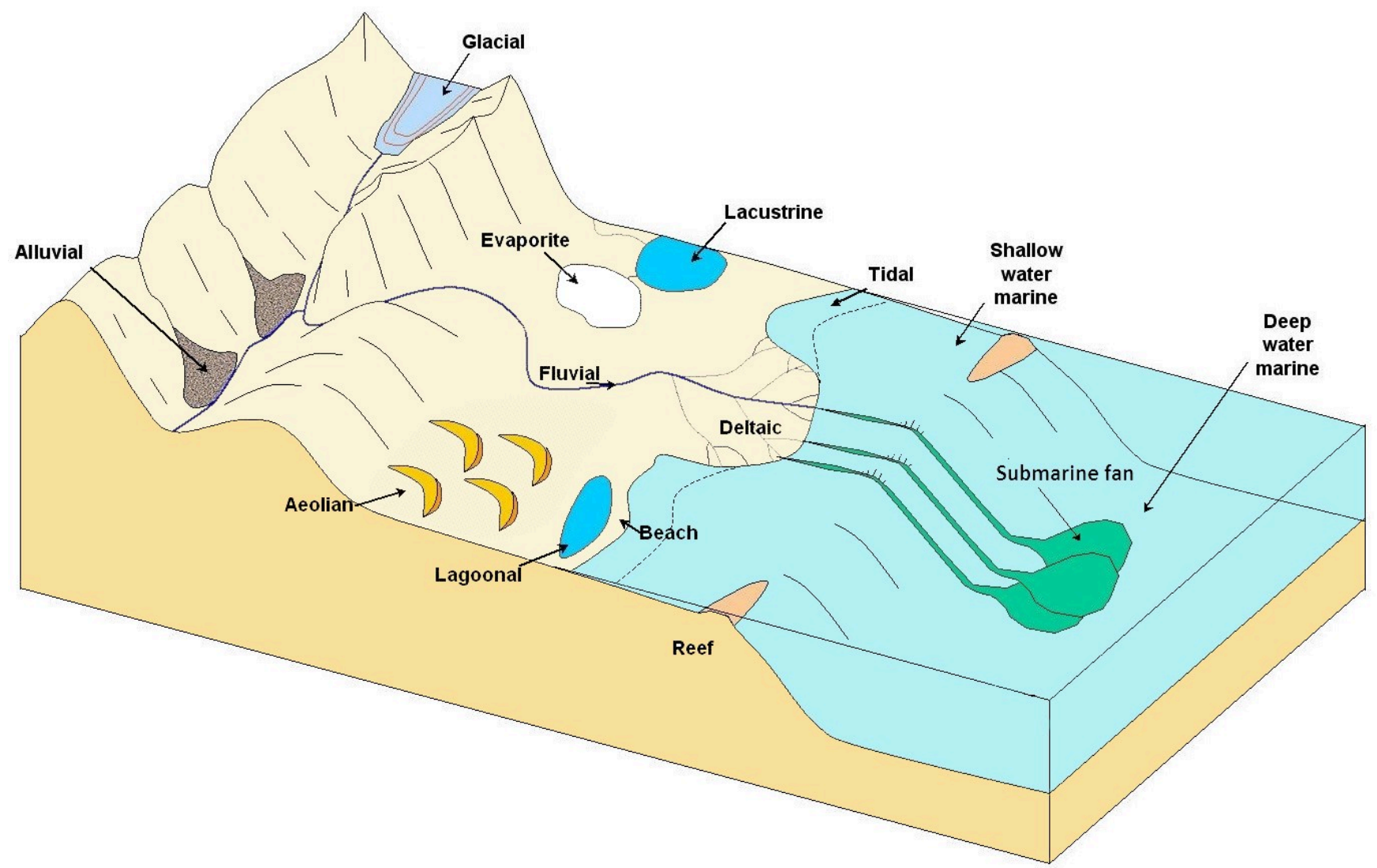

Figure 5.5.1: Some of the important depositional environments for sediments and sedimentary rocks.

Tables 5.6 and 5.7 provide a summary of the processes and sediment types that pertain to the various depositional environments illustrated in Figure 5.5.1. Careful observations of a sedimentary rock, including identifying its composition and texture, can provide clues about the ancient depositional environment in which it formed. We'll look more closely at the types of sediments that accumulate in these environments, and how sedimentary rocks and fossils can be used to interpret ancient environments and climates, in the subsequent geology course: GEOL 1103 Earth Through Time. The characteristics of these various environments, and the processes that take place within them, are also discussed in GEOL 1103. 
Table 5.6 The important terrestrial depositional environments and their characteristics

\begin{tabular}{llll}
\hline Environment & Important transport processes & Depositional environments & Typical sediment types \\
Glacial & gravity, moving ice, moving water & $\begin{array}{l}\text { valleys, plains, streams, } \\
\text { lakes }\end{array}$ & $\begin{array}{l}\text { glacial till, gravel, sand, silt, and } \\
\text { clay }\end{array}$ \\
Alluvial & gravity & steep-sided valleys & coarse angular fragments \\
Fluvial & moving water & streams & $\begin{array}{l}\text { gravel, sand, silt, and organic } \\
\text { matter (in swampy parts only) }\end{array}$ \\
Aeolian & wind & deserts and coastal regions & sand, silt \\
Lacustrine & moving water (flowing into a lake) & lakes & $\begin{array}{l}\text { sand (near the edges only), silt, } \\
\text { clay, and organic matter }\end{array}$ \\
Evaporite & moving water (flowing into a lake) & lakes in arid regions & salts, clay \\
\hline
\end{tabular}

Table 5.7 The important transitional and marine depositional environments and their characteristics

\begin{tabular}{llll}
\hline Environment & $\begin{array}{l}\text { Important Transport } \\
\text { Processes }\end{array}$ & Depositional Environments & Typical Sediment Types \\
\hline Deltaic & moving water & deltas & $\begin{array}{l}\text { sand, silt, clay, and organic matter } \\
\text { (in swampy parts only) }\end{array}$ \\
\hline Beach & $\begin{array}{l}\text { waves, longshore } \\
\text { currents }\end{array}$ & beaches, spits, sand bars & gravel, sand \\
\hline Tidal & tidal currents & tidal flats & silt, clay \\
\hline Reefs & waves and tidal currents & reefs and adjacent basins & carbonates \\
\hline Shallow water marine & waves and tidal currents & shelves and slopes, lagoons & $\begin{array}{l}\text { carbonates in tropical climates, } \\
\text { sand/silt/clay elsewhere }\end{array}$ \\
\hline Lagoonal & little transportation & lagoon bottom & carbonates in tropical climates \\
\hline Submarine fan & underwater gravity flows & $\begin{array}{l}\text { continental slopes and } \\
\text { abyssal plains }\end{array}$ & gravel, sand, mud \\
\hline Deep water marine & ocean currents & $\begin{array}{l}\text { deep-ocean abyssal plains } \\
\text { clat, carbonate mud, silica mud }\end{array}$ & clay
\end{tabular}

Most of the sediments that you might see around you, including talus on steep slopes, sand bars in streams, or gravel in road cuts, will never become sedimentary rocks because they have only been deposited relatively recently-perhaps a few centuries or millennia ago-and are likely to be re-eroded before they are buried deep enough beneath other sediments to be lithified. In order for sediments to be preserved long enough to be turned into rock-a process that takes millions or tens of millions of years-they need to have been deposited in a basin that will last that long. Most such basins are formed by plate tectonic processes that create enough space for sediments to accumulate in great thicknesses, and some of the more important examples of tectonic basins are shown in Figure 5.5.2.

Trench basins (a in Figure 5.5.2) form where a subducting oceanic plate dips beneath the overriding continental or oceanic crust. They can be several kilometres deep, and in many cases, host thick sequences of sediments from eroding coastal mountains. There is a well-developed trench basin off the west coast of Vancouver Island, B.C. A forearc basin (b in Figure 5.5.2) lies between the subduction zone and the volcanic arc, and may be formed in part by friction between the subducting plate and the overriding plate, which pulls part of the overriding plate down. The Strait of Georgia, the part of the Pacific Ocean between Vancouver Island and mainland North America, is a forearc basin. A foreland basin (c in Figure 5.5.2) is caused by the mass of the volcanic range depressing the crust on either side. Foreland basins are not only related to volcanic ranges, but can form adjacent to fold belt mountains like the Canadian Rockies. A rift basin ( $d$ in 
Figure 5.5.2) forms where continental crust is being pulled apart, and the crust on both sides of the rift subsides. As rifting continues this eventually becomes a narrow sea, and then an ocean basin. The East African rift basin represents an early stage in this process.

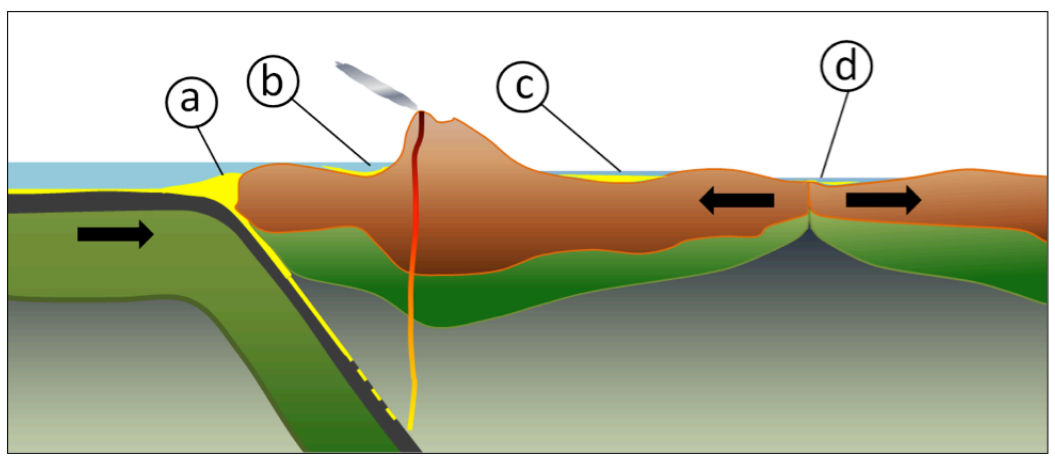

Figure 5.5.2: Some of the more important types of tectonically produced basins: (a) trench basin, (b) forearc basin, (c) foreland basin, and (d) rift basin.

\section{Media Attributions}

- Figure 5.5.1: Schematic diagram showing types of depositional environment (C) Mike Norton. Adapted by Steven Earle. CC BY-SA.

- Figure 5.5.2: (C) Steven Earle. CC BY. 


\section{Lab 5 Exercises}

The exercises below will guide you through the sedimentary rock samples in Rock Kits 1 and 2. Review the background information presented in Chapters 5.1 to 5.5 before you begin these exercises. You may wish to consult the Rock Classification Tables at the back of this manual as you complete the exercises below.

Tips for Classifying Sedimentary Rocks

- Your first step when examining any sedimentary rock is to determine if its texture is clastic or crystalline.

- If the texture is clastic, next determine the predominant size of the grains by looking closely through your hand lens and using the grain size chart (see Table A in the Rock Classification Tables appendix).

- Next, describe the sorting, and the shape (roundness) of the grains (Figure $\mathrm{C}$ in the Rock Classification Tables appendix). Remember that you are not describing the shape or size of the sample, but of the grains within it!

- If the texture is crystalline, test the sample with a drop (only a drop!) of dilute HCl. If the rock reacts with $\mathrm{HCl}$, look carefully to determine what exactly is reacting (e.g., cement between grains of quartz sand? The entire sample of limestone?).

- Quartz grains come in many colours, but always have vitreous lustre.

- Feldspar grains are commonly white or pink in colour, and in very coarse-grained clastic sedimentary rocks, you may even see feldspar grains broken along cleavage planes. Feldspar grains that have been chemically weathered tend to look chalky and dull (see Figure 5.1.4), which can help you differentiate them from quartz grains.

1. Using your hand lens, carefully examine samples R151, R161, R162, and R181 from your Rock Kit to complete the table below. The example provided indicates the level of detail expected of your observations. 


\begin{tabular}{|c|c|c|c|c|c|}
\hline 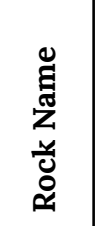 & 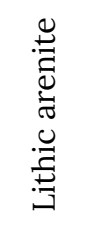 & & & & \\
\hline 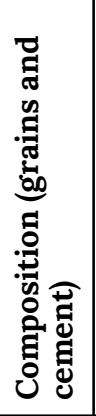 & 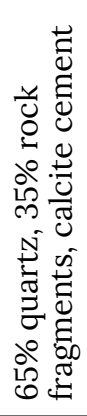 & & & & \\
\hline 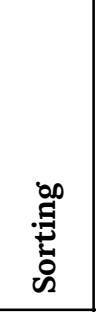 & 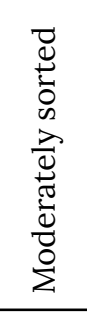 & & & & \\
\hline 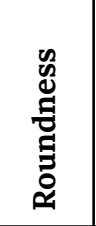 & 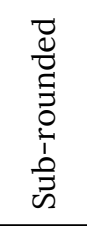 & & & & \\
\hline 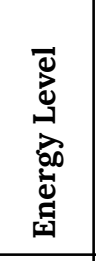 & 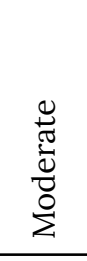 & & & & \\
\hline 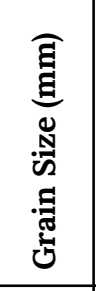 & 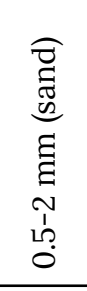 & & & & \\
\hline 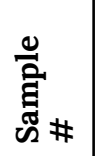 & 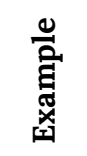 & $\overrightarrow{\underline{D}}$ & $\begin{array}{l}\vec{b} \\
\ddot{\not}\end{array}$ & ्ֶञ & 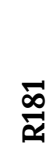 \\
\hline
\end{tabular}


2. Are all four samples in the table above chemical or detrital (clastic) in origin? How can you tell?

3. Indicate where on the diagram each of the samples from the table above is most likely to have formed by considering the grain size, roundness, sorting, and composition.

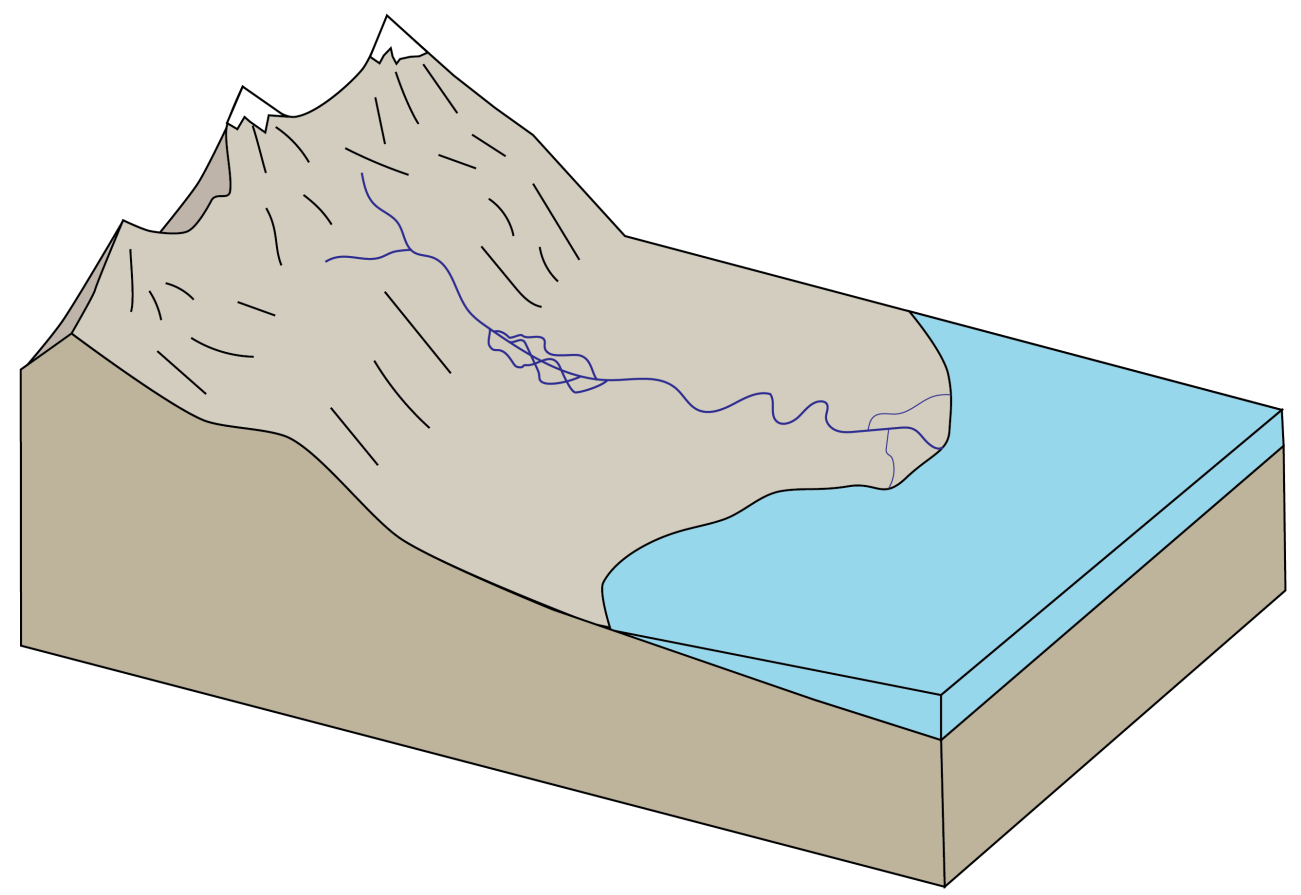

Figure A

4. Imagine a large granite pluton has been uplifted and exposed at the surface. Imagine that this granite is the source material for samples R161 and R162.

a) List the minerals you would expect to find in this granite, and their typical weathering products.

b) If these two samples originated from the same source material, explain what process(es) are responsible for the key difference(s) between them? Hint: examine your answers in the table above. 
5. Examine chemical sedimentary rock samples RI91, R201, R211, R221, R231, R251, R261, R271, and R281. In the table below, name the mineral and chemical sedimentary rock(s) from your rock kits that correspond to the composition provided. As you examine each rock sample, think about what physical properties the mineral and the rock have in common. You may want to review the physical properties of minerals summarized in Labs 2 and 3, and in the mineral identification tables.

\begin{tabular}{|c|c|c|c|c|}
\hline Composition & $\begin{array}{l}\text { Mineral } \\
\text { Name }\end{array}$ & $\begin{array}{l}\text { Rock } \\
\text { Sample } \\
\#\end{array}$ & Rock Name & $\begin{array}{l}\text { Diagnostic Properties Common to Both Rock } \\
\text { and Mineral }\end{array}$ \\
\hline $\mathrm{CaCO}_{3}$ & & & & \\
\hline $\mathrm{SiO}_{2}$ & & & & \\
\hline $\mathrm{NaCl}$ & & & & \\
\hline $\mathrm{CaSO}_{4} \cdot \mathrm{H}_{2} \mathrm{O}$ & & & & \\
\hline C (mostly) & $\mathrm{N} / \mathrm{A}$ & & & \\
\hline
\end{tabular}

6. Examine sample R201. What shape are the grains?

7. The small rounded grains that you see are called ooids, and the textural term for a rock with ooids is

8. How do you think the ooids formed?

9. Name this rock:

10. Examine sample R211 (coquina). Look closely at the larger grains. What would be a more appropriate term than 'grains'?

11. What is the main component of the rock?

12. Compare samples R211 and R221. How are these two samples similar? How do they differ, and how would you distinguish one from the other? 
13. Examine sample R231. This is a type of limestone known as chalk. It is composed mainly of shelly remains of microscopic animals. Scratch this sample with your fingernail. Why does it seem so much softer than a crystal of calcite?

14. Examine sample R251. The black colour is due to the very high organic content of the rock. This type of rock is combustible. Name this rock:

15. How does this type of sedimentary rock form?

16. Examine samples R271 and R281. These are both examples of evaporites - they have formed by precipitation of crystals from a solution. In what ways do these two different samples differ?

17. Studying sedimentary rocks provides geologists with a window into the past. Simple observations about composition and texture of a rock sample can give a geologist important clues about the ancient environment in which a sedimentary rock formed. Use your observations of sedimentary rock samples R151, R161, R181, R221 and R281, and the information provided in Chapter 5.5 to complete the table below. You should find more than one possible depositional environment for most samples. In higher level geology courses, you will learn additional features to observe to narrow down the possible depositional environments for a sample. 


\begin{tabular}{|l|l|l|}
\hline Sample & $\begin{array}{l}\text { Possible environment(s) of } \\
\text { deposition }\end{array}$ & Evidence \\
\hline R151 & & \\
\hline R161 & & \\
\hline R181 & & \\
\hline R281 & & \\
\hline R221 & & \\
\hline
\end{tabular}

\section{Media Attributions}

- Figure A: (C) Siobhan McGoldrick. CC BY. 


\section{Summary}

The topics covered in this chapter can be summarized as follows:

\begin{tabular}{|c|c|}
\hline Section & Summary \\
\hline $\begin{array}{l}5.1 \\
\text { Weathering }\end{array}$ & $\begin{array}{l}\text { Rocks weather when they are exposed to surface conditions, which in most case are quite different } \\
\text { from those at which they formed. The main processes of mechanical weathering include exfoliation, } \\
\text { freeze-thaw, salt crystallization, and the effects of plant growth. Chemical weathering takes place } \\
\text { when minerals within rocks are not stable in their existing environment. Some of the important } \\
\text { chemical weathering processes are hydrolysis of silicate minerals to form clay minerals, oxidation of } \\
\text { iron in silicate and other minerals to form iron oxide minerals, and dissolution of calcite. }\end{array}$ \\
\hline $\begin{array}{l}5.2 \text { The } \\
\text { Products of } \\
\text { Weathering } \\
\text { and Erosion }\end{array}$ & $\begin{array}{l}\text { The main products of weathering and erosion are grains of quartz (because quartz is resistant to } \\
\text { chemical weathering), clay minerals, iron oxide minerals, rock fragments, and a wide range of ions in } \\
\text { solution. Without weathering, there would not be sediment available to eventually form sedimentary } \\
\text { rocks! }\end{array}$ \\
\hline $\begin{array}{l}\text { 5.3 Clastic } \\
\text { Sedimentary } \\
\text { Rocks }\end{array}$ & $\begin{array}{l}\text { Sedimentary clasts are classified based on their size, and variations in clast size and shape have } \\
\text { important implications for transportation and deposition. Clastic sedimentary rocks are classified } \\
\text { based on their grain size and composition. Clast size, sorting, composition, and shape are important } \\
\text { features that allow us to differentiate clastic rocks and understand the processes that took place } \\
\text { during their deposition. }\end{array}$ \\
\hline $\begin{array}{l}\text { 5.4 Chemical } \\
\text { Sedimentary } \\
\text { Rocks }\end{array}$ & $\begin{array}{l}\text { Chemical sedimentary rocks form from ions that were transported in solution, and then converted } \\
\text { into minerals by biological and/or chemical processes. The most common chemical rock, limestone, } \\
\text { typically forms in shallow tropical environments, where biological activity is a very important factor. } \\
\text { Names of limestones can be modified with textural terms like crystalline, oolitic, or fossiliferous. } \\
\text { Chert is a deep-ocean sedimentary rocks. Evaporites (rock salt and rock gypsum) form where the } \\
\text { water of lakes and inland seas becomes supersaturated due to evaporation. Coal forms in swamps } \\
\text { from decaying plant remains. }\end{array}$ \\
\hline $\begin{array}{l}5.5 \\
\text { Depositional } \\
\text { Environments } \\
\text { and } \\
\text { Sedimentary } \\
\text { Basins }\end{array}$ & $\begin{array}{l}\text { There is a wide range of depositional environments, both on land (glaciers, lakes, rivers, etc.) and in } \\
\text { the ocean (deltas, reefs, shelves, and the deep-ocean floor). In order to be preserved, sediments must } \\
\text { accumulate in long-lasting sedimentary basins, most of which form through plate tectonic processes. }\end{array}$ \\
\hline $\begin{array}{l}\text { Lab } 5 \\
\text { Exercises }\end{array}$ & $\begin{array}{l}\text { The best way to learn rock identification is to practice by examining the samples in your Rock Kit } 1 \\
\text { and } 2 \text {. The first step when examining a sedimentary rock is to identify the texture. Clastic } \\
\text { sedimentary rocks have clastic textures, and are classified based on grain size, and for sandstones, } \\
\text { also by composition. Chemical sedimentary rocks are often monomineralic and are classified based } \\
\text { on composition. Chemical sedimentary rocks can have a range of textures (crystalline, clastic, } \\
\text { bioclastic, fossiliferous, oolitic, and amorphous). Knowing the diagnostic properties of the main } \\
\text { minerals that form chemical sedimentary rocks will help you correctly identify the rock. Just as with } \\
\text { mineral samples, different samples of the same rock may not always look exactly the same (e.g., tan } \\
\text { versus blue-grey crystalline limestone), but they can always be identified by closely examining the } \\
\text { mineral composition and texture. }\end{array}$ \\
\hline
\end{tabular}




\section{LAB 6: METAMORPHIC ROCKS AND THE ROCK CYCLE}

\section{Lab Structure}

Recommended additional work

Required materials
Yes - review rock and mineral ID in preparation for Test 2

Mineral ID kit, Rock Kits 1 and 2, hand lens, pencil

\section{Learning Objectives}

After carefully reading this chapter, completing the exercises within it, and answering the questions at the end, you should be able to:

- Summarize the factors that influence the nature of metamorphic rocks and explain why each one is important.

- $\quad$ Recognize foliation and explain the mechanisms for its formation in metamorphic rocks.

- Classify metamorphic rocks on the basis of their texture and mineral content, and explain the origins of these differences.

- $\quad$ Describe the various settings in which metamorphic rocks are formed and the links between plate tectonics and metamorphism.

- $\quad$ Describe the rock cycle and the types of processes that lead to the formation of igneous, sedimentary, and metamorphic rocks.

Key Terms

- Metamorphism

- Metamorphic grade

- Geothermal gradient

- Index minerals

- Protolith

- Recrystallization
- Foliation

- Slaty

- Schistose

- Gneissic

- Massive 


\section{I Metamorphism and Plate Tectonics}

Metamorphism is the change that takes place within a body of rock as a result of it being subjected to conditions that are different from those in which it formed. In most cases-but not all-this involves the rock being deeply buried beneath other rocks, where it is subjected to higher temperatures and pressures than those under which it formed. Metamorphic rocks typically have different mineral assemblages and different textures from their parent rocks, or protoliths, but they may have the same overall chemical composition.

Most metamorphism results from the burial of igneous, sedimentary, or pre-existing metamorphic rocks to the point where they experience different pressures and temperatures than those at which they formed. Metamorphism can also take place if cold rock near the surface is intruded and heated by a hot igneous body. Although most metamorphism involves temperatures above $150^{\circ} \mathrm{C}$, some metamorphism takes place at temperatures lower than those at which the parent rock formed.

The main factors that control metamorphic processes are:

- the mineral composition of the protolith,

- the temperature at which metamorphism takes place,

- the amount and type of pressure during metamorphism,

- the types of fluids (mostly water) that are present during metamorphism, and

- the amount of time available for metamorphism.

\section{Protolith}

The protolith, or "parent rock", is the rock that exists before metamorphism starts. Sedimentary or igneous rocks can be considered the parent rocks for metamorphic rocks. Although an existing metamorphic rock can be further metamorphosed or re-metamorphosed, metamorphic rock doesn't normally qualify as a "parent rock". For example, if a mudstone is metamorphosed to slate and then buried deeper where it is metamorphosed to gneiss, the parent rock of the gneiss is mudstone, not slate. The critical feature of the parent rock is its mineral composition because it is the stability of minerals that counts when metamorphism takes place. In other words, when a rock is subjected to increased temperatures, certain minerals may become unstable and start to recrystallize into new minerals, while remaining in a solid state. 


\section{Temperature}

The temperature that the rock is subjected to is a key variable in controlling the type of metamorphism that takes place. As we learned in the context of igneous rocks, mineral stability is a function of temperature, pressure, and the presence of fluids (especially water). All minerals are stable over a specific range of temperatures. For example, quartz is stable from environmental temperatures (whatever the weather can throw at it) all the way up to about $1800^{\circ} \mathrm{C}$. If the pressure is higher, that upper limit will be even higher. If there is water present, it will be lower. On the other hand, most clay minerals are only stable up to about $150^{\circ}$ or $200^{\circ} \mathrm{C}$; above that, they transform into micas. Most feldspars are stable up to between $1000^{\circ} \mathrm{C}$ and $1200^{\circ} \mathrm{C}$. Most other common minerals have upper limits between $150^{\circ} \mathrm{C}$ and $1000^{\circ} \mathrm{C}$.

Some minerals will crystallize into different poly-

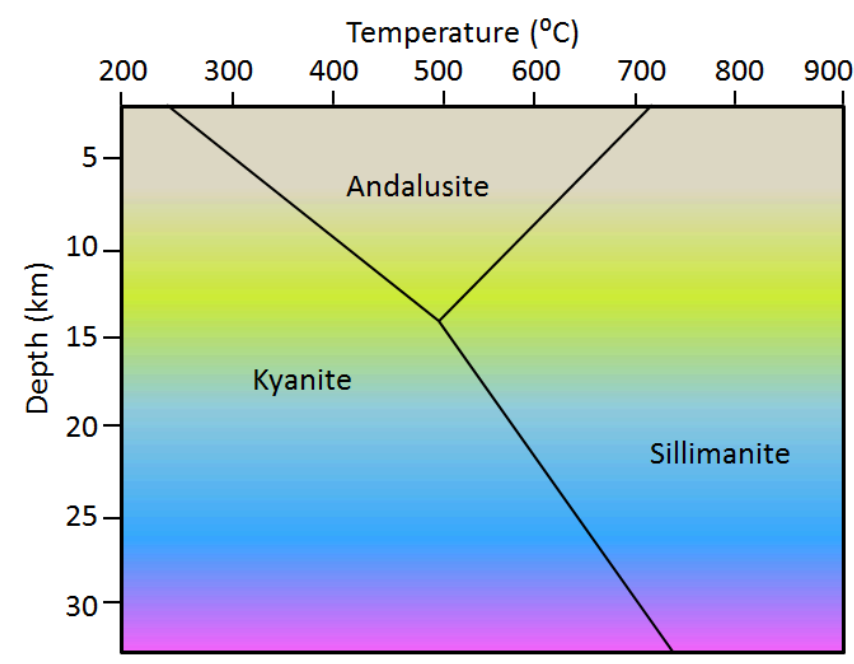

Figure 6.1.1: The temperature and pressure stability fields of the three polymorphs of $\mathrm{Al}_{2} \mathrm{SiO}_{5}$ (Pressure is equivalent to depth). Kyanite is stable at low to moderate temperatures and low to high pressures, andalusite at moderate temperatures

morphs (same composition, but different crysand low pressures, and sillimanite at higher temperatures.)

talline structure) depending on the temperature and pressure. The minerals kyanite, andalusite, and sillimanite are polymorphs with the composition $\mathrm{Al}_{2} \mathrm{SiO}_{5}$. They are stable at different pressures and temperatures, and, as we will see later, they are important indicators of the pressures and temperatures that existed during the formation of metamorphic rocks (Figure 6.1.1).

\section{Pressure}

Pressure is important in metamorphic processes for two main reasons. First, it has implications for mineral stability (Figure 6.1.1). Second, it has implications for the texture of metamorphic rocks. Rocks that are subjected to very high confining pressures are typically denser than others because the mineral grains are squeezed together (Figure 6.1.2a), and also because they may contain minerals that have greater density because the atoms are more closely packed. 
Because of plate tectonics, pressures within the crust are typically not applied equally in all directions. In areas of plate convergence, for example, the pressure in one direction (perpendicular to the direction of convergence) is typically greater than in the other directions (Figure 6.1.2b). In situations where different blocks of the crust are being pushed in different directions, the rocks will likely be subjected to shear stress (Figure 6.1.2c).

One of the results of directed pressure and shear stress is that rocks become foliated-meaning that they'll develop a foliation or directional fabric. Foliation is a very important aspect of metamorphic rocks, and is described in more detail later in this chapter.

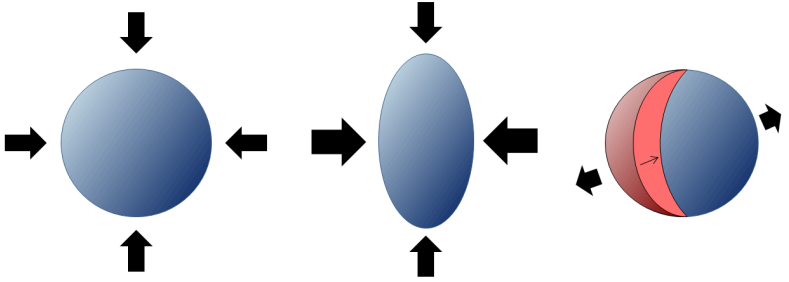

Figure 6.1.2: An illustration of different types of pressure on rocks. (a) confining pressure, where the pressure is essentially equal in all directions, (b) directed pressure, where the pressure form the sides is greater than that from the top and bottom, and (c) sheer stress caused by different blocks of rock being pushed in different directions. (In $a$ and $b$ there is also pressure in and out of the page.)

\section{Fluids}

Water is the main fluid present within rocks of the crust, and the only one that we'll consider here. The presence of water is important for two main reasons. First, water facilitates the transfer of ions between minerals and within minerals, and therefore increases the rates at which metamorphic reactions take place. So, while the water doesn't necessarily change the outcome of a metamorphic process, it speeds the process up so metamorphism might take place over a shorter time period, or metamorphic processes that might not otherwise have had time to be completed are completed.

Secondly, water, especially hot water, can have elevated concentrations of dissolved elements (ions), and therefore it is an important medium for moving certain elements around within the crust. So not only does water facilitate metamorphic reactions on a grain-to-grain basis, it also allows for the transportation of elements from one place to another. This is very important in hydrothermal processes, and in the formation of mineral deposits.

\section{Time}

Most metamorphic reactions take place at very slow rates. For example, the growth of new minerals within a rock during metamorphism has been estimated to be about 1 millimetre per million years. For this reason, it is very difficult to study metamorphic processes in a lab.

While the rate of metamorphism is slow, the tectonic processes that lead to metamorphism are also very slow, so in most cases, the chance for metamorphic reactions to be completed is high. For example, one important metamorphic setting is many kilometres deep within the roots of mountain ranges. A mountain range takes tens of millions of years to form, and tens of millions of years more to be eroded to the extent that we can see the rocks that were metamorphosed deep beneath it. 
This photo shows a sample of garnet-mica schist from the Greek island of Syros. The large reddish crystals are garnet, and the surrounding light coloured rock is dominated by muscovite mica. The Euro coin is 23 millimetres in diameter. Assume that the diameters of the garnets increased at a rate of 1 millimetre per million years.

Based on the approximate average diameter of the garnets visible, estimate how long this metamorphic process might have taken.

See Appendix 2 for Practice Exercise 6.1 answers.

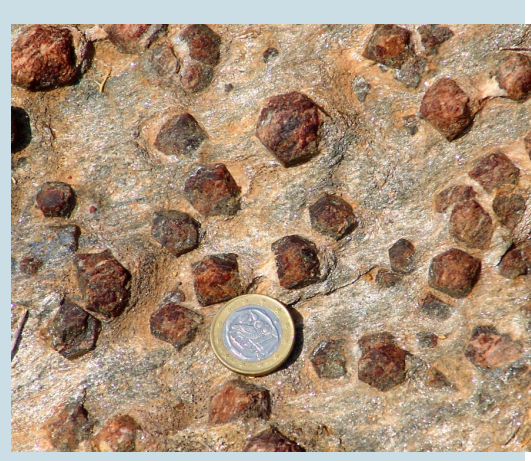

Figure 6.1.3: Garnets in a schist. Euro coin $(23 \mathrm{~mm})$ is for scale.

\section{Plate Tectonics and Metamorphism}

All of the important processes of metamorphism can be understood in the context of geological processes related to plate tectonics. The relationships between plate tectonics and metamorphism are summarized in Figure 6.1.4. Two settings, continent-continent collisions and continental volcanic arcs are also shown in more detail in Figure 6.1.5.

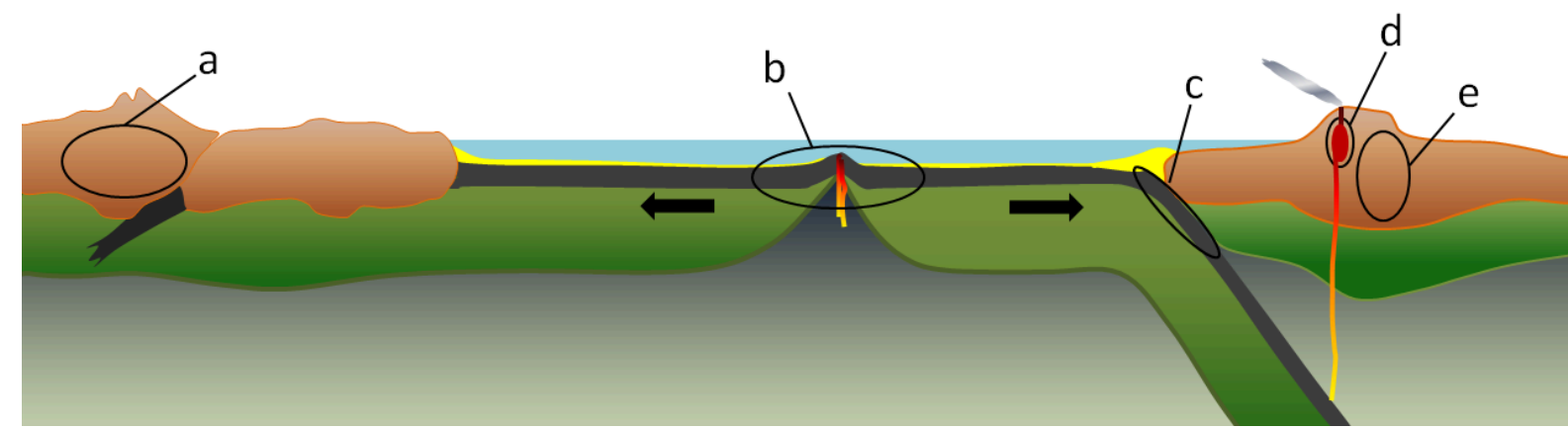

Figure 6.1.4: Environments of metamorphism in the context of plate tectonics: (a) regional metamorphism related to mountain building at a continent-continent convergent boundary, (b) regional metamorphism of oceanic crust in the area on either side of a spreading ridge, (c) regional metamorphism of oceanic crustal rocks within a subduction zone, (d) contact metamorphism adjacent to a magma body at a high level in the crust, and (e) regional metamorphism related to mountain building at a convergent boundary.

Most regional metamorphism takes place within the continental crust. While rocks can be metamorphosed at depth in most areas, the potential for metamorphism is greatest in the roots of mountain ranges where there is a strong likelihood for burial of relatively young sedimentary rock to great depths, as depicted in Figure 6.1.5. An example would be the Himalayan Range. At this continent-continent convergent boundary, sedimentary rocks have been both thrust up to great heights (nearly 9,000 metres above sea level) and also buried to great depths. Considering that the normal geothermal gradient (the rate of increase in temperature with depth) is around $30^{\circ} \mathrm{C}$ per kilometre, rock buried to 9 kilometres below sea level in this situation could be close to 18 kilometres below the surface of the ground, and it is reasonable to expect temperatures up to $500^{\circ} \mathrm{C}$. Metamorphic rocks formed there are likely to be foliated because of the strong directional pressure (compression) of converging plates. 
Typical geothermal gradient (a)

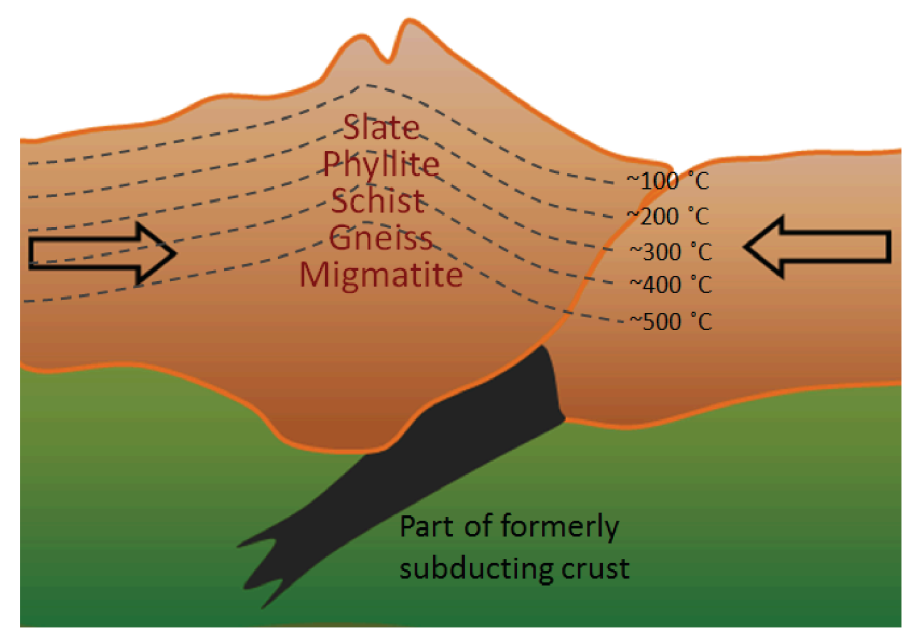

Subduction zone geothermal gradient (c)

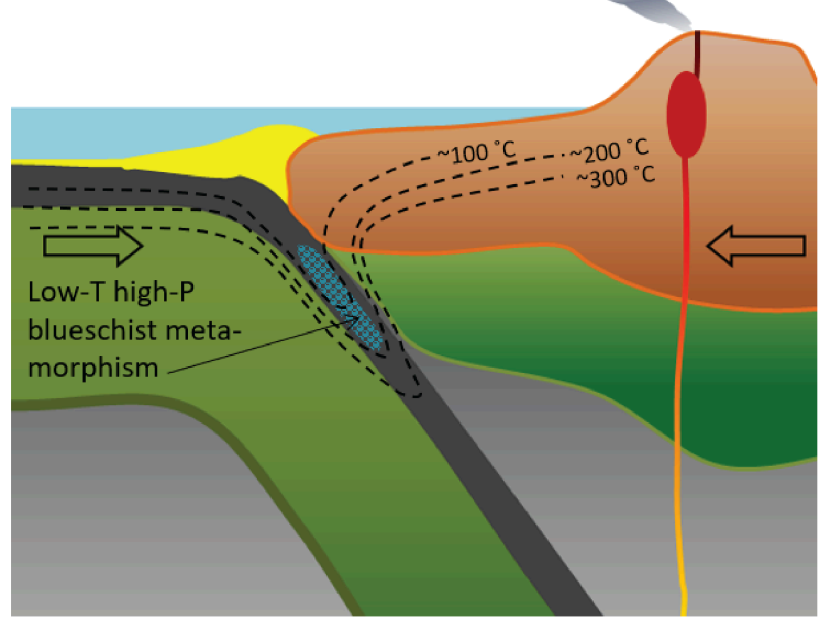

Figure 6.1.5: (left) Regional metamorphism beneath a mountain range related to continent-continent collision (typical geothermal gradient). Example: Himalayan Range. (right) Regional metamorphism of oceanic crust at a subduction zone forming a continental volcanic arc. (Example: Cascadia subduction zone. Rock of this type is exposed in the San Francisco area.)

Metamorphism also occurs at subduction zones, where oceanic crust is forced down into the hot mantle. Because the oceanic crust is typically relatively cool by the time it reaches the subduction zone, especially along its sea-floor upper surface, it does not heat up quickly, and the subducting rock remains several hundreds of degrees cooler than the surrounding mantle (Figure 6.1 .5 right). A special type of metamorphism takes place under these very high-pressure but relatively low-temperature conditions, producing an amphibole mineral known as glaucophane $\left(\mathrm{Na}_{2}\left(\mathrm{Mg}_{3} \mathrm{Al}_{2}\right) \mathrm{Si}_{8} \mathrm{O}_{22}(\mathrm{OH})_{2}\right)$, which is blue in colour, and is an important component of a rock known as blueschist.

You've probably never seen or even heard of blueschist; that's not surprising. What is a little surprising is that anyone has seen it! Most blueschist forms in subduction zones, continues to be subducted, turns into eclogite at about 35 kilometres depth, and then eventually sinks deep into the mantle-never to be seen again because that rock will eventually melt. In only a few places in the world, where the subduction process has been interrupted by some other tectonic process, has partially subducted blueschist rock returned to the surface. One such place is the area around San Francisco; the rock is known as the Franciscan Complex.

Another way to understand metamorphism is by using a diagram that shows temperature on one axis and depth-which is equivalent to pressure-on the other (Figure 6.1.6). The three heavy dotted lines on this diagram represent Earth's geothermal gradients under different conditions. In most areas, the rate of increase in temperature with depth is $30^{\circ} \mathrm{C}$ per kilometre. In other words, if you go 1,000 metres down into a mine, the temperature will be roughly $30^{\circ} \mathrm{C}$ warmer than the average temperature at the surface. In most parts of southern Canada, the average surface temperature is about $10^{\circ} \mathrm{C}$, so at a 1,000 metre depth, it will be about $40^{\circ} \mathrm{C}$. That's uncomfortably hot, so deep mines must have effective ventilation systems. This typical geothermal gradient is shown by the green dotted line in Figure 6.1.6. At a 10 kilometre depth, the temperature is about $300^{\circ} \mathrm{C}$ and at 20 kilometres it's about $600^{\circ} \mathrm{C}$.

In volcanic areas, the geothermal gradient is more like $40^{\circ}$ to $50^{\circ} \mathrm{C}$ per kilometre, so the temperature at a 10 kilometre depth is in the $400^{\circ}$ to $500^{\circ} \mathrm{C}$ range. Along subduction zones, as described above, the cold oceanic crust keeps temperatures low, so the gradient is typically less than $10^{\circ} \mathrm{C}$ per kilometre. The various types of metamorphism described above are represented in Figure 6.1.6 with the same letters (a through e) used in Figures 6.1.4 and 6.1.5. 


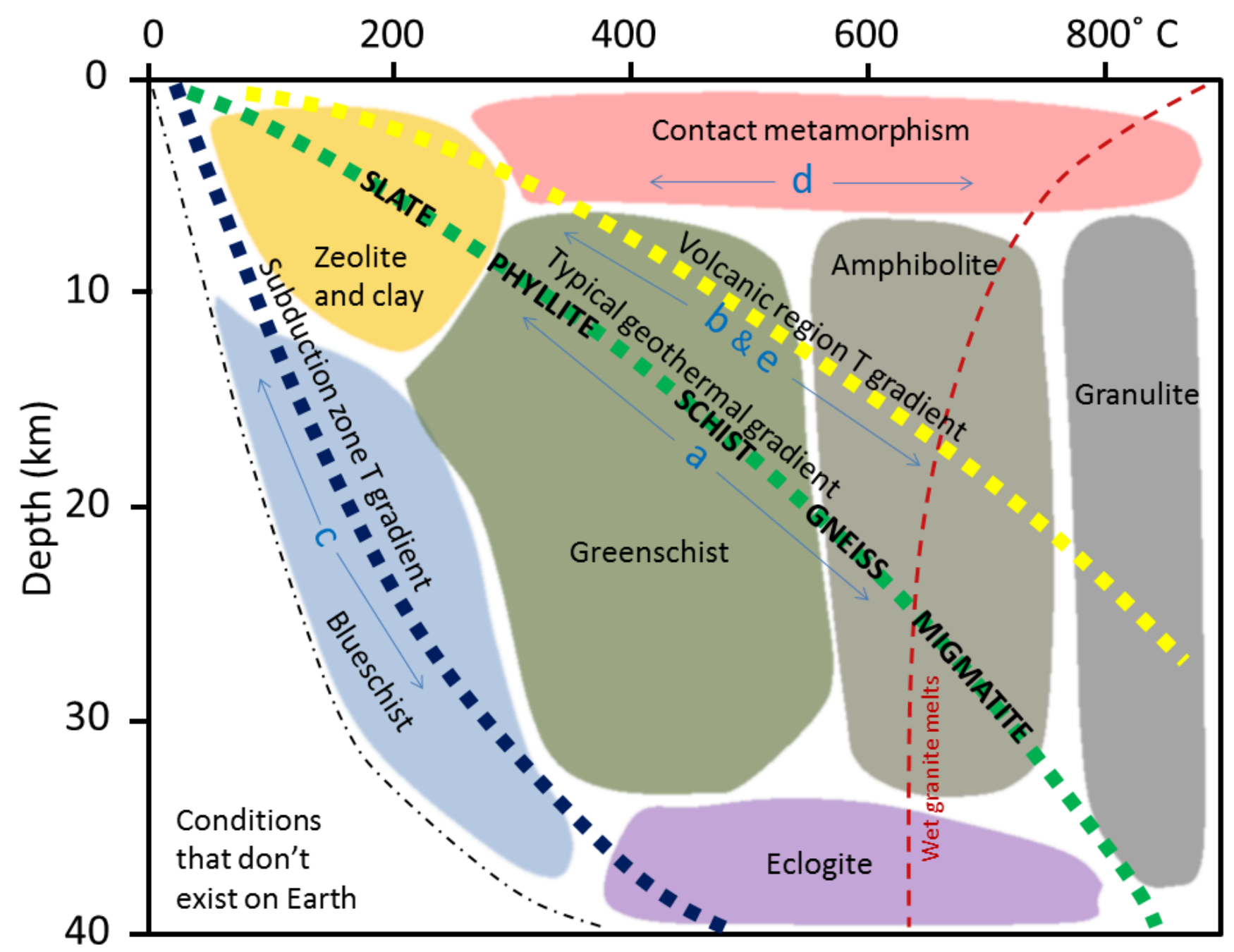

Figure 6.1.6: Types of metamorphism shown in the context of depth and temperature under different conditions. The metamorphic rocks formed from mudrock under regional metamorphism with a typical geothermal gradient are listed. The letters a through e correspond with those shown in Figures 6.1.4 and 6.1.5.

By way of example, if we look at regional metamorphism in areas with typical geothermal gradients, we can see that burial in the 5 kilometre to 10 kilometre range puts us in the clay mineral zone (see Figure 6.1.6), which is equivalent to the formation of slate. At 10 to 15 kilometres, we are in the greenschist zone (where chlorite would form in mafic volcanic rock) and very fine micas form in mudrock, to produce phyllite. At 15 to 20 kilometres, larger micas form to produce schist, and at 20 to 25 kilometres amphibole, feldspar, and quartz form to produce gneiss. Beyond a depth of 25 kilometres in this setting, we cross the partial melting line for granite (or gneiss) with water present, and so we can expect migmatite to form.

Practice Exercise 6.2 Metamorphic rocks in areas with higher geothermal gradients

Figure 6.1.6 shows the types of rock that might form from a mudrock protolith at various points along the curve of the "typical" geothermal gradient (dotted green line). Looking at the geothermal gradient for volcanic regions (dot- 
ted yellow line in Figure 6.1.6), estimate the depths at which you would expect to find the same types of rock forming from a mudrock protolith.

1. Slate

2. Phyllite

3. Schist

4. Gneiss

5. Migmatite

See Appendix 2 for Practice Exercise 6.2 answers.

\section{Media Attributions}

- Figures 6.1.1, 6.1.2, 6.1.4, 6.1.5, 6.1.6: (C) Steven Earle. CC BY.

- Figure 6.1.3: Garnet Mica Schist Syros Greece (C) Graeme Churchard. CC BY. 


\subsection{Classification of Metamorphic Rocks}

There are two main types of metamorphic rocks: those that are foliated because they have formed in an environment with either directed pressure or shear stress, and those that are massive (not foliated) because they have formed in an environment without directed pressure or relatively near the surface with very little pressure at all. Some types of metamorphic rocks, such as quartzite and marble, which can form whether there is directed-pressure or not, tend to be massive because their minerals (quartz and calcite respectively) do not tend to show alignment (see Figure 6.2.1).

When a rock is squeezed under directed pressure during metamorphism it is likely to be deformed, and this can result in a textural change such that the minerals appear elongated in the direction perpendicular to the main stress (Figure 6.2.1). This contributes to the formation of foliation.
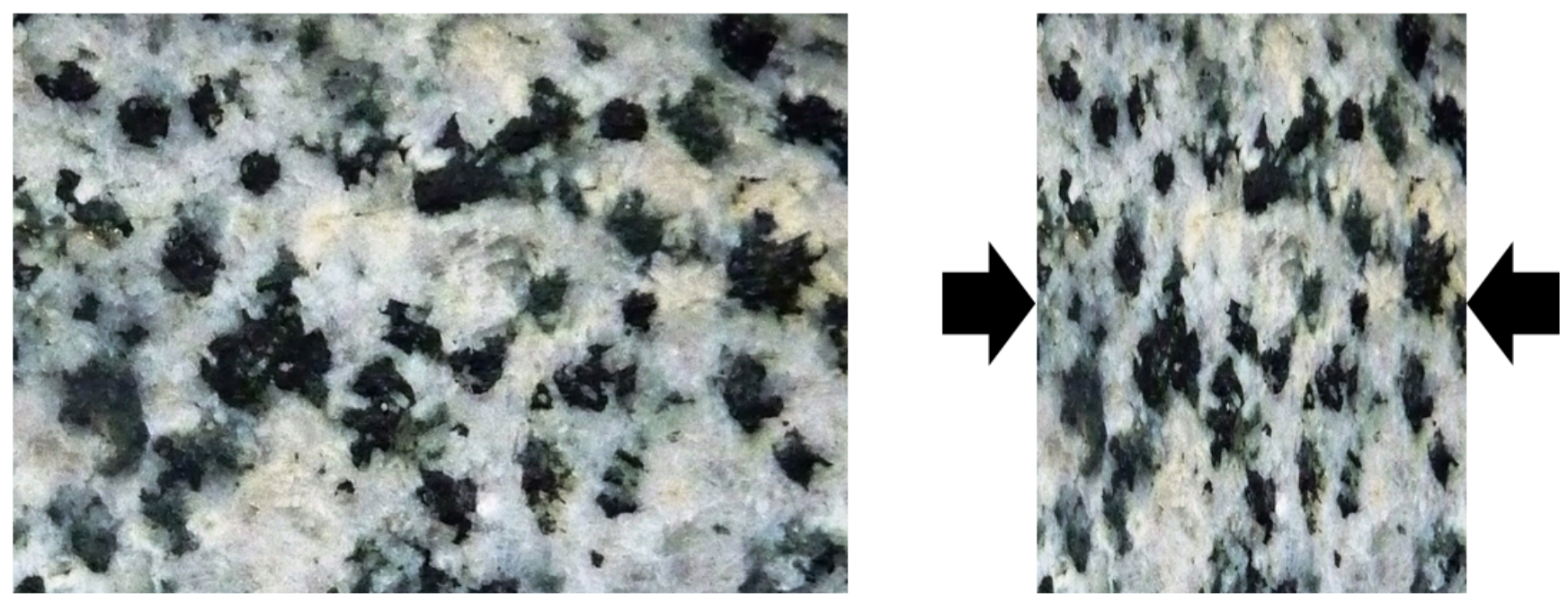

Figure 6.2.1: The textural effects of squeezing during metamorphism. In the original rock (left) there is no alignment of minerals. In the squeezed rock (right) the minerals have been elongated in the direction perpendicular to the squeezing.

When a rock is both heated and squeezed during metamorphism, and the temperature change is enough for new minerals to form from existing ones, there is a strong tendency for new minerals to grow with their long axes perpendicular to the direction of squeezing. This is illustrated in Figure 6.2.2, where the parent rock is shale, with bedding as shown. After both heating and squeezing, new minerals have formed within the rock, generally parallel to each other, and the original bedding has been largely obliterated. 

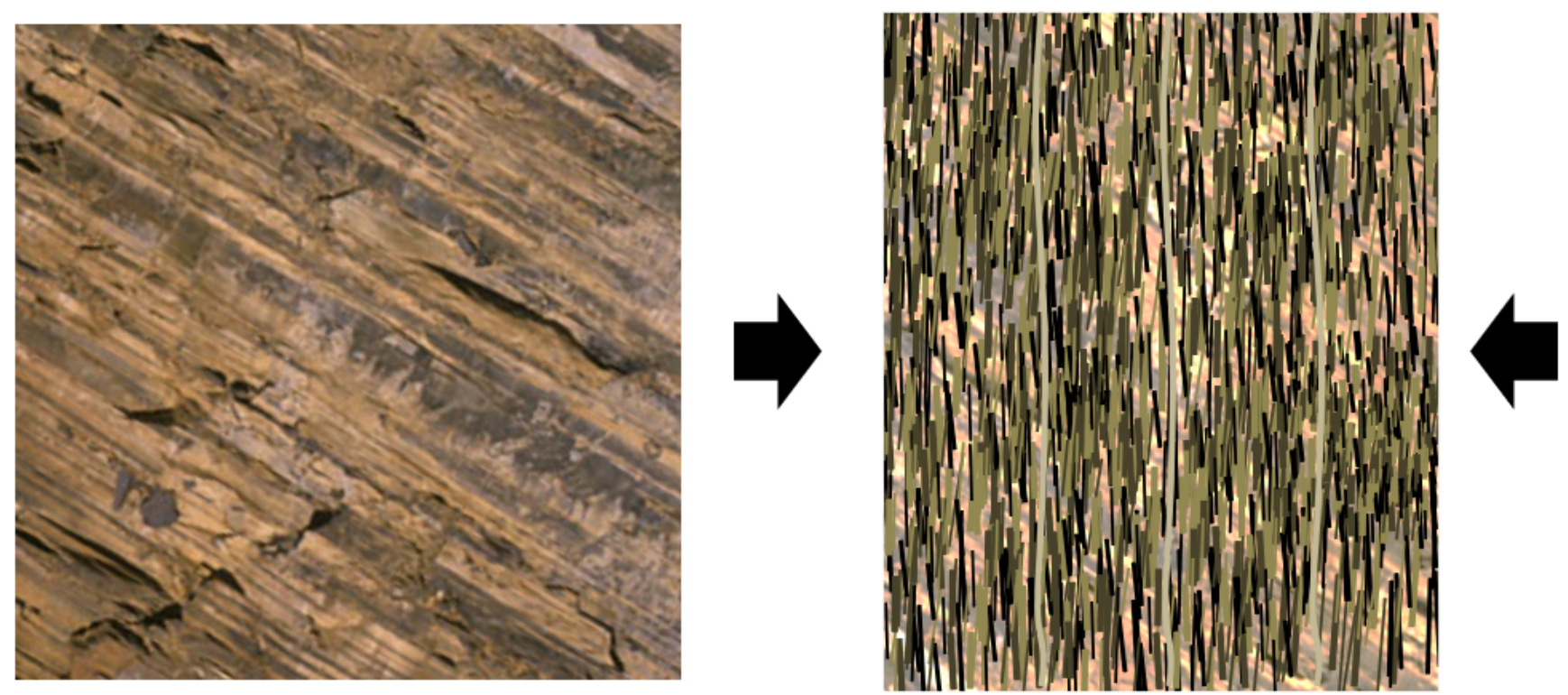

Figure 6.2.2: The textural effects of squeezing and mineral growth during regional metamorphism. The left diagram is shale with bedding slanting down to the right. The right diagram represents schist (derived from that shale), with mica crystals orientated perpendicular to the main stress direction and the original bedding no longer easily visible.

Figure 6.2.3 shows an example of this effect. This large boulder has bedding visible as dark and light bands sloping steeply down to the right. The rock also has a strong slaty foliation, which is horizontal in this view (parallel to the surface that the person is sitting on), and has developed because the rock was being squeezed during metamorphism. The rock has split from bedrock along this foliation plane, and you can see that other weaknesses are present in the same orientation.

Squeezing and heating alone (as shown in Figure 6.2.1) can contribute to foliation, but most foliation develops when new minerals are formed and are forced to grow perpendicular to the direction of greatest stress (Figure 6.2.2). This effect is especially strong if the new minerals are platy like mica or elongated like amphibole. The mineral crystals don't have to be large to produce foliation. Slate, for example, is characterized by aligned flakes of mica that are too small to see. 


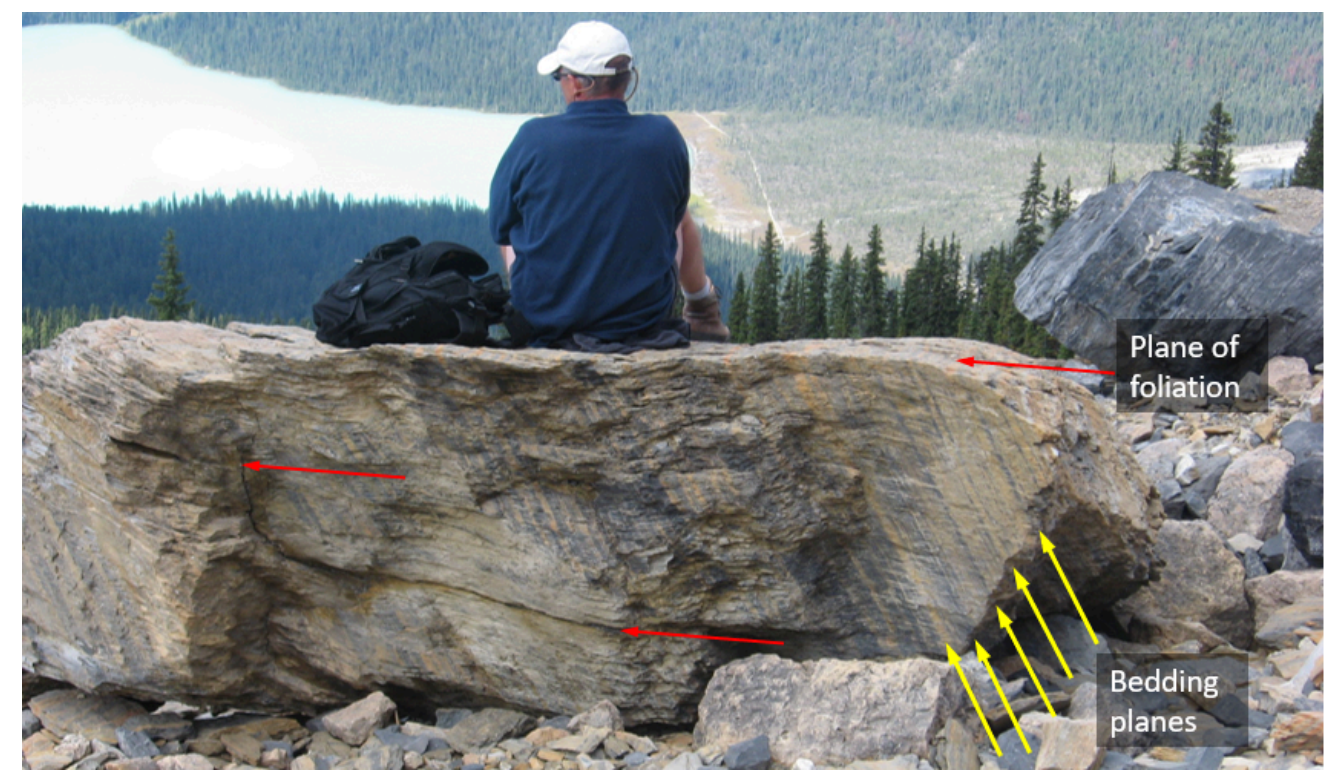

Figure 6.2.3: A slate boulder on the side of Mt. Wapta in the Rockies near Field, B.C. Bedding is visible as light and dark bands sloping steeply to the right (yellow arrows). Slaty cleavage is evident from the way the rock has broken (along the flat surface that the person is sitting on) and also from lines of weakness that are parallel to that same trend (red arrows).

The various types of foliated metamorphic rocks, listed in order of the metamorphic grade or intensity of metamorphism and the type of foliation are: slaty, phyllitic, schistose, and gneissic (Figure 6.2.4). As already noted, slate is formed from the low-grade metamorphism of shale, and has microscopic clay and mica crystals that have grown perpendicular to the stress. Slate tends to break into flat sheets. Phyllite is similar to slate, but has typically been heated to a higher temperature; the micas have grown larger and are visible as a shiny sheen on the surface. Where slate is typically planar, phyllite can form in wavy layers. In the formation of a schist, the temperature has been hot enough so that individual mica crystals are big enough to be visible, and other mineral crystals, such as quartz, feldspar, or garnet may also be visible. In a gneiss, the minerals may have separated into bands of different colours. In the example shown in Figure 6.2.4d, the dark bands are largely amphibole while the light-coloured bands are feldspar and quartz. Most gneiss has little or no mica because it forms at temperatures higher than those under which micas are stable. Unlike slate and phyllite, which typically only form from mudrock, schist, and especially gneiss, can form from a variety of parent rocks, including mudrock, sandstone, conglomerate, and a range of both volcanic and intrusive igneous rocks.

Schist and gneiss can be named on the basis of important minerals that are present. For example a schist derived from basalt is typically rich in the mineral chlorite, so we call it chlorite schist or greenschist. One derived from shale may be a muscovite-biotite schist, or just a mica schist, or if there are garnets present it might be mica-garnet schist. Similarly, a gneiss that originated as basalt and is dominated by amphibole, is an amphibole gneiss or, more accurately, an amphibolite. 


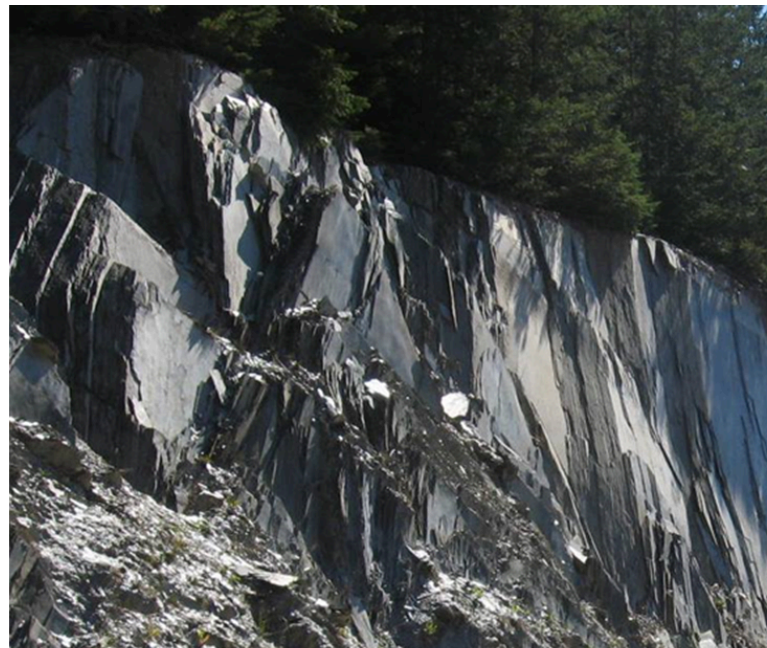

a) Slate, near to Golden, BC

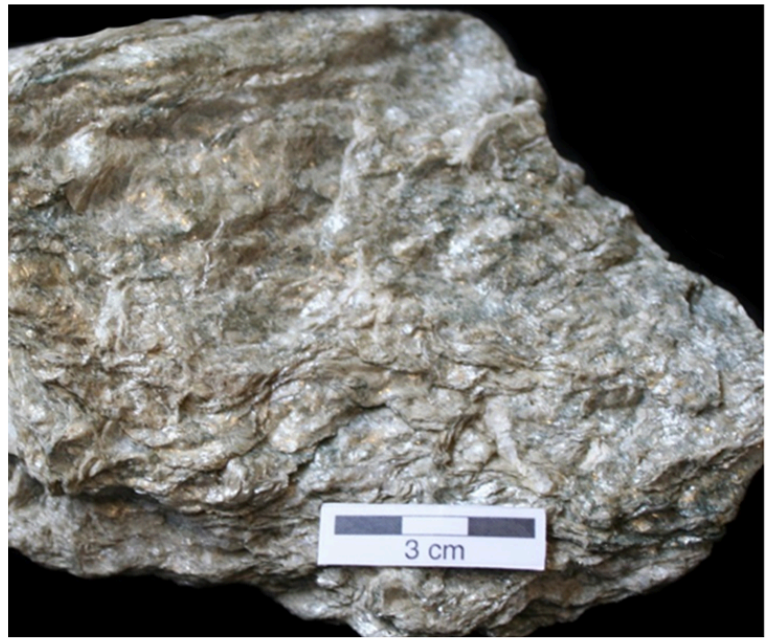

c) Schist, location unknown

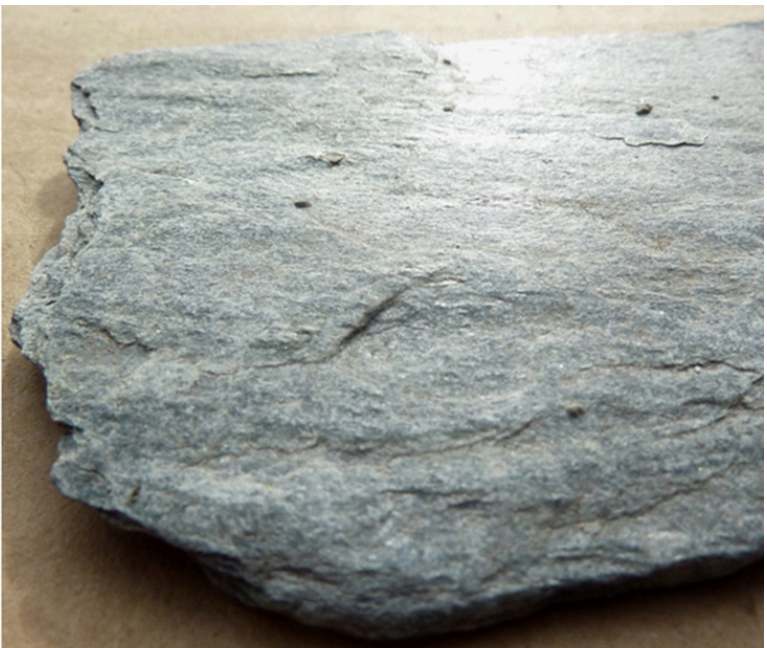

b) Phyllite, location unknown

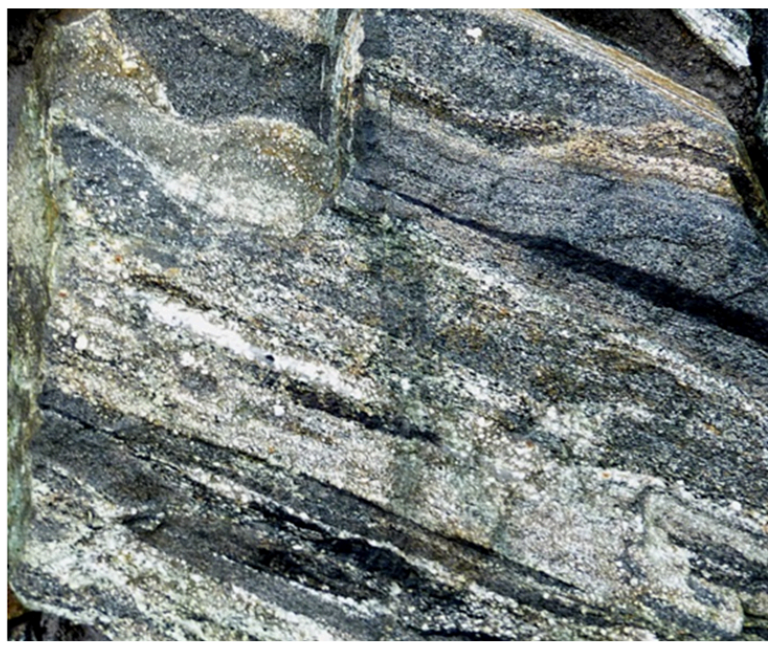

d) Gneiss from the Victoria area, BC

Figure 6.2.4: Examples of foliated metamorphic rocks: (A) Slate, (B) Phyllite, (C) Schist, (D) Gneiss.

Rather than focusing on just the metamorphic rock types (slate, schist, gneiss, etc.), geologists also tend to look at specific index minerals within the rocks that are indicative of different grades of metamorphism. Some common minerals in metamorphic rocks derived from a mudrock protolith are shown in Figure 6.2.5, arranged in order of the temperature ranges over which they tend to be stable. The upper and lower limits of the ranges are intentionally vague because these limits depend on a number of different factors, such as the pressure, the amount of water present, and the overall composition of the rock. 


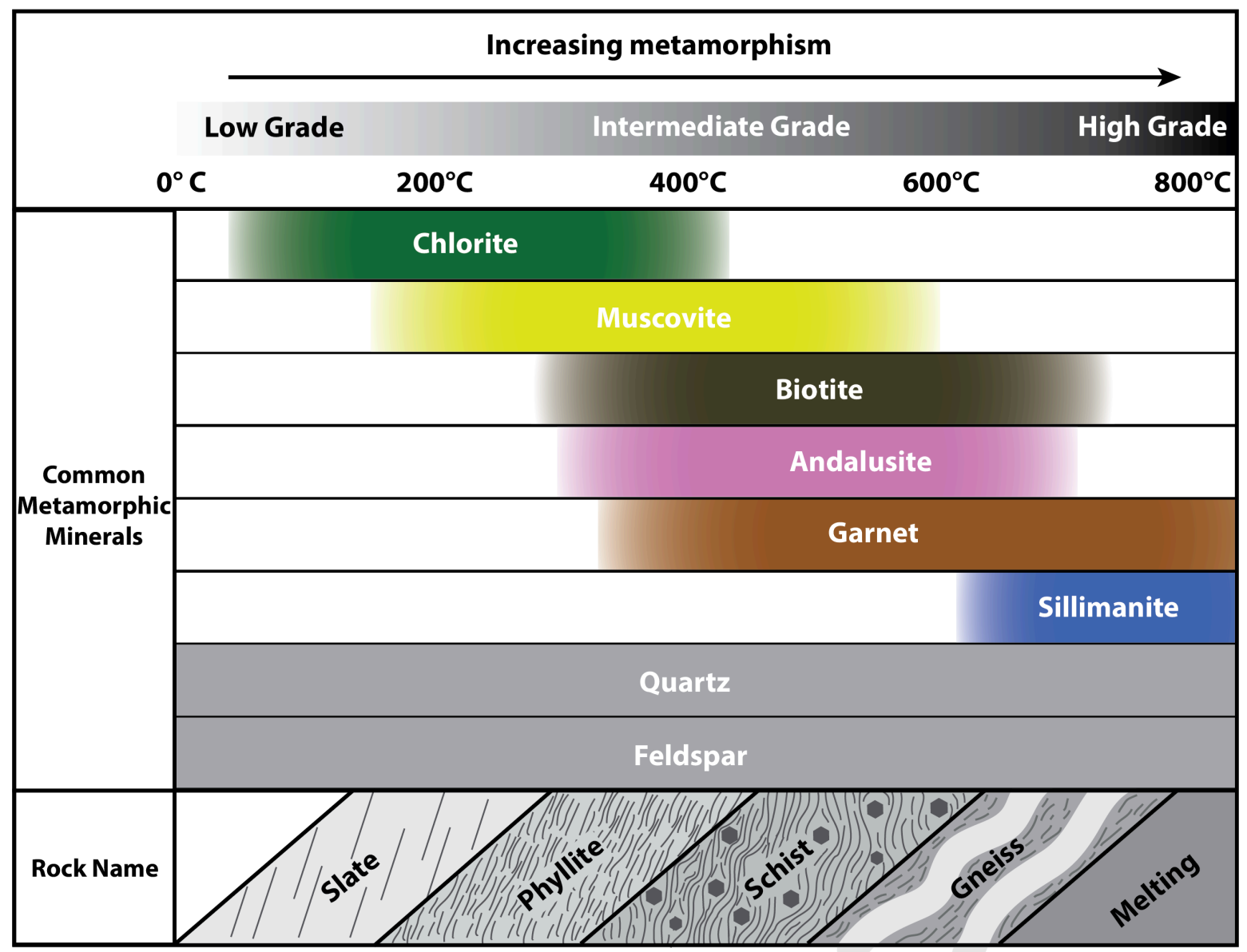

Figure 6.2.5: Metamorphic grades, common metamorphic index minerals, and corresponding rock names for a mudrock protolith under increasing metamorphism (increasing temperature and pressure). [Image description]

If a rock is buried to a great depth and encounters temperatures that are close to its melting point, it may partially melt. The resulting rock, which includes both metamorphosed and igneous material, is known as migmatite (Figure 6.2.6).

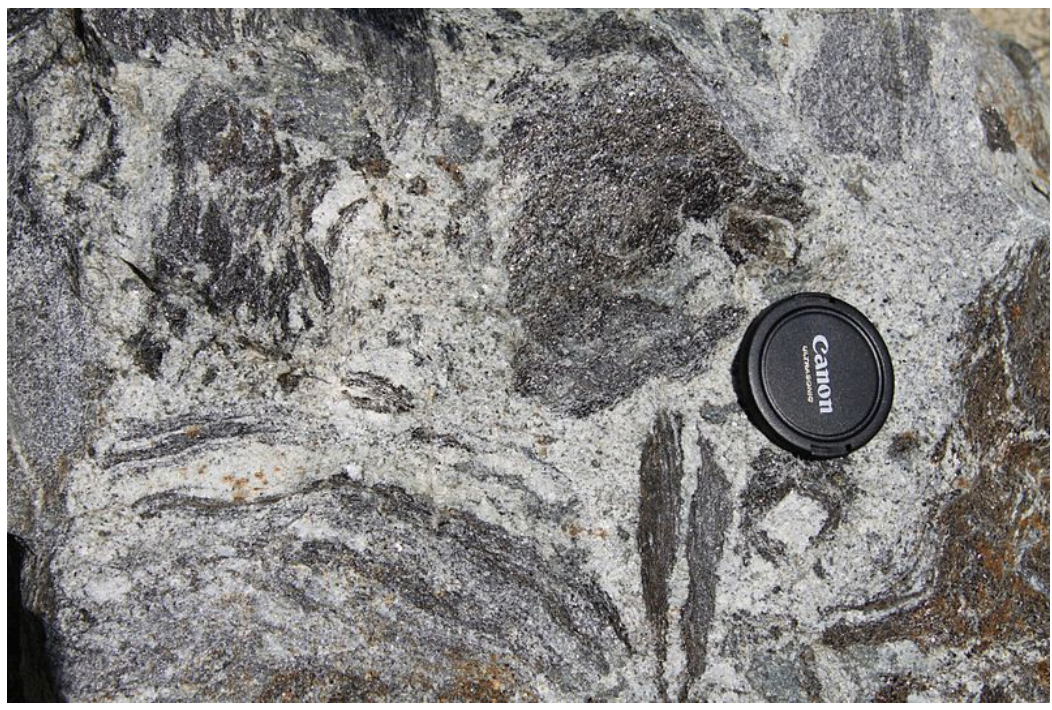

Figure 6.2.6: Migmatite from Prague, Czech Republic 
As already noted, the nature of the parent rock controls the types of metamorphic rocks that can form from it under differing metamorphic conditions. The kinds of rocks that can be expected to form at different metamorphic grades from various parent rocks are listed in Table 6.1. Some rocks, such as granite, do not change much at the lower metamorphic grades because their minerals are still stable up to several hundred degrees.

Table 6.1 A rough guide to the types of metamorphic rocks that form from different parent rocks at different grades of regional metamorphism. You are expected to know the rock names indicated in bold font.

\begin{tabular}{|c|c|c|c|c|}
\hline Protolith & $\begin{array}{l}\text { Very Low Grade } \\
\left(150-300^{\circ} \mathrm{C}\right)\end{array}$ & $\begin{array}{l}\text { Low Grade } \\
\left(300-450^{\circ} \mathrm{C}\right)\end{array}$ & $\begin{array}{l}\text { Medium Grade } \\
\left(450-550^{\circ} \mathrm{C}\right)\end{array}$ & $\begin{array}{l}\text { High Grade (Above } \\
550^{\circ} \mathrm{C} \text { ) }\end{array}$ \\
\hline Mudrock & slate & phyllite & schist & gneiss \\
\hline Granite & no change & no change & almost no change & granite gneiss \\
\hline Basalt & greenschist & greenschist & amphibolite & amphibolite \\
\hline Sandstone & no change & little change & quartzite & quartzite \\
\hline Limestone & little change & marble & marble & marble \\
\hline
\end{tabular}

Metamorphic rocks that form under either low-pressure conditions or just confining pressure do not become foliated, and their texture is described as massive. In most cases, this is because they are not buried deeply, and the heat for the metamorphism comes from a body of magma that has moved into the upper part of the crust. This is contact metamorphism. Some examples of non-foliated metamorphic rocks are marble, quartzite, and hornfels.

Marble is metamorphosed limestone. When it forms, the calcite crystals recrystallize and tend to grow larger, and any sedimentary textures and fossils that might have been present are destroyed. If the original limestone was pure calcite, then the marble will likely be white (as in Figure 6.2.7), but if it had various impurities, such as clay, silica, or magnesium, the marble could be "marbled" in appearance.
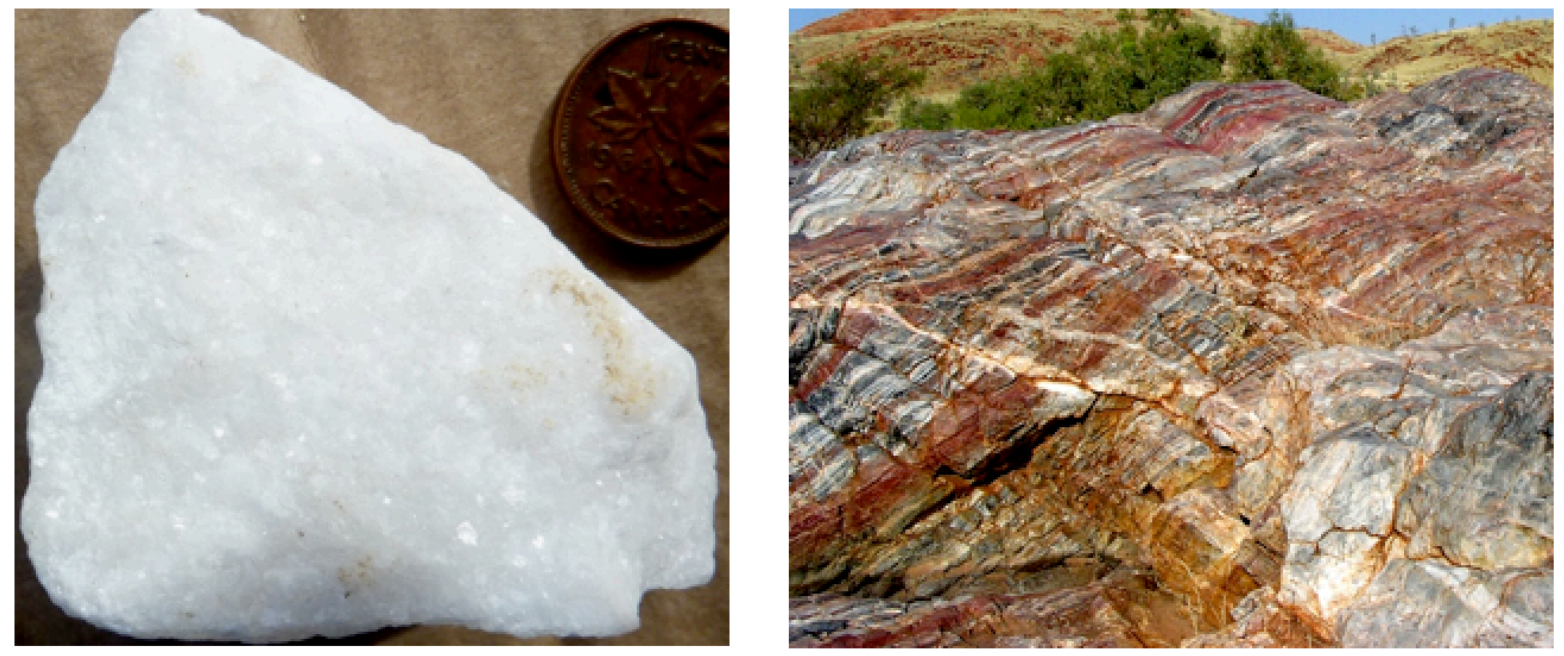

Figure 6.2.7: Marble with visible calcite crystals (left) and an outcrop of banded marble (right).

Quartzite is metamorphosed sandstone (Figure 6.2.8). It is dominated by quartz, and in many cases, the original quartz grains of the sandstone are welded together with additional silica. Most sandstone contains some clay minerals and may also include other minerals such as feldspar or fragments of rock, so most quartzite has some impurities with the quartz. 


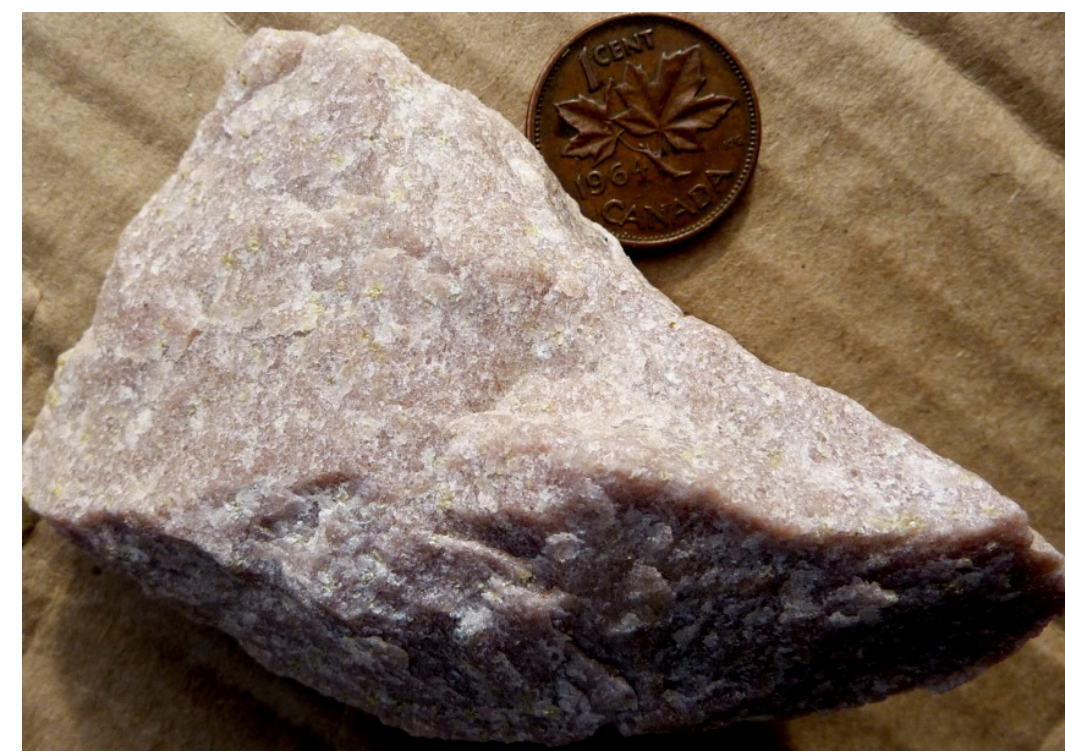

Figure 6.2.8: Quartzite from the Rocky Mountains, found in the Bow River at Cochrane, Alberta.

Even if formed during regional metamorphism, quartzite (like marble) does not tend to look foliated because quartz crystals don't align with the directional pressure.

Provide reasonable names for the following metamorphic rocks based on the description:

1. A rock with visible crystals of mica and with small crystals of andalusite. The mica crystals are consistently parallel to one another.

2. A very hard rock with a granular appearance and a glassy lustre. There is no evidence of foliation.

3. A fine-grained rock that splits into wavy sheets. The surfaces of the sheets have a sheen to them.

4. A rock that is dominated by aligned crystals of amphibole.

See Appendix 2 for Practice Exercise 6.3 answers.

\section{Image Descriptions}

Figure 6.2.5 image description: Metamorphic index minerals for a mudrock protolith. As conditions change with increasing metamorphism, certain minerals become unstable and undergo solid-state changes to form new, stable minerals. For example, between $\sim 300-400^{\circ} \mathrm{C}$, the elements in chlorite will be re-ordered to form the mineral biotite. Note that while garnet, for example, is a common mineral in schist, it is not present in all schists! The new minerals that form in a metamorphic rock are dependent upon the composition of the protolith and a wide variety of minerals are possible. Approximate temperature range of metamorphic index minerals: Chlorite, 50 to $450^{\circ} \mathrm{C}$. Muscovite, 175 to $625^{\circ} \mathrm{C}$. Biotite, 300 to $725^{\circ} \mathrm{C}$. Andalusite, 300 to $650^{\circ} \mathrm{C}$. Garnet, 375 to $900^{\circ} \mathrm{C}$. Sillimanite, 575 to $1000^{\circ} \mathrm{C}$. Not all minerals in a metamorphic rock are indicative of 
a particular metamorphic grade. Quartz, feldspar, and calcite (not shown), for example, are stable over the entire range of temperatures shown in Figure 6.3.1. [Return to Figure 6.2.5]

\section{Media Attributions}

- Figures 6.2.1, 6.2.2, 6.2.3, 6.2.4abd, 6.2.8: (C) Steven Earle. CC BY.

- Figure 6.2.4c: Schist detail (C) Michael C. Rygel. CC BY-SA.

- Figure 6.2.5: (C) Siobhan McGoldrick. CC BY.

- Figure 6.2.6: Migmatite in Geopark on Albertov (C) Chmee2. CC BY.

- Figure 6.2.7 (right): An outcrop of banded marble by the USGS. Public domain. 


\subsection{The Rock Cycle}

Now that you have practiced identifying all three major categories of rock, let's examine how these rocks are slowly but constantly being changed from one form to another. The processes involved in the constant changing of these components of the Earth's crust are summarized in the rock cycle (Figure 6.3.1). The rock cycle is driven by two forces: (1) Earth's internal heat engine, which moves material around in the core and the mantle and leads to slow but significant changes within the crust, and (2) the hydrological cycle, which is the movement of water, ice, and air at the surface, and is powered by the sun.

The rock cycle is still active on Earth because our core is hot enough to keep the mantle moving, our atmosphere is relatively thick, and we have liquid water. On some other planets or their satellites, such as the Moon, the rock cycle is virtually dead because the core is no longer hot enough to drive mantle convection and there is no atmosphere or liquid water.

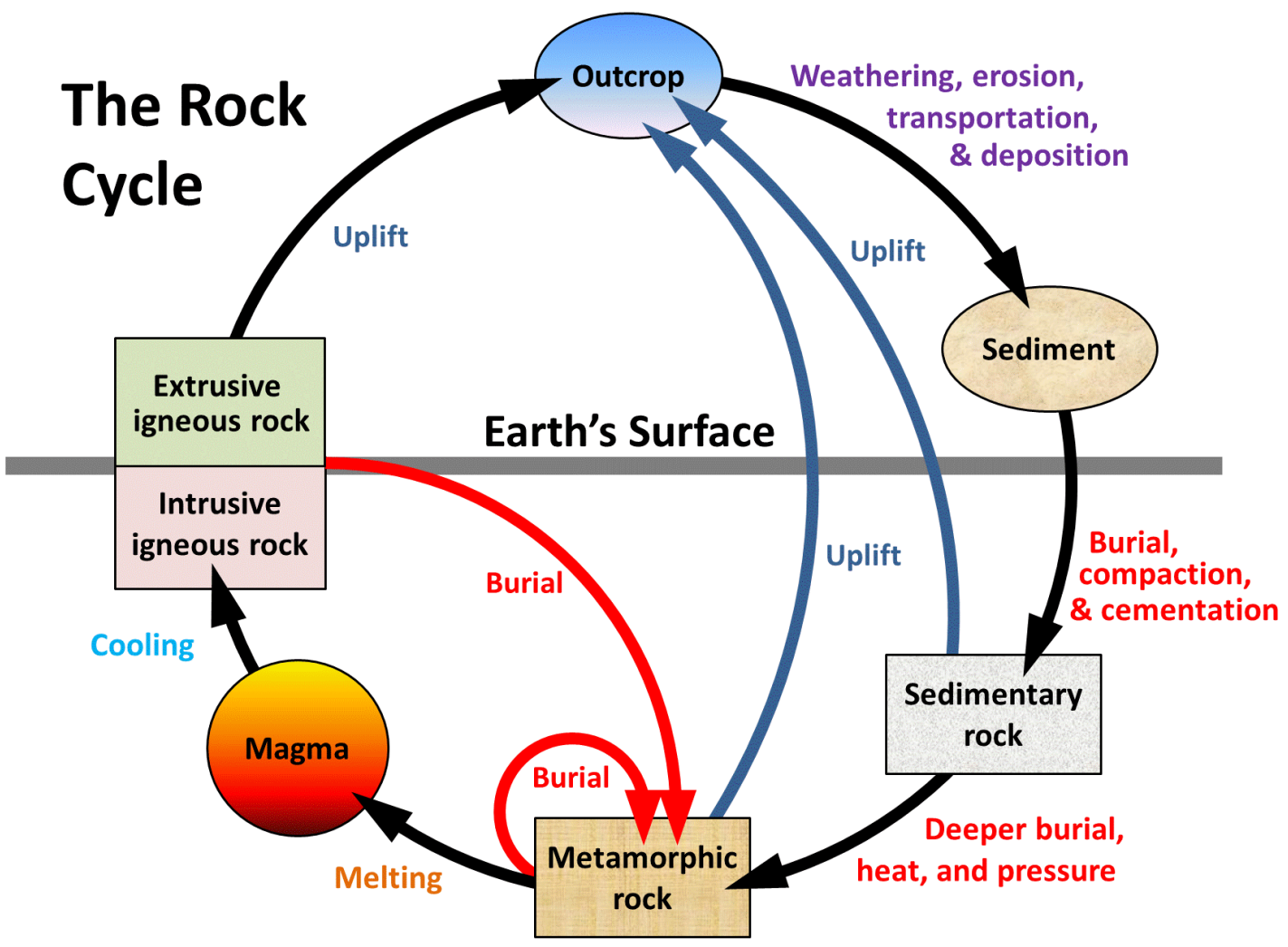

Figure 6.3.1: A schematic view of the rock cycle.

In describing the rock cycle, we can start anywhere we like, although it's convenient to start with magma. As you learned in Lab 4, magma is rock that is hot to the point of being entirely molten, with a temperature of between about $800^{\circ}$ and $1300^{\circ} \mathrm{C}$, depending on the composition and the pressure.

Magma can either cool slowly within the crust (over centuries to millions of years)-forming intrusive igneous rocks, or erupt onto the surface and cool quickly (within seconds to years)-forming extrusive igneous rocks (volcanic rocks). Intrusive igneous rocks typically crystallize at depths of hundreds of metres to tens of kilometres below the surface. To change its position in the rock cycle, intrusive igneous rock has to be uplifted and then exposed by the erosion of the overlying rocks. 
Through the various plate tectonics-related processes of mountain building, all types of rocks are uplifted and exposed at the surface. Once exposed, they are weathered, both physically (by mechanical breaking of the rock) and chemically (by weathering of the minerals), and the weathering products-mostly small rock and mineral fragments-are eroded, transported, and then deposited as sediments. Transportation and deposition occur through the action of glaciers, streams, waves, wind, and other agents, and sediments are deposited in rivers, lakes, deserts, and the ocean.

Practice Exercise 6.4 Rock around the rock-cycle clock

Referring to the rock cycle (Figure 6.3.1), list the steps that are necessary to cycle some geological material starting with a sedimentary rock, which then gets converted into a metamorphic rock, and eventually a new sedimentary rock.

A conservative estimate is that each of these steps would take approximately 20 million years (some may be less, others would be more, and some could be much more). How long might it take for this entire process to be completed?

See Appendix 2 for Exercise 6.4 Answers.

Unless they are re-eroded and moved along, sediments will eventually be buried by more sediments. At depths of hundreds of metres or more, they become compressed and cemented into sedimentary rocks. Again through various means, largely resulting from plate-tectonic forces, different kinds of rocks are either uplifted, to be re-eroded, or buried deeper within the crust where they are heated up, squeezed, and changed into metamorphic rock.

\section{Media Attributions}

- Figure 6.3.1: @ Steven Earle. CC BY. 


\section{Lab 6 Exercises}

\section{Part I: Metamorphic Rocks}

The exercises below will guide you through the metamorphic rock samples in Rock Kits 1 and 2. Review the background information presented in Chapters 6.1 and 6.2 before you begin these exercises. You may wish to consult the Rock Classification Tables at the back of this manual as you complete the exercises below.

\section{Tips for Classifying Metamorphic Rocks}

- Your first step when examining a metamorphic rock is to determine if its texture is foliated or massive.

- If the rock is foliated, next determine the type of foliation:

- Slaty foliations are flat, smooth surfaces along which a slate breaks. They might have a slightly shinier lustre than a shale.

- Larger crystals of micas that define a schistose foliation give it a shiny, wavy appearance and any sheet-like or elongate minerals will be aligned in a preferred orientation.

- Gneissic foliation, or gneissic banding, is defined by segregated bands of light-coloured quartz and feldspars and dark-coloured ferromagnesian minerals.

- If the texture is massive, test the sample with a drop of dilute $\mathrm{HCl}$. Marble reacts with $\mathrm{HCl}$ just like its protolith - limestone!

- If the sample is massive and does not react with $\mathrm{HCl}$, try testing the hardness. Quartzite is composed predominantly of quartz, giving it a hardness $\sim 7$.

- Lastly, if the metamorphic rock is foliated but has a distinctly green-colour to it, and contains abundant ferromagnesian minerals chlorite and green amphibole, it is called a greenschist.

- Figure E and Table D in the Rock Classification Tables appendix may be helpful resources as you complete these lab exercises.

1. The best way to really appreciate the metamorphic changes to a rock is to meet its parent! Examine each of the sample pairs listed below. Each pair contains a metamorphic rock and its protolith (parent rock). Identify which of the two samples is the metamorphic rock, and then carefully compare the two. In what ways are the metamorphic rock and its protolith similar? In what ways do they differ? Record your observations in the table below.

- Pair A: R221 and R361

- Pair B: R301 and R181

- Pair C: R1 and R331

- Paid D: R351 and R161 


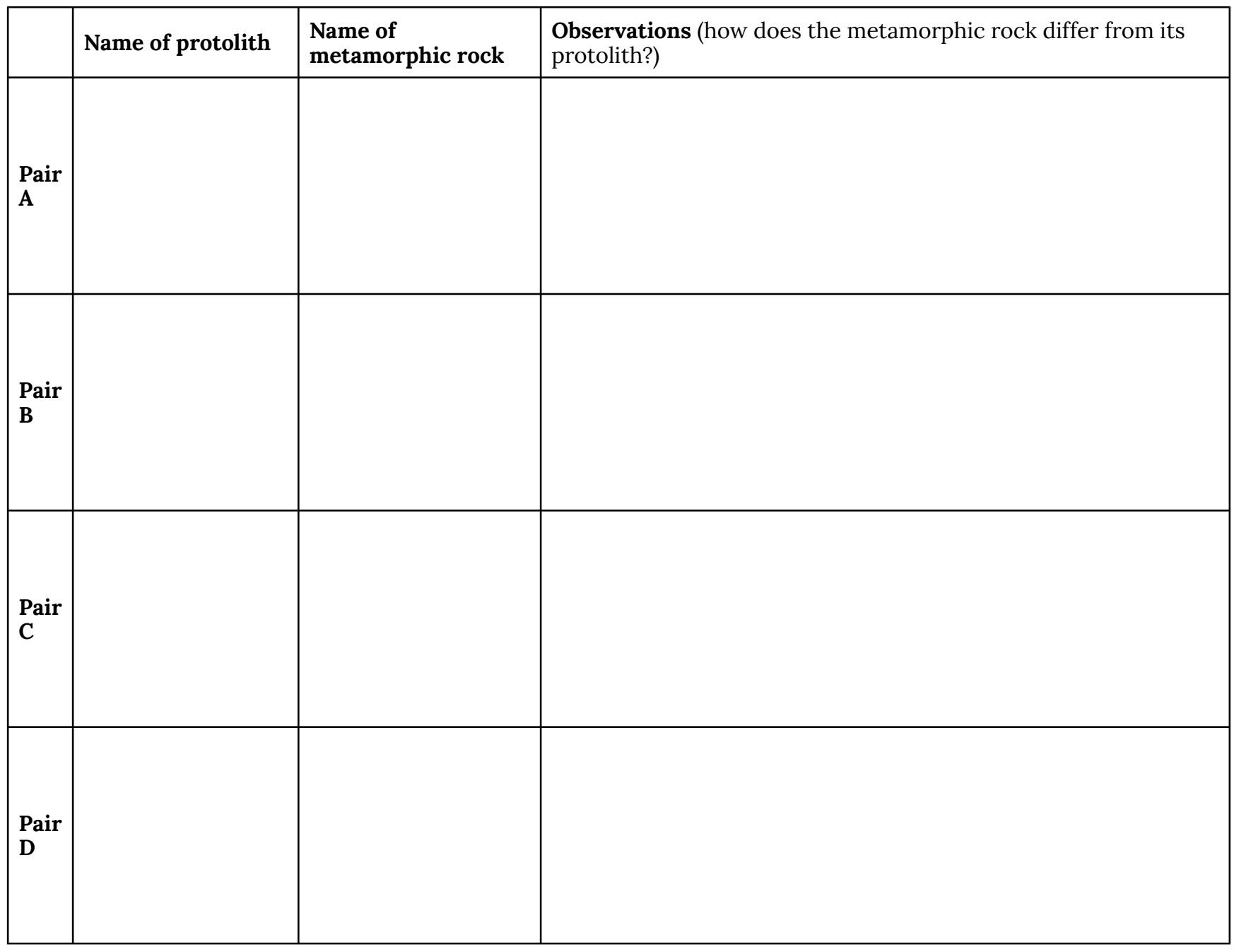

2. Examine samples R181, R301, R321, R331, and R332. These samples show the progression of changes from a protolith (shale) to a high grade metamorphic rock (gneiss). Complete the table below by recording the changes you observe in mineralogy and texture with increasing metamorphism. For the changes in mineralogy, record what new minerals you see and note any minerals that have disappeared. For the changes in texture, look for changes in grain size or the development of a foliation. 


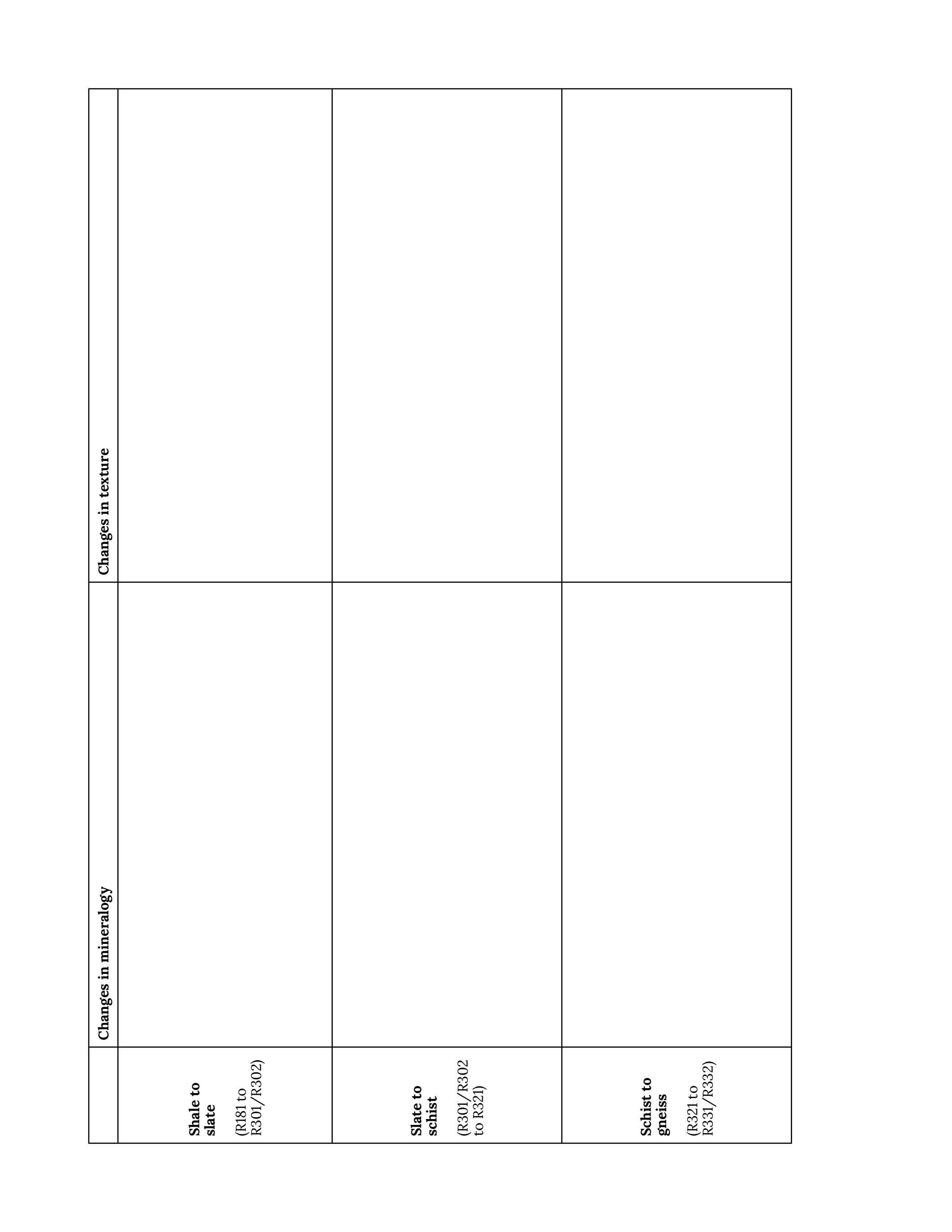


3. This progression of foliated metamorphic rocks from slate to gneiss is typical of mudrocks that are metamorphosed during regional metamorphism with a typical geothermal gradient. Using Figure 6.1.6 and Figure $\mathrm{E}$ in the Rock Classification Tables as a guide, complete the table below to summarize the range of temperatures and depths (pressure) responsible for the metamorphism of samples R301, R321, and R332.

\begin{tabular}{|l|l|l|l|}
\hline $\begin{array}{l}\text { Sample } \\
\#\end{array}$ & Approx. temperature $\left({ }^{\circ} \mathrm{C}\right)$ & Approx. Depth $(\mathbf{k m})$ & $\begin{array}{l}\text { Metamorphic Grade (low, } \\
\text { intermediate, high) }\end{array}$ \\
\hline R301 & & & \\
\hline R321 & & & \\
\hline R332 & & & \\
\hline
\end{tabular}

4. Which two samples in your Rock Kits 1 and 2 represent non-foliated (or massive) metamorphic rocks?

5. Do these two samples exhibit crystalline or clastic textures?

6. Examine sample R351. Try to scratch this sample with the tools from your mineral ID kit. How hard is this sample?

7. Based on your answer above, and any other physical properties you observe, name the main mineral(s) present in this rock:

8. Examine sample R361. Try to scratch this sample with the tools from your mineral ID kit. How hard is this sample?

9. Place a small drop of $\mathrm{HCl}$ on a fresh surface of the sample. What happens?

10. On the basis of these two tests name the main mineral present in this rock:

11. Metamorphism may affect the texture or the mineral composition or both of these properties of the protolith. Do samples R351 and R361 have the same mineral composition as their respective sedimentary protoliths? Do they have the same texture? Explain your answers.

\section{Part II: The Rock Cycle}

The exercises below are a review of the rock cycle processes by which one type of rock is transformed into another over geological time. You will review all the rock samples in Rock Kits 1 and 2 that you have examined to date in preparation for Test 2. Review the background information presented in Chapter 6.3 before you begin these exercises. To benefit the most from these review exercises, remove all your rock samples from the Rock Kits and set the empty kits aside, so that you cannot see the names of the rocks.

All rocks are connected through the rock cycle. Any rock that you see today will at some point in the future be transformed into a different rock through the rock cycle (see Figure 6.3.1). This exercise focuses on the processes that are responsible for the transformation of one rock type into another. As a starting point, summarize the main processes involved in the formation of the three main categories of rock: 
- Igneous:

- Sedimentary:

- Metamorphic:

The example presented below illustrates how you should complete question 12, by explaining the processes that formed the rocks in the second column. This example begins with granite, and the processes responsible for the formation of the granite are explained first. Then, the processes that explain how granite is transformed into quartz sandstone are outlined, and so on.

\begin{tabular}{|c|c|c|l|}
\hline Order & Rock Name & $\begin{array}{c}\text { Sample } \\
\#\end{array}$ & Rock Cycle Processes Responsible \\
\hline $\mathbf{1}$ & Granite & R1 & $\begin{array}{l}\text { Partial melting of pre-existing rock to generate magma. Felsic magma cools and } \\
\text { crystallizes at depth to form granite, a felsic intrusive igneous rock. }\end{array}$ \\
\hline $\mathbf{2}$ & $\begin{array}{c}\text { Quartz } \\
\text { sandstone }\end{array}$ & R161 & $\begin{array}{l}\text { Granite is uplifted to surface, chemically and mechanically weathered, and eroded. } \\
\text { Sand-sized grains of quartz, feldspar and some ferromagnesian minerals are } \\
\text { transported. Feldspars and ferromagnesian minerals chemically weather to form clay } \\
\text { minerals and ions in solution. Quartz grains become more rounded and better sorted } \\
\text { with transport. Eventually quartz grains are deposited in a moderate to high energy } \\
\text { environment (depending on grain size). Grains of quartz are lithified into sandstone } \\
\text { through burial by other sediments, compaction, and cementation by mineral(s) } \\
\text { precipitated from a fluid. }\end{array}$ \\
\hline $\mathbf{3}$ & Quartzite & R351 & $\begin{array}{l}\text { Quartz sandstone is metamorphosed through regional or contact metamorphism. } \\
\text { Grains of quartz recrystallize into coarser grains to form a crystalline texture. }\end{array}$ \\
\hline
\end{tabular}

12. For each of the rocks specified below, find the corresponding rock sample from your collection of rocks. Remember, for this to be an effective review activity, do this without looking at the rock names in the kit! Complete the table with the appropriate sample number, and explain the processes from the rock cycle that have transformed the previous sample into the present sample. Begin by explaining how pebble-sized clasts of basalt formed, and then how shale could form from those basalt pebbles, and so on. 


\begin{tabular}{|c|c|c|c|}
\hline Order & $\begin{array}{c}\text { Rock } \\
\text { Name }\end{array}$ & Sample \# & Rock Cycle Processes Responsible \\
\hline 1 & $\begin{array}{c}\text { Basalt } \\
\text { pebbles } \\
\text { (sediment) }\end{array}$ & N/A & \\
\hline 2 & Shale & & \\
\hline 3 & $\begin{array}{l}\text { Garnet } \\
\text { gneiss }\end{array}$ & & \\
\hline 4 & Diorite & & \\
\hline
\end{tabular}

\section{Part III: Rock Review}

13. Use the flow chart below to review igneous, sedimentary, and metamorphic rocks from Labs 4-6. This review will help you prepare for Test 2. The words "fine", "medium", and "coarse" on the flow chart refer to grain size. Chemical formulae are listed for any monomineralic rocks. The words "light", "intermediate", and "dark" refer to the colour (and therefore composition) of aphanitic igneous rocks. 


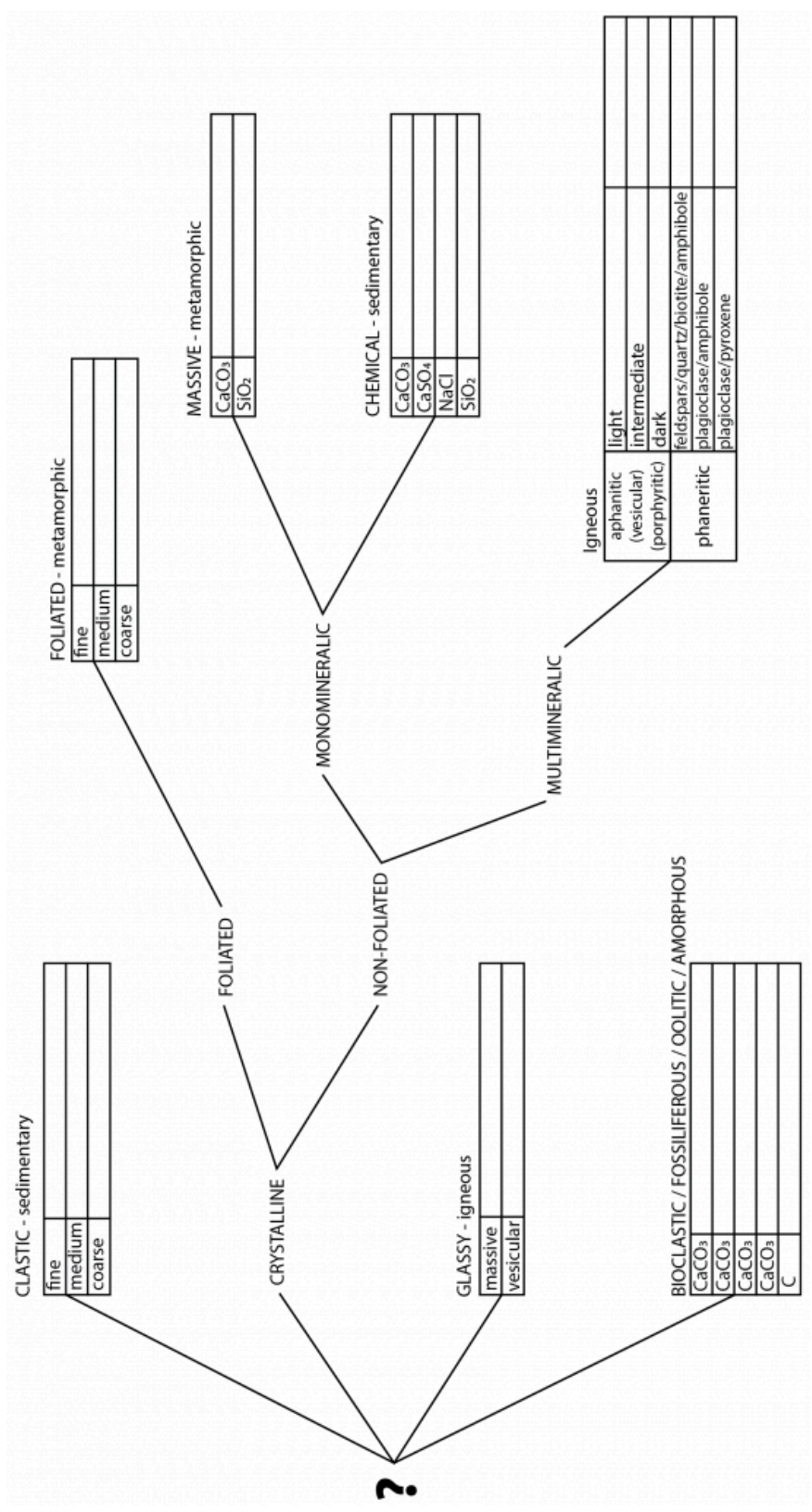

Lab 6 Exercises | 176 


\section{Summary}

The topics covered in this chapter can be summarized as follows:

\begin{tabular}{|c|c|}
\hline Section & Summary \\
\hline & $\begin{array}{l}\text { Metamorphism is controlled by five main factors: the composition of the parent rock, the } \\
\text { temperature to which the rock is heated, the amount and type of pressure, the volumes and }\end{array}$ \\
\hline & metamorphic reactions to take place. Almost all metamorphism can be explained by plate tectonic \\
\hline Tectonics & $\begin{array}{l}\text { created, which are most common at convergent boundaries. Contact metamorphism takes place } \\
\text { convergent boundaries. }\end{array}$ \\
\hline & Metamorphic rocks are classified on the basis of texture and mineral composition. Foliation is a \\
\hline & e of metamorphic rocks formed under directed pressure. Foliated metamorphic rocks \\
\hline & $\begin{array}{l}\text { incluae slate, pnyllite, scnist, and gneiss. Metamorpnic rocks that ao not tend to be rollated, } \\
\text { if formed under directed pressure, include marble and quartzite. Geologists also classify }\end{array}$ \\
\hline Rocks & $\begin{array}{l}\text { metamorphic rocks based on some key minerals - such as chlorite, garnet, andalusite, and } \\
\text { sillimanite-that form at specific temperatures and pressures. }\end{array}$ \\
\hline $\begin{array}{l}6.3 \text { The Rock } \\
\text { Cycle }\end{array}$ & $\begin{array}{l}\text { The three types of rocks are igneous: formed from magma; sedimentary: formed from fragments } \\
\text { of other rocks or precipitation from solution; and metamorphic: formed when existing rocks are } \\
\text { altered by heat, pressure, and/or chemical action. The rock cycle summarizes the processes that } \\
\text { contribute to cycling of rock material among these three types. The rock cycle is driven by Earth's } \\
\text { internal heat, and by processes happening at the surface, which are driven by solar energy. }\end{array}$ \\
\hline Lab 6 Exercises & $\begin{array}{l}\text { Metamorphic rocks are classified according to their mineral composition, and texture (foliated or } \\
\text { massive). Knowing the diagnostic properties of the common metamorphic minerals like chlorite, } \\
\text { muscovite, biotite, and garnet will help you estimate the metamorphic grade of the rock (low, } \\
\text { intermediate, or high grade). Just as with mineral samples, different samples of the same rock may } \\
\text { not always look exactly the same, but they can always be identified by closely examining the } \\
\text { mineral composition and texture. For example, schist can contain a wide variety of new } \\
\text { metamorphic minerals with different colours and shapes, but all schists are characterized by } \\
\text { schistose foliation. }\end{array}$ \\
\hline
\end{tabular}




\section{Review of Minerals and Rocks}

Mineral and Rock Review

Now that we've covered minerals and all three types of rocks it's important for you to convince yourself that you've got them straight in your mind. As already noted, one of the most common mistakes that geology students make on assignments, tests, and exams is to confuse minerals with rocks and then give a wrong answer when asked to name one or the other based on information provided.

In this exercise you are given a list of names of minerals and rocks and asked to determine which ones are minerals and which are rocks. For those that you think are minerals you should then indicate which mineral group it belongs to (e.g., oxide, sulphate, silicate, carbonate, halide etc.). For those that you think are rocks, you should describe what type of rock it is (e.g., intrusive igneous, extrusive igneous, clastic sedimentary, chemical sedimentary, foliated metamorphic and non-foliated (massive) metamorphic). If the rock is metamorphic, list its protolith. The answers can be found in Appendix 3.

\begin{tabular}{|c|c|c|}
\hline $\begin{array}{l}\text { Mineral or } \\
\text { rock name }\end{array}$ & $\begin{array}{l}\text { Rock or } \\
\text { mineral? }\end{array}$ & If it's a mineral, which group does it belong to? If it's a rock, what type is it? \\
\hline \multicolumn{3}{|l|}{ Feldspar } \\
\hline \multicolumn{3}{|l|}{ Calcite } \\
\hline \multicolumn{3}{|l|}{ Slate } \\
\hline \multicolumn{3}{|l|}{ Hematite } \\
\hline \multicolumn{3}{|l|}{ Rhyolite } \\
\hline \multicolumn{3}{|l|}{ Sandstone } \\
\hline \multicolumn{3}{|l|}{ Diorite } \\
\hline \multicolumn{3}{|l|}{ Olivine } \\
\hline \multicolumn{3}{|l|}{ Pyrite } \\
\hline \multicolumn{3}{|l|}{ Quartzite } \\
\hline \multicolumn{3}{|l|}{ Granite } \\
\hline \multicolumn{3}{|l|}{ Amphibole } \\
\hline \multicolumn{3}{|c|}{ Conglomerate } \\
\hline \multicolumn{3}{|l|}{ Chert } \\
\hline \multicolumn{3}{|l|}{ Halite } \\
\hline \multicolumn{3}{|l|}{ Gneiss } \\
\hline \multicolumn{3}{|l|}{ Mica } \\
\hline \multicolumn{3}{|l|}{ Pyroxene } \\
\hline \multicolumn{3}{|l|}{ Chlorite } \\
\hline \multicolumn{3}{|l|}{ Limestone } \\
\hline Andesite & & \\
\hline
\end{tabular}




\section{LAB 7: RELATIVE DATING AND GEOLOGICAL TIME}

\section{Lab Structure}

Recommended additional work

Required materials
None

Pencil

\section{Learning Objectives}

After carefully reading this chapter, completing the exercises within it, and answering the questions at the end, you should be able to:

- Apply basic geological principles to the determination of the relative ages of rocks.

- $\quad$ Explain the difference between relative and absolute age-dating techniques.

- Summarize the history of the geological time scale and the relationships between eons, eras, periods, and epochs.

- Understand the importance and significance of unconformities.

- Explain why an understanding of geological time is critical to both geologists and the general public.

Key Terms

- Eon

- Era

- Period

- Relative dating

- Absolute dating

- Isotopic dating

- Stratigraphy

- Strata

- Superposition
- Original horizontality

- Cross-cutting

- Inclusions

- Faunal succession

- Unconformity

- Angular unconformity

- Disconformity

- Nonconformity

- Paraconformity

Time is the dimension that sets geology apart from most other sciences. Geological time is vast, and Earth has changed enough over that time that some of the rock types that formed in the past could not form today. Furthermore, as we've discussed, even though most geological processes are very, very slow, the vast amount of time that has passed has allowed for the formation of extraordinary geological features, as shown in Figure 7.0.1. 


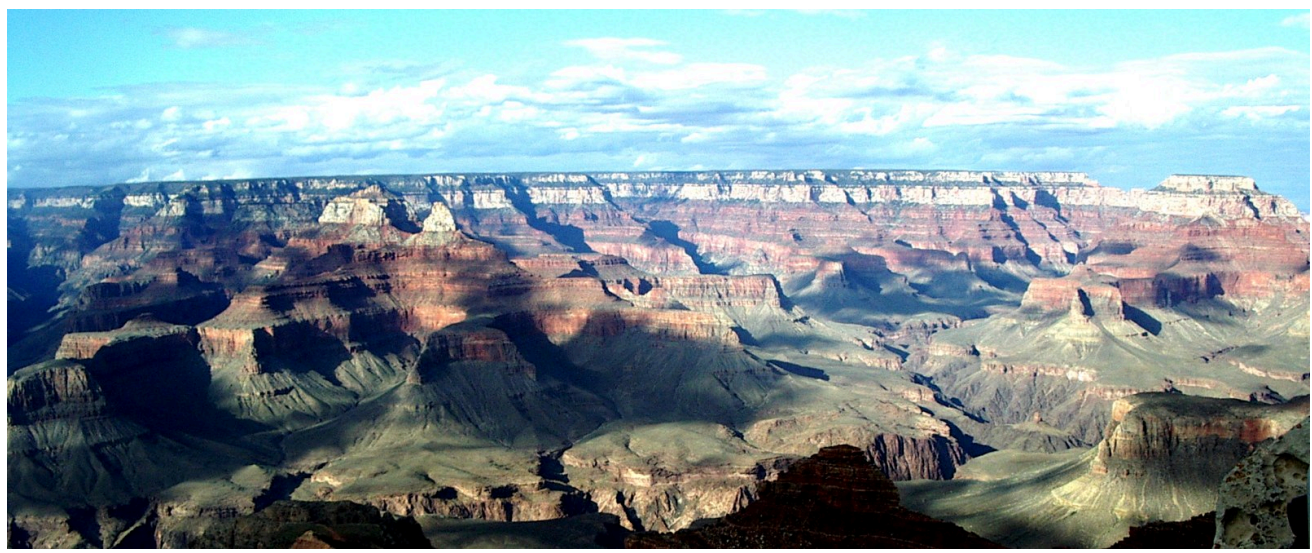

Figure 7.0.1: Arizona's Grand Canyon is an icon for geological time; 1,450 million years are represented by this photo. The light-coloured layered rocks at the top formed at around 250 $\mathrm{Ma}$, and the dark rocks at the bottom (within the steep canyon) at around 1,700 Ma.

We have numerous ways of measuring geological time. We can tell the relative ages of rocks (for example, whether one rock is older than another) based on their spatial relationships; we can use fossils to date sedimentary rocks because we have a detailed record of the evolution of life on Earth; and we can use a range of isotopic techniques to determine the actual ages (in millions of years) of igneous and metamorphic rocks. We will explore the use of fossils in dating sedimentary rocks, and interpreting past changes in climate and depositional environment through geologic time in the subsequent geology course, GEOL 1103 - Earth Through Time.

But just because we can measure geological time doesn't mean that we understand it. One of the biggest hurdles faced by geology students-and geologists as well-in mastering geology, is to really come to grips with the slow rates at which geological processes happen and the vast amount of time involved. The problem is that our lives are short and our memories are even shorter. Our experiences span only a few decades, so we really don't have a way of knowing what 11,700 years means. What's more, it's hard for us to understand how 11,700 years differs from 65.5 million years, or even from 1.8 billion years. It's not that we can't comprehend what the numbers mean-we can all get that figured out with a bit of practice-but even if we do know the numerical meaning of $65.5 \mathrm{Ma}$, we can't really appreciate how long ago it was.

You may be wondering why it's so important to really "understand" geological time. One key reason is to fully appreciate how geological processes that seem impossibly slow can produce anything of consequence. For example, the slow movement of tectonic plates that over geological time can travel many thousands of kilometres!

One way to wrap your mind around geological time is to put it into the perspective of single year, as we did in Table I1 the introductory chapter, because we all know how long it is from one birthday to the next. At that rate, each hour of the year is equivalent to approximately 500,000 years, and each day is equivalent to 12.5 million years. It's worth repeating: on this time scale, the earliest ancestors of the animals and plants with which we are familiar did not appear on Earth until mid-November, the dinosaurs disappeared after Christmas, and most of Canada was periodically locked in ice from 6:30 to 11:59 p.m. on New Year's Eve. As for people, the first to inhabit Alberta got here about one minute before midnight, and the first Europeans arrived about two seconds before midnight. 


\section{Media Attributions}

- Figure 7.0.1: (C) Steven Earle. CC BY.

181 | Lab 7: Relative Dating and Geological Time 


\section{I The Geological Time Scale}

Perhaps the most important contributor to geology, ideas of geological time, and the first person to create a geological map, was William Smith. Smith worked as a surveyor in the coal-mining and canal-building industries in southwestern England in the late 1700s and early 1800s. While doing his work, he had many opportunities to look at the Paleozoic and Mesozoic sedimentary rocks of the region, and he did so in a way that few had done before. Smith noticed the textural similarities and differences between rocks in different locations, and more importantly, he discovered that fossils could be used to correlate rocks of the same age. Smith is credited with formulating the principle of faunal succession (the concept that specific types of organisms lived during different time intervals), and he used it to great effect in his monumental project to create a geological map of England and Wales, published in 1815. For more on William Smith, including a large-scale digital copy of the famous map, see the William Smith Wikipedia page.

Inset into Smith's great geological map is a small diagram showing a schematic geological cross-section extending from the Thames estuary of eastern England all the way to the west coast of Wales. Smith shows the sequence of rocks, from the Paleozoic rocks of Wales and western England, through the Mesozoic rocks of central England, to the Cenozoic rocks of the area around London (Figure 7.1.1). Although Smith did not put any dates on these-because he didn't know them-he was aware of the principle of superposition (the idea, developed much earlier by the Danish theologian and scientist Nicholas Steno, that young sedimentary rocks form on top of older ones), and so he knew that this diagram represented a stratigraphic column. And because almost every period of the Phanerozoic is represented along that section through Wales and England, it is a primitive geological time scale.

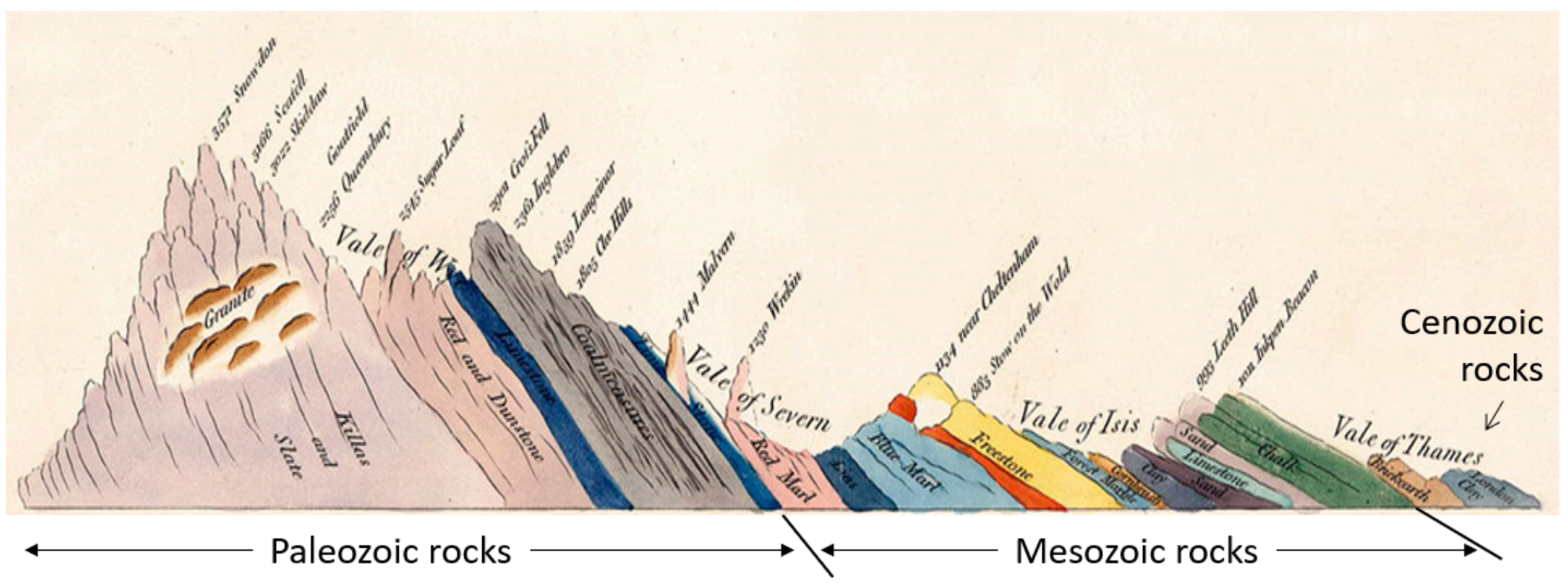

Figure 7.1.1: William Smith's "Sketch of the succession of strata and their relative altitudes," an inset on his geological map of England and Wales (with era names added).

Smith's work set the stage for the naming and ordering of the geological periods, which was initiated around 1820, first by British geologists, and later by other European geologists. Many of the periods are named for places where rocks of that age are found in Europe, such as Cambrian for Cambria (Wales), Devonian for Devon in England, Jurassic for the Jura Mountains in France and Switzerland, and Permian for the Perm region of Russia. Some are named for the type of rock that is common during that age, such as Carboniferous for the coal- and carbonate-bearing rocks of England, and Cretaceous for the chalks of England and France.

The early time scales were only relative because 19th century geologists did not know the ages of the 
rocks. That information was not available until the development of isotopic dating techniques early in the 20th century.

The geological time scale is currently maintained by the International Commission on Stratigraphy (ICS), which is part of the International Union of Geological Sciences. The time scale is continuously being updated as we learn more about the timing and nature of past geological events. You can view the 2020 version of the ICS time scale online. It would be a good idea to print a copy (in colour) to put on your wall while you are studying geology.

Geological time has been divided into four eons: Hadean (4570 to $4850 \mathrm{Ma}$ ), Archean (3850 to $2500 \mathrm{Ma}$ ), Proterozoic (2500 to $540 \mathrm{Ma}$ ), and Phanerozoic (540 Ma to present). As shown in Figure 7.1.2, the first three of these represent almost $90 \%$ of Earth's history. The last one, the Phanerozoic (meaning "visible life"), is the time that we are most familiar with because Phanerozoic rocks are the most common on Earth, and they contain evidence of the life forms that we are familiar with to varying degrees.

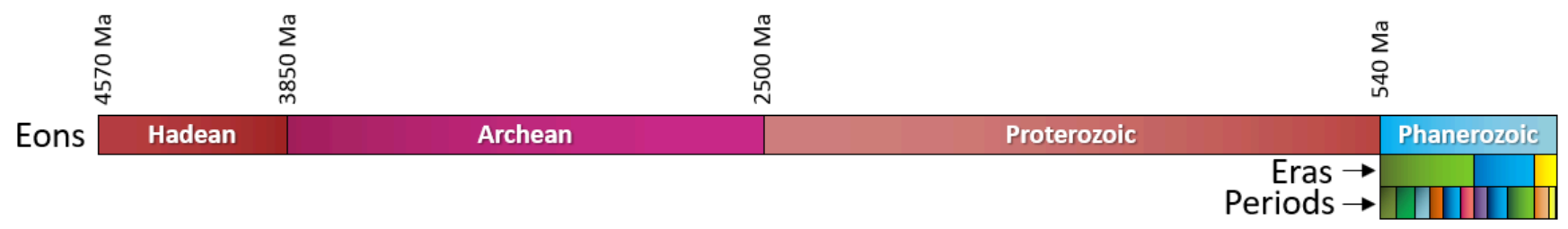

Figure 7.1.2: The four eons of Earth's history.

The Phanerozoic eon-the past 540 Ma of Earth's history-is divided into three eras: the Paleozoic ("early life"), the Mesozoic ("middle life"), and the Cenozoic ("new life"), and each of these is divided into a number of periods (Figure 7.1.3). Most of the organisms that we share Earth with evolved at various times during the Phanerozoic.

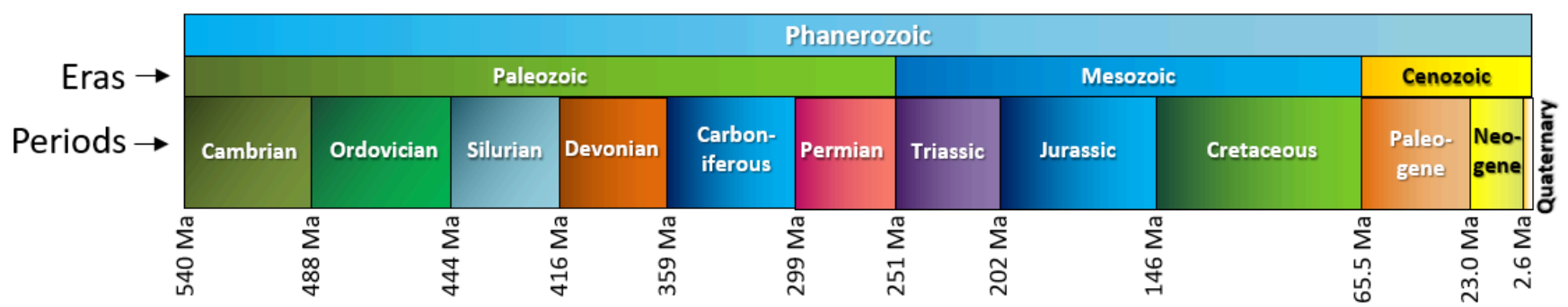

Figure 7.1.3: The eras (middle row) and periods (bottom row) of the Phanerozoic eon.

The Cenozoic era, which represents the past $65.5 \mathrm{Ma}$, is divided into three periods: Paleogene, Neogene, and Quaternary, and seven epochs (Figure 7.1.4). Dinosaurs became extinct at the start of the Cenozoic, after which birds and mammals radiated to fill the available habitats. Earth was very warm during the early Eocene and has steadily cooled ever since. Glaciers first appeared on Antarctica in the Oligocene and then on Greenland in the Miocene, and covered much of North America and Europe by the Pleistocene. The most recent of the Pleistocene glaciations ended around 11,700 years ago. The current epoch is known as the Holocene. Epochs are further divided into ages (a.k.a. stages), but we won't be going into that level of detail here. 


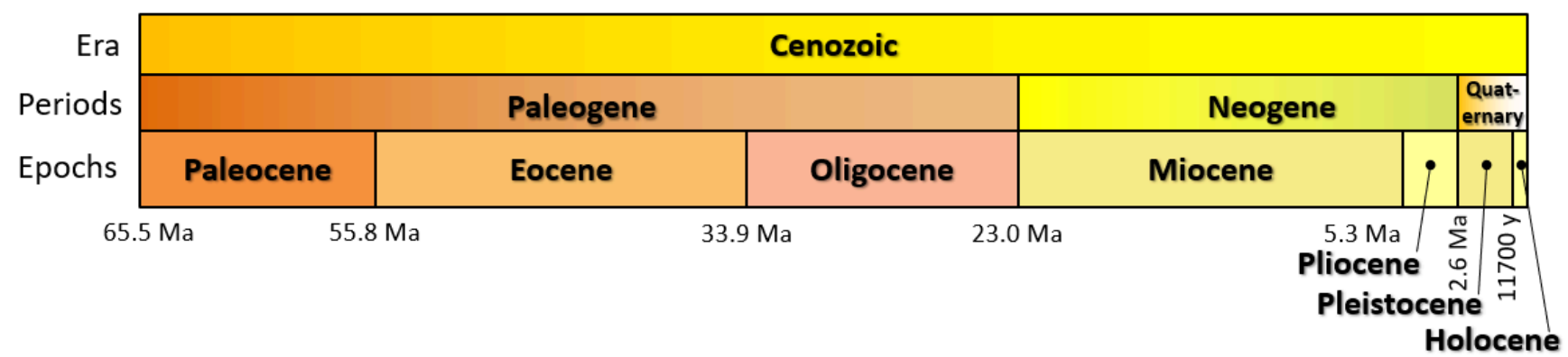

Figure 7.1.4: The periods (middle row) and epochs (bottom row) of the Cenozoic era.

Most of the boundaries between the periods and epochs of the geological time scale have been fixed on the basis of significant changes in the fossil record. For example, as already noted, the boundary between the Cretaceous and the Paleogene coincides exactly with a devastating mass extinction. That's not a coincidence. The dinosaurs and many other types of organisms went extinct at this time, and the boundary between the two periods marks the division between sedimentary rocks with Cretaceous organisms (including dinosaurs) below, and Paleogene organisms above.

\section{Media Attributions}

- Figure 7.1.1: "Sketch of the succession of strata and their relative altitudes" by William Smith. Adapted by Steven Earle. Public domain.

- Figures 7.1.2, 7.1.3, 7.1.4: (C) Steven Earle. CC BY. 


\subsection{Relative Dating Methods}

There are two main ways in which geologists have built an understanding of geological time by dating geological materials: absolute dating and relative dating.

Absolute dating uses isotopic dating of rocks, or the minerals in them, based on the fact that we know the decay rates of certain unstable isotopes of elements and that these rates have been constant over geological time. It was only in the early part of the 20th century, when isotopic dating methods were first applied, that it became possible to discover the absolute ages of the rocks containing fossils. In most cases, we cannot use isotopic techniques to directly date fossils or the sedimentary rocks they are found in, but we can constrain their ages by dating igneous rocks that cut across sedimentary rocks, or volcanic layers that lie within sedimentary layers.

Relative dating, on the other hand, is the simplest and most intuitive way of dating geological features by examining the spatial relationships between them. There are a few simple rules for doing this, called the principles of stratigraphy. ${ }^{1}$

Through careful observation over the past few centuries, geologists have discovered that the accumulation of sediments and sedimentary rocks, as well as the eruption of some extrusive igneous rocks, takes place according to some important geological principles, as follows:

- The principle of original horizontality is that sediments accumulate in essentially horizontal layers, called beds. The implication is that tilted sedimentary beds observed to day must have been subjected to tectonic forces (Figure 7.2.1, right).

- The principle of superposition is that sedimentary layers are deposited in sequence, and that unless the entire sequence has been turned over by tectonic processes, the layers at the bottom are older than those at the top.

- The principle of inclusions is that any rock fragments in a sedimentary layer must be older than the layer. For example, the cobbles in a conglomerate must have been formed before the conglomerate was formed. Another example of this principle is shown in Figure 7.2.1 (left).

- The principle of faunal succession is that there is a well-defined order in which organisms have evolved through geological time, and therefore the identification of specific fossils in a rock can be used to determine its age. We won't be covering fossils in any detail in this book as they are covered in the subsequent geology course (GEOL 1103), but they are extremely important for understanding sedimentary rocks. Of course, fossils can be used to date sedimentary rocks, but equally importantly, they tell us a great deal about the depositional environment of the sediments and the climate at the time. For example, they can help to differentiate marine versus terrestrial environments; estimate the depth of the water; detect the existence of currents; and estimate average temperature and precipitation.

- The principle of cross-cutting relationships is that a body or discontinuity that cuts across a stratum must have formed after that stratum. For example, a fault that cuts across sedimentary strata must be be younger than the strata. The analogy to remember is that of a sandwich: the sandwich must be made before it can be cut. The strata must exist before the fault can cut across them. An example of this is given in Figure 7.2.2, which shows three different sedimentary layers. The lower sandstone layer is disrupted by two faults, so we can conclude that the faults are younger than that layer. But the faults do not appear to continue into the coal seam, and they certainly do not continue into the upper sandstone. So we can infer that coal seam is younger than the faults (because it cuts them off), and of course the upper sandstone is youngest of all, because it lies on top of the coal seam. 

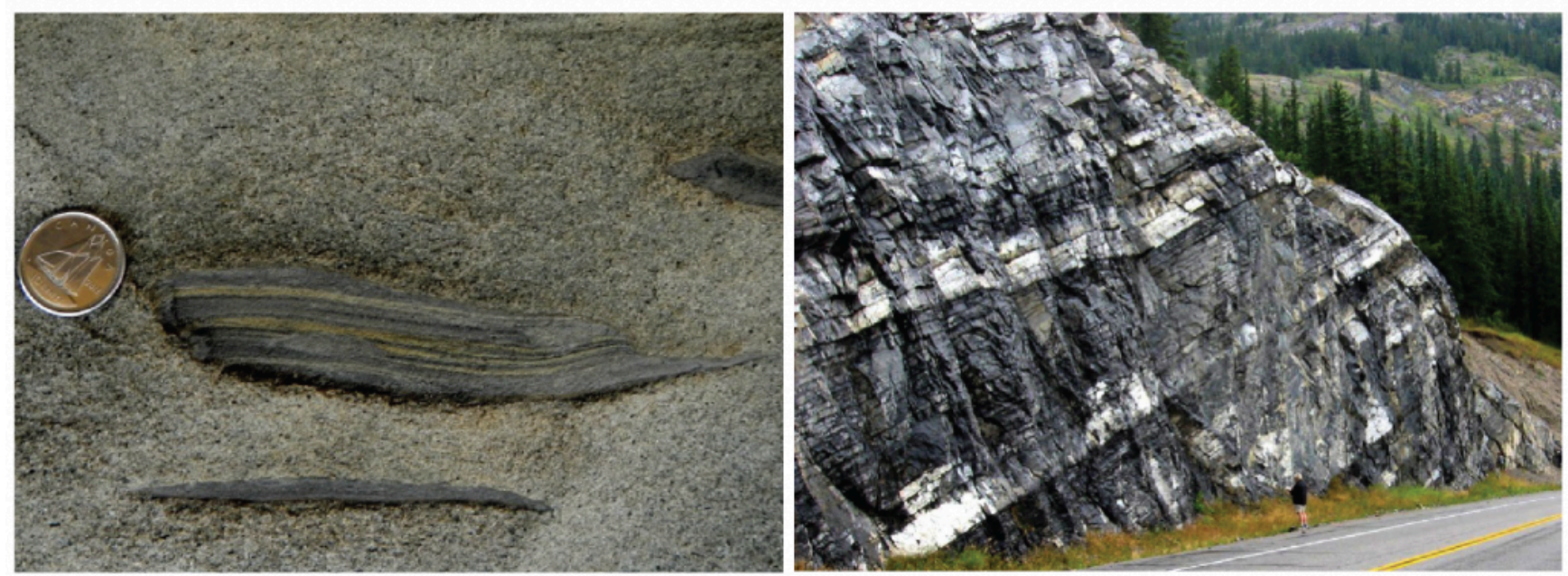

Figure 7.2.1: (left) Rip-up clasts of shale embedded in Gabriola Formation sandstone, Gabriola Island, B.C. The pieces of shale were eroded as the sandstone was deposited, so the shale is older than the sandstone. (right) The Triassic Sulphur Mt. Formation near Exshaw, Alberta. Bedding is defined by differences in colour and texture, and also by partings (gaps) between beds that may otherwise appear to be similar. The beds in the Sulphur Mt. Formation have been tilted by tectonic forces. Using the principle of original horizontality, we can infer that this tilting happened after the rocks formed.
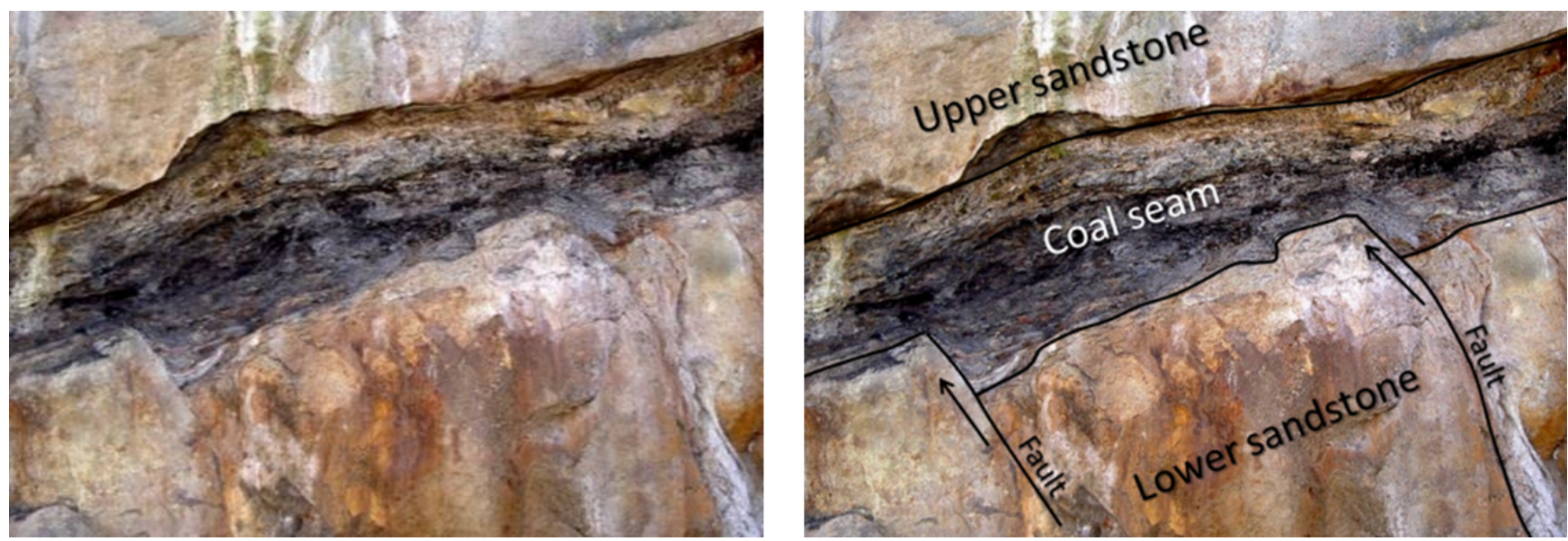

Figure 7.2.2: Superposition and cross-cutting relationships in Cretaceous Nanaimo Group rocks in Nanaimo, B.C. The coal seam is about 50 centimetres thick. The sequence of events is as follows: a) deposition of lower sandstone, b) faulting of lower sandstone, $c$ ) deposition of coal seam and d) deposition of upper sandstone. [Image description] 


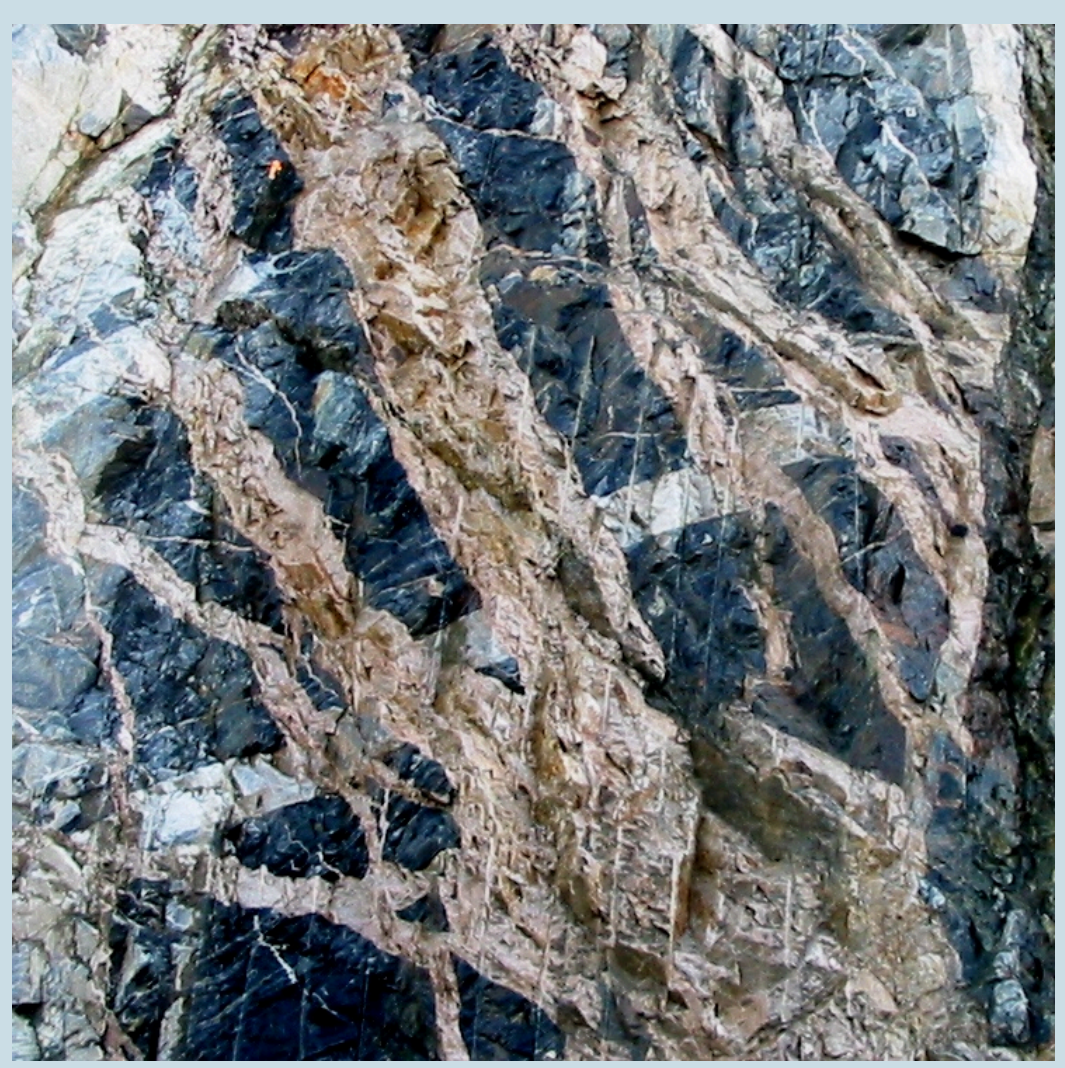

Figure 7.2.3

The outcrop shown here (at Horseshoe Bay, B.C.) has three main rock types:

1. Buff/pink felsic intrusive igneous rock present as somewhat irregular masses trending from lower right to upper left

2. Dark grey metamorphosed basalt

3. A 50 centimetres wide light-grey felsic intrusive igneous dyke extending from the lower left to the middle right - offset in several places

Using the principle of cross-cutting relationships outlined above, determine the relative ages of these three rock types.

(The near-vertical stripes are blasting drill holes. The image is about 7 metres across.)

See Appendix 2 for Practice Exercise 7.1 answers. 
One final important concept in the understanding of geologic time is the notion of missing segments of the rock record, recognized by unconformities. An unconformity represents an interruption in the process of deposition of sedimentary rocks. Recognizing unconformities is important for understanding time relationships in sedimentary sequences. An example of an unconformity is shown in Figure 7.2.4. The Proterozoic rocks of the Grand Canyon Group have been tilted and then eroded to a flat surface prior to deposition of the younger Paleozoic rocks. The difference in time between the youngest of the Proterozoic rocks and the oldest of the Paleozoic rocks is close to 300 million years. Tilting and erosion of the older rocks took place during this time, and if there was any deposition going on in this area, the evidence of it is now gone.

There are four types of unconformities, as summarized in Table 7.1, and illustrated in Figure 7.2.5.

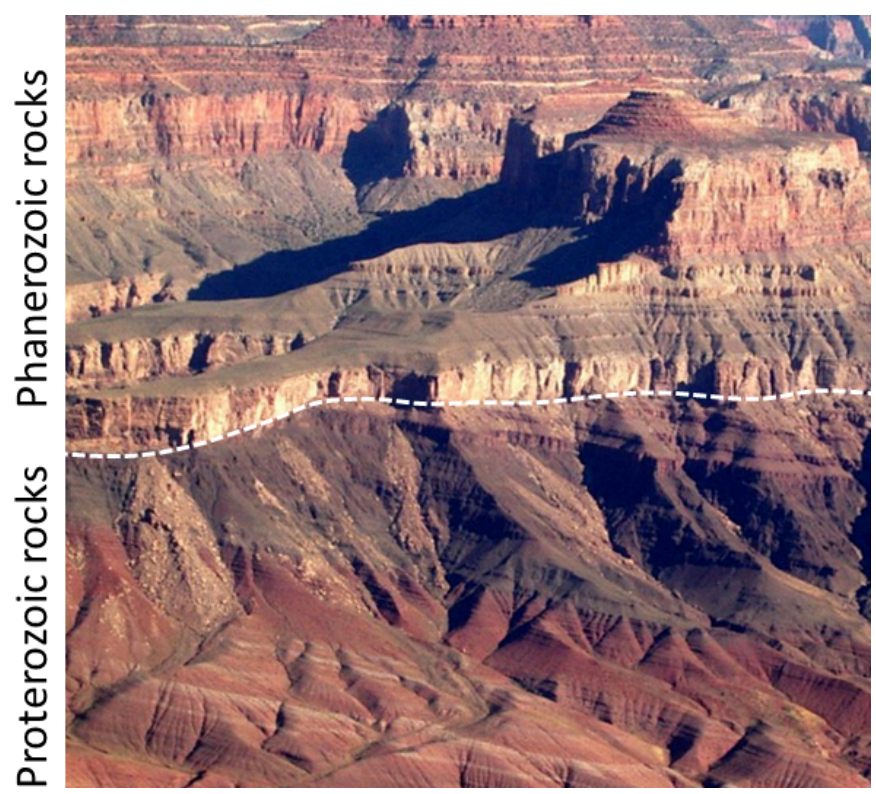

Figure 7.2.4: The great angular unconformity in the Grand Canyon, Arizona. The tilted rocks at the bottom are part of the Proterozoic Grand Canyon Group (aged 825 to 1,250 Ma). The flat-lying rocks at the top are Paleozoic (540 to $250 \mathrm{Ma}$ ). The boundary between the two represents a time gap of nearly 300 million years.

Table 7.1 The characteristics of the four types of unconformities

\begin{tabular}{|l|l|}
\hline $\begin{array}{l}\text { Unconformity } \\
\text { Type }\end{array}$ & Description \\
\hline Nonconformity & A boundary between non-sedimentary rocks (below) and sedimentary rocks (above) \\
\hline $\begin{array}{l}\text { Angular } \\
\text { unconformity }\end{array}$ & $\begin{array}{l}\text { A boundary between two sequences of sedimentary rocks where the underlying ones have been } \\
\text { tilted (or folded) and eroded prior to the deposition of the younger ones (as in Figure 7.2.4) }\end{array}$ \\
\hline Disconformity & $\begin{array}{l}\text { A boundary between two sequences of sedimentary rocks where the underlying ones have been } \\
\text { eroded (but not tilted) prior to the deposition of the younger ones }\end{array}$ \\
\hline Paraconformity & $\begin{array}{l}\text { A time gap in a sequence of sedimentary rocks that does not show up as an angular } \\
\text { unconformity or a disconformity }\end{array}$ \\
\hline
\end{tabular}



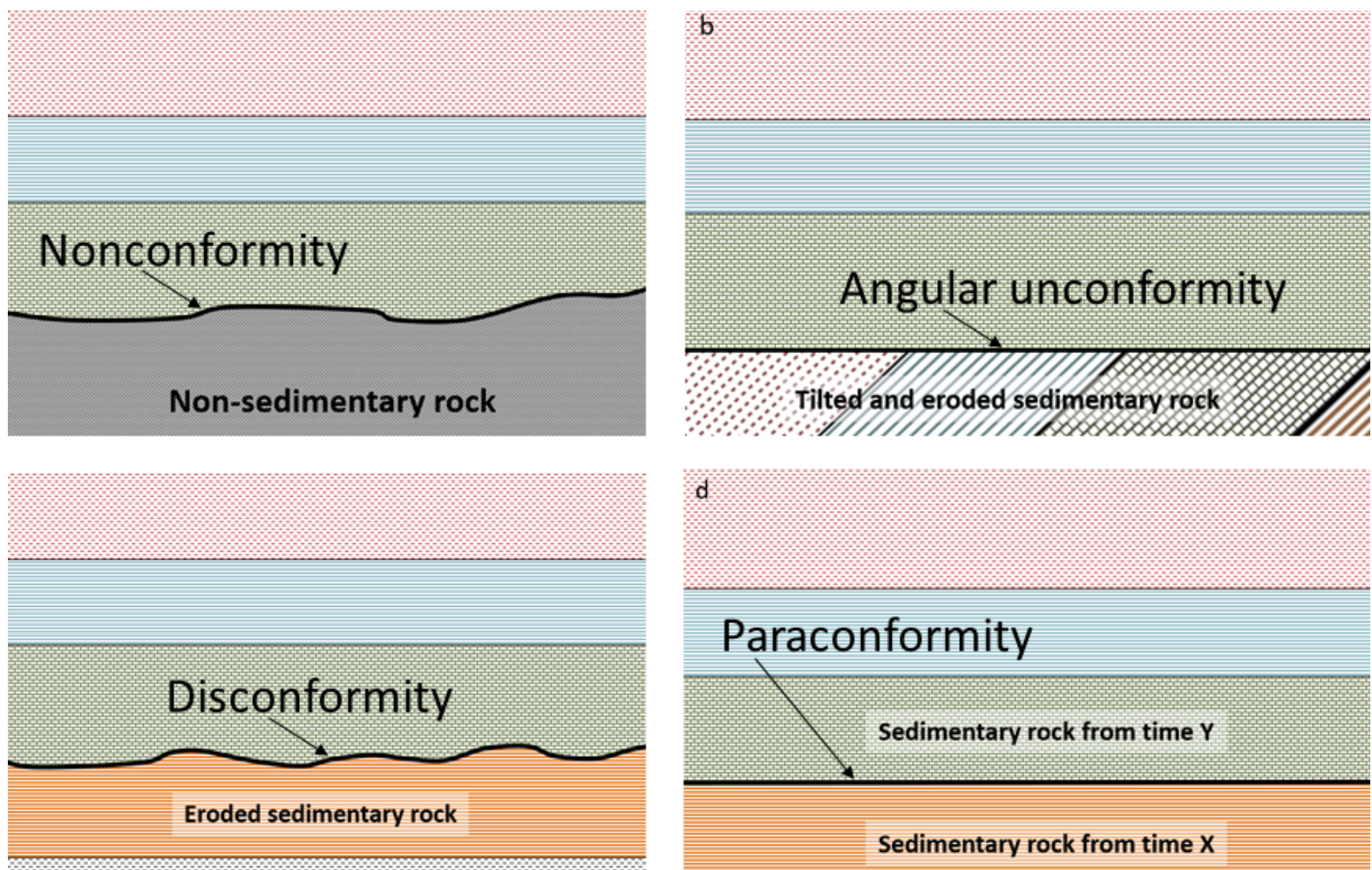

Figure 7.2.5: The four types of unconformities: (a) a nonconformity between older non-sedimentary rock and sedimentary rock, (b) an angular unconformity, (c) a disconformity between layers of sedimentary rock, where the older rock has been eroded but not tilted, and (d) a paraconformity where there is a long period (typically millions of years) of non-deposition between two parallel layers.

Key Takeaways

A common misconception when students think about unconformities is that an unconformity represents "missing time". This is not the case: time continued to pass, it cannot be "missing". What is "missing" is the record of this time in the stratigraphy of a given area, what geologists refer to as the rock record. For example, in the rock record of the southern plains of Alberta, the contact between the Jurassic Ellis Group and the Mississippian Rundle Group is an unconformity that represents over 150 million years! We can form two hypotheses to explain this missing section of the rock record in southeastern Alberta:

1. No sediments were deposited in this area during that 150 million years, meaning that the unconformity represents a period of non-deposition, and/or

2. Any sediments that were deposited during that 150 million years were eroded away before the deposition of the Ellis Group during the Jurassic, meaning that the unconformity represents a period of erosion.

\section{Image Description}

Figure 7.2.2 image description: The photograph shows three different sedimentary layers. The lower sandstone layer is disrupted by two faults, so we can conclude that the faults are younger than that layer. But 
the faults do not appear to continue into the coal seam, and they certainly do not continue into the upper sandstone. So we can infer that coal seam is younger than the faults (because it cuts them off), and of course the upper sandstone is youngest of all, because it lies on top of the coal seam.

[Return to Figure 7.2.2]

\section{Media Attributions}

- Figures 7.2.1, 7.2.2, 7.2.3, 7.2.4, 7.2.5: (C) Steven Earle. CC BY.

\section{Notes}

1. Stratigraphy is the branch of geology that deals with the formation, composition, sequence, and correlation of stratified rocks. Broadly speaking that includes all types of rock (igneous, sedimentary, and metamorphic), but often stratigraphers focus their studies on only sedimentary strata. 


\section{Lab 7 Exercises}

Figure A represents two road cuts, or cliff faces, exposed along a road way. You can see that at first glance, the road cuts look almost identical as they both expose the same four types of rock: granite, sandstone, limestone, and shale.

1. As a quick review from Labs 4,5 , and 6 , how did each of these rocks form? Briefly summarize the origin of each rock in the table below.
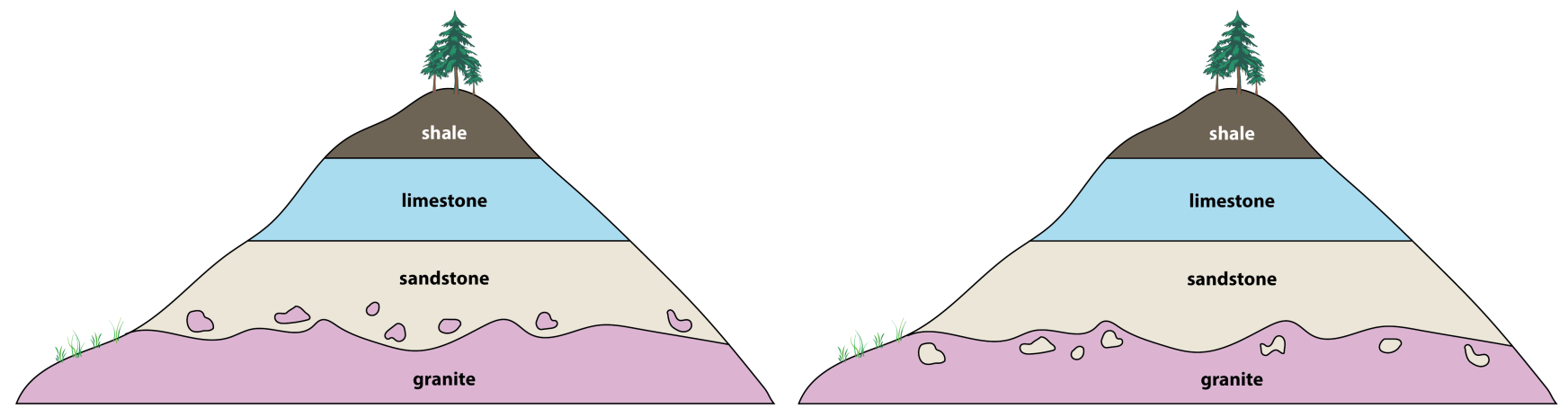

Figure A

\begin{tabular}{|l|l|l|l|l|}
\hline $\begin{array}{l}\text { Rock } \\
\text { Type }\end{array}$ & Granite & Sandstone & Limestone & Shale \\
\hline Origin & & & & \\
\hline
\end{tabular}

2. Examine the two road cuts carefully, and using the principles of stratigraphy, write a point-form geologic history for each road cut. A geologic history is a written sequence of events that describes what geological processes happened in the past to produce the stratigraphy in a given area, like a timeline. Your geologic history should use proper terms to describe each event. For example, we would say that a sedimentary rock was deposited and then lithified. We would not say that a sedimentary rock "intruded" or "erupted" because these terms are reserved for intrusive and extrusive igneous rocks, respectively. If there are any unconformities present, identify which type (review Figure 7.2.6) and briefly describe what the unconformity represents. This might include: a period of uplift and erosion, a period of non-deposition, or both. 


\begin{tabular}{|l|l|l|}
\hline $\begin{array}{c}\text { Youngest } \\
\text { Event }\end{array}$ & Road Cut A (left) & Road Cut B (right) \\
\hline & $\bullet$ & $\bullet$ \\
\hline & $\bullet$ & $\bullet$ \\
\hline & $\bullet$ & $\bullet$ \\
\hline & $\bullet$ & $\bullet$ \\
\hline $\begin{array}{c}\text { Oldest } \\
\text { Event }\end{array}$ & $\bullet$ & $\bullet$ \\
\hline
\end{tabular}

3. Do the two road cuts share the same geologic history? Why or why not?

4. Which key principle of stratigraphy helped you determine the difference between the two road cuts?

Road cuts and naturally-occurring cliffs provide us with a view into the subsurface to help us understand the nature of the layers of rock beneath our feet. Another way to visualize the subsurface is using a block diagram, or block model (Figure B). The top of the diagram shows the plan view, or map view, of the Earth's surface. The sides of the diagram show two different cross-sectional views down into the subsurface. These vertical cross-sections illustrate the geology below the surface.

We can see in Figure B, for example, that at the surface there is an active volcano (venting steam) that is connected at depth to a shallow magma chamber (E). The letters shown in this diagram, and in all the figures in this lab, are randomly assigned. In Figure B, layers G, H, J, and K are all sedimentary. Units B, C, D, E, $\mathrm{L}$, and $\mathrm{M}$ are igneous. 


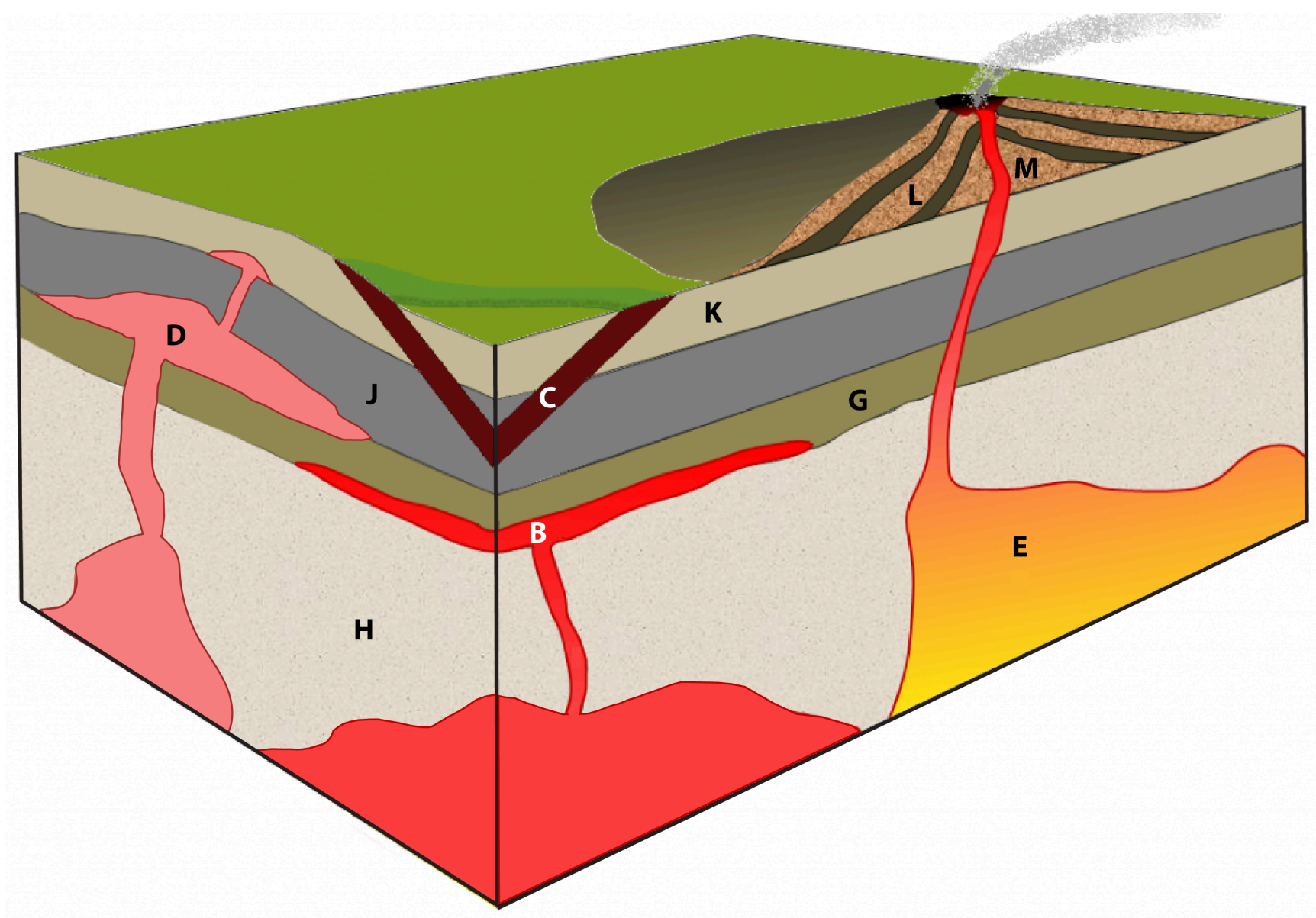

Figure B

5. Write a point-form geologic history for Figure B in the table below. Specify which stratigraphic principle(s) you used to justify the position of each event in the timeline. 


\begin{tabular}{|l|l|l|}
\hline $\begin{array}{c}\text { Youngest } \\
\text { Event }\end{array}$ & \multicolumn{1}{|c|}{ Geologic History of Figure B } & Justification (which principle of stratigraphy did \\
\hline & $\bullet$ & $\bullet$ \\
\hline & $\bullet$ & $\bullet$ \\
\hline & $\bullet$ & $\bullet$ \\
\hline & $\bullet$ & $\bullet$ \\
\hline & $\bullet$ & $\bullet$ \\
\hline & $\bullet$ & $\bullet$ \\
\hline & $\bullet$ & $\bullet$ \\
\hline Event & $\bullet$ & $\bullet$ \\
\hline
\end{tabular}

6. Write a point-form geologic history for Figure $\mathrm{C}$ in the table below. Specify which stratigraphic principle(s) you used to justify the position of each event in the timeline. If there are any unconformities present, identify which type and briefly describe what the unconformity represents. This might include: a period of uplift and erosion, a period of non-deposition, or both. All the units in Figure C are sedimentary rocks, except B which represents an erosional surface.

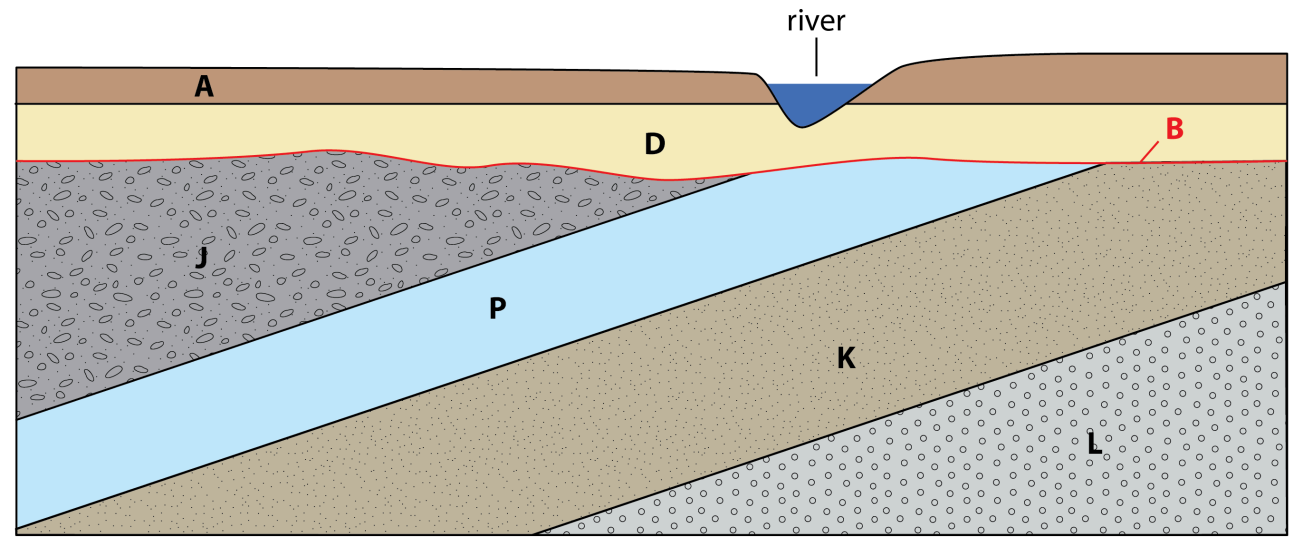

Figure C 


\begin{tabular}{|l|l|l|}
\hline $\begin{array}{c}\text { Youngest } \\
\text { Event }\end{array}$ & Geologic History of Figure C & Justification \\
\hline & $\cdot$ & $\bullet$ \\
\hline & $\bullet$ & $\bullet$ \\
\hline & $\bullet$ & $\bullet$ \\
\hline & $\bullet$ & $\bullet$ \\
\hline & $\bullet$ & $\bullet$ \\
\hline Eldest & $\bullet$ & $\bullet$ \\
\hline
\end{tabular}

7. In the space below, write a short paragraph (<150 words) describing the geologic history for Figure D using complete sentences. To describe the sequence of sedimentary rocks, you may want to use the term "overlain", as in "the Pennsylvanian conglomerate is overlain by the Permian shale", or as an adjective, "the overlying Permian shale". Unit D is a basalt dyke (a type of igneous intrusion), and the line labeled as $\mathrm{F}$ is a fault. Read more about faulting in section 10.3.

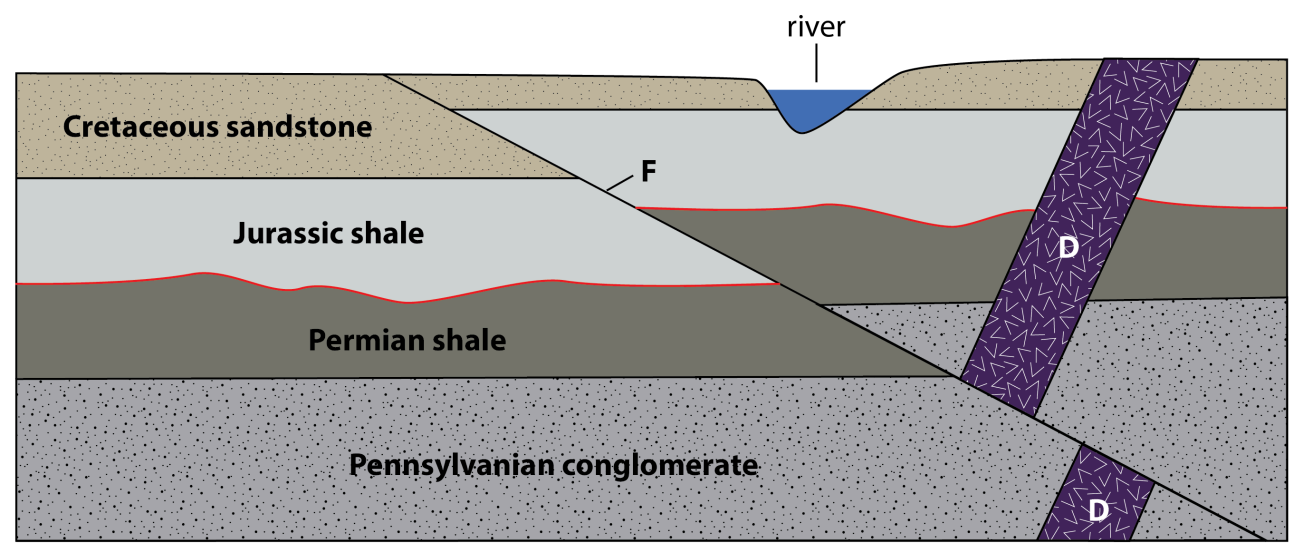

Figure D 
8. Write a point-form geologic history for Figure $\mathrm{E}$ in the table below. Specify which stratigraphic principle(s) you used to justify the position of each event in the timeline. Unit $\mathrm{J}$ is a granite pluton and sill (two types of igneous intrusion), and the line labeled as $\mathrm{F}$ is a fault. Read more about faulting in section 10.3.

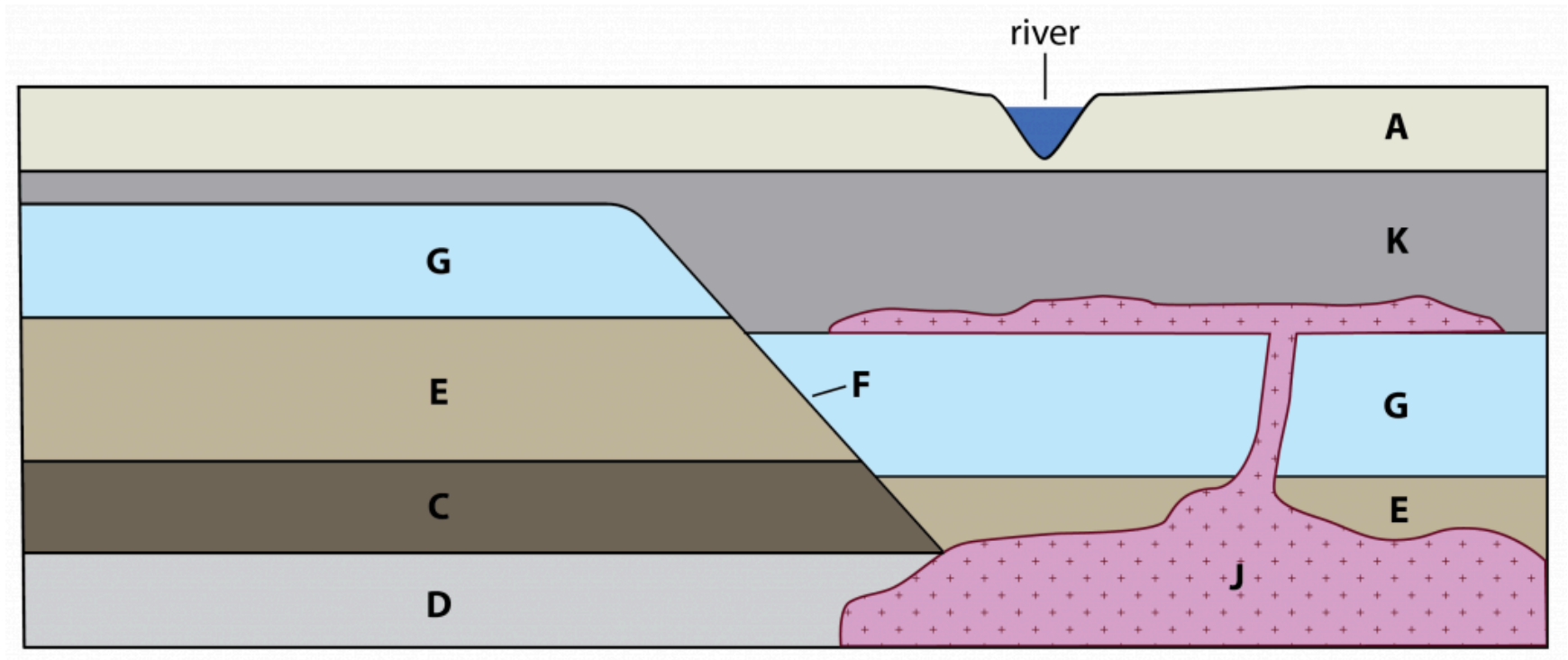

Figure E 


\begin{tabular}{|l|l|l|}
\hline $\begin{array}{c}\text { Youngest } \\
\text { Event }\end{array}$ & Geologic History of Figure E & Justification \\
\hline & $\bullet$ & $\bullet$ \\
\hline & $\bullet$ & $\bullet$ \\
\hline & $\bullet$ & $\bullet$ \\
\hline & $\bullet$ & $\bullet$ \\
\hline & $\bullet$ & $\bullet$ \\
\hline Event & $\bullet$ & $\bullet$ \\
\hline
\end{tabular}

9. Write a point-form geologic history for Figure F in the table below. Specify which stratigraphic principle(s) you used to justify the position of each event in the timeline. If there are any unconformities present, identify which type and briefly describe what the unconformity represents. Unit L represents a rhyolite dome formed by felsic lava. Letter A refers to the surface denoted by the red line. Letter F represents a fault plane. All other letters refer to sedimentary rocks. Note that units B, C, and D have been folded into anticlines and synclines. Read more about folds in section 10.2.

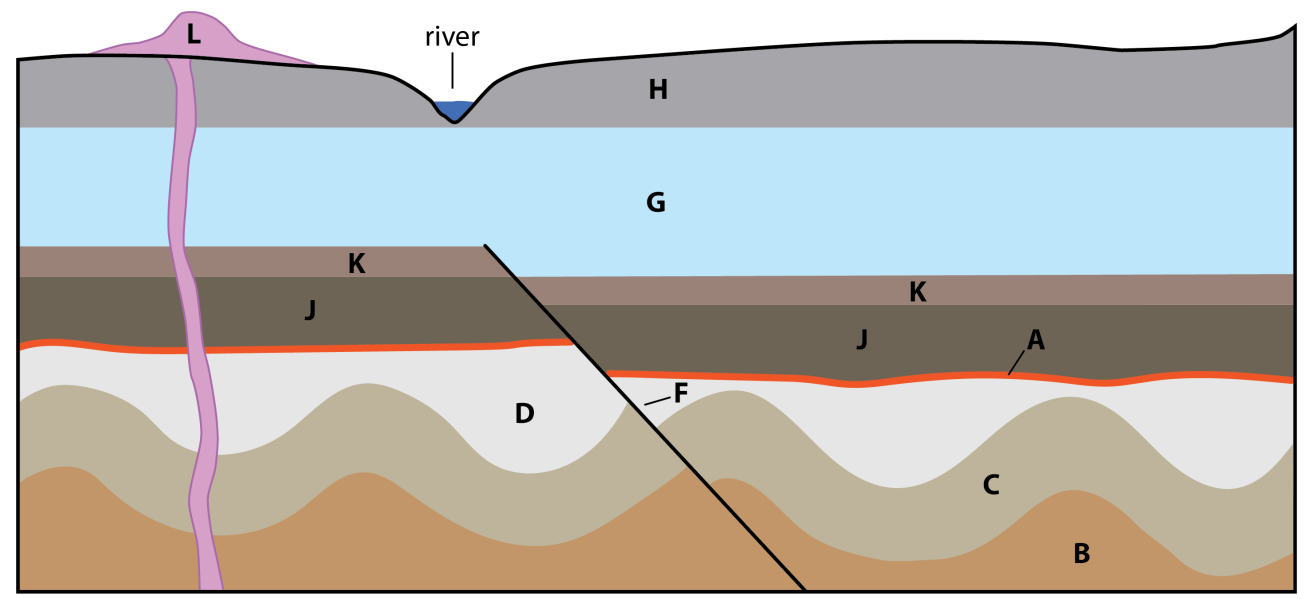

Figure F 


\begin{tabular}{|l|l|l|}
\hline $\begin{array}{c}\text { Youngest } \\
\text { Event }\end{array}$ & Geologic History of Figure F & Justification \\
\hline & $\cdot$ & $\bullet$ \\
\hline & $\cdot$ & $\bullet$ \\
\hline & $\bullet$ & $\bullet$ \\
\hline & $\bullet$ & $\bullet$ \\
\hline & $\bullet$ & $\bullet$ \\
\hline Event & $\bullet$ & $\bullet$ \\
\hline & $\bullet$ & $\bullet$ \\
\hline
\end{tabular}

\section{Media Attributions}

- Figures A, C, D, E, F: (C) Siobhan McGoldrick. CC BY.

- Figure B: (C) Siobhan McGoldrick. Adapted after Figure 3.5.2 (c) Steven Earle. CC BY. 


\section{Summary}

The topics covered in this chapter can be summarized as follows:

\section{Section Summary}

7.1 The The work of William Smith was critical to the establishment of the first geological time scale early in the Geological 19th century, but it wasn't until the 20th century that geologists were able to assign reliable dates to the Time various time periods. Geological time is divided into eons, eras, periods, and epochs and the geological Scale time scale is maintained and updated by the International Commission on Stratigraphy.

7.2 Relative Dating

Methods

We can determine the relative ages of different rocks by observing and interpreting relationships among them, and applying the principles of stratigraphy. Gaps in the geological record are represented by various types of unconformities.

Lab 7

The principles of stratigraphy can be applied to determine the geologic history of an area. Road cuts, cliff faces, and cross-sections give us an excellent insight into the geology of the subsurface, and the

Exercises sequence of geologic events responsible for the strata observed can be solved like a puzzle. Keep in mind, that these stratigraphic principles can also be applied to relationships displayed in any outcrop, hand sample, and even in thin section! For example, using the principle of inclusions: a microscopic fluid inclusion within a crystal of quartz must be older than the quartz itself. 


\section{LAB 8: MAPPING FLUVIAL LANDSCAPES}

\section{Lab Structure}

\begin{tabular}{ll}
\hline Assignment & Yes - submit fluvial features map \\
Recommended additional work & Yes - Practice Exercise 8.3 \\
Required materials & Tracing paper, pencil, pencil crayons, ruler, printed \\
& Elbow River Map Area base image \\
\hline
\end{tabular}

\section{Learning Objectives}

After reading the background information in this chapter, and completing the exercises within it, you should be able to:

- Understand and interpret maps as a geologist.

- Identify erosional and depositional features associated with fluvial environments.

- Describe the evolution of a meandering stream.

- $\quad$ Locate topographic maps within Canada using the National Topographic System (NTS).

- Describe locations using UTM coordinates.

- Understand map scale and how to determine distances on a map.

- Understand how elevation data are presented on a topographic map as contour lines.

- Create a surficial geology map of fluvial features.

\section{Key Terms}

- Meandering stream

- Braided stream

- Stream gradient

- Stream channel

- Flood plain

- Discharge

- Erosion

- Deposition

- Cut bank

- Point bar

- Oxbow lake
- Meander scar

- Scroll bar

- Delta

- Levée

- Legend

- Map scale

- UTM coordinates

- National Topographic System (NTS)

- Topographic contour lines

- Contour interval

Streams are the most important agents of erosion and transportation of sediments on Earth's surface. They are responsible for the creation of much of the topography that we see around us. They are also places of great beauty and tranquility, and of course, they provide much of the water that is essential to our exis- 
tence. But streams are not always peaceful and soothing. During large storms and rapid snowmelts, they can become raging torrents capable of moving cars and houses and destroying roads and bridges. When they spill over their banks, they can flood huge areas, devastating populations and infrastructure. Over the past century, many of the most damaging natural disasters in Canada have been floods, and we can expect them to become even more severe in the near future as the climate changes.

Canada's most costly flood ever was the June 2013 flood in southern Alberta, affecting the communities of Canmore, Calgary, Okotoks, and High River (Figure 8.0.1). The flooding was initiated by snowmelt and worsened by heavy rains in the Rockies due to an anomalous flow of moist air from the Pacific and the Caribbean. At Canmore, rainfall amounts exceeded 200 millimetres in 36 hours, and at High River, 325 millimetres of rain fell in 48 hours.

In late June and early July, the discharges of several rivers in the area, including the Bow River in

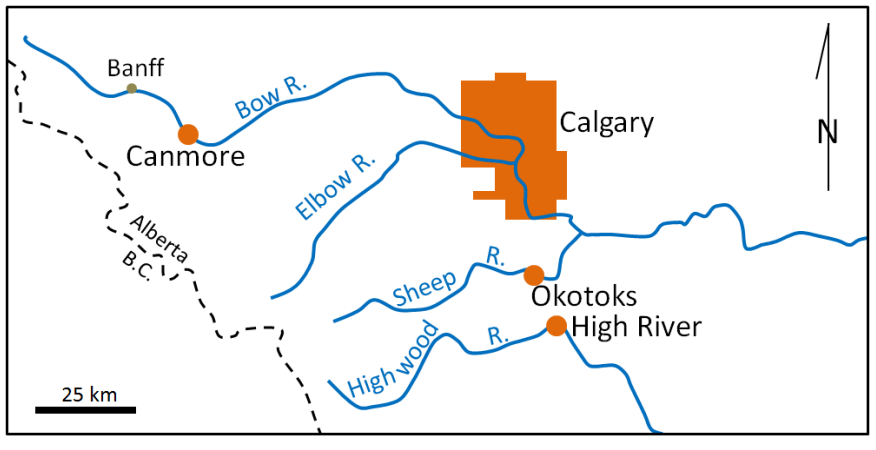

Figure 8.0.1: Map of the communities most affected by the 2013 Alberta floods (in orange).

Banff, Canmore, and Exshaw, the Bow and Elbow

Rivers in Calgary, the Sheep River in Okotoks, and the Highwood River in High River, reached levels that were 5 to 10 times higher than normal for the time of year! Large areas of Calgary, Okotoks, and High River were flooded and five people died. The cost of the 2013 flood is estimated to be approximately $\$ 5$ billion.

One of the things that the 2013 flood on the Bow River teaches us is that we cannot predict when a flood will occur or how big it will be, so in order to minimize damage and casualties we need to be prepared. Some of the ways of doing that are as follows:

- Mapping flood plains and not building within them

- Building dykes or dams where necessary

- Monitoring the winter snowpack, the weather, and stream discharges

- Creating emergency plans

- Educating the public

\section{Media Attributions}

- Figure 8.0.1: (C) Steven Earle. CC BY.

- Elbow River Map Area satellite image used under the following Google Maps and Google Earth guidelines. 


\section{8.r Stream Erosion and Deposition}

As we discussed in Lab 5, flowing water is a very important mechanism for erosion, transportation and deposition of sediments. Water flow in a stream is primarily related to the stream's gradient, but it is also controlled by the geometry of the stream channel. As shown in Figure 8.1.1, water flow velocity is decreased by friction along the stream bed, so it is slowest at the bottom and edges and fastest near the surface and in the middle. In fact, the velocity just below the surface is typically a little higher than right at the surface because of friction between the water and the air. On a curved section of a stream, flow is fastest on the outside and slowest on the inside.
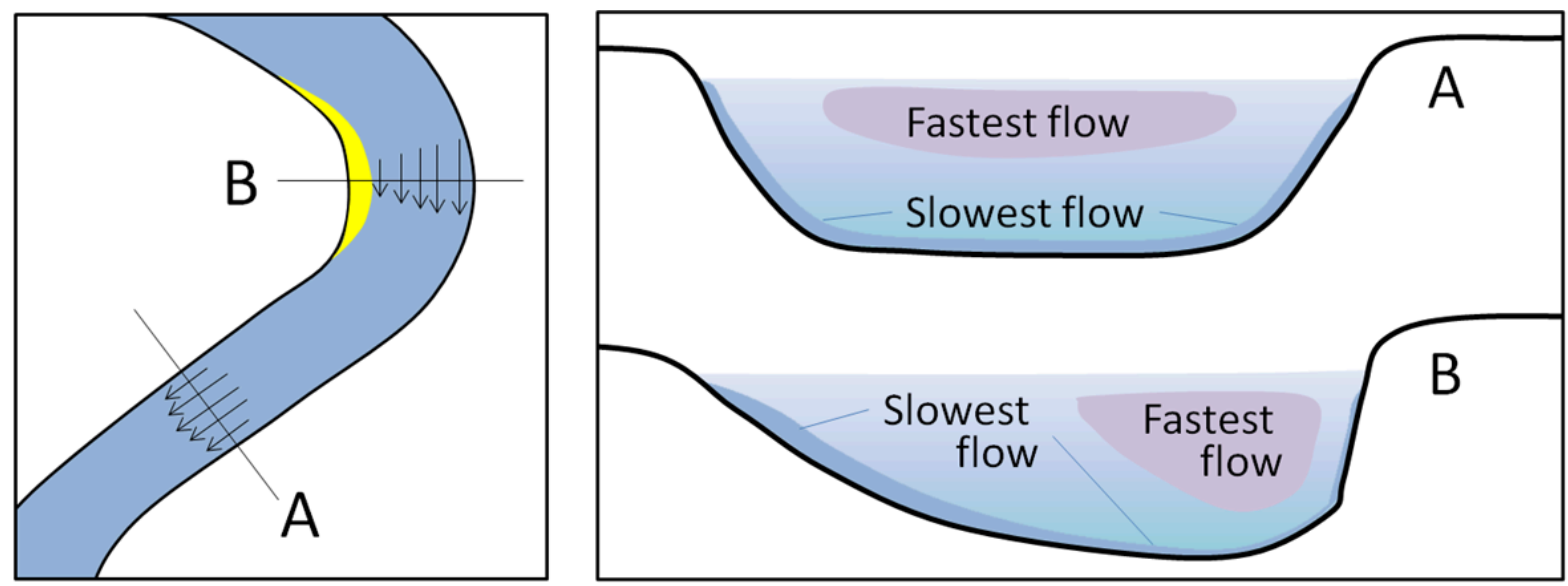

Figure 8.1.1: The relative velocity of stream flow depending on whether the stream channel is straight or curved (left), and with respect to the water depth (right). [Image Description]

Other factors that affect stream-water velocity are the size of sediments on the stream bed-because large particles tend to slow the flow more than small ones-and the discharge, or volume of water passing a point in a unit of time (e.g., cubic metres $\left(\mathrm{m}^{3}\right)$ per second). During a flood, the water level always rises, so there is more cross-sectional area for the water to flow in, however, as long as a river remains confined to its channel, the velocity of the water flow also increases.

Figure 8.1.2 shows the nature of sediment transportation in a stream. Large particles rest on the bottom-bed load-and may only be moved during rapid flows under flood conditions. They can be moved by saltation (bouncing) and by traction (being pushed along by the force of the flow).

Smaller particles may rest on the bottom some of the time, where they can be moved by saltation and traction, but they can also be held in suspension in the flowing water, especially at higher velocities. As you know from intuition and from experience, streams that flow fast tend to be turbulent (flow paths are chaotic and the water surface appears rough) and the water may be muddy, while those that flow more slowly tend to have laminar flow (straight-line flow and a smooth water surface) and clear water. Turbulent flow is more effective than laminar flow at keeping sediments in suspension.

Stream water also has a dissolved load, which represents (on average) about $15 \%$ of the mass of material transported, and includes ions such as calcium $\left(\mathrm{Ca}^{+2}\right)$ and chloride $\left(\mathrm{Cl}^{-}\right)$in solution. The solubility of these ions is not affected by flow velocity. 


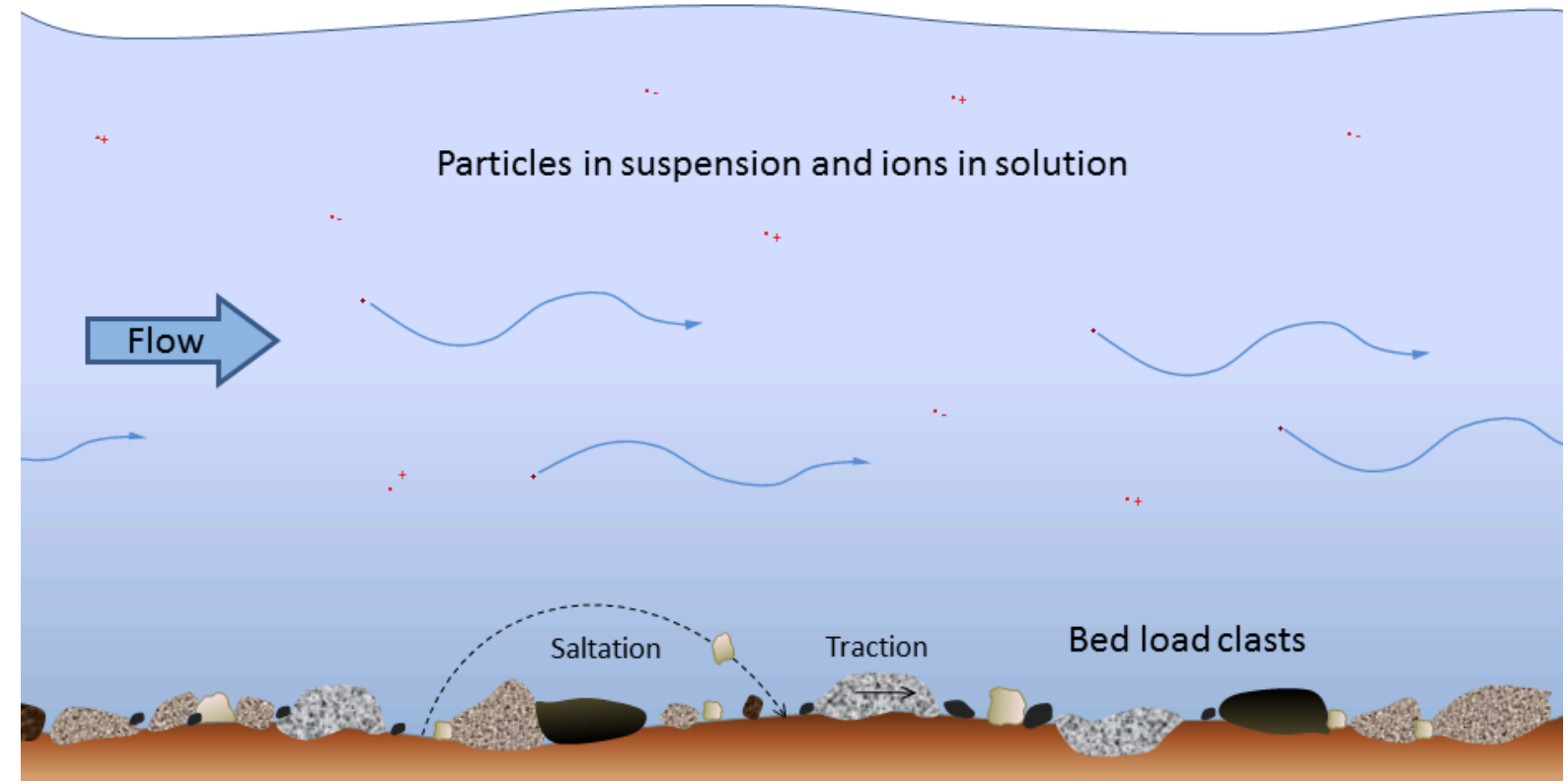

Figure 8.1.2: Modes of transportation of sediments and dissolved ions (represented by red dots with + and signs) in a stream.

The faster the water is flowing, the larger the particles that can be kept in suspension and transported within the flowing water. However, as Swedish geographer Filip Hjulström discovered in the 1940s, the relationship between grain size and the likelihood of a grain being eroded, transported, or deposited is not as simple as one might imagine (Figure 8.1.3). Consider, for example, a 1 millimetre grain of sand. If it is resting on the bottom, it will remain there until the velocity is high enough to erode it, around 20 centimetres per second $(\mathrm{cm} / \mathrm{s})$. But once it is in suspension, that same $1 \mathrm{~mm}$ particle will remain in suspension as long as the velocity doesn't drop below $10 \mathrm{~cm} / \mathrm{s}$. For a $10 \mathrm{~mm}$ gravel grain, the velocity is $105 \mathrm{~cm} / \mathrm{s}$ to be eroded from the bed but only $80 \mathrm{~cm} / \mathrm{s}$ to remain in suspension.

On the other hand, a $0.01 \mathrm{~mm}$ silt particle only needs a velocity of 0.1 centimetres per second $(\mathrm{cm} /$ s) to remain in suspension, but requires $60 \mathrm{~cm} / \mathrm{s}$ to be eroded. In other words, a tiny silt grain requires a greater velocity to be eroded than a grain of sand that is 100 times larger! For clay-sized particles, the discrepancy is even greater. In a stream, the most easily eroded particles are small sand grains between $0.2 \mathrm{~mm}$ and $0.5 \mathrm{~mm}$. Anything smaller or larger requires a higher water velocity to be eroded and entrained in the flow. The main reason for this is that small particles, and especially the tiny grains of clay, have a strong tendency to stick together, and so are difficult to erode from the stream bed.

It is important to be aware that a stream can both erode and deposit sediments at the same time. At

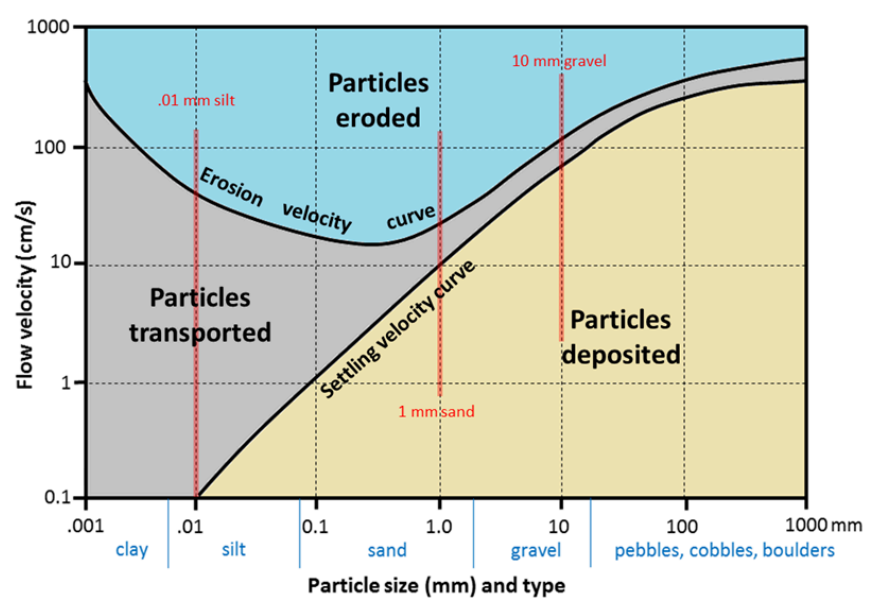

Figure 8.1.3: The Hjulström-Sundborg diagram showing the relationships between particle size and the tendency to be eroded, transported, or deposited at different current velocities. [Image Description] $100 \mathrm{~cm} / \mathrm{s}$, for example, silt, sand, and medium gravel will be eroded from the stream bed and transported in suspension, coarse gravel will be held in suspension, pebbles will be both transported and deposited, and cobbles and boulders will remain stationary on the stream bed. 
Refer to the Hjulström-Sundborg diagram (Figure 8.1.3) to answer these questions.

1. A fine sand grain ( 0.1 millimetres) is resting on the bottom of a stream bed.

1. What stream velocity will it take to get that sand grain into suspension?

2. Once the particle is in suspension, the velocity starts to drop. At what velocity will it finally come back to rest on the stream bed?

2. A stream is flowing at 10 centimetres per second (which means it takes 10 seconds to go 1 metres, and that's pretty slow).

1. What size of particles can be eroded at 10 centimetres per second?

2. What is the largest particle that, once already in suspension, will remain in suspension at 10 centimetres per second?

See Appendix 2 for Practice Exercise 8.1 answers.

A stream typically reaches its greatest velocity when it is close to flooding over its banks. This is known as the bank-full stage, as shown in Figure 8.1.4. As soon as the flooding stream overtops its banks and occupies the wide area of its flood plain, the water has a much larger area to flow through and the velocity drops significantly. At this point, sediment that was being carried by the high-velocity water is deposited near the edge of the channel, forming a natural bank or levée.

\section{Image Descriptions}

Figure 8.1.1 image description: When a stream curves, the flow of water is fastest on the outside of the curve and slowest on the inside of the curve. When the stream is straight and a uniform depth, the stream flows fastest in the middle near the top and slowest along the edges. When the depth is not uniform, the stream flows fastest in the deeper section. [Return to Figure 8.1.1]

Figure 8.1.3 image description:

- Erosion velocity curve: A 0.001 millimetre particle would erode at a flow velocity of 500 centimetres

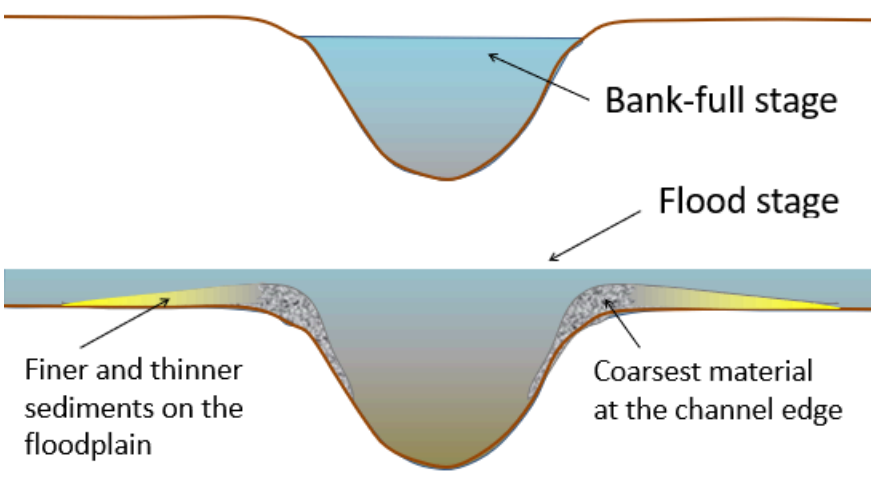

Natural levées from

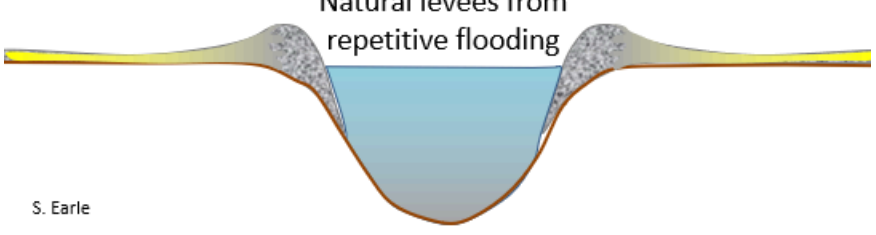

Figure 8.1.4: The development of natural levées during flooding of a stream. The sediments of the levée become increasingly fine away from the stream channel, and even finer sediments - clay, silt, and fine sand - are deposited across most of the flood plain. 
per second or greater. As the particle size gets larger, the minimum flow velocity needed to erode the particle decreases, with the lowest flow velocity being 30 centimetres per second to erode a 0.5 millimetre particle. To erode particles larger than 0.5 millimetres, the minimum flow velocity rises again.

- Settling velocity curve: A 0.01 millimetre particle would be deposited with a flow velocity of 0.1 centimetre per second or less. As the flow velocity increases, only larger and larger particles will be deposited.

- Particles between these two curves (either moving too slow or being too small to be eroded or deposited) will be transported in the stream.

[Return to Figure 8.1.3]

\section{Media Attributions}

- Figure 8.1.1, 8.1.2, 8.1.3, 8.1.4: (C) Steven Earle. CC BY. 


\subsection{Stream Types}

Stream channels can be straight or curved, deep and slow, or rapid and choked with coarse sediments. The cycle of erosion has some influence on the nature of a stream, but there are several other factors that are important including gradient, discharge, and sediment load. A few key types of streams are described below.

Youthful streams that are actively down-cutting their channels tend to be relatively straight and are typically ungraded (meaning that rapids and falls are common). They also have steep gradients and steep and narrow V-shaped valleys-in some cases steep enough to be called canyons.

In mountainous terrain, such as that in western Alberta and B.C., steep youthful streams typically flow into wide and relatively low-gradient U-shaped glaciated valleys. The youthful streams have high sediment loads, and when they flow into the lower-gradient glacial valleys where the velocity isn't high enough to carry all of the sediment braided patterns develop, characterized by a series of narrow channels separated by gravel bars.

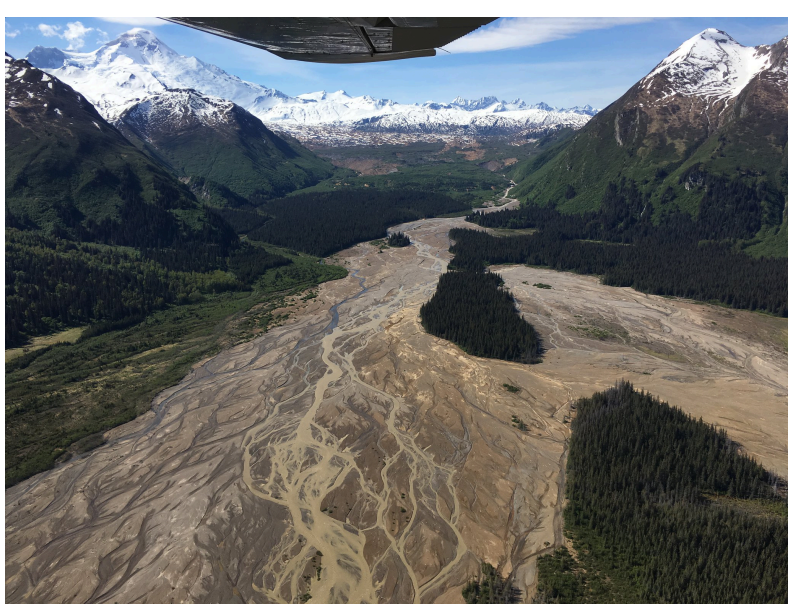

Figure 8.2.2: Red River in Lake Clark National Park, Alaska, is an example of a sediment-laden braided stream. This braided stream transports glaciofluvial sediments from the Red Glacier, an alpine glacier formed on Iliamna Volcano (highest peak to the left of the stream), to Cook Inlet.

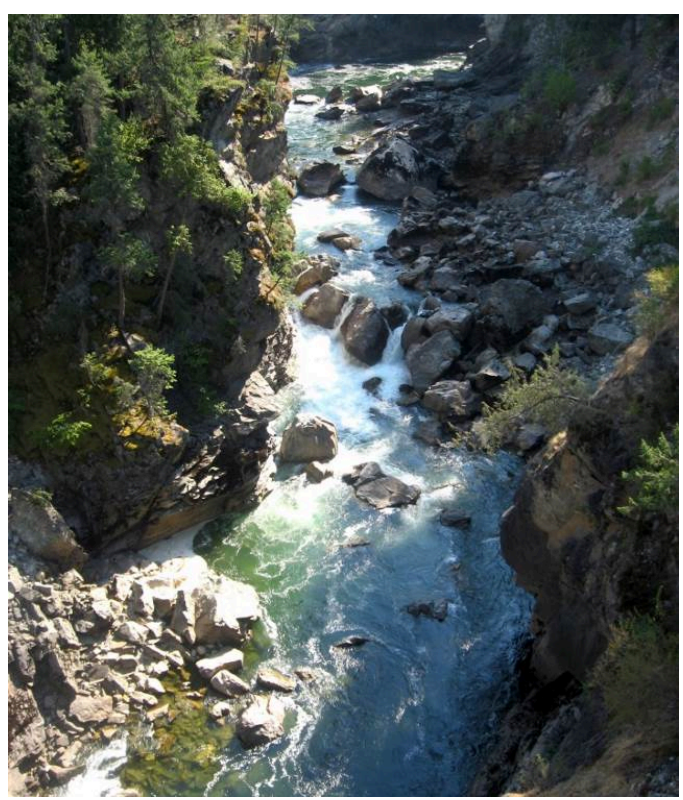

Figure 8.2.1: The Cascade Falls area of the Kettle River, near Christina Lake, B.C. This stream cuts a deep narrow channel through the ment than a cuts a deen
is bedrock able to

transport. One such environment is in mountainous areas, where streams carry glaciofluvial sediments from alpine glaciers (Figure 8.2.2). Another such environment is in volcanic regions, where explosive eruptions produce large amounts of unconsolidated material that gets washed into streams. Streams in the volcanic Mt. Meager area of southwestern British Columbia are good examples of this.

A meandering stream that occupies a wide, flat flood plain with a low gradient typically carries only sandsized and finer sediments and develops a sinuous flow pattern. As you saw in Figure 8.1.1, when a stream flows around a corner, the water on the outside has farther to go and tends to flow faster. This leads to erosion of the cut banks on the outside of the curve, deposition on the inside, and formation of a point bar (Figure 8.2.3). Over time, the sinuosity of the stream becomes increasingly exaggerated, and the channel migrates around within its flood plain, forming a meandering pattern. As point bars develop over time, their surfaces form ridges called scroll bars. There is even evidence of these scroll bars and meandering channels on Mars (Figure 8.2.4)! 
A well-developed meandering river is shown in Figure 8.2.3. The meander in the middle of the photo has reached the point where the thin neck of land between two parts of the channel is about to be eroded through. When this happens, an oxbow lake will form. When an oxbow lake dries up, it leaves behind a curved meander scar filled with muddy sediment.

At the point where a stream enters a still body of water-a lake or the ocean-sediment is deposited and a delta forms. The Fraser River has created a large delta, which extends out into the Strait of Georgia (Figure 8.2.5). Much of the Fraser delta is very young in geological terms. Shortly after the end of the last glaciation $(10,000$ years ago), the delta did not extend past New Westminster. Since that time, all of the land that makes up Richmond, Delta, and parts of New Westminster and south Surrey has formed from sediment from the Fraser River.

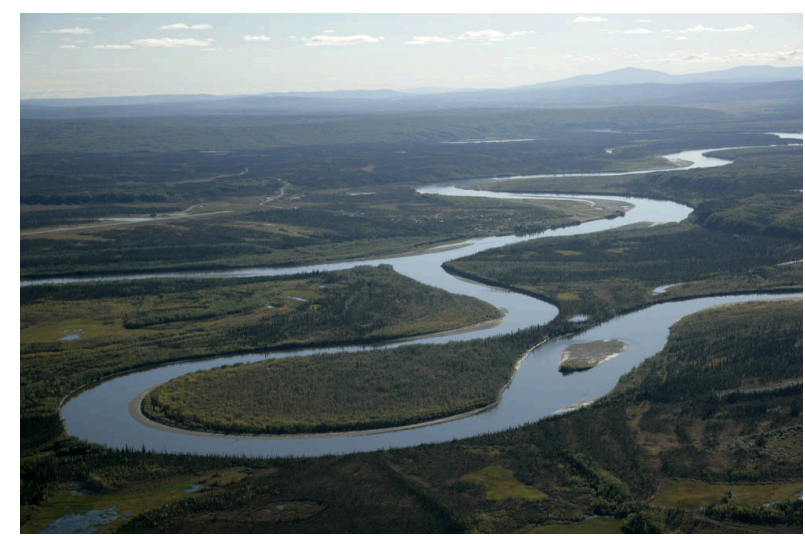

Figure 8.2.3: The confluence of the Alatna and Koyukuk Rivers near the western border of the Kanuti National Wildlife Refuge in Alaska. Both rivers pictured are examples of meandering streams, with sinuous channels, deposition of sediment on point bars, and erosion along the cut banks. Notice the narrow neck separating the channel in the foreground. When this neck is eventually eroded away, the meander in the foreground will be abandoned and will create an oxbow lake. [Image description]

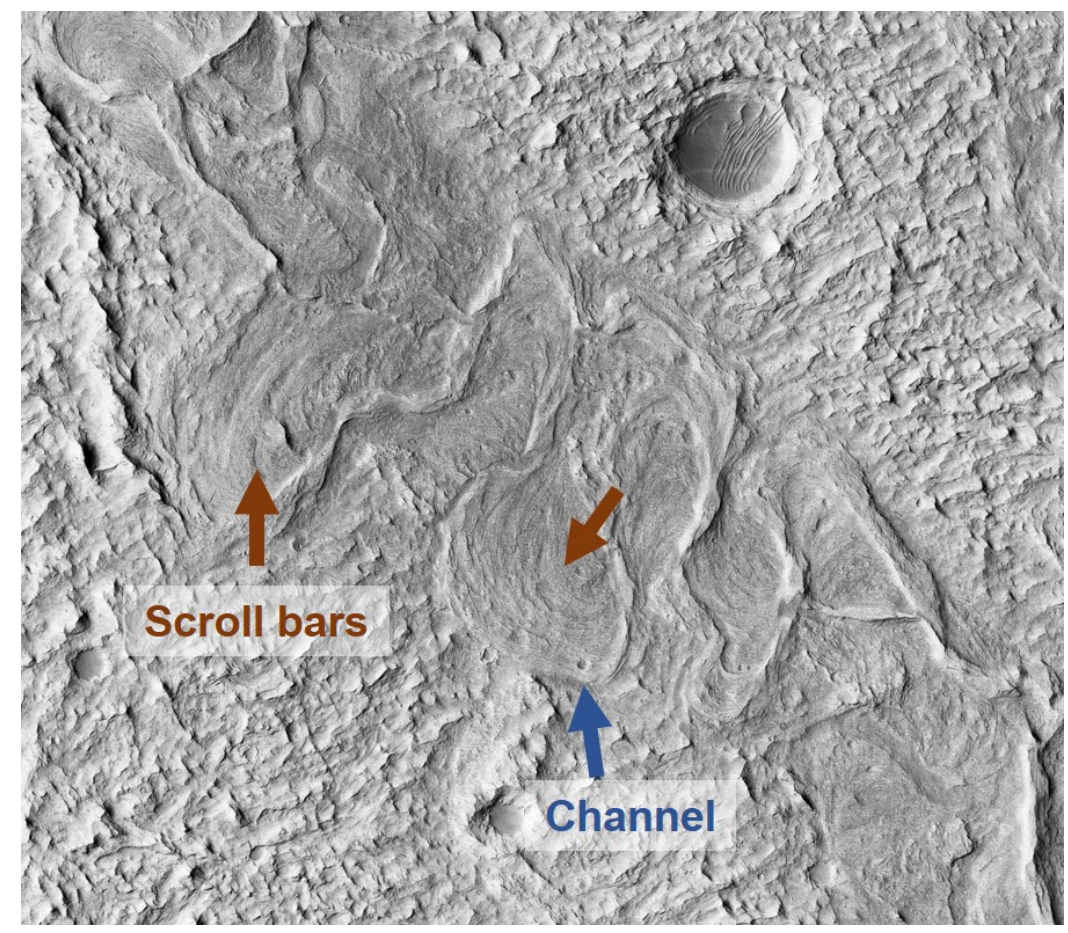

Figure 8.2.4: A sinuous channel in the Aeolis Planum region of Mars taken by the HiRISE camera on the Mars Reconnaissance Orbiter. Blue arrow indicates the sinuous channel-like form, and orange arrows indicate areas with scroll bars (curved ridges). 


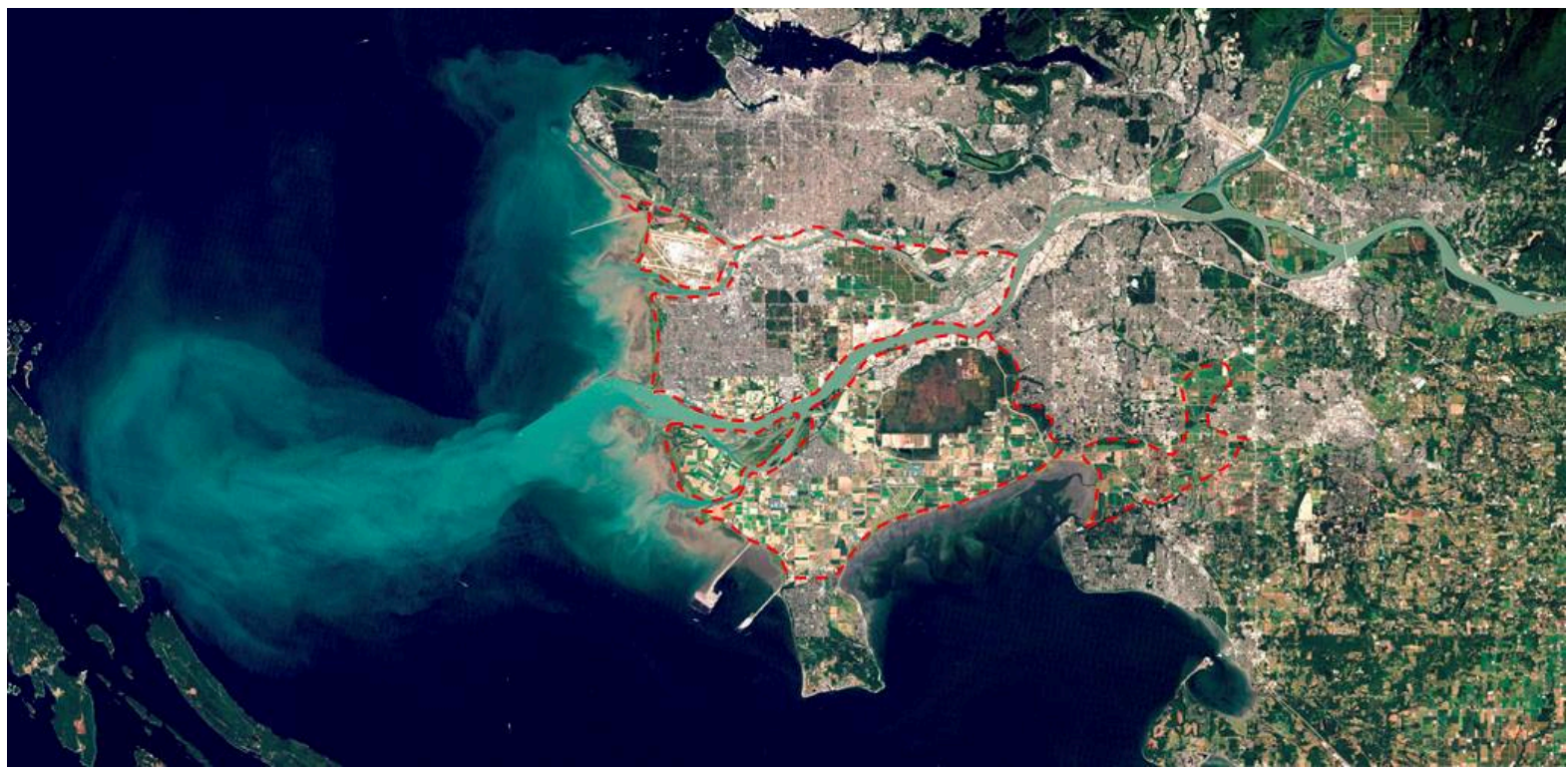

Figure 8.2.5: The delta of the Fraser River and the plume of suspended sediment that extends across the Strait of Georgia in British Columbia. The land outlined in red has formed over the past 10,000 years.

\section{Image Descriptions}

Figure 8.2.3 image description: A part of the Alatna River near its confluence with the Koyukuk River has curved around so sharply that it almost forms a circle before curving the other way again. Eventually, as the barrier between these two parts of the channel erodes, they will be joined and form an oxbow lake. [Return to Figure 8.2.3]

\section{Media Attributions}

- Figure 8.2.1: (C) Steven Earle. CC BY.

- Figure 8.2.2: Braided Rivers Lake Clark National Park by K. Lewandowski (NPS). Taken June 2017. Public domain.

- Figure 8.2.3: Alatna and Koyukuk River confluence near Allakaket by Steve Hillebrand (USFWS). Taken August 2006. Public domain.

- Figure 8.2.4: Yardangs and Ridges of the Edge of Aeolis Planum by NASA/JPL/University of Arizona. Taken December 2007. Public domain.

- Figure 8.2.5: Delta of the Fraser River by NASA. Taken September 2011. Adapted by Steven Earle. Public domain. 


\subsection{What Makes a Map?}

The purpose of a map is not limited to navigation. Maps are used in the geosciences to show data or information in a spatial context. Maps are used to convey information about where observations were recorded in the field, or to show a geologist's interpretations of the materials exposed or deposited on the Earth's surface. Geologists often use topographic maps as a base on which to display the geological information or data they wish to share. A topographic map is a graphic two-dimensional representation of the three-dimensional surface of the Earth. The features shown on a topographic map may be divided into three groups:

- Relief - hills, valleys, mountains, and plains

- Water features - lakes, ponds, rivers, canals, swamps, and streams

- Cultural features - roads, railways, buildings, and land boundaries

You were introduced to some important concepts about maps in the Google Earth Tutorial and Lab 1 Exercises. You learned that all maps are drawn to scale; that is, a designated distance on the map is equal to a corresponding real distance on the actual surface of the Earth. You also learned that locations on maps are specified using grid systems that might include the geographic or UTM systems. This lab will build upon those concepts to give you a deeper understanding of what elements make a map and what information you can convey in a map.

\section{Map scale}

Map scale refers to the fixed ratio between the distance you measure on a map (or in satellite imagery or air photos) and the actual distance on the ground, in the real world. You were introduced to the concept of scale at the beginning of the term, when you completed the Google Earth Tutorial and Lab 1 Exercises. In that tutorial, you used a scale bar to understand distances in Google Earth. Scale bars, also called graphic scale, are one way to represent scale on a map. Graphic scales are used to quickly determine the distance between two points on the map, by comparing the length you measure on the map with your ruler to the scale bar. In Figure 8.3.1 below, each of the long bars on the scale is $2 \mathrm{~cm}$ long and represents a distance of $1 \mathrm{~km}$ on the ground. Let's say you measured the distance between two points on a map to be $5 \mathrm{~cm}$. By comparing that length to the scale bar, you can see that $5 \mathrm{~cm}$ on the map represents $2.5 \mathrm{~km}$ on the ground. Note that the scale bar may be distorted by your screen if you are reading this on an e-reader, smartphone or computer depending on your display settings.

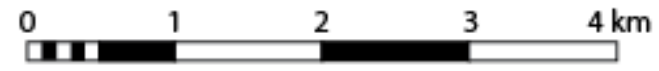

Figure 8.3.1: An example of a scale bar, or graphic scale.
Another way to represent map scale is using a representative fraction (R.F.). The representative fraction is a ratio written in numbers on a map. Two of the common scales for topographic maps in Canada are 1:250,000 and 1:50,000. A R.F. of 1:250,000 means that 1 unit of measurement on the map represents

250,000 of the same unit of measurement on the ground. You can use any unit of measurement (centimetres, inches) as long as you are consistent! A map with a scale of 1:250,000 means that $1 \mathbf{c m}$ on the map is equal to $250,000 \underline{\mathbf{c m}}$ on the ground, and that $1 \underline{\text { inch }}$ on the map is equal to 250,000 inches on the ground. 
What R.F. is shown by the scale bar drawn above? Assume that each of the long bars on the scale bar is $2 \mathrm{~cm}$ in length. Hint: you will have to do some unit conversions!

See Appendix 2 for Practice Exercise 8.2answers.

\section{Determining the scale of an air photo or satellite image}

In some cases, you may want to create a map using a base image rather than a base map. Base images could include air photos, captured by a low-flying aircraft along a set flight path, or satellite imagery like the images available in Google Earth Pro. While images can provide valuable details not captured on a topographic map, they typically lack scale. You can calculate the scale of your base image by comparing the length of a distinctive feature in the base image and a topographic map using a simple formula:

Your map scale $=\frac{\text { (length of the feature on topographic map) } x \text { (map scale) }}{\text { length of the feature on your map }}$

\section{National Topographic System (NTS)}

Standard topographic maps, published by the provincial and federal governments, are usually bounded and divided by parallels of latitude and meridians of longitude. In Canada, topographic maps are subdivided into numerous sections and subsections for the purpose of indexing all of the topographic maps of the nation in the National Topographic System (NTS). All topographic maps have a National Topographic Index Number that indicates the scale of the map and helps catalogue all the NTS maps of Canada. For example, the 1:1,000,000 NTS map sheet 82 covers most of southern Alberta, and is divided into indexed subsections as shown in Figure 8.3.2. The relationship between map scale and index number is outlined in table below.

\begin{tabular}{|l|l|}
\hline Map index number & Map scale \\
\hline 82 & $1: 1,000,000$ \\
\hline $82 \mathrm{NE}$ & $1: 500,000$ \\
\hline $82 \mathrm{O}$ & $1: 250,000$ \\
\hline $82 \mathrm{O} / 1$ & $1: 50,000$ \\
\hline
\end{tabular}

You should always begin the study of a map by observing the title which gives clues to the location of the map in its wider setting. For your reference, the 1:50,000 scale topographic map that covers the city of Calgary is located on NTS map sheet $82 \mathrm{O} / 1$. 


\section{Three-dimensional relief on a two-dimensional map}

Relief on a topographic map is illustrated using contour lines. These are imaginary lines drawn on a map to join points of equal elevation. Every point on a contour line is at the same elevation. Elevation is measured from a predetermined datum line: mean sea level, which is assigned an elevation of 0 . Contour lines separate points of higher elevation (uphill) from points of lower elevation (downhill), therefore points between two contour lines are no lower than the contour line below and no higher than the contour line above. Contour lines never intersect or cross, except in very rare cases of overhanging cliffs. Contour lines always close; this closure may take place outside the map area as shown for the $50 \mathrm{~m}$ contour line in Figure 8.3.3. The contour interval (C.I) of a map is the difference in elevation between two adjacent topographic contour lines. The space between adjacent contour lines on a map reflects how steep or gentle the slope is: the closer the contour lines, the steeper the slope. Evenly spaced contour lines represent a uniform slope.

\section{Practice Exercises 8.3}

Examine the example topographic map in Figure 8.3.3. The map shows two hills separated by a small valley that has two streams.

1. Which hill is the tallest? Or, in other words, which hill has the highest elevation?

2. What is the approximate elevation of the red star?

3. Toward which direction is each stream flowing?

4. Can you see anywhere on the map where topography would be relatively steep?

5. Can you see anywhere on the map where topography would be relatively gentle or flat?

6. How can you tell the difference between areas with steep versus gentle topography using the contour lines?

7. Notice that the $50 \mathrm{~m}$ and $100 \mathrm{~m}$ contour lines forms a "V" shape as they cross the stream. Topographic contour lines always form a " $\mathrm{V}$ " shape as they cross a stream, and the point of the " $\mathrm{V}$ " always points upstream. Imagine there is a third stream that originates at the red star and flows toward the NE. Draw in this third stream and using dashed lines, modify the contour lines where they cross this stream. 


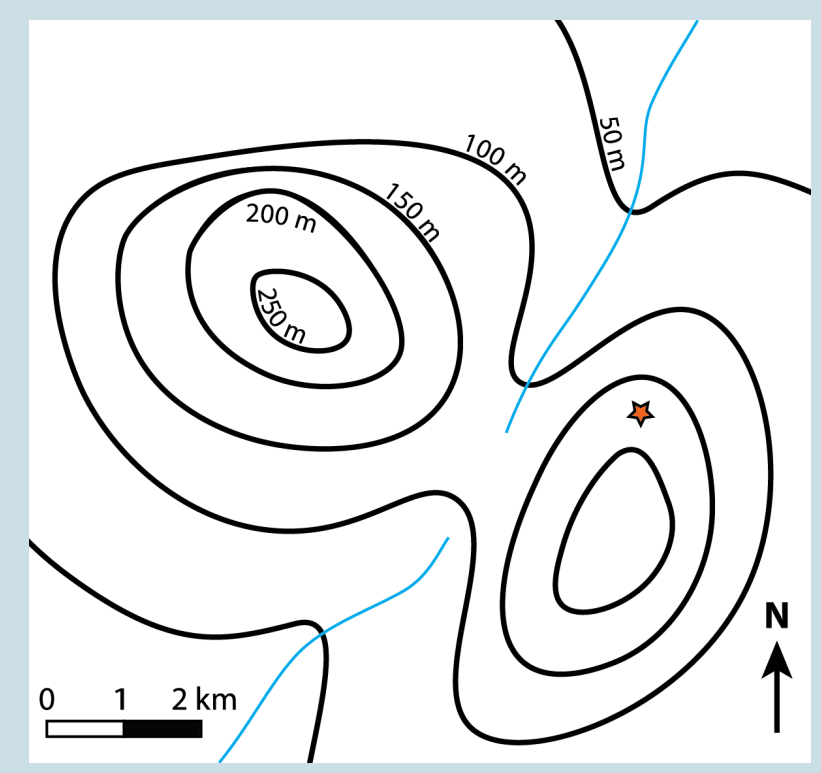

Figure 8.3.3: Example of a topographic map including contour lines with a contour interval of $50 \mathrm{~m}$.

See Appendix 2 for Practice Exercise 8.3 answers.

\section{Media Attributions}

- Figures 8.3.1, 8.3.2, 8.3.3: (C) Siobhan McGoldrick. CC BY. 


\section{Lab 8 Exercises}

In this activity you will learn to identify features of a stream using satellite imagery in Google Earth Pro. You will create a hand-drawn map of the fluvial features you identify along a segment of the Elbow River in Calgary, Alberta on the homelands of the Niitsitapi (the Siksika, Piikani, and Kainai), the Îyârhe Nakoda and Tsuut'ina Nations. Located just south of Mount Royal University's campus, this segment of the Elbow River was one of the areas affected by the 2013 flooding. Elbow River also plays a crucial role in supplying Calgary's drinking water.

You have been provided with the following starting materials to complete this mapping activity:

- A base image from Google Earth satellite imagery (Elbow River Map Area) that you must print out

- A digital copy of the 082J-16 NTS Priddis map sheet on which your map area resides (do not print this)

The purpose of your map is to show your reader the locations of erosional and depositional features of the Elbow River. To convey that information in a way that is useful, your map needs to include some standard cartographic elements including:

- Title

- Scale

- North arrow

- Legend

- Sources (e.g., satellite imagery, base map, reference map)

- UTM coordinates for a reference point on your map

- Refrence to the National Topographic System (NTS) map sheet on which your map resides

Title

Your map should have a succinct but descriptive title that includes some reference to the geographic area. This could include the name of the river, the NTS map sheet on which your map resides, or the name of a prominent local landmark that is featured on your map. Your title must also include what type of map you have drawn, e.g., topographic map, geological map, map of glacial landforms, map of population distributions, etc.

Scale

Your map must indicate scale using both a scale bar and a representative fraction. Remember, you can calculate the scale on your map by comparing the length of a distinctive feature on your map and a topographic map of the same area. But first, because you are examining an electronic version of the topographic map on a computer screen rather than a printed version you need to ensure that you are viewing the topographic map at the correct scale (as your device may distort the size of the image on the screen).

To check if your topographic map PDF is being displayed correctly, measure the scale bar on the map. For 
a 1:50,000 map sheet like the one you are using, $1 \mathrm{~cm}$ on the scale bar should represent $500 \mathrm{~m}$ on the ground. By holding up a ruler to measure, zoom in and out until this is true on your computer screen before you follow the steps below.

1. Measure a feature that is visible and distinctive on both your map and the topographic map. Record your measurements in the same units for both. The distance between intersections along a road, or in a straight line between two distinctive features are good places to measure.

2. Use the formula below:

$$
\text { Your map scale }=\frac{(\text { length of the feature on topographic map) } x \text { (map scale })}{\text { length of the feature on your map }}
$$

For example, for a feature $5 \mathrm{~cm}$ long on your map and $2.5 \mathrm{~cm}$-long on the 1:50,000 topographic map:

$$
\text { Your map scale }=\frac{(2.5 \mathrm{~cm}) \times(50,000)}{5 \mathrm{~cm}}=1: 25,000
$$

The scale of the base image in this example is therefore 1:25,000. This result is not particularly realistic as air photo or satellite imagery scales rarely work out to such a nice, even number.

\section{North arrow}

Exactly as it sounds: a north arrow on a map shows the reader the direction of north in the area.

Legend

The purpose of a legend is to define all symbols, abbreviations or colours used on a map to the reader. Every feature that you draw or label on your map should be explained or defined in the legend. For example:

\begin{tabular}{ll}
\hline Abbreviation or symbol on the map & Meaning \\
\hline Fp & Flood plain \\
Ms & Meander scar \\
--- & Trail \\
\hline
\end{tabular}

Feel free to create your own abbreviations or symbols for features on your map, but make sure you choose unique abbreviations or symbols for each feature. 


\section{Reference location}

To help your reader put the information from your map into a real-world context, you should provide the UTM coordinates for a reference location on your map. You may want to refresh your memory on grid coordinates by reviewing the Google Earth Tutorial. This location should be something visible and distinctive on both your map and the topographic map provided. Furthermore, this location should be a feature that is unlikely to move over time, e.g., a point bar would be a poor choice as the shape and position of the point bar migrates over time. You will also need to tell your reader where your mapped area fits into Canada's National Topographic System (NTS).

\section{Instructions}

1. Examine the area you will be mapping (Elbow River Map Area).

2. Open Google Earth Pro on your computer and navigate to this area. Spend some time examining the features of this area using the 3D capabilities of Google Earth Pro.

3. Attach a piece of tracing paper to your printed satellite imagery with a paper clip or piece of clear tape. Be gentle; tracing paper tears easily! Be very careful when erasing!

4. Set up your map area. Make sure that you have enough space on your tracing paper set aside for your legend and other cartographic elements (see checklist below). The example shown here illustrates one possible layout, but feel free to choose a layout that works with your map area.

5. With a pencil, lightly and neatly draw in the major landforms that you see in the satellite imagery. Focus on fairly large-scale structures; don't clutter up your map with a lot of detail. Think about what features are relevant to the fluvial features map you are drawing, and then make a judgement call for yourself about what features to include. For example, is it important to your map to draw in every building? Or to highlight areas with different types of vegetation? Probably not. But is it important to have a few key roads on your map to help a reader situate your map? Yes, it is.

6. Think about neatness. Examine the topographic map provided. What

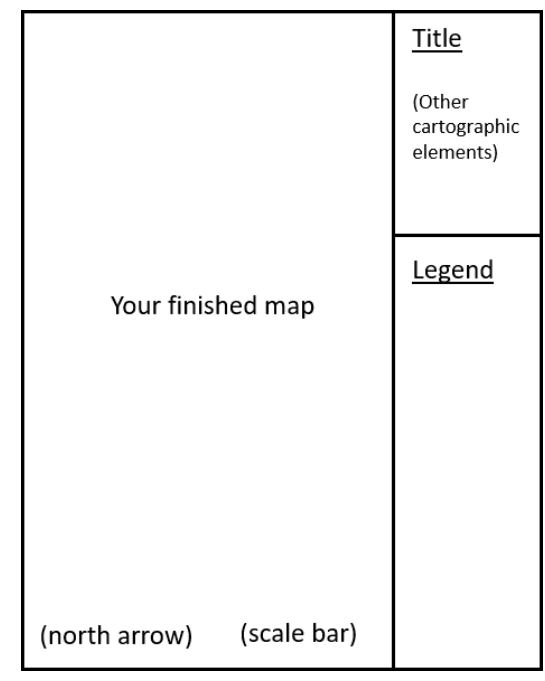
characteristics make it neat and easy to read? It is drawn carefully and the features are not shaded in. Remember: you are producing a map, which is drawn in plan view. It should not have any 3D aspect to it, including shading. Your finished product should be a line drawing only.

7. Use the topographic map provided to help you identify named geographic features.

8. Trace out the different fluvial features that you have interpreted, and assign each feature a unique abbreviation or symbol. Keep track of the abbreviations or symbols that you use on a spare sheet of paper to help format your legend once you have finished your map.

9. If the feature you are tracing is a polygon (an enclosed area that defines the borders of the specific feature), make sure your polygon is fully closed and labeled with an abbreviation, symbol or colour. Make sure every polygon you draw is labeled.

10. Review the checklist below and ensure that your finished map contains all the required information. 


\begin{tabular}{|l|l|l|}
\hline Fluvial Features & $\begin{array}{l}\text { Cultural } \\
\text { Features }\end{array}$ & Cartographic Elements \\
\hline Active channel & Roads & Title \\
\hline Cut bank & Bridges & North arrow \\
\hline Point bar & $\begin{array}{l}\text { Buildings or } \\
\text { subdivisions }\end{array}$ & Scale bar \\
\hline $\begin{array}{l}\text { Abandoned } \\
\text { channel }\end{array}$ & & Scale as representative fraction \\
\hline Oxbow lake & & Legend \\
\hline Delta & & Reference to NTS sheet on which this map resides \\
\hline Flood plain & & Reference point in UTM coordinates \\
\hline Meander scar & & $\begin{array}{l}\text { Elevation of reference point in metres (estimate using the topographic } \\
\text { contours) }\end{array}$ \\
\hline & Date of satellite imagery and source of satellite imagery \\
\hline & & Author's name (your name) \\
\hline
\end{tabular}

\section{Summary Questions}

1. What is the National Topographic Index Number for the topographic map provided?

2. What is the National Topographic Index Number for the topographic map directly to the north of this map?

3. What colour are grid lines for UTM Zone 11 on the topographic map sheet provided?

4. What colour are the topographic contour lines on the topographic map sheet provided?

5. What is the contour interval (C.I.) on this topographic map?

6. Examine the spacing between adjacent contour lines on the topographic map provided. In what general part of the map do you see relatively steep topography? In what general part of the map do you see relatively gentle topography? How can you tell the difference using the contour lines?

7. Draw a sketch of a few contour lines, with elevations labeled, as they cross a stream. On your sketch, indicate the direction of stream flow with an arrow.

8. Where would you expect to find the fastest water flow on a straight stretch of a stream?

9. Sand grains can be moved by traction and saltation. What minimum stream velocities might be required to move 1 millimetre sand grains?

10. Under what circumstances might a braided stream develop?

11. What do you think controls the variability in the colour of the water in Glenmore Reservoir in this satellite image? 
12. What factors or forces influence the behaviour of the Elbow River? Hint: Examine the most recent satellite imagery for your map area in Google Earth Pro.

If you have the opportunity to do so, and provincial health authorities deem it safe, you are encouraged to safely and respectfully visit this area, called Weaselhead Flats, yourself. Walk around the Weaselhead Flats and see what fluvial features you can identify in person. Grab a handful of sediment from a point bar and examine the size, shape and composition of the grains. As for any field work, always:

- Stay on the trails, be mindful of other trail users and maintain $2 \mathrm{~m}$ of physical distancing.

- Dress appropriately for changing weather conditions. Think layers!

- Bring water, a hat and sunscreen.

- Wear appropriate footwear that covers your foot completely, provides some ankle support, and has a good tread in case the path is slippery.

- If you are exploring along the river bank, walk cautiously and be mindful of loose soil or sediment that may collapse.

- Make a plan! Make sure you tell someone when you are expected home and check in with them once you return.

\section{Media Attributions}

- Elbow River Map Area and Glenmore Reservoir and area satellite images used under the following Google Maps and Google Earth guidelines.

- 082J-16 NTS Priddis topographic map: (C) Natural Resources Canada. The Government of Canada retains the copyright of this image but allows for reproduction for non-commercial use.

- Example map layout: (C) Siobhan McGoldrick. CC BY. 


\section{Summary}

The topics covered in this chapter can be summarized as follows:

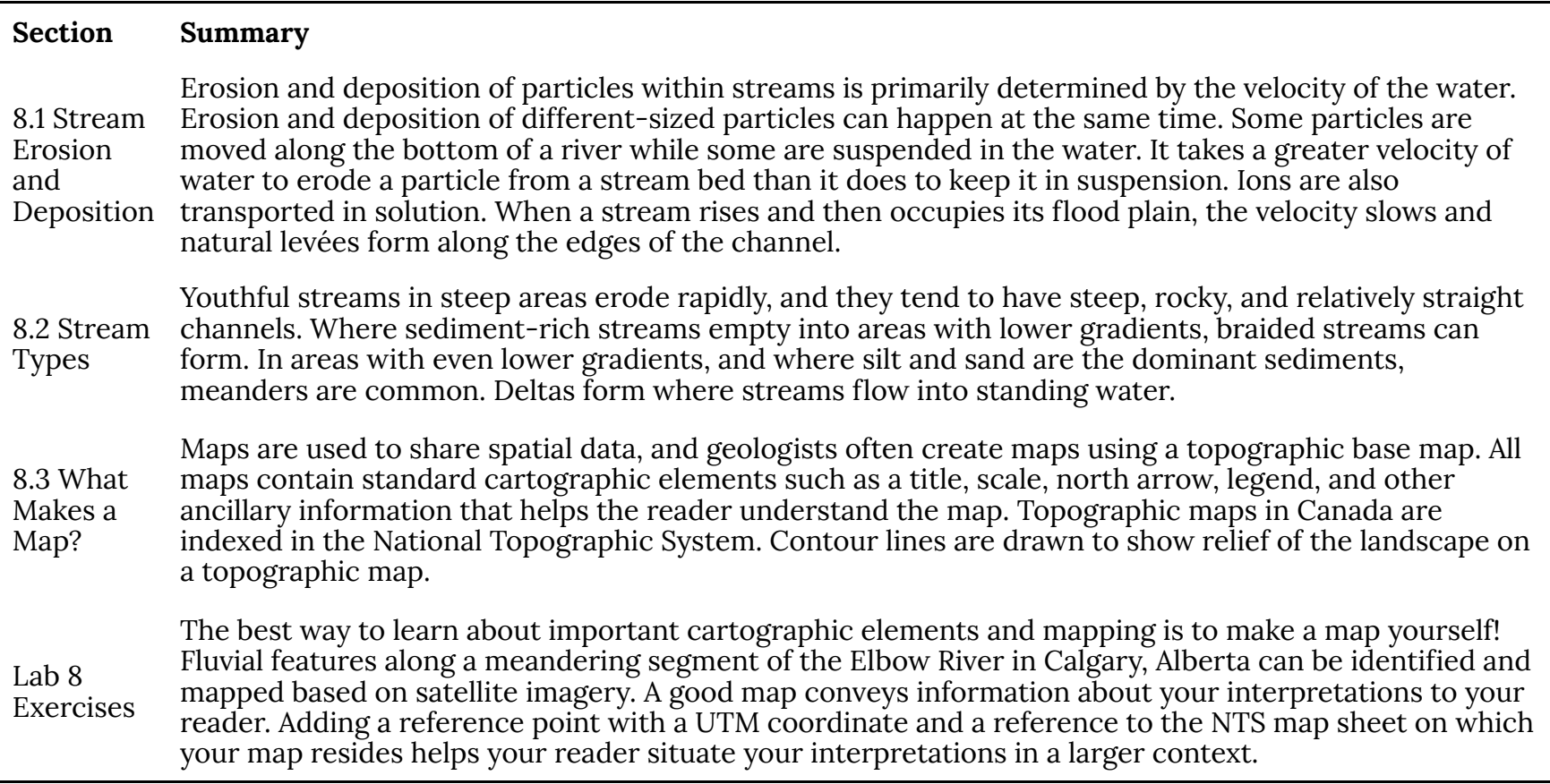




\section{LAB 9: STRUCTURAL GEOLOGY PART I}

\section{Lab Structure}

\begin{tabular}{ll}
\hline Assignment & $\begin{array}{l}\text { Yes - take-home mapping assignment } \\
\text { Tracing paper, pencil, pencil crayons, ruler, printed } \\
\text { Sheep Mountain map area base image }\end{array}$ \\
\hline & \\
Learning Objectives & \\
After reading the information in this chapter, and completing the exercises within it, you should be able to: \\
- $\quad$ Visualize topographic contours in Google Earth and review the concepts of topographic maps presented in \\
- $\quad$ Risualize layers of rocks as planes in three-dimensional space, in areas of variable topography. \\
- $\quad$ Understand the significance of the information presented on a geological map. \\
- Understand the concept of dip and dip direction of inclined strata. \\
- $\quad$ Estimate dip direction of inclined strata in map view using the Rule of V's.
\end{tabular}

Key Terms

- Strata

- Planar

- Contact

- Cardinal direction

- Ordinal direction

- Contour lines

- Dip

- Dip direction
- Lithology

- Unit

- Map scale

- Formation

- Group

- Member

- Bed

- Rule of V's 


\section{I Introduction to Structural Geology}

Structural geology is a branch of geology that studies the three-dimensional distribution of rocks and the geometric relationships between rocks. Structural geologists aim to understand the processes that result in the complex geological features we see on Earth today. In this lab, we will explore the foundational aspects of structural geology and how geological maps are used to display structural geological information. We will use block models to introduce the concepts in this section. Block models provide a useful tool for visualizing geology in three dimensions. The top surface of the block represents the surface of the Earth, and the four sides provide four cross-sectional views of the geology in the subsurface.

Layers of rocks are planar

In Lab 5 we discussed how sedimentary rocks form layers as sediments are deposited over time and are eventually lithified into rock. Many sedimentary rocks, and some igneous rocks like those formed from lava flows, form planar layers. A planar layer has flat surfaces above and below it, just like the hard front and back covers of a hardcover textbook. The planar surface between two different layers of rock is called a contact. In the figures below, the black lines represent the contacts between planar layers of rocks.An important note: planar does not mean horizontal. For example, both figures 9.1.1 and 9.1.2 show layers of rock, called strata (plural) or stratum (singular), that are planar. In Figure 9.1.1, these strata and the contacts between them are horizontal, but in Figure 9.1.2 the strata and the contacts are tilted or inclined. Recall that in Lab 7 we discussed how the principles of stratigraphy are used to determine relative age.

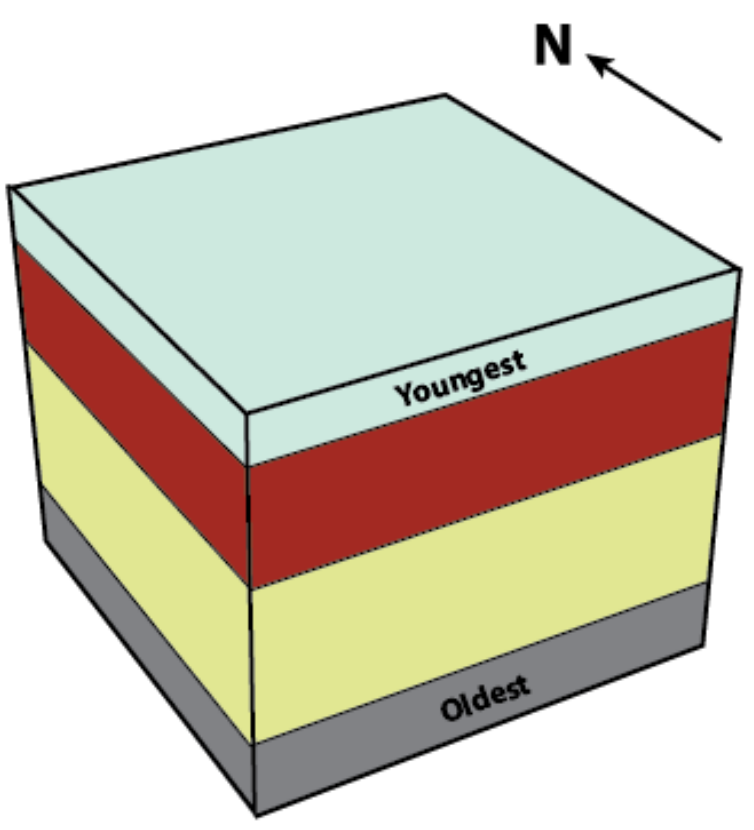

Figure 9.1.1: Block diagram of horizontal strata showing four distinct planar layers. 


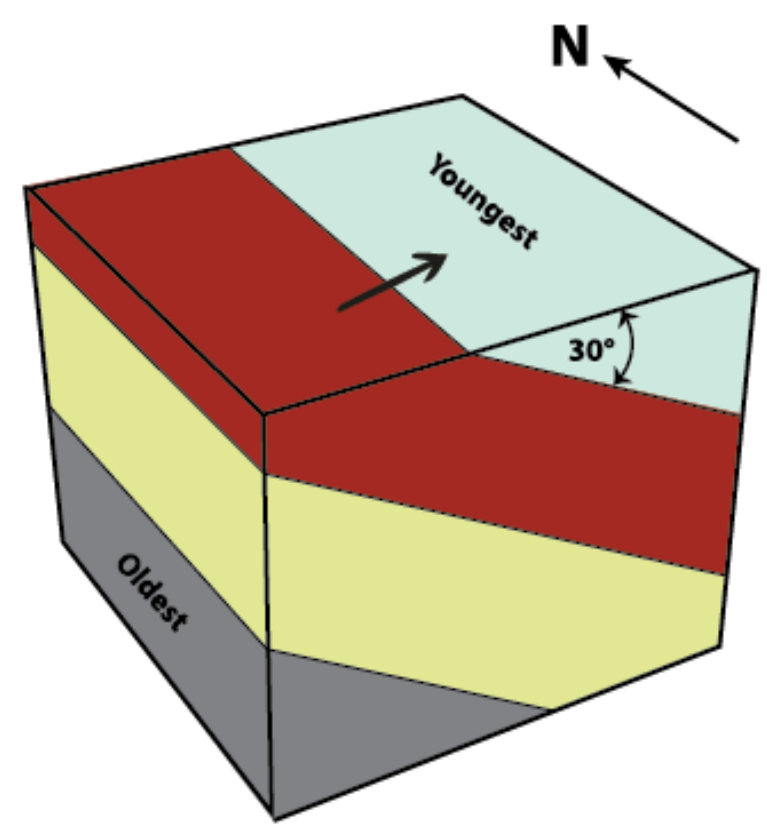

Figure 9.1.2: Block diagram of dipping strata. The same four distinct planar layers from Figure 9.1.1 are now dipping $30^{\circ}$. Black arrow indicates the dip direction.

\section{Describing the attitude of a plane: Dip and dip direction}

Planar layers of rock can be horizontal (Figure 9.1.1), vertical, or tilted at any angle in between (Figures 9.1.2, 9.1.3, 9.1.4). Geologists need to describe the attitude of a layer of rock, meaning exactly how the layer is oriented in three-dimensional space, in order to properly study and map it. Two pieces of information that help describe the attitude of a layer of rock are dip and dip direction.

Dip refers to the angle measured in degrees $\left(^{\circ}\right)$ between horizontal and the tilted plane. Horizontal strata have a dip of $0^{\circ}$, whereas vertical strata have a dip of $90^{\circ}$. Figure 9.1.2 shows strata that are dipping $30^{\circ}$. You can use a protractor to measure the angle between horizontal and the dipping strata to confirm that the dip is indeed $30^{\circ}$.

To understand dip direction, it can help to visualize pouring a glass of water onto dipping strata, as illustrated in Figure 9.1.3. The water runs down the tilted surface of the stratum in the direction of maximum dip, also known as the dip direction. In this course, we will use cardinal directions and ordinal directions to describe dip direction but in subsequent geology courses we will discuss another way to specify dip direction using azimuths or bearings. Using the north arrow provided in Figure

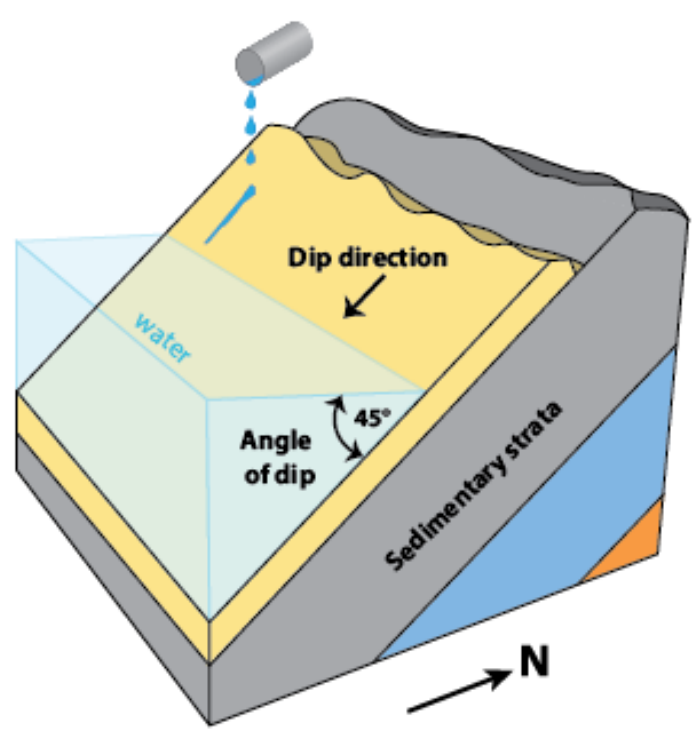

Figure 9.1.3: A schematic diagram to illustrate the concepts of dip and dip direction for a sequence of sedimentary strata. 
9.1.2, we can deduce that the dip direction of the strata shown is east. We would say that the strata are dipping to the east, because we can imagine water poured onto the stratum would flow down toward the east.

Practice Exercises 9.1

1. In Figures 9.1.1 and 9.1.2, which principle was used to determine the oldest and youngest sedimentary rocks in the diagram?

2. In Figure 9.1.2, which principle tells you that these strata were tilted after deposition and lithification?

3. Toward which direction are the strata dipping in Figure 9.1.3?

4. $\quad$ How steeply are the strata dipping in Figure 9.1.3?

See Appendix 2 for Practice Exercise 9.1 answers.

\section{Media Attributions}

- Figure 9.1.1, 9.1.2, 9.1.3: (C) Siobhan McGoldrick. CC BY. 


\subsection{Geological Maps}

As we learned in Lab 8, the purpose of a map is not limited to navigation. A geological map is arguably the most important tool a geologist uses to understand the Earth. Geological maps are used to convey information about where measurements were recorded in the field, to show the ages, distribution and orientation of rocks, and to locate important geological features like faults. While geological maps only show what is exposed on the surface of the Earth, they are used as a tool to help geologists interpret the geology of the subsurface. You will learn more about this in Lab 10.

Geologists use geological maps as a tool to answer a number of questions, such as:

- Where can we find a particular geological feature, like a notable shale bed rich in dinosaur fossils or the contact between two rock layers of interest?

- What is the geological history of this area, and how has it changed throughout geologic time?

- Are there potential geologic hazards like volcanoes, sinkholes, areas prone to landslides, or faults, in this area? How can this information be conveyed to the public?

- Where can we find mineral deposits or energy resources, and how can we safely extract them?

- How can we better understand and visualize the geology below the Earth's surface?

\section{Geological maps: the intersection of geology and topography}

Geological maps are often drawn as an overlay on top of a topographic base map to be easily linked to local geographic landmarks. Geological maps, therefore, display many of the same cartographic features as topographic maps, including: contour lines, map scale, north arrow, and a legend.

The map patterns on a geological map and the geology we can observe on the Earth's surface are influenced by topography. Imagine a geological map in an area where strata are horizontal and where the topography is completely flat. How would the geological map of this area look? Now imagine the same geology (strata are horizontal) but in an area with rugged, mountainous topography. How would the geological map of this area look? These questions may seem abstract now, but with practice you will be able to picture how the map pattern on a geological map varies with topography and the attitude of the strata.

For example, examine the three panels of Figure 9.2.1. Each panel shows the plan view and the corresponding block model for three areas with different topography. Notice that the geology, meaning the strata and their attitude, is the same in all three panels. All three show four distinct layers that are horizontal, with $0^{\circ}$ of dip. The map patterns differ dramatically even though the actual orientation of the rocks has not changed. Figure 9.2.1 highlights how geological maps show the interaction between geology and topography. 


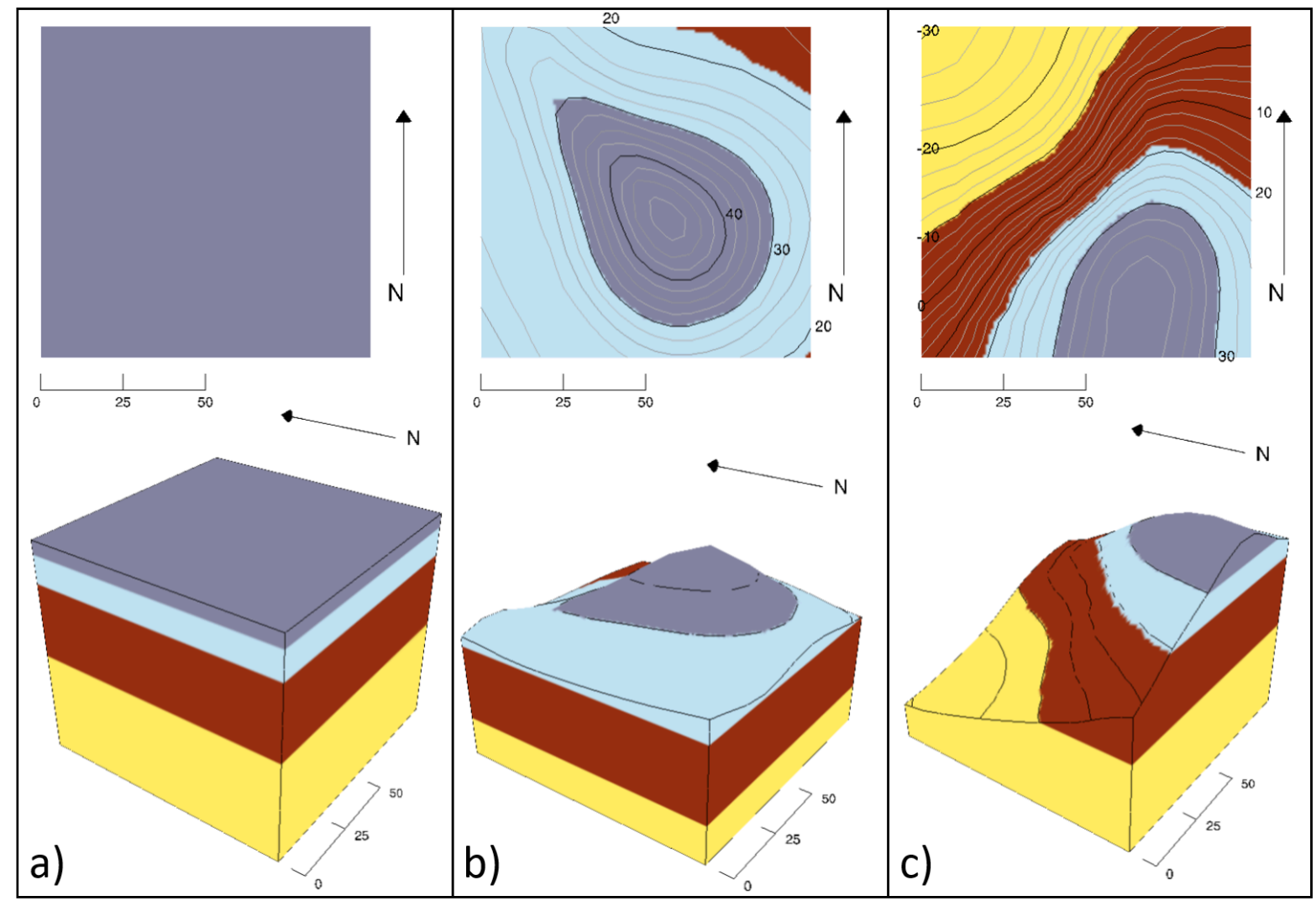

Figure 9.2.1: The same geology (horizontal strata) shown in map view (top) and in block diagram (bottom) in three areas with distinctly different topography.

It is important to remember that geology also affects topography. The nature of the topography in an area is strongly influenced by the relative strength of the geologic materials at and below the surface. For example, steep cliffs tend to form in relatively strong rocks that are resistant to weathering, whereas depressions might indicate the presence of a fault, or that the area is underlain by rocks that are more susceptible to weathering. In this way, topography can provide clues (although not definitive answers!) about the nature of the bedrock geology.

\section{What is "mappable"?}

Most geological maps do not show the distribution of every rock type separately as this would produce a chaotic map with too much information to be of use. Instead, the map patterns drawn on a geological map are those of mappable units. A mappable unit is informally defined as being:

- Distinct from the units above and below it

- Extensive enough to be shown on a map (think about map scale!)

Geologists who study sedimentary rocks, in particular, need ways to divide them into manageable units, and they also need to give those units names so that they can easily be referred to and compared with other rocks deposited in other places. The International Commission on Stratigraphy (ICS) has established a set of conventions for grouping, describing, and naming sedimentary rock units. In North America, these units are 
defined by the North American Stratigraphic Code. In order of decreasing scale, the conventional names for these units are: groups, formations, members, and beds (sedimentary) or flows (igneous).

The main stratigraphic unit is a formation, which according to the ICS, should be established with the following principles in mind:

The contrast in lithology between formations required to justify their establishment varies with the complexity of the geology of a region and the detail needed for geologic mapping and to work out its geologic history. No formation is considered justifiable and useful that cannot be delineated at the scale of geologic mapping practiced in the region. The thickness of formations may range from less than a meter to several thousand meters.

In other words, a formation is a series of beds that is distinct from other beds above and below, and is thick enough to be shown on the geological maps that are widely used within the area in question. In most parts of the world, geological mapping is done at a relatively coarse scale, and so most formations are in the order of a few hundred metres thick. At that thickness, a typical formation would appear on a typical geological map as an area that is at least a few millimetres thick.

A series of formations can be classified together to define a group, which could be as much as a few thousand metres thick, and represents a series of rocks that were deposited within a single basin (or a series of related and adjacent basins) over a few million to a few tens of millions of years.

Often a series of beds or members with some aspect in common will be mapped as a single formation, and two or more formations with some aspect in common might be mapped as a single group. Depending on the purpose of the map, these designations might be made on the basis of the main rock type, a compositional change (often indicated by a change in colour or in metamorphic rocks by the appearance of a new mineral), a textural change (grain size, foliation, change of igneous texture), or a change in the fossil assemblage.

The units on a geological map are defined in the legend. As we learned in Lab 8, the purpose of a legend is to define all symbols, abbreviations or colours used on a map to the reader. For every unit mapped, the legend should state the map code, colour, name, rock types, and age of the unit, as shown in the example in Figure 9.2.2.

The colour refers to the colour of the polygon drawn on the map. The map code is the combination of letters that typically indicate the age (e.g., "J" for Jurassic) and a link to the name of the unit (e.g., "F" for Fernie, "P" for Palliser). The age of the unit is indicated by the most specific name of the eon, era, period or epoch in the geological time scale (e.g., Jurassic, Devonian). A brief description of the different rock types included in each mapped unit is provided for reference. Notice that often several different rock types of similar age are mapped together as a single unit. Legends on a geological map are always formatted such that the oldest unit is at the bottom and the youngest unit is at the top.

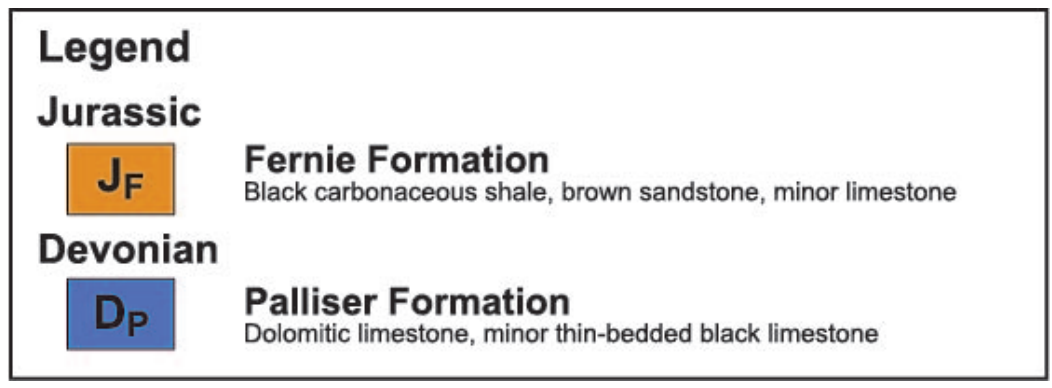

Figure 9.2.2: Example of a legend on a geological map. 


\section{Media Attributions}

- Figure 9.2.1: Images created using Visible Geology. All rights reserved.

- Figure 9.2.2: (C) Siobhan McGoldrick. CC BY. 


\subsection{Estimating Dip Direction from a Geological Map}

You have now observed how topography and geology interact to produce the patterns on a geological map. There are a few rules of thumb to help you interpret the attitude of the strata on a geological map based on the map patterns you observe.

Horizontal strata: contacts between horizontal strata follow the topographic contours (as in Figure 9.2.1). Vertical strata: contacts between vertical strata are not deflected or influenced by topographic contours. These contacts often appear to cut topographic contours at a high angle.

Dipping strata: contacts between dipping strata are deflected or bent by topographic contours (as in Figure 9.3.1). This deflection can help us determine the dip direction of a mapped unit simply by examining its map pattern, using the Rule of V's.

The Rule of V's is a visual, qualitative method to determine dip direction by examining the map pattern of the contact between two dipping units as it crosses a stream or a valley. There are a few select instances where the following does not hold true, but as a general guideline: a dipping contact forms a "V" shape as it crosses a stream or valley, and the point of the "V" points in the direction of dip. For example, the map in Figure 9.3.1 shows two units, one white and the other orange. The black line is the mapped contact between the two units. Notice how the contact makes a "V" shape as it crosses the stream (blue line). The "V" points towards the southwest because the contact is dipping towards the southwest.

Important: The Rule of V's is used to describe the deflection of dipping geological contacts as they cross a stream - it is not used to describe the behaviour of topographic contour lines!

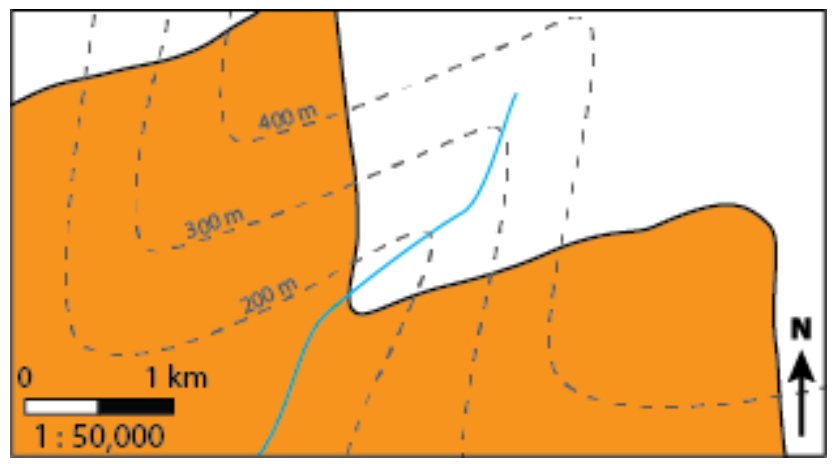

Figure 9.3.1: Use the Rule of V's to determine the dip direction of the two planar units (orange and white) shown on the map.

To better understand the Rule of V's, it is helpful to visualize the geology in three-dimensions. The University of Leeds has developed an excellent, interactive tool to examine the Rule of V's in a virtual landscape. As you examine the virtual landscape on the University of Leeds website, think about the following questions:

1. How does changing the dip change the map pattern? 
2. How can you distinguish horizontal or shallowly dipping strata from vertical or steeply dipping strata in map view?

Remember, unlike the examples in Figure 9.2.1, in this case the topography remains fixed and the map pattern is changing in response to variations in the attitude of the geology (variations in the dip of the strata).

\section{Media Attributions}

- Figure 9.3.1: @ Siobhan McGoldrick. CC BY. 


\section{Lab 9 Exercises}

Today, you will be learning the basic principles of geological mapping. In this activity you will learn to identify layers of rock, group them into mappable layers, and identify dip direction using satellite imagery in Google Earth Pro. The take-home assignment you will complete aims to link together all the topics covered in this lab to introduce you to geological mapping using satellite imagery.

Before you get started, download Google Earth Pro (free) for desktop. Web or Mobile versions are also available but they do not have all the features you will be required to use in this activity.

\section{Instructions}

Download the 1101 Lab 9.kmz file provided by your instructor. In Google Earth Pro, click File, Open and navigate to wherever you saved the downloaded .kmz file.

In the left panel you should see a list of places in this kmz file, double click on "Raplee Anticline". We will begin by examining the Google Earth satellite imagery only, so uncheck the box next to "Mexican Hat Topographic Map".

1. Examine the area around Raplee Anticline from an altitude of $\sim 5 \mathrm{~km}$. Write down any observations you have about this area.

2. Notice the different colours. What might these different colours represent?

3. Why are we examining this area to study bedrock geology? Why not look around Calgary? Why not look around Vancouver, BC?

Turn on the "Mexican Hat Topographic Map" layer by checking the box next to it in the Places sidebar. Make sure the map is $100 \%$ opaque (not transparent at all).

- To adjust the transparency, right click on the name of the layer in the Places sidebar, and select Properties.

- A dialogue box should appear. Click and drag the bar to adjust the transparency of the topographic map overlay. 
Now that you are examining a topographic map draped over the 3D landscape in Google Earth, let's review some concepts about topographic maps from Lab 8.

4. What units are used to show elevation on this topographic map?

5. What is the contour interval on this topographic map?

6. What do topographic contour lines do when they cross a stream? If you're not sure, examine one of the streams to the northwest of the Raplee Anticline, but still on the east side of the San Juan River.

Adjust the transparency of the topographic map such that it is almost transparent but the topographic contour lines are still visible.

7. Examine the immediate area around the Raplee Anticline in plan view (remember, you can press $r$ on your keyboard to return to plan view). What do you notice about the contour lines relative to the contacts? Hint: the contacts are the planes between layers of rocks of different colours.

8. Rotate the view to examine the area in 3D. Circle the correct answer: do these layers in the immediate area around Raplee Anticline appear to be horizontal, vertical, or dipping?

9. If you were to walk $500 \mathrm{~m}$ from Raplee Anticline, heading due west, would you be walking over progressively younger or older rocks? What principle of stratigraphy did you use to determine this?

10. Examine the strata directly to the west of Raplee Anticline but still on the east side of the San Juan River. Again, compare the strata that you can recognize by the variations in colour to the contour lines. Do these strata appear to be horizontal as well? Why or why not?

11. Rotate the view until you are looking directly east toward Raplee Anticline. Look closely at the jaggedlooking layers of red and grey rocks. Notice how if you try to trace a single layer of rock it makes a jagged line? That is because these layers are dipping. Rotate your view to see this in $3 \mathrm{D}$ and confirm these layers are indeed tilted, or using proper terminology, they are dipping.

Let's practice using the Rule of V's to determine the dip direction of these strata. To make this easier, turn off the topographic map by unchecking the box.

- Take another look at one of the streams you examined earlier, just to the NW of Raplee Anticline.

- Zoom in, press $r$ to return to plan view, and pick a distinctive stratum (a single layer of rock) to trace. 
- Trace your chosen stratum across this stream. Notice how it makes a "V" shape and the point of the "V" points in the direction of dip.

12. What is the dip direction of these dipping strata? Remember, think of dip direction as the direction water would flow if poured onto the layer of rock.

So far, you have seen that dry, arid climates make excellent areas for virtual field work because there is little vegetation to obscure your view of the geology! You have observed that different rock units may be distinguished even in satellite imagery based on colour differences. You have seen how horizontal strata have contacts that are parallel to topographic contour lines, and how dipping strata have contacts that deflect across contour lines. You have also practiced using the Rule of V's to determine dip direction.

Let's explore a couple more arid regions of the world with spectacular geology: Karkh, Pakistan and Dekhuyeh, Iran.

13. Use the Rule of V's to determine the dip direction of the light beige coloured layers of rock near Karkh, Pakistan.

14. Use the Rule of V's to determine the dip direction of the light beige coloured layers of rock near Dekhuyeh, Iran.

Finally, let's explore one more field area to relate the geology you can see in Google Earth to a geological map. Navigate to "Sheep Canyon Area" and examine this area from an altitude of $\sim 9 \mathrm{~km}$. Notice how you can see the different layers clearly because this area has very little overburden and vegetation to hide the bedrock geology. Turn on the "Sheep Canyon Geological Map" layer. Toggle the layer on and off, or adjust the transparency.

15. How are the rocks of different colours that you could see in the satellite imagery depicted on the geological map?

In Lab 8 you created a fluvial surficial geology map - a map of sediment deposited by a river. That is one type of map used in geology, to show deposits of loose sediment on the Earth's surface. Another type of geological map shows the bedrock, meaning the layers of hard, fully-lithified rocks that are exposed at the Earth's surface. All the layers of rock you have been studying today are examples of bedrock.

Rocks are typically mapped in packages that are often formally named formations or groups. Notice how each formation on the Sheep Canyon geological map has a map code associated with it to link each formation to the legend.

16. Can you see anywhere on this map or in the Google Earth satellite imagery where you could use the Rule of V's to determine dip direction? For which unit could you do this? State the complete formation name, the map code, and the dip direction.

Now that you have a sense of how to visualize layers of rocks in three-dimensions, and what the different colours on a geological map represent, we are going to focus in on how to read geological maps. Close 
Google Earth Pro, and open the digital PDF copy Sheep Canyon Geological Map to answer the following questions.

17. What is the full title of this map?

18. Who is the author of this map?

19. What is the scale of this map?

20. What is the distance in kilometers measured along Highway 14-16-20 from the intersection with Highway 310 to the intersection with the pipeline?

21. What information is provided for each mapped unit in the legend of a geological map?

22. In what order are the formations listed in the legend?

23. What is the map code, name, age, and lithology of the oldest unit on this map?

24. In what general area of the map would you find this unit exposed at the surface?

25. What is the map code, name, age, and lithology of the youngest formation on this map?

26. In what general area of the map would you find this formation exposed at the surface?

27. What are the full names of the two formations deposited during the Pennsylvanian? Which of the two is oldest? 
28. If you were going to start a drywall manufacturing business, which formation(s) would you be most interested in exploring?

\section{Media Attributions}

- 1101 Lab 9.kmz file by Siobhan McGoldrick. Derivative of Kmz file of placemarks for other structural mapping examples by Barbara Tewksbury, Locations in Google Earth for teaching geologic mapping and map interpretation, used under CC-BY-NC-SA 3.0.

- Mexican Hat Topographic Map (C) USGS. Public domain.

- Sheep Canyon Geological Map by Robert E. Ladd C Wyoming State Geological Survey. All rights reserved. Used with permission. 


\section{Summary}

The topics covered in this chapter can be summarized as follows:

\begin{tabular}{|c|c|}
\hline Section & Summary \\
\hline $\begin{array}{l}9.1 \\
\text { Introduction } \\
\text { to } \\
\text { Structural } \\
\text { Geology }\end{array}$ & $\begin{array}{l}\text { Visualizing layers of rocks as 3D forms is a fundamental skill for any geologist. Layers of rocks often } \\
\text { form as planes, and the attitude of any plane can be described by specifying its dip and dip direction. } \\
\text { Dip is the angle between } 0^{\circ} \text { (horizontal) and } 90^{\circ} \text { (vertical) measured from horizontal to the inclined } \\
\text { plane. Dip direction refers to the direction of maximum dip, or the direction towards which water } \\
\text { would flow if it was poured onto the dipping plane. In this course, we will use cardinal (e.g., W for } \\
\text { west) and ordinal directions (e.g., SE for southeast) to describe dip direction. }\end{array}$ \\
\hline $\begin{array}{l}9.2 \\
\text { Geological } \\
\text { Maps }\end{array}$ & $\begin{array}{l}\text { Geological maps share many common cartographic elements with topographic maps. The legend on a } \\
\text { geological map displays information about each unit, including map code, full unit name (e.g., } \\
\text { formation name), age, and a brief description of lithology. Legends are formatted such that the oldest } \\
\text { rocks are listed at the bottom, and the youngest rocks at the top. Map patterns of units on a geological } \\
\text { map reflect the intersection of geology (i.e., the attitude of the strata) and topography. }\end{array}$ \\
\hline $\begin{array}{l}9.3 \\
\text { Estimating } \\
\text { Dip } \\
\text { Direction } \\
\text { from a } \\
\text { Geological } \\
\text { Map }\end{array}$ & $\begin{array}{l}\text { Determining the dip direction in a block model, where the top surface is perfectly flat, is } \\
\text { straightforward. In real life, topography influences the map pattern of a unit. Some clues in map view } \\
\text { can help estimate the dip and dip direction of strata: horizontal strata have contacts that are parallel } \\
\text { to topographic contour lines, and vertical strata have contacts that appear to cut across contour lines } \\
\text { at a high angle. For dipping units, the Rule of V's provides a quick, visual method of estimating the dip } \\
\text { direction by examining how a dipping contact is deflected across a stream or valley in map view. }\end{array}$ \\
\hline $\begin{array}{l}\text { Lab } 9 \\
\text { Exercises }\end{array}$ & $\begin{array}{l}\text { Satellite imagery of areas with arid climates is often clear enough to distinguish different layers of } \\
\text { bedrock where they are exposed at the Earth's surface. In the same way that we can group together } \\
\text { and map layers of rocks seen in satellite imagery based on common visible features (i.e., colour), } \\
\text { geologists group together mappable units of rock to create a geological map. In arid areas where } \\
\text { exposure of the bedrock is extensive, and visible differences between units are distinct, map patterns } \\
\text { and dip direction can be determined using satellite imagery and the Rule of V's. }\end{array}$ \\
\hline
\end{tabular}




\section{TAKE-HOME MAPPING ASSIGNMENT}

Complete Lab 9 before you attempt this assignment.

Learning Objectives

After completing this take-home activity, you should be able to:

- Draw a geological map from satellite imagery, including all required cartographic elements and symbols to indicate dip direction.

\section{Geological Map of Sheep Mountain}

As a take-home assignment, create a hand-drawn geological map of the northern part of Sheep Mountain in Wyoming. This map area has been outlined in the $1101 \mathrm{Lab} 9 . \mathrm{kmz}$ file for you to examine in Google Earth Pro, and is located on the homelands of Arapaho, Arikara, Bannock, Blackfoot, Cheyenne, Crow, Gros Ventre, Kiowa, Nez Perce, Sheep Eater, Sioux, Shoshone and Ute tribes. Sheep Mountain was selected for this activity because of the clear colour contrasts in the rocks, and because this area has very little vegetation to obscure your view of the rocks. Both of these features make it possible for you to actually map the bedrock geology based solely on satellite imagery.

The purpose of your geological map is to show your reader where different geologic units are exposed at the surface of the Earth. These units will be defined by you based on differences you observe in the satellite imagery.

\section{Instructions for creating your geological map}

1. Examine the area you will be mapping (Sheep Mountain Map Area).

2. In Google Earth Pro you can navigate to this area, saved as a polygon called "Sheep Mountain Map Area" in the $1101 \mathrm{Lab} 9 . \mathrm{kmz}$ file. Spend some time examining the features of this area using the 3D capabilities of Google Earth Pro.

3. Attach a piece of tracing paper to your printed satellite imagery with a paper clip or piece of clear tape. Be gentle; tracing paper tears easily! Be very careful when erasing!

4. Set up your map area. Make sure that you have enough space on your tracing paper set aside for your legend and other cartographic elements (review the checklist below). You may also format your legend on a separate piece of paper.

5. As you examine the base image and explore the map area in 3D using Google Earth Pro, decide how many different units you wish to include on your map. Remember, any geological map requires some degree of "lumping" (grouping together layers of rocks with something in common) or "splitting" (separating layers of rock into distinct units to be mapped separately). Your map must have at least four, distinct units. Think 
about how you would briefly describe each of your units in the legend of your map. In this case because you are working only from an image and cannot reliably identify lithology, your description will likely focus on the colour of the rocks.

6. With a pencil, lightly and neatly draw in the contacts that you see between different units in the satellite imagery. The contacts (lines) that you draw around a particular area will delineate a polygon that contains a rock unit. Once you are confident with the contacts you have drawn, trace over them in black pen.

7. Colour in and write a map code inside each polygon. Keep track of the colours and map codes that you use on a spare sheet of paper to help format your legend once you have finished your map.

8. Review the checklist below and ensure that your finished map contains all the required information.

9. Scan OR take a clear photograph of your finished map to submit. It is your responsibility to ensure that your submission is legible. If your instructor cannot read your work, they cannot mark it!

10. Submit your finished map on Blackboard.

\begin{tabular}{|l|l|l|}
\hline Geological Features & $\begin{array}{l}\text { Geographic } \\
\text { Features }\end{array}$ & Cartographic Elements \\
\hline $\begin{array}{l}\text { At least four distinct } \\
\text { units mapped and } \\
\text { neatly coloured }\end{array}$ & $\begin{array}{l}\text { Rivers or } \\
\text { streams }\end{array}$ & $\begin{array}{l}\text { Legend (includes the colour, map code, and a brief description of each of } \\
\text { your units. Remember that the legend on a geological map always list the } \\
\text { oldest unit at the bottom and the youngest unit on top! How can you } \\
\text { determine which of your units is the oldest?) }\end{array}$ \\
\hline $\begin{array}{l}\text { Contacts between units } \\
\text { drawn in black pen }\end{array}$ & Roads (if any) & North arrow \\
\hline $\begin{array}{l}\text { Black arrows to indicate } \\
\text { dip direction on the NE } \\
\text { and SW sides of the } \\
\text { mountain }\end{array}$ & & Scale bar \\
\hline & & Scale as representative fraction \\
\hline & Title \\
\hline & Reference point in UTM coordinates \\
\hline & Date of satellite imagery and source of satellite imagery \\
\hline & Author's name (your name) \\
\hline
\end{tabular}

\section{Media Attributions}

- 1101 Lab 9.kmz file (C) Siobhan McGoldrick. CC-BY-NC-SA 4.0. Derivative of Kmz file of placemarks for other structural mapping examples (C) Barbara Tewksbury, Locations in Google Earth for teaching geologic mapping and map interpretation, used under CC-BY-NC-SA 3.0.

- Sheep Mountain Map Area satellite image used under the following Google Maps and Google Earth guidelines. 


\section{LAB Io: STRUCTURAL GEOLOGY PART II}

\section{Lab Structure}

\begin{tabular}{ll}
\hline Recommended additional work & Yes - review for final lab project \\
Required materials & $\begin{array}{l}\text { Printed block models 1 to 6, pencil, pencil crayons, ruler, } \\
\text { protractor }\end{array}$ \\
\hline
\end{tabular}

Learning Objectives

After carefully reading this chapter, completing the exercises within it, and answering the questions at the end, you should be able to:

- $\quad$ Describe the types of stresses that exist within the Earth's crust.

- Explain how rocks respond to those stresses by brittle, elastic, or plastic deformation, or by fracturing.

- Summarize how rocks become folded and know the terms used to describe the features of folds.

- $\quad$ Summarize the different types of faults, including normal, reverse, thrust, and strike-slip.

- Visualize layers of rocks that form complex geologic structures in three-dimensional space.

- $\quad$ Recognize and describe geologic structures in block models and on geological maps.

- $\quad$ Describe the geologic history of a structurally complex area.

Key Terms

- Stress

- Strain

- Compression

- Tension

- Shear

- Ductile

- Brittle
- Deformation

- Anticline

- Syncline

- Limbs

- Axial plane

- Hinge zone

- Fracture
- Hanging wall

- Footwall

- Normal fault

- Reverse fault

- Strike-slip fault

- Left-lateral

- Right-lateral

Observing and understanding geological structures helps us to determine the kinds of stresses that have existed within Earth's crust in the past. This type of information is critical to our understanding of plate tectonics, earthquakes, the formation of mountains, metamorphism, and Earth resources. Some of the types of geological structures that are important to study include bedding planes, planes of foliation, dykes and sills, fractures, faults, and folds. Structural geologists make careful observations of the orientations of these structures and the amount and direction of offset along faults. Locating and mapping these structural features is important for safe engineering of infrastructure such as roads and housing. A good understanding of geological structures in the subsurface is also critical for mineral and petroleum exploration. 


\section{IO.I Stress and Strain}

Rocks are subject to stress-mostly related to plate tectonics but also to the weight of overlying rocks-and their response to that stress is strain (deformation). In regions close to where plates are converging stress is typically compressional-the rocks are being squeezed. Where plates are diverging the stress is tensional-rocks are being pulled apart. At transform plate boundaries, where plates are moving side by side there is sideways or shear stress-meaning that there are forces in opposite directions parallel to a plane. Rocks have highly varying strain responses to stress because of their different compositions and physical properties, and because temperature is a big factor and rock temperatures within the crust can vary greatly.

We can describe the stress applied to a rock by breaking it down into three dimensions-all at right angles to one-another (Figure 10.1.1). If the rock is subject only to the pressure of burial, the stresses in all three directions will likely be the same. If it is subject to both burial and tectonic forces, the pressures will be different in different directions.
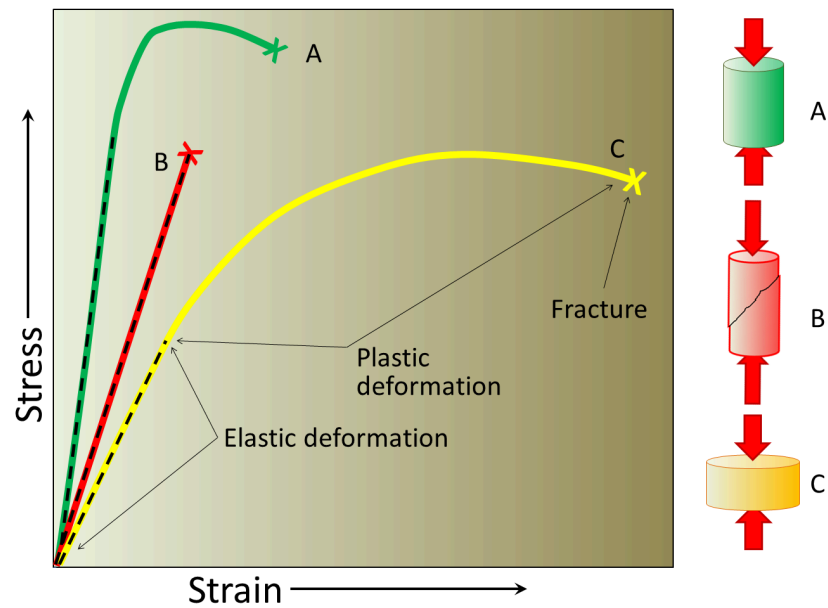

Figure 10.1.2: The varying types of response of geological materials to stress. The straight dashed parts are elastic strain and the curved parts are plastic strain. In each case the $\mathrm{X}$ marks where the material fractures. A, the strongest material, deforms relatively little and breaks at a high stress level. B, strong but brittle, shows no plastic deformation and breaks after relatively little elastic deformation. $\mathrm{C}$, the most deformable, breaks only after significant elastic and plastic strain. The three deformation diagrams on the right show A and $\mathrm{C}$ before breaking and $\mathrm{B}$ after breaking.
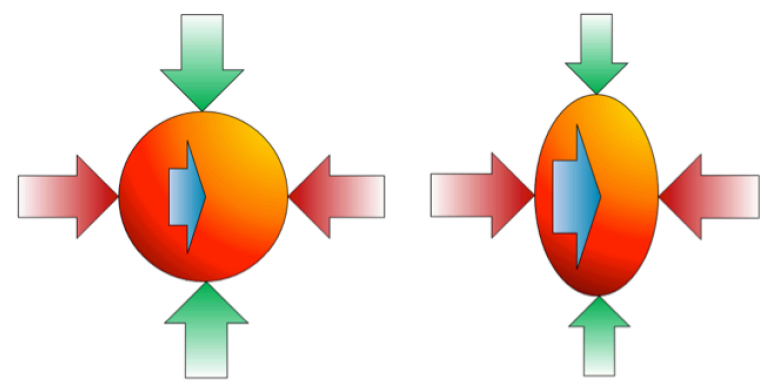

Figure 10.1.1: Depiction of the stress applied to rocks within the crust. The stress can be broken down into three components. Assuming that we're looking down in this case, the green arrows represent north-south stress, the red arrows represent east-west stress, and the blue arrows (the one underneath is not visible) represent up-down stress. On the left, all of the stress components are the same. On the right, the north-south stress is least and the up-down stress is greatest. Rock can respond to stress in three ways: it can deform elastically, it can deform plastically, and it can break or fracture. Elastic strain is reversible; if the stress is removed, the rock will return to its original shape just like a rubber band that is stretched and released. Plastic strain is not reversible. As already noted, different rocks at different temperatures will behave in different ways to stress. Higher temperatures lead to more plastic behaviour. Some rocks or sediments are also more plastic when they are wet. Another factor is the rate at which the stress is applied. If the stress is applied quickly (for example, because of an extraterrestrial impact or an earthquake), there will be an increased tendency for the rock to fracture. Some different types of strain response are illustrated in Figure 10.1.2.

The outcomes of placing rock under stress are highly variable, but they include fracturing, tilting and folding, stretching and squeezing, and faulting. A fracture is a simple break that does not involve significant movement of the rock on either side. Fracturing is particularly common in volcanic rock, which shrinks as it cools. The basalt columns in Figure 10.1.3a are a good example of fracture. Beds are sometimes tilted by tectonic forces, as shown in Figure 10.1.3b, or folded. 


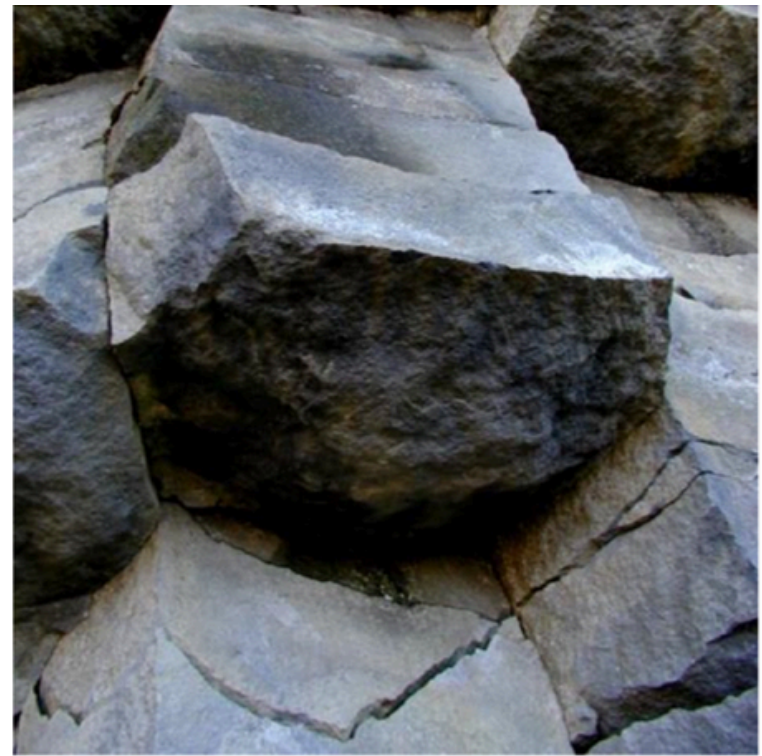

a) Fracturing in basalt near to Whistler $\mathrm{BC}$

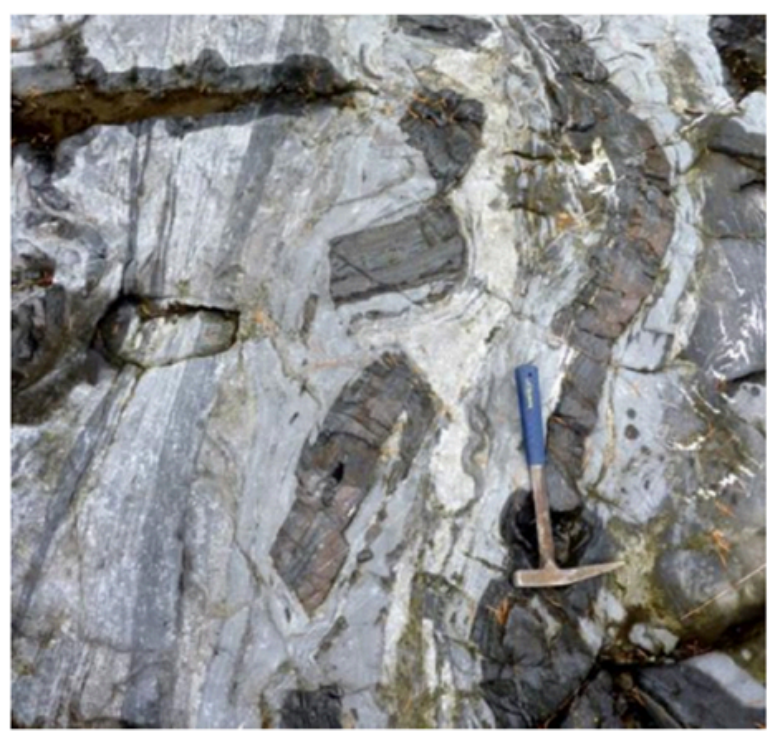

a) Stretching of limestone at Quadra Island, BC. The light grey rock is limestone and the dark rock is chert. The body of rock has been stretched parallel to bedding. The chert, which is not elastic, has broken into fragments which are called boudins.

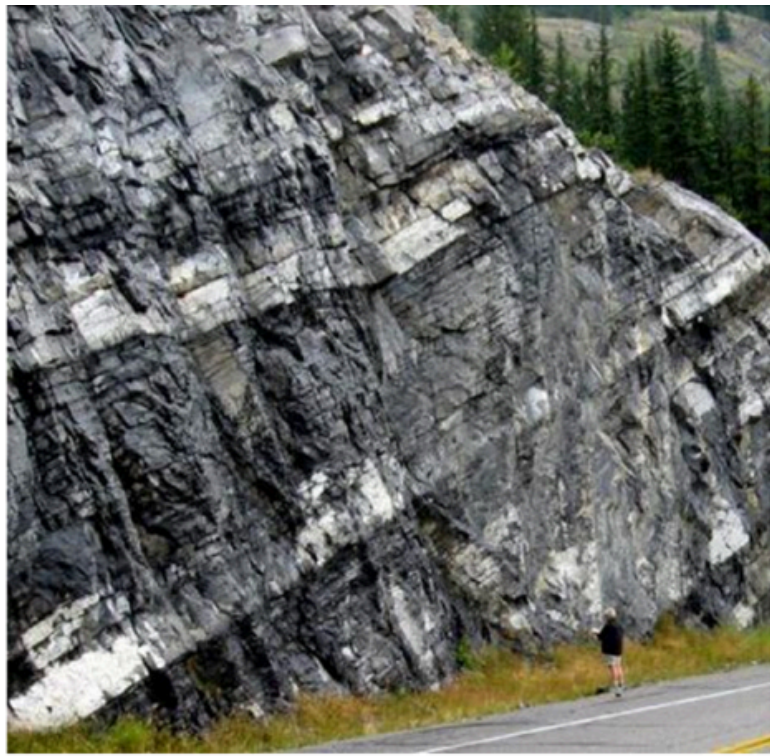

b) Tilting of sedimentary rock near to Exshaw, $\mathrm{AB}$

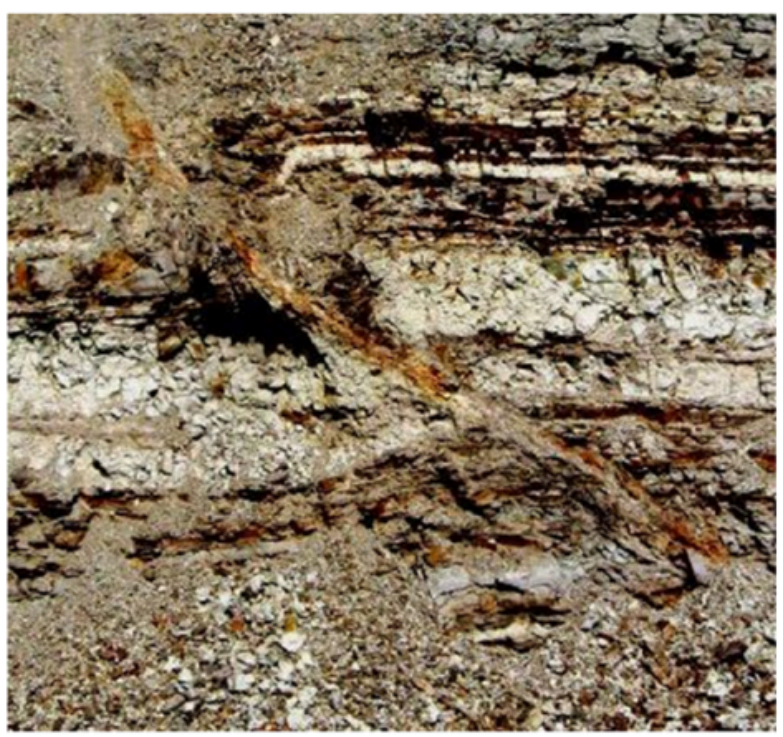

d) Faulting within shale beds at McAbee, near to Cache Creek, BC. The fault runs from the lower right to the upper left, and the upper rock body has been pushed up and to the left.

Figure 10.1.3: Rock structures caused by various types of strain within rocks that have been stressed.

When a body of rock is compressed in one direction it is typically extended (or stretched) in another. This is an important concept because some geological structures only form under compressional stress, while others only form under tensional stress. Most of the rock in Figure 10.1.3c is limestone, which is relatively weak and easily deformed when heated. The dark rock is chert, which is relatively stronger and remains brittle. As the limestone stretched (parallel to the hammer handle) the brittle chert was forced to break into fragments to accommodate the change in shape of the body of rock. Figure 10.1.3d shows another type of brittle structure called a fault. Like fractures, faults result from brittle breaking of a rock unit. The key difference is that the bodies of rock on either side of the fault have been displaced relative to each other by the faulting. 


\section{Media Attributions}

- Figures 10.1.1, 10.1.2, 10.1.3: (C) Steven Earle. CC BY. 


\section{IO.2 Folding}

When a body of rock, especially sedimentary rock, is squeezed from the sides by tectonic forces, it is likely to fracture and/or become faulted if it is cold and brittle, or become folded if it is warm enough to behave in a ductile manner.

The nomenclature and geometry of folds are summarized in Figure 10.2.1. An upward fold is called an anticline (or, more accurately, an antiform if we don't know if the beds have been overturned or not), while a downward fold is called a syncline, (or a synform if we don't if the beds have been overturned). In many areas it's common to find a series of antiforms and synforms (as in Figure 10.2.1), although some sequences of rocks are folded into a single antiform or synform. A plane drawn through the crest of a fold in a series of beds is called the axial plane of the fold. The sloping beds on either side of an axial plane are called the limbs of the fold. An antiform or synform is described as symmetrical if the angles between each of limb and the axial plane are generally similar, and asymmetrical if they are not. If the axial plane is sufficiently tilted that the beds on one side have been tilted past vertical, the fold is known as an overturned antiform or synform.

If the limbs dip away from one another, they form an antiform. If the limbs dip toward one another, they form a synform.

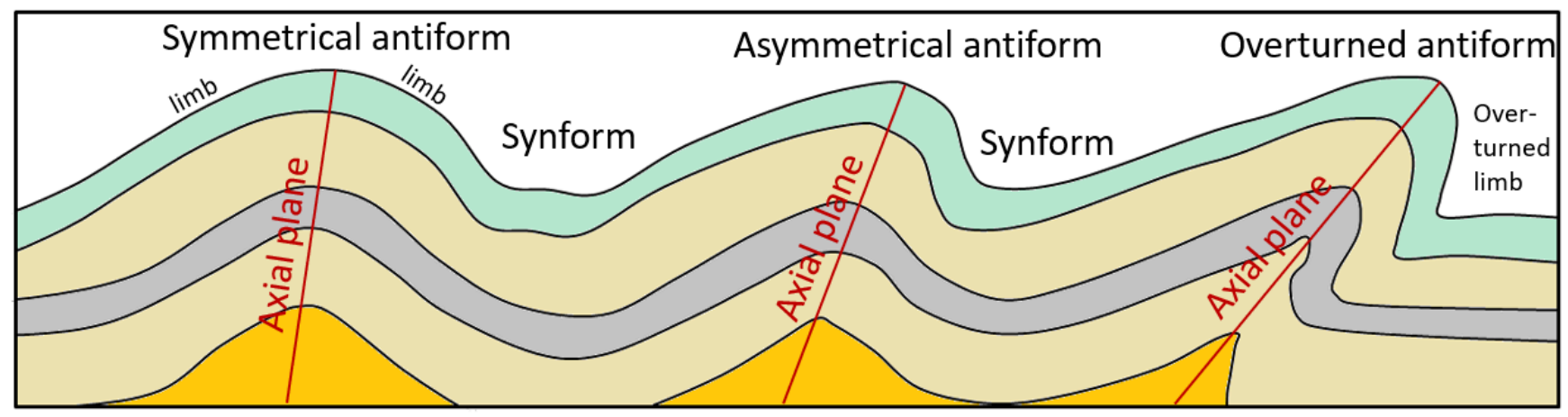

Figure 10.2.1: Examples of different types of folds and fold nomenclature. Axial planes are only shown for the anticlines, but synclines also have axial planes.

A very tight fold, in which the limbs are parallel or nearly parallel to one another is called an isoclinal fold (Figure 10.2.2). Isoclinal folds that have been overturned to the extent that their limbs are nearly horizontal are called recumbent folds.

Folds can be of any size, and it's very common to have smaller folds within larger folds (Figure 10.2.3). Large folds can have wavelengths of tens of kilometres, and very small ones might be visible only under a microscope.

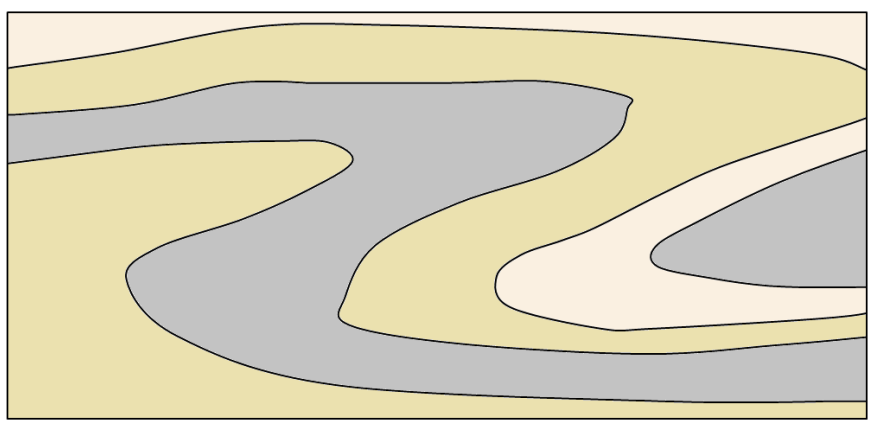

Figure 10.2.2: An isoclinal recumbent fold. 


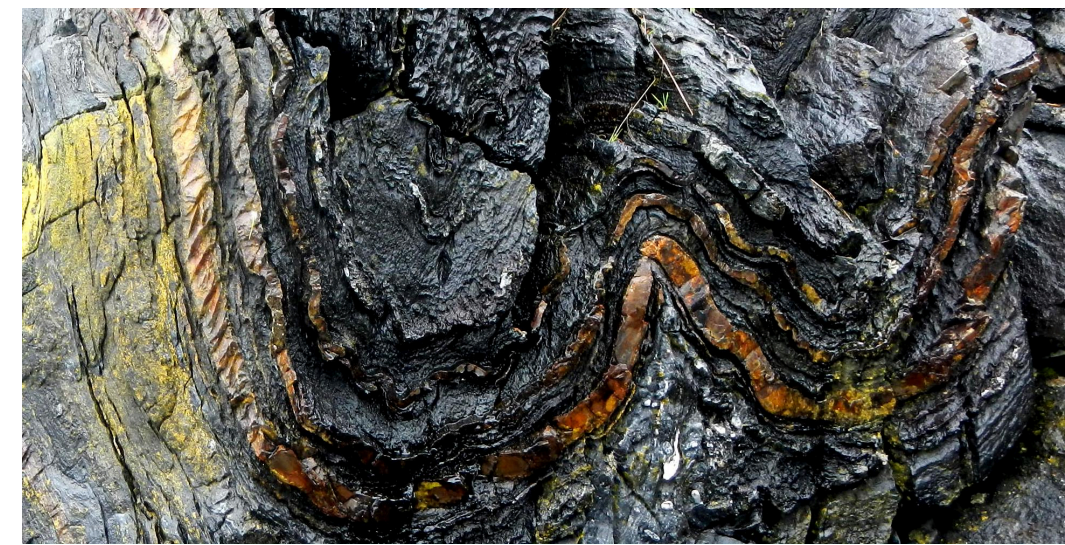

Figure 10.2.3: Folded limestone (grey) and chert (rust-coloured) in Triassic Quatsino Formation rocks on Quadra Island, B.C. The image is about 1 metre across.

Antiforms are not necessarily, or even typically, expressed as ridges in the terrain, nor synforms as valleys. Folded rocks get eroded just like all other rocks and the topography that results is typically controlled mostly by the resistance of different layers to erosion (Figure 10.2.4).

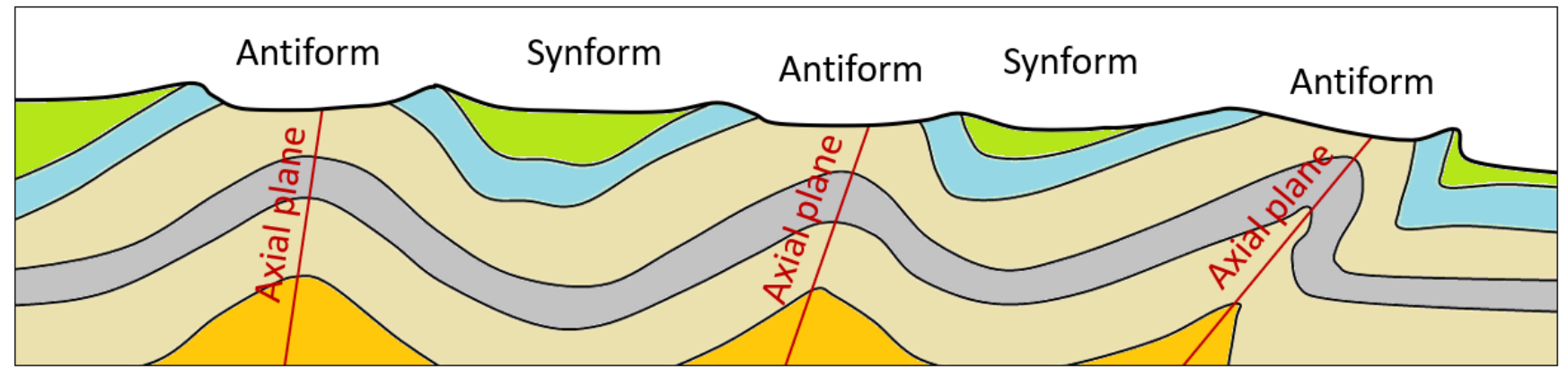

Figure 10.2.4: Example of the topography in an area of folded rocks that has been eroded. In this case the blue and green rocks are most resistant to erosion, and are represented by hills. The pale cream-coloured rocks are the least resistant to erosion, and are represented by valleys. 
As folded rocks are eroded away, anticlines and synclines can be recognized not only by the dip directions of their limbs, but also by examining their map patterns in plan view (Figure 10.2.5). Eroded anticlines expose older rocks near the surface trace of the axial plane, and the rocks get progressively younger as you move away from the axial plane in either direction. Eroded synclines have the youngest rocks exposed near the surface trace of the axial plane, and the rocks get progressively older as you move away from the axial plane in either direction. Examine Figure 10.2.5 to confirm this: the youngest rock in the diagram (labeled ' 6 ') is exposed in the centre of the syncline, whereas the oldest rock visible in plan view is exposed in the centre of the anticline (labeled as ' 4 ').

Practice Exercise 10.1 Folding style

Figure 10.2.6 shows folding near near Golden, B.C. in the Rocky Mountains. Describe the types of folds using the appropriate terms from above (symmetrical, asymmetrical, isoclinal, overturned, recumbent etc.). You might find it useful to first sketch the outcrop by tracing one or two beds to get a better idea of the shapes of the folds, then sketch in the axial planes.
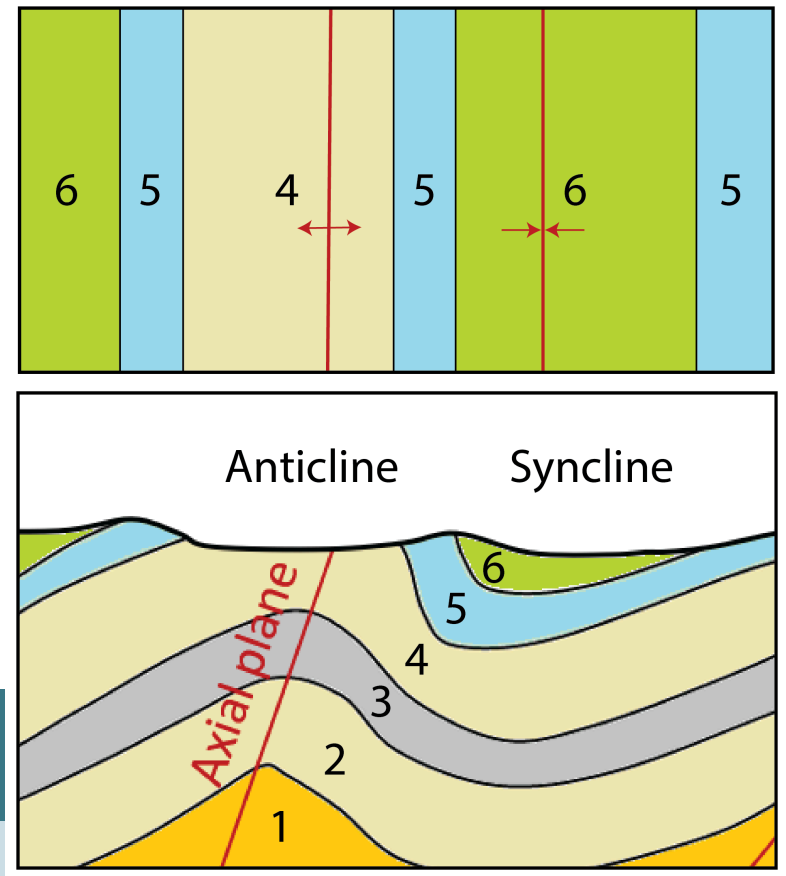

Figure 10.2.5: Plan view (top) and cross-section (bottom) of a portion of Figure 10.2.4. Numbers 1 to 6 refer to the relative ages of the layers, where 1 is the oldest and 6 is the youngest. The surface traces of the axial planes are shown for both the anticline and the syncline (red lines with arrows).

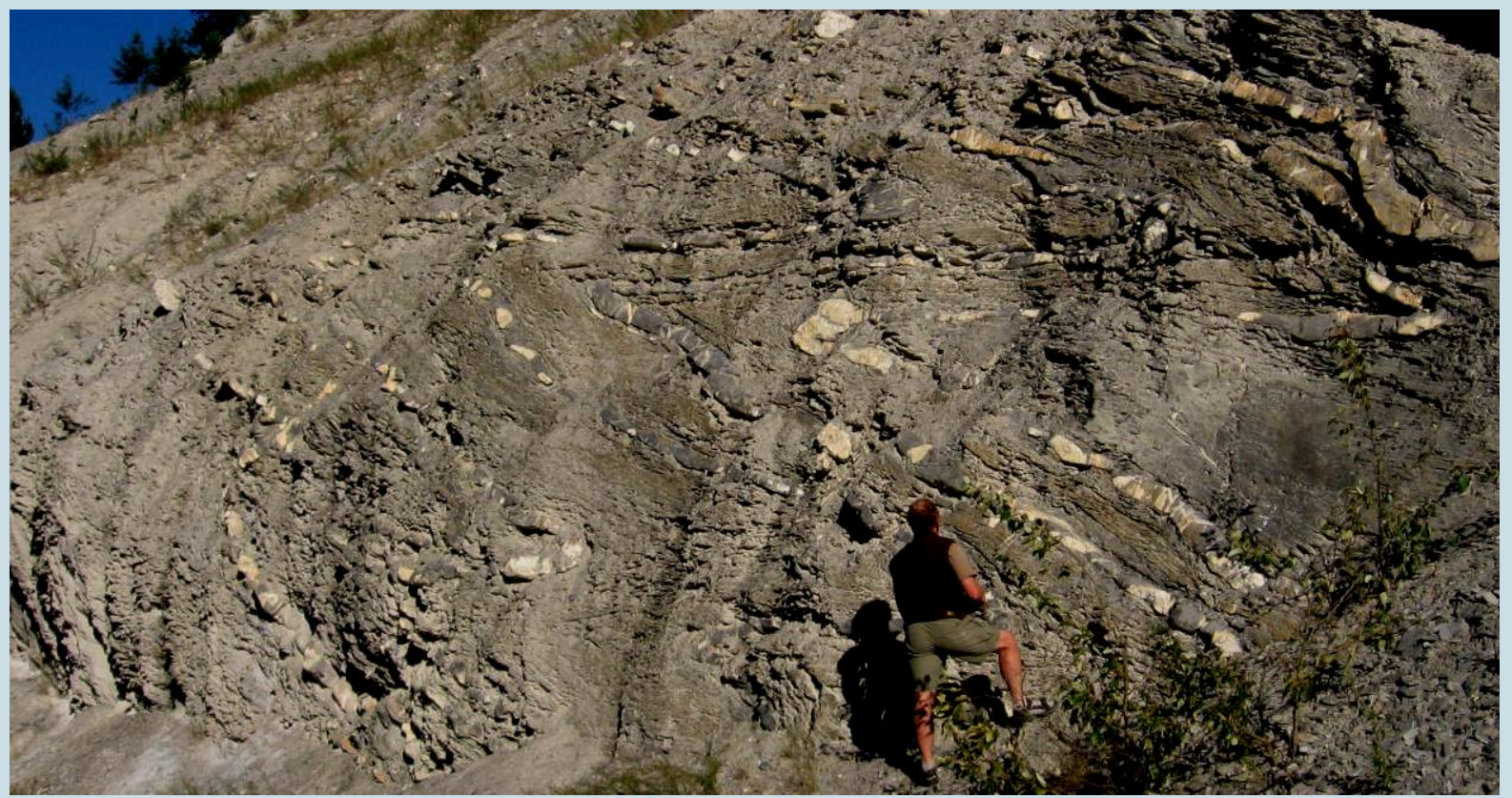

Figure 10.2.6

See Appendix 2 for Practice Exercise 10.1 answers. 


\section{Media Attributions}

- Figures 10.2.1, 10.2.2, 10.2.3, 10.2.4, 10.2.6: (C) Steven Earle. CC BY.

- Figure 10.2.5: (C) Siobhan McGoldrick. Derivative of Figure 10.2.4 by Steven Earle. CC BY. 


\section{I0.3 Faulting}

A body of rock that is brittle-either because it is cold or because of its composition, or both- is likely to break rather than fold when subjected to stress, and the result is fracturing or faulting.

\section{Fracturing}

Fracturing is common in rocks near the surface, either in volcanic rocks that have shrunk on cooling (Figure 10.1.3a), or in other rocks that have been exposed by erosion and have expanded (Figure 10.3.1). Fractures, by definition, do not displace rock. There is no movement on a fracture plane.
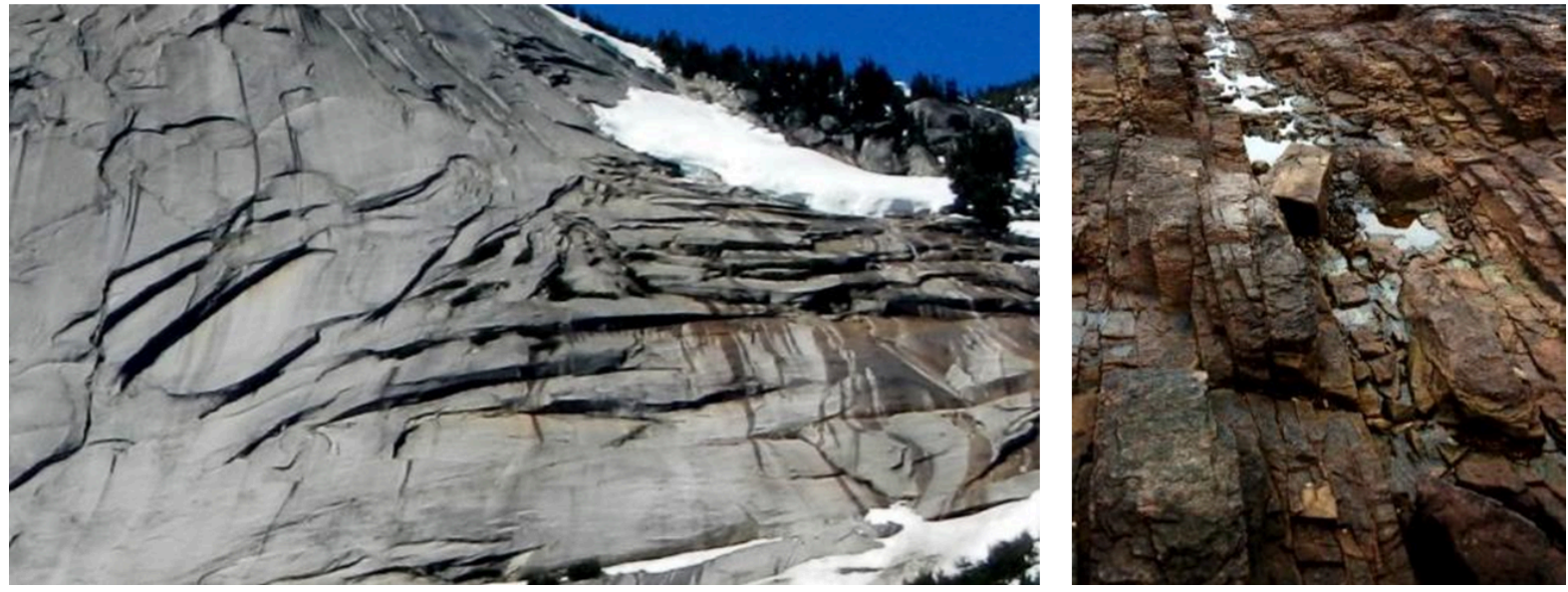

Figure 10.3.1: Granite in the Coquihalla Creek area, B.C. (left) and sandstone at Nanoose, B.C. (right), both showing fracturing that has resulted from expansion due to removal of overlying rock.

\section{Faulting}

A fault is a boundary between two bodies of rock along which there has been relative motion (Figure 10.1.3d). You may recall from lecture that an earthquake involves the sliding of one body of rock past another. Earthquakes don't necessarily happen on existing faults, but once an earthquake takes place a fault will exist in the rock at that location. Some large faults, like the San Andreas Fault in California or the Tintina Fault, which extends from northern B.C. through central Yukon and into Alaska, show evidence of hundreds of kilometres of motion, while others show less than a millimetre. In order to estimate the amount of motion on a fault, we need to find some geological feature that shows up on both sides and has been offset (Figure 10.3.2). 


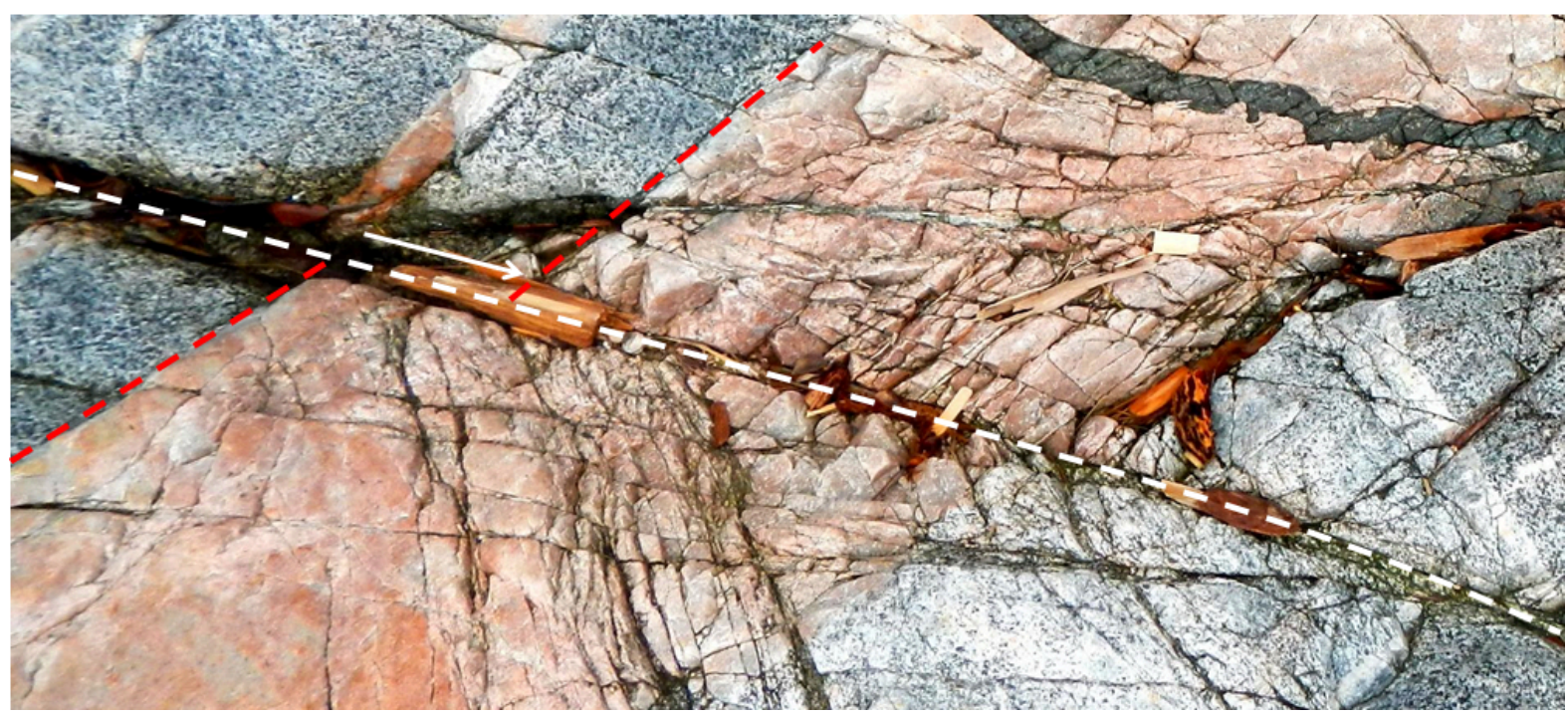

Figure 10.3.2: A fault (white dashed line) in intrusive rocks on Quadra Island, B.C. The pink dyke has been offset by the fault and the extent of the offset is shown by the white arrow (approximately 10 centimetres). Because the far side of the fault has moved to the right, this is a right-lateral fault. If the photo were taken from the other side, the fault would still appear to have a right-lateral offset.

There are several kinds of faults, as illustrated on Figure 10.3.3, and they develop under different stress conditions. The terms hanging wall and footwall in the diagrams apply to situations where the fault is not vertical. The body of rock above the fault is called the hanging wall, and the body of rock below it is called the footwall. If the fault develops in a situation of compression, then it will be a reverse fault because the compression causes the hanging wall to be pushed up relative to the footwall. If the fault develops in a situation of extension, then it will be a normal fault, because the extension allows the hanging wall to slide down relative to the footwall in response to gravity. The map symbols for these types of faults are illustrated in Figure 10.3.4.

The third situation is where the bodies of rock are sliding sideways with respect to each other, as is the case along a transform fault (see Lab 1). This is known as a strike-slip fault because the displacement is along the "strike" or the length of the fault. On strike-slip faults the motion is typically only horizontal, or with a very small vertical component, and as discussed above the sense of motion can be right lateral (the far side moves to the right), as in Figure 10.3.2, or it can be left lateral (the far side moves to the left). Map symbols for these strike-slip faults are illustrated in Figure 10.3.5. Transform faults are strike-slip faults. 


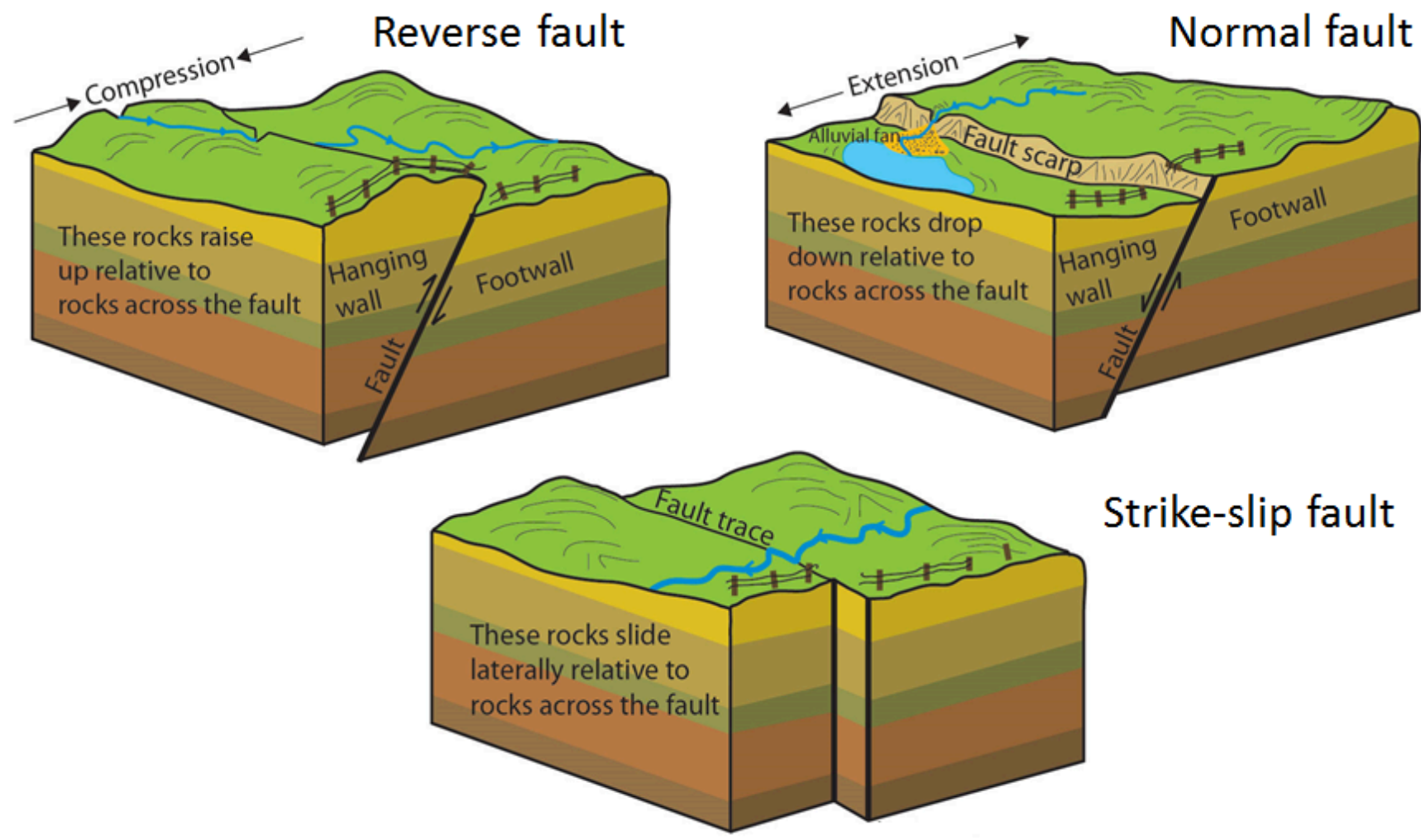

Figure 10.3.3: Depiction of reverse, normal, and strike-slip faults. Reverse faults happen during compression while normal faults happen during extension. Most strike-slip faults are related to transform boundaries. 

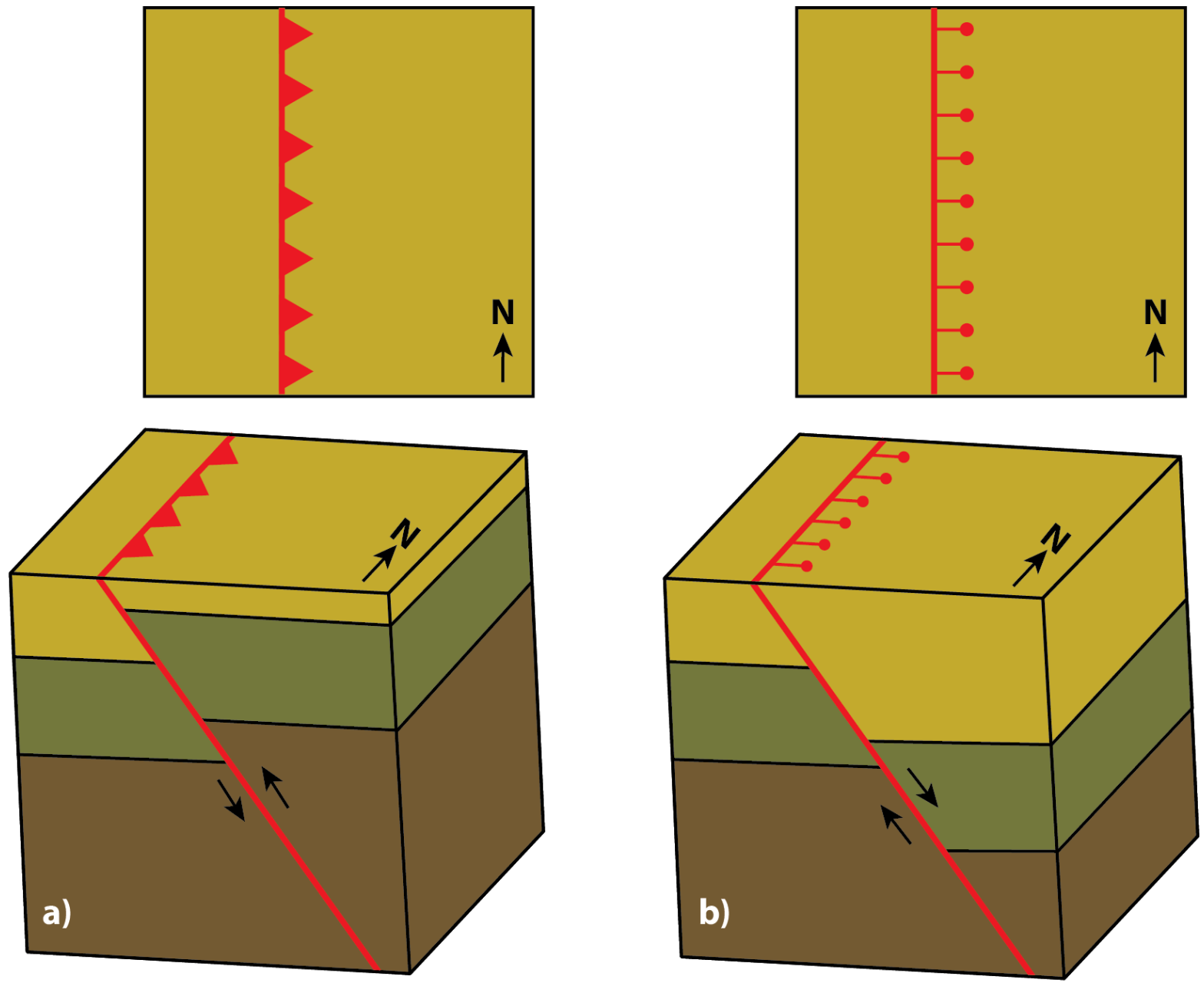

Figure 10.3.4: Block model and corresponding plan view depictions of reverse (a) and normal (b) faulting. Black arrows on the south-facing side of each block indicate the sense of displacement along the fault. Symbols in plan view indicate the type of fault and are always drawn on the hanging wall side. 

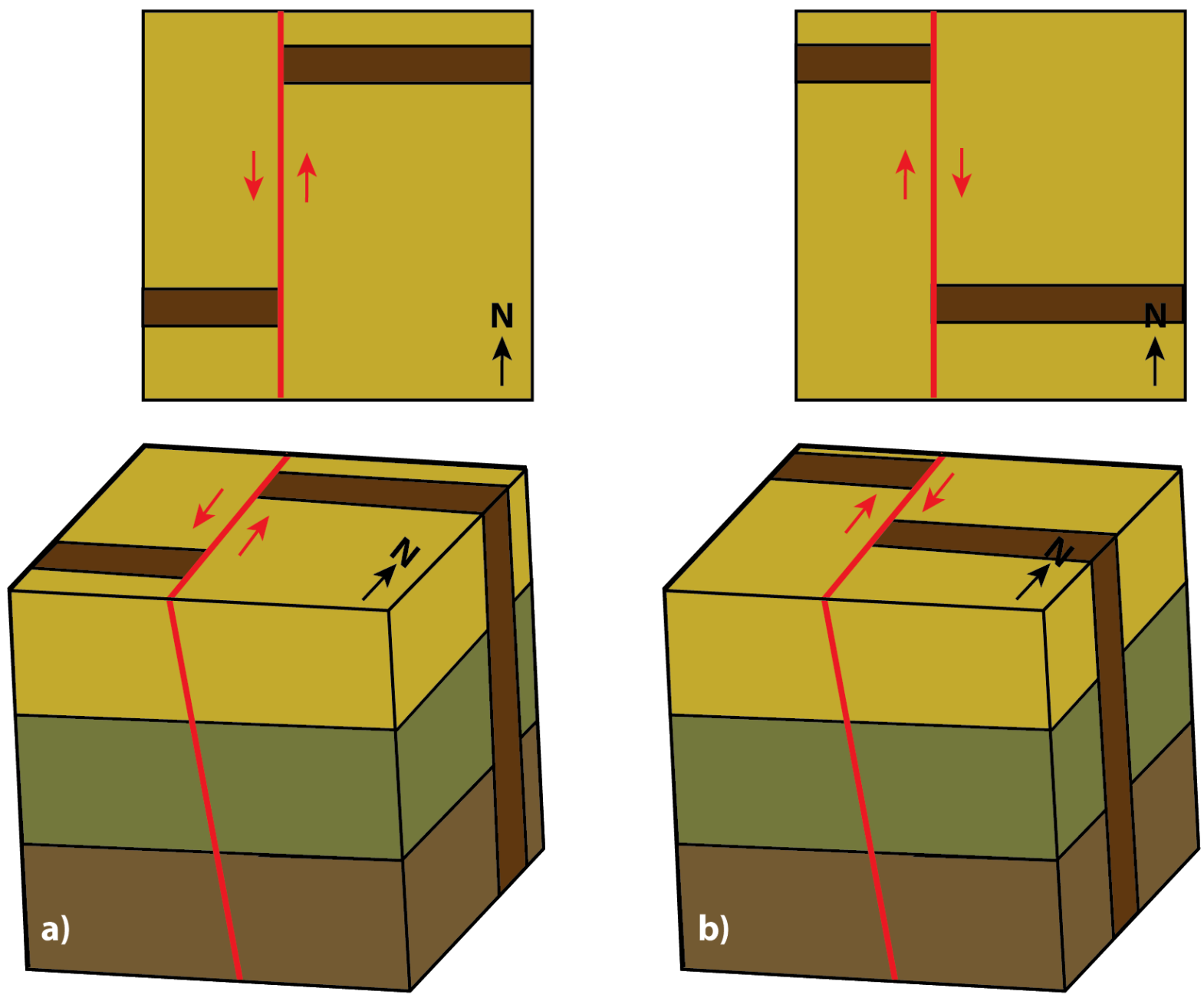

Figure 10.3.5: Block model and plan view depictions of left-lateral (a) and right-lateral (b) strike-slip faulting resulting in the offset of a dyke in plan view. Symbols in plan view indicate the sense of displacement along the fault.

In areas that are characterized by extensional tectonics, it is not uncommon for a part of the upper crust to subside with respect to neighbouring parts. This is typical along areas of continental rifting, such as the Great Rift Valley of East Africa or in parts of Iceland, but it is also seen elsewhere. In such situations a downdropped block is known as a graben(German for ditch), while an adjacent block that doesn't subside is called a horst (German for heap) (Figure 10.3.6). There are many horsts and grabens in the Basin and Range area of the western United States, especially in Nevada.

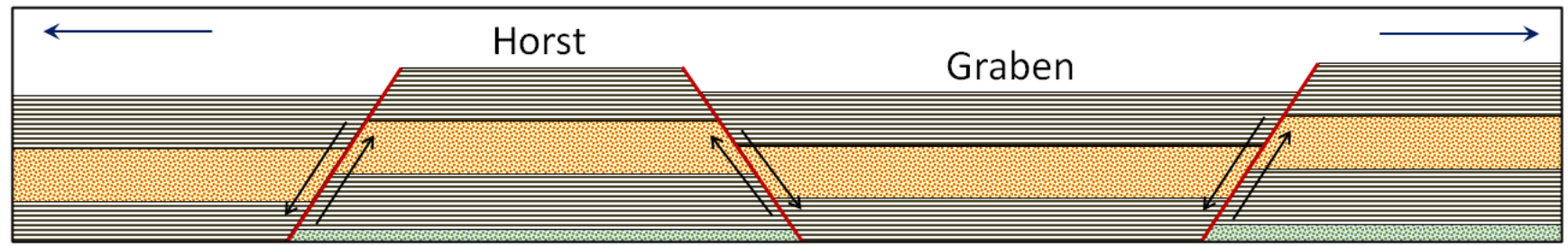

Figure 10.3.6: Depiction of graben and horst structures that form in extensional situations. All of the faults are normal faults. 
A special type of reverse fault, with a very lowangle fault plane, is known as a thrust fault. Thrust faults are relatively common in areas where foldbelt mountains have been created during continent-continent collision. Some represent tens of kilometres of thrusting, where thick sheets of sedimentary rock have been pushed up and over top of other rock (Figure 10.3.7).

There are numerous thrust faults in the Rocky Mountains, and a well-known example is the
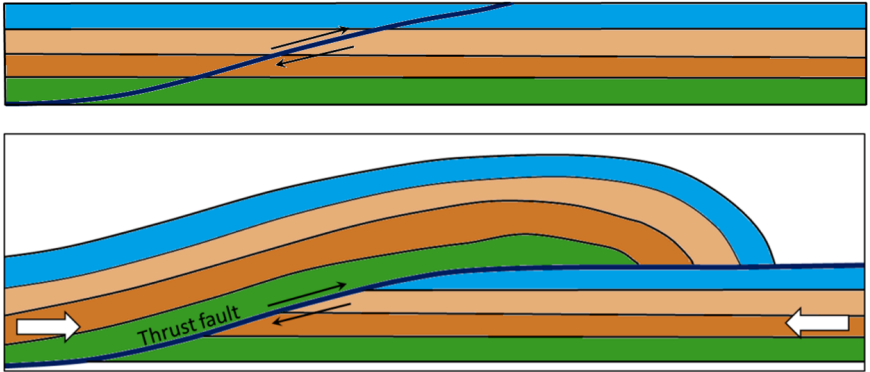

Figure 10.3.7: Depiction a thrust fault. Top: prior to faulting. Bottom: after significant fault offset. McConnell Thrust, along which a sequence of sedimentary rocks about 800 metres thick has been pushed for about 40 kilometres from west to east (Figure 10.3.8). The thrusted rocks range in age from Cambrian to Cretaceous, so in the area around Mt. Yamnuska Cambrian-aged rock (around $500 \mathrm{Ma}$ ) has been thrust over, and now lies on top of Cretaceous-aged rock (around $75 \mathrm{Ma}$ ) (Figure 10.3.9).

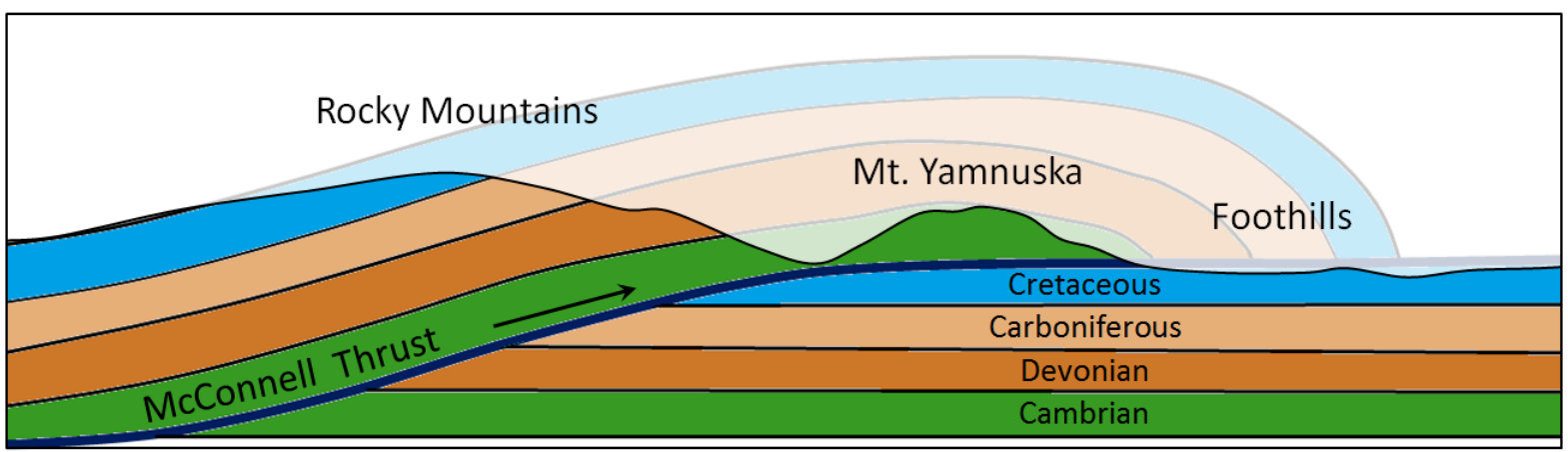

Figure 10.3.8: Depiction of the McConnell Thrust in the eastern part of the Rockies. The rock within the faded area has been eroded

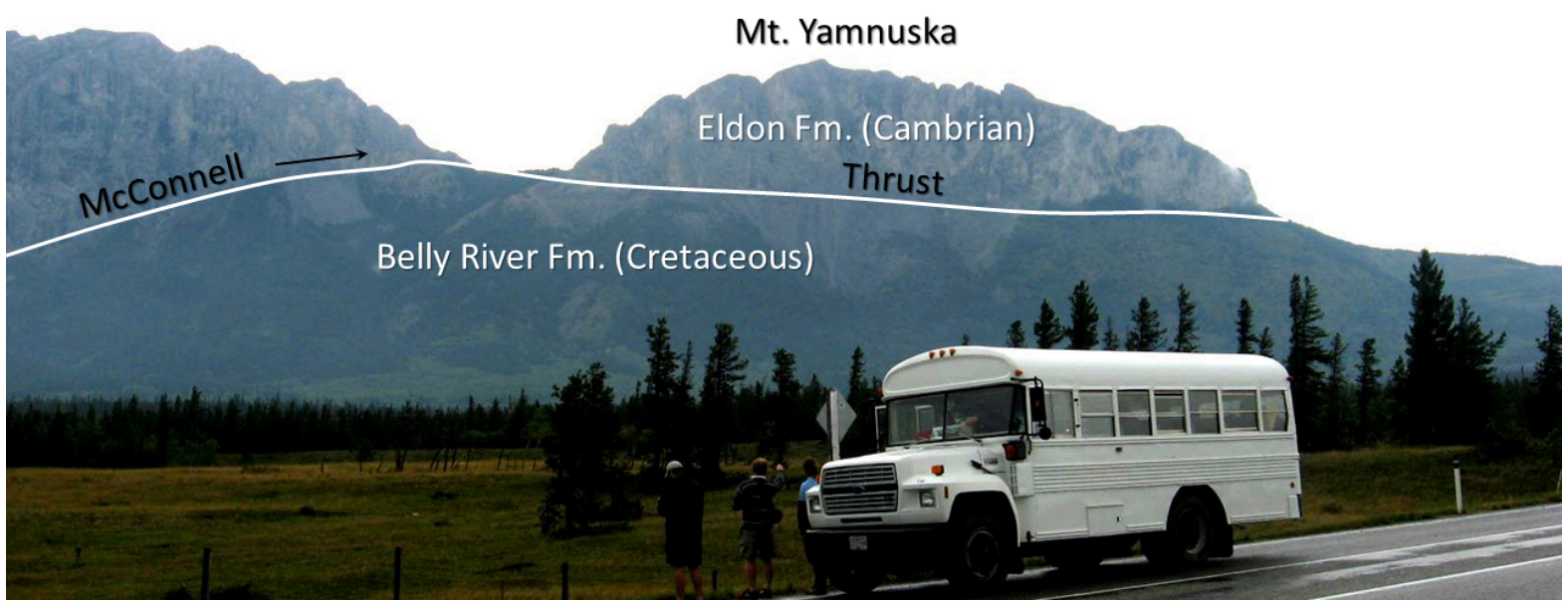

Figure 10.3.9: The McConnell Thrust at Mt. Yamnuska near Exshaw, Alberta. Carbonate rocks (limestone) of Cambrian age have been thrust over top of Cretaceous mudstone. 

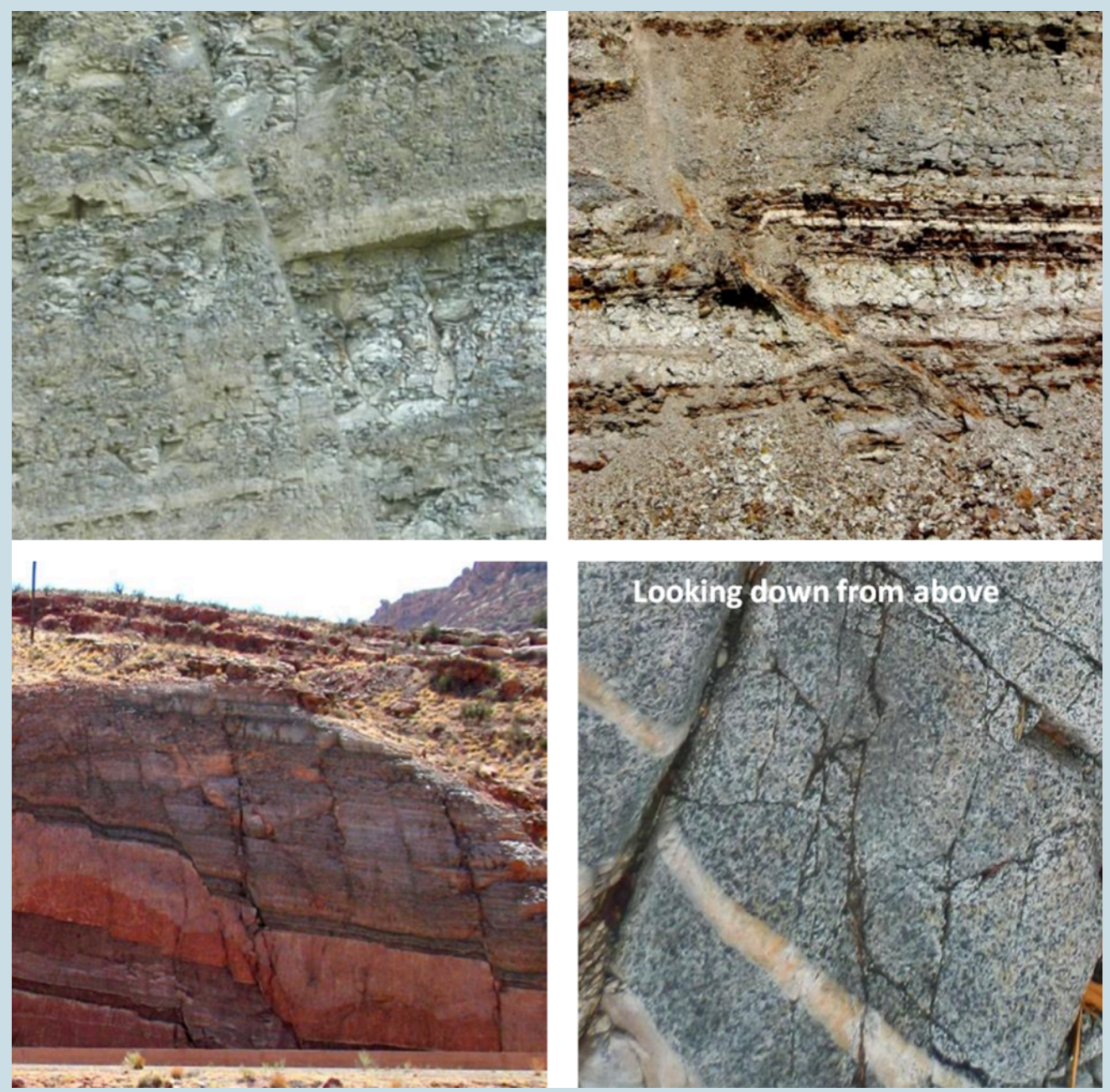

Figure 10.3.10

The four images are faults that formed in different tectonic settings. Identifying the type of fault allows us to determine if the body of rock was under compression or extension at the time of faulting. Complete the table below the images, identifying the types of faults (normal or reversed) and whether each one formed under compressional or tensional stress.

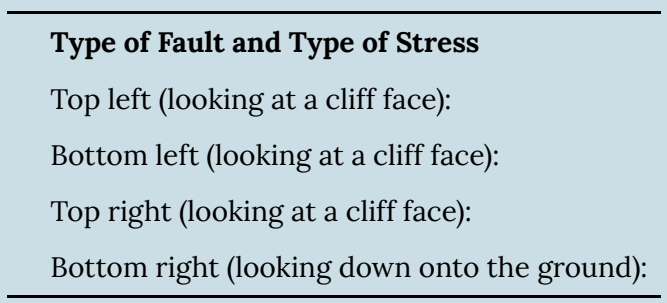

See Appendix 2 for Practice Exercise 10.2 answers. 


\section{Media Attributions}

- Figure 10.3.1, 10.3.2, 10.3.6, 10.3.7, 10.3.8, 10.3.9: (C) Steven Earle. CC BY.

- Figure 10.3.3: "Fault Types" by the National Park Service. Adapted by Steven Earle. Public domain.

- Figure 10.3.4, 10.3.5: (C) Siobhan McGoldrick. CC BY.

- Figure 10.3.10 (all except bottom left): (C) Steven Earle. CC BY.

- Figure 10.3.10 (Bottom left): "Moab fault with vehicles for scale" (C) Andrew Wilson. CC BY-SA. 


\section{Lab io Exercises}

The ability to visualize strata in three-dimensions is a spatial skill that is fundamental to understanding geology in the real world. For some, this skill comes easily. Bur for others, spatial thinking and visualization can be difficult concepts, especially at first. Regardless of which category of student you fall into, while these skills may come more naturally to some, they can be taught and will improve with practice! To practice visualizing in three-dimensions, think about the difference between how an object looks from above (in plan view), and how a slice through that object would look (in cross-section).

Spatial thinking and cross-sections

Imagine an apple. How would the apple look in plan view?

Now imagine slicing the apple in half, along a straight line. If you pull the two halves apart to examine the internal structure of the apple, you are looking at a cross-section. The photographs below show how the apple looks in plan view (left), and in cross-section (right). The dashed white line is the line of cross-section, from $\mathrm{X}$ to $\mathrm{Y}$.

For more practice, imagine and sketch what the crosssection of the following objects would be:

- an orange

- a lemon cut in half from end to end

- a round loaf of sourdough bread, cut into slices

Figure A

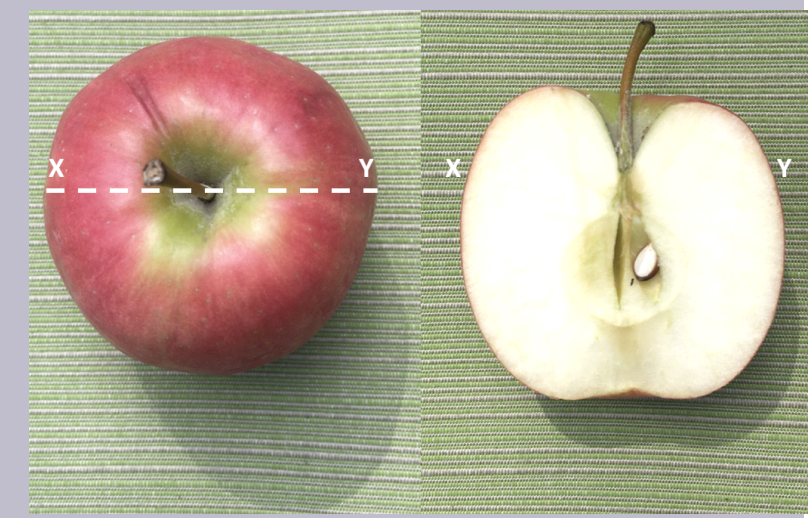

- $\quad$ a pyramid with a square base, cut along a diagonal line from corner to corner

Today you will use printed copies of the block models in Appendix 5 to explore geologic structures. Recall that the top surface of a block model represents the plan view of the Earth's surface, and the four sides represent four cross-sectional views down into the subsurface. On each of the six block models below, the geology drawn on the south- and west-facing sides shows the geology of the subsurface. This will give you some clues about the attitude (dip and dip direction) of the formations, as well as any structures present. Examine each of the block models, complete the missing sides, and use your completed model to answer the questions below. Unless otherwise stated, assume all the formations below represent sedimentary rocks.

For some of the models you will be asked to write a point-form geologic history based on what you observe in the model. This is an excellent way to review the relative dating and geologic time concepts from Lab 7. For example, try writing a point-form geologic history for Block Model 1 that shows a sequence of Cambrian (brown), Ordovician (light grey), Silurian (cream), Devonian (blue grey), and Mississippian (orange) formations that are dipping to the east, as well as a Cretaceous gabbro dyke (dark brown).

A point-form geologic history for Block Model 1 would look something like this: 


\section{Youngest (most recent)}

- Erosion +/- uplift to present

- Intrusion of Cretaceous gabbro dyke (cross-cutting relationships)

- Tilting of the Cambrian to Mississippian formations toward the east (original horizontality)

- Deposition and lithification of the Mississippian formation (superposition)

- Deposition and lithification of the Devonian formation (superposition)

- Deposition and lithification of the Silurian formation (superposition)

- Deposition and lithification of the Ordovician formation (superposition)

- Deposition and lithification of the Cambrian formation (superposition)

\section{$\underline{\text { Oldest }}$}

Notice how the history is formatted such that the oldest event is at the bottom, and the youngest or most recent event is listed at the top. The italic font in parentheses indicates the principle of stratigraphy used to justify the position of each event in the timeline. Also note that the terms used to describe the different geologic events match the type of rocks: deposition for sedimentary rocks, intrusion for the igneous dyke. Recall from Lab 3, that gabbro is a mafic intrusive igneous rock, that cooled beneath the Earth's surface. Since the gabbro dyke is now exposed at the surface of the Earth, the most recent event must be that the area has been uplifted and any overlying rocks or sediment have been eroded away.

\section{Block model I}

Cut out block model 1, then construct the model by folding along the red lines. Fold in the corners of the model to create a 3D rectangular shape. Do not staple or tape the corners yet, as the model is easier to complete when laid flat on a hard surface. Later, you may want to staple or tape these corners so that your model maintains its shape.

This model shows a sequence of Cambrian (brown), Ordovician (light grey), Silurian (cream), Devonian (blue grey), and Mississippian (orange) formations that are dipping to the east. A Cretaceous (dark brown) dyke is also shown.

1. Complete the north- and east-facing sides of the block by drawing in the geology. You do not need to colour in the block model, but your formations must be labeled.

2. Draw a black arrow in plan view to indicate the dip direction of the Ordovician formation (O) at point $i$.

3. Using your protractor, measure the dip of the Ordovician formation on the south-facing side of the block. Remember, dip is measured in degrees from horizontal $\left(0^{\circ}\right)$ down to the inclined plane. Review Figures 9.1.2 and 9.1.3 if you are unsure where the angle of dip should be measured on your block model. Dip:

4. Draw a black arrow in plan view to indicate the dip direction of the Cretaceous dyke (K) at point ii.

5. Using your protractor, measure the dip of the Cretaceous dyke on the south-facing side of the block. Dip: 


\section{Block model 2}

This model shows a sequence of Cambrian (brown), Ordovician (cream), Silurian (light grey), and Devonian (blue grey) formations. This model is a little more complex than Model 1, as the strata here have been folded.

1. Complete the north- and east-facing sides of the block by drawing in the geology. You do not need to colour in the block model, but your formations must be labeled.

2. Draw a black arrow in plan view to indicate the dip direction(s) of the Silurian formation (S) at points i, ii, and iii.

3. Draw on the axial plane for each fold in red pen on the south- and north-facing sides of the model.

4. In plan view and using a ruler, draw the surface traces of the axial planes for the folds in red pen. Add the appropriate symbols to indicate the type of fold (see Figure 10.2.5).

5. What type of stress is required to produce the geologic structures observed in this block model?

\section{Block model 3}

This model shows a faulted sequence of Cambrian (green), Ordovician (blue), Silurian (grey), and Devonian (cream), and Mississippian (brown) formations. Examine the offset of the formations shown in the southfacing side of the block.

1. Complete the north- and east-facing sides of the block by drawing in the geology. You do not need to colour in the block model, but your formations must be labeled.

2. Draw a black arrow in plan view to indicate the dip direction of the Mississippian formation (M) at point i.

3. Draw a black arrow in plan view to indicate the dip direction of the fault at point ii.

4. Draw a black arrow in plan view to indicate the dip direction of the Silurian formation (S) at point iii.

5. Label the hanging wall and footwall on the south- and north-facing sides of the model (the blocks above and below the fault).

6. Draw red arrows on either side of the fault to indicate the sense of displacement along the fault.

7. Is the fault in this model a normal or reverse fault? Why?

8. Draw the appropriate map symbol for the fault in plan view. Consult Figure 10.3.4 for more information on map symbols for faults.

9. What type of stress is required to produce the fault observed in this block model? 


\section{Block model 4}

This model shows a faulted sequence of Cambrian (green), Ordovician (blue), Silurian (grey), and Devonian (cream), and Mississippian (brown) formations. Examine the offset of the formations shown in the southfacing side of the block.

1. Complete the north- and east-facing sides of the block by drawing in the geology. You do not need to colour in the block model, but your formations must be labeled.

2. Draw a black arrow in plan view to indicate the dip direction of the Mississippian formation (M) at point i.

3. Draw a black arrow in plan view to indicate the dip direction of the fault at point ii.

4. Draw a black arrow in plan view to indicate the dip direction of the Ordovician formation $(\mathrm{O})$ at point iii.

5. Label the hanging wall and footwall on the south- and north-facing sides of the model (the blocks above and below the fault).

6. Draw red arrows on either side of the fault to indicate the sense of displacement along the fault.

7. Is the fault in this model a normal or reverse fault? Why?

8. Draw the appropriate map symbol for the fault in plan view. Consult Figure 10.3.4 for more information on map symbols for faults.

9. What type of stress is required to produce the fault observed in this block model?

\section{Block model 5}

This model shows a faulted sequence of Cambrian (orange), Devonian (grey), and Mississippian (cream) formations, as well as a younger Cretaceous dyke (dark brown). Examine the offset of the dyke shown in the south-facing side of the block.

1. Complete the north- and east-facing sides of the block by drawing in the geology. You do not need to colour in the block model, but your formations must be labeled.

2. What is the dip of the Mississippian formation (M) at point i? Dip:

3. What is the dip and dip direction of the Cretaceous dyke $(\mathrm{K})$ at point ii?

4. Draw red arrows on either side of the fault at point iii to indicate the sense of displacement along the fault.

5. What type of strike-slip fault is this? Why? 
6. Write a point-form geologic history for this block model. Be sure to specify any unconformities (if present), and which principles of stratigraphy you use as evidence for your timeline.

7. What type of stress is required to produce the fault observed in this block model?

\section{Block model 6}

This is a structurally-complex block model. This model shows a deformed sequence of Cambrian (brown), Ordovician (cream), Silurian (pale grey), and Devonian (blue grey) formations, as well as a Jurassic dyke (dark brown). The black unit on the south-facing side labeled ' $M$ ' is a Mississippian sill, a type of igneous intrusion.

1. Complete the north- and east-facing sides of the block by drawing in the geology. You do not need to colour in the block model, but your formations must be labeled.

2. What is the dip of the Silurian formation (S) at points $i$ and ii? Indicate the dip direction in plan view at points i and ii by drawing black arrows.

3. Draw on the axial plane for the fold in red pen on the south- and north-facing sides of the model.

4. In plan view and using a ruler, draw the surface trace of the axial plane for the fold in red pen. Add the appropriate symbol to indicate the type of fold.

5. What is the dip and dip direction of the Jurassic dyke (J) at point iii?

6. What is the dip and dip direction of the fault at point iv?

7. Label the hanging wall and footwall on the east- and west-facing sides of the model.

8. Draw red arrows on either side of the fault to indicate the sense of displacement along the fault.

9. Is the fault in this model a normal or reverse fault? Why?

10. Write a point-form geologic history for this block model. Be sure to specify any unconformities (if present), and which principles of stratigraphy you use as evidence for your timeline.

\section{Media Attributions}

- Figure A: (C) Siobhan McGoldrick. CC BY.

- Block Models 1, 2, 3, 4, 5, 6: C Siobhan McGoldrick. CC BY. 


\section{Summary}

The topics covered in this chapter can be summarized as follows:

\begin{tabular}{|c|c|}
\hline Section & Summary \\
\hline $\begin{array}{l}\text { 10.1 Stress } \\
\text { and Strain }\end{array}$ & $\begin{array}{l}\text { Stress within rocks-which includes compression, extension and shearing-typically originates from } \\
\text { plate-boundary processes. Rock that is stressed responds with either elastic or plastic strain, and may } \\
\text { eventually break. The way a rock responds to stress depends on its composition and structure, the rate } \\
\text { at which strain is applied, and also to the temperature of the rock body and the presence of water. }\end{array}$ \\
\hline $\begin{array}{l}10.2 \\
\text { Folding }\end{array}$ & $\begin{array}{l}\text { Folding is generally a plastic response to compressive stress, although some brittle behaviour can } \\
\text { happen during folding. An upward fold is an antiform. A downward fold is a synform. The axis of a fold } \\
\text { can be vertical, inclined, or even horizontal. If we know that the folded beds have not been overturned, } \\
\text { then we can use the more specific terms: anticline and syncline. }\end{array}$ \\
\hline $\begin{array}{l}10.3 \\
\text { Faulting }\end{array}$ & $\begin{array}{l}\text { Fractures (joints) typically form during extension, but can also form during compression. Faulting, which } \\
\text { involves the displacement of rock, can take place during compression or extension, as well as during } \\
\text { shearing at transform boundaries. Thrust faulting is a special form of reverse faulting. }\end{array}$ \\
\hline $\begin{array}{l}\text { Lab } 10 \\
\text { Exercises }\end{array}$ & $\begin{array}{l}\text { Block models are useful tools for examining and recognizing geologic structures in } 3 \mathrm{D} \text {. Writing a } \\
\text { geologic history for the units shown on a block model is an excellent way to practice using the principles } \\
\text { of stratigraphy to determine relative ages. }\end{array}$ \\
\hline
\end{tabular}




\section{Mineral Identification Tables}

All mineral identification tables: (C) Siobhan McGoldrick. CC BY.

\begin{tabular}{|c|c|c|c|c|c|c|}
\hline \multicolumn{7}{|c|}{ MINERALS WITH METALLIC LUSTRE } \\
\hline & Streak & Cleavage / Fracture & H & SG & Other Properties & $\begin{array}{l}\text { Mineral Name } \\
\text { and Formula }\end{array}$ \\
\hline \multirow{3}{*}{ 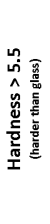 } & $\begin{array}{l}\text { Distinct red- } \\
\text { brown }\end{array}$ & No cleavage & 5 to 6.5 & 5.3 & $\begin{array}{l}\text { Typically earthy lustre and red-brown } \\
\text { colour. Rare steel grey variety has } \\
\text { metallic lustre (specular hematite). }\end{array}$ & $\begin{array}{l}\text { Hematite } \\
\left(\mathrm{Fe}_{2} \mathrm{O}_{3}\right)\end{array}$ \\
\hline & Grey-black & $\begin{array}{l}\begin{array}{l}\text { No cleavage, uneven } \\
\text { fracture }\end{array} \\
\end{array}$ & 6 & 5.2 & Strongly magnetic. & $\begin{array}{c}\text { Magnetite } \\
\left(\mathrm{Fe}_{3} \mathrm{O}_{4}\right) \\
\end{array}$ \\
\hline & $\begin{array}{l}\text { Greenish-black to } \\
\text { brownish-black }\end{array}$ & No cleavage & 6 & 5 & $\begin{array}{l}\text { Brassy yellow, tarnishes rusty brown. } \\
\text { Cubic or pyritohedron crystal habit, } \\
\text { often with striated faces. Also forms } \\
\text { granular masses. }\end{array}$ & $\begin{array}{l}\text { Pyrite } \\
\left(\mathrm{FeS}_{2}\right)\end{array}$ \\
\hline \multirow{2}{*}{ 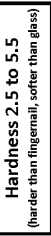 } & Pale yellow & 6 good cleavage directions & 3.5 to 4 & 4 & $\begin{array}{l}\text { Submetallic or resin ous lustre. Yellow, } \\
\text { red, green, brown, and black varietles } \\
\text { possible. Streak smells like sulphur. }\end{array}$ & $\begin{array}{c}\text { Sphalerite } \\
\text { (ZnS) }\end{array}$ \\
\hline & Greenish-black & $\begin{array}{l}\text { No cleavage, uneven } \\
\text { fracture }\end{array}$ & 3.5 to 4 & 4 & $\begin{array}{l}\text { Golden yellow but often tarnished to } \\
\text { bright purple-blue-yellow. May be } \\
\text { confused with pyrite but does not } \\
\text { form cubic crystals. }\end{array}$ & $\begin{array}{c}\text { Chalcopyrite } \\
\text { (CuFeS }{ }_{2} \text { ) }\end{array}$ \\
\hline \multirow{2}{*}{ 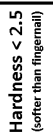 } & Grey & 3 directions at $90^{\circ}$ (cubic) & 2.5 & 7.5 & $\begin{array}{l}\text { Bright lead grey coloured commonly } \\
\text { cubic crystals. }\end{array}$ & $\begin{array}{l}\text { Galena } \\
(\mathrm{PbS})\end{array}$ \\
\hline & Dark grey-black & $\begin{array}{l}\text { Perfect in one direction, } \\
\text { rarely seen }\end{array}$ & 1 & 1.75 & $\begin{array}{l}\text { Silver-grey colour, very soft (writes on } \\
\text { paper), feels greasy. }\end{array}$ & $\begin{array}{l}\text { Graphite } \\
\text { (C) }\end{array}$ \\
\hline
\end{tabular}

\begin{tabular}{|c|c|c|c|c|c|c|}
\hline \multicolumn{7}{|c|}{$\begin{array}{l}\text { DARK MINERALS WITH NON-METALLIC LUSTRE } \\
\qquad \mathrm{H}=\text { hardness, } \mathrm{SG}=\text { specific gravity }\end{array}$} \\
\hline & Streak & Cleavage / Fracture & $\mathrm{H}$ & SG & Other Properties & $\begin{array}{l}\begin{array}{c}\text { Mineral Name and } \\
\text { Formula }\end{array} \\
\end{array}$ \\
\hline 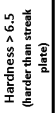 & $\begin{array}{l}\text { None (scratches } \\
\text { streak plate) }\end{array}$ & $\begin{array}{l}\text { No cleavage. Conchoidal } \\
\text { fracture }\end{array}$ & 7 & \begin{tabular}{c|}
3.5 to \\
4.3
\end{tabular} & \begin{tabular}{|l|} 
Vitreous to resinous lustre. Variable \\
colour (red to reddish brown most \\
common). Commonly seen as equant \\
12-sided crystals that may appear \\
rounded if small in size.
\end{tabular} & $\begin{array}{c}\text { Garnet family } \\
\text { (Complex Ca, Fe, Mg, } \\
\mathrm{Al}, \mathrm{Cr}, \mathrm{Mn} \text { isolated } \\
\text { silicate) }\end{array}$ \\
\hline \multirow{6}{*}{ 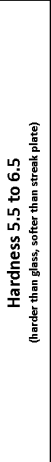 } & $\begin{array}{l}\text { Colourless to pale } \\
\text { green }\end{array}$ & $\begin{array}{l}\text { No cleavage. Conchoidal } \\
\text { fracture. }\end{array}$ & 6.5 to 7 & 3 to 3.3 & $\begin{array}{l}\begin{array}{l}\text { Olive green to vellow-green. } \\
\text { Commonly form small, granular glassy } \\
\text { crystals. }\end{array} \\
\end{array}$ & $\begin{array}{c}\text { Olivine } \\
\left(\left(\mathrm{Fe}, \mathrm{Mg}_{2} \mathrm{SiO}_{4}\right)\right.\end{array}$ \\
\hline & \begin{tabular}{|l} 
Colourless to pale \\
green
\end{tabular} & $\begin{array}{l}2 \text { planes: } 1 \text { perfect, } 1 \\
\text { poor, not at } 90^{\circ}\end{array}$ & 6 to 7 & 3.3 & $\begin{array}{l}\text { Pale green - yellow to dark green. } \\
\text { Pistachio green common. }\end{array}$ & \begin{tabular}{|c|} 
Epidote \\
(Complex Ca, Al, Fe, \\
OH ring silicate)
\end{tabular} \\
\hline & \begin{tabular}{|l} 
Colourless to pale \\
green
\end{tabular} & 2 directions at $\sim 90^{\circ}$ & 5 to 6 & $\begin{array}{c}3.2 \text { to } \\
3.4\end{array}$ & $\begin{array}{l}\text { Greenish-black to shades of green. } \\
\text { Commonly seen as vitreous black } \\
\text { short prismatic crrystals. }\end{array}$ & 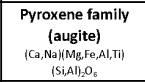 \\
\hline & \begin{tabular}{|l|}
$\begin{array}{l}\text { Colourless to pale } \\
\text { green }\end{array}$ \\
\end{tabular} & $\begin{array}{l}2 \text { directions not at } 90^{\circ}\left(56^{\circ}\right. \\
\left.\text { and } 124^{\circ}\right)\end{array}$ & 5 to 6 & 3 to 3.4 & $\begin{array}{l}\text { Greenish-black to shades of green. } \\
\text { Commonly seen as vitreous black } \\
\text { elongate crystals. }\end{array}$ & 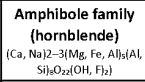 \\
\hline & White & 2 directions at $\sim 90^{\circ}$ & 6 & 2.6 & \begin{tabular}{|l|}
$\begin{array}{l}\text { Variable colour (white to dark grey). } \\
\text { Labradorite commonly dark blue-grey } \\
\text { and irredescent. Striations on some } \\
\text { faces. }\end{array}$ \\
\end{tabular} & $\begin{array}{l}\text { Feldspar family } \\
\text { (anorthite) } \\
\left(\mathrm{CaAl}_{2} \mathrm{~S}_{2} \mathrm{O}_{8}\right)\end{array}$ \\
\hline & \begin{tabular}{|l} 
Distinct red- \\
brown re
\end{tabular} & No cleavage & 5 to 6.5 & 5.3 & $\begin{array}{l}\text { Typically earthy lustre and red-brown } \\
\text { colour. Rare steel grey variety has } \\
\text { metallic lustre (specular hematite). }\end{array}$ & $\begin{array}{l}\text { Hematite } \\
\left(\mathrm{Fe}_{2} \mathrm{O}_{2}\right)\end{array}$ \\
\hline 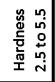 & Pale yellow & 6 good cleavage directions & 3.5 to 4 & 4 & $\begin{array}{l}\text { Submetallic or resinous lustre. Yellow, } \\
\text { red, green, brown, and black varieties } \\
\text { possible. Streak smells like sulphur. }\end{array}$ & $\begin{array}{l}\text { Sphalerite } \\
\text { (ZnS) }\end{array}$ \\
\hline \multirow{3}{*}{ 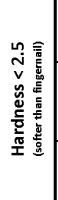 } & Greenish-brown & Perfect in one direction & 2.5 to 3 & 3 & $\begin{array}{l}\text { Dark-coloured (brown to black), flakes } \\
\text { into thin elastic sheets }\end{array}$ & 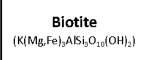 \\
\hline & Yellow-brown & Rarely seen & 1 to 3 & 3.5 & $\begin{array}{l}\text { Yellow-brown to dark brown, earthy } \\
\text { lustre, powders easily. Often seen } \\
\text { coating other minerals. }\end{array}$ & $\begin{array}{c}\text { Limonite } \\
\left(\mathrm{FeO}(\mathrm{OH})_{n} \mathrm{H}_{2} \mathrm{O}\right)\end{array}$ \\
\hline & \begin{tabular}{|l|} 
White or \\
colourless
\end{tabular} & $\begin{array}{l}\text { Perfect in one direction, } \\
\text { rarely seen }\end{array}$ & 2 to 2.5 & $\begin{array}{c}2.6 \text { to } \\
3.3\end{array}$ & Shades of green, mica-like mineral. & $\begin{array}{c}\text { Chlorite } \\
\text { (Complex Fe-Mg } \\
\text { phyyllosilicate) }\end{array}$ \\
\hline
\end{tabular}


LIGHT MINERALS WITH NON-METALLIC LUSTRE

$H=$ hardness, $S G=$ specific gravity

\begin{tabular}{|c|c|c|c|c|c|c|}
\hline & Streak & Cleavage / Fracture & $\mathrm{H}$ & SG & Other Properties & \begin{tabular}{|c|}
$\begin{array}{c}\text { Mineral Name and } \\
\text { Formula }\end{array}$ \\
\end{tabular} \\
\hline \multirow{2}{*}{ 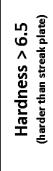 } & \multirow{2}{*}{$\begin{array}{c}\text { None } \\
\text { (scratches } \\
\text { streak plate) }\end{array}$} & $\begin{array}{l}\text { No cleavage. } \\
\text { Conchoidal fracture }\end{array}$ & 7 & 2.65 & $\begin{array}{l}\text { Vitreous lustre. Variable colour. Commonly } \\
\text { seen as irregular-shaped glassy grains in } \\
\text { rocks. Crystal habit is distinctive - elongate } \\
\text { 6-sided prisms with pyramidal end. }\end{array}$ & $\begin{array}{l}\text { Quartz } \\
\left(\mathrm{SiO}_{2}\right)\end{array}$ \\
\hline & & $\begin{array}{l}2 \text { planes with different } \\
\text { hardness }\end{array}$ & 7 and 4 & 3.6 & $\begin{array}{l}\text { Vitreous or pearly lustre. Pale blue to white } \\
\text { Crystals commonly appear bladed (elongate } \\
\text { but flat). }\end{array}$ & $\begin{array}{l}\text { Kyanite } \\
\left(\mathrm{Al}_{2} \mathrm{SiO}_{5}\right)\end{array}$ \\
\hline \multirow{2}{*}{ 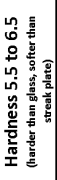 } & \multirow[b]{2}{*}{ White } & \multirow[b]{2}{*}{2 directions at $\sim 90^{\circ}$} & \multirow[b]{2}{*}{6} & \multirow[b]{2}{*}{2.6} & $\begin{array}{l}\text { Variable colour (white to dark grey\}. } \\
\text { Striations on some faces. }\end{array}$ & $\begin{array}{l}\text { Feldspar family } \\
\text { (albite) } \\
\left.\text { (NaAlSis } \mathrm{O}_{\mathrm{g}}\right)\end{array}$ \\
\hline & & & & & $\begin{array}{l}\text { Variable colour (white to pink). No } \\
\text { striations. May have exsolution lamellae } \\
\text { (irregular wavy lines of a different colour, } \\
\text { typically sub-millimetre in width). }\end{array}$ & $\begin{array}{c}\text { Feldspar family } \\
\text { (potassium feldspar } \\
\left(\mathrm{KAlS}_{\mathrm{B}} \mathrm{O}_{\mathrm{B}}\right)\end{array}$ \\
\hline \multirow{5}{*}{ 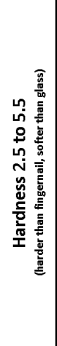 } & Pale yellow & $\begin{array}{l}6 \text { good cleavage } \\
\text { directions }\end{array}$ & 3.5 to 4 & 4 & $\begin{array}{l}\text { Submetallic or resinous lustre. Yellow, red, } \\
\text { greeen, brown, and black varieteties possible. } \\
\text { Streak smells like sulphur. }\end{array}$ & $\begin{array}{c}\text { Sphalerite } \\
(\mathrm{ZnS})\end{array}$ \\
\hline & \multirow{4}{*}{$\begin{array}{l}\text { White or } \\
\text { colourless }\end{array}$} & 4 directions & 4 & 3.2 & $\begin{array}{l}\text { Vitreous lustre. Colour variable (green, } \\
\text { purple, yellow, colourless). }\end{array}$ & $\begin{array}{l}\text { Fluorite } \\
\left(\mathrm{CaF}_{2}\right)\end{array}$ \\
\hline & & $\begin{array}{l}3 \text { directions at } 90^{\circ} \\
\text { (cubic) }\end{array}$ & 3 to 3.5 & 4.5 & $\begin{array}{l}\text { Vitreous lustre. Colourless to white or } \\
\text { cream. Distinctly high S.G. for a non- } \\
\text { metallic mineral. }\end{array}$ & $\begin{array}{c}\text { Barite } \\
\left(\mathrm{BaSO}_{4}\right)\end{array}$ \\
\hline & & $\begin{array}{l}3 \text { directions not at } 90^{\circ} \\
\text { (all at } 775^{\circ} \text {; rhombic) }\end{array}$ & 3 & 2.7 & $\begin{array}{l}\text { Vitreous I Iustre. Commonly white to } \\
\text { colourless. Forms rhombohedral shapes. } \\
\text { Reacts vigorously with dilute HCI. }\end{array}$ & $\begin{array}{l}\text { Calcite } \\
\left(\mathrm{CaCO}_{3}\right)\end{array}$ \\
\hline & & $\begin{array}{l}3 \text { directions at } 90^{\circ} \\
\text { (cubic) }\end{array}$ & 2.5 & 2 & $\begin{array}{l}\text { Vitreous lustre. Colourless to white cubic } \\
\text { crystals, often seen with sylvite (KCl), which } \\
\text { can be variably coloured. Salty taste. }\end{array}$ & $\begin{array}{l}\text { Halite } \\
(\mathrm{NaCl})\end{array}$ \\
\hline \multirow{4}{*}{ 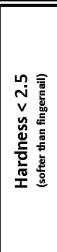 } & \multirow{4}{*}{$\begin{array}{l}\text { White or } \\
\text { colourless }\end{array}$} & Perfect in one direction & 2 to 2.5 & 2.8 & $\begin{array}{l}\text { Silky to pearly lustre. Colourless to pale } \\
\text { gold. Breaks into transparent elastic sheets } \\
\text { along cleavage plane. }\end{array}$ & 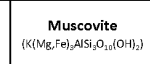 \\
\hline & & $\begin{array}{l}\text { Perfect in one direction, } \\
\text { rarely seen }\end{array}$ & 2 to 2.5 & 2.6 & $\begin{array}{l}\text { Earthy lustre. Dull white and powdery. } \\
\text { Distinctly earthy odour. }\end{array}$ & $\begin{array}{c}\text { Kaolinite } \\
\left(\mathrm{Al}_{2} \mathrm{~S}_{2} \mathrm{O}_{5}\left(\mathrm{O} \mathrm{H}_{4}\right)\right.\end{array}$ \\
\hline & & $\begin{array}{l}3 \text { cleavage directions: } 1 \\
\text { perfect, } 2 \text { good. Only } 1 \\
\text { typically seen. }\end{array}$ & 2 & 2.3 & $\begin{array}{l}\text { White to transparent. May be fibrous with } \\
\text { silky lustre (selenite) or massive. }\end{array}$ & $\underset{\left(\mathrm{CaSO}_{4} \cdot 2 \mathrm{H}_{2} \mathrm{O}\right)}{\text { Gypsum }}$ \\
\hline & & $\begin{array}{l}\text { Perfect in one direction, } \\
\text { rarely seen }\end{array}$ & 1 & $\begin{array}{c}2.7 \text { to } \\
2.8\end{array}$ & $\begin{array}{l}\text { Greasy or soapy feel. Pearly lustre. Colour } \\
\text { variable (pale green, vellow, grey and silver- } \\
\text { white) }\end{array}$ & $\begin{array}{c}\text { Talc } \\
\left(\mathrm{Mg}_{3} \mathrm{~S}_{4} \mathrm{O}_{10}\left(\mathrm{OH}_{2}\right)\right.\end{array}$ \\
\hline
\end{tabular}




\title{
Rock Classification Tables
}

\author{
Igneous Rocks
}

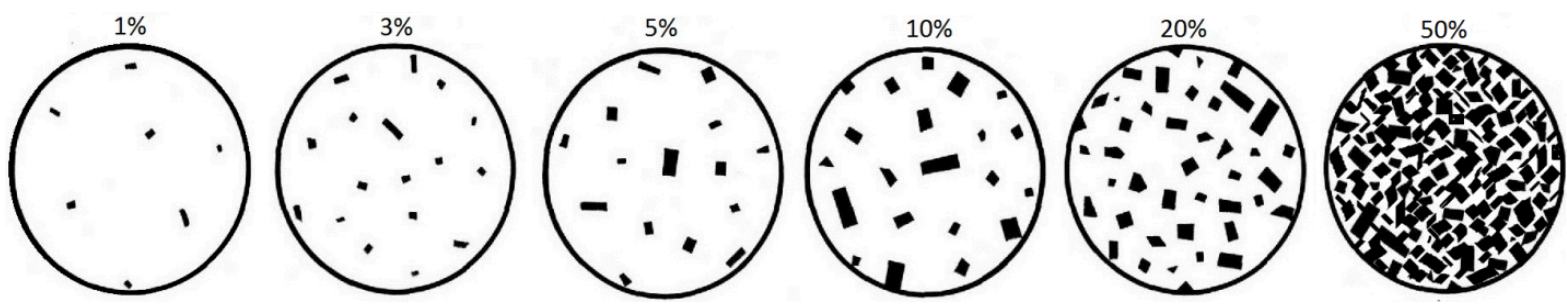

Figure A: Visual guide to estimating the proportions of dark minerals in light-coloured rocks.

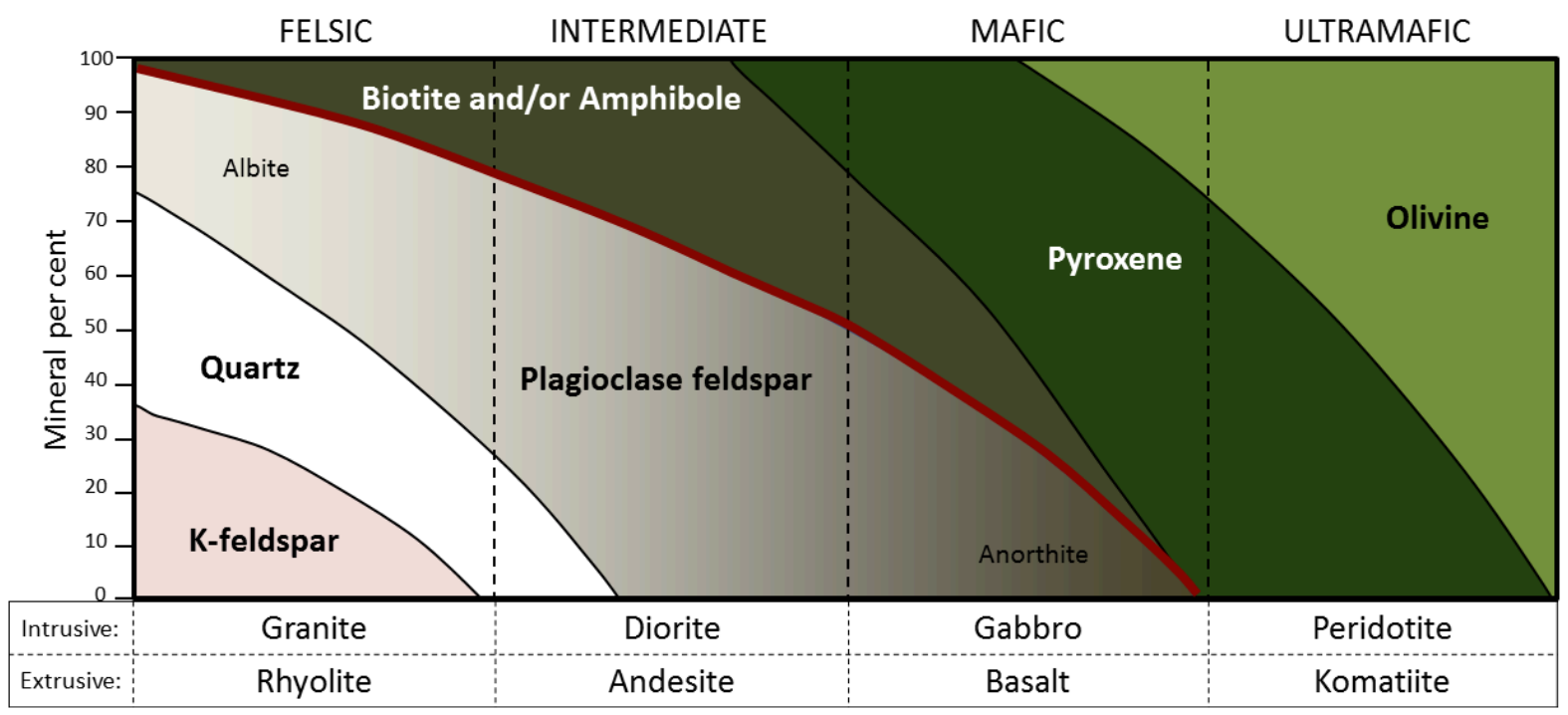

Figure B: A simplified classification diagram for igneous rocks based on their mineral compositions. Note that glassy igneous rocks pumice and obsidian are not included on this diagram. 


\section{Sedimentary Rocks}

Table A: The Udden-Wentworth grain-size scale for classifying sediments and the grains that make up clastic sedimentary rocks

\begin{tabular}{|c|c|c|c|}
\hline Type & Description & Size range (millimetres, $\mathrm{mm}$ ) & Size range (microns, $\mu \mathrm{m}$ ) \\
\hline \multirow{3}{*}{ Boulder } & large & 1024 and up & \\
\hline & medium & 512 to 1024 & \\
\hline & small & 256 to 512 & \\
\hline \multirow{2}{*}{ Cobble } & large & 128 to 256 & \\
\hline & small & 64 to 128 & \\
\hline \multirow{5}{*}{ Pebble (Granule) } & very coarse & 32 to 64 & \\
\hline & coarse & 16 to 32 & \\
\hline & medium & 8 to 16 & \\
\hline & fine & 4 to 8 & \\
\hline & very fine & 2 to 4 & \\
\hline \multirow{5}{*}{ Sand } & very coarse & 1 to 2 & 1000 to 2000 \\
\hline & coarse & 0.5 to 1 & 500 to 1000 \\
\hline & medium & 0.25 to $0.5(1 / 4$ to $1 / 2 \mathrm{~mm})$ & 250 to 500 \\
\hline & fine & 0.125 to $0.25(1 / 8$ to $1 / 4 \mathrm{~mm})$ & 125 to 250 \\
\hline & very fine & 0.063 to $0.125(1 / 16$ to $1 / 8 \mathrm{~mm})$ & 63 to 125 \\
\hline \multirow{5}{*}{ Silt } & very coarse & & 32 to 63 \\
\hline & course & & 16 to 32 \\
\hline & medium & & 8 to 16 \\
\hline & fine & & 4 to 8 \\
\hline & very fine & & 2 to 4 \\
\hline Clay & clay & & 0 to 2 \\
\hline
\end{tabular}


Table B: The main types of clastic sedimentary rocks and their characteristics. You are expected to be able to identify the bolded rock names in this course.

\begin{tabular}{|c|c|c|}
\hline Group & Examples & Characteristics \\
\hline Conglomerate & & $\begin{array}{l}\text { Dominated by rounded clasts, granule size and larger }(>2 \mathrm{~mm}) \text {, poorly to very } \\
\text { poorly sorted }\end{array}$ \\
\hline Breccia & & $\begin{array}{l}\text { Dominated by angular clasts, granule size and larger }(>2 \mathrm{~mm}) \text {, poorly to very } \\
\text { poorly sorted }\end{array}$ \\
\hline \multirow{3}{*}{ Sandstone } & $\begin{array}{l}\text { quartz } \\
\text { sandstone }\end{array}$ & $\begin{array}{l}\text { Dominated by sand ( } 1 / 16 \text { to } 2 \mathrm{~mm}) \text {, greater than } 90 \% \text { quartz, range of roundness } \\
\text { and sorting possible }\end{array}$ \\
\hline & $\begin{array}{l}\text { arkose } \\
\text { (feldspathic } \\
\text { sandstone) }\end{array}$ & $\begin{array}{l}\text { Dominated by sand (1/16 to } 2 \mathrm{~mm}) \text {, greater than } 10 \% \text { feldspar, range of roundness } \\
\text { and sorting possible }\end{array}$ \\
\hline & lithic wacke & $\begin{array}{l}\text { Dominated by sand ( } 1 / 16 \text { to } 2 \mathrm{~mm}) \text {, greater than } 10 \% \text { rock fragments, greater than } \\
15 \% \text { silt and clay, range of roundness and sorting possible }\end{array}$ \\
\hline \multirow{2}{*}{ Mudrock } & mudstone & $\begin{array}{l}\text { Greater than } 75 \% \text { silt }(1 / 256 \text { to } 1 / 16 \mathrm{~mm}) \text { and clay }(<1 / 256 \mathrm{~mm}) \text {, not bedded, } \\
\text { well-sorted, grains too fine to judge roundness using hand lens }\end{array}$ \\
\hline & shale & $\begin{array}{l}\text { Greater than } 75 \% \text { silt }(1 / 256 \text { to } 1 / 16 \mathrm{~mm}) \text { and clay }(<1 / 256 \mathrm{~mm}) \text {, thinly bedded, } \\
\text { well-sorted, grains too fine to judge roundness using hand lens }\end{array}$ \\
\hline
\end{tabular}
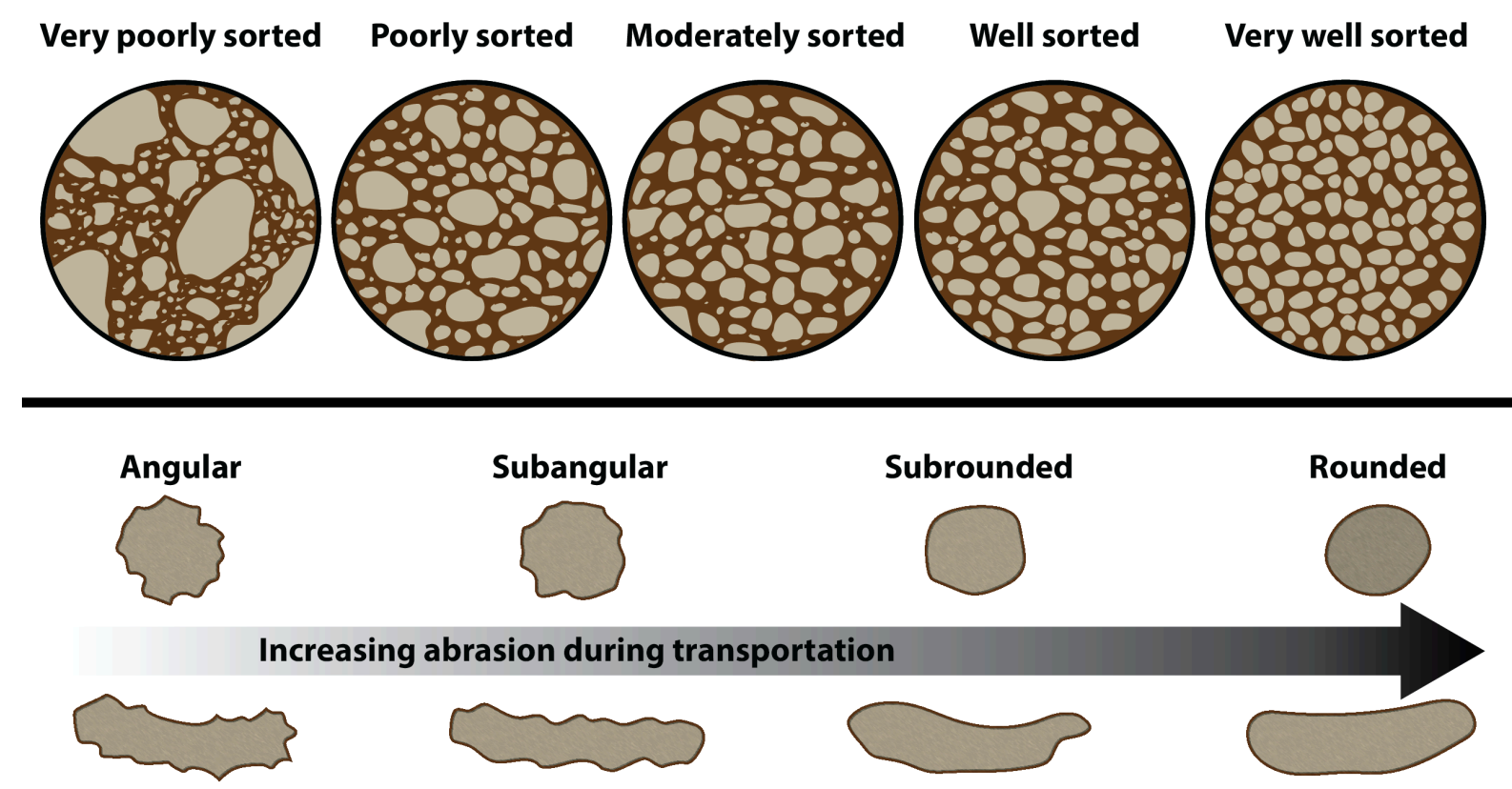

Figure C: A visual reference for descriptions of sorting (top) and roundness (bottom) of sediments and grains in clastic sedimentary rocks. 


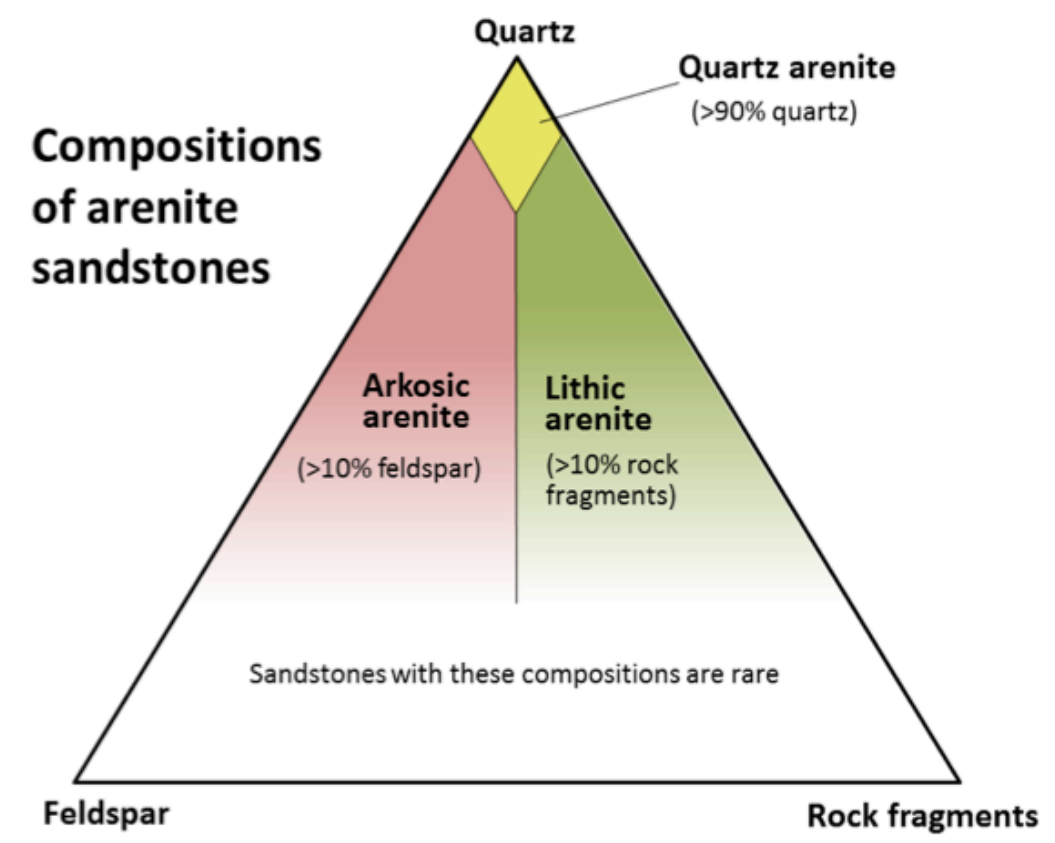

Figure D: A compositional triangle for arenite sandstones, with the three most common components of sand-sized grains: quartz, feldspar, and rock fragments. Arenites have less than $15 \%$ silt or clay. Sandstones with more than $15 \%$ silt and clay are called wackes (e.g., quartz wacke, lithic wacke).

Table C: Classification chart for chemical sedimentary rocks

\begin{tabular}{|c|c|c|c|}
\hline Composition & Texture & Distinctive Properties & Rock Name \\
\hline \multirow{5}{*}{$\begin{array}{l}\text { Calcite }\left(\mathrm{CaCO}_{3}\right) \\
\text { *Note that all lime- } \\
\text { stones will react with } \\
\text { dilute } \mathrm{HCl} \text {. }\end{array}$} & Crystalline & Crystalline; fine to coarse grained & Crystalline limestone \\
\hline & Fossiliferous & $\begin{array}{l}\text { Various fossil fragments well } \\
\text { cemented together }\end{array}$ & Fossiliferous limestone \\
\hline & Oolitic & $\begin{array}{l}\text { Comprised of ooids (spheroidal } \\
\text { particles typically }<2 \mathrm{~mm} \text { in } \\
\text { diameter) }\end{array}$ & Oolitic limestone \\
\hline & Bioclastic & $\begin{array}{l}\text { Visible shell fragments weakly } \\
\text { cemented together }\end{array}$ & Coquina \\
\hline & Bioclastic & Soft rock made of microscopic shells & Chalk \\
\hline Quartz $\left(\mathrm{SiO}_{2}\right)$ & Microcrystalline & $\begin{array}{l}\text { Microcrystalline; hardness of } \sim 7 \text { (can } \\
\text { scratch glass); may exhibit } \\
\text { conchoidal fracture }\end{array}$ & $\begin{array}{l}\text { Chert (note that dark coloured } \\
\text { varieties may be called flint and red } \\
\text { coloured varieties may be called } \\
\text { jasper) }\end{array}$ \\
\hline Halite $(\mathrm{NaCl})$ & Crystalline & $\begin{array}{l}\text { Crystalline; fine to coarse grained; } \\
\text { commonly forms cubic crystals; } \\
\text { tastes salty }\end{array}$ & Rock salt \\
\hline Gypsum $\left(\mathrm{CaSO}_{4} \cdot \mathrm{H}_{2} \mathrm{O}\right)$ & Crystalline & $\begin{array}{l}\text { Crystalline; fine to coarse grained; } \\
\text { hardness } \sim 2 \text { (can scratch with } \\
\text { fingernail) }\end{array}$ & Rock gypsum \\
\hline $\begin{array}{l}\text { Organic material } \\
\text { (plant fragments) }\end{array}$ & Amorphous & $\begin{array}{l}\text { Black brittle rock with amorphous } \\
\text { texture; low density }\end{array}$ & Coal \\
\hline
\end{tabular}




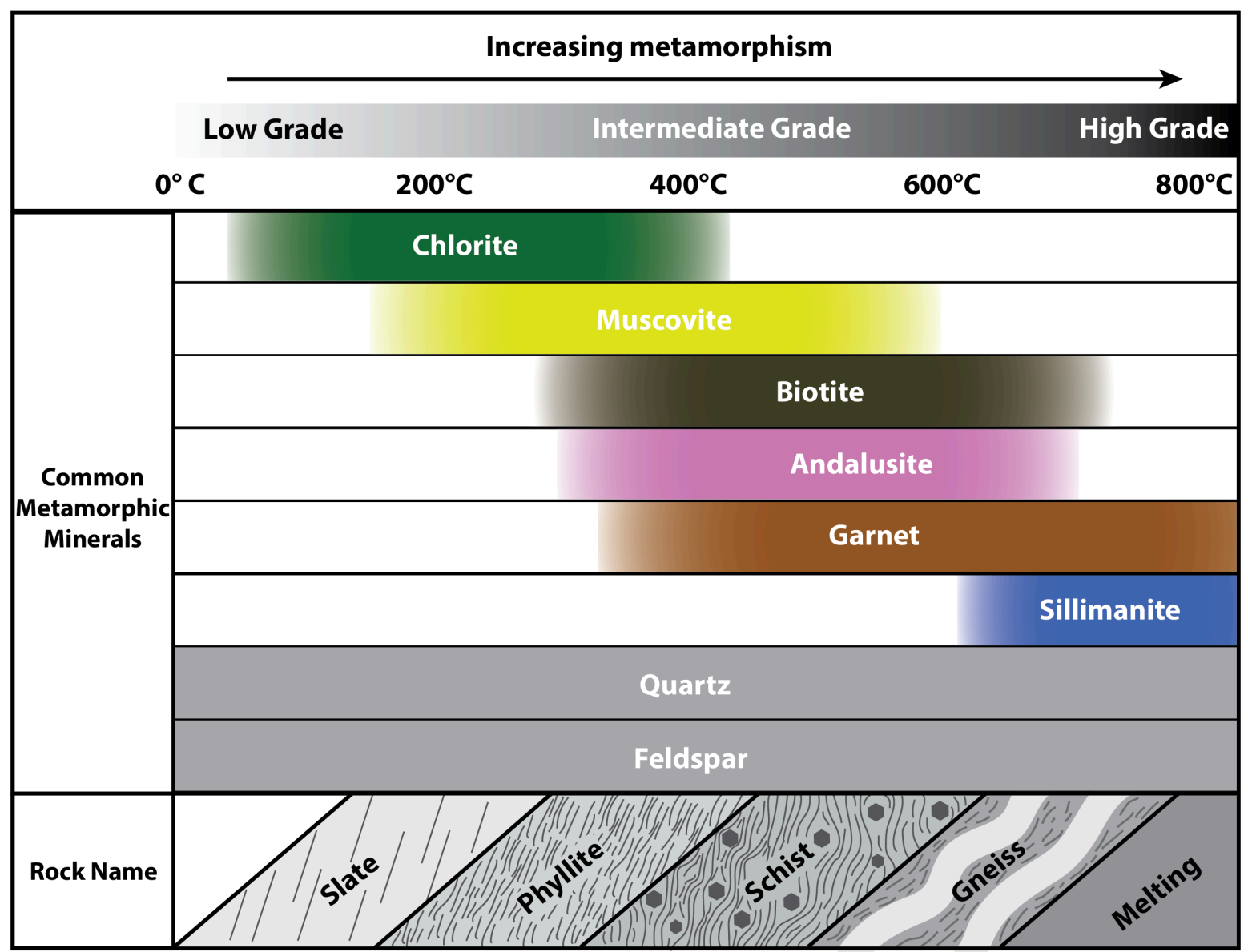

Figure E: Metamorphic grades, common metamorphic index minerals, and corresponding rock names for a mudrock protolith under increasing metamorphism (increasing temperature and pressure).

Table D: A rough guide to the types of metamorphic rocks that form from different protoliths at different grades of regional metamorphism. You are expected to know the rock names indicated in bold font.

\begin{tabular}{|c|c|c|c|c|}
\hline Protolith & $\begin{array}{l}\text { Very Low Grade } \\
\left(150-300^{\circ} \mathrm{C}\right)\end{array}$ & $\begin{array}{l}\text { Low Grade } \\
\left(300-450^{\circ} \mathrm{C}\right)\end{array}$ & $\begin{array}{l}\text { Medium Grade } \\
\left(450-550^{\circ} \mathrm{C}\right)\end{array}$ & $\begin{array}{l}\text { High Grade (Above } \\
550^{\circ} \mathrm{C} \text { ) }\end{array}$ \\
\hline Mudrock & slate & phyllite & schist & gneiss \\
\hline Granite & no change & no change & almost no change & granite gneiss \\
\hline Basalt & greenschist & greenschist & amphibolite & amphibolite \\
\hline Sandstone & no change & little change & quartzite & quartzite \\
\hline Limestone & little change & marble & marble & marble \\
\hline
\end{tabular}

\section{Media Attributions}

- Figures A, B, D: (C) Steven Earle. CC BY. 
- Figures C, E: @ Siobhan McGoldrick. CC BY. 


\section{Glossary}

acid rock drainage

the production of acid from oxidation of sulphide minerals (especially pyrite) in either naturally or anthropogenically exposed rock

aeolian

processes related to transportation and deposition of sediments by wind

albite

Sodium-rich plagioclase feldspar.

amorphous

the texture in a rock composed of very fine non-crystalline material created by organic or chemical activity

amphibole

A double-chain ferromagnesian silicate mineral (e.g., hornblende).

amphibolite

a foliated metamorphic rock in which the mineral amphibole is an important component

andesite

a extrusive (volcanic) rock of intermediate composition

anion

A negatively charged ion.

anorthite

Calcium-rich plagioclase feldspar.

anthropogenic

resulting from the influence of humans

anticline

an upward fold where the beds are known not to be overturned

aphanitic

an igneous texture characterized by crystals that are too small to see with the naked eye 
arenite

a sandstone with less than $15 \%$ clay/silt matrix

arkose

a sandstone with more than $10 \%$ feldspar and more feldspar than lithic fragments

\section{arkosic arenites}

a sandstone with less than $15 \%$ clay/silt matrix, and with $>10 \%$ feldspar clasts and more feldspar clasts than lithic clasts

asthenosphere

the part of the mantle, from about 100 to 200 kilometres below surface, within which the mantle material is close to its melting point, and therefore relatively weak

\section{asymmetrical}

in the context of folds, where the two sides of the fold make significantly different angles with respect to the axial plane

\section{attitude}

the orientation of a sloping geological feature, such as a bedding plane or fracture

axial plane

a plane that can be traced through all of the hinge lines of a fold

\section{azimuth}

The direction, measured in degrees $\left(000^{\circ}\right.$ to $\left.360^{\circ}\right)$ away from magnetic north $\left(000^{\circ}\right)$.

\section{back reef}

the zone of shallow water on the shore-side of a reef

\section{background (geochemistry)}

the typical level of an element in average rocks or sediments

\section{bank-full stage}

the water level of stream when it is in flood and just about to flow over its banks

\section{basalt}

a mafic extrusive (volcanic) rock 


\section{base level}

in the context of a stream the base level is the lowest level that it can erode down to, as defined by the ocean, a lake or another stream that it flows into

\section{base map}

a layer with geographic information that serves as a background, provides context for additional layers or data plotted on the map

\section{batholith}

an irregular body of intrusive igneous rock that has an exposed surface of at least $100 \mathrm{~km} 2$

bed

The smallest formal lithostratigraphic unit of sedimentary rocks.

\section{bed load}

the fraction of a stream's sediment load that typically rests on the bottom and is moved by saltation and traction

\section{bedding}

repeated layering in a sedimentary rock

\section{bioclastic}

the texture in a rock formed from the accumulation of fragmented remains of living organisms, most commonly shell fragments

\section{biotite}

A sheet silicate mineral (mica) that includes iron and or magnesium, and is therefore a ferromagnesian silicate.

\section{block models}

a cubic or rectangular model used for study purposes to display geology in three-dimensions

\section{blueschist}

a metamorphic facies characterized by relatively low temperatures and high pressures, such as can exist within a subduction zone

\section{boulder}

a sediment clast with a diameter of at least 256 millimetres

\section{Bowen reaction series}

the scheme that defines the typical order of crystallization of minerals from magma 


\section{braided}

a stream pattern which is characterized by abundant sediment and numerous intertwining channels around bars

\section{breccia}

a sedimentary- or volcanic-rock texture characterized by angular clasts

\section{carbonate}

A mineral in which the anion group is $\mathrm{CO} 3-2$

\section{cardinal directions}

the four main points of a compass: north, south, east, and west

\section{cartographic elements}

standard elements on a map that help the reader understand what is being presented and how it relates to places and distances in the real world

\section{cation}

A positively charged ion.

\section{cement}

Crystals, commonly calcite, quartz, or hematite, formed between grains in a clastic sedimentary rock during lithification. Without cementation, a sedimentary rock is merely a deposit of loose, unconsolidated sediment.

\section{cementation}

the process during lithification by which minerals are precipitated between grains in sediments such that the grains are glued together

\section{Cenozoic}

The most recent of the eras, representing the past 65.5 Ma of geological time.

\section{chalk}

a type of soft white limestone formed from the skeletal remains of sea creatures

\section{chemical sedimentary rock}

a sedimentary rock comprised of material that was transported as ions in solution

chert

a microcrystalline chemical sedimentary rock formed almost entirely of silica 


\section{chlorite}

A ferromagnesian sheet silicate mineral, typically present as fine crystals and forming from the lowtemperature metamorphism of mafic rock.

clast

a sedimentary fragment of mineral or rock

clastic

a rock texture consisting of grains of pre-existing geologic material cemented together

clastic sedimentary rock

a sedimentary rock comprised of material that was transported as clasts or fragments

clay

sediment particle that is less than 1/256 millimetres in diameter

\section{clay mineral}

a hydrous sheet silicate mineral that typically exists as clay-sized grains

claystone

a sedimentary rock comprised mostly of clay-sized grains

cleavage

The tendency for a mineral to break along smooth planes that are predetermined by its lattice structure.

cobble

sediment particle that is between 64 and 256 millimetres in diameter

compressional

stress that tends to squeeze something together

concentrate (mining)

a product of ore processing that includes a specific ore mineral, separated from the rest of the rock

conchoidal fracture

a type of fracture distinguished by smooth, curved mineral surfaces resembling broken glass

conglomerate

a sedimentary rock that is comprised predominantly of rounded grains that are larger than $2 \mathrm{~mm}$ 
contact

the surface that represents the boundary between two different bodies of rock.

contact metamorphism

metamorphism that takes place adjacent to a source of heat, such as a body of magma

\section{continental arc}

A chain of volcanoes formed on the upper plate at a ocean-continent convergent boundary. Volcanoes are built on continental crust.

\section{continental crust}

The relatively thick and buoyant outermost layer of Earth's internal structure composed of predominantly intermediate to felsic igneous rocks, as well as sedimentary and metamorphic rocks.

\section{continental drift}

the concept that tectonic plates can move across the surface of the Earth

\section{continental slope}

the steeper part of a continental margin, that slopes down from a continental shelf towards the abyssal plain

\section{contour interval}

the difference in elevation between two adjacent topographic contour lines

\section{contour lines}

imaginary lines on Earth's surface that connect points of equal elevation

\section{convergent}

a plate boundary at which the two plates are moving towards each other

\section{coordinates}

A set of numbers referring to a grid system used to specify an exact location on Earth.

coquina

a weak, poorly-cemented type of limestone consisting almost entirely of shells and shell fragments

core

The metallic interior part of the Earth, extending from a depth of 2900 kilometres to the centre.

\section{covalent bond}

A bond between two atoms in which electrons are shared. 
cross-bedding

small-scale inclined bedding within larger horizontal beds

crust

The uppermost layer of the Earth, ranging in thickness from about 5 kilometres (in the oceans) to over 50 kilometres (on the continents).

\section{crystalline}

a rock composed of interlocking crystals

cut banks

A steep stream bank on the outside of a meander formed by erosion.

\section{datum line}

an assumed surface used as a reference for the measurement of elevations and depths

decline

in mining a decline is a sloped tunnel used to access lower parts of a mine with wheeled equipment

decompression melting

melting (or partial melting) of rock resulting from a reduction in pressure without a significant reduction in temperature

\section{deformation}

In geology, deformation refers to folding (ductile bending) or faulting and fracturing (brittle breaking) of rocks in response to stress.

\section{degrees}

In the context of the geographic grid system, a distance equal to 60 minutes.

\section{density}

Weight per volume of a substance (e.g., g/cm3) used widely in the context of minerals or rocks.

diatom

photosynthetic algae that make their tests (shells) from silica

diorite

an intermediate intrusive igneous rock 
$\operatorname{dip}$

the angle below horizontal at which a planar layer of rock (e.g., sedimentary bed), or other planar feature, slopes

dip direction

direction of maximum dip, the direction water poured onto a dipping plane would flow

discharge

the volume of water flow in a stream expressed in terms of volume per unit time (e.g., m3/s)

divalent

An ion with a charge or +2 or -2 .

\section{divergent}

a plate boundary at which the two plates are moving towards away from each other

dodecahedron

An object with twelve surfaces, such as a garnet crystal.

dolomite

a calcium-magnesium carbonate mineral $(\mathrm{Ca}, \mathrm{Mg}) \mathrm{CO} 3$

\section{dolomitization}

the addition of magnesium to limestone during which some or all of the calcium carbonate (calcite) is converted to dolomite

\section{dolostone}

a carbonate rock made up primarily of the mineral dolomite

\section{easting}

The eastward-measured distance, or x-coordinate, used in the Universal Transverse Mercator (UTM) grid system. Reported in metres.

\section{eclogite}

a garnet-pyroxene-glaucophane bearing rock that is the product of high-pressure metamorphism of oceanic crustal rock (e.g., basalt), typically within a subduction zone

\section{elastic strain}

the deformed rock returns to its original shape and size when the deforming stress is removed 
equator

Parallel of latitude defined to be $0^{\circ}$.

erosion

the action of surface processes (like running water or wind) that remove soil, rock, or dissolved material from one location on or near the Earth's surface, and then transports it to another location.

evaporites

various different types of minerals and rocks that form when bodies of water evaporate

\section{exceptional circumstance}

A situation clearly beyond your control such as an academic conflict, documented illness or family emergency.

Please note that work-related commitments do not qualify as an exceptional circumstance for which accommodation may be sought.

\section{exsolution lamellae}

wavy, irregular 'veiny' lines that may appear as a slightly different colour than the rest of the feldspar crystal (e.g., paler pink, cloudy more opaque white)

\section{extrusive}

igneous rock that cooled at surface

\section{fault}

a boundary in rock or sediment along which displacement has taken place

\section{feldspar}

A very common family of framework silicate minerals.

\section{felsic}

silica rich $(>65 \% \mathrm{SiO} 2)$ in the context of magma or igneous rock

\section{ferric}

The oxidized form of an ion of iron (Fe3+).

\section{ferromagnesian}

Referring to a silicate mineral that contains iron and or magnesium.

\section{ferrous}

the reduced (non-oxidized) form of an ion of iron $(\mathrm{Fe} 2+)$ 


\section{flood plain}

a low-lying area adjacent to a river, formed mainly of river sediments and subject to flooding.

flow

the smallest formal lithostratigraphic unit of volcanic rocks. A discrete volcanic rock body distinguishable by texture, composition, order of superposition, paleomagnetism, or other objective criteria.

\section{flux melting}

melting of rock that is facilitated by the addition of a flux (typically water) which lowers the rocks melting point

\section{foliated}

the texture of a metamorphic rock with a foliation

\section{footwall}

the lower surface of a non-vertical fault

\section{foraminifera}

a single-celled protist with a shell that is typically made of $\mathrm{CaCO} 3$

\section{fore reef}

the zone on the ocean side of a reef

\section{formation}

A body of rock identified by lithic characteristics and stratigraphic position; it is prevailingly but not necessarily tabular and is mappable at the Earth's surface or traceable in the subsurface.

\section{fossiliferous}

a rock that contains the remains of living organisms (fossils) or evidence of past life (footprints, burrows)

\section{fracture}

A break within a body of rock in which the rock on either side is not displaced.

\section{fracture (mineral)}

a broken surface of a mineral that might be described as irregular, splintery, or conchoidal

\section{frost wedging}

the situation where the expansion of freezing water pries rock apart

\section{Ga}

(Giga annum) billions of years before the present. 


\section{gabbro}

a mafic intrusive igneous rock

\section{Geographic}

A grid system used to specify locations on Earth using coordinates of latitude and longitude.

\section{geologic history}

a written description of the timeline of geological processes responsible for the sequence of rocks in an area

\section{geothermal gradient}

The rate of increase of temperature with depth in the Earth (typically around $30^{\circ} \mathrm{C} / \mathrm{km}$ within the crust).

\section{glaciofluvial sediments}

referring to sediments deposited from a stream that is derived from a glacier

\section{glaucophane}

a blue-coloured sodium-magnesium bearing amphibole mineral that forms during metamorphism at high pressures and relatively low pressures, typically within a subduction zone

\section{gneiss}

high-grade metamorphic rock in which the mineral components are separated into bands

\section{gneissic}

Type of foliation defined by segregation bands of light and dark coloured minerals in a gneiss.

\section{graben}

a down-dropped fault block, bounded on either side by normal faults

grade

in the context of a mineral deposit, the amount of a specific metal or mineral expressed as a proportion of the whole rock

\section{gradient}

the slope of a stream bed over a specific distance, typically expressed in $\mathrm{m}$ per $\mathrm{km}$

\section{granite}

A felsic intrusive igneous rock. 


\section{granule}

a sedimentary particle ranging in size from 2 to 4 millimetres in diameter

greenschist

a foliated metamorphosed rock (typically derived from basalt) in which the green colouration is derived from either chlorite, epidote or green amphibole

\section{greywacke}

a sandstone with more than $15 \%$ silt and clay, and with a significant proportion of sand-sized rock fragments

\section{grid reference}

A shortened version of full UTM coordinates for a specific location on Earth's surface.

\section{grid system}

A system used to divide the Earth's surface into squares using two sets of perpendicular lines for the purpose of specifying locations and navigation.

\section{groundmass}

finer grained, typically aphanitic, crystals surrounding distinctly larger crystals (phenocrysts) in an igneous rock that formed from two-staged cooling

\section{group}

The lithostratigraphic unit next higher in rank to formation; a stratigraphically-continuous series of related formations.

habit

A characteristic crustal form or combination of forms of a mineral.

\section{Hadean}

The first eon of Earth history, extending from 4.57 to $3.80 \mathrm{Ga}$.

\section{halide}

A mineral in which the anion is one of the halide elements (e.g., halite - $\mathrm{NaCl}$ or fluorite $-\mathrm{CaF} 2$ ).

halite

$\mathrm{NaCl}$, a halide mineral also known as table salt.

\section{halogen}

An element in the second-last column of the periodic table that forms anions with a negative- 1 charge. 


\section{hanging wall}

the upper surface of a non-vertical fault

\section{hornfels}

a fine-grained metamorphic rock that is not foliated

\section{horst}

an uplifted fault block, bounded on either side by normal faults

\section{hot spot}

the surface area of volcanism and high heat flow above a mantle plume

\section{hydrolysis}

a reaction between a mineral and water in which $\mathrm{H}^{+}$ions are added to the mineral and a chemically equivalent amount of cations are released into solution

\section{hydroxide}

The anion $\mathrm{OH}^{-}$or an mineral that includes that anion.

igneous

a rock formed from the cooling of magma

\section{illite}

A clay mineral with a composition similar to that of muscovite mica.

\section{index minerals}

specific metamorphic minerals indicative of a particular metamorphic grade or range of pressure and temperature conditions

\section{industrial mineral}

includes all materials extracted from the Earth except for fuels, metallic ores, water, and gemstones.

\section{intrusive}

an igneous rock that has cooled slowly beneath the surface

ion

An atom that has either gained or lost electrons and has thus become charged (or a group of atoms that also has a charge - e.g., HCO3-).

\section{ionic bond}

A bond in which electrons are transferred from one atom to another, thus forming ions. 
island arc

A chain of volcanoes formed on the upper plate at a ocean-ocean convergent boundary. Volcanoes are built on oceanic crust.

\section{isoclinal fold}

a tight fold in which the limbs are parallel to each other

isotope

an form of an element that differs from other forms because it has a different number of neutrons (e.g., $16 \mathrm{O}$ has 8 protons and 8 neutrons while $18 \mathrm{O}$ has 8 protons and 10 neutrons)

\section{isotopic dating}

the absolute dating (dating in years) of a geologic material using the decay of radio-isotopes within the material

joint

a fracture in rock

ka

(Kilo annum) thousands of years before the present.

kaolinite

A clay mineral that does not have cations other than $\mathrm{Al}$ and $\mathrm{Si}$.

latitude

A measurement of the angular distance north or south from the equator of a point on Earth's surface. Coordinates are reported in degrees, minutes, and seconds.

lattice

The regular and repeating three-dimensional structure of a mineral.

levée

along a stream, the ridge that naturally forms along the edge of the channel during flood events level

in mining, a horizontal mine opening

\section{limbs}

the layers of rock on either side of a fold 


\section{limestone}

a sedimentary rock that is comprised mostly of calcite

\section{lithic arenite}

an arenite in which there is more than $10 \%$ lithic clasts and in which there are more lithic clasts than feldspar clasts

\section{lithification}

the conversion of unconsolidated sediments into rock by compaction and cementation

\section{lithosphere}

The rigid outer part of the Earth, including the crust and the mantle down to a depth of about 100 kilometres.

\section{longitude}

A measurement of the angular distance on Earth's surface east or west from the Prime Meridian in Greenwich, England. Coordinates are reported in degrees, minutes, and seconds.

Ma

(Mega annum) millions of years before the present.

mafic

silica poor $(<45 \% \mathrm{SiO} 2)$ in the context of magma or igneous rock

magma

Molten rock typically dominated by silica.

\section{magnetometer}

an instrument used to measure the intensity of a magnetic field

\section{mantle}

The middle layer of the Earth, dominated by iron and magnesium rich silicate minerals and extending for about 2900 kilometres from the base of the crust to the top of the core.

\section{mantle plume}

a plume of hot rock (not magma) that rises through the mantle (either from the base or from part way up) and reaches the surface where it spreads out and also leads to hot-spot volcanism

\section{map patterns}

In the context of a geological map, this refers to how a rock unit is drawn on the map, or the way a rock unit looks in map view. 
marble

metamorphosed limestone (or dolostone) in which the calcite or dolomite has been recrystallized into larger crystals

mass wasting

the mass failure, by gravity, of rock or unconsolidated material on a slope

massive

the texture of a metamorphic rock that is not foliated

meander scar

a mud-filled curved scar on the flood plain that marks the former location of an oxbow lake.

\section{meandering}

the sinuous path taken by a stream within a wide flat flood plain

mechanical weathering

the physical breakdown of rock into smaller fragments

member

A formal lithostratigraphic unit next in rank below a formation and is always a part of some formation. It is named as a member within a formation because it possesses characteristics distinguishing it from adjacent parts of the formation.

meridians of longitude

Imaginary lines that run north-south and are used to measure longitude in the geographic grid system.

\section{metallic lustre}

The lustre of a mineral into which light does not penetrate but only reflects off of the surface.

\section{metamorphic grade}

a descriptive term for the relative temperature and pressure conditions under which metamorphic rocks form e.g., low grade, intermediate grade or high grade

\section{metamorphic rock}

a rock formed by metamorphic processes that change the composition, texture or both of a preexisting parent rock (protolith)

\section{metamorphism}

the transformation of a parent rock into a new rock as a result of heat and pressure that leads to the formation of new minerals, or recrystallization of existing minerals, without melting 
mica

A sheet silicate mineral (e.g., biotite).

\section{migmatite}

a rock that is a mixture of metamorphic and igneous rock, formed at very high grades of metamorphism when a part of the metamorphic rock starts to melt

\section{minutes}

In the context of the geographic grid system, a distance equal to 60 seconds.

monomineralic

a rock composed of a single mineral

\section{mudrock}

an inclusive term for mudstone, shale and claystone

\section{muscovite}

A potassium-bearing non-ferromagnesian mica.

\section{National Topographic System}

The system used by Natural Resources Canada for providing general purpose topographic maps of the country.

native element

(Also native element mineral) a mineral that consists of only one element (e.g., native gold).

\section{non-ferromagnesian mineral}

A silicate mineral that does not contain iron or magnesium (e.g., feldsspar).

\section{non-metallic lustre}

The lustre of a mineral into which light does penetrate.

\section{normal fault}

a non-vertical fault along which the hanging wall (upper surface) has moved down relative to the footwall

northing

The northward-measured distance, or y-coordinate, used in the Universal Transverse Mercator (UTM) grid system. Reported in metres. 


\section{obsidian}

Volcanic glass formed by quenched lava in which few (if any) crystals form. Has obvious conchoidal fracture.

\section{oceanic crust}

The relatively thin and dense outermost layer of Earth's internal structure predominantly composed of mafic igneous rocks including gabbro intrusions, sheeted dikes, and pillow basalts. Formed by partial melting of the mantle beneath a spreading centre (ocean-ocean divergent boundary).

\section{olivine}

A silicate mineral made up of isolated silica tetrahedra and with either iron or magnesium (or both) as the cations.

ooid

Spheroidal particles $<2 \mathrm{~mm}$ in diameter composed of thin concentric layers of calcite or quartz precipitated from a solution around a nucleus. Typically formed in warm, shallow water with strong currents.

\section{oolitic}

a rock containing ooids (spheroidal particles $<2 \mathrm{~mm}$ in diameter composed of thin concentric layers of calcite or quartz precipitated from a solution around a nucleus)

\section{open-pit mine}

a mine that is open to the surface

\section{ordinal directions}

the direction found at the point equally between each cardinal direction: northeast (NE), southeast (SE), southwest (SW), and northwest (NW)

ore

a natural occurrence of rock or sediment that contains enough minerals with economically important elements that can be extracted at a profit

\section{outcrop}

To a geologist, an outcrop is an exposure of bedrock, the solid rock of the crust.

\section{overturned}

a geological feature that has been tilted to the point where it is upside down

\section{oxbow}

a part of a stream meander that has become isolated from the rest of the stream as the result of a meander cutoff 


\section{oxidation}

the reaction between a mineral and oxygen

\section{oxide}

A mineral in which the anion is oxygen (e.g., hematite Fe2O3).

\section{paleomagnetic}

past variations in the intensity and polarity of the Earth's magnetic field

\section{parallels of latitude}

Imaginary lines that run east-west and are used to measure latitude in the geographic grid system.

\section{partial melting}

the process during which a only specific mineral components of a rock melt in response to changing conditions

\section{partings}

a narrow gap between individual sedimentary layers

pebble

a sedimentary particle ranging in size from 2 to 64 millimetres (includes granule)

\section{phaneritic}

a rock texture in an igneous rock in which the individual crystals or grains are visible to the naked eye

\section{Phanerozoic}

The most resent eon of geological time, encompassing the Paleozoic, Mesozoic and Cenozoic.

\section{phenocrysts}

a relatively large crystal within an igneous rock that is distinctly coarser grained than the crystals forming the groundmass

\section{phosphate}

A mineral in which the anion is PO43-

\section{phyllite}

a foliated metamorphic rock and a sheen on the surface produced by aligned micas (phyllitic foliation).

\section{phyllosilicate}

A silicate mineral in which the silica tetrahedra are made up of sheets. 
planar

in the form of a plane, meaning a flat or level surface

plastic strain

The deformed rock cannot return to an un-deformed state once the deforming stress is removed. Irreversible strain.

plate

a region of the lithosphere that is considered to be moving across the surface of the Earth as a single unit

\section{plate tectonics}

The concept that the Earth's crust and upper mantle (lithosphere) is divided into a number of plates that move independently on the surface and interact with each other at their boundaries.

pluton

a body of intrusive igneous rock

point bar

Formed on the inside of a meander, where flow velocity is lower, by the deposition of sediment.

polymerize

the formation of molecular chains within a fluid (e.g., a magma) that lead to an increase in the fluid's viscosity

polymorph

two or more minerals with the same chemical formula but different crystal structures

porphyritic

an igneous texture in which some of the crystals (called phenocrysts) are distinctly larger than the rest

porphyry deposit

a mineral deposit (of copper or molybdenum especially) in which part of the host rock is a porphyritic stock

potassium feldspar

Feldspar with the formula KAlSi3O8.

prime meridian

The line of longitude defined to be $0^{\circ}$. Located in Greenwich, England. 


\section{principle of cross-cutting relationships}

the principle that a body of rock that cuts across or through another body of rock is younger than that other body

\section{principle of faunal succession}

the principle that life on Earth has evolved in an orderly way, and that we can expect to always find fossils of a specific type in rocks of a specific age

\section{principle of inclusions}

the principle that inclusions within a body of rock must be older than the rock

\section{principle of original horizontality}

the principle that sedimentary beds are originally deposited in horizontal layers

\section{principle of superposition}

the principle that in a sequence of layered rocks that is not overturned or interrupted by faulting, the oldest will be at the bottom and the youngest at the top

\section{principles of stratigraphy}

a series of principles used to interpret strata (layers of rocks) and determine the geologic history of a given sequence of rocks

\section{protolith}

the original, un-metamorphosed parent rock from which a given metamorphic rock is formed

\section{proton}

A sub-atomic particle with a mass of 1 and a charge of 1 .

\section{pumice}

a highly vesicular felsic volcanic rock (typically composed mostly of frothy glass fragments)

\section{pyroxene}

A single chain silicate mineral.

quartz

A silicate mineral with the formula $\mathrm{SiO} 2$.

quartzite

a non-foliated metamorphic rock formed from the contact or regional metamorphism of sandstone 


\section{recrystallization}

A purely physical process (no change in composition) that occurs in a solid-state during metamorphism. Atoms in a mineral are re-organized and typically grain size increases.

\section{recumbent fold}

a fold that is overturned such that its limbs are close to horizontal

reef

a mound of carbonate formed in shallow tropical marine environments by corals, algae and a wide range of other organisms

\section{regional metamorphism}

metamorphism caused by burial of the parent rock to depths greater than 5 kilometres (typically takes place beneath mountain ranges, and extends over areas of hundreds of km2)

\section{relative dating}

the interpretation of a relative order of events applied to a sequence of rocks using the principles of stratigraphy

relief

the amount of variation in elevation and slope in an area

\section{remnant magnetism}

magnetism of a body of rock that formed at the time the rock formed and is consistent with the magnetic field orientation that existed at that time and place

\section{representative fraction}

A fixed ratio (e.g., 1:50,000) between linear measurements on the map and the corresponding distances on the ground. An R.F. of 1:50,000 implies that $1 \mathrm{~cm}$ on the map represents 50,000 $\mathrm{cm}$ on the ground.

\section{reverse fault}

a non-vertical fault along which the hanging wall (upper surface) has moved up relative to the footwall

\section{rhyolite}

a felsic extrusive (volcanic) rock

\section{ridge push}

the concept that at least part of the mechanism of plate motion is the push of oceanic lithosphere down from a ridge area

\section{rock cycle}

the series of processes through which rocks are transformed from one type to another 


\section{roundness}

The degree of smoothing of a clast or grain due to abrasion of other sediments. Described by the terms: very angular, angular, sub-angular, sub-rounded, rounded, or well-rounded. Does not imply sphericity.

\section{Rule of V's}

a general rule for determining dip direction of dipping planar contacts deflected or bent as they cross a valley or stream

sand

a mineral or rock fragment ranging in size from $1 / 16$ th to 2 millimetres

\section{sandstone}

A clastic sedimentary rock that is primarily comprised of sand-sized particles.

scale bar

graphic or visual representation of the scale of a map

schist

A foliated metamorphic rock with visible aligned mica crystals.

\section{schistose}

Type of foliation defined by scaly layers of visible mica minerals or other platy or elongate minerals. Rocks with this texture appear shiny or sparkly, as the light glints off cleavage planes of the aligned minerals.

\section{scroll bars}

Curved ridges on the flood plain surface associated with the growth of a meander bend. Formed by sediment deposited on point bars.

\section{sea-floor spreading}

the formation of new oceanic crust by volcanism at a divergent plate boundary

\section{seconds}

In the context of the geographic grid system, a measurement of distance. Sixty seconds corresponds to one minute.

\section{sedimentary rock}

rock that has formed by the lithification of sediments

\section{sediments}

unconsolidated particles of mineral or rock 
seismograph stations

Station containing seismographs, which are instruments used to measure the vibrations produced by earthquakes. Data recorded by a seismograph are used to pinpoint the exact location and depth of an earthquake.

shaft

a vertical opening at a mine

shale

a silt- and clay-rich rock that has evidence of layering

shear stress

the stress placed on a body of rock or sediment adjacent to a fault

sheet silicate

A silicate mineral in which the silica tetrahedra are combined within sheets.

silica

A form of the mineral quartz (SiO2).

\section{silica tetrahedron}

A combination of 1 silicon atom and 4 oxygen atoms that form a tetrahedron.

silicate

A mineral that includes silica tetrahedra.

silicon

The 14th element.

silicone

A flexible synthetic material made up of $\mathrm{Si}-\mathrm{O}$ chains with attached organic molecules

silt

sedimentary particles ranging is size from $1 / 256$ th to $1 / 16$ th of a millimetres

slate

a fine-grained foliated metamorphic rock that splits easily into sheets

slaty

Type of foliation defined by closely spaced, flat surfaces along which a slate splits. Formed by the growth of microscopic mica minerals. 
smectite

A fine-grained sheet silicate mineral that can accept water molecules into interlayer spaces, resulting is swelling.

smelter

a refinery at which minerals are processed to produce pure metals

solid solution

The substitution of one element for another in a mineral (e.g., iron can be substituted for magnesium in the mineral olivine).

sorting

describes the distribution or range of grain sizes, either in unconsolidated sediments or in clastic sedimentary rocks

specific gravity

A number representing the ratio of a mineral's weight to the weight of an equal volume of water. A measure that geologist's use to describe the density of a mineral.

speleothem

a solutionally-formed feature within a limestone cave (e.g., a stalactite)

spring

the flow of groundwater onto the surface

stalactite

a cone-shaped speleothem that is suspended from the roof of a cave

stalagmite

a cone-shaped speleothem that forms on the floor of a cave

step-pool

a characteristic of stream flow in which water flows from one pool to another, typically on a stream with a steep gradient

strain

the deformation of rock that is subjected to stress

strata

layers of sedimentary, extrusive igneous, metasedimentary, or metavolcanic rocks 


\section{stratum}

a single layer of sedimentary, extrusive igneous, metasedimentary, or metavolcanic rock

streak

The mark left on a porcelain plate when a mineral sample is ground to a powder by being rubbed across the plate (typically considered to provide a more reliable depiction of the colour than the whole sample).

stream channel

The physical boundaries of a stream (or a river), consisting of a bed and stream (or river) banks.

stress

describes the force per unit area that acts on a rock unit to change its shape or volume

\section{striations}

a growth pattern that looks like a set of hairline grooves or faint parallel lines, visible on crystal faces of some minerals

strike

the compass direction of a horizontal line on a dipping planar surface (e.g., bedding plane, fracture etc.)

\section{strike-slip fault}

a fault that is characterized by motion that is close to horizontal and parallel to the strike direction of the fault

subducted

When part of a plate is forced beneath another plate along a subduction zone.

\section{sulphate}

A mineral in which the anion is SO42-.

\section{sulphide}

A mineral in which the anion is S2a mineral in which the anion is S2-.

\section{symmetrical}

a fold in which the limbs are at the same angle to the hinge

\section{syncline}

a downward fold where the beds are known not to be overturned

\section{tailings}

the fine-grained waste rock from a plant used to concentrate ore minerals 
talus slope

a sloped deposit of angular rock fragments at the base of a rocky escarpment or cliff

tectonic plate

A region of the lithosphere that is considered to be moving across the surface of the Earth as a single unit.

tensional

stress that tends to pull something apart

test

the shell-like hard parts (either silica or carbonate) of small organisms such as radiolarian and foraminifera

thin section

a fragment of rock or mineral cut and ground to a thickness of $\sim 0.03 \mathrm{~mm}$, and mounted on a glass slide to be closely examined under a petrographic microscope

\section{thrust fault}

a low angle reverse fault

till

unsorted sediment transported and deposited by glacial ice

\section{transform}

a boundary between two plates that are moving horizontally in opposing directions with respect to each other

\section{transform fault}

a boundary between two plates that are moving horizontally with respect to each other in opposing directions

\section{travertine}

a deposit of calcium carbonate that forms at springs, hot springs or within limestone caves

tufa

a form of travertine that is especially porous as it forms around existing vegetative material

\section{unconformity}

a geological boundary representing a period of erosion and/or non-deposition, where a portion of the rock record is missing 


\section{Universal Transverse Mercator}

A grid system used to specify locations on Earth's surface using easting and northing coordinates measured in metres.

vesicle

a small open cavity in a volcanic rock, produced by gas bubbles

vesicular

an igneous texture characterized by holes left by gas bubbles

volcanic glass

Magma that has cooled rapidly or quenched, not allowing time for the formation of crystals.

wacke

a sandstone with more than $15 \%$ clay and silt

weathering

a range of processes taking place in the surface environment, through which solid rock is physically broken into smaller fragments and transformed into sediment and ions in solution

\section{xenolith}

a fragment of "foreign rock", typically a fragment of the surrounding rock into which magma is intruding, incorporated into an igneous rock

youthful stream

a stream that is actively down-cutting its valley in an area that has recently been uplifted 


\section{Appendix i: List of Geologically Important Elements and the Periodic Table}

The following table includes 36 of the geologically important elements, listed alphabetically by their element name, along with their atomic number and the atomic mass of their most stable isotope.

The geologically most important elements are bolded identified with a tilde $(\sim)$, and the eight main elements of silicate minerals are identified with an asterisk $(*)$. 
36 important geological elements, listed alphabetically by their element name, along with their atomic number and the atomic mass of their most stable isotope

\begin{tabular}{|c|c|c|c|}
\hline Symbol & Name & Atomic Number & Atomic Mass \\
\hline $\mathrm{Al}^{*}$ & Aluminum & 13 & 27 \\
\hline As & Arsenic & 33 & 75 \\
\hline $\mathrm{Ba}$ & Barium & 56 & 137 \\
\hline $\mathrm{Be}$ & Beryllium & 4 & 9 \\
\hline B & Boron & 5 & 11 \\
\hline $\mathrm{Cd}$ & Cadmium & 48 & 112 \\
\hline $\mathrm{Ca}^{*}$ & Calcium & 20 & 40 \\
\hline $\mathrm{C} \sim$ & Carbon & 6 & 12 \\
\hline $\mathrm{Cl} \sim$ & Chlorine & 17 & 35 \\
\hline $\mathrm{Cr}$ & Chromium & 24 & 52 \\
\hline Co & Cobalt & 27 & 59 \\
\hline $\mathrm{Cu} \sim$ & Copper & 29 & 64 \\
\hline F & Fluorine & 9 & 19 \\
\hline $\mathrm{Au} \sim$ & Gold & 79 & 197 \\
\hline $\mathrm{He}$ & Helium & 2 & 4 \\
\hline $\mathrm{H} \sim$ & Hydrogen & 1 & 1 \\
\hline $\mathrm{Fe}^{*}$ & Iron & 26 & 56 \\
\hline $\mathrm{Pb} \sim$ & Lead & 82 & 207 \\
\hline$M g^{*}$ & Magnesium & 12 & 24 \\
\hline $\mathrm{Mn} \sim$ & Manganese & 25 & 55 \\
\hline Mo & Molybdenum & 42 & 96 \\
\hline $\mathrm{Ne}$ & Neon & 10 & 20 \\
\hline $\mathrm{Ni} \sim$ & Nickel & 28 & 59 \\
\hline $\mathrm{N}$ & Nitrogen & 7 & 14 \\
\hline $\mathrm{O}^{*}$ & Oxygen & 8 & 16 \\
\hline $\mathbf{P} \sim$ & Phosphorus & 15 & 31 \\
\hline $\mathrm{Pt}$ & Platinum & 78 & 195 \\
\hline $\mathrm{K}^{*}$ & Potassium & 19 & 39 \\
\hline $\mathrm{Si}^{*}$ & Silicon & 14 & 28 \\
\hline $\mathrm{Ag}$ & Silver & 47 & 108 \\
\hline $\mathrm{Na}^{*}$ & Sodium & 11 & 23 \\
\hline $\mathrm{Sr}$ & Strontium & 38 & 88 \\
\hline $\mathbf{S} \sim$ & Sulfur & 16 & 32 \\
\hline Ti $\sim$ & Titanium & 22 & 48 \\
\hline $\mathrm{U}$ & Uranium & 92 & 238 \\
\hline
\end{tabular}




\begin{tabular}{|c|c|c|c|}
\hline Symbol & Name & Atomic Number & Atomic Mass \\
\hline $\mathrm{Zn} \sim$ & Zinc & 30 & 65 \\
\hline
\end{tabular}

The periodic table is a list of all of the elements arranged in groups according to their atomic configuration. For an accessible version of the periodic table please see Syngenta Period Table of Elements. 


\section{Appendix 2: Answers to Practice Exercises}

The following are suggested answers to the practice exercises embedded in the various chapters of A Practical Guide to Introductory Geology. Answers to the questions in each lab exercise are provided in Appendix 3.

\section{Google Earth Tutorial}

Try typing these coordinates into the search bar in Google Earth. What geographic feature is located at 5102'39" N 11403'47" W? Answer: Calgary Tower.

1. What are the UTM coordinates (easting and northing) of the point in Figure T12 b? Answer: (orange diamond) $11 \mathrm{U} 708400 \mathrm{~m}$ E $5659200 \mathrm{~m} \mathrm{~N}$.

2. Try plotting the coordinate $11 \mathrm{U} 707500 \mathrm{~m}$ E $5658200 \mathrm{~m} \mathrm{~N}$ on Figure T12 b. Answer: see star on diagram

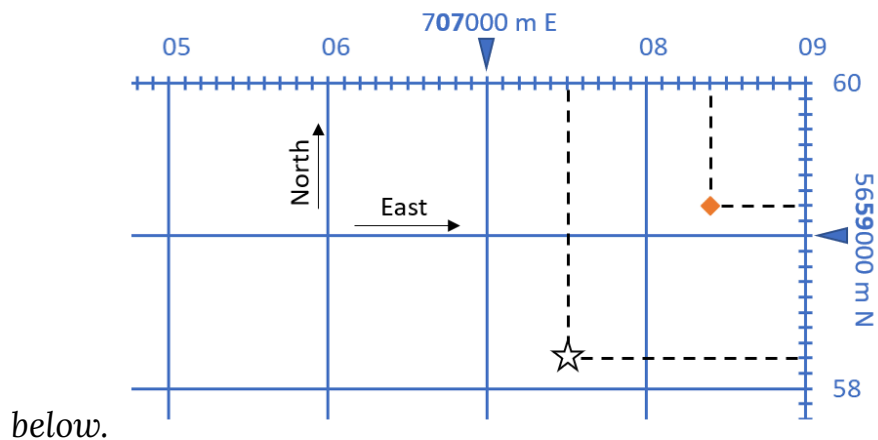

3. In the UTM grid shown in Figure T12 b, what is the length in metres of each side of each square on the grid? Answer: $1000 \mathrm{~m}$ or $1 \mathrm{~km}$ grid.

4. To see the grid lines for each system in Google Earth, click on View, Grid. Try zooming in and out to see how each grid type looks. Try this using the geographic grid (lat/long) and the UTM grid.

5. Type "Mount Royal University" into the search bar and click Search. Hover your cursor right on the place marker. What are the coordinates for MRU in lat/long? Remember, you must specify that MRU is north of the equator and west of the prime meridian! Answer: approximately $51^{\circ} 00^{\prime} 41^{\prime \prime} \mathrm{N} 114^{\circ} 07^{\prime} 52^{\prime \prime} \mathrm{W}$.

6. What are the coordinates for MRU in UTM coordinates? Remember, you must specify the zone number! Answer: approximately 11 U $701228 \mathrm{~m}$ E $5655021 \mathrm{~m} \mathrm{~N}$.

7. What are the coordinates for MRU in UTM as a grid reference? Remember, you must specify the zone number! Answer: 11 U 012550. 


\section{Introduction}

\section{Practice Exercise: Using geological time notation}

1. $2.75 \mathrm{ka}$ is 2,750 years.

2. $0.93 \mathrm{Ga}$ is $930,000,000$ years or 930 million years.

3. $14.2 \mathrm{Ma}$ is $14,200,000$ years or 14.2 million years.

\section{Practice Exercise: Take a trip through geological time}

1. The oxygenation of the atmosphere started at around $2.5 \mathrm{Ga}(2500 \mathrm{Ma})$. It was a catastrophe for many organisms because they could not survive the strong oxidizing effects of free oxygen.

2. We don't really know the answer to this, but it's not very long if you include insects, and there is evidence of insect damage to some of the earliest plants.

3. Plants on land allowed for animals on land, so without land plants, we wouldn't be here.

\section{Lab r: Plate Tectonics}

\section{Practice Exercise I.I Volcanoes and the rate of plate motion}

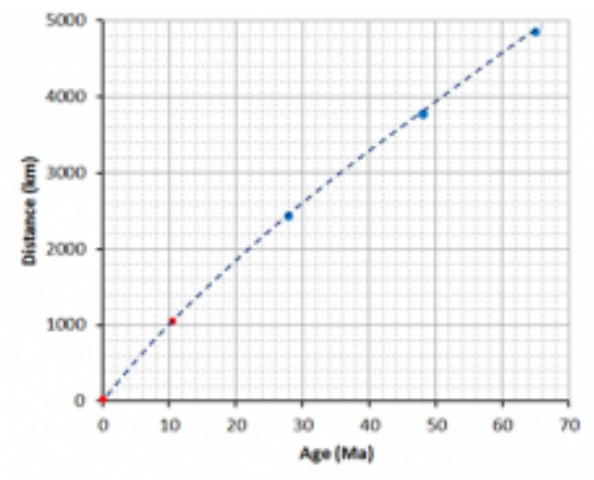

\begin{tabular}{|c|cc|c|}
\hline & Age $(\mathrm{Ma})$ & Distance $(\mathrm{km})$ & Rate $(\mathrm{cm} / \mathrm{y})$ \\
\hline Hawaii & 0 & 0 & - \\
\hline Necker & 10.3 & 1,058 & 10.2 \\
\hline Midway & 27.7 & 2,432 & 8.8 \\
\hline Koko & 48.1 & 3,758 & 7.8 \\
\hline Suiko & 64.7 & 4,860 & 7.5 \\
\hline
\end{tabular}

Pacific Plate rates of motion [Image by Steven Earle] 


\section{Lab 2: Mineral Properties and Non-Silicate Minerals}

\section{Practice Exercise 2.I}

Amethyst $\left(\mathrm{SiO}_{2}\right)$, halite $(\mathrm{NaCl})$, and (surprisingly) ice $\left(\mathrm{H}_{2} \mathrm{O}\right)$ are all minerals. Although sugar is a naturally occurring solid, it is an organic compound and therefore is not a mineral. Cubic zirconia $\left(\mathrm{ZrO}_{2}\right)$ is not a mineral because it is synthetically produced to be used as a gemstone, as it closely resembles diamonds. Obsidian is a naturally occurring volcanic glass. Like all glasses, obsidian does not have an orderly crystalline structure and is therefore not a mineral.

\section{Practice Exercise 2.2}

\begin{tabular}{|c|c|c|}
\hline Name & Formula & Group \\
\hline sphalerite & $\mathrm{ZnS}$ & sulphide \\
\hline magnetite & $\mathrm{Fe}_{3} \mathrm{O}_{4}$ & oxide \\
\hline pyroxene & $\mathrm{MgSiO}_{3}$ & silicate \\
\hline anglesite & $\mathrm{PbSO}_{4}$ & sulphate \\
\hline sylvite & $\mathrm{KCl}$ & halide \\
\hline silver & $\mathrm{Ag}$ & native \\
\hline fluorite & $\mathrm{CaF}_{2}$ & halide \\
\hline ilmenite & $\mathrm{FeTiO}_{3}$ & oxide \\
\hline siderite & $\mathrm{FeCO}_{3}$ & carbonate \\
\hline feldspar & $\mathrm{KAlSi}_{3} \mathrm{O}_{8}$ & silicate \\
\hline sulphur & S & native \\
\hline xenotime & $\mathrm{YPO}_{4}$ & phosphate \\
\hline
\end{tabular}

\section{Practice Exercise 2.3}

Responses will vary. 


\section{Practice Exercise 2.4}

\begin{tabular}{|c|c|c|c|c|c|}
\hline Element & Silicon & Calcium & Sodium & Potassium & Magnesium \\
\hline Source(s) & $\begin{array}{l}\text { quartz } \\
\text { sand }\end{array}$ & lime-stone & $\begin{array}{l}\text { halite } \\
(\mathrm{NaCl})\end{array}$ & $\begin{array}{l}\text { sylvite } \\
(\mathrm{KCl})\end{array}$ & $\begin{array}{l}\text { dolomite }\left((\mathrm{Ca}, \mathrm{Mg}) \mathrm{CO}_{3}\right) \text {, magnesite }\left(\mathrm{MgCO}_{3}\right) \text {, salt lakes and } \\
\text { the ocean }\end{array}$ \\
\hline
\end{tabular}

\section{Lab 3: Silicate Minerals}

\section{Practice Exercise 3.I Ferromagnesian silicates}

\begin{tabular}{lll}
\hline Mineral & Formula & Ferromagnesian Silicate? \\
olivine & $(\mathrm{Mg}, \mathrm{Fe})_{2} \mathrm{SiO}_{4}$ & yes \\
pyrite & $\mathrm{FeS}_{2}$ & no (it's a sulphide, not a silicate) \\
plagioclase & $\mathrm{CaAl}_{2} \mathrm{Si}_{2} \mathrm{O}_{8}$ & no \\
pyroxene & $\mathrm{MgSiO}_{3}$ & yes \\
hematite & $\mathrm{Fe}_{2} \mathrm{O}_{3}$ & no (it's an oxide, not a silicate) \\
orthoclase & $\mathrm{KAlSi}_{3} \mathrm{O}_{8}$ & no \\
quartz & $\mathrm{SiO}_{2}$ & no \\
\hline
\end{tabular}

\section{Lab 4: Igneous Rocks}

\section{Practice Exercise 4.I Rock types based on magma composition}

\begin{tabular}{|c|c|c|c|c|c|c|c|c|}
\hline $\begin{array}{l}\text { Rock } \\
\text { Sample }\end{array}$ & $\mathrm{SiO} 2$ & $\mathrm{Al}_{2} \mathrm{O}_{3}$ & $\mathrm{FeO}$ & $\mathrm{CaO}$ & MgO & $\mathrm{Na}_{2} \mathrm{O}$ & $\mathrm{K}_{2} \mathrm{O}$ & What type of magma is it? \\
\hline Rock 1 & $55 \%$ & $17 \%$ & $5 \%$ & $6 \%$ & $3 \%$ & $4 \%$ & $3 \%$ & $\begin{array}{l}\text { intermediate (although the } \mathrm{SiO} 2 \text { level is borderline, there is } \\
\text { too little } \mathrm{FeO}, \mathrm{MgO} \text { and } \mathrm{CaO} \text { to be mafic) }\end{array}$ \\
\hline Rock 2 & $74 \%$ & $14 \%$ & $3 \%$ & $3 \%$ & $0.5 \%$ & $5 \%$ & $4 \%$ & felsic \\
\hline Rock 3 & $47 \%$ & $14 \%$ & $8 \%$ & $10 \%$ & $8 \%$ & $1 \%$ & $2 \%$ & mafic \\
\hline Rock 4 & $65 \%$ & $14 \%$ & $4 \%$ & $5 \%$ & $4 \%$ & $3 \%$ & $3 \%$ & $\begin{array}{l}\text { intermediate (although the } \mathrm{SiO} 2 \text { level is borderline, there is } \\
\text { too much } \mathrm{MgO} \text { and } \mathrm{CaO} \text { to be felsic) }\end{array}$ \\
\hline
\end{tabular}




\section{Practice Exercise 4.2 Porphyritic minerals}

1. only olivine phenocrysts

2. pyroxene and amphibole phenocrysts, along with plagioclase with a composition that is about halfway between the Ca-rich and the Na-rich end-members.

\section{Practice Exercise 4.3 Mineral proportions in igneous rocks}

1. Roughly $25 \% \mathrm{~K}$-feldspar, $30 \%$ quartz, $35 \%$ albitic plagioclase and 10 biotite/amphibole,

2. Roughly $65 \%$ plagioclase and $35 \%$ biotite/amphibole (most likely amphibole),

3. Roughly $45 \%$ anorthitic plagioclase, $25 \%$ amphibole and $35 \%$ pyroxene

4. Roughly $50 \%$ pyroxene and $50 \%$ olivine.

\section{Practice Exercise 4.4 Proportions of Ferromagnesian Silicates}

The approximate proportions are: $10 \%, 50 \%, 30 \%$ and $2 \%$, and the corresponding rock names are granite, gabbro (although it's right on the boundary between gabbro and diorite), diorite and granite.

\section{Lab 5: Sediments and Sedimentary Rocks}

\section{Practice Exercise 5.I Chemical weathering}

\section{Chemical change}

1. Pyrite to hematite

2. Calcite to calcium and bicarbonate ions
Process

oxidation

dissolution 


\section{Practice Exercise 5.2 Describing the weathering origins of sands}

\section{Sand description}

Fragments of coral etc. from a shallow water area near to a reef in Belize

Angular quartz and rock fragments from a glacial stream deposit near Osoyoos

Rounded grains of olivine and volcanic glass from a beach in Hawaii

\section{Possible processes}

Reefs are constantly being eroded by ocean waves, and the fragments are washed inshore by currents and then further eroded by wave action.

Quartz-bearing rocks have been eroded and transported by a glacier. The fragments may have been moved a short distance by a stream, but not enough to produce rounding.

The olivine and glass grains are eroded by waves from volcanic rock and then thoroughly rounded by waves on the beach

\section{Practice Exercise 5.3 Classifying sandstones}

\section{Description}

Angular grains, 85\% quartz, 15\% feldspar, less than 5\% silt and clay

Rounded grains, $99 \%$ quartz, less than $2 \%$ silt and clay

Angular grains, 70\% quartz, 20\% lithic and 10\% feldspar, roughly 20\% silt and clay

\section{Rock name}

Arkosic arenite

Quartz arenite

Lithic wacke

\section{Lab 6: Metamorphic Rocks and the Rock Cycle}

\section{Practice Exercise 6.I How long did it take?}

It might have taken in the order of 20 to 25 million years for these garnets to form, but even more time is needed than that to produce the rock because we have to account for the sedimentary process and then burial and lithification and then deeper burial to reach metamorphic environment - several tens of millions more years. 


\section{Practice Exercise 6.2 Metamorphic rocks in areas with higher geothermal gradients}

\begin{tabular}{ll}
\hline Metamorphic Rock Type & Depth $(\mathbf{k m})$ \\
1. Slate & 2 to 5 \\
2. Phyllite & 5 to 8 \\
3. Schist & 8 to 12 \\
4. Gneiss & 12 to 17 \\
5. Migmatite & 17 to 25 \\
\hline
\end{tabular}

\section{Practice Exercise 6.3 Naming metamorphic rocks}

Rock Description

1. A rock with visible minerals of mica and with small crystals of andalusite. The mica crystals are consistently parallel to one another.

2. A very hard rock with a granular appearance and a glassy lustre. There is no evidence of foliation.

3. A fine-grained rock that splits into wavy sheets. The surfaces of the sheets have a sheen to them.

4. A rock that is dominated by aligned crystals of amphibole.

\section{Name}

Schist or (preferably)

Mica-andalusite schist

Probably quartzite

Phyllite

Amphibolite

\section{Practice Exercise 6.4 Rock around the rock-cycle clock}

Sedimentary rock is buried deeper to make metamorphic rock, the metamorphic rock is uplifted and during this process the material overhead is eroded so that it can be exposed at surface. The metamorphic rock is then eroded to make more sediments, which are transported by wind, water, or ice, deposited and then buried to make sedimentary rock. This would likely take at least 60 million years. 


\section{Lab 7: Relative Dating and Geological Time}

\section{Practice Exercise 7.I Cross-cutting relationships}

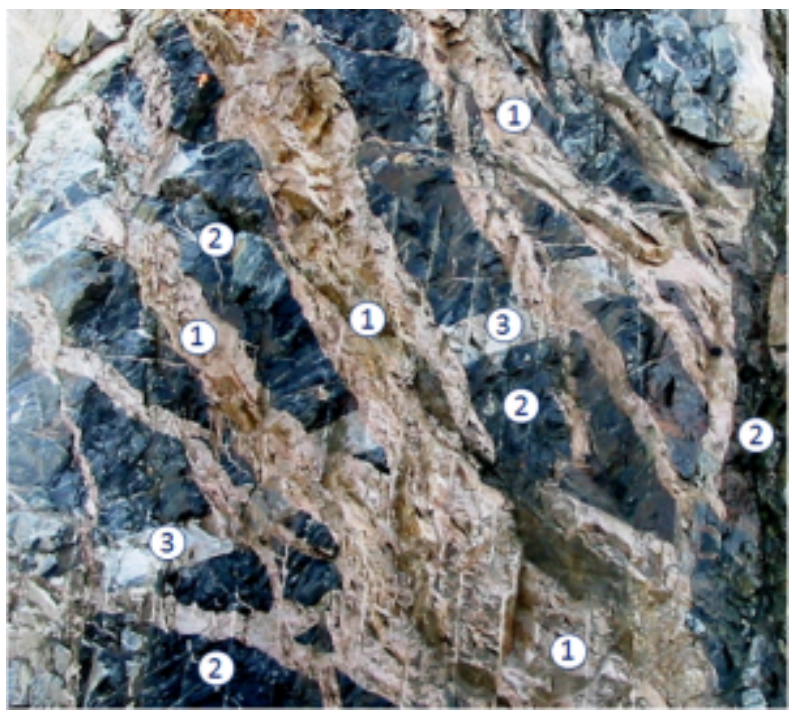

Relative ages: 2: oldest: 3: middle, 1: youngest [Steven Earle]

\section{Lab 8: Mapping Fluvial Landscapes}

\section{Practice Exercise 8.I Understanding the Hjulström-Sundborg Diagram}

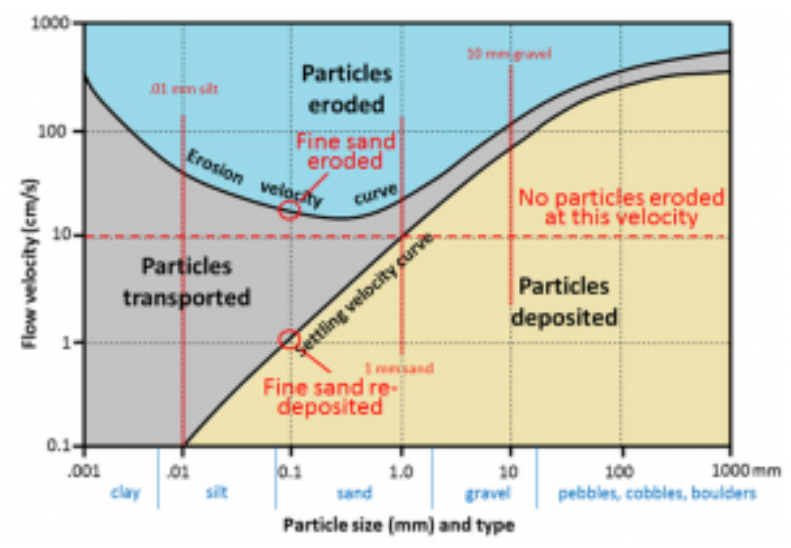

[Image by Steven Earle]

1. A fine sand grain ( 0.1 millimetres) is resting on the bottom of a stream bed. 
1. What stream velocity will it take to get that sand grain into suspension? Roughly 20 centimetres per second.

2. Once the particle is in suspension, the velocity starts to drop. At what velocity will it finally come back to rest on the stream bed? Roughly 1 centimetres per second.

2. A stream is flowing at 10 centimetres per second (which means it takes 10 seconds to go 1 metre, and that's pretty slow).

1. What size of particles can be eroded at 10 centimetres per second? No particles, of any size, will be eroded at 10 centimetres per second, although particles smaller than 1 millimetre that are already in suspension will stay in suspension.

2. What is the largest particle that, once already in suspension, will remain in suspension at 10 centimetres per second? A 1 millimetre diameter particle should remain in suspension at 10 centimetres per second.

\section{Practice Exercise 8.2 Scale bar}

What R.F. is shown by the scale bar drawn above? Assume that each of the long bars on the scale bar is $2 \mathrm{~cm}$ in length. Hint: you will have to do some unit conversions!

Solution:

$($ Map distance $) /($ Ground distance $)=(1 \mathrm{~cm}) /(0.5 \mathrm{~km})=(1 \mathrm{~cm}) /(50,000 \mathrm{~cm})=1 / 50,000=1: 50,000$

Measuring with your ruler, $1 \mathrm{~cm}$ on the scale bar represents $0.5 \mathrm{~km}$, or $500 \mathrm{~m}$, or $50,000 \mathrm{~cm}$. Therefore, the scale bar represents a R.F. of 1:50,000.

\section{Practice Exercise 8.3 Topographic Contour Lines}

Examine the example topographic map in Figure 8.3.3. The map shows two hills separated by a small valley that has two streams.

1. Which hill is the tallest? Or, in other words, which hill has the highest elevation? The hill to the northwest is the tallest.

2. What is the approximate elevation of the red star? The elevation at the point indicated by the red star would be approximately $175 \mathrm{~m}$, as it is located roughly halfway between the $150 \mathrm{~m}$ and the $200 \mathrm{~m}$ contour lines.

3. Toward which direction is each stream flowing? The stream located northwest of the red star is flowing toward the NE. The stream located southwest of the red star is flowing toward the SW. Streams always flow downhill, by examining the topographic contour lines you can determine which direction is upstream or downstream.

4. Can you see anywhere on the map where topography would be relatively steep? Yes, the area near the "200 m" label is relatively steep.

5. Can you see anywhere on the map where topography would be relatively gentle or flat? Yes, the areas near the two streams have relatively gentle slopes.

6. How can you tell the difference between areas with steep versus gentle topography using the contour lines? Contour lines that are closely spaced on the map indicate steeper slopes, whereas contour lines that 
are spaced far apart indicate gentle topography.

7. Notice that the $50 \mathrm{~m}$ and $100 \mathrm{~m}$ contour lines forms a "V" shape as they cross the stream. Topographic contour lines always form a " $\mathrm{V}$ " shape as they cross a stream, and the point of the "V" always points upstream. Imagine there is a third stream that originates at the red star and flows toward the NE. Draw in this third stream and using dashed lines, modify the contour lines where they cross this stream. Modified contour lines should also form a "V" shape that points upstream (up hill) as they cross this new stream.

\section{Lab 9: Structural Geology Part I}

\section{Practice Exercises 9.I}

1. In Figures 9.1.1 and 9.1.2, which principle was used to determine the oldest and youngest sedimentary rocks in the diagram? Answer: principle of superposition. Even though the strata in Figure 9.1.2 have been tilted, imagine rotating them back to horizontal, and you can still determine the relative ages of the four layers. NOTE: in some cases strata can be completely overturned, therefore this assumption does not always hold true. For the purposes of this course, assume the strata have NOT been overturned.

2. In Figure 9.1.2, which principle tells you that these strata were tilted after deposition and lithification? Answer: principle of original horizontality

3. Toward which direction are the strata dipping in Figure 9.1.3? Answer: south

4. How steeply are the strata dipping in Figure 9.1.3? Answer: $45^{\circ}$

\section{Lab Io: Structural Geology Part II}

\section{Practice Exercise Io.I Folding style}

In order to help with the interpretation, one of the beds has been traced (in yellow) on the diagram below, and two of the fold axes have been shown (in pink). These folds are symmetrical, and although they are tight they are not isoclinal. They are overturned. 


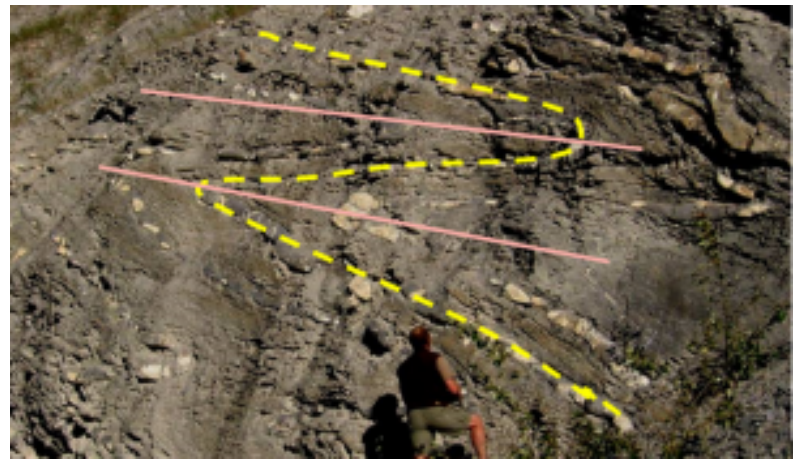

Folded rocks (in yellow) and fold axes (pink) [Image by Steven Earle]

\section{Practice Exercise Io.2 Types of faults}

Top left: a normal fault, implying extension

Bottom left: a series of normal faults, extension

Top right: A reverse fault, compression

Bottom right: a right lateral fault (implies that there is shearing, but it is not possible to say if there is extension or compression) 


\section{Appendix 3: Answers to Lab Exercises}

The following are suggested answers to the lab exercises for Labs 1 to 10 in A Practical Guide to Introductory Geology. Answers to the practice exercises are provided in Appendix 2.

\section{Lab i: Plate Tectonics}

Click to view Table 1.1 Answers.

1. Approximate lat/long coordinates of volcanoes along Hawaii-Emperor chain:

- Kilauea Volcano: $19^{\circ} 24^{\prime} 00^{\prime \prime} \mathrm{N} 155^{\circ} 18^{\prime} 00^{\prime \prime} \mathrm{W}$

- Diakakuji Seamount: $32^{\circ} 8^{\prime} 43^{\prime \prime} \mathrm{N} 172^{\circ} 22^{\prime} 39^{\prime \prime} \underline{\mathbf{E}}$ (note that this seamount lies on the opposite side of the 180th meridian from the Kilauea Volcano and Midway Island, and its longitude is therefore described as east)

- Midway Island: $28^{\circ} 13^{\prime} 10^{\prime \prime} \mathrm{N} 177^{\circ} 22^{\prime} 25^{\prime \prime} \mathrm{W}$

2. Approximate UTM coordinates of volcanoes along Hawaii-Emperor chain:

- Mauna Kea: 5 Q 238012 m E 2185749 m N

- 75.82 Ma volcano near the Detroit Seamount: 58 U 692456 m E 5647840 m N

- 5.77 Ma volcano on Kaua'i: 4 Q 448389 m E 2432911 m N

\section{Roughly $2,450 \mathrm{~km}$}

4. Rate of plate motion: $88.4 \mathrm{~km} / \mathrm{Ma}$

5. Rate of plate motion: $8.8 \mathrm{~cm} / \mathrm{yr}$

6. The "elbow-like" kink in the Hawaii-Emperor chain is widely ascribed to a change in direction of the Pacific Plate moving over the stationary mantle plume, but a more plausible explanation is that the Hawaiian mantle plume has not actually been stationary throughout its history, and in fact moved at least 2,000 km south over the period between 81 and $45 \mathrm{Ma}$. 


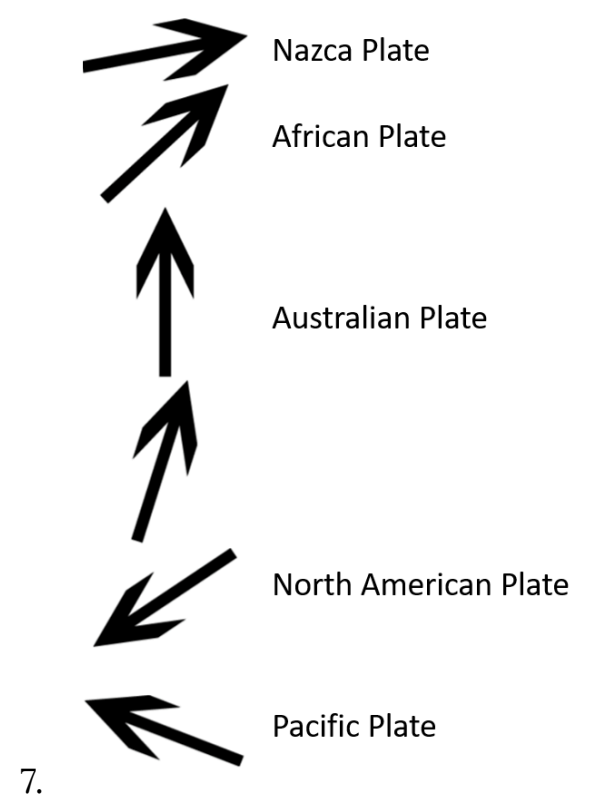

8. a) and b) are both divergent boundaries.

\section{Lab 2: Mineral Properties and Non-Silicate Minerals}

Part I: Cleavage and Fracture

1.

\begin{tabular}{llllllll}
\hline Sample & M226S & M225S & M1S & M251S & M111S & M223S & M131S \\
$\begin{array}{l}\text { Cleavage or } \\
\text { fracture }\end{array}$ & $\begin{array}{l}\text { Conchoidal } \\
\text { frature }\end{array}$ & $\begin{array}{l}\text { Conchoidal } \\
\text { frature }\end{array}$ & 3 at $90^{\circ}$ & 3 not at $90^{\circ}$ & $* 2$ not at $90^{\circ}$ & Fracture & Fracture \\
\hline
\end{tabular}

*Note it can be challenging to see the two cleavage planes in this sample.

2. Not much! Both crystal faces and cleavage planes reflect light well and appear as flat surfaces. Crystal faces may have striations. Remember that cleavage planes (but not crystal faces!) repeat throughout the mineral, so look for the same plane, in the same orientation throughout the sample.

3. Any of the feldspar samples (potassium feldspar or plagioclase) as well as the pyroxene sample also have two cleavage planes at $\sim 90^{\circ}$.

4. Hornblende (amphibole) has two cleavage planes at approximately $56^{\circ}$ and $124^{\circ}$ (describe this at 2 not at $90^{\circ}$ for the purposes of this course).

5. Muscovite and biotite.

6. Curved, smooth. This sample does not exhibit cleavage.

7. Jasper, flint, any quartz sample.

Part II - Non-silicate Minerals

\section{Graphite}


1. not often - too soft!, 1 plane

2. $\mathrm{H}=1-2$

3. low

4. metallic

5. grey-black

6. writes on paper, hardness $=1-2$, grey-black streak, greasy feel

\section{Magnetite and hematite}

1. no

2. no cleavage

3.

Sample M51/M52

Lustre: metallic/sub-metallic

Sample M53

Lustre: dull or earthy

4. Streak is the same red-brown colour

5. magnetite

6. it is magnetic

7. red-brown streak

\section{Calcite}

1. yes, 3 not at $90^{\circ}$

2. $\mathrm{H}=\sim 3$

3. vitreous

4. yes - vigorously

5. effervesces (reacts) with $\mathrm{HCl}, \mathrm{H}=3$, has 3 cleavage planes not at $90^{\circ}$

Sulphides (pyrite, galena, chalcopyrite, sphalerite)

\begin{tabular}{ll}
\hline Sample M41/M42 & Mineral name: Pyrite \\
Sample M31 & Mineral name: Chalcopyrite \\
Sample M1 & Mineral name: Galena \\
Sample M141 & Mineral name: Sphalerite \\
\hline
\end{tabular}

1. All are part of the sulphide mineral group (all mineral formulae end with a sulphur anion (S)).

2. Pyrite may scratch the glass plate, all others are too soft to scratch glass.

3. pyrite

4. Pale yellow colour, strong sulphur smell (smells like rotten eggs)

5. metallic

6. Varies - can be non-metallic (resinous, vitreous, adamantine) or metallic to sub-metallic

7. galena

8. Sphalerite (6 planes!) and galena (3 at $\left.90^{\circ}\right)$

9. Pyrite is harder, chalcopyrite has a greenish-black streak and tarnishes to bright purple-blue-yellow (peacock-like) colours.

10. High specific gravity

11. Pale yellow streak that smells of sulphur

12. 


\begin{tabular}{llll}
\hline Sample \# & Mineral Name & Mineral Formula & Ore Metal \\
M1 & Galena & $\mathrm{PbS}$ & $\mathrm{Pb}-$ lead \\
M31 & Chalcopyrite & $\mathrm{CuFeS}_{2}$ & $\mathrm{Cu}-$ copper \\
M141 & Sphalerite & $\mathrm{ZnS}$ & $\mathrm{Zn}-$ zinc \\
\hline
\end{tabular}

13. Galena is the principal ore of lead. Lead is used in lead-acid batteries, as well as in ceramics and glass.

14. Galena is extracted along with any other ore minerals and waste rock from a deposit. Depending on the size, shape, and depth of the deposit, this might be via an open pit mine where ore is accessed from the surface, or via an underground mine where ore is accessed along shafts and levels. The rock extracted from the deposit is ground into a fine powder, and then the material is separated into ore concentrate and tailings (waste). The concentrate is sent to a smelter, the lead-zinc smelter in Trail, B.C., to be refined into pure lead metal. This pure metal can then be sold to manufacturers.

\section{Gypsum}

1. $\mathrm{H}=2$ (scratches with a fingernail)

2. vitreous or satiny, can be silky (selenite variety of gypsum forms as fibrous, silky crystals)

3. $\mathrm{H}=2$, vitreous or satiny lustre

4. Gypsum is used to make wallboard or drywall. Nova Scotia is the most productive gypsum mining area in the world!

Halides (halite, fluorite)

1.

Sample M231

Sample M261

Sample M262
Cleavage: 3 planes at $90^{\circ}$

Cleavage: 4 planes

Cleavage: 4 planes

2. What is the approximate hardness of the two minerals on the Mohs scale of hardness?

Halite: $\mathbf{H}=\mathbf{3}$

Fluorite: $\mathbf{H}=\mathbf{4}$

3. fluorite

4. tastes salty, well defined cleavage planes $\left(3\right.$ at $\left.90^{\circ}\right)$

5. $\mathrm{H}=4,4$ cleavage planes

6. Hardness test (fluorite $\mathrm{H}=4$, quartz $\mathrm{H}=7$ ), cleavage (fluorite has 4 planes, quartz has no cleavage)

\section{Lab 3: Silicate Minerals}

\section{Framework Silicates}

1. quartz

2. conchoidal fracture and crystal faces (M221), irregular fracture (M222), conchoidal fracture (M223 and M224)

3. May see striations on crystal faces, cleavage planes (but not crystal faces!) repeat throughout the mineral, so look for the same plane, in the same orientation throughout the sample.

4. $\mathrm{H}=7$ 


\section{Vitreous}

6. $\mathrm{H}=7$, vitreous lustre, conchoidal fracture

7. Yes, flint also has a hardness of 7 and conchoidal fracture.

\section{Sample M201}

Sample M202

Sample M211

\author{
Mineral name: potassium feldspar (white) \\ Mineral name: potassium feldspar (pink) \\ Mineral name: plagioclase (might be albite or \\ labradorite - depends on your kit!)
}

1. $\mathrm{H}=6$ for all feldspar samples

2. 2 cleavage planes at $90^{\circ}$ for all feldspar samples

3. Striations on 'light'-coloured (white) plagioclase feldspar (M211). Iridescence and striations (like the sheen from spilled gasoline in water) on 'dark'-coloured plagioclase feldspar (M211).

4. Only plagioclase feldspar has striations. Only some potassium feldspar have exsolution lamellae - wavy, irregular 'veiny' lines that may appear as a slightly different colour than the rest of the sample (e.g., paler pink, cloudy more opaque white).

\section{Sheet Silicates}

\section{Sample M121}

Sample M271

\section{Mineral name: biotite}

Mineral name: muscovite

1. one perfect 'basal' cleavage plane

2. $\mathrm{H}=2.5$

3. elastic 'sheets' that can bend, one perfect 'basal' cleavage plane

4. Muscovite is light in colour (almost colourless), biotite is dark brown to black in colour due to iron (Fe) and magnesium (Mg).

\section{5. $\mathrm{H}=1$}

6. pearly or dull

7. $\mathrm{H}=1$, will leave pale mark on cloth, greasy or soapy feel

Sample M291 Mineral name: kaolinite

8. earthy or dull

9. earthy lustre, smells like clay when wet

Single Chain Silicates (pyroxene family)

\section{2 at $90^{\circ}$}

2. shades of green to almost black

3. colour (shades of green to almost black), 2 cleavage planes at $90^{\circ}, \mathrm{H}=\sim 5-6$

\section{Double Chain Silicates (amphibole family)}


1. 2 not at $90^{\circ}\left(\sim 56^{\circ}\right.$ and $\left.124^{\circ}\right)$

2. greenish-black to black

3. dark colour, 2 cleavage planes not at $90^{\circ}, \mathrm{H}=\sim 5-6$

Isolated Silicates

Mineral name: garnet

1. yes

2. $\mathrm{H}=6.5-7.5$

3. vitreous, sometimes resinous

4. vitreous lustre, no cleavage, hardness $=6.5-7.5$, and colour (colour can vary but typically shades of red to red-brown)

Sample M301

Mineral name: olivine

5. $\mathrm{H}=6.5-7$ (difficult to test in some samples due to small size of olivine crystals)

6. sugary, granular (small crystals that look like grains of sugar)

7. colour - pale green to green-yellow

Lab 4: Igneous Rocks

1.

\section{Sample R2}

Sample R151

Sample R281
Texture: crystalline (igneous rock)

Texture: clastic (sedimentary rock)

Texture: crystalline (sedimentary rock)

2. The colour of an igneous rock is an indication of its composition (mafic, intermediate, felsic). The composition of the magma controls which minerals will crystallize and the colours of the minerals are reflected by the colour of the rock.

3. Three groups represent phaneritic, aphanitic, and glassy igneous rocks.

4. Grain size is an indication of cooling rate. Larger crystals indicate a slower cooling rate (common for intrusive igneous rocks). Crystals that are too fine to see (forming an aphanitic texture) indicate rapid cooling at or near the surface (extrusive igneous rocks). Rocks with glassy textures and no crystals indicate very rapid cooling or quenching.

\section{Sample R1}

Sample R2

5. look at a fresh surface

6. crystals
Rock name: granite (white)

Rock name: granite (pink) 
7. K-feldspar (pink), K-feldspar (white), white plagioclase

8. phaneritic

9. similar size, $\sim 1-2 \mathrm{~mm}$

10. light

11. 85-90\% non-ferromagnesian, 10-15\% ferromagnesian

12. pink or white K-feldspar, quartz, plagioclase (white), ferromagnesian minerals include biotite and/or hornblende (varies by sample)

13. pink K-feldspar

\section{Sample R11}

Rock name: rhyolite

14. fresh

15. aphanitic

16. light pink-grey, buff coloured, some samples have flow banding

17. texture (grain size)

18. extrusive (rapid cooling)

Sample R21

Rock name: andesite

19. fresh

20. porphyritic

21. phenocrysts

22. yes on plagioclase and amphibole phenocrysts

23. Some samples have only 1-2 mm laths of white plagioclase (bladed elongate shaped crystals), others have only 3-5 $\mathrm{mm}$ amphibole (dark green to black), some may have both.

24. varies with sample

25. intermediate (varying shades of grey)

Sample R31

Rock name: diorite

26. fresh

27. phaneritic

28. no - although size varies depending on which sample you have, within each sample crystals are all of similar size

29. slowly (intrusively)

30. plagioclase, amphibole, $+/$ - quartz, biotite

31. $50 \%$ non-ferromagnesian, $~ 50 \%$ ferromagnesian

32. yes, white plagioclase and amphibole

33. intermediate in colour, black and white rock, no pink minerals

34. fresh

35. phaneritic

315 | Appendix 3: Answers to Lab Exercises 
36. yes, plagioclase (may be dark grey in colour and difficult to tell apart from pyroxene!), pyroxene

37. 10-20\% non-ferromagnesian, 80-90\% ferromagnesian

38. mineralogy, different minerals give each sample a different appearance (colour). R1 is light in colour (felsic), R31 is intermediate, and R51 is dark in colour (mafic).

39. aphanitic

40. no

41. dark grey to black

42. extrusive, aphanitic texture implies rapid cooling at or near the surface

43. texture (grain size), and therefore cooling history. R51 is phaneritic while R41 is aphanitic.

Sample R42

Rock name: vesicular basalt

44. aphanitic and vesicular

45. vesicles. Formed from mafic lava flowing on the surface that cools rapidly as gases escape, leaving gas bubbles preserved in the basalt.

46. texture - one is vesicular and the other is not

Sample R61

Rock name: obsidian

47. glassy, looks like a piece of broken glass

48. no

49. conchoidal fracture

50. Both are glassy, however pumice appears frothy as it consists of small shards of glass welded together with many vesicles whereas obsidian looks like a solid, massive piece of glass. There is also a colour difference: obsidian is dark brown to black in colour whereas pumice is pale in colour (may be white, grey, buff, or tan).

\section{Lab 5: Sediments and Sedimentary Rocks}

1. 


\begin{tabular}{|c|c|c|c|c|c|}
\hline 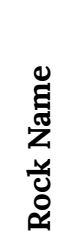 & 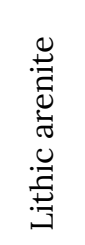 & 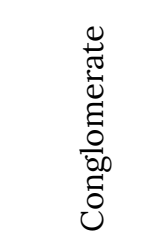 & 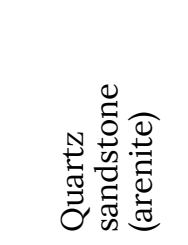 & 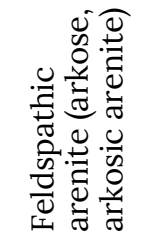 & $\frac{\frac{\pi}{\pi}}{\frac{\pi}{\tilde{2}}}$ \\
\hline 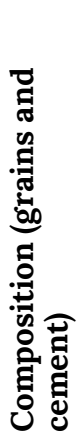 & 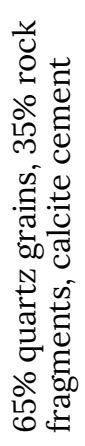 & 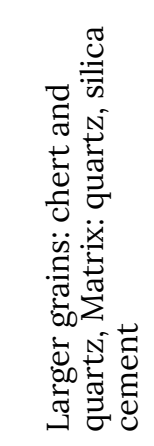 & 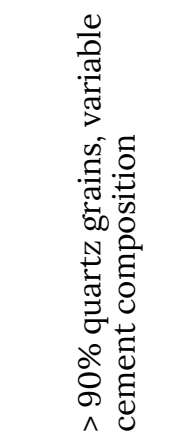 & 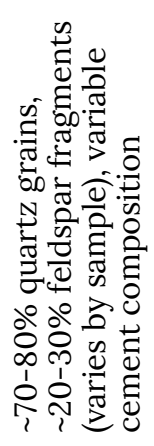 & 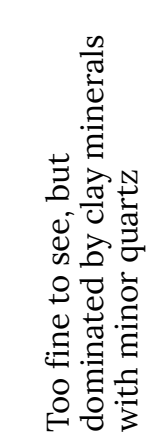 \\
\hline 造 & 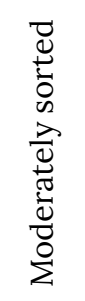 & $\begin{array}{l}\overrightarrow{0} \\
0 \\
0 \\
2 \\
0 \\
0 \\
0 \\
0 \\
0 \\
0 \\
0\end{array}$ & $\begin{array}{l}0 \\
0 \\
0 \\
0 \\
0 \\
\overline{0} \\
3\end{array}$ & 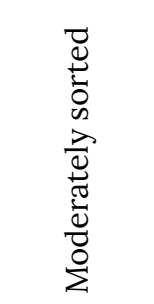 & 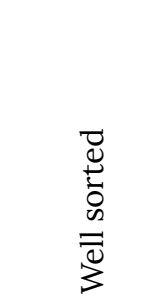 \\
\hline 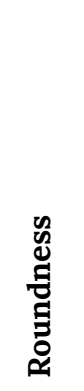 & $\begin{array}{l}\text { D } \\
0 \\
\Xi \\
\vdots \\
0 \\
1 \\
0 \\
0 \\
0\end{array}$ & 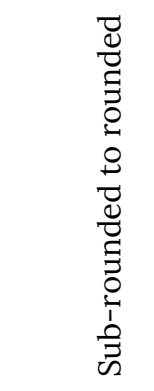 & 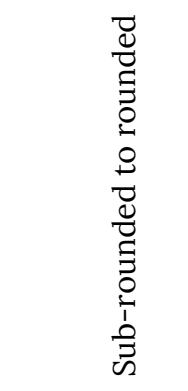 & 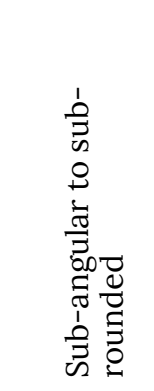 & 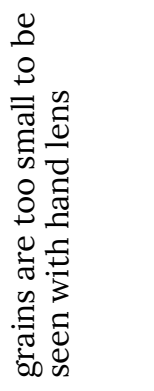 \\
\hline 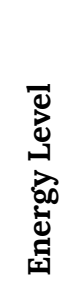 & 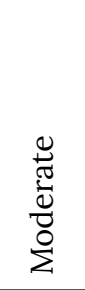 & $\begin{array}{l}\frac{\pi}{00} \\
.0 \\
0\end{array}$ & 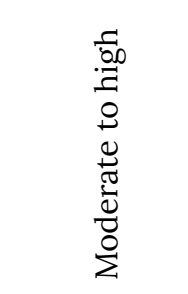 & 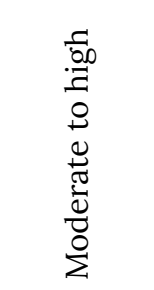 & 3 \\
\hline 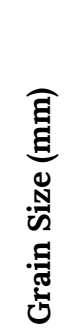 & 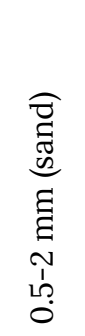 & 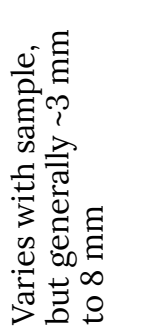 & 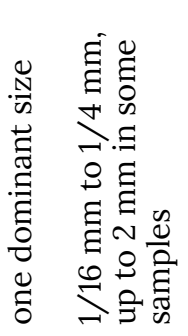 & 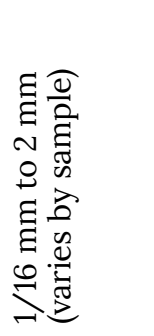 & 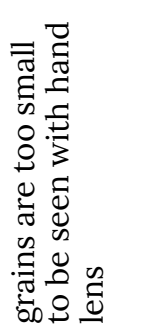 \\
\hline 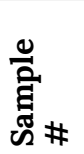 & 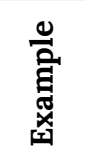 & $\frac{\overrightarrow{p a}}{\bar{a}}$ & $\begin{array}{l}\bar{\emptyset} \\
\bar{\alpha}\end{array}$ & 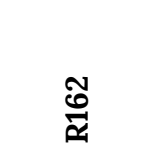 & $\begin{array}{l}\bar{\infty} \\
\vec{\alpha}\end{array}$ \\
\hline
\end{tabular}


2. All four samples are detrital (clastic) in origin. In all but R181 the clasts or grains are large enough to see that the rock clearly has a clastic texture consisting of fragments of pre-existing rocks or minerals cemented together to form a clastic sedimentary rock.

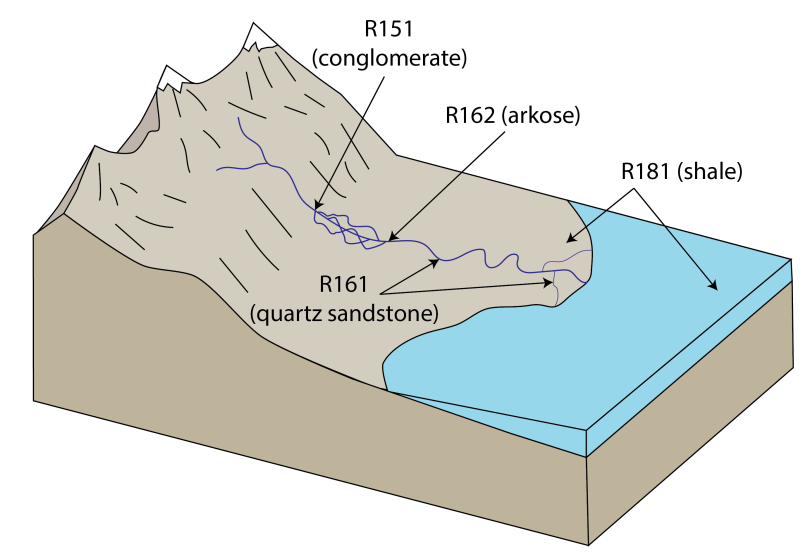

Figure A answer key. (C) Siobhan McGoldrick. CC BY.

3. Note that this is a generalized diagram and other correct answers are possible. The key is to clearly show that:

- the conglomerate formed in a high energy environment (e.g., a fast-flowing stream near the mountains),

- the arkose and quartz sandstone formed in a high to moderate energy environment (e.g., a stream channel),

- the arkose is less well sorted and contains more angular grains than the quartz sandstone, suggesting that it formed closer to the source of the sediment (i.e., grains have not travelled as far as for the quartz sandstone).

- the shale formed in a low energy environment (e.g., floodplain around a meandering stream, floodplain around stream channels in a delta, in the lake).

4. a) The source material (granite) is the same for both samples, consisting of quartz, feldspars, and some ferromagnesian minerals (biotite or amphibole). Quartz mechanically weathers to form finer grains of quartz. Feldspar minerals chemically weather to produce clay minerals and $\mathrm{K}^{+}, \mathrm{Ca}^{+2}$, and $\mathrm{Na}^{+}$ions in solution. Biotite and amphibole (if present) also chemically weather to produce chlorite (eventually clay minerals), and iron and magnesium ions in solution.

b) Mechanical weathering, and later erosion and transport, break the granite into smaller fragments. Chemical weathering acts primarily on the ferromagnesian and feldspar minerals as these are relatively unstable at the Earth's surface. Increased transport typically results in better sorting of grains and in increased rounding. The feldspathic sandstone (R162) still contains feldspar fragments that are sub-angular, suggesting that it has experienced less transport and less chemical weathering than the quartz sandstone (R161), in which unstable minerals have been weathered out leaving predominantly well sorted rounded quartz grains.

5. 


\begin{tabular}{|c|c|c|c|c|}
\hline Composition & $\begin{array}{l}\text { Mineral } \\
\text { Name }\end{array}$ & $\begin{array}{l}\text { Rock } \\
\text { Sample } \\
\#\end{array}$ & Rock Name & Diagnostic Properties Common to Both Rock and Mineral \\
\hline $\mathrm{CaCO}_{3}$ & Calcite & $\begin{array}{l}\text { R191 } \\
\text { R201 } \\
\text { R211 } \\
\text { R221 } \\
\text { R231 }\end{array}$ & $\begin{array}{l}\text { Crystalline } \\
\text { limestone } \\
\text { Oolitic lime- } \\
\text { stone } \\
\text { Coquina } \\
\text { Fossiliferous } \\
\text { limestone } \\
\text { Chalk }\end{array}$ & Hardness $\sim 3$, reaction with dilute $\mathrm{HCl}$ \\
\hline $\mathrm{SiO}_{2}$ & Quartz & R261 & Chert & Hardness $\sim 7$, conchoidal fracture \\
\hline $\mathrm{NaCl}$ & Halite & $\mathrm{R} 281$ & Rock salt & $\begin{array}{l}\text { Hardness } \sim 3 \text {, cleavage planes }\left(3 \text { at } 90^{\circ}\right) \text {, cubic crystals, vitreous } \\
\text { lustre }\end{array}$ \\
\hline $\mathrm{CaSO}_{4} \cdot \mathrm{H}_{2} \mathrm{O}$ & Gypsum & R271 & Rock gypsum & Hardness $\sim 2$, pale colour (white, grey, buff), dull to satiny lustre \\
\hline C (mostly) & N/A & R251 & Coal & Soft, dark grey to black colour, low specific gravity \\
\hline
\end{tabular}

6. well-rounded, oval to almost spherical

7. oolitic

8. Concentric layers of calcite precipitated from warm, tropical ocean water around a nucleus (e.g., shell fragment, grain of quartz sand, etc.) and rounded by constant motion in shallow wave-agitated water.

9. Oolitic limestone

10. shells and shell fragments

11. calcite (shells)

12. Both contain evidence of living organisms (shells), both are composed primarily of calcite and therefore both react with $\mathrm{HCl}$. Coquina is distinguished by poorly cemented shell fragments that create a weak, somewhat crumbly rock. Fossiliferous limestone is a much more competent (i.e., stronger) rock. Fossiliferous limestone can contain a wide variety of fossils, including shells or any number of other organisms whose skeletons are made of calcite.

13. Broken up shells of microscopic organisms cemented together are inherently not as "hard" or as resistant to scratching as a large, solid crystal of calcite.

14. Coal

15. From accumulated plant matter in swamps and bogs, where decaying organic matter is buried and heated to form peat and eventually coal.

16. Rock salt: vitreous, cubic crystals (3 cleavage planes at $\left.90^{\circ}\right)$, pale white or pink to colourless translucent or transparent crystals, tastes salty. Rock gypsum: buff-grey or white in colour, generally opaque to semitransparent, may have "chickenwire" structure.

17. 


\begin{tabular}{|l|l|l|}
\hline Sample & Environment of deposition & Evidence \\
\hline R151 & $\begin{array}{l}\text { Fluvial (river) or glacio-fluvial, } \\
\text { sub-marine fan }\end{array}$ & $\begin{array}{l}\text { Rounded rock fragments, gravel size requires relatively high energy to } \\
\text { transport, poorly sorted }\end{array}$ \\
\hline R161 & $\begin{array}{l}\text { Fluvial (river), beach, lacustrine, } \\
\text { aeolian, deltaic, lagoonal, tidal, } \\
\text { shallow water marine }\end{array}$ & $\begin{array}{l}\text { Rounded quartz sand requires moderate to high energy to transport, } \\
\text { well sorted suggesting relatively long transport (other components } \\
\text { like feldspars have been weathered out) }\end{array}$ \\
\hline R181 & $\begin{array}{l}\text { Fluvial (flood plain), lacustrine, } \\
\text { evaporite, deltaic, tidal, deep } \\
\text { water marine }\end{array}$ & $\begin{array}{l}\text { Well sorted clay-sized particles require low energy conditions to be } \\
\text { deposited }\end{array}$ \\
\hline R221 & $\begin{array}{l}\text { Reefs, lagoonal, shallow water } \\
\text { marine }\end{array}$ & $\begin{array}{l}\text { Composed of halite, which forms from evaporation of surface water in } \\
\text { arid regions }\end{array}$ \\
\hline
\end{tabular}

\section{Lab 6: Metamorphic Rocks and the Rock Cycle}

1.

\begin{tabular}{|l|l|l|l|}
\hline & Name of protolith & $\begin{array}{l}\text { Name of } \\
\text { metamorphic rock }\end{array}$ & $\begin{array}{l}\text { Observations (how does the metamorphic rock differ from its } \\
\text { protolith?) }\end{array}$ \\
\hline $\begin{array}{l}\text { Pair } \\
\text { A }\end{array}$ & $\begin{array}{l}\text { Fossiliferous } \\
\text { limestone (R221) }\end{array}$ & Marble (R361) & $\begin{array}{l}\text { Marble is crystalline and coarser grained (calcite crystals are } \\
\text { large enough to see glints of light off of cleavage planes), marble } \\
\text { does not contain any fossils. }\end{array}$ \\
\hline $\begin{array}{l}\text { Pair } \\
\text { B }\end{array}$ & Shale (R181) & Slate (R301) & $\begin{array}{l}\text { Slate is slightly harder and has a slightly shinier lustre than the } \\
\text { shale, which is dull. Depending on the slate sample there may be } \\
\text { a difference in colour. May see slaty foliation (absent in shale). }\end{array}$ \\
\hline $\begin{array}{l}\text { Pair } \\
\text { C }\end{array}$ & Granite (R1) & Gneiss (R331) & $\begin{array}{l}\text { Gneiss has a gneissic foliation (minerals are aligned and } \\
\text { segregated into light- and dark-coloured bands). }\end{array}$ \\
\hline $\begin{array}{l}\text { Pair } \\
\text { D }\end{array}$ & $\begin{array}{l}\text { Quartz sandstone } \\
\text { (R161) }\end{array}$ & Quartzite (R351) & $\begin{array}{l}\text { Quartzite is often harder than sandstone, as the quartz crystals } \\
\text { are "welded" together during recrystallization. Quartz crystals } \\
\text { may be coarser grained (larger) than in sandstone protolith } \\
\text { (depends on the sample!). Quartzite has a sugary (granular) } \\
\text { appearance. }\end{array}$ \\
\hline
\end{tabular}

2. 


\begin{tabular}{|c|c|c|}
\hline & Changes in mineralogy & Changes in texture \\
\hline $\begin{array}{l}\text { Shale to } \\
\text { slate } \\
\text { (R181 to } \\
\text { R301/ } \\
\text { R302) }\end{array}$ & $\begin{array}{l}\text { Microscopic mica minerals start to grow from clay } \\
\text { minerals } \\
\text { Fluids may add silica (quartz, } \mathrm{SiO}_{2} \text { ) to slate, mak- } \\
\text { ing it slightly harder and stronger than shale } \\
\text { Colour may change depending on composition } \\
\text { of protolith (red - oxidized iron, grey - organic } \\
\text { carbon forming graphite) }\end{array}$ & $\begin{array}{l}\text { Slaty foliation (slaty cleavage) develops from } \\
\text { alignment of microscopic mica crystals (mica } \\
\text { minerals control how the slate breaks into thin } \\
\text { sheets) } \\
\text { Smooth, flat surfaces of the slaty foliation may have a } \\
\text { slight sheen (may be slightly shinier than the shale) } \\
\text { If the shale protolith contained any fossils, these } \\
\text { are generally not preserved in the slate }\end{array}$ \\
\hline $\begin{array}{l}\text { Slate to } \\
\text { schist } \\
\text { (R301/ } \\
\text { R302 to } \\
\text { R321) }\end{array}$ & $\begin{array}{l}\text { Mica minerals (biotite and muscovite) continue to } \\
\text { grow into larger crystals that are easily identified } \\
\text { with the naked eye } \\
\text { New metamorphic minerals may form but are } \\
\text { dependent on the composition of the protolith } \\
\text { and on the pressure - temperature conditions of } \\
\text { metamorphism (e.g., garnet, andalusite, kyanite, } \\
\text { staurolite, magnetite) }\end{array}$ & $\begin{array}{l}\text { Generally, all minerals present are coarser grained } \\
\text { than in slate } \\
\text { Mica minerals are coarse grained and easily seen - } \\
\text { they give the rock a glittery, shiny appearance. Align- } \\
\text { ment of mica minerals defines a strong schistose foli- } \\
\text { ation. } \\
\text { New minerals that do not have elongate or sheeted } \\
\text { crystal shapes (e.g., garnet) do not align with the } \\
\text { schistose foliation, and may stand out as "bumps" } \\
\text { Foliation may be folded or wavy (crenulated) }\end{array}$ \\
\hline $\begin{array}{l}\text { Schist } \\
\text { to } \\
\text { gneiss } \\
\text { (R321 to } \\
\text { R331/ } \\
\text { R332) }\end{array}$ & $\begin{array}{l}\text { Muscovite has disappeared, biotite may also have } \\
\text { disappeared } \\
\text { Amphibole or pyroxene has formed from the } \\
\text { breakdown of biotite } \\
\text { New metamorphic minerals may form but are } \\
\text { dependent on the composition of the protolith } \\
\text { and on the pressure - temperature conditions of } \\
\text { metamorphism (e.g., sillimanite) }\end{array}$ & $\begin{array}{l}\text { "Shiny, glittery" appearance of schist is lost due to } \\
\text { loss of mica minerals } \\
\text { Segregation of ferromagnesian and non-ferromagne- } \\
\text { sian minerals into bands defines strong gneissic foli- } \\
\text { ation } \\
\text { Quartz and feldspar crystals have increased in } \\
\text { grain size (were also present in schist but may have } \\
\text { been less obvious compared to the abundant, coarse } \\
\text { grained micas) }\end{array}$ \\
\hline
\end{tabular}

3.

\begin{tabular}{|l|l|l|l|}
\hline $\begin{array}{l}\text { Sample } \\
\#\end{array}$ & Approx. temperature $\left({ }^{\circ} \mathrm{C}\right)$ & Approx. Depth $(\mathbf{k m})$ & $\begin{array}{l}\text { Metamorphic Grade (low, } \\
\text { intermediate, high) }\end{array}$ \\
\hline $\mathbf{R 3 0 1}$ & $150-300^{\circ} \mathrm{C}$ & 2 to 5 & very low \\
\hline $\mathbf{R 3 2 1}$ & $450-550^{\circ} \mathrm{C}$ & 8 to 12 & intermediate \\
\hline R332 & Above $550^{\circ} \mathrm{C}$ & 12 to 17 & high \\
\hline
\end{tabular}

4. R351 - quartzite and R361 - marble

5. Crystalline

6. Hardness $\sim 7$ (harder than streak plate, harder than steel knife)

7. Quartz

8. Hardness $\sim 3$ (harder than a fingernail, softer than a penny)

9. Rock reacts vigorously with $\mathrm{HCl}$

10. Calcite

11. Yes - broadly speaking they have the same mineral composition. There may be small differences if, for example, the protolith was not a pure calcite limestone or a pure quartz sandstone. Textures have changed and in both cases grain size has increased as a result of metamorphism. The limestone protolith could have exhibited a number of textures (crystalline, oolitic, fossiliferous, bioclastic), but the resulting marble is always crystalline. Quartz sandstone has a clastic texture that recrystallizes to form the crystalline quartzite. 
12.

\begin{tabular}{|c|c|c|l|}
\hline Order & $\begin{array}{c}\text { Rock } \\
\text { Name }\end{array}$ & Sample \# & Rock Cycle Processes Responsible \\
\hline $\mathbf{1}$ & $\begin{array}{c}\text { Basalt } \\
\text { pebbles } \\
\text { (sediment) }\end{array}$ & N/A & $\begin{array}{l}\text { Partial melting of the mantle generates mafic magma. Magma rises and erupts at or } \\
\text { near the surface, forming basalt (an extrusive mafic igneous rock). Basalt is } \\
\text { mechanically weathered to form pebble-sized clasts that may be eroded and } \\
\text { transported. }\end{array}$ \\
\hline $\mathbf{2}$ & Shale & R181 & $\begin{array}{l}\text { Basalt pebbles are further mechanically and chemically weathered. Ferromagnesian } \\
\text { minerals and plagioclase feldspar in the basalt chemically weather to form clay } \\
\text { minerals and ions in solution. Clay minerals are transported, and eventually } \\
\text { deposited in a very low energy environment. Clay minerals and other silt- and } \\
\text { clay-sized clasts are lithified into shale through burial by other sediments, } \\
\text { compaction, and cementation by mineral(s) precipitated from a fluid. }\end{array}$ \\
\hline $\mathbf{3}$ & $\begin{array}{l}\text { Garnet } \\
\text { gneiss }\end{array}$ & R332 & $\begin{array}{l}\text { Shale undergoes regional metamorphism to form a high grade metamorphic rock. } \\
\text { As pressure and temperature increase, clay minerals become unstable and } \\
\text { transform into mica minerals and then into amphibole or pyroxene, garnet, and } \\
\text { feldspar minerals. Grain size increases with increasing metamorphic grade. Under } \\
\text { directed pressure and shear stress, minerals align to form a foliation and segregate } \\
\text { into bands of ferromagnesian and non-ferromagnesian minerals (gneissic foliation). }\end{array}$ \\
\hline $\mathbf{4}$ & Diorite & R31 & $\begin{array}{l}\text { Gneiss continues to be subjected to increasing temperature and/or pressure until } \\
\text { it begins to partially melt, forming migmatite. As melting continues, eventually } \\
\text { enough melt is generated to form an intermediate magma that rises through the } \\
\text { crust. Magma cools and crystallizes at depth to form diorite, an intermediate } \\
\text { intrusive igneous rock. }\end{array}$ \\
\hline
\end{tabular}

13.

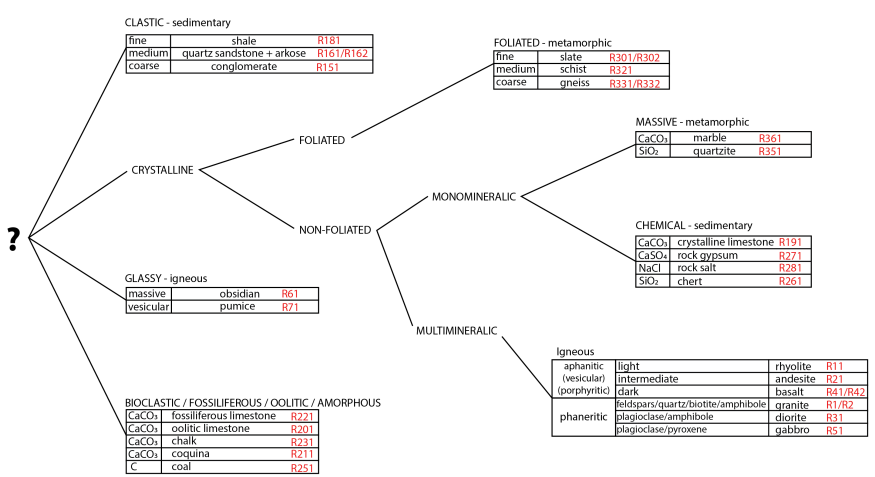




\section{Mineral and Rock Review}

\begin{tabular}{|c|c|c|}
\hline Mineral or rock name & Rock or mineral? & $\begin{array}{l}\text { If it's a mineral, which group does it } \\
\text { belong to? If it's a rock, what type is } \\
\text { it? }\end{array}$ \\
\hline Feldspar & Mineral & Framework silicate \\
\hline Calcite & Mineral & Carbonate \\
\hline Slate & Rock & $\begin{array}{l}\text { Metamorphic (low grade, mudrock } \\
\text { protolith) }\end{array}$ \\
\hline Hematite & Mineral & Oxide \\
\hline Rhyolite & Rock & Igneous (extrusive, felsic) \\
\hline Sandstone & Rock & Sedimentary (clastic) \\
\hline Diorite & Rock & Igneous (intrusive, intermediate) \\
\hline Olivine & Mineral & Isolated silicate \\
\hline Pyrite & Mineral & Sulphide \\
\hline Quartzite & Rock & $\begin{array}{l}\text { Metamorphic (massive, sandstone } \\
\text { protolith) }\end{array}$ \\
\hline Granite & Rock & Igneous (intrusive, felsic) \\
\hline Amphibole & Mineral & Double chain silicate \\
\hline Conglomerate & Rock & Sedimentary (clastic) \\
\hline Chert & Rock & Sedimentary (chemical) \\
\hline Halite & Mineral & Halide \\
\hline Gneiss & Rock & $\begin{array}{l}\text { Metamorphic (high grade, } \\
\text { sedimentary or igneous protolith) }\end{array}$ \\
\hline Mica & Mineral & Phyllosilicate (sheet silicate) \\
\hline Pyroxene & Mineral & Single chain silicate \\
\hline Chlorite & Mineral & Phyllosilicate (sheet silicate) \\
\hline Limestone & Rock & Sedimentary (chemical) \\
\hline Andesite & Rock & Igneous (extrusive, intermediate) \\
\hline
\end{tabular}

\section{Lab 7: Relative Dating and Geological Time}

1. 


\begin{tabular}{|l|l|l|l|l|}
\hline $\begin{array}{l}\text { Rock } \\
\text { Type }\end{array}$ & \multicolumn{1}{|c|}{ Granite } & \multicolumn{1}{c|}{ Sandstone } & \multicolumn{1}{c|}{ Limestone } \\
\hline Origin & $\begin{array}{l}\text { Intrusive igneous rock } \\
\text { - formed from cooling } \\
\text { magma deep beneath } \\
\text { the surface of the } \\
\text { Earth. }\end{array}$ & $\begin{array}{l}\text { Clastic sedimentary rock } \\
\text { - formed from the } \\
\text { deposition of sand-sized } \\
\text { grains in a moderate to } \\
\text { high energy environment. }\end{array}$ & $\begin{array}{l}\text { Chemical (or } \\
\text { biochemical) } \\
\text { sedimentary rock - } \\
\text { formed either from } \\
\text { chemical precipitation of } \\
\text { calcite or from } \\
\text { accumulated organisms } \\
\text { with shells made of } \\
\text { calcite. }\end{array}$ & $\begin{array}{l}\text { Clastic sedimentary rock } \\
\text { dermed from the } \\
\text { grains in a low energy } \\
\text { environment. }\end{array}$ \\
\hline
\end{tabular}

2.

\begin{tabular}{|c|c|c|}
\hline $\begin{array}{l}\text { Youngest } \\
\text { Event }\end{array}$ & Road Cut A (left) & Road Cut B (right) \\
\hline & - Uplift and erosion to present & \\
\hline & - Deposition and lithification of shale & - Uplift and erosion to present \\
\hline & - Deposition and lithification of limestone & - Intrusion of granite \\
\hline & - Deposition and lithification of sandstone & - Deposition and lithification of shale \\
\hline & - Nonconformity - uplift and erosion of granite & $\begin{array}{l}\text { - Deposition and lithification of } \\
\text { limestone }\end{array}$ \\
\hline $\begin{array}{l}\text { Oldest } \\
\text { Event }\end{array}$ & - Intrusion of granite & $\begin{array}{l}\text { - Deposition and lithification of } \\
\text { sandstone }\end{array}$ \\
\hline
\end{tabular}

3. No, they do not share the same geologic history. The timing of the granite intrusion is different: in Road Cut A the granite is the oldest rock, whereas in Road Cut B the granite is at least younger than the lithification of the sandstone. The exact placement of the granite in the geologic history for Road Cut B is somewhat flexible based on the evidence presented: it could have intruded any time after the lithification of the sandstone and before the uplift and erosion to present day.

4. The principle of inclusions. In Road Cut A, the granite is the oldest rock because the overlying sandstone contains inclusions of granite. Based on the principle of superposition, we know that the sandstone is the oldest sedimentary rock and therefore the granite must be even older than the sandstone. In Road Cut B, the granite contains inclusions of the sandstone, meaning that the sandstone existed before the granite intrusion. This implies that the granite intruded up into the sandstone, and fragments of sandstone rock fell into the magma chamber.

5. 


\begin{tabular}{|c|c|c|}
\hline $\begin{array}{l}\text { Youngest } \\
\text { Event }\end{array}$ & Geologic History of Figure B & $\begin{array}{l}\text { Justification (which principle of stratigraphy did } \\
\text { you use?) }\end{array}$ \\
\hline & - Intrusion of magma chamber $\mathrm{E}$ & - Cross-cutting \\
\hline & - Eruption of lava flow $\mathrm{L}$ & - Superposition \\
\hline & - Eruption of lava flow M & - Superposition \\
\hline & - Intrusion of dike $\mathrm{C}$ & - Cross-cutting \\
\hline & - Intrusion of laccolith D & - Cross-cutting \\
\hline & - Deposition and lithification of $\mathrm{K}$ & - Superposition \\
\hline & - Deposition and lithification of $\mathrm{J}$ & - Superposition \\
\hline & - Intrusion of sill B & - Cross-cutting \\
\hline & - Deposition and lithification of $\mathrm{G}$ & - Superposition \\
\hline $\begin{array}{l}\text { Oldest } \\
\text { Event }\end{array}$ & - Deposition and lithification of $\mathrm{H}$ & - Superposition \\
\hline
\end{tabular}

6. 


\begin{tabular}{|c|c|c|}
\hline $\begin{array}{c}\text { Youngest } \\
\text { Event }\end{array}$ & Geologic History of Figure C & Justification \\
\hline & - Uplift and erosion to present & - Incision of river down into A \\
\hline & - Deposition and lithification of A & - Superposition \\
\hline & - Deposition and lithification of D & - Superposition \\
\hline & $\begin{array}{l}\text { - Angular unconformity (B) - period of uplift and } \\
\text { erosion }\end{array}$ & $\begin{array}{l}\text { Difference in orientation of layers (A and D } \\
\text { are not tilted) - this must represent a large } \\
\text { period of time required to tilt, uplift, erode, } \\
\text { subside, and finally deposit new sediments }\end{array}$ \\
\hline & - Tilting of units L, K, P and J & - Original horizontality \\
\hline & - Deposition and lithification of J & - Superposition \\
\hline & - Deposition and lithification of $\mathrm{P}$ & - Superposition \\
\hline & - Deposition and lithification of $\mathrm{K}$ & - Superposition \\
\hline $\begin{array}{l}\text { Oldest } \\
\text { Event }\end{array}$ & - Deposition and lithification of $\mathrm{L}$ & $\begin{array}{l}\text { - Superposition (even though units are tilted, } \\
\text { we can still determine which was originally } \\
\text { on the bottom - assuming these units were } \\
\text { not completely overturned) }\end{array}$ \\
\hline
\end{tabular}

7. Figure illustrates a sequence of faulted sedimentary strata and an igneous dyke. The oldest event illustrated in Figure D is the deposition and lithification of conglomerate during the Pennsylvanian. The conglomerate is overlain by shale, deposited and lithified in the Permian. A disconformity separates the Pennsylvanian and Permian strata from the overlying Jurassic shale. This disconformity likely represents a period of uplift and erosion of any sediment deposited during the Triassic. Following the deposition and lithification of the Jurassic shale, sandstone was deposited during the Cretaceous. At some time following the deposition of the sandstone, an igneous dyke intruded and cross-cut the older sedimentary strata. Later, a fault cross-cut all units. Continued uplift and erosion exposed these units at the surface.

8. 


\begin{tabular}{|c|c|c|}
\hline $\begin{array}{c}\text { Youngest } \\
\text { Event }\end{array}$ & Geologic History of Figure E & Justification \\
\hline & - Uplift and erosion to present & - Incision of river down into A \\
\hline & - Deposition and lithification of A & - Superposition \\
\hline & - Intrusion of pluton and sill J & - Cross-cutting \\
\hline & - Deposition and lithification of $\mathrm{K}$ & - Superposition \\
\hline & - Faulting of C, D, E and $\mathrm{G}$ by fault $\mathrm{F}$ & - Cross-cutting \\
\hline & - Deposition and lithification of $\mathrm{G}$ & - Superposition \\
\hline & - Deposition and lithification of $E$ & - Superposition \\
\hline & - Deposition and lithification of $\mathrm{C}$ & - Superposition \\
\hline $\begin{array}{l}\text { Oldest } \\
\text { Event }\end{array}$ & - Deposition and lithification of D & - Superposition \\
\hline
\end{tabular}

9. 


\begin{tabular}{|c|c|c|}
\hline $\begin{array}{c}\text { Youngest } \\
\text { Event }\end{array}$ & Geologic History of Figure F & Justification \\
\hline & - Uplift and erosion to present & - Incision of river down into $\mathrm{H}$ \\
\hline & - Intrusion of dyke feeding eruption of rhyolite (L) & - Cross-cutting \\
\hline & - Deposition and lithification of $\mathrm{H}$ & - Superposition \\
\hline & - Deposition and lithification of $\mathrm{G}$ & - Superposition \\
\hline & - Faulting of all existing strata by fault $\mathrm{F}$ & - Cross-cutting \\
\hline & - Deposition and lithification of $\mathrm{K}$ & - Superposition \\
\hline & - Deposition and lithification of J & - Superposition \\
\hline & $\begin{array}{l}\text { - Angular unconformity (A) - uplift and erosion of } \\
\text { folded strata }\end{array}$ & $\begin{array}{l}\text { Underlying units B, C, and D are folded but } \\
\text { overlying units A through } \mathrm{H} \text { are not. Missing } \\
\text { portion of the rock record reflects the } \\
\text { millions of years required to uplift, erode, } \\
\text { subside and renew deposition. }\end{array}$ \\
\hline & - Folding of sedimentary rocks B, C, and D & - Original horizontality \\
\hline $\begin{array}{l}\text { Oldest } \\
\text { Event }\end{array}$ & - Deposition and lithification of B, C, and then D & - Superposition \\
\hline
\end{tabular}

\section{Lab 8: Mapping Fluvial Landscapes}

Please consult your instructor for feedback on your map.

1. NTS map sheet $82 \mathrm{~J} / 16$.

2. NTS map sheet $82 \mathrm{O} / 1$.

3. UTM zone 11 grid lines are blue.

4. Contour lines are brown. 
5. The contour interval is $20 \mathrm{~m}$.

6. The topography in the western part of the map is relatively steep whereas the topography in much of the northeastern parts of the map is fairly gentle. Steep topography is indicated by closely spaced contour lines. Gentle topography is indicated by widely spaced contour lines.

7. Sketch should show stream flowing from higher elevation contour line toward lower elevation. All contour lines that cross the stream form a "V" shape that points upstream.

8. The fastest water flow on a straight stretch of a stream will be in the middle of the stream near the surface.

9. 1 millimetre sand grains will be eroded if the velocity if over 20 centimetres per second and will be kept in suspension as long as the velocity is over 10 centimetres per second.

10. A braided stream can develop where there is more sediment available than can be carried in the amount of water present at the rate at which that water is flowing. This may happen where the gradient drops suddenly, or where there is a dramatic increase in the amount of sediment available (e.g., following an explosive volcanic eruption).

11. The variable water colour is a result of the sediment in suspension and its effect on how light interacts with the water. Where the water is carrying fine grained sediments in suspension the water appears paler in colour. Where there is little sediment in suspension (i.e., where most sediment had already settled out of the water column and has been deposited) the water appears darker in colour. The amount of sediment in suspension decreases as you move away from the mouth of the Elbow River and further into the Glenmore Reservoir, and therefore there is a gradual change in the water colour.

12. Factors or forces that influence the behaviour of the Elbow River include but are not limited to: changes in base level (in this case, the water level in the Glenmore Reservoir that is controlled by the dam), changes in discharge associated with seasonal variations or weather events, changes to the vegetation that stabilizes the river banks, and engineered changes to the flood plain (e.g., to build the new Ring Road).

\section{Lab 9: Structural Geology Part I}

\section{Answers may vary.}

2. Different colours map represent different rock types (different lithologies), or simply different compositions (e.g., white quartz sandstone cemented with silica vs red quartz sandstone cemented with hematite). Different colours may also indicate a difference in how adjacent rocks are weathering in response to chemical weathering (e.g., the rusty red staining of rocks containing and/or stained by iron oxide or hydroxide minerals).

3. This area has very little overburden (e.g., soil, glacial till) and very sparse vegetation, meaning that the exposure of bedrock at the surface is excellent. Furthermore, there are strong colour contrasts between the different units that are easily visible in satellite imagery. The areas around Calgary and Vancouver have very little exposure of bedrock at the surface, and are largely covered with overburden, vegetation, and infrastructure. Most areas in Canada, with the exception of some steep mountains and coastal areas, are not well suited to this type of activity using satellite imagery.

4. Feet.

5. C.I. $=40 \mathrm{ft}$

6. Topographic contour lines are deflected to form a "V" shape as they cross a stream. The point of the "V" shape always points upstream.

7. Contour lines are approximately parallel to the contacts between the layers of rock in the immediate area around the place marker for Raplee Anticline. 
8. The layers of rock in the immediate area around the place marker for Raplee Anticline are approximately horizontal.

9. You would be walking through progressively older rocks. You are starting from the "top" of the pile at the place marker for Raplee Anticline, and as you walk down the slope, over the horizontal layers of rock, you are walking "back in time" following the principle of superposition.

10. No, these strata are not horizontal. The contacts between the layers here form jagged "V" shapes that cross the topographic contour lines at a high angle, indicating that these layers are dipping. If these layers were horizontal their contacts would be parallel to the contour lines, much like they were around the place marker for Raplee Anticline. If these layers were vertical, their contacts would not be deflected at all by the contour lines - they would cut straight across the topography.

11. Using the 3D capabilities of Google Earth Pro (and in plan view, using the Rule of V's) we can confirm that these layers are dipping.

12. Dip direction (using the Rule of V's): W (west)

13. Dip direction: SE or ESE (either are acceptable here as we are just estimating)

14. Dip direction: $\mathrm{N}$

15. Rocks of different colours in the satellite imagery correspond to different mapped units on the geological map. Bedrock map units are shown by coloured polygons with map codes. Notice that some mapped units (e.g., unit Km) include layers of rocks with variable colours. Recall that most geological maps do not map each individual rock type, but instead describe rocks together as formations or groups. Note that the satellite imagery and the units on the map may not line up perfectly as the geological map is not "pinned" directly to the ground in Google Earth.

16. Answers may vary. Some examples are listed below.

- Unit Pp (Phosphoria Formation), in the NE corner of the map, dip direction: WSW to SW

- Unit Pt (Tensleep Sandstone), in the NE corner of the map, dip direction: WSW to SW

- Units Kf (Frontier Formation) and Kc (Cody Shale), near 44 35' 03" N $108^{\circ} 09^{\prime} 33^{\prime \prime}$ W, dip direction: SW

17. Geologic Map of Sheep Canyon Quadrangle, Wyoming

18. Robert E. Ladd

19. $1: 24,000$

$20.1 .6 \mathrm{~km}$

21. Map code, colour of unit on the map, full unit name, age, description of lithology(ies), thickness. Note that not all geological maps include unit thickness in the legend.

22. Oldest at the bottom, youngest at the top.

23. Unit Mm, Madison Limestone, Mississippian, limestone and limestone breccia.

24. Exposed up in the NE corner of the map.

25. Unit Twl, Willwood Formation, Eocene, siltstone and sandstone. Note that while there are younger materials on this map, carefully reading the legend reveals that these are not formations because they are not yet rocks! The younger Quaternary units are deposits of unconsolidated sediments.

26. Exposed up in the SW corner of the map.

27. Unit Pt (Tensleep Sandstone) and Unit PMa (Amsden Formation; deposited during the Mississippian and Pennsylvanian). Amsden is the oldest of the two.

28. Phosphoria and Gypsum Spring formations, as they contain thickly-bedded and massive gypsum, respectively. Possibly also the Dinwoody Formation, although mining thin stringer veins is unlikely to ever be profitable for an industrial mineral like gypsum. 


\section{Lab Io: Structural Geology Part II}

Block model keys are not provided. Consult your instructor for feedback on your completed block models.

Block Model I

3. Dip of Ordovician: $35^{\circ}$

5. Dip of dyke: $80^{\circ}$ 


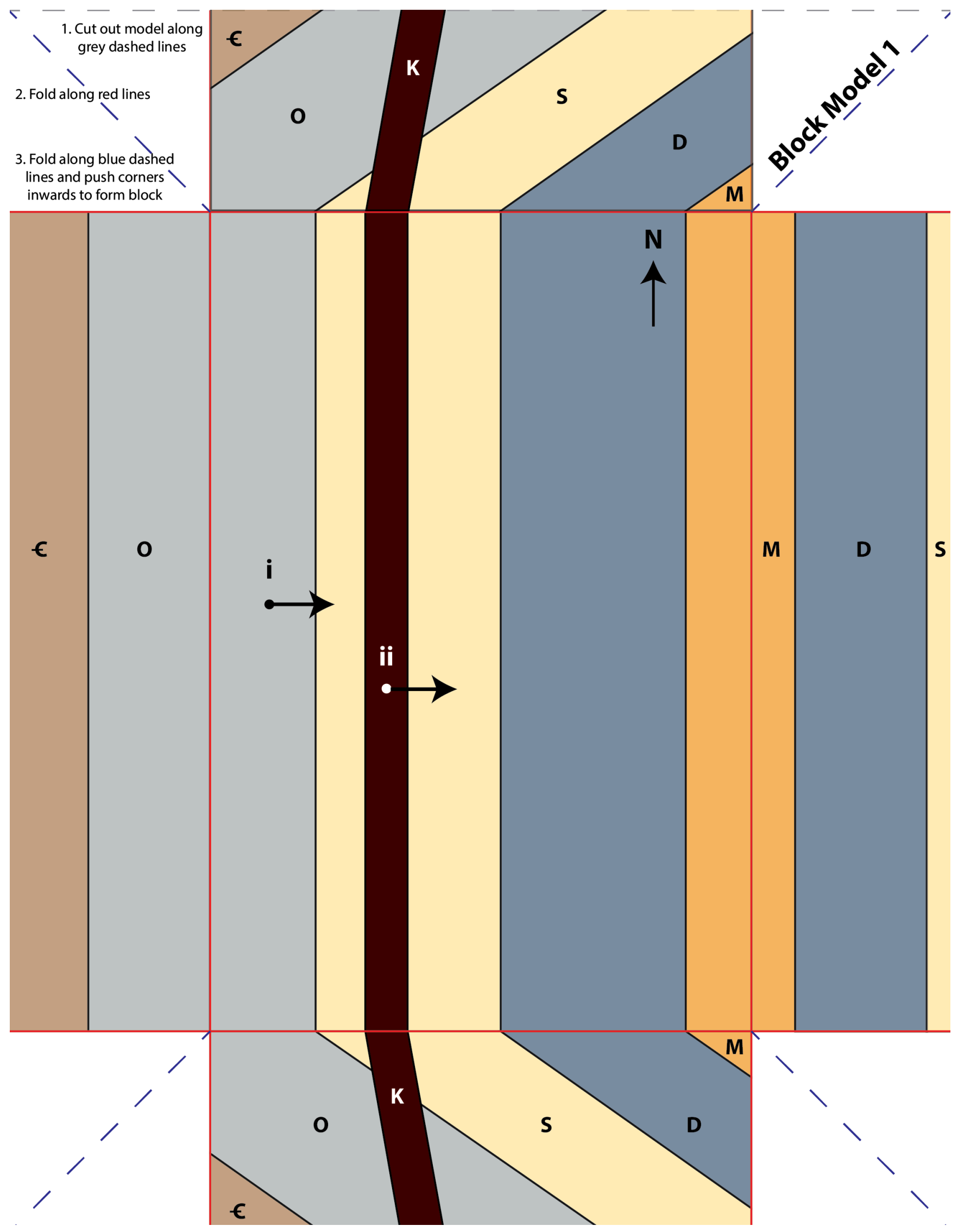


Block Model 2

5. Compressional stress.

333 | Appendix 3: Answers to Lab Exercises 


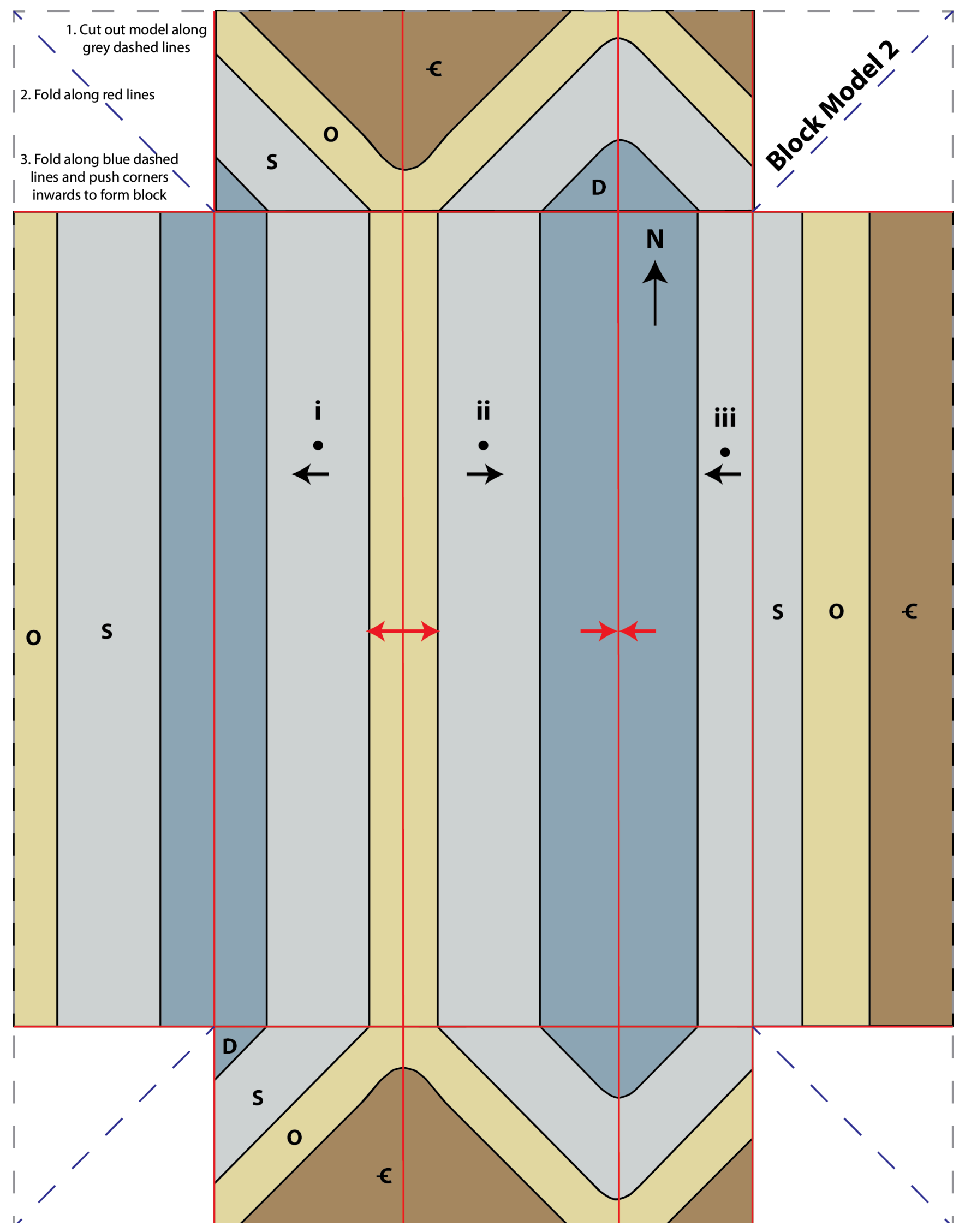


Block Model 3

7. Normal fault. Hanging wall has moved down relative to the footwall. 9. Tensional stress (extension). 


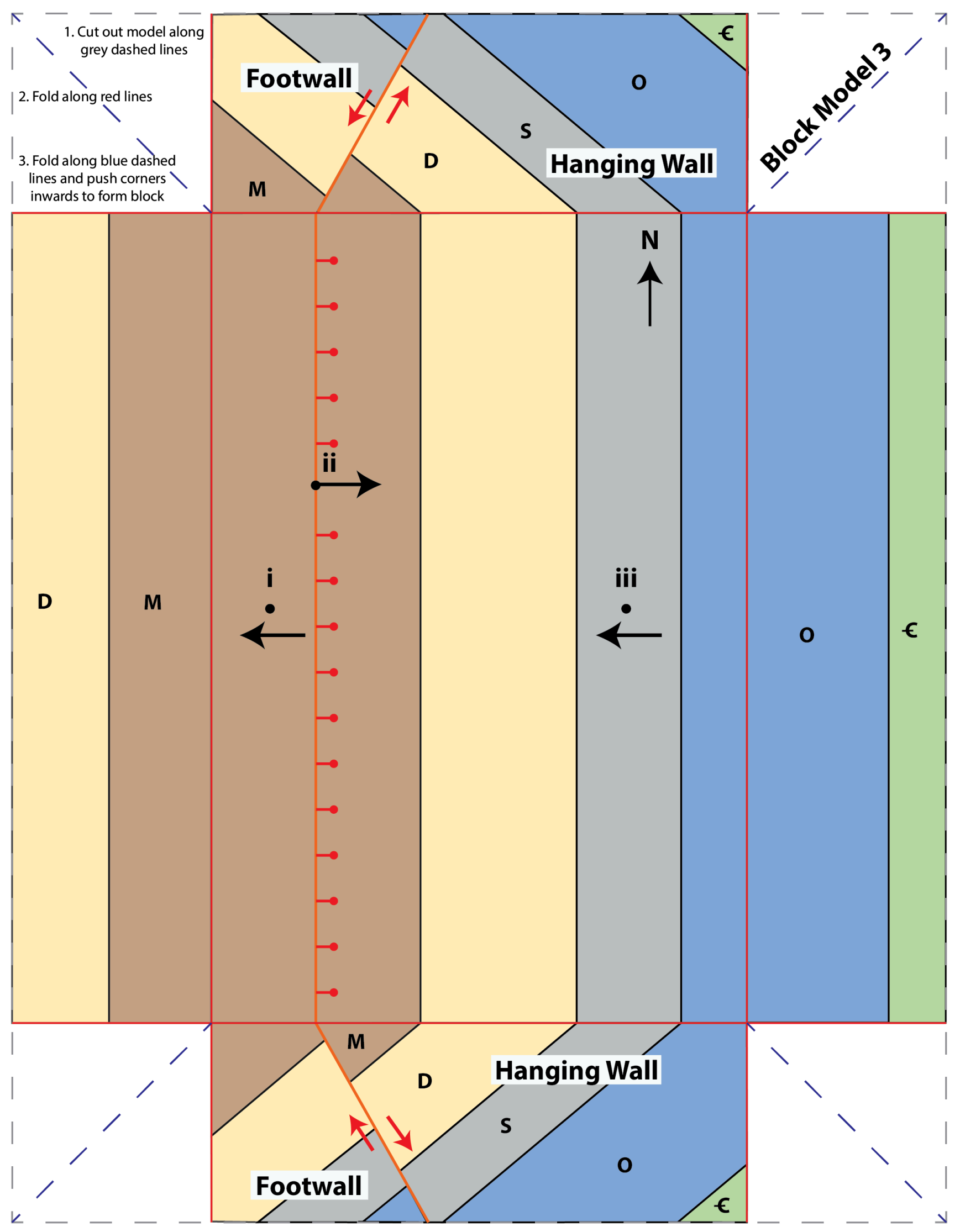


Block Model 4

7. Reverse fault. Hanging wall has moved up relative to the footwall. 9. Compressional stress. 


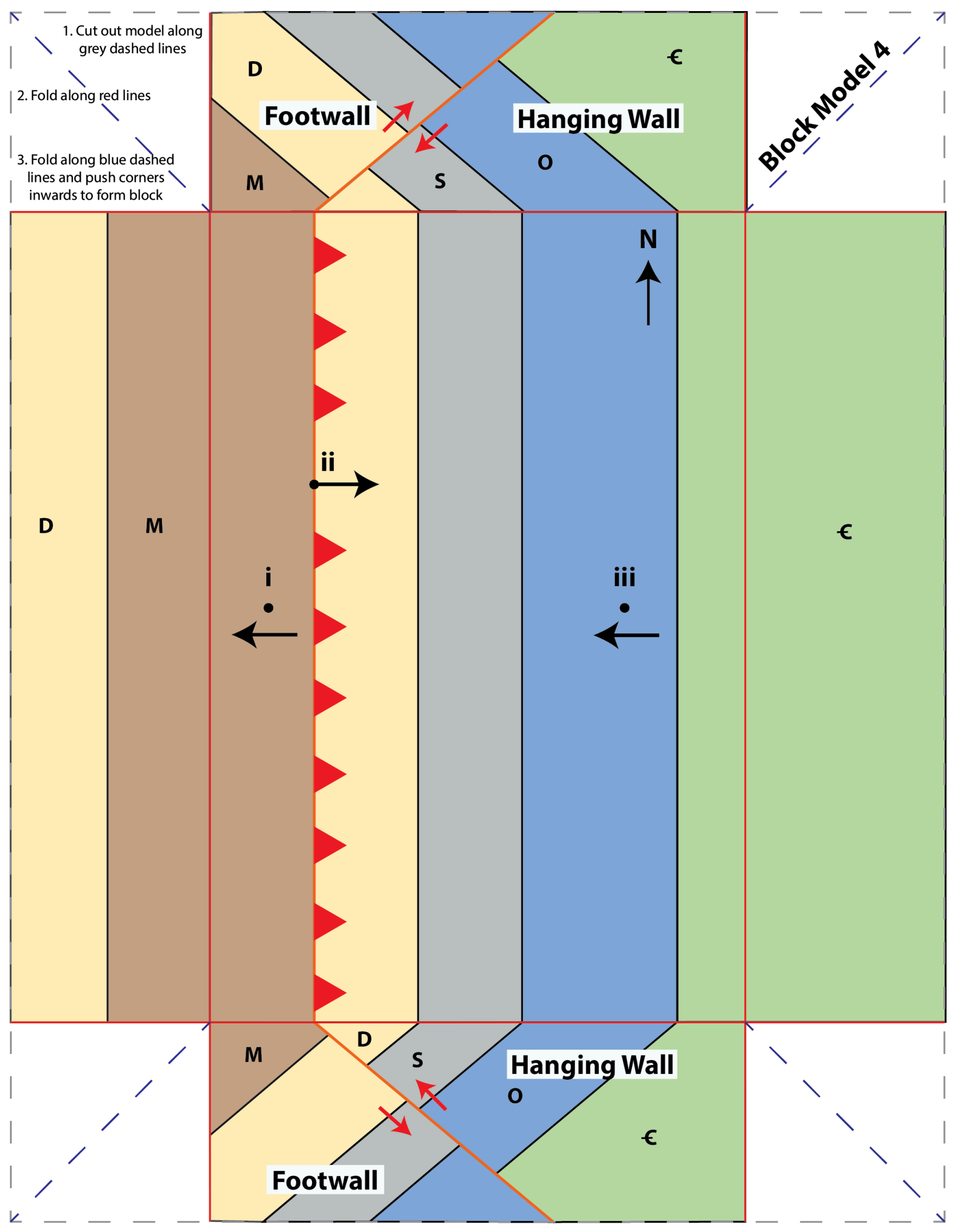


Block Model 5

2. The Mississippian formation is horizontal at point $\mathrm{i}$, it is not dipping (dip of $0^{\circ}$ ).

3. Dip: $80^{\circ}$, Dip direction: south (S)

4. Red arrows should indicate that dyke has been displaced along a left-lateral strike-slip fault.

5. Left-lateral strike-slip fault, looking across the fault the dyke appears to have been displaced to the left and there is not vertical offset of any other units.

6. Point-form geologic history (oldest event at the bottom, italic font indicates principle used to justify position of event in the timeline):

- All units cut by left-lateral strike-slip fault (cross-cutting)

- Intrusion of Cretaceous dyke (cross-cutting)

- Deposition and lithification of Mississippian formation (superposition)

- Deposition and lithification of Devonian formation (superposition)

- Paraconformity - period of non-deposition and/or erosion - missing Ordovician and Silurian (superposition)

- Deposition and lithification of Cambrian formation (superposition)

7. Shear stress. 


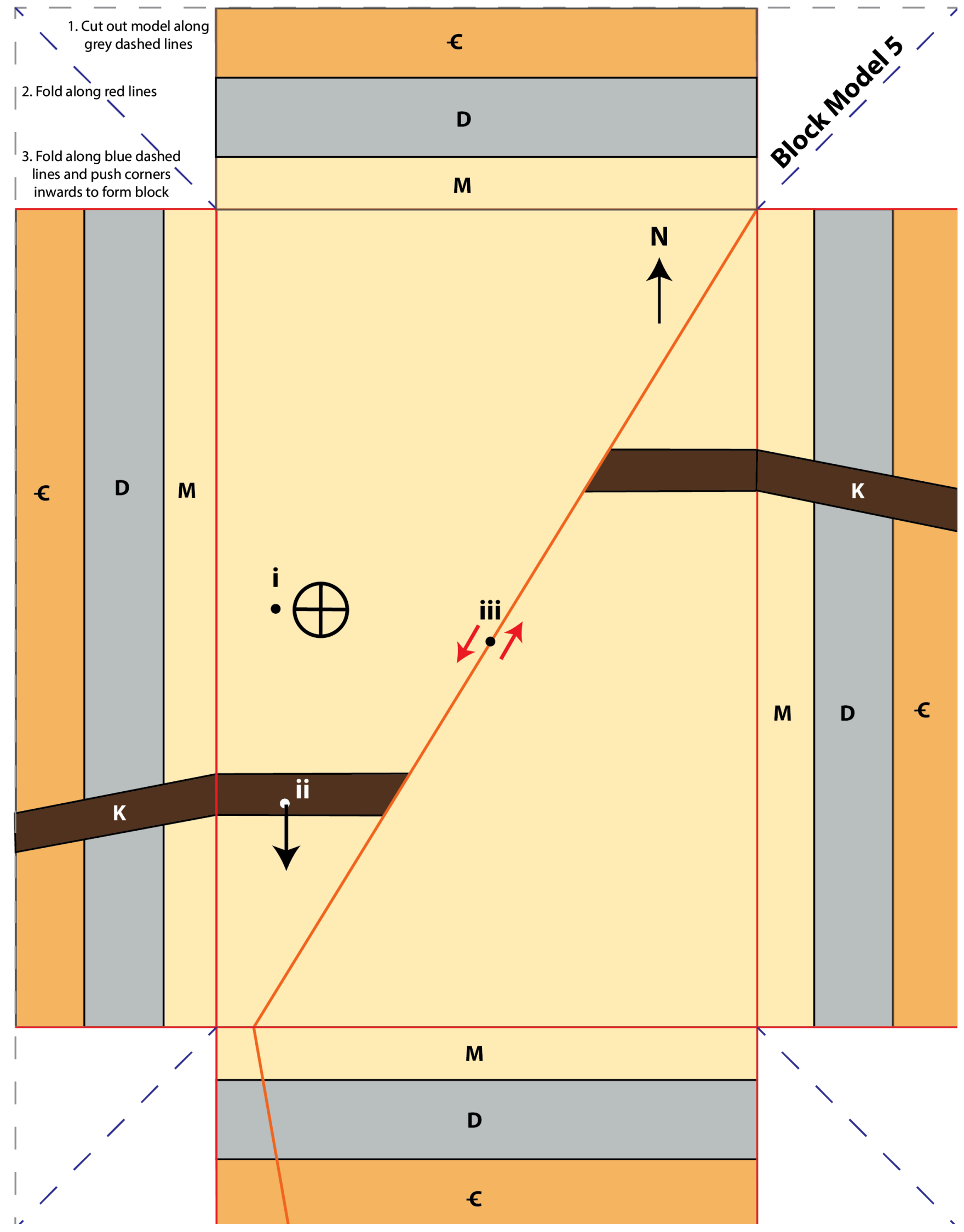


Block Model 6

2. Arrows should indicate that the Silurian formation is dipping toward the following directions:

- Point i: W, Dip: $38^{\circ}$

- Point ii: E, Dip: $37^{\circ}$

5. Dip: $80^{\circ}$, Dip direction: east (E)

6. Dip: $60^{\circ}$, Dip direction: north (N)

9. Normal fault. Hanging wall has moved down relative to the footwall. Also, notice that the core of the anticline in the hanging wall block does not expose the Ordovician formation because this block has dropped down.

10. Point-form geologic history (oldest event at the bottom, italic font indicates principle used to justify position of event in the timeline):

- All units cut by normal fault related to extension (tensional stress) (cross-cutting)

- Intrusion of Jurassic dyke (cross-cutting)

- Folding of Cambrian to Devonian strata and Mississippian sill into anticline by compressional stress (original horizontality)

- Intrusion of Mississippian sill (cross-cutting)

- Deposition and lithification of Devonian formation (superposition)

- Deposition and lithification of Silurian formation (superposition)

- Deposition and lithification of Ordovician formation (superposition)

- Deposition and lithification of Cambrian formation (superposition) 


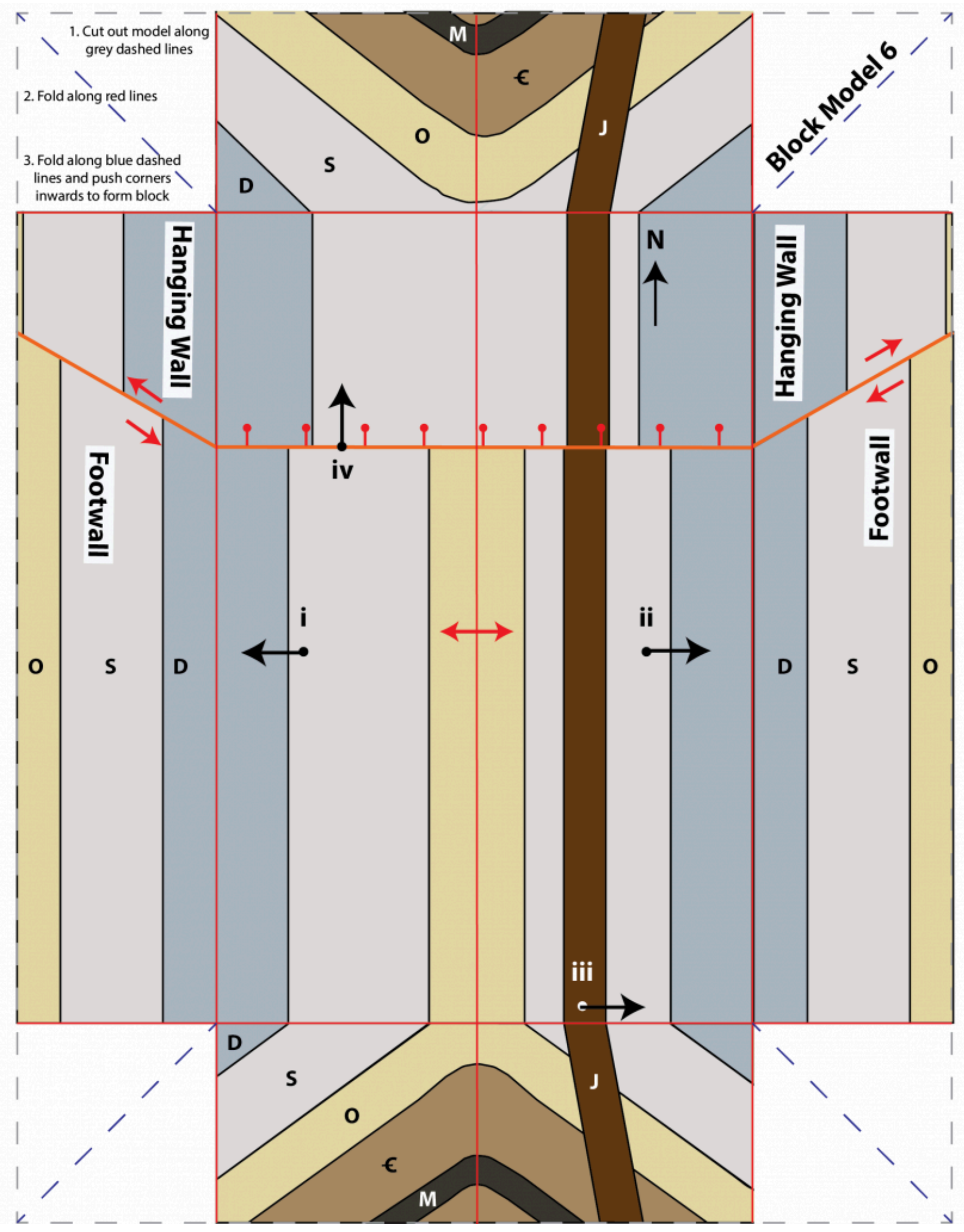




\section{Appendix 4: Economic Minerals}




\begin{tabular}{|c|c|c|c|}
\hline Mineral & $\begin{array}{l}\text { Ore or } \\
\text { Industrial } \\
\text { Mineral }\end{array}$ & Uses & Notable Canadian Sources \\
\hline Azurite \& malachite & $\begin{array}{l}\text { Ore - } \\
\text { Cu-bearing } \\
\text { carbonates }\end{array}$ & Ornamental stones, gemstones & \\
\hline Barite $\left(\mathrm{BaSO}_{4}\right)$ & Industrial & $\begin{array}{l}\text { High specific gravity, useful additive to } \\
\text { drill mud when drilling for oil. }\end{array}$ & $\begin{array}{l}\text { Fireside Mine near Watson } \\
\text { Lake, Yukon, and Walton } \\
\text { Barite Mine in Nova Scotia }\end{array}$ \\
\hline Bauxite (Al oxide) & Ore - Aluminum & Used to produce synthetic corundum & $\begin{array}{l}\text { Bauxite is mined primarily } \\
\text { in Australia, China and } \\
\text { Guinea, but is refined at } \\
\text { several smelters across } \\
\text { Canada including in } \\
\text { Kitimat, BC and in Québec }\end{array}$ \\
\hline Bornite $\left(\mathrm{Cu}_{5} \mathrm{FeS}_{4}\right)$ & Ore - Copper & $\begin{array}{l}\text { Source of copper for electrical equipment, } \\
\text { wiring, construction }\end{array}$ & $\begin{array}{l}\text { Sudbury mining district, } \\
\text { Ontario }\end{array}$ \\
\hline Calcite $\left(\mathrm{CaCO}_{3}\right)$ & Industrial & $\begin{array}{l}\text { Fertilizer, filler in paints, used to make } \\
\text { lime }(\mathrm{CaO}) \text { for use in remediation of acid } \\
\text { rock drainage, decorative (marble statues) }\end{array}$ & $\begin{array}{l}\text { The limestone quarry in } \\
\text { Exshaw feeds directly into } \\
\text { the Lafarge Exshaw } \\
\text { Cement Plant, the largest in } \\
\text { Canada! }\end{array}$ \\
\hline Chalcopyrite $\left(\mathrm{CuFeS}_{2}\right)$ & Ore - Copper & $\begin{array}{l}\text { Source of copper for electrical equipment, } \\
\text { wiring, construction }\end{array}$ & $\begin{array}{l}\text { Highland Valley Copper } \\
\text { Mine near Kamloops, B.C. }\end{array}$ \\
\hline Corundum $\left(\mathrm{Al}_{2} \mathrm{O}_{3}\right)$ & Industrial & $\begin{array}{l}\text { Abrasive (hardness }=9 ! \text { ), gemstones (ruby } \\
\text { and sapphire) }\end{array}$ & \\
\hline Diamond $(\mathrm{C})$ & Industrial & Abrasive (hardness $=10$ !), gemstones & $\begin{array}{l}\text { Northwest Territories, } \\
\text { northern Ontario and } \\
\text { Alberta }\end{array}$ \\
\hline Dolomite $\left(\mathrm{CaMg}\left(\mathrm{CO}_{3}\right)_{2}\right)$ & Industrial & $\begin{array}{l}\text { Building stone, ornamental stone, source } \\
\text { of } \mathrm{Mg} \text { for metallurgy and chemical } \\
\text { industry (Mg-salts) }\end{array}$ & \\
\hline $\begin{array}{l}\text { Feldspar minerals } \\
\text { (framework silicates) }\end{array}$ & Industrial & $\begin{array}{l}\text { Porcelain, glass, and ceramics; also used as } \\
\text { gemstones (e.g., moonstones) }\end{array}$ & \\
\hline Fluorite $\left(\mathrm{CaF}_{2}\right)$ & Industrial & $\begin{array}{l}\text { Source of fluorine for metallurgy, chemical } \\
\text { industries (e.g., production of hydrofluoric } \\
\text { acid), clear varieties used to make lenses }\end{array}$ & $\begin{array}{l}\text { Madoc, Ontario, and Rock } \\
\text { Candy Mine in B.C. }\end{array}$ \\
\hline Galena (PbS) & Ore - Lead & $\begin{array}{l}\text { Lead-acid batteries, ceramics and glasses, } \\
\text { ammunition }\end{array}$ & $\begin{array}{l}\text { Silvertip Mine in northern } \\
\text { B.C., Sullivan Mine near } \\
\text { Kimberley, B.C. }\end{array}$ \\
\hline Graphite (C) & Industrial & $\begin{array}{l}\text { Industrial lubricant for machinery, pencil } \\
\text { "lead" }\end{array}$ & \\
\hline Gypsum $\left(\mathrm{CaSO}_{4} \cdot 2 \mathrm{H}_{2} \mathrm{O}\right)$ & Industrial & $\begin{array}{l}\text { Wallboard (dry wall) for its natural fire } \\
\text { retardant properties }\end{array}$ & $\begin{array}{l}\text { Nova Scotia - the most } \\
\text { productive gypsum mining } \\
\text { area in the world! }\end{array}$ \\
\hline Halite $(\mathrm{NaCl})$ & Industrial & $\begin{array}{l}\text { Table and road salt, source of } \mathrm{Na} \text { and } \mathrm{Cl} \\
\text { for chemical industry }\end{array}$ & $\begin{array}{l}\text { Goderich, Ontario - largest } \\
\text { salt mine in the world! }\end{array}$ \\
\hline Hematite $\left(\mathrm{Fe}_{2} \mathrm{O}_{3}\right)$ & Ore - Iron & $\begin{array}{l}\text { Source of iron for production of steel for } \\
\text { building, historically used as a pigment }\end{array}$ & $\begin{array}{l}\text { Québec-Labrador border, } \\
\text { Baffinland Iron Mines in } \\
\text { Nunavut }\end{array}$ \\
\hline
\end{tabular}




\begin{tabular}{|c|c|c|c|}
\hline $\begin{array}{l}\text { Kaolinite } \\
\left(\mathrm{Al}_{2} \mathrm{Si}_{2} \mathrm{O}_{5}(\mathrm{OH})_{4}\right)\end{array}$ & Industrial & $\begin{array}{l}\text { Source of clay for ceramics, very pure clay } \\
\text { is required to produce high quality } \\
\text { ceramics like porcelain }\end{array}$ & \\
\hline Magnetite $\left(\mathrm{Fe}_{3} \mathrm{O}_{4}\right)$ & Ore - Iron & $\begin{array}{l}\text { Source of iron for production of steel for } \\
\text { building, used to produce "heavy concete" } \\
\text { for nuclear power plants }\end{array}$ & $\begin{array}{l}\text { Québec-Labrador border, } \\
\text { Baffinland Iron Mines in } \\
\text { Nunavut }\end{array}$ \\
\hline $\begin{array}{l}\text { Muscovite } \\
\left.\left(\mathrm{KAl}_{2}\left(\mathrm{AlSi}_{3} \mathrm{O}_{10}\right)(\mathrm{OH})_{2}\right)\right)\end{array}$ & Industrial & $\begin{array}{l}\text { Adds the "glitter" to cosmetics, used as an } \\
\text { insulator in some electrical equipment }\end{array}$ & $\begin{array}{l}\text { Most muscovite is mined in } \\
\text { India, Brazil, and China, but } \\
\text { phlogopite, a similar mica } \\
\text { mineral, is mined near } \\
\text { Ottawa, Ontario }\end{array}$ \\
\hline Pyrite $\left(\mathrm{FeS}_{2}\right)$ & Industrial & $\begin{array}{l}\text { Source of sulphur for chemical industry } \\
\text { (e.g., production of sulphuric acid) }\end{array}$ & \\
\hline Quartz $\left(\mathrm{SiO}_{2}\right)$ & Industrial & $\begin{array}{l}\text { As pure quartz sand used to make glass, } \\
\text { minor gemstone, fracking sand for oil } \\
\text { extraction }\end{array}$ & \\
\hline Sylvite $(\mathrm{KCl})$ & Industrial & $\begin{array}{l}\text { Main source of potash for fertilizer, source } \\
\text { of potassium }\end{array}$ & $\begin{array}{l}\text { Saskatchewan - sylvite is } \\
\text { the provincial mineral! }\end{array}$ \\
\hline Sphalerite (ZnS) & Ore - Zinc & $\begin{array}{l}\text { Metallurgy (creating metal alloys), } \\
\text { pharmaceutical and manufacturing } \\
\text { industries, used in paints, rubber, } \\
\text { cosmetics, electrical equipment }\end{array}$ & $\begin{array}{l}\text { Silvertip Mine in northern } \\
\text { B.C., Sullivan Mine near } \\
\text { Kimberley, B.C. }\end{array}$ \\
\hline Talc $(\mathrm{Mg}(\mathrm{OH})$ silicate) & Industrial & $\begin{array}{l}\text { Key ingredient in talcum powder (baby } \\
\text { powder), also used in cosmetics, paper } \\
\text { making, paint, pharmaceuticals }\end{array}$ & $\begin{array}{l}\text { Appalachians region in } \\
\text { southwestern Québec }\end{array}$ \\
\hline Uraninite $\left(\mathrm{UO}_{2}\right)$ & Ore - Uranium & $\begin{array}{l}\text { Nuclear power generation, used to } \\
\text { produce radioisotopes for medical } \\
\text { purposes (e.g., chemotherapy for cancer } \\
\text { patients) }\end{array}$ & $\begin{array}{l}\text { Athabasca Basin in } \\
\text { northern Saskatchewan - } \\
\text { hosts the world's largest } \\
\text { high-grade deposits! }\end{array}$ \\
\hline
\end{tabular}




\section{Appendix 5: Block Models}

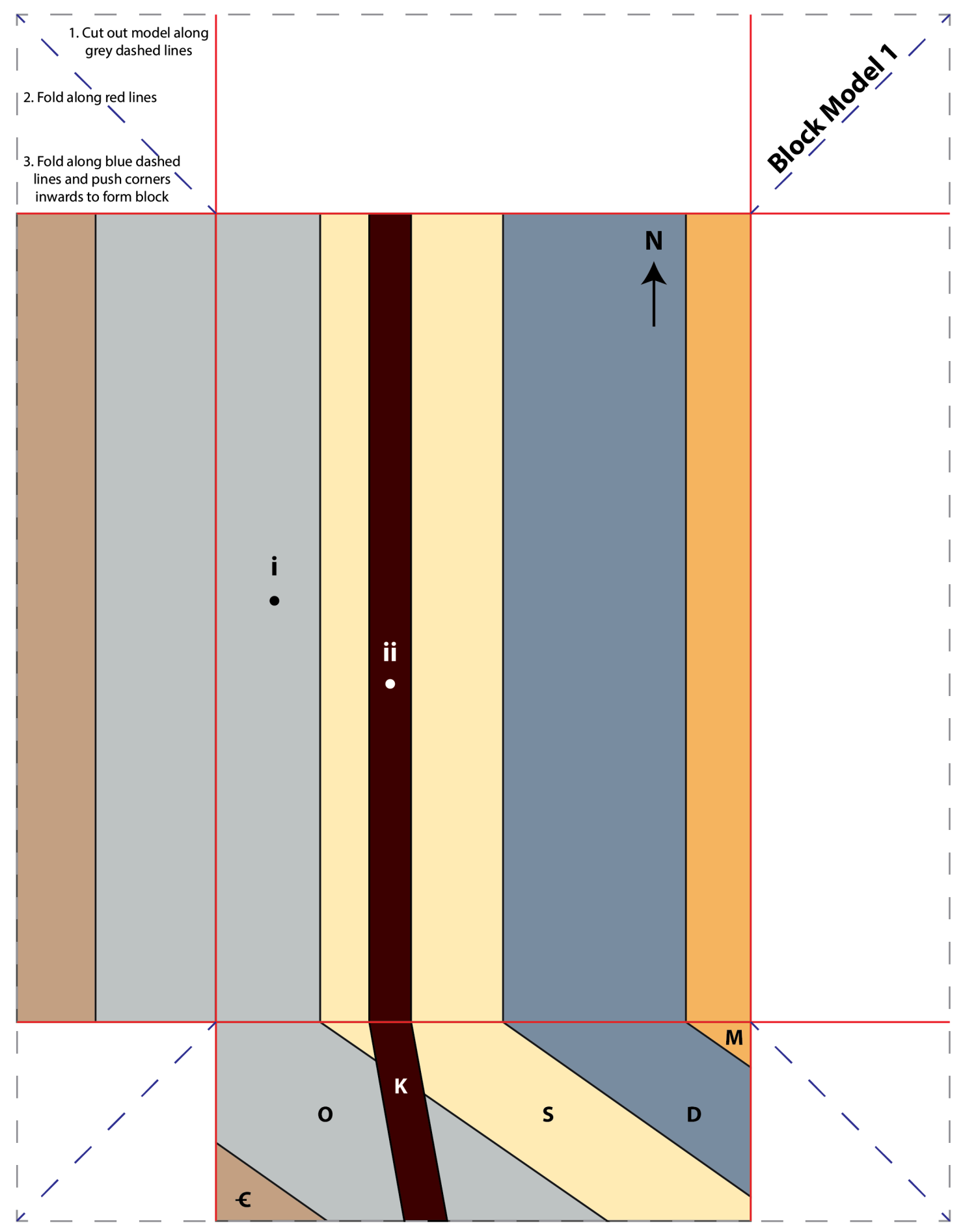




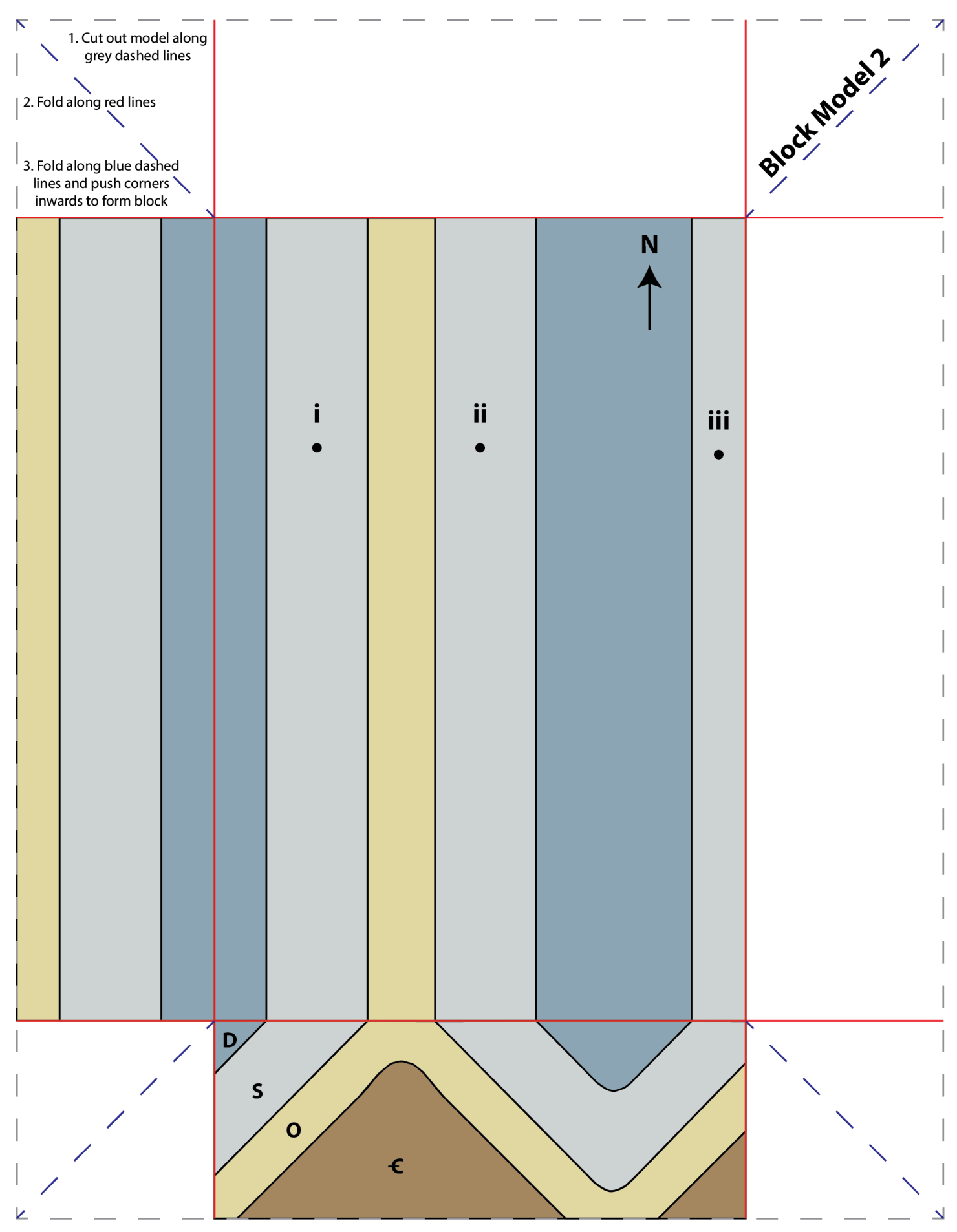




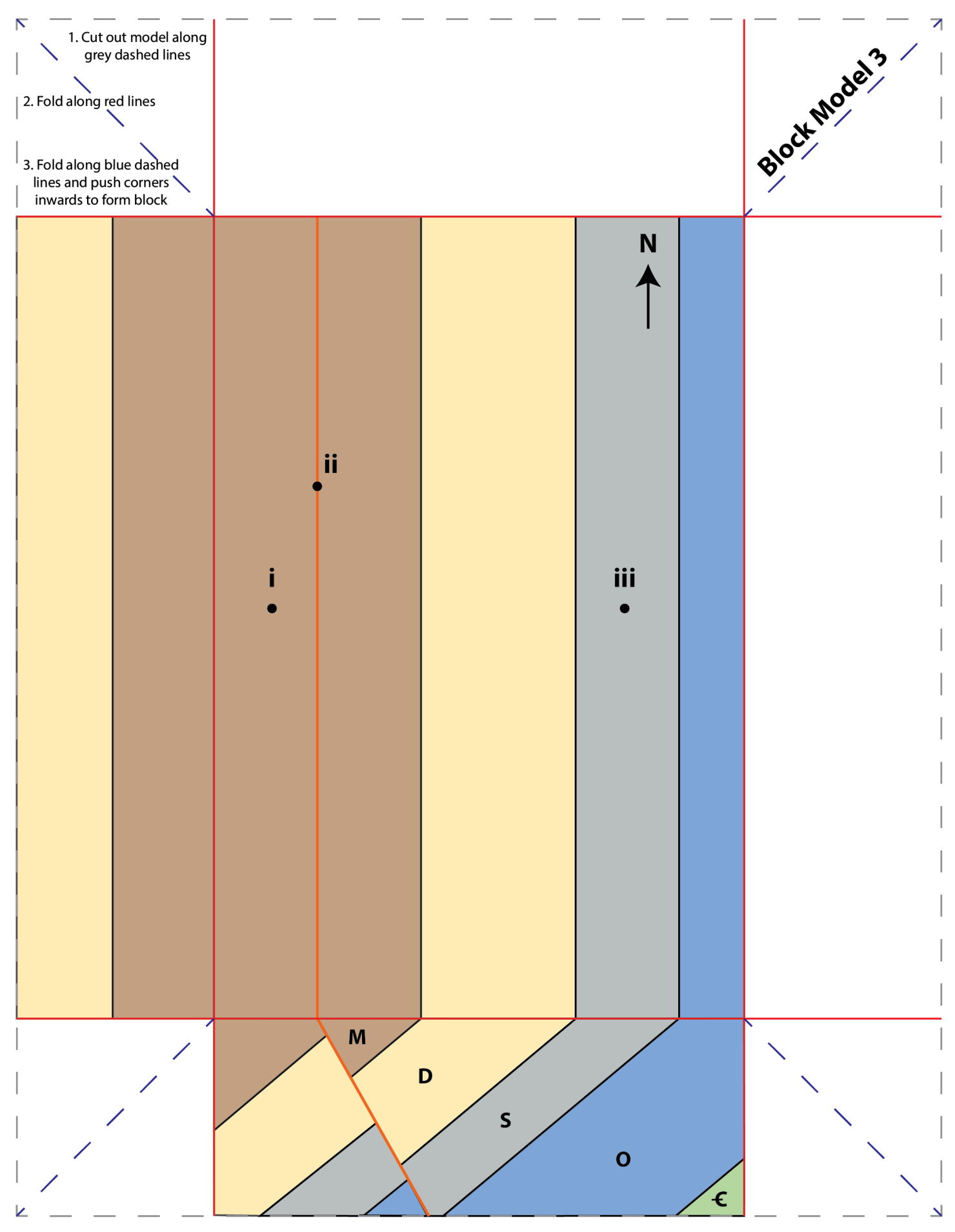




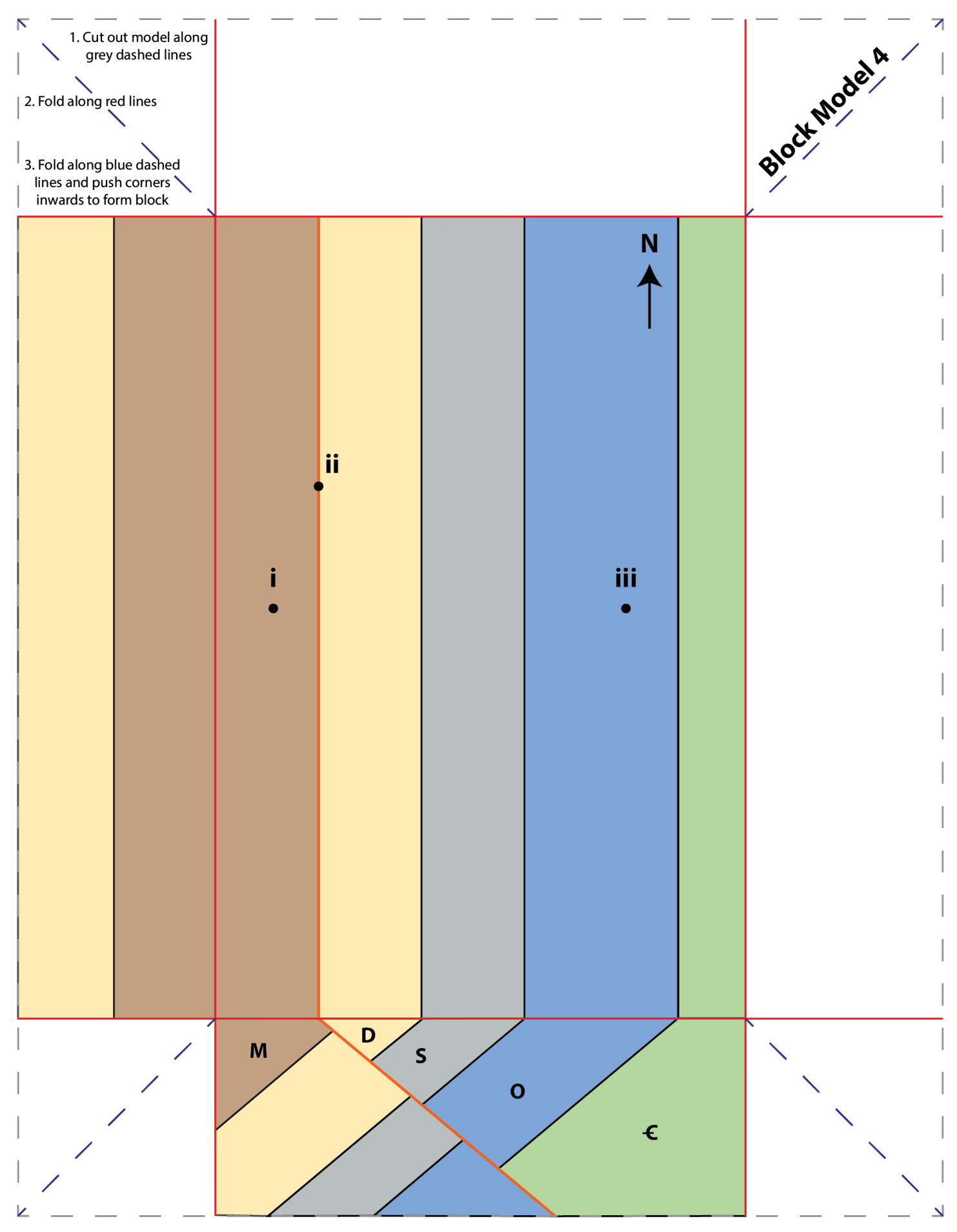




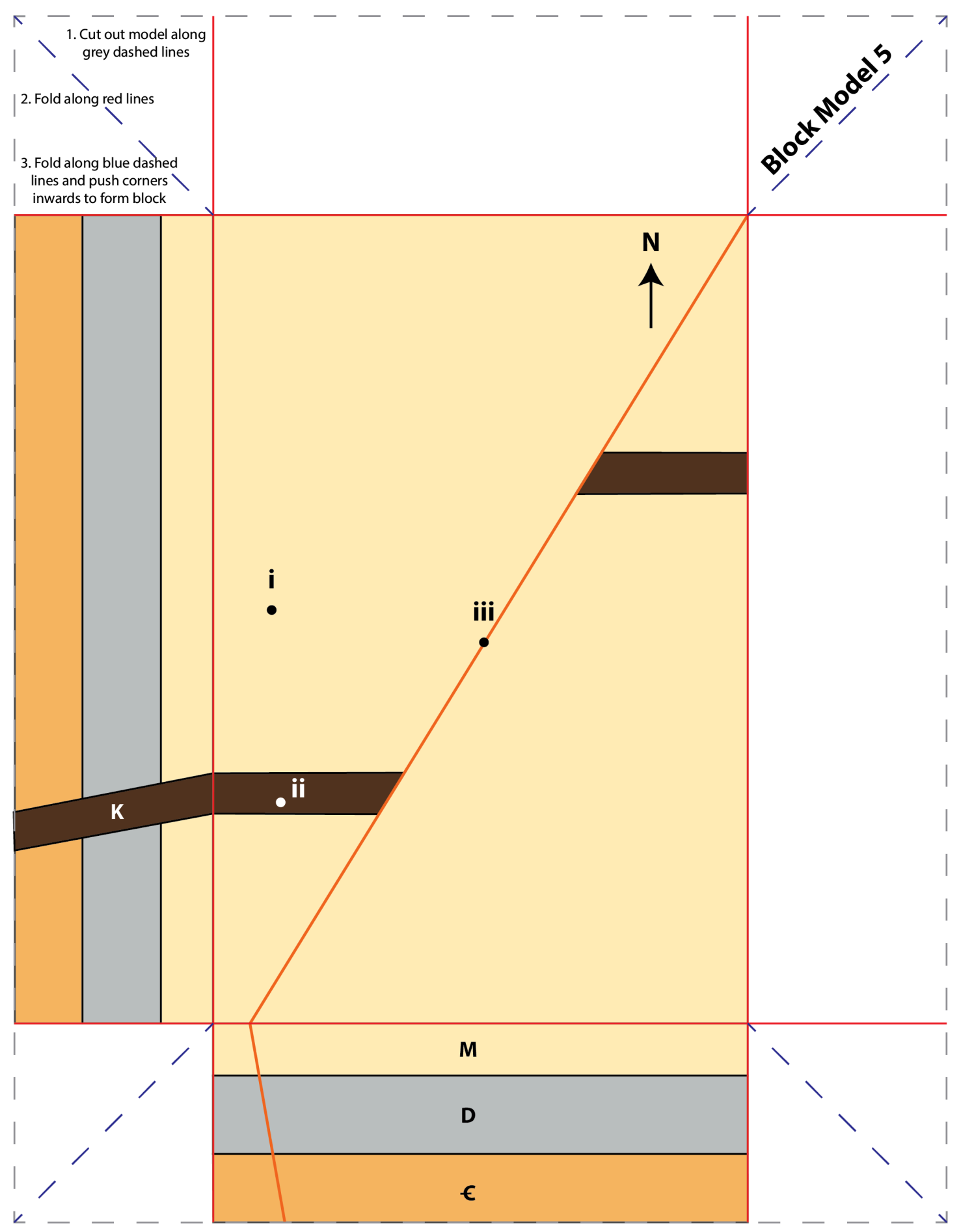




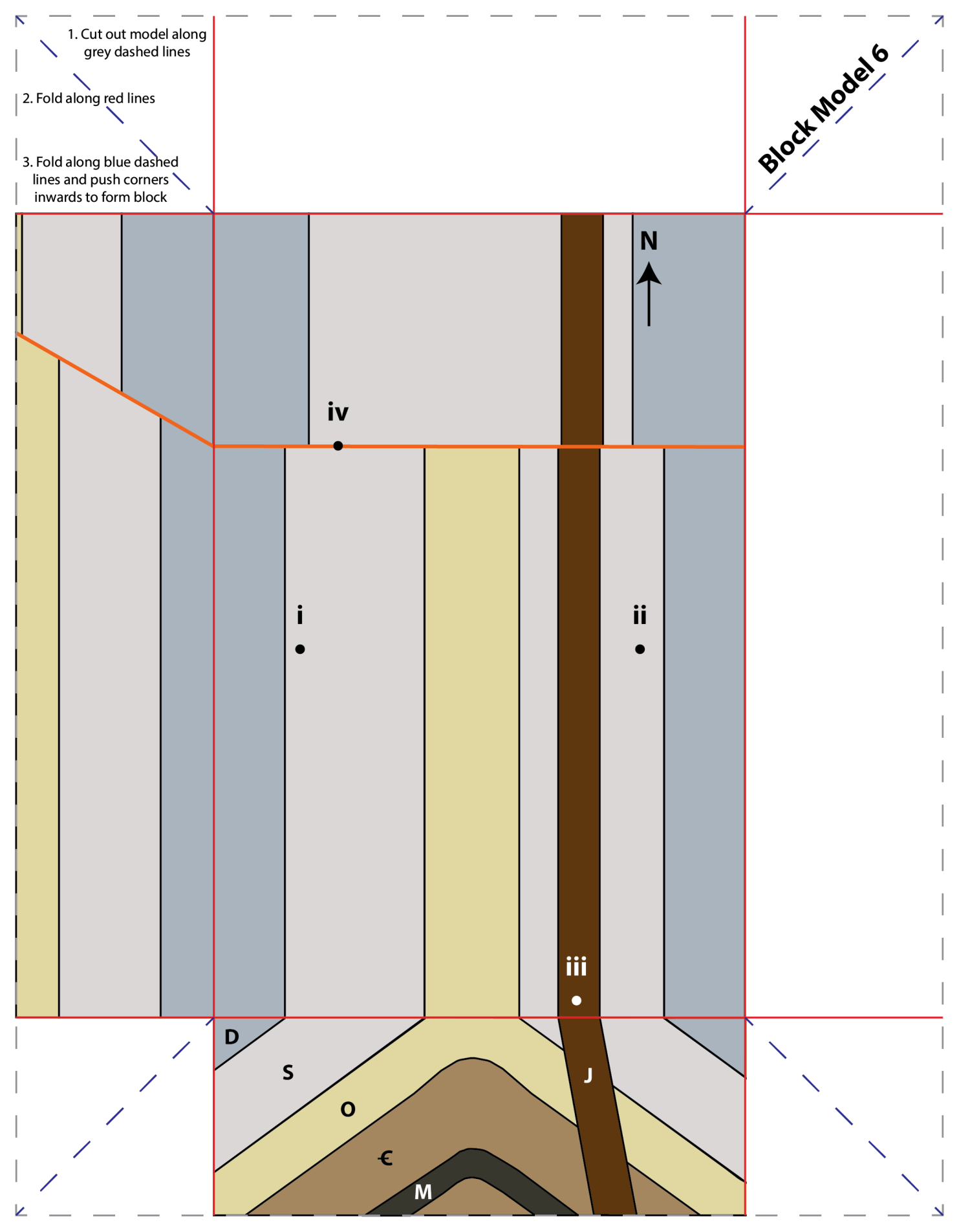




\section{Media Attributions}

- Block Models 1, 2, 3, 4, 5, 6: (C) Siobhan McGoldrick. CC BY. 


\title{
Links for Print Edition
}

\author{
Google Earth Tutorial
}

- Google Earth Pro: https://www.google.com/earth/versions/

- Google Earth Image Use Guidelines: https://www.google.com/permissions/geoguidelines/

\section{Introduction to Geology}

- Association of Professional Engineers and Geoscientists of Alberta: https://www.apega.ca/

- Virtual Roadtrip: https://barabus.tru.ca/geol2051/road_trip/road_trip.html

- Future of Geoscience Poster: https://www.geolsoc.org.uk/ /media/shared/documents/education\%20and\%20careers/Resources/Posters/Geoscience\%20for\%20the\%20Future\%20poster.pdf?la=en

$\mathrm{Lab}$ I

- Plate boundaries map by Dale S. Sawyer: https://openeducationalberta.ca/practicalgeology/wp-content/uploads/sites/66/2020/06/plate-boundaries-numbered.11×17.pdf

- Seismology map by Dale S. Sawyer: https://openeducationalberta.ca/practicalgeology/wp-content/ uploads/sites/66/2020/06/earthquakes.11×17.pdf

- Volcanology map by Dale S. Sawyer: https://openeducationalberta.ca/practicalgeology/wp-content/ uploads/sites/66/2020/06/volcano.11×17.pdf

- Seafloor age map by Dale S. Sawyer: https://openeducationalberta.ca/practicalgeology/wp-content/ uploads/sites/66/2020/06/age.11×17.pdf

- Topography/bathymetry map by Dale S. Sawyer: https://openeducationalberta.ca/practicalgeology/ wp-content/uploads/sites/66/2020/06/topo.11×17.pdf

- Table 1.1: https://openeducationalberta.ca/practicalgeology/wp-content/uploads/sites/66/2020/ 06/age.11×17.pdf

Lab 7

- ICS time scale: http://www.stratigraphy.org/index.php/ics-chart-timescale

- International Commission on Stratigraphy (ICS): http://www.stratigraphy.org/

- William Smith Wikipedia page: http://en.wikipedia.org/wiki/William_Smith_\%28geologist\%29 
- Elbow River Mapping Area satellite imagery: https://openeducationalberta.ca/practicalgeology/wpcontent/uploads/sites/66/2020/06/Elbow-River-no-scale.pdf

- Priddis NTS map: https://geoscan.nrcan.gc.ca/starweb/geoscan/servlet.starweb?path=geoscan/ downloade.web\&search1 $=\mathrm{R}=242896$

\section{Lab 9}

- Sheep Mountain Mapping Area satellite imagery: https://openeducationalberta.ca/practicalgeology/ wp-content/uploads/sites/66/2020/06/Sheep-Mountain-base-imagery-reduced-size.pdf

- International Commission on Stratigraphy (ICS): http://www.stratigraphy.org/

- North American Stratigraphic Code: https://ngmdb.usgs.gov/Info/NACSN/05_1547.pdf

- Virtual Landscape designed by the University of Leeds: http://www.see.leeds.ac.uk/virtual-landscapes/block/index.html

- Sheep Canyon Geological Map: http://sales.wsgs.wyo.gov/geologic-map-of-sheep-canyon-quadrangle-wyoming-1986/

\section{Appendix i: List of Geologically Important Elements and the Periodic Table}

- Syngenta Period Table of Elements: http://www.syngentaperiodictable.co.uk/periodictable.php?keyStage $=5$ 